JOINT TRANSPORTATION RESEARCH PROGRAM

FHWA/IN/JTRP-2008/23

Final Report

SAFETY AND OPERATIONAL IMPACTS OF ALTERNATIVE INTERSECTIONS

VOLUME I

RESEARCH REPORT

Andrew P. Tarko

Mike Inerowicz

Brandon Lang

December 2008 


\section{TECHNICAL Summary}

INDOT Research

Technology Transfer and Project Implementation Information

\section{Safety and Operational Impacts of Alternative Intersections}

\section{Introduction}

As the degradation of service at some conventional intersections increases, there becomes a need for alternative solutions other than expensive interchanges. Many alternative intersections have been proposed in the past. Under certain traffic and local conditions some solutions are more promising than other. In some cases, the conventional intersection may still be the optimal choice.

The presented research focused on developing guidelines that would help planners and designers identify the most promising solutions for further analysis. This objective has been addresses in two ways. Firstly, the existing knowledge on alternative intersections has been identified. Secondly, the performance of conventional and alternative intersections under a range of Indiana traffic conditions has been evaluated using microsimulation model - VISSIM.

\section{Findings}

Although a large number of sources could be found on the research subject, the existing knowledge about performance of alternative intersection design is incomplete. Only a few designs proposed in the past have been applied at a considerable number of locations including roundabouts, median U-turns, and jag-handle intersections. Other types still await implementation. The available sources are not comprehensive and deal with conditions that might be different from Indiana. The knowledge of the safety impact of these intersections is very limited.

\section{Implementation}

The presented research developed guidelines for using alternative intersection designs. The guidelines compile the existing knowledge found in existing publications and research reports with the simulation experiments performed with VISSIM. The guidelines are ready
A large number of more than 1,300 scenarios were simulated runs performed with VISSIM calibrated to Indiana conditions. The simulated types of intersections included: conventional, roundabouts, jag-handle near-sided and far-sided, median U-turns, and continuousflow intersection. Except roundabouts, all other intersections were signalized to test their capacity limits and delay-based performance. Although the roundabouts were the lowest delays at low volumes they also reached the capacity before other did. The most promising solutions for heavy volumes are median U-turns and continuous-flow intersections. to use and will help planners and designers determine which intersection types are the most promising under considered conditions and should be considered in a detailed way. The simulation results have been summarized in an easy to use format of graphs. 


\section{Contacts}

For more information:

Prof. Andrew Tarko

Principal Investigator

School of Civil Engineering

Purdue University

West Lafayette IN 47907

Phone: (765) 494-5027

Fax: (765) 496-7996

E-mail: tarko@purdue.edu
Indiana Department of Transportation

Division of Research

1205 Montgomery Street

P.O. Box 2279

West Lafayette, IN 47906

Phone: (765) 463-1521

Fax: (765) 497-1665

Purdue University

Joint Transportation Research Program

School of Civil Engineering

West Lafayette, IN 47907-1284

Phone: (765) 494-9310

Fax: (765) 496-7996

E-mail: jtrp@ecn.purdue.edu

http://www.purdue.edu/jtrp 
Final Report

FHWA/IN/JTRP-2008/23

\title{
SAFETY AND OPERATIONAL IMPACTS OF ALTERNATIVE INTERSECTIONS
}

\author{
Volume 1 \\ Research Report \\ By \\ Andrew P. Tarko \\ Professor \\ Mike Inerowicz \\ Graduate Research Assistant \\ Brandon Lang \\ Graduate Student \\ School of Civil Engineering \\ Purdue University \\ Joint Transportation Research Program \\ Project No. C-36-17ZZ \\ File No. 8-5-52 \\ SPR-3102 \\ Conducted in Cooperation with the \\ Indiana Department of Transportation and the \\ U.S. Department of Transportation \\ Federal Highway Administration
}

The contents of this report reflect the views of the authors, who are responsible for the facts and the accuracy of the data presented herein. The contents do not necessarily reflect the official views or policies of the Indiana Department of Transportation or the Federal Highway Administration at the time of publication. The report does not constitute a standard, specification, or regulation.

Purdue University

West Lafayette, Indiana

December 2008 
TECHNICAL REPORT STANDARD TITLE PAGE

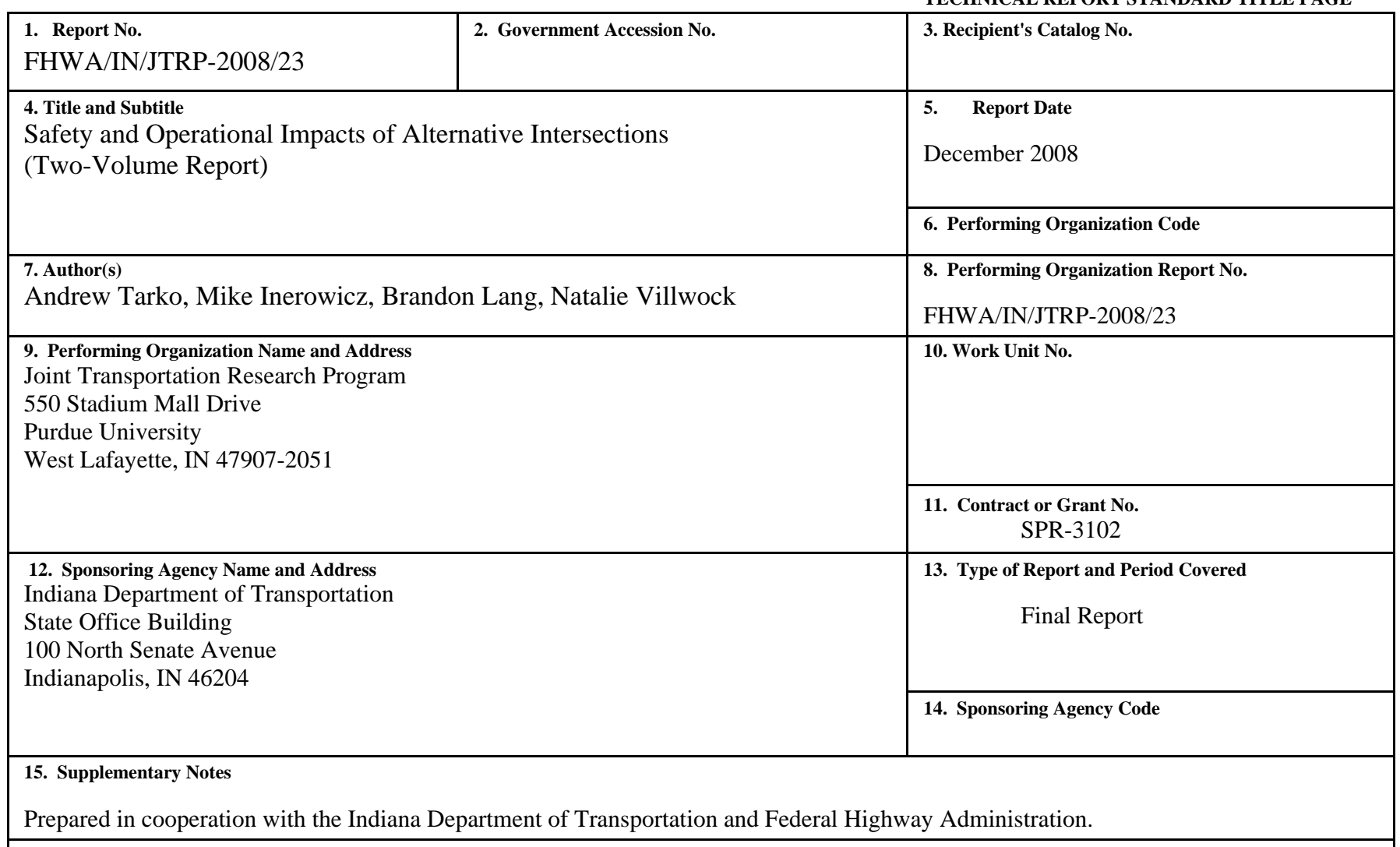

\section{Abstract}

As the degradation of service at some conventional intersections increases, there becomes a need for alternative solutions other than expensive interchanges. Many alternative intersections have been proposed in the past. Under certain traffic and local conditions some solutions are more promising than other. In some cases, the conventional intersection may still be the optimal choice.

The presented research focused on developing guidelines that would help planners and designers identify the most promising solutions for further analysis. This objective has been addresses in two ways. Firstly, the existing knowledge on alternative intersections has been identified. Secondly, the performance of conventional and alternative intersections under a range of Indiana traffic conditions has been evaluated using micro-simulation model - VISSIM.

Although a large number of sources could be found on the research subject, the existing knowledge about performance of alternative intersection design is incomplete. Only a few designs proposed in the past have been applied at a considerable number of locations including roundabouts, median U-turns, and jag-handle intersections. Other types still await implementation. The available sources are not comprehensive and deal with conditions that might be different from Indiana. The knowledge of the safety impact of these intersections is very limited.

A large number of more than 1,300 scenarios were simulated runs performed with VISSIM calibrated to Indiana conditions. The simulated types of intersections included: conventional, roundabouts, jag-handle near-sided and far-sided, median U-turns, and continuous-flow intersection. Except roundabouts, all other intersections were signalized to test their capacity limits and delay-based performance. Although the roundabouts were the lowest delays at low volumes they also reached the capacity before other did. The most promising solutions for heavy volumes are median U-turns and continuous-flow intersections.

The presented research developed guidelines for using alternative intersection designs. The guidelines compile the existing knowledge found in existing publications and research reports with the simulation experiments performed with VISSIM. The guidelines are ready to use and will help planners and designers determine which intersection types are the most promising under considered conditions and should be considered in a detailed way. The simulation results have been summarized in an easy to use format of graphs.

\begin{tabular}{|l|l|l|l|l|}
\hline \multicolumn{2}{|l|}{ 17. Key Words } & \multicolumn{1}{l|}{$\begin{array}{l}\text { 18. Distribution Statement } \\
\text { No restrictions. This document is available to the public through the } \\
\text { National Technical Information Service, Springfield, VA 22161 }\end{array}$} \\
\hline $\begin{array}{l}\text { 19. Security Classif. (of this report) } \\
\text { Unclassified }\end{array}$ & $\begin{array}{l}\text { 20. Security Classif. (of this page) } \\
\text { Unclassified }\end{array}$ & $\begin{array}{l}\text { 21. No. of Pages } \\
168\end{array}$ & 22. Price \\
\hline
\end{tabular}


TABLE OF CONTENTS

Page

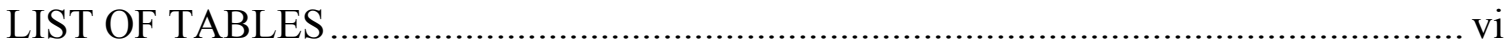

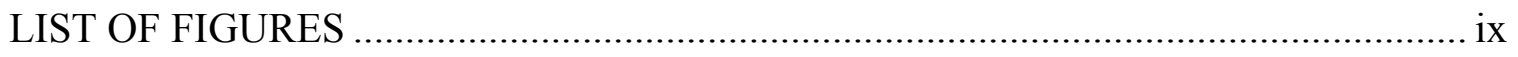

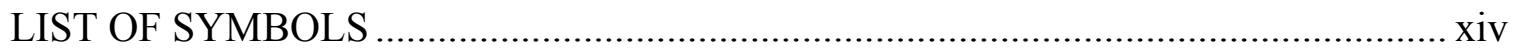

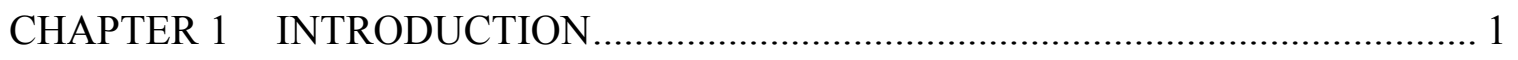

CHAPTER 2 LITERATURE REVIEW ................................................................ 4

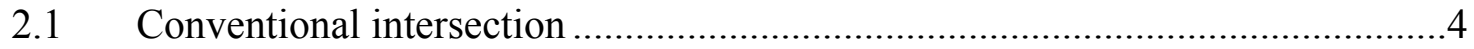

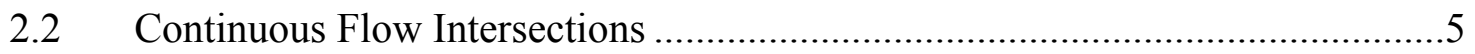

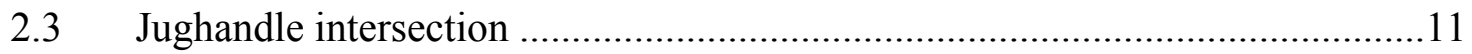

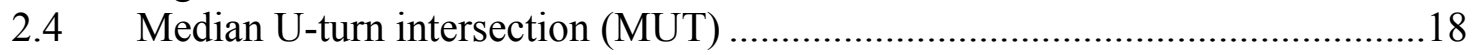

2.4.1 Median u-turn in an arterial corridor ................................................... 22

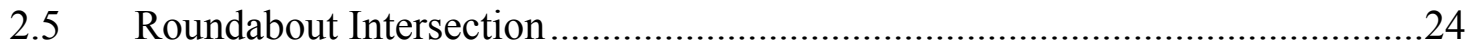

2.6 Superstreet median (SSM) crossover intersection...........................................29

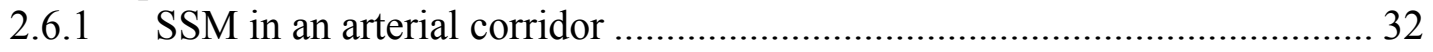

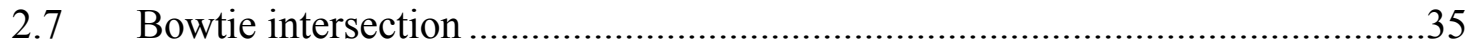

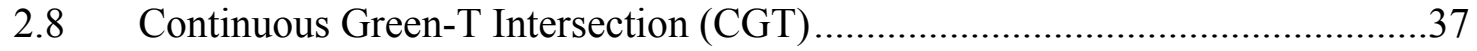

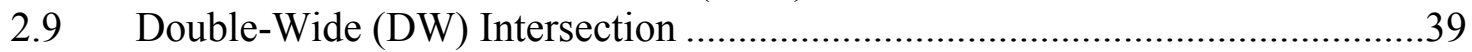

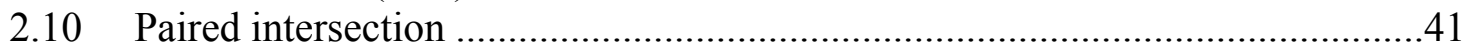

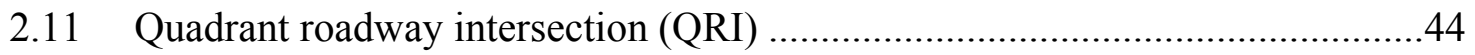

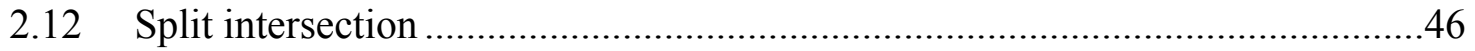

2.13 Upstream Signalized Crossover.....................................................................48

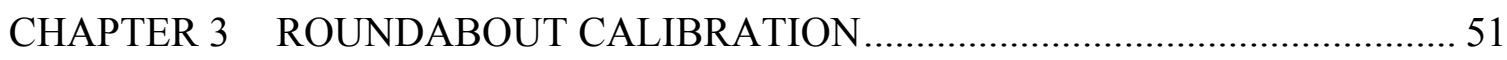

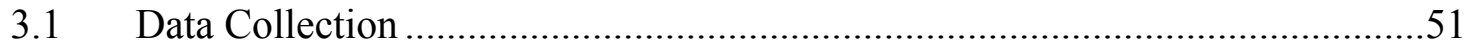

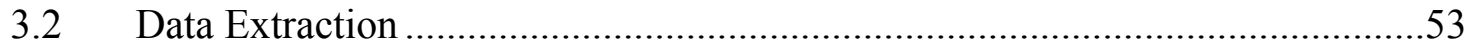

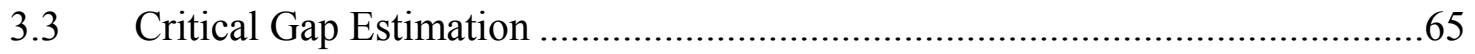

3.4 Evaluation of critical gap estimation methods based on service time ..............68

3.4.1 Determining roundabout turning movements .............................................. 69

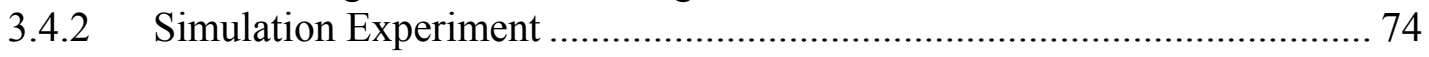

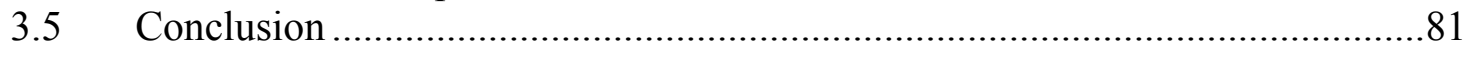

CHAPTER 4 SIGNALIZED INTERSECTIONS CALIBRATION ………………....... 83

4.1 Effect of VISSIM driver behavior parameters on saturation flow rate...............83 
4.2 Calibration of saturation flow rate to Indiana conditions ................................94

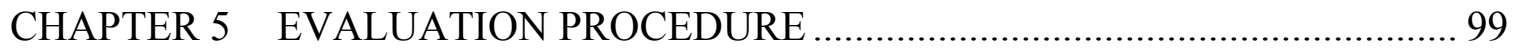

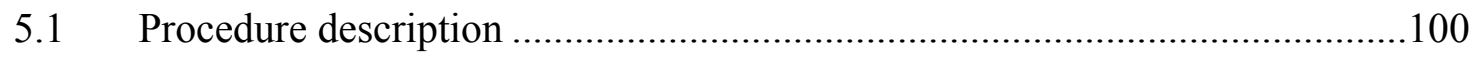

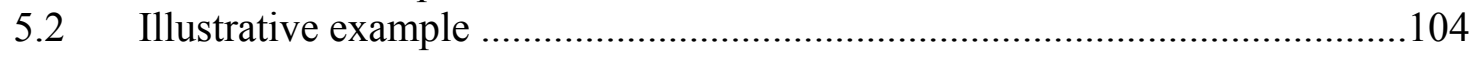

CHAPTER 6 SIMULATION EXPERIMENT DESIGN …....................................... 117

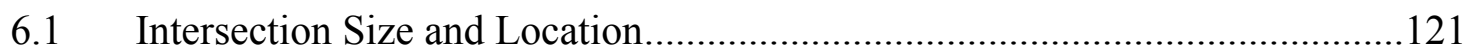

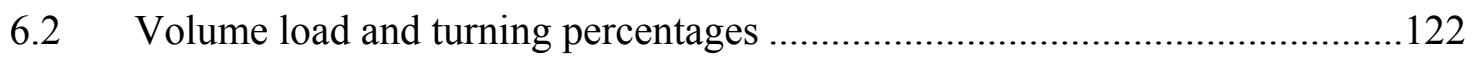

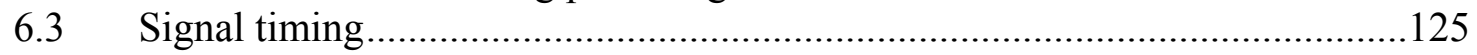

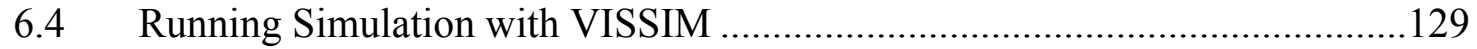

CHAPTER 7 PRESENTATION OF THE SIMULATION RESULTS ..................... 133

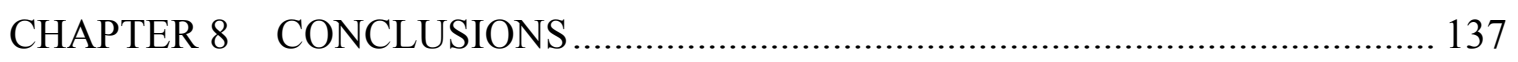

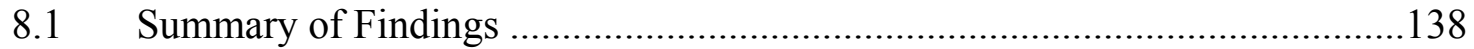

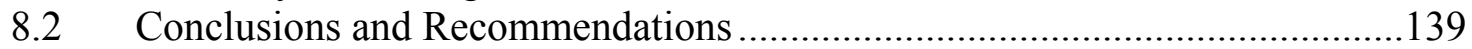

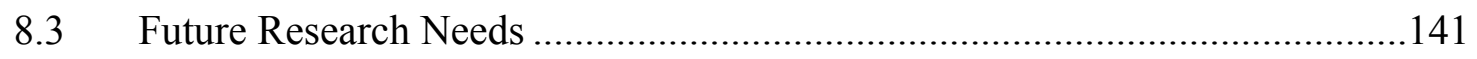

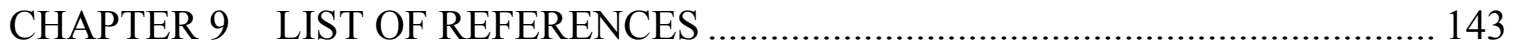

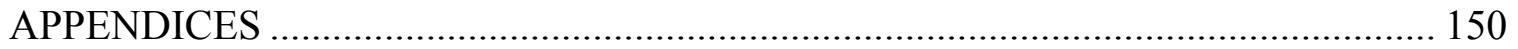

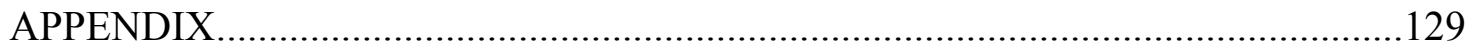




\section{LIST OF TABLES}

Table

Page

Table 2-1 Characteristics of CFI (Tabernero and Sayed, 2006; Hummer and Reid, 2000) 9

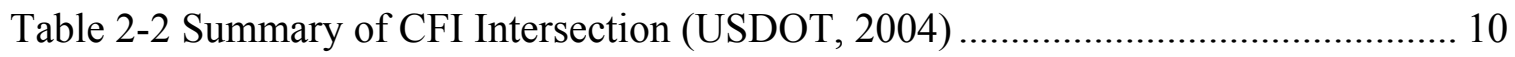

Table 2-3 Characteristics of a Forward Jughandle (Tabernero and Sayed, 2006; Hummer

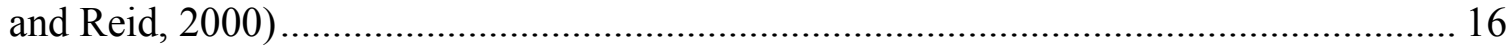

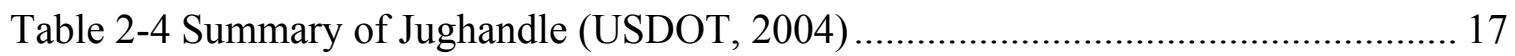

Table 2-5 Characteristics of a Median U-turn (Jagannathan, 2007; Tabernero and Sayed,

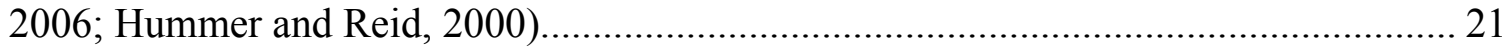

Table 2-6 MUT Corridor Relative to a TWLTL Corridor (Reid et al., 1999).................. 22

Table 2-7 Summary of Median U-turn Intersection (USDOT, 2004) ........................... 23

Table 2-8 Characteristics of SSM Design (Hummer, 1998; Hummer and Reid, 2000) ... 32

Table 2-9 SSM Corridor Relative to a TWLTLC (Reid et al., 1999)............................ 33

Table 2-10 Summary of SSM Intersection Adapted from (USDOT, 2004) .................... 34

Table 2-11 Characteristics of a Bowtie Intersection (Hummer, 1998; Hummer and Reid,

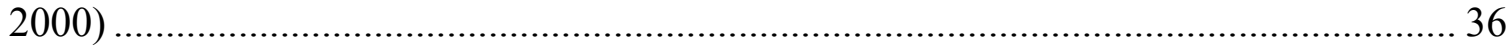

Table 2-12 Characteristics of Continuous Green-T (Tabernero and Sayed, 2006) .......... 38

Table 2-13 Characteristics of Paired Intersection (Tabernero and Sayed, 2006) ............ 43

Table 2-14 Characteristics of QRI Intersection Based on (Reid, 2000) ......................... 46

Table 2-15 USC Intersection Characteristic (Tabernero et al.; Tarek et al., 2006) .......... 50 
Table

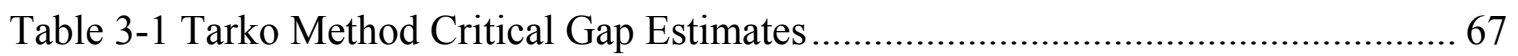

Table 3-2 Maximum Likelihood Method Critical Gap Estimates ................................. 68

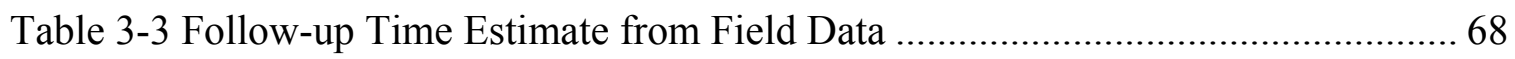

Table 4-1 VISSIM Parameters Effecting Roadway Segment Capacity (Lownes and

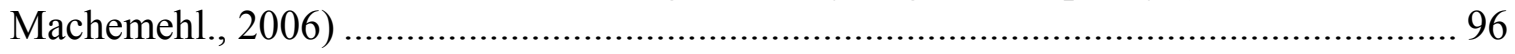

Table 4-2 Recommended Saturation Flow Rates for Indiana (Perez-Cartagena and Tarko, 2004) 95

Table 4-3 Assumed Values for Urban and Rural Setting .......................................... 95

Table 4-4 Summary of Saturation Flow Rate Calibration ........................................... 97

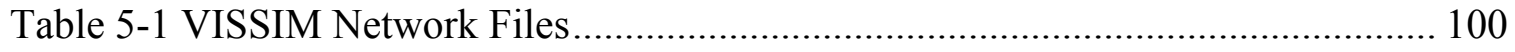

Table 5-2 Distance at Which Vehicles Reach their Desired Speed .............................. 104

Table 5-3 Conventional Intersection Total Delay..................................................... 114

Table 5-4 Extracted Measures for a Conventional Intersection.................................. 114

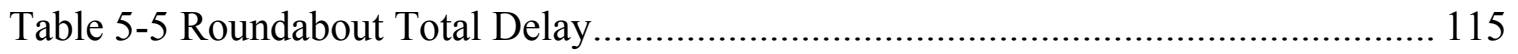

Table 5-6 Extracted Measures for a Roundabout ................................................... 115

Table 6-1 Intersection types, intersection geometric configuration and intersection

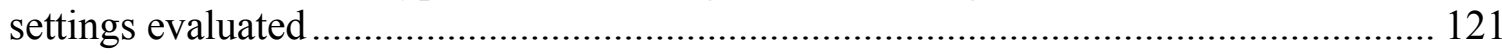

Table 6-2 Characteristics of Urban and Rural settings ............................................ 122

Table 6-3 Sample results for total delay .............................................................. 132

Table 6-4 Sample results for stop delay and number of stops ................................. 132 
Table 7-1 Example presentation of the number of stops per vehicle (urban intersection, lanes $2 \times 2$, intersection split 55/45, directional split 55/45, left turns on both roads $10 \%$ )

Table 7-2 Example simulation results header ....................................................... 136 


\section{LIST OF FIGURES}

Figure

Page

Figure 2-1 Effect of Intersection Spacing on Progression (Nichols and Bullock, 2001) ... 5

Figure 2-2 Vehicle Movement at a Full Continuous-flow Intersection (Tarko et al., 2008)

Figure 2-3 Signal Phasing of Continuous-flow Intersection (USDOT, 2004).................. 7

Figure 2-4 Turning Movements for a Forward-forward Jughandle (Tarko et al., 2008).. 11

Figure 2-5 Turning Movements for a Reverse-reverse Jughandle (Tarko et al., 2008)... 12

Figure 2-6 Turning Movements for a Forward-reverse (Tarko et al., 2008) ................... 12

Figure 2-7 Signal Phasing for a Jughandle (USDOT, 2004) ....................................... 14

Figure 2-8 Median U-turn Turning Movements (Tarko et al., 2008) ............................. 18

Figure 2-9 Roundabout Turning Movements-Example (Tarko et al., 2008) ................... 24

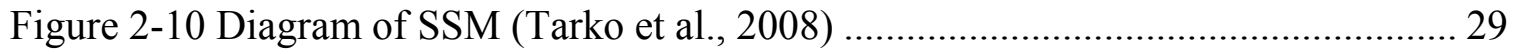

Figure 2-11 Super-street Traffic Movement (Tarko et al., 2008) .................................. 30

Figure 2-12 Typical Phasing for the Super-street Intersection (USDOT, 2004) ............. 30

Figure 2-13 Bowtie Intersection Diagram (Tarko et al., 2008) .................................... 35

Figure 2-14 Diagram of a Continuous Green T-Intersection (Tarko et al., 2008)........... 37

Figure 2-15 Diagram of Double-Wide intersection (Tarko et al., 2008) ........................ 40

Figure 2-16 Traffic Flows for a Paired Intersection (Tarko et al., 2008) ....................... 42

Figure 2-17 Diagram of QRI Intersection (Reid and Hummer, 2001) ........................... 44 
$\begin{array}{lll}\text { Figure } & \text { Page }\end{array}$

Figure 2-18 Example QRI Traffic Pattern (Tarko et al., 2008) ........................................ 45

Figure 2-19 Phasing Plan for QRI Intersection (Hummer and Reid, 1999) ..................... 45

Figure 2-20 Diagram of Split Intersection (Polus and Cohen, 1997) .............................. 47

Figure 2-21 Diagram of USC Intersection (Tabernero et al.) ........................................... 48

Figure 3-1 Hazel Dell Pkwy \& E 131st Street Roundabout ............................................. 52

Figure 3-2 Events Collected During Video Extraction..................................................... 54

Figure 3-3 Sample of Recorded Data by Event Log Tool .............................................. 55

Figure 3-4 Simple Accepted Gap Event Sequence ………………………………....... 56

Figure 3-5 Simple Rejected Gap Event Sequence ........................................................ 57

Figure 3-6 Rejected Lag Event Sequence ………………............................................ 58

Figure 3-7 Accepted Lag Event Sequence..................................................................... 59

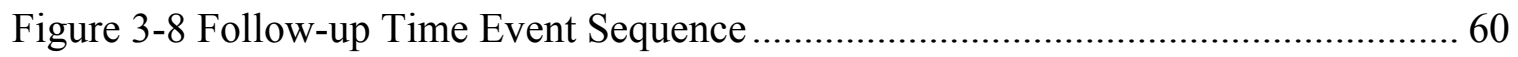

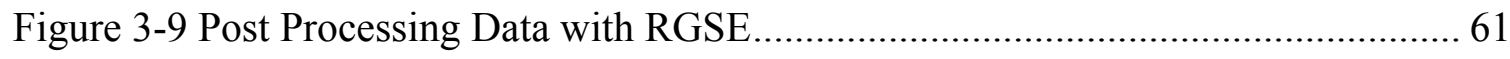

Figure 3-10 RGS Software Sample Output I .............................................................. 75

Figure 3-11 RGS Software Sample Output I ............................................................... 76

Figure 3-12 Data Collection Points at Roundabout ....................................................... 70

Figure 3-13 Counts at Data Collection Points Extracted from Field Data ....................... 82

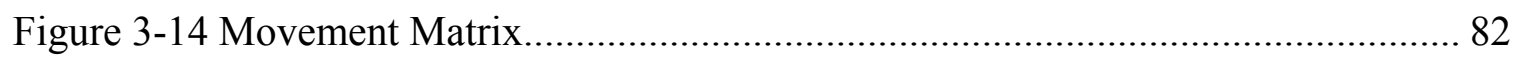

Figure 3-15 Estimated Turning Movements Using Matrix Method ................................ 74

Figure 3-16 Loading Volumes for Simulation Experiment …………………………..... 75

Figure 3-17 Follow-up Calibration Data Collection Setup............................................. 76 
Figure

Figure 3-18 Follow-up Time Based on Headway Parameter...................................... 77

Figure 3-19 Effect of CC8 on Roundabout Follow-up Time for Different CC1 Values.. 78 Figure 3-20 Summary of Tested Combination of Parameters on Follow-up Time .......... 79

Figure 3-21 Data Collection Points in Simulation ................................................. 80

Figure 3-22 Service Time Simulation Experiment ................................................. 81

Figure 4-1 Determination of Saturation Flow Rate in Simulation Experiment ................ 84

Figure 4-2 Discharge Rate Evaluation Output....................................................... 86

Figure 4-3 Three Dimension View of Simulation Experiment................................... 88

Figure 4-4 Effect of Standstill Distance (CC0) Parameter on Saturation Flow Rate ....... 89

Figure 4-5 Effect of Standstill Acceleration on Saturation Flow Rate .......................... 90

Figure 4-6 Effect of $|\mathrm{CC} 4|$ \& CC5 on Saturation Flow Rate ....................................... 91

Figure 4-7 Effect of Following Variation (CC2) on the Saturation Flow Rate ............... 92

Figure 4-8 Illustration of Safety Distance in VISSIM ............................................. 92

Figure 4-9 Effect of Headway Time (CC1) on Saturation Flow Rate ............................ 93

Figure 4-10 Effect of Trucks on Saturation Flow Rate............................................... 94

Figure 4-11 Calibration of Saturation Flow Rate for 45 mph Speed Roadway ............... 96

Figure 4-12 Calibration of Saturation Flow Rate for 60mph Speed .............................. 97

Figure 5-1 Evaluation Network Files I ........................................................... 101

Figure 5-2 Evaluation Network Files II ......................................................... 102

Figure 5-3 Evaluation Network Files III............................................................ 104

Figure 5-4 Traffic Conditions for Analyzed Case .................................................... 105 
Figure $\quad$ Page

Figure 5-5 Entering Volumes in SYNCHRO ….................................................. 105

Figure 5-6 Optimizing Signal Timing in SYNCHRO .............................................. 106

Figure 5-7 Optimized signal timing plans in SYNCHRO .......................................... 106

Figure 5-8 Entering Approach Volumes in VISSIM ............................................. 107

Figure 5-9 Specifying Turning Movements in VISSIM ............................................ 107

Figure 5-10 Signal Control Window....................................................................... 108

Figure 5-11Entered Signal Settings into NEMA Controller....................................... 109

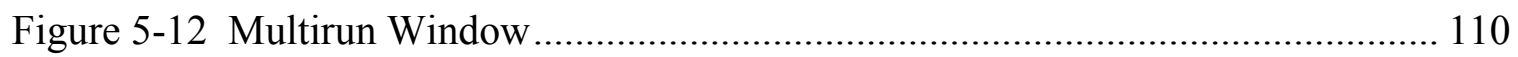

Figure 5-13 Sample Travel Time Measurement Output File....................................... 111

Figure 5-14 Partial View of Travel Time Data ....................................................... 111

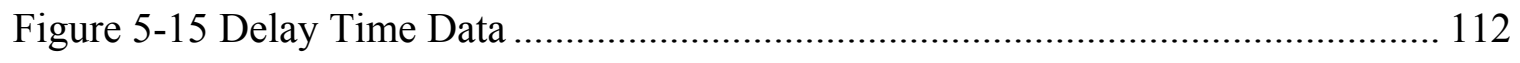

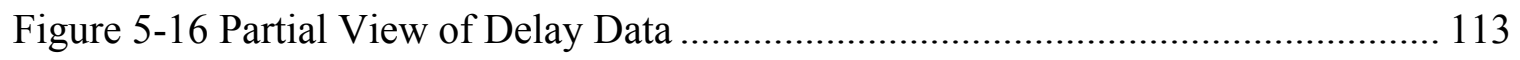

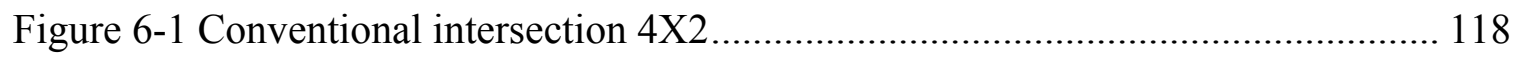

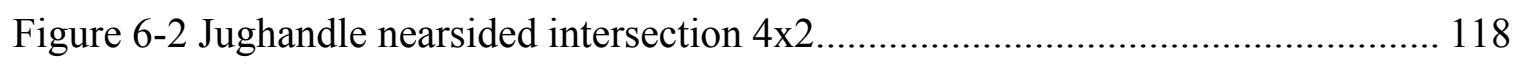

Figure 6-3 Jug handle far-sided intersection 4x2 ............................................... 119

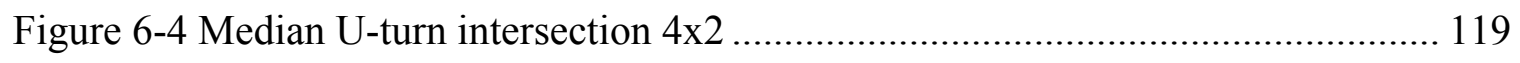

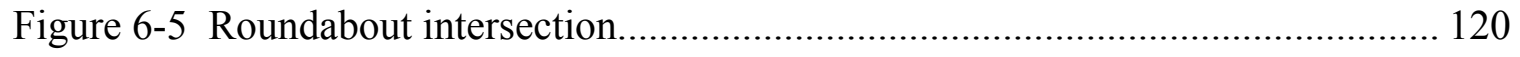

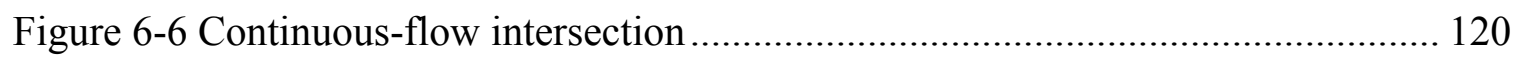

Figure 6-7 Results of the example calculations of directional traffic .......................... 124

Figure 6-8 Conventional intersection 4x2 Synchro file ........................................ 125

Figure 6-9 Jug handle far-sided intersection 4x2 Synchro file ................................. 125 
Figure

Figure 6-10 Jughandle nearsided intersection 4x2 Synchro file 126

Figure 6-11 Median U-turn intersection 4x2 Synchro file 127

Figure 6-12 Continuous-flow intersection 4x2 Synchro file 128

Figure 6-13 Flowchart for running a simulation scenario 130

Figure 6-14 Travel time sections definition in VISSIM 131

Figure 7-1 Example presentation of the delay at the busiest approach (urban intersection, lanes $2 \times 2$, intersection split 55/45, directional split 55/45, left turns on both roads $10 \%$ )

Figure 7-2 Example presentation of the intersection delay (urban intersection, lanes $2 \times 2$, intersection split 55/45, directional split 55/45, left turns on both roads $10 \%$ ) 135 


\section{LIST OF SYMBOLS}

2X2 four leg intersection with four entering lanes

$4 \mathrm{X} 2$ four leg intersection with six entering lanes

$\sigma_{c} \quad$ standard deviation of critical gap

$\mathrm{g}_{\mathrm{a}} \quad$ accepted gap

$\mathrm{g}_{\mathrm{c}} \quad$ critical gap

$\bar{g}_{c} \quad$ average critical gap

$\mathrm{g}_{\mathrm{r}} \quad$ rejected gap 


\section{ACKNOWLEDGEMENTS}

The authors would like to express their gratitute to the Study Advisory Council members, Rick Drumm, David Lane, Shuo Li, John Nagle, Brad Steckler, Ernie Stoops, and Jim Sturdevant for their guidance. Additionally, the authors would like to acknowledge the contributions made by Brandon Lang, Apichai Issariyanukula, and Aidin Mohammadi who helped run the numerous simulation scenarios and process the results. 


\section{CHAPTER 1 INTRODUCTION}

An alternative intersection often involves displacement of the left-turn movement from the primary intersection, which could result in additional surrounding minor intersections. The need for alternative intersections has developed in response to an increase in the degradation of service at conventional intersections under specific traffic conditions and roadway limitations. Left-turn movements at alternative intersections may not need to be displaced but rather have some treatment other than a direct left-turn.

The left-turn movement is the primary focus in alternative intersections because it is often one of the major contributors to delays at conventional intersections. From an operational standpoint, if an intersection is signalized, left-turn movements may require a separate traffic signal phase. The addition of these separate phases results in an increased cycle-length. As a result of these considerations, alternative treatments of the left-turn movement are found in almost every alternative intersection.

Many alternative intersections have been proposed. Each alternative intersection has advantageous and disadvantages. No single alternative intersection is a superior alternative under all traffic circumstancess. Choosing the appropriate alternative intersection depends upon the conditions of the intersection under consideration. In some cases, a conventional intersection will be the preferred alternative. Not all alternative intersections have been implemented in the field; some have only been assessed on the conceptual level and their operations evaluated using microscopic simulation. 
At the present time evaluating alternative intersections is a problem because most of them are fairly new and have been implemented for a short period of time, if at all. Furthermore, some alternative intersection installations are only partial implementations. From an operational standpoint, the lack of an implemented alternative intersection can be overcome to a certain degree through the use of microsimulation.

The alternative intersections reviewed and considered in this study are at-grade intersections and include: continuous flow intersections, jughandles, median u-turns, roundabouts, superstreet median crossovers, bowties, continuous green T-intersections, double-wide intersections, paired intersections, quadrant roadway intersections, split intersections, and upstream signalized crossover intersections.

The effects of different VISSIM model parameters (PTV_Vision, 2007) on the saturation flow rate were investigated and a single headway ( $\mathrm{CC} 1)$ parameter was used to adjust the saturation flow rate to Indiana field-measured values. Investigating different speed limits indicated that different values of headway parameter need to be used for different speed limits to obtain a targeted saturation flow rate value.

For a roundabout, data were collected at a carefully chosen site in Carmel, Indiana with continuous queuing present a majority of the time on at least one approach during data recording. With queuing on a roundabout approach, it is possible to extract drivers' accepted gaps, rejected lags, and rejected gaps. Driver accepted gaps are particularly important when estimating the critical gap. It was determined in this research that using gaps as opposed to gaps and legs in the critical gap estimation procedure more accurately predicts a driver's critical gap.

The most promising network files were constructed in Synchro and VISSIM and calibrated for Indiana conditions. These files are the starting points of the evaluation procedure. In the evaluation procedure, measures of effectiveness such as average delay 
and average number of stops were collected in VISSIM simulation by a defined travel section and were aggregated based on a one-hour simulation run for each movement. VISSIM user-defined travel sections allowed flexibility in defining and collecting measures for unconventional movements along their paths. 


\section{CHAPTER 2 LITERATURE REVIEW}

\subsection{Conventional intersection}

A conventional intersection is generally defined as an intersection where all movements are direct. This can be a two-way or four-way stop controlled intersection, or it may be signalized. It may have as little as one lane on each leg or more; and finally, the intersection may be in a rural, suburban, or urban setting.

Conventional intersections with direct left turns can serve only a limited number of vehicles with strong conflicting through-movements. Signalized intersections with protected left-turn movements will require long left turn phases with heavy left turns, thus increasing cycle length and delay for conflicting through-movements. Increasing the number of approach lanes on a given leg of an intersection increases the width of the crossing roadway for perpendicular approaches, thus increasing the red clearance intervals for vehicles and the pedestrian clearance intervals for pedestrians. At unsignalized intersections, strong left turns do not allow for the near simultaneous crossing of vehicles through an intersection from opposing directions like opposing through movements do; thus, with high left turn volumes, less vehicles can be served. Increasing demand at conventional intersections slowly degrades their performance.

In terms of arterial progression, good coordination for conventional intersections with protected turn bays can only be achieved in both directions for even intersection spacing. With uneven intersection spacing, progression can usually be accommodated only in one direction (Figure 2-1). 


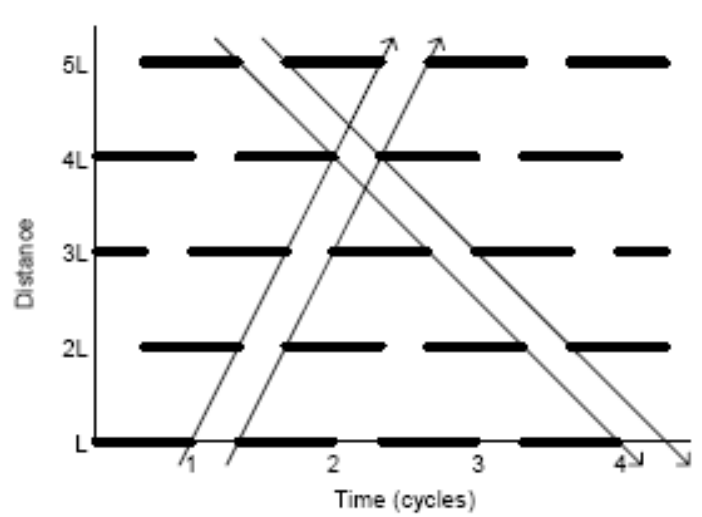

(a) Evenly Spaced Intersections

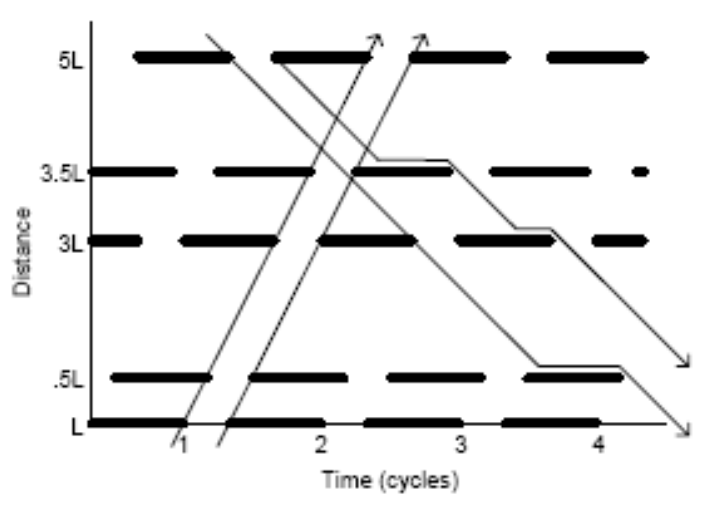

(b) Randomly Spaced Intersections

Figure 2-1 Effect of Intersection Spacing on Progression (Nichols and Bullock, 2001)

\subsection{Continuous Flow Intersections}

A continuous-flow intersection (CFI), sometimes called the crossover-displaced leftturn (XDL) intersection, provides ramps left to the arterial and cross street upstream of the main intersection to handle left turning movements from the arterial and cross-street, respectively. Figure 2-2 demonstrates how left and right-turning vehicles from Street A (a) and Street B (b) would traverse the intersection. 


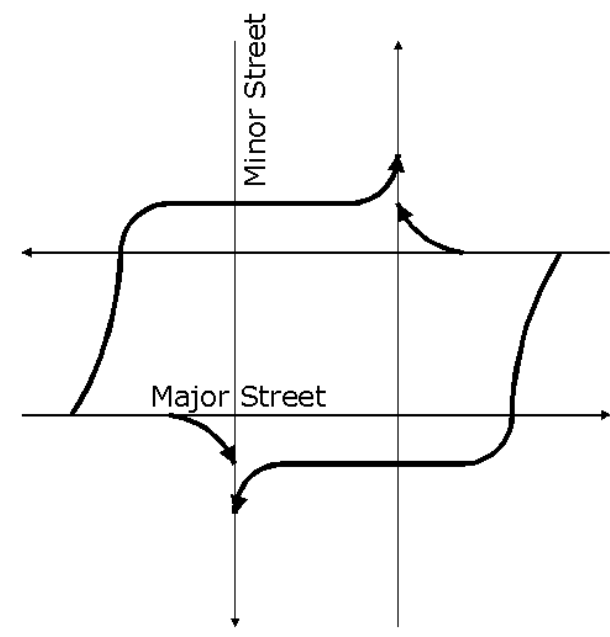

(a) Major Street Turning Movements

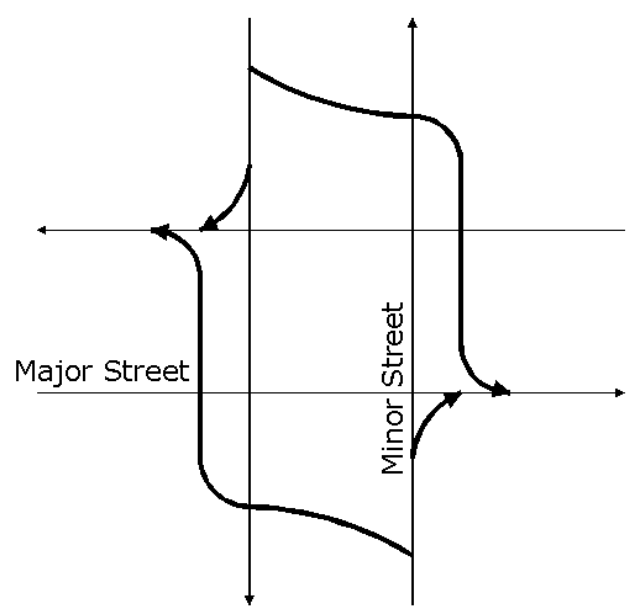

(b) Minor Street Turning Movements

Figure 2-2 Vehicle Movement at a Full Continuous-flow Intersection (Tarko et al., 2008)

Partial continuous-flow intersections (CFI) have also been implemented. A partial CFI only has two ramps on the major roadway, which typically is the arterial.

The major advantage with this design is that through traffic and traffic using the left-turn ramp can move during the same signal phase without conflicting. The signals at the ramps should be coordinated with the primary intersection signal so through arterial traffic does not stop more than once. A single signal controller which operates the primary intersection and left-turn ramp/minor street intersection (Figure 2-3) helps to achieve this coordination. The left-turn ramp should cross the opposing traffic at a point which prevents spill-back from the primary intersection and blockage of the crossover signal. 


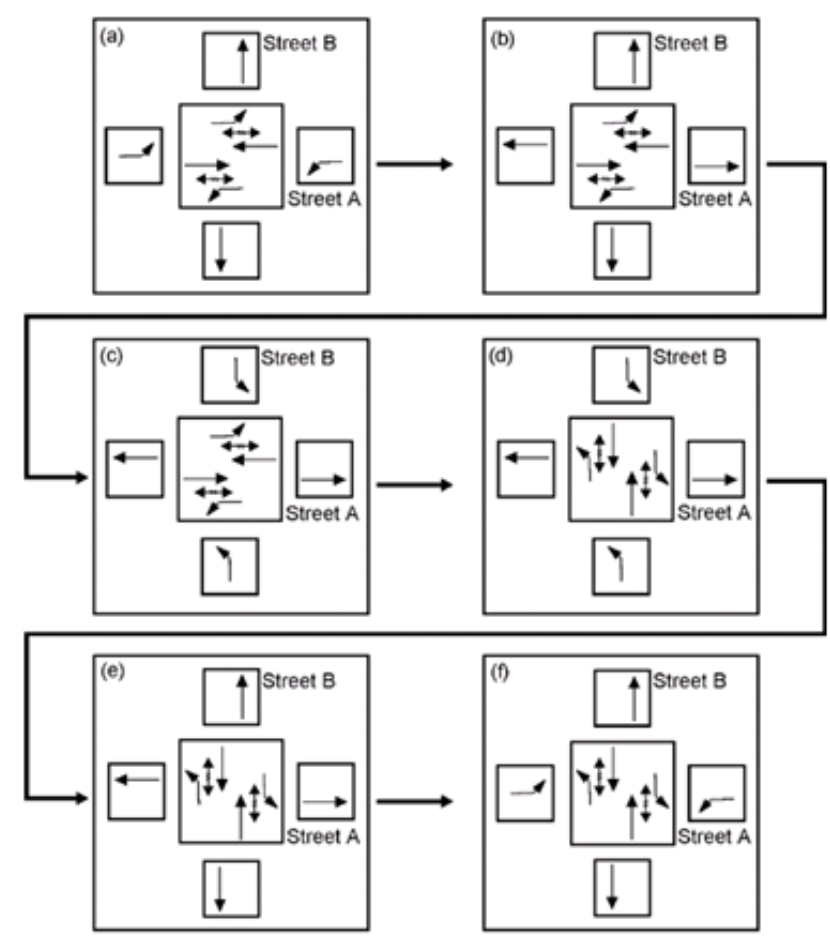

Figure 2-3 Signal Phasing of Continuous-flow Intersection (USDOT, 2004)

Full or partial implementations of a continuous-flow intersection can provide significant savings in delay, can reduce queue length and the average number of stops, and may add additional capacity when compared with a conventional intersection design with left-turn pockets (Hummer and Reid, 2000). Additionally, the benefits of a CFI grow as traffic volumes increase. Locations with high demand balanced throughout the day therefore will experience greater benefits compared to a location that experiences high volumes for only a relatively short period of time, such as a peak period, with declining volumes thereafter.

Under balanced volumes, the advantages of a continuous-flow intersection with respect to a conventional intersection are greatest with high left turn volumes and overcapacity conditions (Goldblatt et al., 1994). As left turn volumes increase, protected left turn phases for a conventional intersection increase, extending the cycle length and increasing delay for the intersection as a whole. Short cycle lengths are not possible for this 
conventional intersection because left turning bays may spillback. For a CFI intersection, on the other hand, left turns can proceed simultaneously with the through movement. Hence, delay is reduced with heavy left-turn and through movements for a continuousflow intersection.

In terms of pedestrian operations, service time for any pedestrian at a continuous-flow intersection can be accommodated within two cycle lengths (Jagannathan and Bared, 2005). A continuous-flow intersection may increase the maximum average delay per stop and maximum average delay for a pedestrian crossing in a diagonal across two legs of an intersection when compared with a conventional intersection. These findings should be considered when heavy pedestrian volumes are present.

A continuous-flow intersection has characteristics summarized as follows: 
Table 2-1 Characteristics of CFI (Tabernero and Sayed, 2006; Hummer and Reid, 2000)

\begin{tabular}{|c|c|c|c|}
\hline Advantages & Disadvantages & When to Consider & $\begin{array}{l}\text { When not to } \\
\text { Consider }\end{array}$ \\
\hline $\begin{array}{l}\text {-Reduced delay } \\
\text { for through } \\
\text { arterial traffic } \\
\text {-Reduced stops } \\
\text { for through traffic } \\
\text {-Easier } \\
\text { progression for } \\
\text { through arterial } \\
\text { traffic } \\
\text {-Applicable to all } \\
\text { median cases } \\
\text { including roads } \\
\text { with no and } \\
\text { narrow median } \\
\text {-Reduced and } \\
\text { more separated } \\
\text { conflict points }\end{array}$ & $\begin{array}{l}\text {-Driver and } \\
\text { pedestrian confusion } \\
\text {-Increased stops for } \\
\text { left turns from the } \\
\text { arterial } \\
\text {-Restricted U-turn } \\
\text { possibilities } \\
\text {-Pedestrians must } \\
\text { cross ramps and the } \\
\text { main intersection } \\
\text { (and pedestrians } \\
\text { must cross the four- } \\
\text { quadrant design in a } \\
\text { slow two-stage } \\
\text { maneuver) } \\
\text {-Additional right-of- } \\
\text { way for ramps } \\
\text {-Additional } \\
\text { construction and } \\
\text { maintenance costs } \\
\text { for ramps } \\
\text {-Lack of access to } \\
\text { arterial for parcels } \\
\text { next to ramps } \\
\text {-There may be costs } \\
\text { associated with } \\
\text { obtaining the rights } \\
\text { to use the design }\end{array}$ & $\begin{array}{l}\text {-High through } \\
\text { volumes with } \\
\text { little demand for } \\
\text { U-turns } \\
\text {-Sufficient } \\
\text { intersection } \\
\text { spacing to } \\
\text { outweigh the } \\
\text { savings elsewhere } \\
\text {-Restricted access } \\
\text { to the arterial for } \\
\text { parcels near } \\
\text { intersection }\end{array}$ & $\begin{array}{l}\text {-Narrow right } \\
\text { of way at the } \\
\text { intersection and } \\
\text { no possibility } \\
\text { for obtaining } \\
\text { extra right of } \\
\text { way at the } \\
\text { intersection }\end{array}$ \\
\hline
\end{tabular}


Table 2-2 Summary of CFI Intersection (USDOT, 2004)

\begin{tabular}{|c|c|c|}
\hline Characteristics & Potential Benefits & Potential Liabilities \\
\hline Safety & $\begin{array}{l}\text { Left turns removed from } \\
\text { main intersection }\end{array}$ & None identified \\
\hline Operations & More green for through & $\begin{array}{l}\text { More stops and delay for } \\
\text { left turns }\end{array}$ \\
\hline \multirow[t]{2}{*}{ Multimodal } & \multirow[t]{2}{*}{$\begin{array}{l}\text { No conflicts during } \\
\text { pedestrian crossing }\end{array}$} & $\begin{array}{l}\text { Two-stage pedestrian } \\
\text { crossing }\end{array}$ \\
\hline & & $\begin{array}{l}\text { Layout may not be } \\
\text { immediately apparent, } \\
\text { especially for visually } \\
\text { impaired persons }\end{array}$ \\
\hline \multirow[t]{3}{*}{ Physical } & \multirow{3}{*}{$\begin{array}{l}\text { Similar footprint than } \\
\text { interchange alternative }\end{array}$} & Right-of-way needed \\
\hline & & $\begin{array}{l}\text { Larger footprint than } \\
\text { conventional intersection }\end{array}$ \\
\hline & & Access management \\
\hline \multirow[t]{2}{*}{ Socioeconomic } & \multirow[t]{2}{*}{ Air quality } & Construction cost \\
\hline & & Access management \\
\hline $\begin{array}{l}\text { Enforcement, Education, } \\
\text { and Maintenance }\end{array}$ & None identified & $\begin{array}{l}\text { Public information } \\
\text { campaign may be needed }\end{array}$ \\
\hline
\end{tabular}

When considering pedestrian/vehicle interactions, the continuous-flow intersection might be confusing to pedestrians due to more complex geometry. Compared with other alternatives, the total number of roadways and the number of free-flowing roadways that need to be crossed by a pedestrian is relatively high (Jagannathan and Bared, 2005). Furthermore, the more complex intersection geometry might cause driver confusion, thus compromising pedestrian and vehicle safety. 


\subsection{Jughandle intersection}

The jughandle intersection uses ramps diverging to the right side of the arterial to accommodate the left and right turns from the arterial. For example, in Figure 2-4, the jughandle on the top of the figure was designed to remove left and right turns from traffic traveling towards the left of the figure. Therefore, the left and right turning movements exit onto the jughandle ramp, to the right of the arterial, and then make either a left or right turn onto the minor street, as shown in part (a) of Figure 2-4. The minor street turning movements proceed as normal, as shown in part (b).

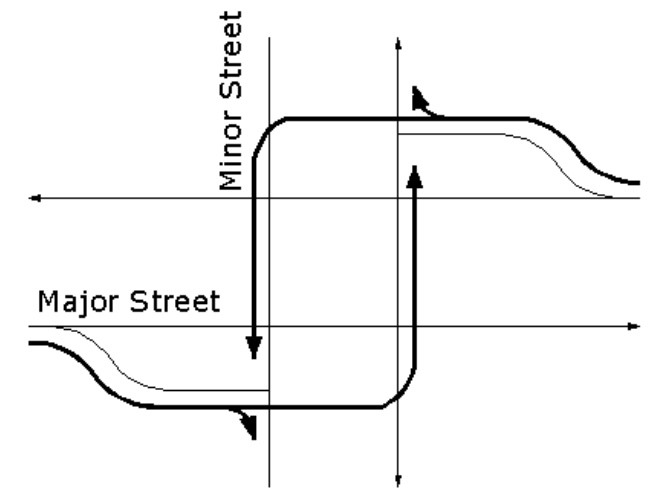

(a) Major Street Turning Movements

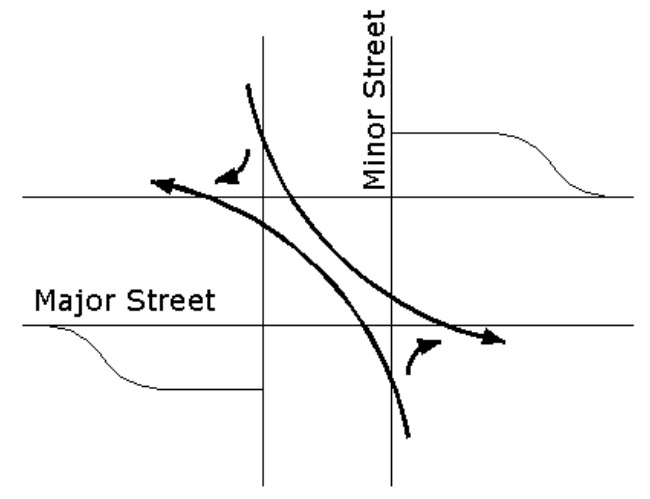

(b) Minor Street Turning Movements

Figure 2-4 Turning Movements for a Forward-forward Jughandle (Tarko et al., 2008)

Figure 2-5 and Figure 2-6 show how turning vehicles proceed at reverse-reverse and forward-reverse jughandle intersections. 


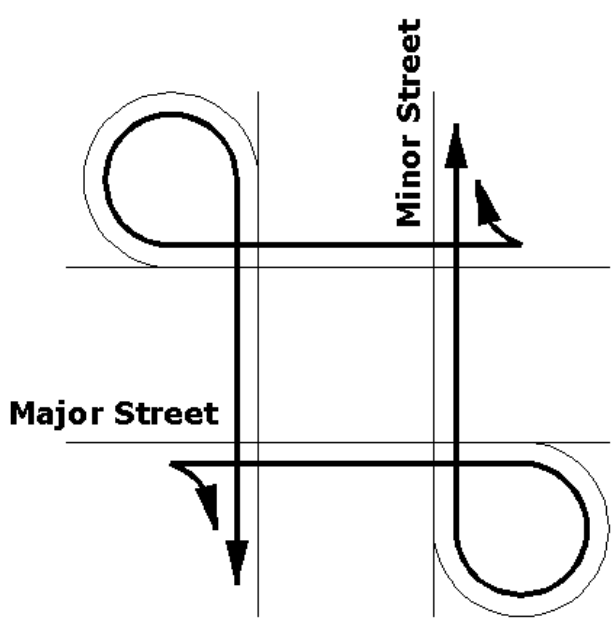

(a) Major Street Turning Movements

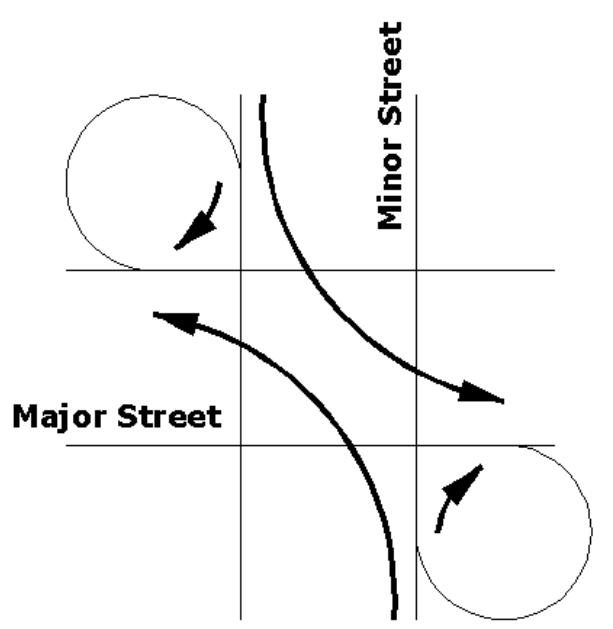

(b) Minor Street Turning Movements

Figure 2-5 Turning Movements for a Reverse-reverse Jughandle (Tarko et al., 2008)

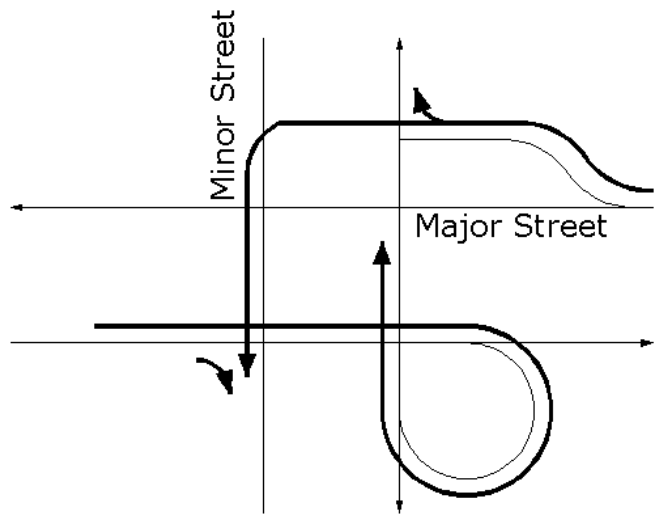

(a) Major Street Turning Movements

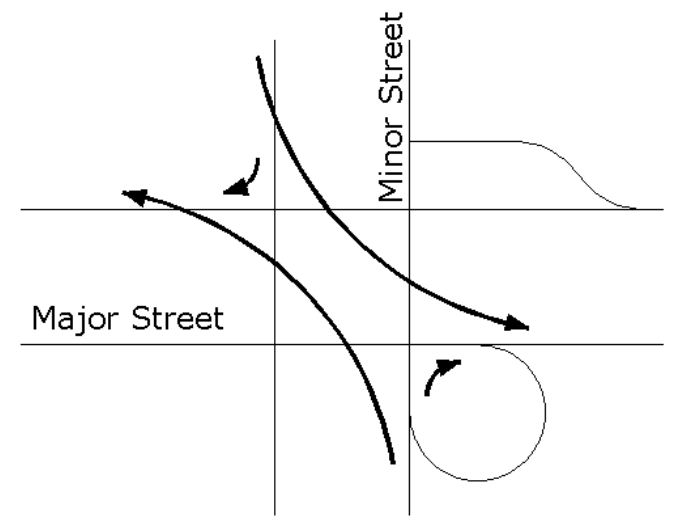

(b) Minor Street Turning Movements

Figure 2-6 Turning Movements for a Forward-reverse (Tarko et al., 2008)

There are two types of jughandle ramps, combinations of which can form the intersection configurations shown in Figure 2-4 through Figure 2-6. The first type is a forward ramp (also called a near-sided ramp), as shown in Figure 2-4; and the second is a reverse ramp (also called a far-sided ramp), as shown in Figure 2-5. There is no back-tracking on a forward ramp. Left and right turn movements for a forward-forward jughandle ramp 
configuration are shown in Figure 2-4. A reverse ramp, on the other hand, requires the user to first proceed through the intersection then exit on the reverse ramp. The user is redirected back onto the minor roadway via the reverse ramp. The user then proceeds through the primary intersection for a second time (i.e., backtracking) to complete a lefthand turn. The left and right turn movements for a reverse-reverse jughandle ramp are shown in Figure 2-5. Additionally, the implementation of a combination of forward and reverse jughandle ramps can be used to accommodate right-of-way restrictions. A conceptual configuration and left and right turn movements are shown in Figure 2-6 for the combination.

The New Jersey Department of Transportation (NJDOT) developed a design manual for jughandle intersections. Design features like ramp speed, desirable exit curve, ramp right turn radius at a cross-street and guidance regarding ramp length, ramp placement, length of deceleration lane and signage are found in this manual (Robinson et al., 2000). The NJDOT manual identifies three types of jughandles: Type A, Type B, and Type C. Type A is most similar to a forward jughandle, as described previously. Type B resembles the median U-turn alternative intersection design, as discussed in Section 5, although there are some differences. There are implications that this type of jughandle has been infrequently implemented. Type $\mathrm{C}$ resembles the forward-reverse jughandle configuration previously described.

The control at the primary intersection of a jughandle is signalized. The settings for the signal at the primary intersection should be set so that queues on the minor street do not spill back to block the termini of the jughandle ramps. Additionally, the primary intersection signal may have two or three phases. A three-phase signal will be utilized if the left-turning movement from the minor street needs to be protected. These alternatives are shown in Figure 2-7. 


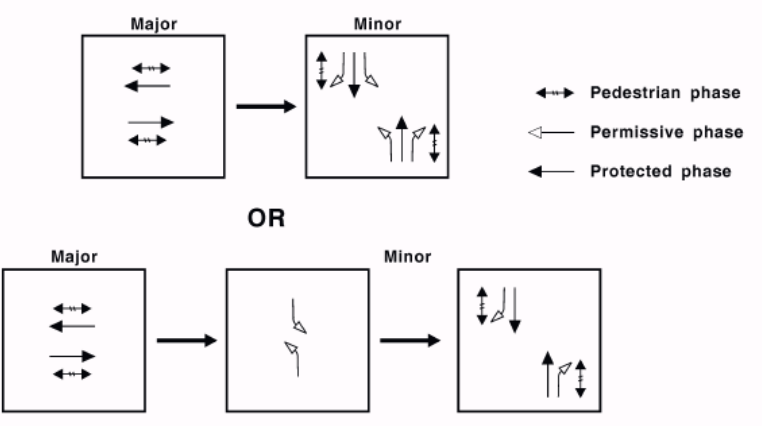

Figure 2-7 Signal Phasing for a Jughandle (USDOT, 2004)

Depending on the volume of traffic using the jughandle intersection, the control at the secondary intersections created by the jughandle can be a combination of stop and yield control or can be signalized. If the secondary intersection is not signalized, the left-turn movements at the secondary intersection are typically stop controlled, and the right-turn movements are typically yield controlled.

The forward jughandle can accommodate light to moderate left turn movements on the major road. This configuration might experience potential problems with large through movements if the queue from the primary intersection extends back to block the jughandle.

The Type B jughandle is used to provide a u-turn possibility for heavy vehicles on roadway sections with a narrow median. It can also be used as a directional crossover for left turns.

The reverse jughandle can be used to accommodate heavier left turns than experienced with a forward jughandle. The length of the reverse ramp should be designed to accommodate the queue that could build up during one cycle length. Designing the reverse ramp in this manner will prevent spillback which subsequently blocks through movements. An important consideration associated with the reverse jughandle is the 
provision of an additional lane for motorists exiting the reverse jughandle onto the minor street. A potential drawback associated with this design is that greater right-of-way is needed.

Jughandles require left-turning vehicles to drive a longer distance through the intersection, which may lead to longer delay and travel distance. Under heavy volumes, on a forward jughandle, the queue spillback from the primary intersection might block the termini of the jughandle ramps, which would result in an additional delay for left-turning movements. Additionally, if a forward jughandle ramp is controlled with a stop sign, the number of stops that a left-turning vehicle might encounter when traversing a jughandle increases. It is extremely important to evaluate the advantages and disadvantages to through movements versus left turn movements for this design. However, even with an increase in travel distance for left turns, the intersection might operate at a lower average delay than experienced at a conventional solution (USDOT, 2004).

Table 2-3 shows the characteristics of a forward jughandle intersection. 
Table 2-3 Characteristics of a Forward Jughandle (Tabernero and Sayed, 2006; Hummer and Reid, 2000)

\begin{tabular}{|c|c|c|c|}
\hline Advantages & Disadvantages & $\begin{array}{l}\text { When to } \\
\text { Consider }\end{array}$ & When not to Consider \\
\hline $\begin{array}{l}\text {-Reduced } \\
\text { delay for } \\
\text { through } \\
\text { arterial } \\
\text { traffic } \\
\text {-Reduced } \\
\text { stops for } \\
\text { through } \\
\text { traffic } \\
\text {-Easier } \\
\text { progression } \\
\text { for through } \\
\text { arterial } \\
\text { traffic } \\
\text {-Narrower } \\
\text { right-of-way } \\
\text { needed along } \\
\text { the arterial } \\
\text {-Fewer and } \\
\text { more } \\
\text { separated } \\
\text { conflict } \\
\text { points }\end{array}$ & $\begin{array}{l}\text {-Driver confusion } \\
\text {-Driver disregard for } \\
\text { left-turn prohibitions at } \\
\text { the main intersection } \\
\text {-Increased travel } \\
\text { distances for left turns } \\
\text { from the arterial } \\
\text {-Increased delay for left } \\
\text { turns from the arterial, } \\
\text { especially if queues of } \\
\text { cross-street vehicles } \\
\text { block the ramp terminal } \\
\text {-Increased stops for left } \\
\text { turns form the arterial } \\
\text {-Additional } \\
\text { construction and } \\
\text { maintenance costs for } \\
\text { ramps } \\
\text {-Lack of access to } \\
\text { arterial for parcels next } \\
\text { to ramps } \\
\text {-Pedestrians must cross } \\
\text { ramps and the main } \\
\text { intersection }\end{array}$ & $\begin{array}{l}\text {-High arterial } \\
\text { through volumes } \\
\text { with low and } \\
\text { moderate cross } \\
\text { street left-turn } \\
\text { volumes } \\
\text {-Narrow right of } \\
\text { way }\end{array}$ & $\begin{array}{l}\text {-Sufficient spacing } \\
\text { between intersections } \\
\text { so right-of-way and } \\
\text { ramp costs do not } \\
\text { overwhelm the savings } \\
\text { elsewhere }\end{array}$ \\
\hline
\end{tabular}


Table 2-4 Summary of Jughandle (USDOT, 2004)

\begin{tabular}{|c|c|c|}
\hline Characteristics & Potential Benefits & Potential Liabilities \\
\hline Safety & $\begin{array}{l}\text { Potential reduction in left- } \\
\text { turn collisions }\end{array}$ & None identified \\
\hline Operations & $\begin{array}{l}\text { Potential reduction in } \\
\text { overall travel time and stops }\end{array}$ & $\begin{array}{l}\text { Longer travel time and } \\
\text { more stops for left-turning } \\
\text { vehicles using the jughandle }\end{array}$ \\
\hline \multirow[t]{3}{*}{ Multimodal } & $\begin{array}{l}\text { Pedestrian crossing distance } \\
\text { may be less due to lack of } \\
\text { left-turn lanes on the major } \\
\text { street }\end{array}$ & $\begin{array}{l}\text { Increased exposure for } \\
\text { pedestrians crossing the } \\
\text { ramp terminal }\end{array}$ \\
\hline & \multirow[t]{2}{*}{$\begin{array}{l}\text { Pedestrian delay may be } \\
\text { reduced due to potentially } \\
\text { shorter cycle lengths }\end{array}$} & $\begin{array}{l}\text { Ramp diverges may create } \\
\text { higher speed conflicts } \\
\text { between bicyclists and } \\
\text { motor vehicles }\end{array}$ \\
\hline & & $\begin{array}{l}\text { Transit stops may need to } \\
\text { be relocated outside the } \\
\text { influence area of the } \\
\text { intersection }\end{array}$ \\
\hline \multirow[t]{2}{*}{ Physical } & \multirow[t]{2}{*}{ None identified } & $\begin{array}{l}\text { Additional right-of-way } \\
\text { may be required }\end{array}$ \\
\hline & & Access management \\
\hline Socioeconomic & None identified & None identified \\
\hline $\begin{array}{l}\text { Enforcement, } \\
\text { Education, and } \\
\text { Maintenance }\end{array}$ & None identified & $\begin{array}{l}\text { Education may be needed } \\
\text { unless good visual cues are } \\
\text { provided }\end{array}$ \\
\hline
\end{tabular}




\subsection{Median U-turn intersection (MUT)}

The Median U-turn (MUT) intersection requires a motorist that wants to turn left to use a directional crossover in the median located downstream of the primary intersection (Figure 2-8). Left turns proceed through the intersection, make a u-turn at the median crossover, and then turn right once entering the primary intersection for the second time. Direct left turns are prohibited at the primary intersection. Right turns proceed as usual.

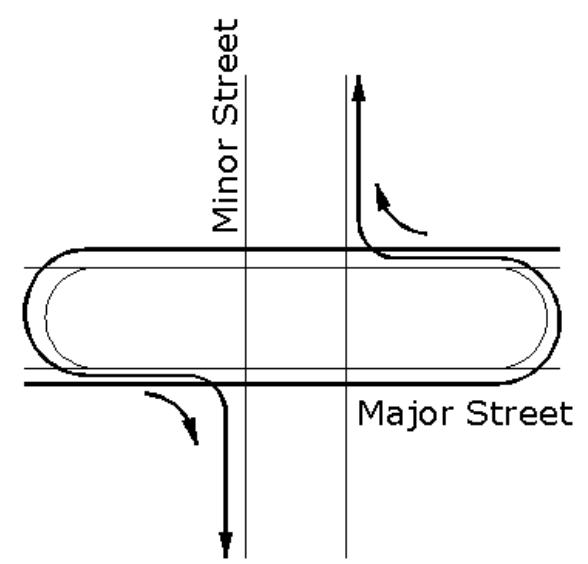

(a) Major Street Turning Movements

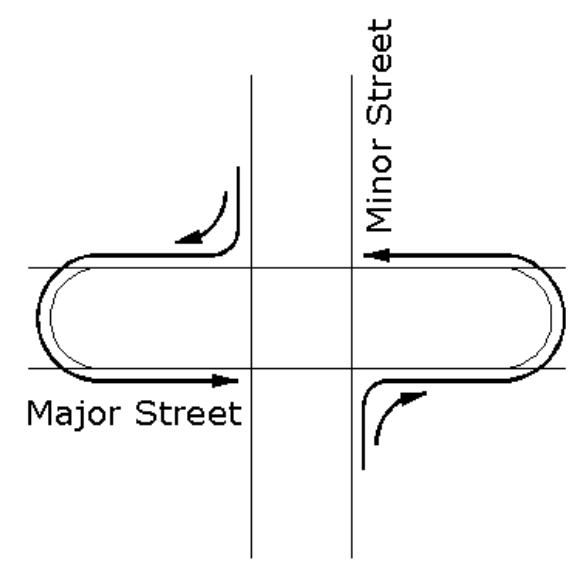

(b) Minor Street Turning Movements

Figure 2-8 Median U-turn Turning Movements (Tarko et al., 2008)

A true median u-turn intersection does not allow bi-directional crossovers. Bi-directional crossovers are not considered, as they have the possibility of interlocking (Jagannathan, 2007).

Median u-turns can be implemented on the major road, the secondary road, or both. The road on which a median u-turn is implemented is often restricted by the width of the median. The median width of a median u-turn intersection depends on the design vehicle's turning radius and the number of opposing lanes (Jagannathan, 2007). 
A median u-turn intersection can be stop-controlled at both the primary and secondary intersections, signalized at the primary intersection and stop-controlled at the secondary intersections created by the median u-turns, or signalized at both the primary and secondary intersections. If the primary intersection is signalized, it will have two phases. If both the primary and secondary intersections are signalized, the primary and secondary intersections should be coordinated. Coordinating the signals requires through vehicles to stop only once.

A median u-turn with a crossover controlled by a signal would only work in states which allow a left turn on a red signal on one-way facilities.

Michigan DOT has used median u-turns for many years and presently operates over 1,000 miles of them.

The location of the crossovers downstream of the primary intersection should be carefully considered. Agencies provide varying recommendations for the location, which range from 400 to 760 feet beyond the primary intersection (Hummer, 1998; AASHTO, 2004; Jagannathan, 2007). The location of a crossover is a tradeoff between the travel time for left turns and the storage capacity for left-turning vehicles. As the placement of a crossover from the primary intersection increases, the travel time for left turns will increase; however, with heavy left turns, increasing the distance of the crossover from the primary intersection will prevent spillback and blockage of through movements.

Implementing loons in the median u-turn design can help reduce the required median width.

Using the scheme proposed by (Jagannathan, 2007), tapering the median width when approaching the primary intersection can reduce the minimum green time for the cross street. From a safety standpoint, this would result in a reduction in the time during which 
the pedestrian is exposed to vehicular traffic because their path is shorter. From an operational standpoint, this would result in a reduced cycle length, which results in a reduction in delay. No indication was given that this concept was implemented, or if so, the effects quantified.

Special attention should also be considered to address key design elements such as the deceleration length, storage, location and spacing of the crossovers on the arterial. The design guide developed by the Michigan Department of Transportation can assist in addressing these design issues (Michigan DOT, n.d.).

The introduction of crossovers in the median u-turn design allows for the removal of left turn phases from the primary intersection, thus reducing the cycle length and delay for through movements and at the same time providing the possibility for better coordination.

Signage is an important feature in median u-turn design for efficient operations. The Michigan DOT has developed signage plans based on past experience (Michigan DOT, n.d.). Existing alternative intersections, like the median u-turn, have shown that agencies can mitigate confusion when rerouting certain movements through proper understandable traffic control devices and signing (Hummer and Reid, 2000).

When comparing the median u-turn design with conventional intersection, considerable savings in delay occur when left turn volumes are small (Bared and Kaisar, 2002). As the volume of left turns increases, the benefits decrease. Additionally, at larger through volumes, the median u-turn design substantially outperforms a conventional intersection; at low to median through volumes, the median u-turn will perform similarly to a comparable conventional intersection (Bared and Kaisar, 2002; Ourston and Hall, 2003).

Table 2-5 shows the general characteristics of the median u-turn design and can be used for initial screening. 
Table 2-5 Characteristics of a Median U-turn (Jagannathan, 2007; Tabernero and Sayed, 2006; Hummer and Reid, 2000)

\begin{tabular}{|c|c|c|c|}
\hline Advantages & Disadvantages & $\begin{array}{l}\text { When to } \\
\text { Consider }\end{array}$ & $\begin{array}{l}\text { When not to } \\
\text { Consider }\end{array}$ \\
\hline $\begin{array}{l}\text {-Reduced delay } \\
\text { for through } \\
\text { arterial traffic } \\
\text {-Easier } \\
\text { progression for } \\
\text { through arterial. } \\
\text {-Fewer stops for } \\
\text { through traffic, } \\
\text { particularly on } \\
\text { approaches } \\
\text { without } \\
\text { signalized } \\
\text { directional } \\
\text { crossover } \\
\text {-Fewer threats to } \\
\text { crossing } \\
\text { pedestrians } \\
\text {-Fewer and more } \\
\text { separated } \\
\text { conflict points } \\
\text {-increase } \\
\text { capacity at } \\
\text { primary } \\
\text { intersection } \\
\text {-Allows to } \\
\text { operate signal at } \\
\text { shorter cycle } \\
\text { lengths }\end{array}$ & $\begin{array}{l}\text {-Driver confusion } \\
\text {-Driver disregard of } \\
\text { the left-turn } \\
\text { prohibition at main } \\
\text { intersection } \\
\text {-Increased delay for } \\
\text { left turning traffic } \\
\text {-Increased travel } \\
\text { distance for left } \\
\text { turning traffic } \\
\text {-Increased stops for } \\
\text { left turning traffic } \\
\text {-Higher operation cost } \\
\text { if for extra signals } \\
\text { - Longer cross street } \\
\text { minimum green times } \\
\text { or two cycle } \\
\text { pedestrian crossing } \\
\text {-Larger right of way } \\
\text { to accommodate } \\
\text { required median width }\end{array}$ & $\begin{array}{l}\text {-High arterial } \\
\text { through volumes } \\
\text { with low and } \\
\text { moderate left } \\
\text { turn volumes and } \\
\text { any cross street } \\
\text { volumes }\end{array}$ & $\begin{array}{l}\text {-Arterials with } \\
\text { narrow median } \\
\text { with no prospect } \\
\text { for obtaining extra } \\
\text { right of way are } \\
\text { poor candidates } \\
\text { except where } \\
\text { agencies can build } \\
\text { wide median and } \\
\text { crossovers on the } \\
\text { cross street } \\
\text {-With high left } \\
\text { turn volumes, } \\
\text { extra delay and } \\
\text { travel distance } \\
\text { with spillback } \\
\text { potential will } \\
\text { outweigh the } \\
\text { savings for } \\
\text { through traffic }\end{array}$ \\
\hline
\end{tabular}

The median u-turn design allows for a faster mean vehicle speed throughout the day compared to a conventional design. Additionally, the median u-turn has improved operations in terms of total system time during the peak period. During the off-peak 
period, the median u-turn will perform roughly the same as a conventional intersection in terms of total system time (Hummer and Reid, 2000).

A considerable gain in capacity can be achieved for median u-turn design compared to conventional design with dual left turns (Levinson et al., 2000).

\subsubsection{Median u-turn in an arterial corridor}

A median u-turn corridor with uneven spacing can improve system travel time by 17 percent and average speed by 25 percent compared to conventional design during peak periods (Reid et al., 1999). During off-peak periods, a median u-turn corridor will operate with similar efficiency when compared to a corridor composed of conventional intersections (Reid et al., 1999).

When analyzing the median u-turn design as a corridor, a higher margin of benefits are achieved with higher left to through ratios than at lower ratios when compared to a conventional intersection (Reid et al., 1999). For the majority of cases tested, the authors have found that a median u-turn corridor increases the number of stops.

Table 2-6 summarizes the advantages and the disadvantages of a median u-turn corridor as compared to a conventional two-way left-turn lane (TWLTL) corridor.

Table 2-6 MUT Corridor Relative to a TWLTL Corridor (Reid et al., 1999)

\begin{tabular}{|c|c|}
\hline Advantages & Disadvantages \\
\hline $\begin{array}{l}\text { - Two-phase signal operation by } \\
\text { removal of left turns from main } \\
\text { intersection } \\
\text { - Progression Strengthened } \\
\text { - Potential reduction for through } \\
\text { movements delay } \\
\text { - Reduced conflict points } \\
\text { - Better visual aesthetics }\end{array}$ & $\begin{array}{l}\text { Increases in VMT due to } \\
\text { increased travel distance for left } \\
\text { turns and delays for low volumes } \\
\text { - } \text { Driver confusion } \\
\text { - Greater right-of-way } \\
\text { requirements }(25-50 \text { feet })\end{array}$ \\
\hline
\end{tabular}


The MUT may be applied as a corridor treatment or at isolated intersections (Jagannathan, 2007). Implementing a MUT intersection in a coordinated arterial composed of conventional intersections is not encouraged.

Table 2-7 Summary of Median U-turn Intersection (USDOT, 2004)

\begin{tabular}{|c|c|c|}
\hline Characteristics & Potential Benefits & Potential Liabilities \\
\hline \multirow[t]{2}{*}{ Safety } & $\begin{array}{l}\text { Potential reduction in left- } \\
\text { turn collisions }\end{array}$ & None identified \\
\hline & $\begin{array}{l}\text { Potential minor reduction in } \\
\text { merging/diverging } \\
\text { collisions }\end{array}$ & \\
\hline \multirow[t]{3}{*}{ Operations } & $\begin{array}{l}\text { Potential reduction in } \\
\text { overall travel time. }\end{array}$ & $\begin{array}{l}\text { Mixed findings with } \\
\text { respect to overall stops }\end{array}$ \\
\hline & $\begin{array}{l}\text { Reduction in stops for } \\
\text { mainline through } \\
\text { movements }\end{array}$ & \\
\hline & $\begin{array}{l}\text { Mixed findings with respect } \\
\text { to overall stops }\end{array}$ & \\
\hline \multirow[t]{2}{*}{ Multimodal } & $\begin{array}{l}\text { Number of conflicting } \\
\text { movements at intersections } \\
\text { is reduced }\end{array}$ & $\begin{array}{l}\text { Increased crossing } \\
\text { distance for pedestrians. }\end{array}$ \\
\hline & & $\begin{array}{l}\text { Turning paths of the } \\
\text { median U-turn may } \\
\text { encroach in bike lanes }\end{array}$ \\
\hline Physical & None identified & $\begin{array}{l}\text { May be additional right- } \\
\text { of-way needs depending } \\
\text { on width of existing } \\
\text { median }\end{array}$ \\
\hline Socioeconomic & None identified & $\begin{array}{l}\text { Access may need to be } \\
\text { restricted within the } \\
\text { influence of the median U- } \\
\text { turn locations }\end{array}$ \\
\hline $\begin{array}{l}\text { Enforcement, Education, } \\
\text { and Maintenance }\end{array}$ & None identified & $\begin{array}{l}\text { Enforcement and } \\
\text { education may be } \\
\text { necessary to prevent } \\
\text { illegal left turns at the } \\
\text { main intersection }\end{array}$ \\
\hline
\end{tabular}




\subsection{Roundabout Intersection}

Roundabout intersections allow multiple vehicles to enter the intersection simultaneously from any approach when no conflicting vehicle is present in the circulatory roadway. The entry onto a roundabout is controlled by a yield sign. Roundabouts are characterized by the number of circulatory lanes, the number of entry lanes, the central island diameter, the deflection of approaches, flared entries, and splitter islands. The Federal Highway Administration (FHWA) Roundabout Guide (Robinson et al., 2000) can help classify and determine roundabout geometrical dimensions based on the desired operational characteristics. This guide was developed based on research from Europe and Australia and is currently being updated with U.S. roundabout data. Figure 2-9 provides an example of how a vehicle approaching from the major (a) and minor (b) streets would traverse a roundabout. Note that the figure only demonstrates the movement from one direction for each street, although entry from both directions for both the minor and major street are permitted.

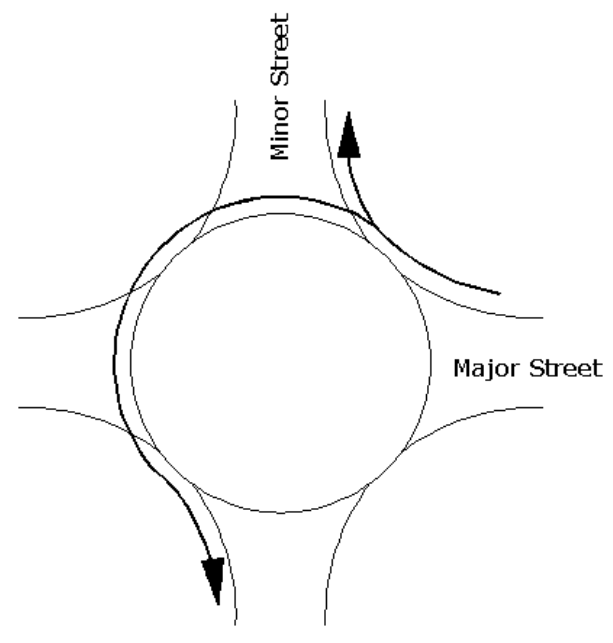

(a) Major Street Turning Movements

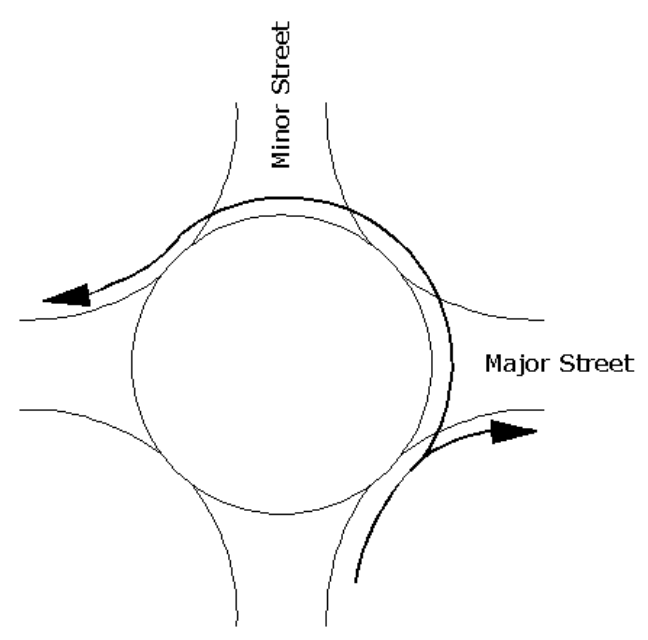

(b) Minor Street Turning Movements

Figure 2-9 Roundabout Turning Movements-Example (Tarko et al., 2008) 
It is important to distinguish roundabouts from the old traffic circles or rotaries. The different is that entering traffic must yield to circulating traffic in a roundabout, while in a rotary, circulating traffic must yield to entering traffic. Furthermore, roundabouts have deflection on the approach legs so that the speed of the vehicle entering the roundabout is sufficiently reduced to minimize the speed differential between the vehicle in the circulatory roadway and the vehicle on the approach.

Prior to construction of roundabouts in communities not accustomed to them, designers and planners might experience opposition mainly due to unfamiliarity with the design (Retting et al., 2002). Opposition to roundabout intersections can also be attributed to people confusing a roundabout with traffic circles, rotaries, or traffic calming islands (Russell et al., 2002). Agencies should consider providing educational classes and informational sessions regarding roundabouts when implementing them within communities unfamiliar with this design. After implementation of well designed roundabouts, agencies can expect a sufficient decline in the opposition to roundabouts. Once people experience roundabouts, they tend to favor the design (Retting et al., 2002; Russell, 2006).

Roundabouts have the potential to provide improved traffic flow operations at locations with high left-turn volumes, skewed approaches, and conditions with limited queue storage. In general, roundabouts require a shorter sight distance than conventional intersections due to lower speeds on approaches compared to conventional intersections and right turn merge on entry. Traffic leaving roundabouts tends to be more random than at intersections with other types of control. Furthermore, the gaps downstream tend to be shorter but more random and frequent compared to signalized intersections. Thus, roundabouts have the potential to provide more opportunities for side street traffic downstream of the roundabout to enter the major street. Important factors in roundabout design include overall size; entry angles; entry widths; flare length; speed; presence of trucks; pedestrians and bicycles; proper signing; and markings (Johnson and Hange, n.d.). 
For multilane roundabouts, special attention to design details such as vehicle path alignment, especially the shortest path, lane widths, and positive guidance to drivers through the use of lane markings, should be carefully considered to achieve a successful roundabout design (rodegerdts et al., 2007).

The two most important driver behavior parameters considered during roundabout design are critical gap and follow-up time. For cities with no prior roundabout experience, these parameters can be assumed to be more conservative than for cities with prior installations of roundabouts. Therefore, when using the guidelines provided by FHWA, longer critical gaps and follow-up times should be assumed than those provided because the FHWA guidelines are based on international research. The critical gaps and follow-up times are longer due to the more conservative nature of U.S. driver behavior on roundabouts compared to driver behavior in other countries (Rodegerdts et al., 2007; Eisenman and List).

The level of service (LOS) for roundabouts should be determined based on the HCM LOS criteria for unsignalized intersections. Control delay should be estimated for each approach separately, not for the intersection as a whole, since it may mask movements with a severe delay. The procedure for determining roundabout LOS can be found in Appendix M (Draft Highway Capacity Manual Chapter 17) of (Rodegerdts, 2007). Roundabouts with heavy traffic are expected to have a higher capacity than roundabouts with light traffic due to drivers accepting shorter gaps in the circulatory flow (Polus et al., 2003).

Microsimulation packages (i.e., VISSIM, Paramics, and others) or macroscopic methods (i.e., RODEL, aaSIDRA, and FHWA methodology) are two other approaches that can be used to determine roundabout capacity (Bared and Edara, 2005; Flannery et al., 1998; Stanek and Milam, 2005). A discussion of these approaches can be found in Appendix A. 
To determine roundabout feasibility for a given site, data on the vehicle and pedestrian volumes, and the horizontal and vertical alignment should be considered (Chapman and Benekohal, 2002). Factors that favor roundabout construction include (Chapman and Benekohal, 2002):

$>$ Geometric realignment of the approaches

$>$ Current alignment is not conducive to the installation of a traffic signal system without geometric improvements

$>$ More than four approaches to an intersection exist at a single unsignalized location

Factors that discourage roundabout consideration include (Chapman and Benekohal, 2002; Retting et al., 2002):

$>$ Grades through the intersection are greater than four percent

$>$ Crest vertical curves with steep approaches are present

$>$ Vertical profile cannot be adjusted without a significant expense

$>$ Intersection cannot be relocated

$>$ Highly unbalanced volumes

$>$ Locations where the terrain or right-of-way limit appropriate geometry

$>$ Close proximity to persistent bottlenecks

Volumes that favor conversion of a signalized intersection to a roundabout can be found in (Chapman and Benekohal, 2002). Also, there are cases where certain geometric and site characteristics may favor roundabouts over signals. Specific case studies where roundabouts proved to be more efficient than signals can be found in (Johnson and Hange, n.d.). Placing roundabouts within a signalized arterial requires careful analysis, including the possibility of a queue spillback from signalized intersections to the roundabout, and generally is discouraged above low volumes (Chapman and Benekohal, 2002). Placing roundabouts on arterials with light traffic are easier to justify. 
When converting stop-controlled intersections to roundabouts for low and moderate volumes (up to 20,000 veh/day), control delay will be reduced or distributed more fairly between approaches (Flannery et al., 1998). Fair distribution of delay becomes a factor on two-way stop-controlled intersections where the stop-controlled legs experience rapid increases in volume and excessive approach delay even when the average delay for the intersection does not indicate any problems.

Construction of roundabouts at signalized interchanges with high left turn volumes can in some cases reduce costly structure widening and increase capacity (Robinson et al., 2000; Johnson and Hange, n.d.). Roundabouts can also prove to be the most cost-effective solution at the ends of tunnels and bridges, where storage and turning lanes required by a traffic signal would be expensive (Robinson et al., 2000).

Converting stop-controlled intersections to roundabouts reduces delays and vehicle stops. Reduction of the average intersection delay can range from relatively low to significant when converting stop-controlled intersections to roundabouts (Retting et al., 2002; Russell, 2006).

Where an actuated signalized crossing for pedestrians at a roundabout is required, the alternative solution is to locate the crossing downstream of the exit lane. This placement reduces the chance of a queue spilling back to block the circulatory roadway, which is preferred to placing the actuated signalized crosswalk at a splitter island. Placing the crosswalk at a downstream location primarily only affects the exiting vehicles on that particular leg (Rouphail, et al., 2005). The above consideration applies only to signalized pedestrian crossings. 


\subsection{Superstreet median (SSM) crossover intersection}

The Superstreet median (SSM) crossover intersection requires cross-street through movements and left turns to and from the arterial to use the directional crossover (Figure 2-10). This geometric layout allows each direction of the arterial to have its own signal pattern, including different cycle lengths for achieving good progression. The cross street through movement is required to make a right turn at the main intersection, make use of the directional crossover located in the median downstream of the primary signal, and then turn right when coming back to the primary intersection (Figure 2-11). Left turns at the main intersection are direct and protected. There is an alternative SSM design which removes the direct left turns from the major roadway and allows this movement through a directional crossover similar to the median u-turn design.

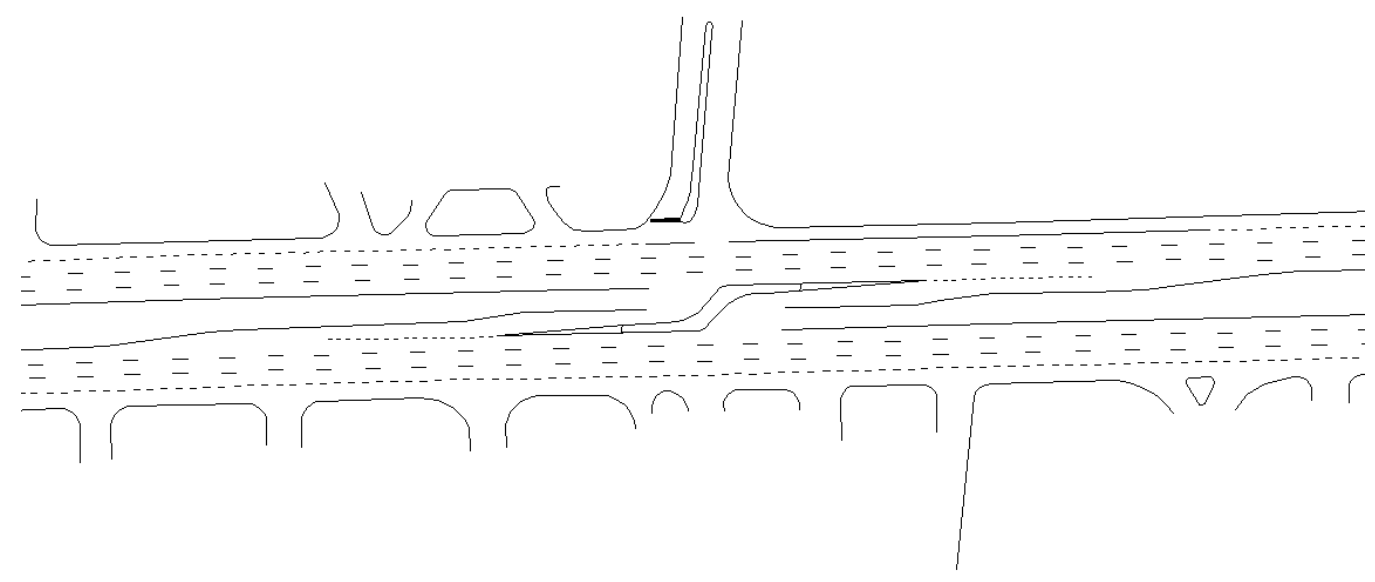

Figure 2-10 Diagram of SSM (Tarko et al., 2008) 


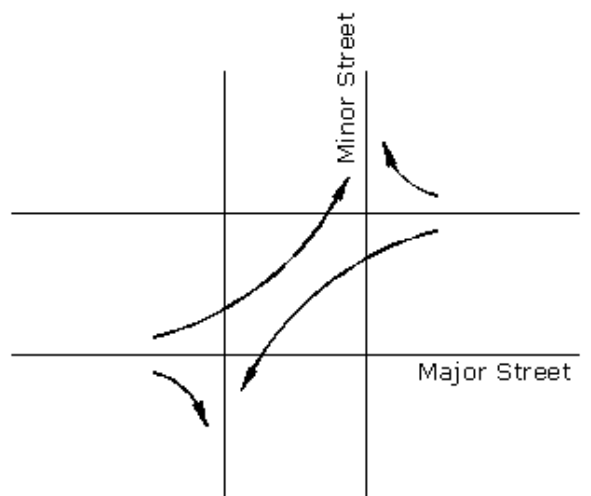

(a) Major Street Turning Movements

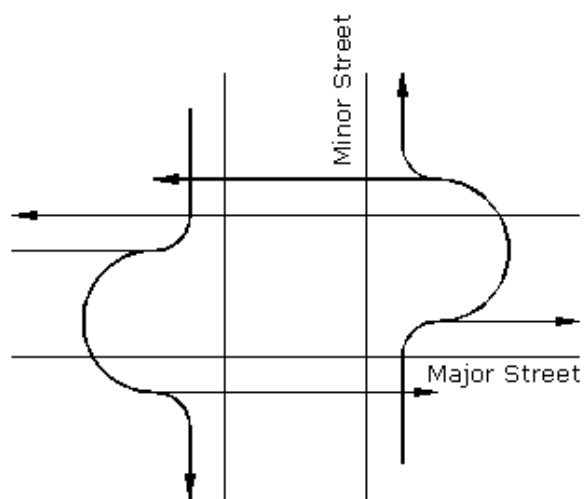

(b) Minor Street Turning Movements

Figure 2-11 Super-street Traffic Movement (Tarko et al., 2008)

The superstreet median crossover utilizes a two-phased signal which is shown in Figure 2-10. Prohibition of direct through and left turning movements for the cross street allows the two phase signals to function independently. Thus, different cycle lengths can be used for each direction (Figure 2-12). This concept can be used to achieve good coordination with uneven intersection spacing. A conventional intersection, on the other hand, can be coordinated for one direction of an arterial, with uneven intersection spacing since the other direction would be compromised.

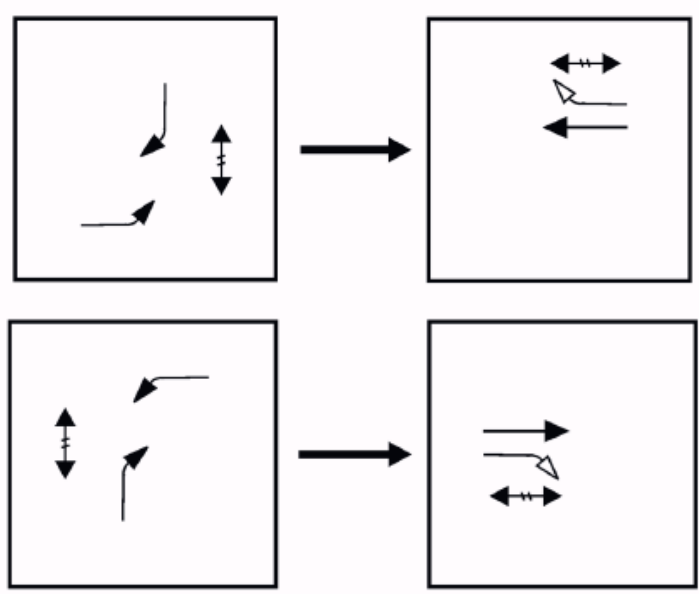

Figure 2-12 Typical Phasing for the Super-street Intersection (USDOT, 2004) 
The SSM intersection compromises travel time and delay for the minor street through and left turn traffic to achieve an improvement in major road through and left turn movements. When the streets crossing are of equal importance, this intersection solution is not desirable.

Table 2-8 shows the general characteristics of the SSM design and can be used for initial screening for applicable designs. 
Table 2-8 Characteristics of SSM Design (Hummer, 1998; Hummer and Reid, 2000)

\begin{tabular}{|c|c|c|c|}
\hline Advantages & Disadvantages & When to Consider & $\begin{array}{l}\text { When not to } \\
\text { Consider }\end{array}$ \\
\hline $\begin{array}{l}\text {-Reduced delay } \\
\text { for through } \\
\text { arterial traffic } \\
\text { and for one pair } \\
\text { of left turns } \\
\text {-"Perfect" two- } \\
\text { way progression } \\
\text { with any signal } \\
\text { spacing } \\
\text {-Fewer stops for } \\
\text { through traffic } \\
\text {-Fewer threats to } \\
\text { crossing } \\
\text { pedestrians } \\
\text {-Fewer and more } \\
\text { separated conflict } \\
\text { points }\end{array}$ & $\begin{array}{l}\text {-Driver confusion } \\
\text {-Driver disregard of } \\
\text { the left-turn } \\
\text { prohibition at main } \\
\text { intersection } \\
\text {-Increased delay for } \\
\text { one pair of left } \\
\text { turning traffic and } \\
\text { cross street through } \\
\text { traffic } \\
\text {-Increased travel } \\
\text { distance for left } \\
\text { turning traffic and } \\
\text { cross street through } \\
\text { traffic } \\
\text {-Increased stops for } \\
\text { cross street through } \\
\text { traffic and one pair } \\
\text { of left turning } \\
\text { traffic } \\
\text {-Slow two stage } \\
\text { crossing for } \\
\text { pedestrians on the } \\
\text { arterial }\end{array}$ & $\begin{array}{l}\text {-High arterial } \\
\text { through volumes } \\
\text { with low and } \\
\text { moderate cross } \\
\text { street through } \\
\text { volumes. Usually } \\
\text { in suburban } \\
\text { arterials where } \\
\text { roadside } \\
\text { development } \\
\text { generates most of } \\
\text { the traffic } \\
\text {-50/50 arterial } \\
\text { through traffic split } \\
\text { exists for most of } \\
\text { the day with } \\
\text { uneven street } \\
\text { spacing }\end{array}$ & $\begin{array}{l}\text {-Arterials with } \\
\text { narrow medians } \\
\text { and no prospect for } \\
\text { obtaining extra } \\
\text { right of way for } \\
\text { widening }\end{array}$ \\
\hline
\end{tabular}

\subsubsection{SSM in an arterial corridor}

With uneven intersection spacing, a SSM corridor provides slight improvements in system travel time and average speed as compared to a conventional design during peak periods (Reid et al., 1999). The benefits of a conventional intersection corridor converted to a SSM corridor may be less significant than a conventional corridor converted to a 
median u-turn corridor. During off-peak periods, a SSM corridor will operate with similar efficiency as a corridor composed of conventional intersections (Reid et al., 1999).

Analyzing the SSM design as a corridor, a higher margin of benefits is achieved, compared with a conventional intersection corridor with higher left to through ratios (Reid et al., 1999). Overall, a SSM corridor seems to be associated with an increased number of stops compared to a conventional intersection corridor.

Table 2-9 summarizes the advantages and disadvantages of a SSM corridors compared to a conventional two-way left-turn lane (TWLTL) corridor.

Table 2-9 SSM Corridor Relative to a TWLTLC (Reid et al., 1999)

\begin{tabular}{|c|c|}
\hline Advantage & Disadvantage \\
\hline $\begin{array}{l}\text { Two-phase signal operation by } \\
\text { removal of direct left and } \\
\text { through from the cross street } \\
\text { - Perfect progression in both } \\
\text { directions of arterial } \\
\text { - Each direction of arterial can } \\
\text { operate on different cycle length }\end{array}$ & 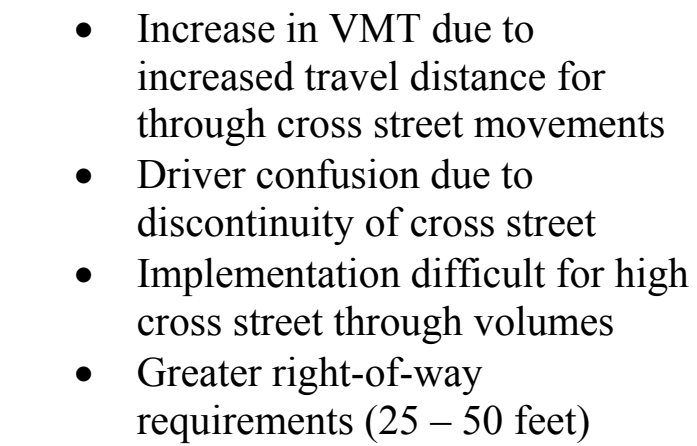 \\
\hline
\end{tabular}


Table 2-10 Summary of SSM Intersection Adapted from (USDOT, 2004)

\begin{tabular}{|c|c|c|}
\hline Characteristics & Potential Benefits & Potential Liabilities \\
\hline Safety & Fewer conflict points & None identified \\
\hline Operations & $\begin{array}{l}\text { Reduced delay for major } \\
\text { street movements }\end{array}$ & $\begin{array}{l}\text { Longer travel distance } \\
\text { and time for minor street } \\
\text { movements }\end{array}$ \\
\hline \multirow[t]{2}{*}{ Multimodal } & None identified & $\begin{array}{l}\text { Two-stage pedestrian } \\
\text { crossing }\end{array}$ \\
\hline & & $\begin{array}{l}\text { Potential way-finding } \\
\text { challenges }\end{array}$ \\
\hline Physical & None identified & Wide median needed \\
\hline Socioeconomic & None identified & $\begin{array}{l}\text { May result in restrictions } \\
\text { to access }\end{array}$ \\
\hline $\begin{array}{l}\text { Enforcement, Education, } \\
\text { and Maintenance }\end{array}$ & None identified & $\begin{array}{l}\text { Potential for driver and } \\
\text { pedestrian confusion }\end{array}$ \\
\hline
\end{tabular}




\subsection{Bowtie intersection}

The bowtie intersection is an alternative intersection which uses roundabouts on the cross street to accommodate left turns (Figure 2-13). The concept of the bowtie is similar to an interchange with roundabouts without grade separation. All left turns are prohibited at the primary intersection. The distance from the primary intersection to each roundabout, varies from 200 to 600 feet, which allows a tradeoff between limiting the extra distance to cover by left turning vehicles and the required storage for vehicle queues. An essential feature to this design is the provision of u-turns on a crossing road through roundabouts to facilitate indirect left turns.

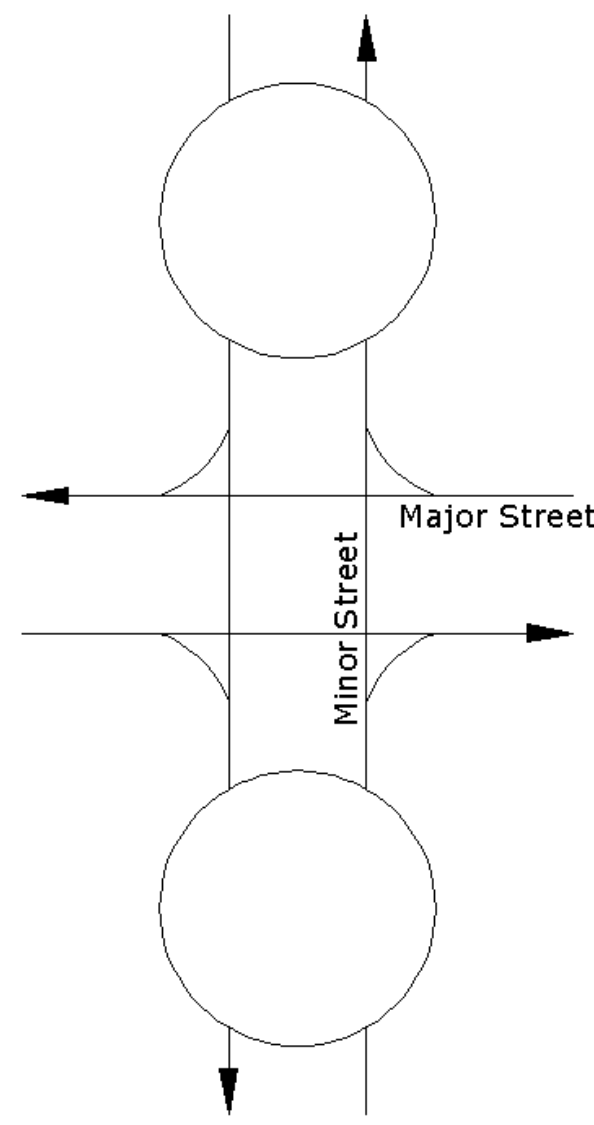

Figure 2-13 Bowtie Intersection Diagram (Tarko et al., 2008) 
Table 2-11 shows the general characteristics of bowtie design, which and can be used for initial screening for applicable designs.

Table 2-11 Characteristics of a Bowtie Intersection (Hummer, 1998; Hummer and Reid, 2000)

\begin{tabular}{|c|c|c|c|}
\hline Advantages & Disadvantages & When to Consider & $\begin{array}{l}\text { When not to } \\
\text { Consider }\end{array}$ \\
\hline $\begin{array}{l}\text {-Reduced delay } \\
\text { for through } \\
\text { arterial traffic } \\
\text {-Easier } \\
\text { progression for } \\
\text { through arterial } \\
\text {-Fewer stops for } \\
\text { through traffic } \\
\text {-Fewer threats to } \\
\text { crossing } \\
\text { pedestrians } \\
\text {-Fewer and more } \\
\text { separated conflict } \\
\text { points } \\
\text {-Increased } \\
\text { capacity at the } \\
\text { main intersection }\end{array}$ & $\begin{array}{l}\text {-Driver confusion } \\
\text {-Driver disregard of } \\
\text { the left-turn } \\
\text { prohibition at main } \\
\text { intersection } \\
\text {-Increased stops for } \\
\text { left turning traffic } \\
\text { and cross street } \\
\text { through traffic } \\
\text {-Increased travel } \\
\text { distance for left } \\
\text { turning traffic } \\
\text {-Difficult U-turn }\end{array}$ & $\begin{array}{l}\text {-High arterial } \\
\text { through volumes } \\
\text { with low and } \\
\text { moderate left turn } \\
\text { volumes and low } \\
\text { and moderate cross } \\
\text { street volumes } \\
\text {-Arterials with } \\
\text { narrow or } \\
\text { nonexistent } \\
\text { medians }\end{array}$ & $\begin{array}{l}\text {-High left turn } \\
\text { volumes with } \\
\text { spillback potential } \\
\text {-Close spacing } \\
\text { between adjacent } \\
\text { intersections }\end{array}$ \\
\hline
\end{tabular}

For more information regarding simulation results of bowtie intersections see Boone and Hummer; Boone and Hummer, 1995; and Hummer and Boone. 


\subsection{Continuous Green-T Intersection (CGT)}

The continuous green t-intersection (CGT) can only be applied to t-intersections (3-legged intersections). A three-phase signal controls left turns to and from the major road. The outside lane receives a green signal display during all phases.

An important aspect of this design is the clear separation between the inside lane from the lane with the continuous green signal. This separation can be achieved by using raised reflectors or rumble strips (Tabernero and Sayed, 2006). Traffic turning left onto the major road inside lane should be guided by pavement markings. The separation between the inside lane and the lane with the continuous green signal indication should extend several hundred feet upstream and downstream from the intersection to minimize weaving. There should be a raised median between the through lanes during their separation to prevent vehicles from crossing the separation (Tabernero and Sayed, 2006). A limitation of the continuous green T-intersection is that it does not provide a phase for pedestrian crossing (Tabernero and Sayed, 2006). This aspect of the design limits its use with heavy pedestrian volumes unless the warrants of an alternative crossing can be met.

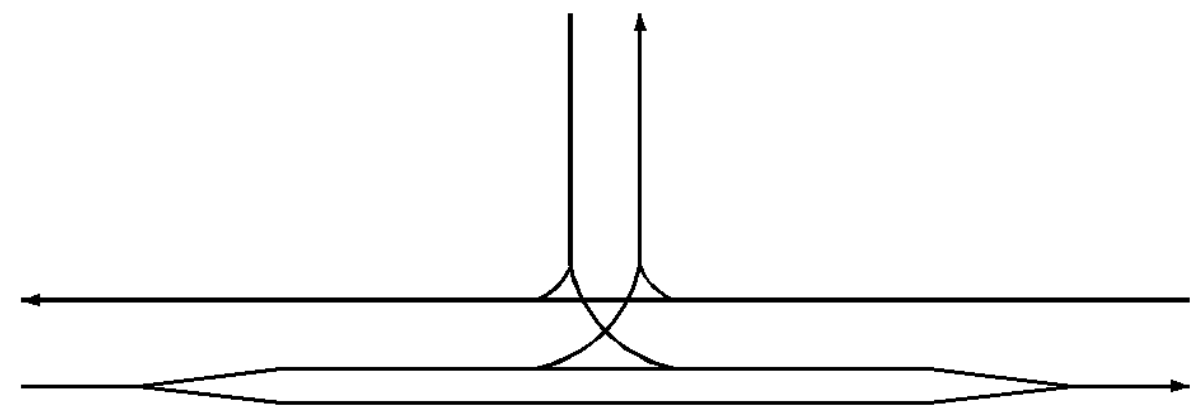

Figure 2-14 Diagram of a Continuous Green T-Intersection (Tarko et al., 2008)

The benefits achieved with the continuous green T-intersection (CGT) design are highly dependent on the percentage of drivers choosing the continuous green movement. For a 
four-lane arterial, you might expect approximately $75 \%$ of drivers to choose the continuous green lane. Only a slight increase may be observed on a six-lane arterial (Boone and Hummer, pp. 184-192).

Table 2-12 shows the general characteristics of CGT design, which and can be used for initial screening for applicable designs.

Table 2-12 Characteristics of Continuous Green-T (Tabernero and Sayed, 2006)

\begin{tabular}{|c|c|c|}
\hline Advantages & Disadvantages & When to Consider \\
\hline $\begin{array}{l}\text {-Reduced delay for through } \\
\text { arterial traffic in one } \\
\text { direction } \\
\text { - Reduced stops for through } \\
\text { arterial traffic in one } \\
\text { direction }\end{array}$ & $\begin{array}{l}\text {-Driver and pedestrian } \\
\text { confusion } \\
\text {-Driver disregard of the } \\
\text { separation between the } \\
\text { through lanes } \\
\text {-No signal protection for } \\
\text { pedestrians to cross the } \\
\text { arterial } \\
\text {-Increased lane changing } \\
\text { conflicts before and after } \\
\text { the separation of through } \\
\text { lanes } \\
\text {-Restricted access to } \\
\text { parcels adjacent to the } \\
\text { continuous green through } \\
\text { lanes }\end{array}$ & $\begin{array}{l}\text {-At signalized three } \\
\text { approach intersections } \\
\text { with moderate to low } \\
\text { left-turn volumes from } \\
\text { the minor-street and high } \\
\text { arterial through volumes, } \\
\text { where there are no } \\
\text { crossing pedestrians and } \\
\text { few driveways along the } \\
\text { top of the T }\end{array}$ \\
\hline
\end{tabular}




\subsection{Double-Wide (DW) Intersection}

The concept of a double wide (DW) intersection design is to move as many through vehicles as possible past the primary intersection, then reincorporate those vehicles back into the break between platoons. Figure 2-15 provides a schematic of a double-wide intersection. In this intersection design, all of the geometric changes take place on the major street. A low, but narrow, forgiving and highly visible barrier separates the through lane prior to the intersection. Some distance downstream of the intersection, a second signal is present. The second signal would be a simple two-phase signal, most likely coordinated with the signal at the primary intersection to allow some progression. The second signal eliminates the expenses associated with long extra lanes beyond the intersection. The lengths of the extra lanes prior to the intersection and beyond the intersection in a double-wide design are a function of the signal timing at the primary intersection and should be able to store the through traffic waiting to be served on a single green phase (Hummer, 2000). 


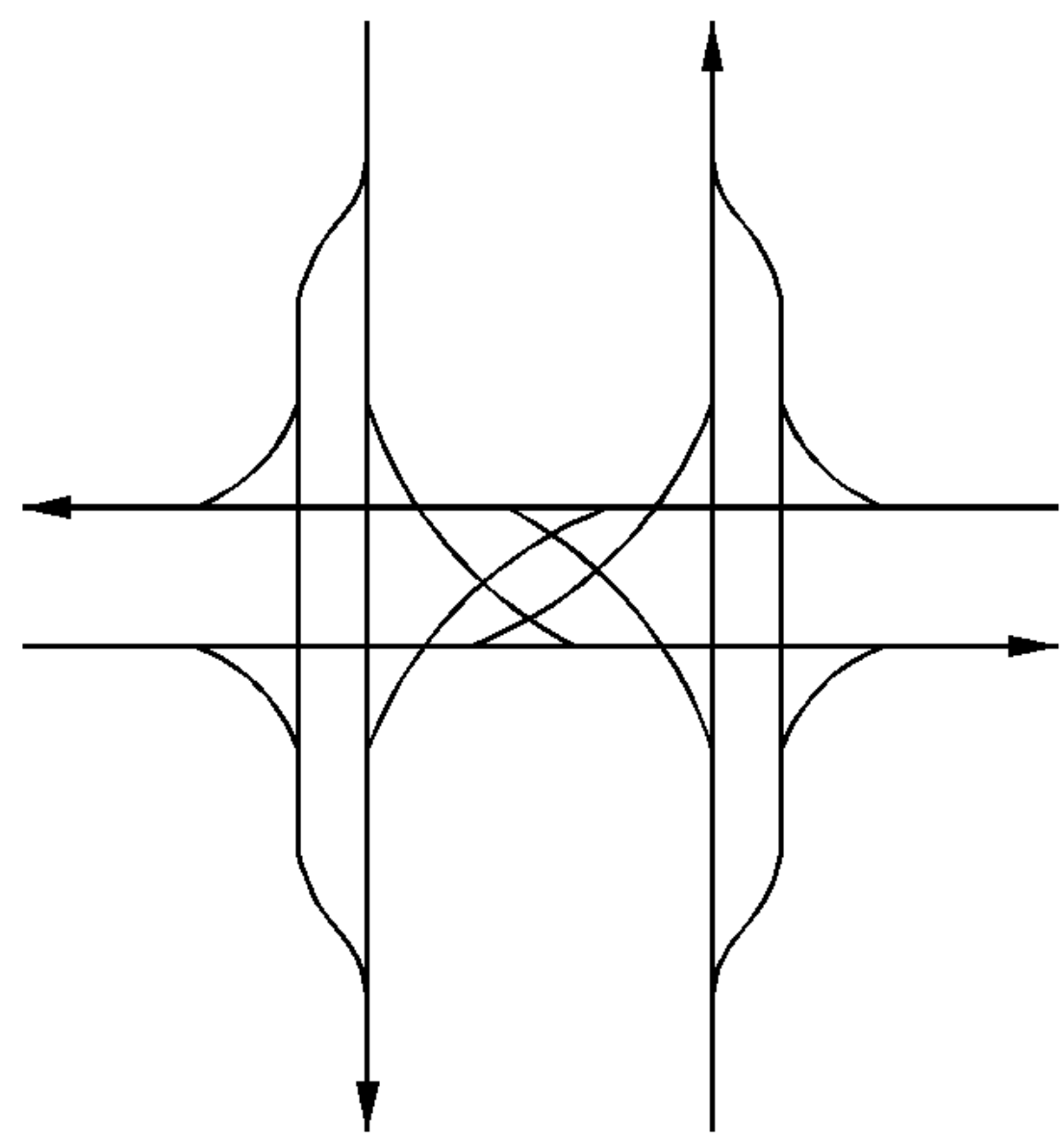

Figure 2-15 Diagram of Double-Wide intersection (Tarko et al., 2008)

The double-wide intersection design performs more efficiently than an intersection with dual left-turn and through lanes and one right-turn lane (LLTTR $\left.{ }^{1}\right)$, dual left-turn and through lanes where the right most through lane also accommodates right-turns (LLTTS ${ }^{1}$ ) and dual left-turn, three through lanes, and one right-turn lane (LLTTTR ${ }^{1)}$ when the major street has higher arterial through volumes relative to the turning volumes. The benefit of this design is that you can always add an additional turning bay to the doublewide design. Other designs cannot realistically be expanded any further (Hummer, 2000).

\footnotetext{
${ }^{1}$ letter designates lane in specific direction L-left, T-through, S-shared through and right and R right only
} 
A double-wide intersection is applicable at isolated arterial intersections with no possibility for progression (Hummer, 2000). The capacity of a double-wide intersection design is the same as a LLTTTR intersection, somewhat greater than a LLTTS intersection, and significantly greater than a LLTTR intersection.

\subsection{Paired intersection}

Paired intersections use directional crossovers for left turns from the major street at one intersection of the pair and directional crossovers for left turns to the major street at the second intersection of the pair. Complete circulation throughout the corridor requires that continuous two-way collector roads are parallel to the arterial. The collector roads must be set back at least several hundred feet from the arterial to avoid spillback and provide developable parcels fronting the arterial (Tabernero and Sayed, 2006). The intersections between the cross streets and the parallel collector roads may be stop-controlled or signalized depending on the traffic volumes and site factors (Tabernero and Sayed, 2006). Figure 2-16 provides a schematic of the split intersection. 


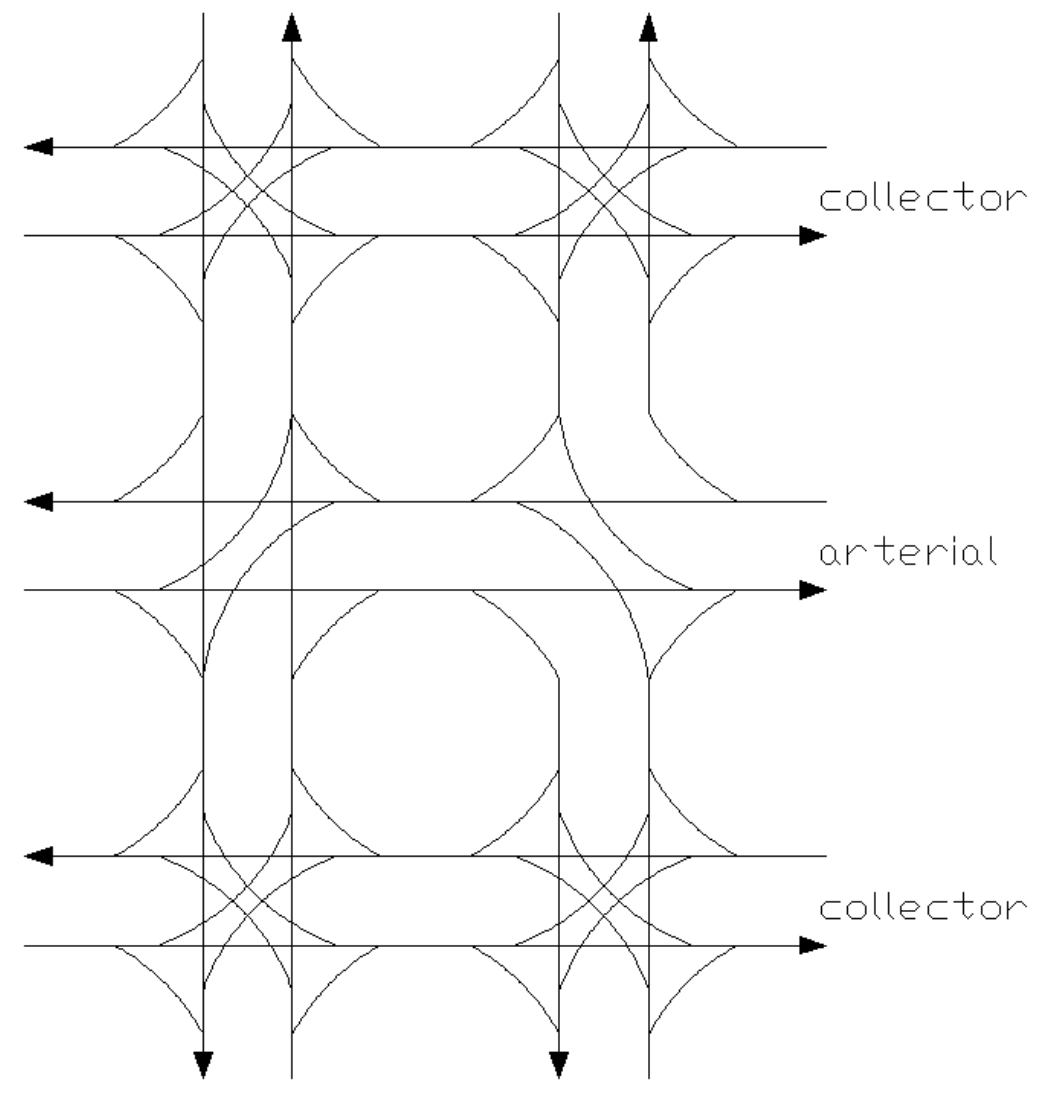

Figure 2-16 Traffic Flows for a Paired Intersection (Tarko et al., 2008)

Table 2-13 shows the general characteristics of a paired intersection design and can be used for initial screening for applicable designs. 
Table 2-13 Characteristics of Paired Intersection (Tabernero and Sayed, 2006)

\begin{tabular}{|c|c|c|c|}
\hline Advantages & Disadvantages & When to Consider & $\begin{array}{l}\text { When not to } \\
\text { Consider }\end{array}$ \\
\hline $\begin{array}{l}\text {-Reduced delay } \\
\text { for through } \\
\text { arterial traffic. } \\
\text {-Fewer stops for } \\
\text { through traffic } \\
\text {-Easier } \\
\text { progression for } \\
\text { through arterial } \\
\text { traffic, and with } \\
\text { the left merge } \\
\text { variation } \\
\text { "perfect" two- } \\
\text { way progression } \\
\text {-Fewer threats to } \\
\text { crossing } \\
\text { pedestrians } \\
\text {-Fewer and more } \\
\text { separated conflict } \\
\text { points }\end{array}$ & $\begin{array}{l}\text {-Driver and } \\
\text { pedestrian } \\
\text { confusion } \\
\text {-Increased travel } \\
\text { distances for cross- } \\
\text { street through traffic } \\
\text { and for some left- } \\
\text { turning traffic } \\
\text {-Increased delay for } \\
\text { cross street through } \\
\text { traffic and for some } \\
\text { left turn traffic } \\
\text {-Increased stops for } \\
\text { cross street through } \\
\text { traffic and for some } \\
\text { left turning traffic } \\
\text {-Slow two-stage } \\
\text { crossing for } \\
\text { pedestrians on the } \\
\text { arterial }\end{array}$ & $\begin{array}{l}\text {-High arterial } \\
\text { through volumes } \\
\text { with low cross } \\
\text { street through } \\
\text { volumes } \\
\text {-Means to build } \\
\text { and operate the } \\
\text { parallel collector } \\
\text { road are available }\end{array}$ & $\begin{array}{l}\text {-existing parallel } \\
\text { streets are not } \\
\text { capable of carrying } \\
\text { additional traffic } \\
\text {-there is no means } \\
\text { to build and operate } \\
\text { parallel collector } \\
\text { roads }\end{array}$ \\
\hline
\end{tabular}




\subsection{Quadrant roadway intersection (QRI)}

The quadrant roadway (QRT) intersection eliminates left turns at the main intersection by providing a three-lane roadway which can be located in any of the four quadrants. Like the jughandle alternatives, the flexibility associated with which the three-way roadway can be applied, makes this alternative appealing when existing developments may otherwise eliminate the possibility of applying alternative intersections. In Figure 2-17 the three-lane roadway is located in the south-west quadrant. The minor two tintersections allow for direct left turns and may be stop-controlled or signalized. Instead of making a left turn at the primary intersection, drivers will have to make appropriate turning maneuvers on the minor t-intersections to direct them on the desired route (Figure 2-18). Turning maneuvers carried out by drivers on the minor t-intersections will depend on the quadrant in which the three-lane roadway is located.

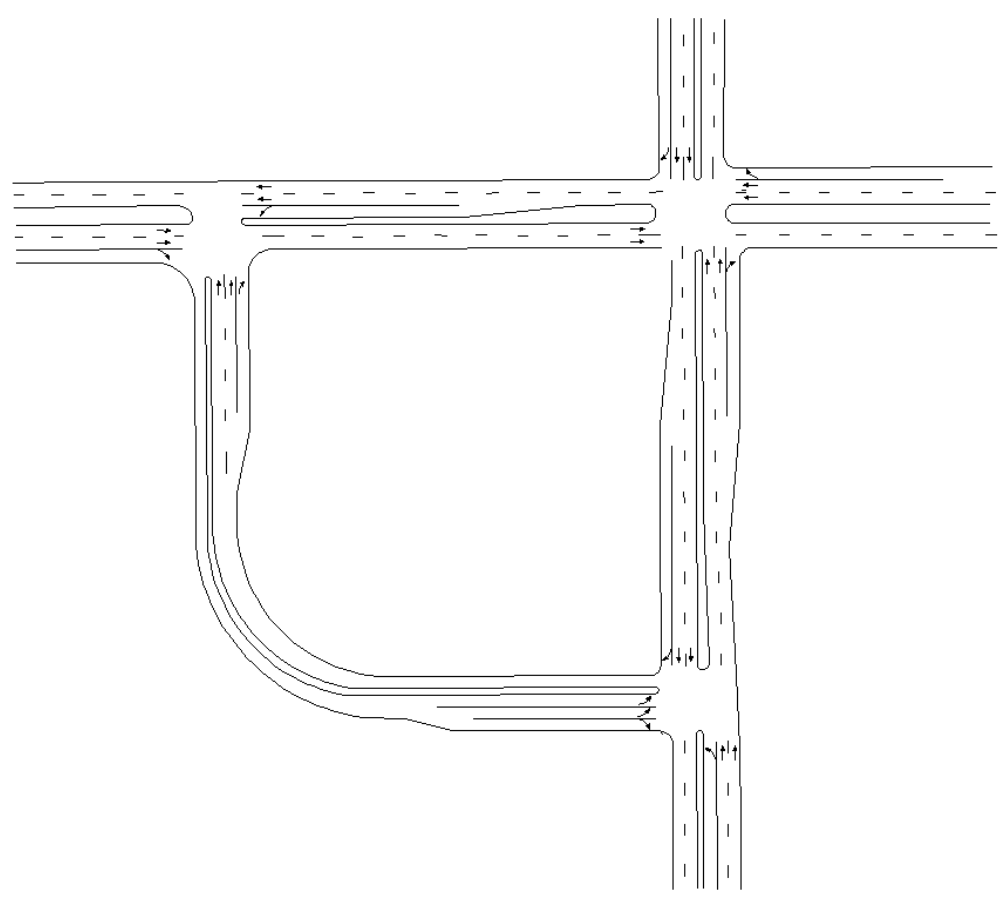

Figure 2-17 Diagram of QRI Intersection (Reid and Hummer, 2001) 


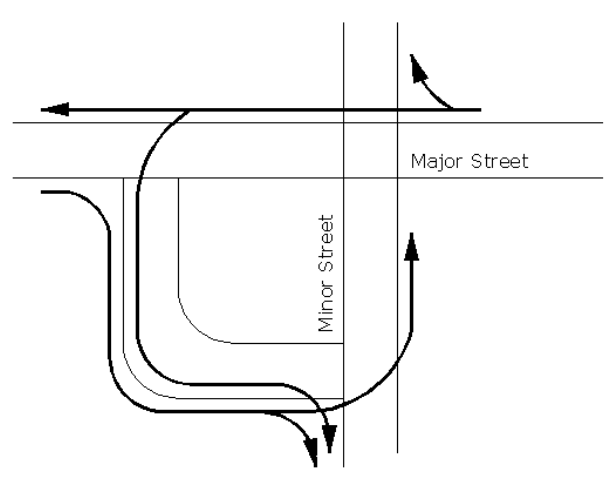

(a) Major Street Turning Movements

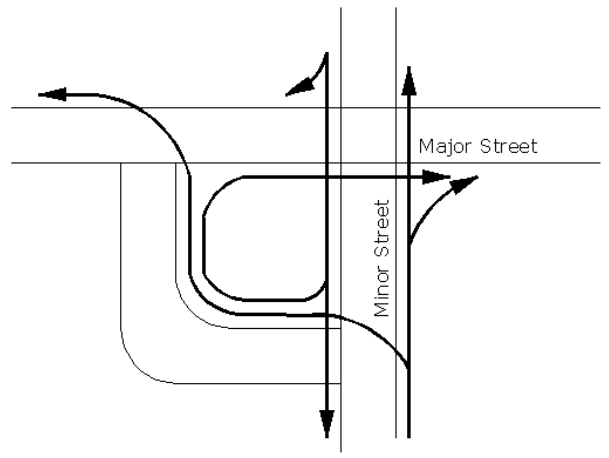

(b) Minor Street Turning Movements

Figure 2-18 Example QRI Traffic Pattern (Tarko et al., 2008)
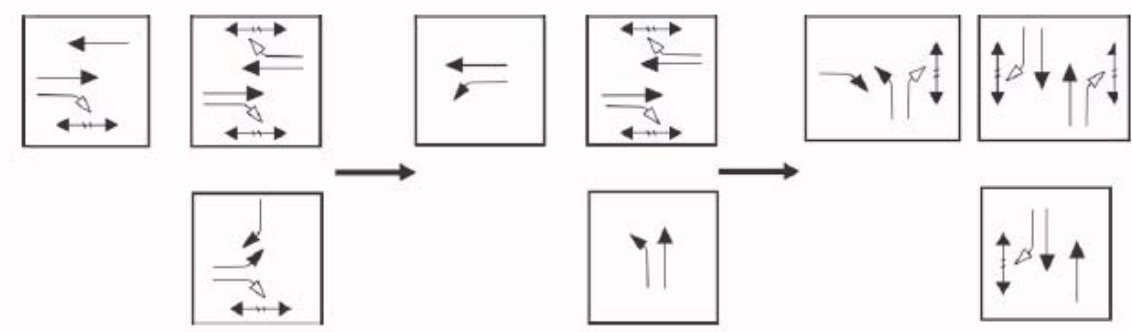

Figure 2-19 Phasing Plan for QRI Intersection (Hummer and Reid, 1999)

A quadrant roadway intersection (QRI) operated by a single controller can bring slight reductions in travel time and more significant reductions in queuing compared to a conventional intersection (Reid, 2000). The reduction in travel time for the through movement will be slight, while the delay at the primary intersection and maximum queue length will be substantially reduced (Reid, 2000). Such a large reduction of delay and maximum queue length at the primary intersection is due to the fact that the delay for the QRI is distributed between the primary intersection and the two secondary t-intersections. As the through and left-turn volumes increase, the QRI design will outperform the conventional design by a higher margin (Reid, 2000). The secondary intersection on the major road should be coordinated with the primary intersection so that the through movement does not require more than one. 
The quadrant roadway intersection reduces stopped delay and system travel time without adding lanes on the major road.

Table 2-14 Characteristics of QRI Intersection Based on (Reid, 2000)

\begin{tabular}{|c|c|}
\hline Advantages & Disadvantages \\
\hline $\begin{array}{l}\text { - Greater progression possibility } \\
\text { - Reduced total intersection delay } \\
\text { - Reduced queuing under heavy } \\
\text { - } \text { volumes } \\
\text { - Fewer vehicular conflict points } \\
\text { - Narrower intersection width }\end{array}$ & $\begin{array}{l}\text { - Increased travel distance for left } \\
\text { - } \text { Inrns } \\
\text { - } \text { left turns } \\
\text { - Driver confusion } \\
\text { - Additional right-of-way for the } \\
\text { - } \text { quadrant roadway } \\
\text { - Additional signing }\end{array}$ \\
\hline
\end{tabular}

\subsection{Split intersection}

The split intersection separates the primary intersection into two one-way streets resembling an at-grade diamond (Figure 2-20). As such, the split intersection can be used as an intermediate phase to the creation of an interchange (Bared and Kaisar, 2000; Polus and Cohen, 1997). Both signals at the separated intersections run on a three-phase cycle operation. It is recommended that a single controller operate both intersections. Using a single controller eliminates the possibility of a poor offset setting, which can occur when two separate controllers are used. A potential consequence of poor offsets is a failure in the function of the intersection under heavy volumes. 


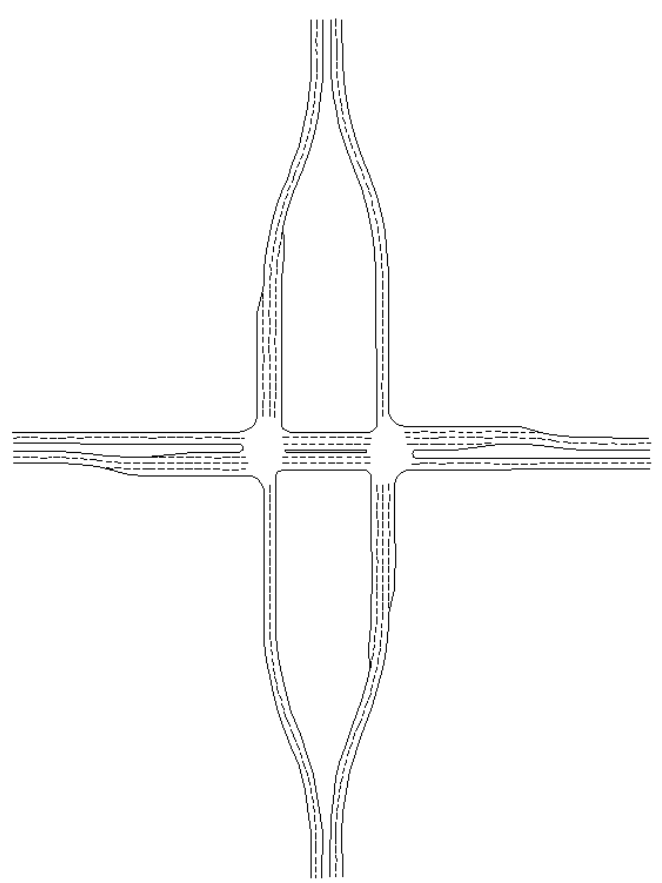

Figure 2-20 Diagram of Split Intersection (Polus and Cohen, 1997)

A split intersection has the potential to carry higher traffic volumes and reduce the delay for each vehicle with appropriate timing in the signal controller (Bared and Kaisar, 2000). The timing plan for a split intersection, when operated by a single controller, should not be obtained from Synchro by optimization because Synchro does not provide good signal timing in this case. With an increase in approach volumes and proportion of left turns, the benefits in reducing delays at a split intersection, compared to a conventional intersection, increase (Bared and Kaisar, 2000). 


\subsection{Upstream Signalized Crossover}

The upstream signalized crossover (USC) intersection is an alternative intersection which eliminates left turn opposing conflicts by crossing left turns with the through traffic to the left side of the roadway prior to the primary intersection on all four approaches (Figure 2-21). Crossing of the through movements and left turns prior to the primary intersection is accomplished through secondary signals coordinated with the primary signal. Traffic is allowed to cross back to the right side of the road after the primary intersection at a second secondary signal. The optimum location of the secondary intersection is a function of the operating speed and the desired green-band widths (Tabernero et al.).

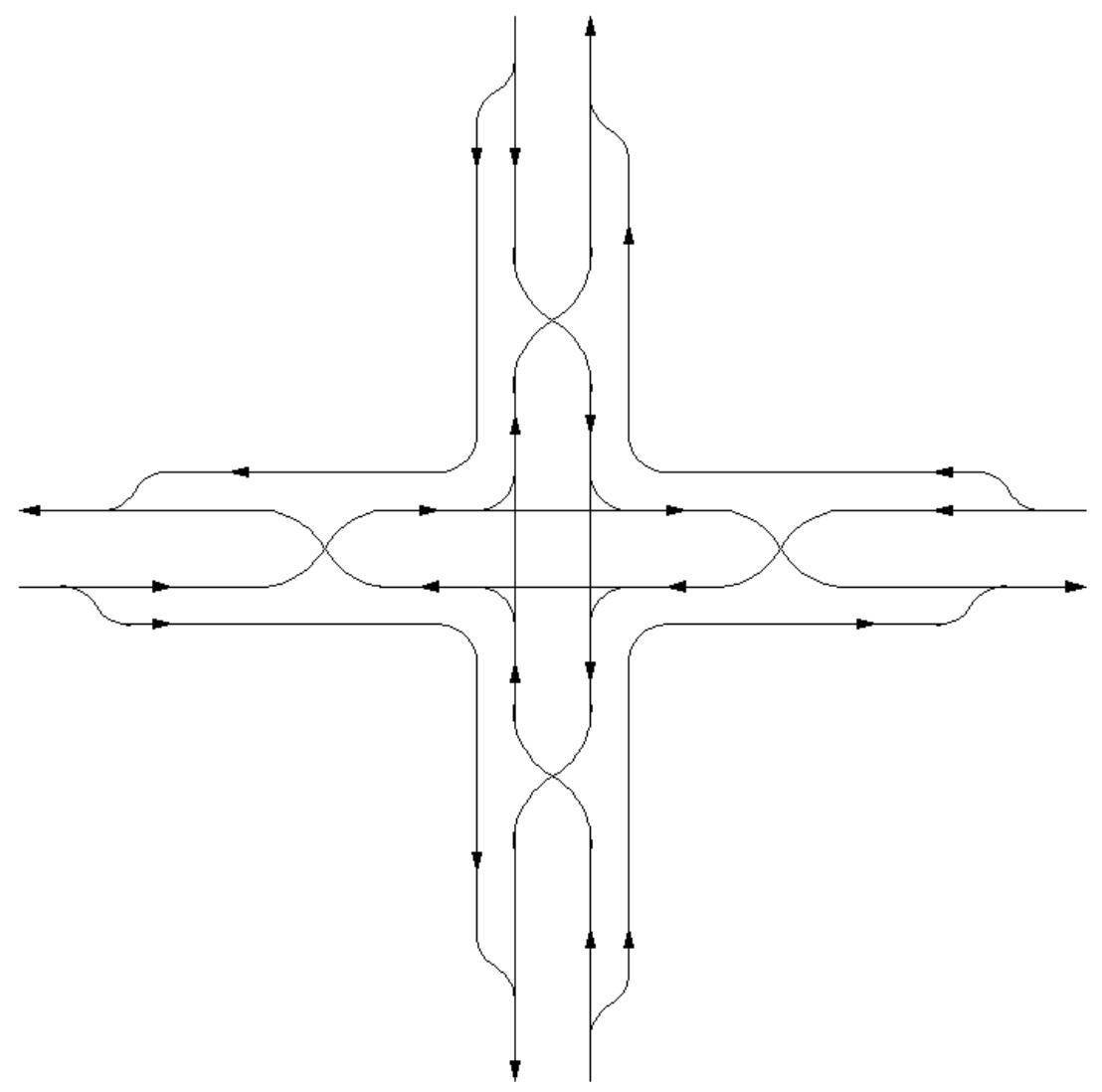

Figure 2-21 Diagram of USC Intersection (Tabernero et al.) 
To prevent drivers from entering the wrong side of the road, a central median should be extended towards the intersection to properly channel traffic at the secondary intersection where the approaches meet (Tarek et al., 2006).

The upstream signalized crossover (USC) intersection has a higher capacity for left turns and can serve greater volumes before reaching saturation compared to a conventional intersection, assuming balanced approach volumes (Tabernero et al.). The operational performance of through vehicles is not compromised in this design. The USC performs with at least the same efficiency as a conventional intersection, again assuming balanced volume conditions. It should be noted that the delay for left turns does not decrease; however, split intersection operations are less affected by an increase in left turn volumes than at conventional intersections (Tabernero et al.).

A shorter distance between the primary and secondary intersections for a USC will perform better for lower traffic volumes and reduce the average delay compared to longer spacing between the primary and secondary intersections (Tarek et al., 2006). However, shorter spacing between primary and secondary intersections reduces capacity (Tarek et al., 2006).

For unbalanced volumes, the USC intersection will perform worse than conventional intersections unless the conventional intersection is near its capacity. For mildly unbalanced volumes, the impact will not be as severe, and the USC will perform similarly to a conventional solution, even for volumes below the capacity of the conventional intersection (Tarek et al., 2006). An optimized signal timing of a USC intersection based on design volumes will perform better than setting signal timings based on simple progression between primary and secondary intersections which are separated by a specific distance (Tarek et al., 2006). 
Table 2-15 USC Intersection Characteristic (Tabernero et al.; Tarek et al., 2006)

\begin{tabular}{|l|ll|}
\hline \multicolumn{1}{|c|}{ When to Consider } & \multicolumn{1}{c|}{ Disadvantages } \\
\hline Balanced high volumes near & $\bullet$ Driver confusion \\
capacity of conventional & - Additional right-of-way \\
intersection design & $\bullet \quad$ Limited access to/from adjacent \\
- Somewhat unbalanced volumes & corner properties to right- \\
which are over capacity of & in/right-out and restricted exiting \\
conventional design & vehicles to a right turn only \\
Heavy left turn volumes with & \\
excessive delays & \\
\hline
\end{tabular}




\section{CHAPTER 3 ROUNDABOUT CALIBRATION}

For roundabouts, the minimum gap and follow-up time are the most important driver behavior parameters that affect capacity (Rodegerdts et al., 2007). These two parameters were estimated and adjusted in a simulation experiment to Indiana conditions based on field collected data. In the simulation experiment, the calibrated follow-up times ensured that the proper vehicle discharged from a stopped position in a queue for vehicles using the same available time headway in the circulatory roadway. The estimated critical gaps determined appropriate vehicle throughput (capacity) in conjunction with the known conflicting flows. Knowing these two parameters and the magnitude of the conflicting flow, it was possible to determine roundabout capacity for single and multilane sites based on Equations A.2 and A.3 respectively (Appendix A). In this research, the critical gap was estimated with four different approaches and two distinct assumptions about a driver's consistency when accepting gaps/lags. The estimated critical gaps were evaluated in a simulation experiment based on service time at the first position in the queue (time at yield line) to determine the most accurate critical gap estimation method.

\subsection{Data Collection}

A roundabout in Carmel, Indiana (Hazel Dell Parkway and East 131st Street) was videotaped during a period of 2.45 hours, which included the afternoon peak hour, using two directional cameras mounted on a 35 feet high mast on a traffic van. For the critical gap and average followup time estimation for a roundabout, each approach lane and circulatory roadway crossing area is a separate data collection area since it encounters an entering event and a conflicting event. The video cameras were positioned in such a way 
that all four approaches of the roundabout could be simultaneously captured by the two cameras and used for data extraction. Out of the four approaches recorded, the queue length could be seen only on two approaches. Six approach lanes comprised 15 hours of data for extraction (Figure 3-1).

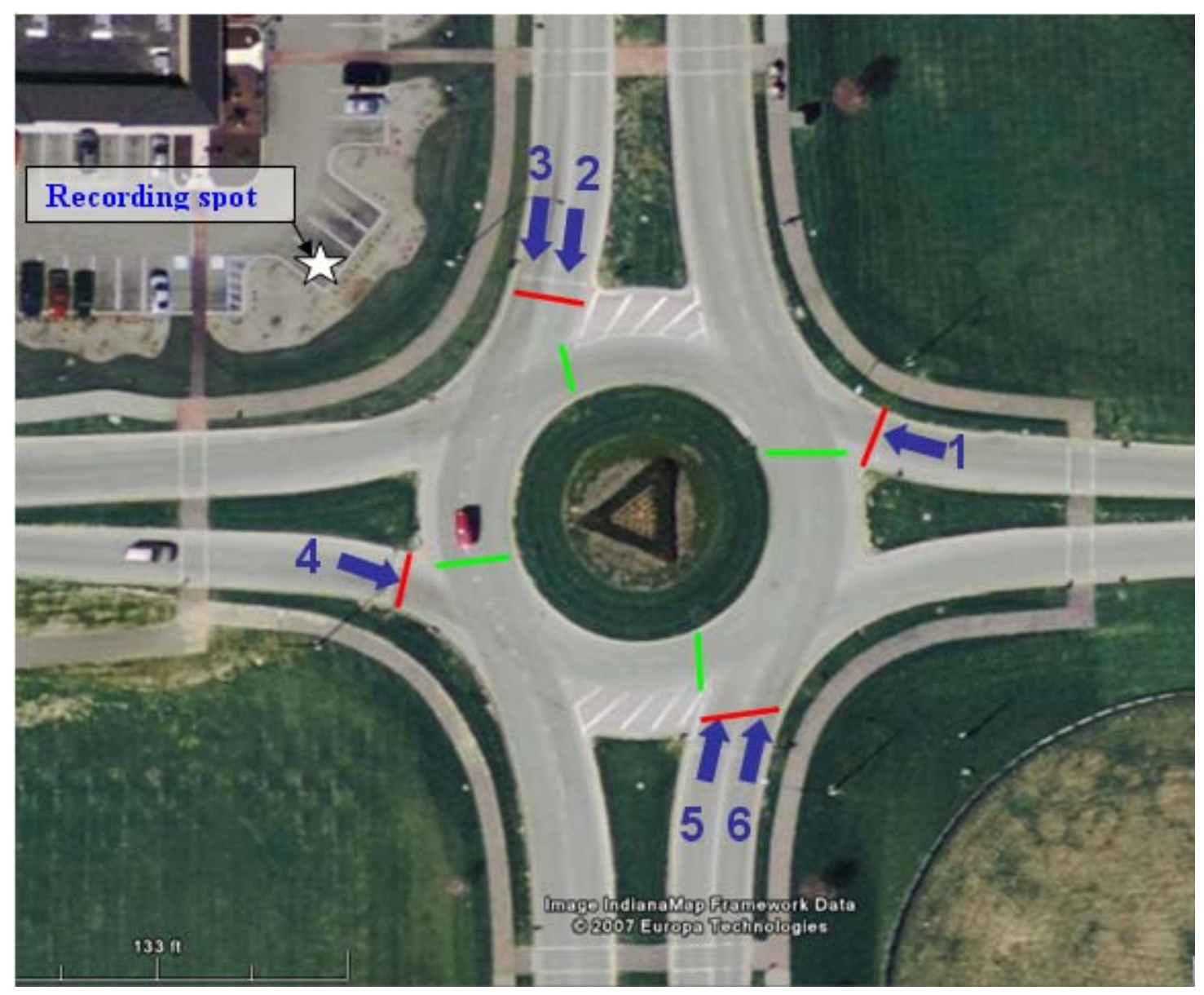

Figure 3-1 Hazel Dell Pkwy \& E 131st Street Roundabout

Hazel Dell Parkway and East 131st Street roundabout was selected for data collection due to its specific geometry and expected heavy volumes. Data on the expected traffic volume levels were provided to us by the Carmel City Engineer involved in the design and implementation of the roundabouts. 
Only a small number of roundabouts experience heavy or even medium volumes in the U.S. since the majority of roundabout have been built in low volume locations due to the unfamiliarity of agencies with this design since early 2000 , thus the data for such sites were limited. Data collected at low volumes sites without continuous queuing present for a majority of the time on at least one approach lane would have a limited number of observations for drivers rejected gaps/lags and accepted gaps, thereby limiting the number of observations for critical gap estimation.

Installation of roundabouts in Carmel began in the early 1990s so drivers in the Carmel area are familiar with this intersection type. Interviewing several Carmel residents revealed a positive attitude towards this intersection type.

\subsection{Data Extraction}

Data from the Hazel Dell Parkway and East 131st Street roundabout were extracted in two steps. The first step involved watching 15 hours of video and collecting simple events at the merging areas of the circulatory lane(s) and the approach lanes. To extract critical gaps and follow-up times, five simple events where used. These events included:

- Event 0: vehicle on roundabout approach stops near the stop bar and the driver is looking for a gap (time)

- Event 2: vehicle on roundabout approach enters the conflict area by crossing the stop bar (time)

- Event 3: vehicle approaching the stop bar was in queue (flag that the first vehicle in queue is followed by another vehicle in queue in the same lane)

- Event 1: circulatory vehicle crosses conflict marker on circulatory roadway outside lane (time)

- Event 4: circulatory vehicle crosses conflict marker on circulatory roadway inside lane (time) 


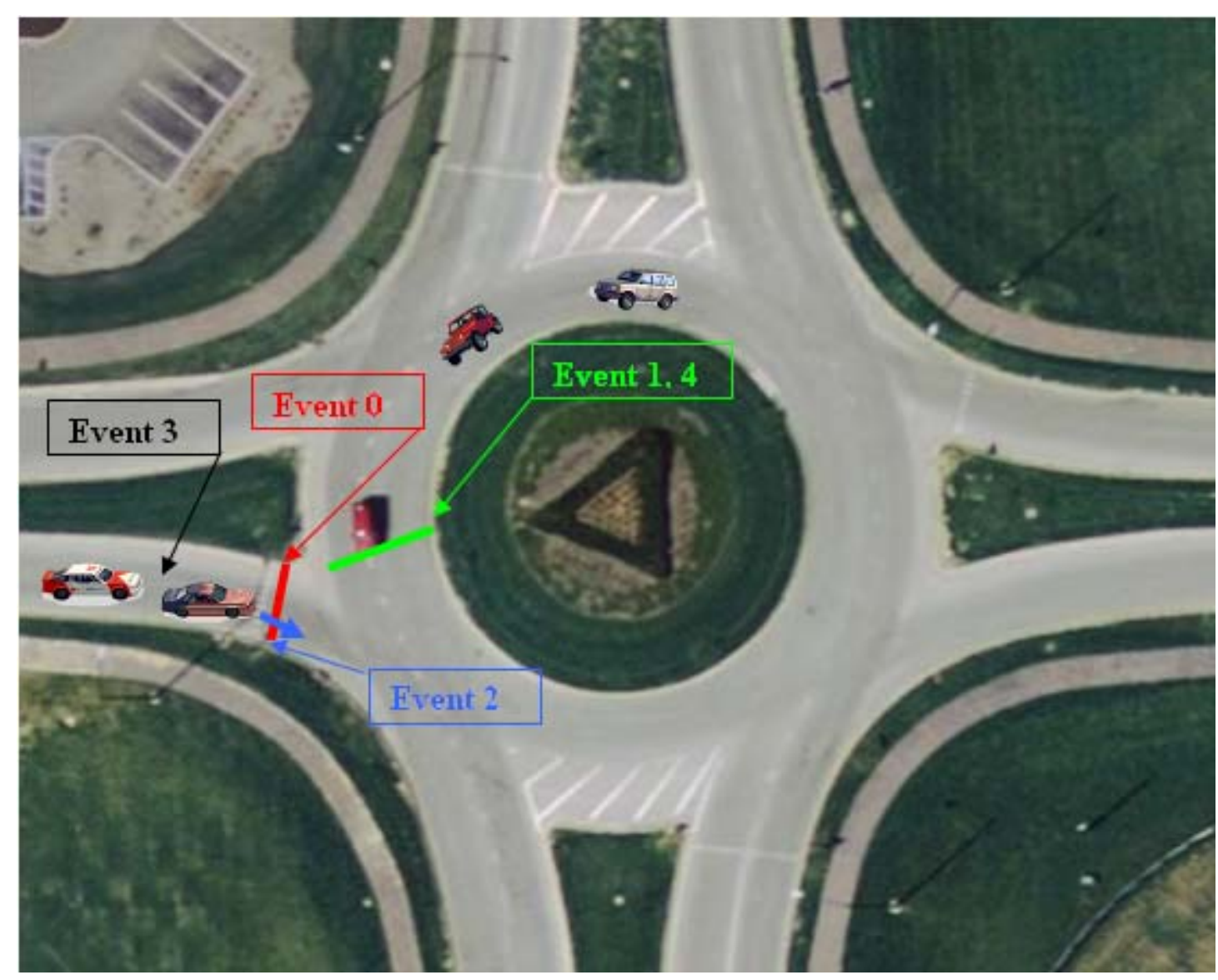

Figure 3-2 Events Collected During Video Extraction

Collecting these simple events from video was accomplished by using an event log tool, which was developed by Jorge Ramos at Purdue University. The event log tool allows storing simple events while the tool is running in the background during video playback. After recording each individual conflicting area, data were saved in an Excel file (Figure 3-3). 


\begin{tabular}{|c|c|c|}
\hline & $\mathrm{A}$ & $B$ \\
\hline 1 & Event & Time \\
\hline 2 & 1 & $21: 57: 13.17$ \\
\hline 3 & 1 & $21: 57: 15.32$ \\
\hline 4 & 1 & $21: 57: 29.56$ \\
\hline 5 & 0 & $21: 57: 34.78$ \\
\hline 6 & 1 & 21:57:35.09 \\
\hline 7 & 1 & $21: 57: 43.03$ \\
\hline 8 & 1 & $21: 57: 44.59$ \\
\hline 9 & 1 & $21: 57: 46.20$ \\
\hline 10 & 2 & $21: 57: 51.45$ \\
\hline 11 & 3 & 21:57:53.00 \\
\hline 12 & 2 & $21: 57: 54.35$ \\
\hline 13 & 3 & $21: 57: 55.68$ \\
\hline 14 & 2 & $21: 57: 57.56$ \\
\hline 15 & 1 & 21:58:00.20 \\
\hline 16 & 1 & 21:58:05.54 \\
\hline 17 & 2 & $21: 58: 06.71$ \\
\hline 18 & 1 & 21:58:19.60 \\
\hline 19 & 1 & 21:58:26.06 \\
\hline
\end{tabular}

Figure 3-3 Sample of Recorded Data by Event Log Tool

The second step of data extraction involved determining the rejected gaps/lags and the accepted gaps/lags based on the collected event data at each approach lane conflict area. A specific sequence of events determined if a gap or lag occurred. Since this step involved investigating thousands of sequences of events, a computer macro tool (RGS) was written in Visual Basic to extract gaps and legs based on the event Excel file obtained during video playback. The simple sequences of events which define an accepted gap (Figure 3-4), a rejected gap (Figure 3-5), a rejected lag (Figure 3-6), an accepted lag (Figure 3-7) and follow-up time (Figure 3-8) are explained below. 
An accepted gap occurs when a vehicle stopped at a yield bar enters the circulatory roadway and a conflicting vehicle passes the conflict point of a given roundabout approach lane. The time that elapses when the yielding vehicle starts entering the roundabout and the circulatory vehicle passes the conflict point defines the accepted gap event.

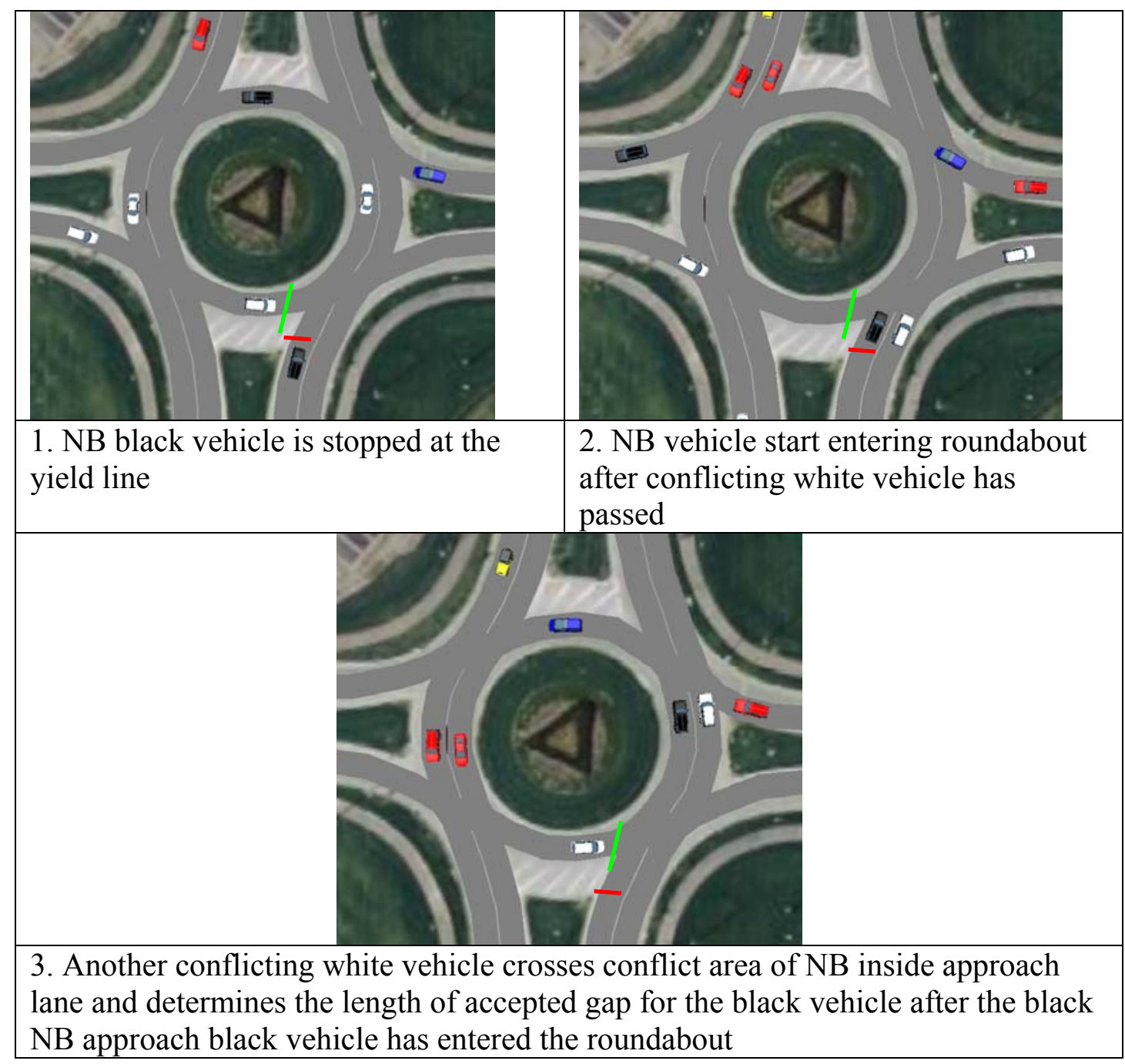

Figure 3-4 Simple Accepted Gap Event Sequence 
A rejected gap event occurs when a vehicle stops at a yield bar and determines not to enter the roundabout during passage of the next two consecutive conflicting vehicles on the circulatory roadway. The time which elapsed between conflicting vehicles passing the conflict marker (green bar) define the rejected gap event.

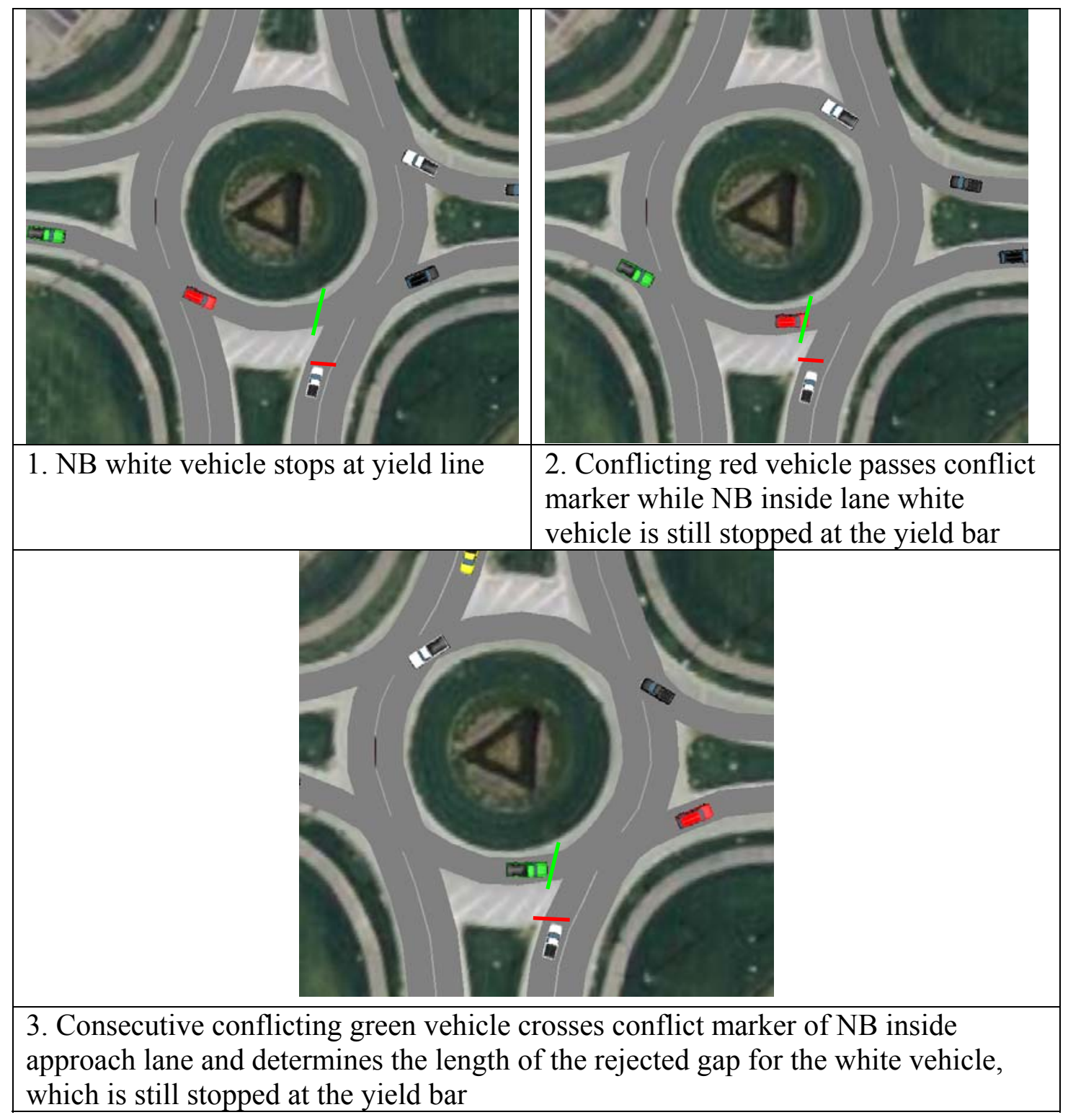

Figure 3-5 Simple Rejected Gap Event Sequence 
A rejected lag event occurs when a vehicle approaching a yield bar determines that the available time between this vehicle and the conflicting vehicle is too short to safely enter the roundabout and therefore stops. Time that elapses when an entering vehicle stops at the yield line and the conflicting vehicle crosses the conflict marker defines the rejected lag event.

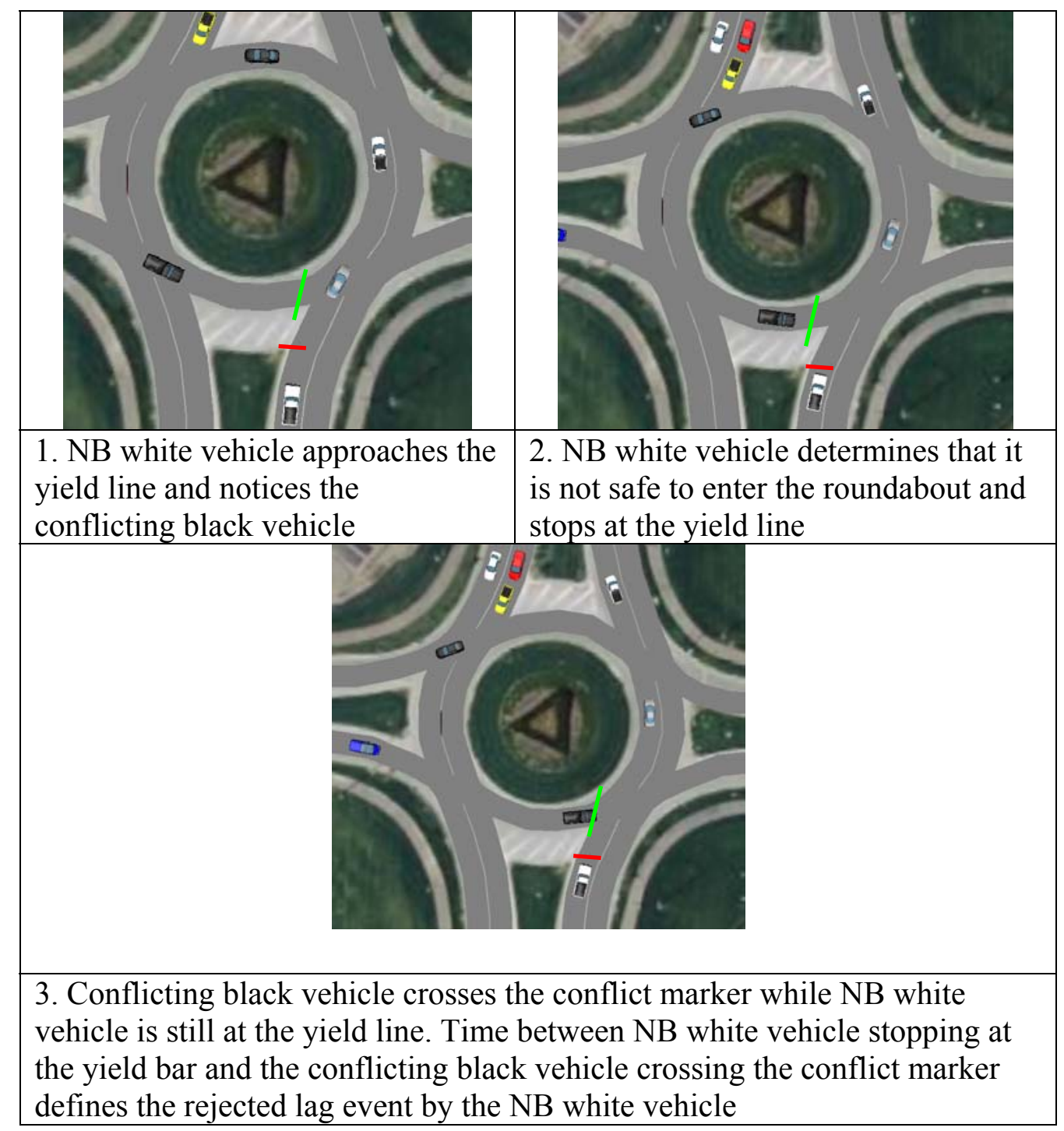

Figure 3-6 Rejected Lag Event Sequence 
An accepted lag event occurs when a vehicle approaching a yield bar determines that it is safe for him to enter the roundabout and crosses the yield bar without stopping. Time that elapses when an entering vehicle passes the yield bar and the conflicting vehicle crosses the conflict marker defines the accepted lag event.

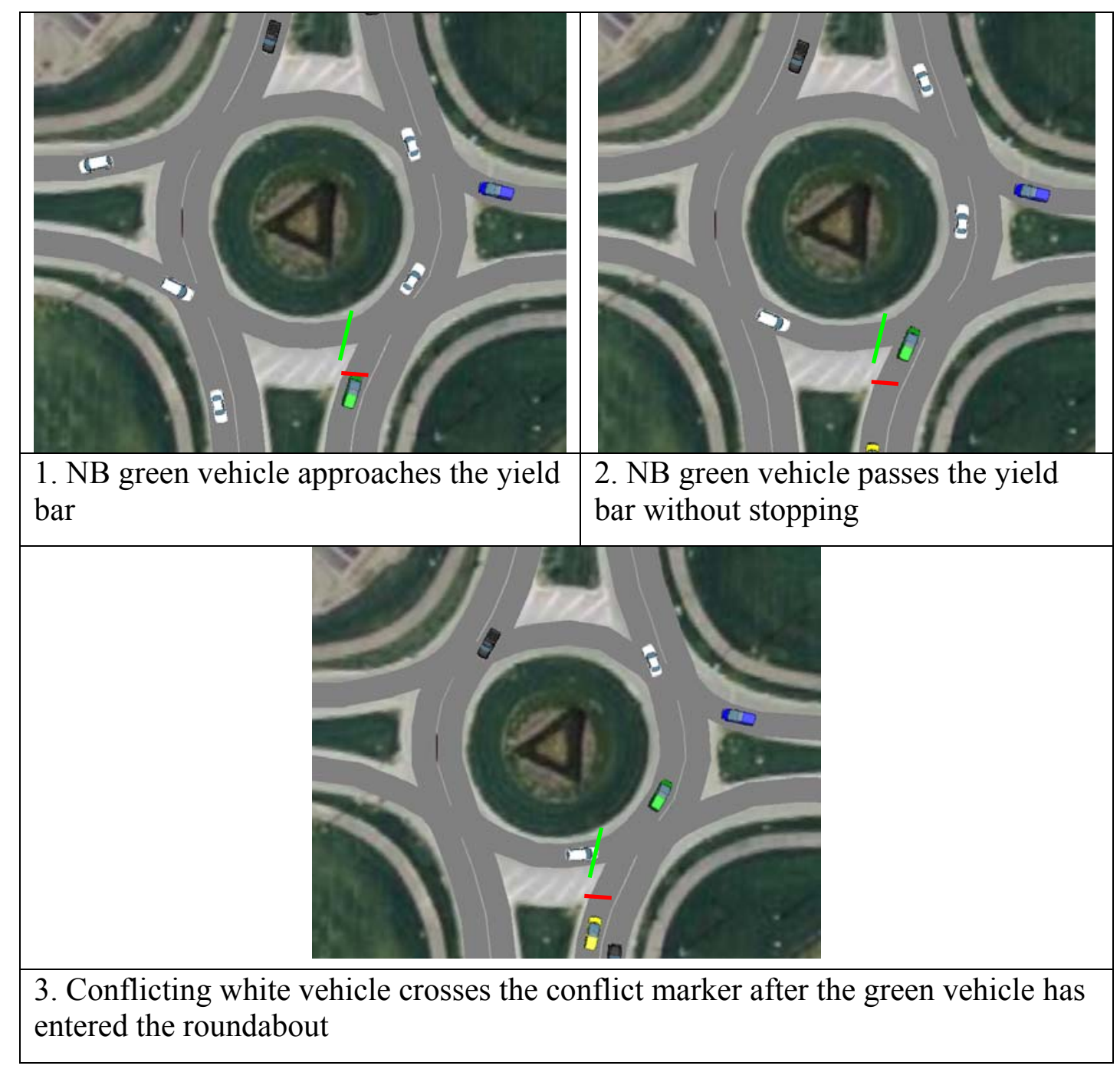

Figure 3-7 Accepted Lag Event Sequence

A follow-up event occurs when a vehicle stopped at the yield bar enters the roundabout and a vehicle(s) is stopped behind in the same lane (also stopped in queue). When either vehicle (or any subsequent number of vehicles in a queue in the same lane) enters the 
roundabout prior to a conflicting vehicle crossing the conflict marker, the time between each consecutive vehicle crossing the yield bar defines the follow-up time.

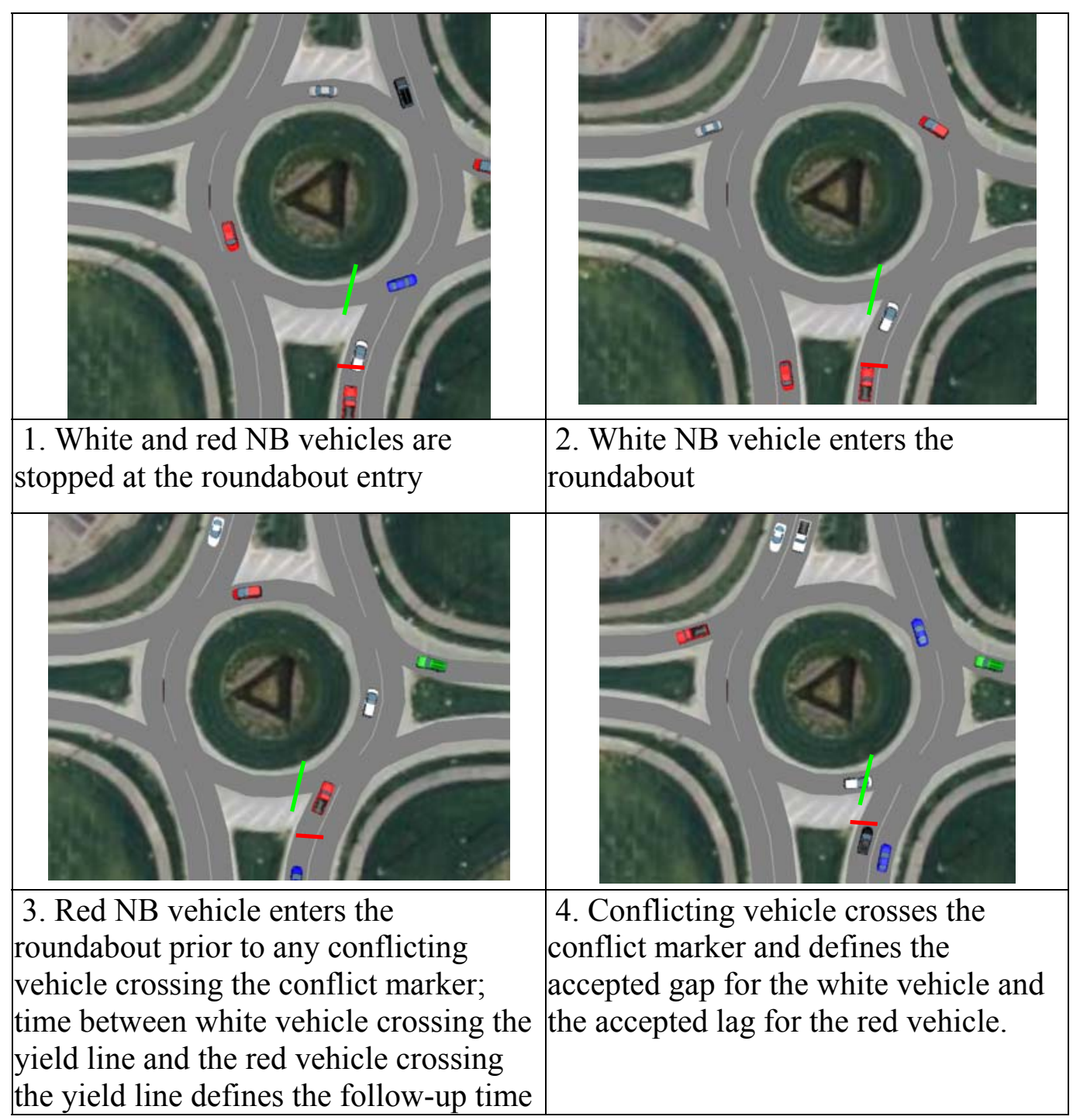

Figure 3-8 Follow-up Time Event Sequence

Having collected event data from video for all six roundabout approach lanes, the developed Roundabout Gap Sequence (RGS) macro tool was used to extract the rejected gaps, the accepted gaps, the rejected lags, the accepted gaps, and the follow-up times (Figure 3-10). As can be seen from Figure 3-10, the developed RGS macro calculates all 
of the required sequences of events for critical gap estimation. The time at the yield bar extracted by the RGS was used to determine the most accurate method for critical gap estimation based on the service time of the vehicle at the first position in the queue (yield line).

Figure 3-11 aggregates the sample data based on each individual vehicle as follows. Vehicle 1 rejected a lag of 0.9 seconds, was stopped at the yield bar for 2.0 seconds, and accepted a gap of 8.6 seconds. Vehicle 2 entered the roundabout 2.5 seconds after Vehicle 1 (follow-up time) and accepted a lag of 6.1 seconds. It should be noticed that the same conflicting vehicle determines the gap time for the first vehicle and the lag time for the second vehicle.

The extracted data from the RGS macro tool were prepared for critical gap estimation using another macro, Roundabout Gap Sequence Extract (RGSE), which prepares data for direct use in the Maximum Likely Method and the Tarko Method for estimating critical gap

\begin{tabular}{|c|c|c|c|c|c|}
\hline 4 & 5 & 6 & 10 & 11 & 12 \\
\hline Time at stop bar[sec) & Event time[sec] & Event Type & largest rejected & accepted & all rejected \\
\hline & & & & & \\
\hline & & & & & \\
\hline & 00:01.1 & Lag Rejected & & & \\
\hline & $00: 02.1$ & Gap Rejected & & & 00:01.1 \\
\hline & $00: 02.7$ & Gap Rejected & \rangle & & $00: 02.1$ \\
\hline & $00: 01.9$ & Gap Rejected & & & $00: 02.7$ \\
\hline 0:00:09 & $00: 04.0$ & Gap Accepted & $00: 02.7$ & $00: 04.0$ & $00: 01.9$ \\
\hline
\end{tabular}

Figure 3-9 Post Processing Data with RGSE 


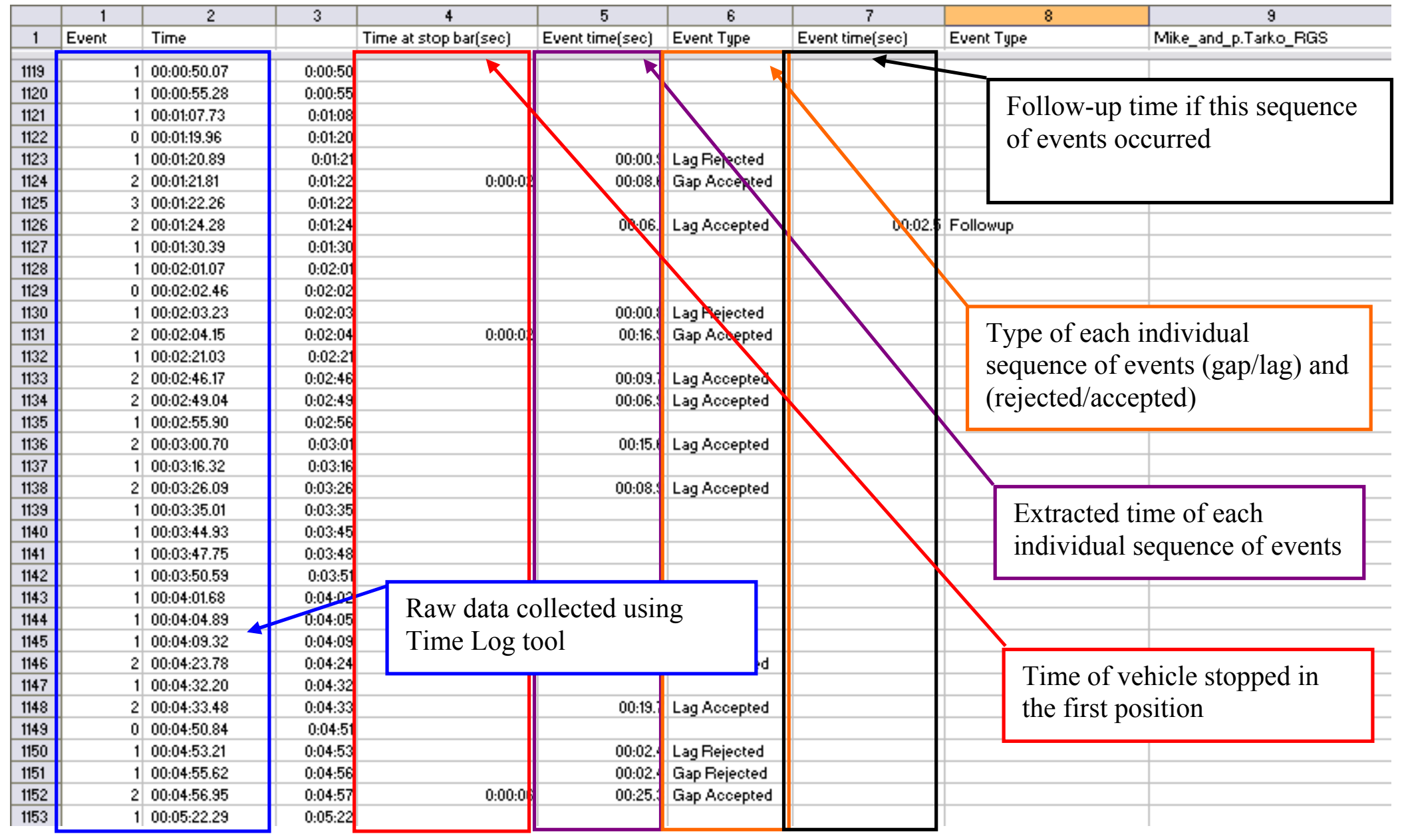

Figure 3-10 RGS Software Sample Output I 


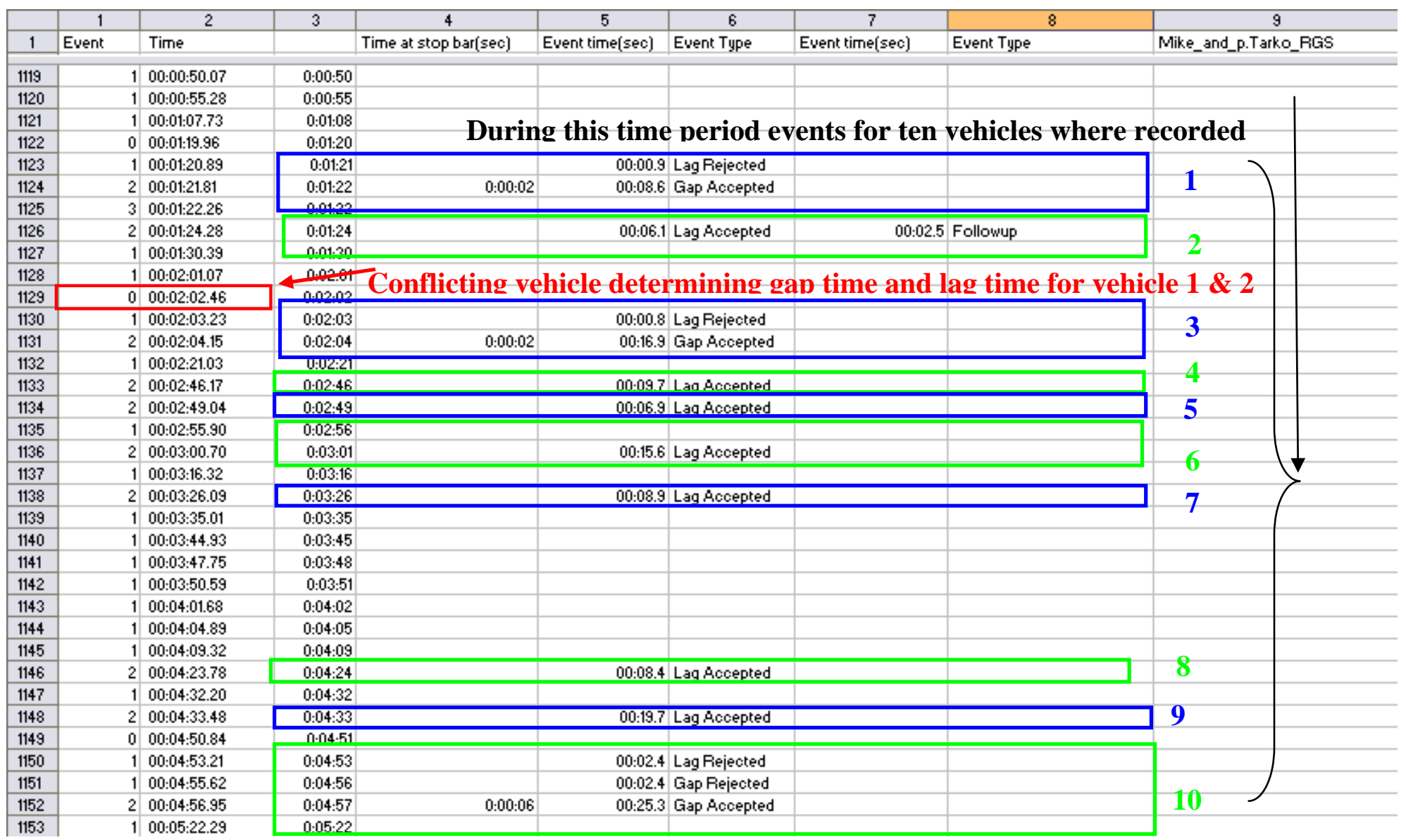

Figure 3-11 RGS Software Sample Output I 
It should be mentioned that a single vehicle entering a roundabout which stops at the yield line will have a rejected lag; can have none, one or multiple rejected gaps; and will have one accepted gap. A vehicle that enters a roundabout without stopping will have one accepted lag. This distinction is important when the critical gap is estimated using different driver behavior assumptions.

\subsection{Critical Gap Estimation}

Extracted gaps and lags were used to determine the critical gap representative for drivers in Indiana accustomed to a roundabout intersection. Two major assumptions about drivers were tested using two distinct critical gap estimation procedures. For each procedure, two different methods were used; one method included using only gap event in the critical gap estimation procedure, and the other included using gaps and lags in the critical gap estimation procedure. This combination gives a total of four estimates for the critical gap. The follow-up time was obtained by averaging all of the follow-up events extracted during the data collection period

The two procedures tested were the Maximum Likelihood Method and the Tarko Method. The Maximum Likelihood Method has been proven to be one of the best methods for critical gap estimation (Brilon et al., 1999). The Maximum Likelihood Method assumes that drivers are consistent and, if subjected to the same sequence of events, will behave in an identical fashion i.e., that is drivers will always reject gaps/lags smaller than their critical gap and accept gaps/lags larger than their critical gap. This assumption about the Maximum Likelihood Method implies that each driver is represented in the data set by the largest rejected gap and accepted gap. For those drivers that do not stop at the yield line, the largest rejected gap is zero.

The Tarko method assumes that drivers are not always consistent and will sometimes reject longer gaps/lags then their accepted gap. With this assumption, each vehicle contributes to the data set with all of its rejected gaps/lags and accepted gap. 
These two procedures represent two distinct assumptions about a driver's gap acceptance behavior. The Maximum Likelihood Method assumes consistent drivers while the Tarko Method assumes drivers are not always consistent with their gap acceptance behavior. The Tarko Method emerged as data were extracted and was noticed that for some drivers their largest rejected gap, were higher than their accepted gaps so those observations had to be removed from the Maximum Likelihood Method but not from the Tarko Method.

The procedure for estimating critical gap using the Maximum Likelihood Method:

1. For each driver estimate, the longest gap rejected is $g_{r}$ and the gap accepted is $g_{a}$. The critical gap $g_{c}$ of the driver is between $g_{r}$ and $g_{a}$. If the first gap (lag) is accepted then $g_{r}=0 \mathrm{sec}$ (in this case critical gap $g_{c}$ is between 0 and $g_{a}$ ).

2. Assume a specific gap distribution for the critical gap (lognormal). Thus $f\left(g_{c}\right)$ is the probability density function and $\mathrm{F}\left(\mathrm{g}_{\mathrm{c}}\right)$ is the cumulative distribution function.

3. The probability that $g_{c}$ is between $g_{r}$ and $g_{a}$ is equal to $F\left(g_{a}\right)-F\left(g_{r}\right)$ and the likelihood for multiple drivers is

$$
L^{*}=\prod_{i}\left[\mathrm{~F}\left(\mathrm{~g}_{\mathrm{a}_{\mathrm{i}}}\right)-\mathrm{F}\left(\mathrm{g}_{\mathrm{r}_{\mathrm{i}}}\right)\right], \quad L=\log L^{*}=\sum_{\mathrm{i}} \log \left[\mathrm{F}\left(\mathrm{g}_{\mathrm{a}_{\mathrm{i}}}\right)-\mathrm{F}\left(\mathrm{g}_{\mathrm{r}_{\mathrm{i}}}\right)\right]
$$

4. Find the average $\bar{g}_{c}$ and standard deviation $\sigma_{c}$, by solving:

$$
\max _{\left\{\bar{g}_{c}, \sigma_{c}\right\}} \sum_{\mathrm{i}} \log \left[\mathrm{F}\left(\mathrm{g}_{\mathrm{a}_{\mathrm{i}}}\right)-\mathrm{F}\left(\mathrm{g}_{\mathrm{r}_{\mathrm{i}}}\right)\right]
$$

, where $\bar{g}_{c}$ and $\sigma_{c}$ are parameters of the distribution $\mathrm{f}\left(\mathrm{g}_{\mathrm{c}}\right)$ 
The procedure for estimating critical gap using Tarko Method:

In this method we assume $\mathrm{g}_{\mathrm{c}}$ varies across drivers and across the decisions of the same driver (implies drivers are not consistent).

1. Estimate each gap rejected $g_{r}$ and each gap accepted $g_{a}$ for each driver.

2. The likelihood of $g_{c}$ higher then $g_{r}$ is $1-F\left(g_{r}\right)$.

The likelihood of $g_{c}$ shorter then $g_{a}$ is $F\left(g_{a}\right)$.

3. The likelihood for all drivers in the population is

$$
L=\sum_{\mathrm{i}} \log \left[1-\mathrm{F}\left(\mathrm{g}_{\mathrm{r}_{\mathrm{i}}}\right)\right]+\sum_{\mathrm{j}} \log \mathrm{F}\left(\mathrm{g}_{\mathrm{a}_{\mathrm{j}}}\right)
$$

4. Find the average $\bar{g}_{c}$ and standard deviation $\sigma_{c}$, by solving:

$$
\max _{\left\{\bar{g}_{c}, \sigma_{c}\right\}} \sum_{\mathrm{i}} \log \left[1-\mathrm{F}\left(\mathrm{g}_{\mathrm{r}_{\mathrm{i}}}\right)\right]+\sum_{\mathrm{j}} \log \mathrm{F}\left(\mathrm{g}_{\mathrm{a}_{\mathrm{j}}}\right)
$$

, where $\bar{g}_{c}$ and $\sigma_{c}$ are parameters of distribution $\mathrm{f}\left(\mathrm{g}_{c}\right)$

To maximize the likelihood for each method, the Excel solver feature was used. Four different estimates for critical gap were determined and included the Maximum Likelihood Method using only gap events, the Maximum Likelihood Method using gap and lag events, the Tarko Method using gap events, and the Tarko Method using gap and lag events. Four different estimates were obtained (Table 3-1, Table 3-2).

Table 3-1 Tarko Method Critical Gap Estimates

\begin{tabular}{|l|r|r|}
\hline \multicolumn{1}{|c|}{ Tarko Method } & & \\
\hline \multicolumn{1}{|c|}{} & Gaps\&Lags & Gaps \\
\hline $\max _{\left\{\bar{g}_{c}, \sigma_{c}\right\}} \sum_{\mathrm{i}} \log \left[1-\mathrm{F}\left(\mathrm{g}_{\mathrm{r}_{\mathrm{i}}}\right)\right]+\sum_{\mathrm{j}} \log \mathrm{F}\left(\mathrm{g}_{\mathrm{a}_{\mathrm{j}}}\right)$ & -2425.5165 & -1209.01 \\
\hline Critical gap (sec) & 2.4 & 3.5 \\
\hline Standard deviation (sec) & 1.7 & 1.7 \\
\hline
\end{tabular}


Table 3-2 Maximum Likelihood Method Critical Gap Estimates

\begin{tabular}{|c|r|r|}
\hline \multicolumn{1}{|c|}{ Maximum Likelihood Method } & & \\
\hline \multicolumn{1}{|c|}{$\max _{\left\{\bar{g}_{c}, \sigma_{c}\right\}} \sum_{\mathrm{i}} \log \left[\mathrm{F}\left(\mathrm{g}_{\mathrm{a}_{\mathrm{i}}}\right)-\mathrm{F}\left(\mathrm{g}_{\mathrm{r}_{\mathrm{i}}}\right)\right]$} & Gaps\&Lags & \multicolumn{1}{|c|}{ Gaps } \\
\hline Critical gap (sec) & -1675.5571 & -829.049 \\
\hline Standard deviation (sec) & 1.9 & 3.1 \\
\hline
\end{tabular}

Table 3-3 Follow-up Time Estimate from Field Data

\begin{tabular}{|c|c|}
\hline Average Follow-up time (sec) & $\begin{array}{l}\text { Number of } \\
\text { observations }\end{array}$ \\
\hline 2.42 & 1076 \\
\hline
\end{tabular}

To evaluate which critical gap estimate most accurately reflects the field data, a simulation experiment, replicating field conditions, was conducted using the counts collected at roundabout conflicting areas. The procedure for estimating roundabout turning movements based on the counts collected at the conflicting areas, data collection points, is explained. By applying this procedure to estimate turning movements, tracking individual vehicles was not required and saved a lot of time.

\subsection{Evaluation of critical gap estimation methods based on service time}

The critical gaps were evaluated based on service time in the queue first position, which is equivalent to the time spent at the yield bar (column 4 in Figure 3-10, Figure 3-11). Vehicles that did not stop at the yield line when entering the roundabout had a time in the first position equal to zero. Prior to running the simulation experiment, the follow-up time was calibrated within VISSIM by modifying the headway parameter (CC1) of the Wiedemann 1999 model since the default values, follow-up time was below the targeted field extracted value of $2.42 \mathrm{sec}$ (Table 3-3). By calibrating the follow-up time to the field collected value in the simulation, the only parameter having an impact on roundabout operation with the entering volumes on the approaches and the turning movements replicating the field data was the critical gap. By adjusting the critical gap in 
the calibrated simulation from $1.9 \mathrm{sec}$ to $3.5 \mathrm{sec}$ and conducting this simulation for a period of 1.25 hours of replicated field traffic conditions, the average service time on all approaches was measured and compared to the field measured values, thus the best estimate for critical gap could be found. Field-measured service time in the first position was obtained by the RGS macro tool explained in the previous section.

\subsubsection{Determining roundabout turning movements}

Turning movements at the roundabout were determined based on counts collected at data collection points at each approach lane and the circulatory lane conflict area. Counts are simply the 1,2, and 4 events which were used for estimating the critical gap (for definitions of these events, see Section 3.2).

Figure 3-12 shows the data collection points for the videotaped roundabout. Each blue dot represents a data collection point and the black lines track the movements of entering vehicles from a particular approach. Each movement of the roundabout passes through a particular number of data collection points; for example, the NBL movement passes thorough data collection points 1,10 , and 12, which implies that for each data collection point, there are a particular number of movements passing through it. This is the basis for constructing the movement matrix which maps all movements passing a particular data collection point (Figure 3-14). 


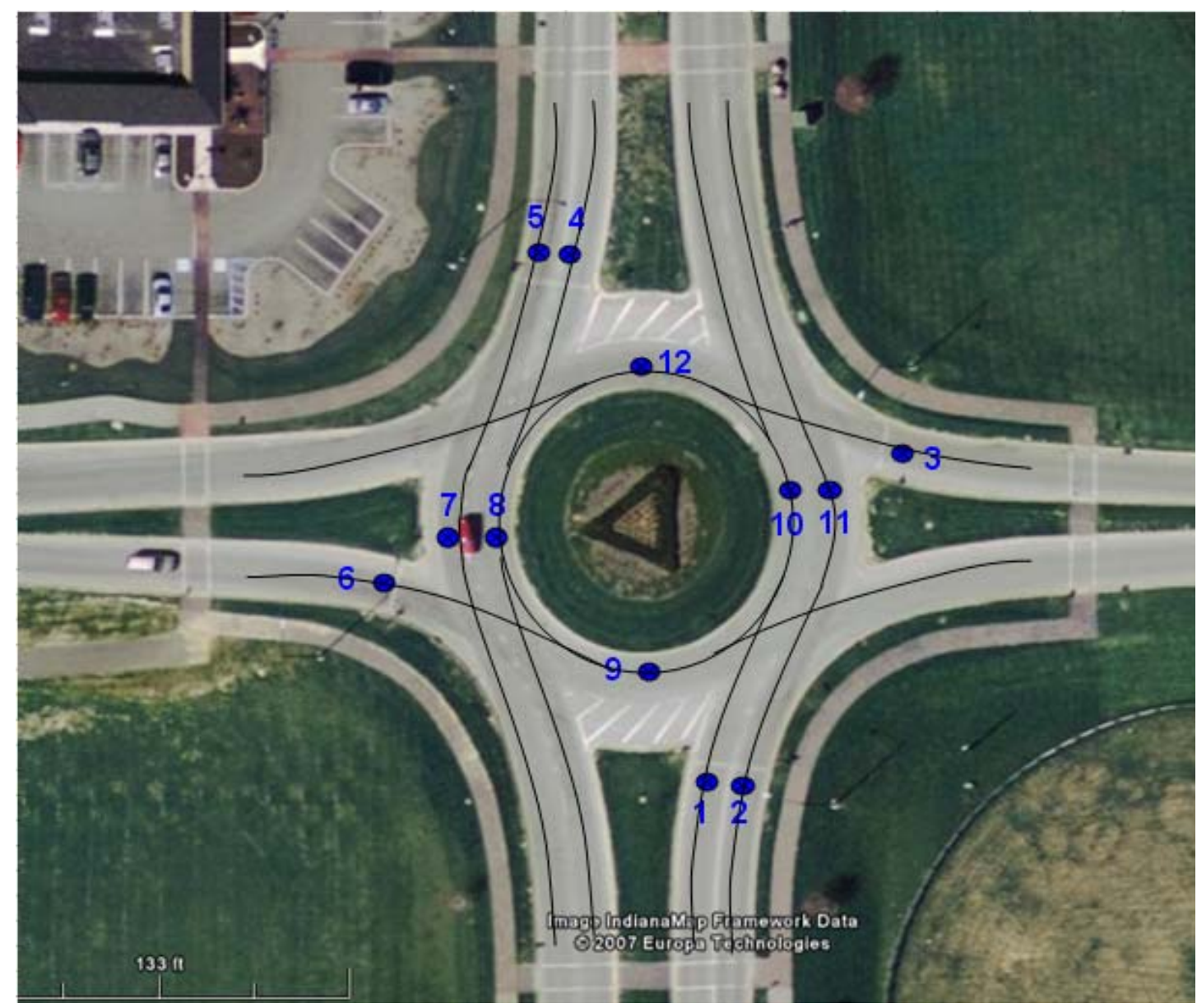

Figure 3-12 Data Collection Points at Roundabout

As can be seen from Figure 3-14 and Figure 3-12, Data Collection Point 1 has a north bound left turn movement passing through it and a north bound trough inside lane movement passing through it. 


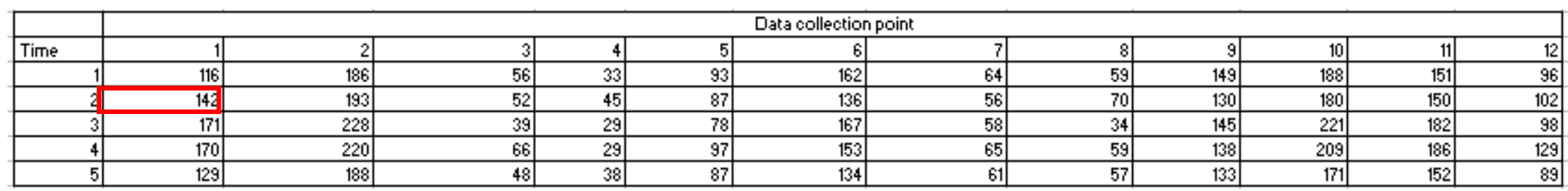

Figure 3-13 Counts at Data Collection Points Extracted from Field Data

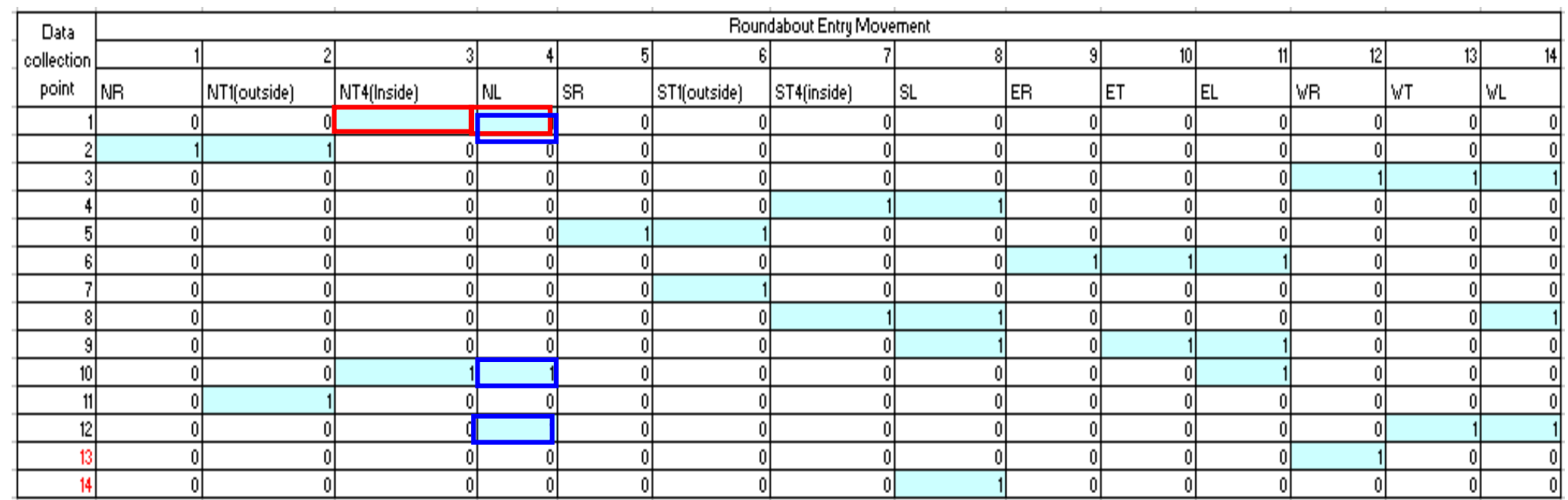

Figure 3-14 Movement Matrix 
Since these movements pass through Data Collection Point 1, we put a " 1 " in the movement matrix (Figure 3-14) in (row 1; column3) and (row1; column 4), which represent in the matrix the intersection of Data Collection Point 1 with column 3 (NT4 Inside) and Data Collection Point 1 with column 4 (NL). NT4 Inside and NL represent the north bound through inside lane movement and the north bound left turn movement respectively. The first row in Figure 3-14 gives us this equation:

$$
\text { NT4 }+ \text { NL }=\text { count at Data Collection Point } 1
$$

An alternative approach is to track each movement separately and put a " 1 " in every data collection point this movement passes through; for example, let us look at the north bound left turn movement (NL). This movement passes through Data Collection Points 1, 10 , and 12, thus we would put " 1 " in column 3 and rows 1, 10, and 12 (Figure 3-14).

Following this process for all data collection points, we fill in the matrix with " 1 " everywhere a movement passes through a particular data collection point. This implies that a data collection point can have multiple movements passing through it and will have a " 1 " in the matrix in the appropriate row and column entries.

The counts at each data collection point have been obtained from field data for a consecutive period of 1.25 hours in 15-minute intervals, giving a total of five intervals with counts collected for each data collection point during each interval (Figure 3-13).

Following this process yields a total of 12 equations since the field count at each data collection point were known. However, we end up with 14 unknowns (14 entering movements) due to a $4 \times 2$-lanes roundabout geometry and 12 equations. Thus, two additional equations were needed. Those two additional equations were obtained by making an assumption about left turns and right turns (based on watching the video) with the smallest entering counts, thereby minimizing error. The assumptions made were Southbound Left (SL) is equal to 15 percent and Westbound Right is equal to 10 percent, 
which gave us the required two additional equations (data collection point 13 and 14 Figure 3-14).

WR=count at Data Collection Point 13 (assumed to be 10 percent of Data Collection Point 6)

$\mathrm{SL}=$ count at Data Collection Point 14 (assumed to be 15 percent of Data Collection Point 4)

It should be noted that Data Collection Points 1 through 12 are actual measurements taken in the field, whereas Data Collection Points 13 and 14 were obtained by assumptions. If Westbound Right turns and Southbound Left turns were measured in the field. These assumptions therefore would not have to be made. An alternative would have been to measure the exiting movements.

Solving 14 simultaneous equations constructed based on the movement matrix (Figure 3-14) using Excel (solver feature, exact solution) for five different 15-minute intervals gives the turning movement counts for each roundabout approach.

The turning movements were entered to the VISSIM microsimulation package with the exact volumes and the same interval duration, thus exactly replicating entering traffic conditions at the roundabout. The roundabout in VISSIM was constructed in such a way that vehicles were not allowed to change lanes directly on the roundabout. This enforced the exact counts at the data collection points in the simulated network, replicating the counts at the data collection points in the field. 
Figure 3-15 Estimated Turning Movements Using Matrix Method

\begin{tabular}{|l|r|r|r|r|r|}
\hline Interval & 1 & 2 & 3 & 4 & 5 \\
\hline NR & 35 & 43 & 46 & 34 & 36 \\
\hline NT1(outside) & 151 & 150 & 182 & 186 & 152 \\
\hline NT4(Inside) & 70 & 87 & 108 & 100 & 83 \\
\hline NL & 46 & 55 & 63 & 70 & 46 \\
\hline SR & 29 & 31 & 20 & 32 & 26 \\
\hline ST1(outside) & 64 & 56 & 58 & 65 & 61 \\
\hline ST4(inside) & 28 & 39 & 25 & 25 & 32 \\
\hline SL & 5 & 6 & 4 & 4 & 6 \\
\hline ER & 18 & 12 & 26 & 19 & 7 \\
\hline ET & 72 & 86 & 91 & 95 & 85 \\
\hline EL & 72 & 38 & 50 & 39 & 42 \\
\hline WR & 6 & 5 & 4 & 7 & 5 \\
\hline WT & 24 & 22 & 30 & 29 & 24 \\
\hline WL & 26 & 25 & 5 & 30 & 19 \\
\hline
\end{tabular}

\subsubsection{Simulation Experiment}

In VISSIM 4.3, unsignalized intersections can be coded in two ways. The first way is to use priority rules which consist of the stop line and one or more conflict markers. A conflict marker checks the minimum headway (feet) and the minimum gap (sec) upstream of their location to ensure if it is safe for the minor street vehicle to enter the priority stream without conflicting with a vehicle on the priority stream. The use of "conflict areas" is a new alternative to "priority rules" and requires less coding time. However, the parameters used for conflict areas slightly differ from priority rules. Crossing yield/right-of-way conflict areas require a front gap and a rear gap, assuming a constant visibility parameter. The front gap is the minimum gap (sec) between the rear end of a vehicle on the main road and the front end of a vehicle on the minor road i.e., the time that a yielding vehicle waits before entering the conflict area after the vehicle with the right of way has left it. The rear gap is the minimum gap (sec) between the rear end of a vehicle on the minor road and the front end of a vehicle on the main road i.e., the time that a yielding vehicle must provide after it has left the conflict area before a vehicle with the right of way enters the conflict area. Calibrating the conflict areas would require collecting an additional parameter and would add complexity to the data extraction 
process by requiring more events. Thus, priority rules were used for unsignalized intersections, which directly use the minimum gap (sec) between the conflict marker and the front bumper of the vehicle in the priority stream.

In VISSIM, traffic conditions as encountered in the field during data collection were replicated by entering the appropriate vehicle inputs and volumes in routes (turning movements). The turning movements obtained in the previous section were used to determine the loading volumes (in VISSIM, for each time interval, you enter hourly counts) (Figure 3-16).

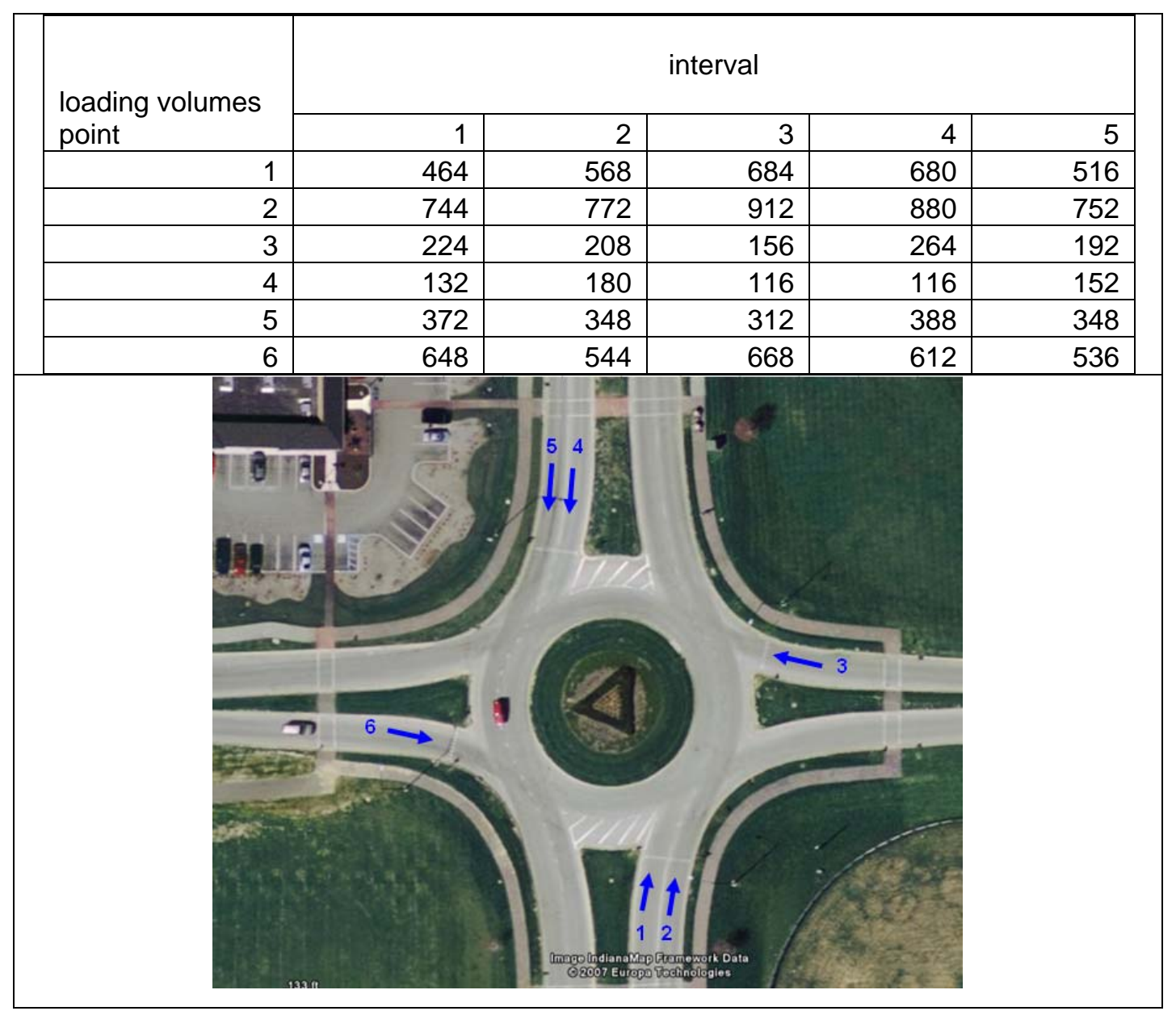

Figure 3-16 Loading Volumes for Simulation Experiment 


\subsubsection{Follow-up time calibration}

To calibrate follow-up time, data collection point measurements were placed in the VISSIM network, replicating the roundabout where the data were collected. For each approach lane, two data collection point were used. Each data collection point recorded the time in the queue of the vehicle as it crossed a given data collection point and the time when the vehicle crossed that particular data collection point.

Consider the Northbound Inside roundabout approach lane (one data collection point is placed at the yield bar and the other 20 feet upstream) (Figure 3-17).

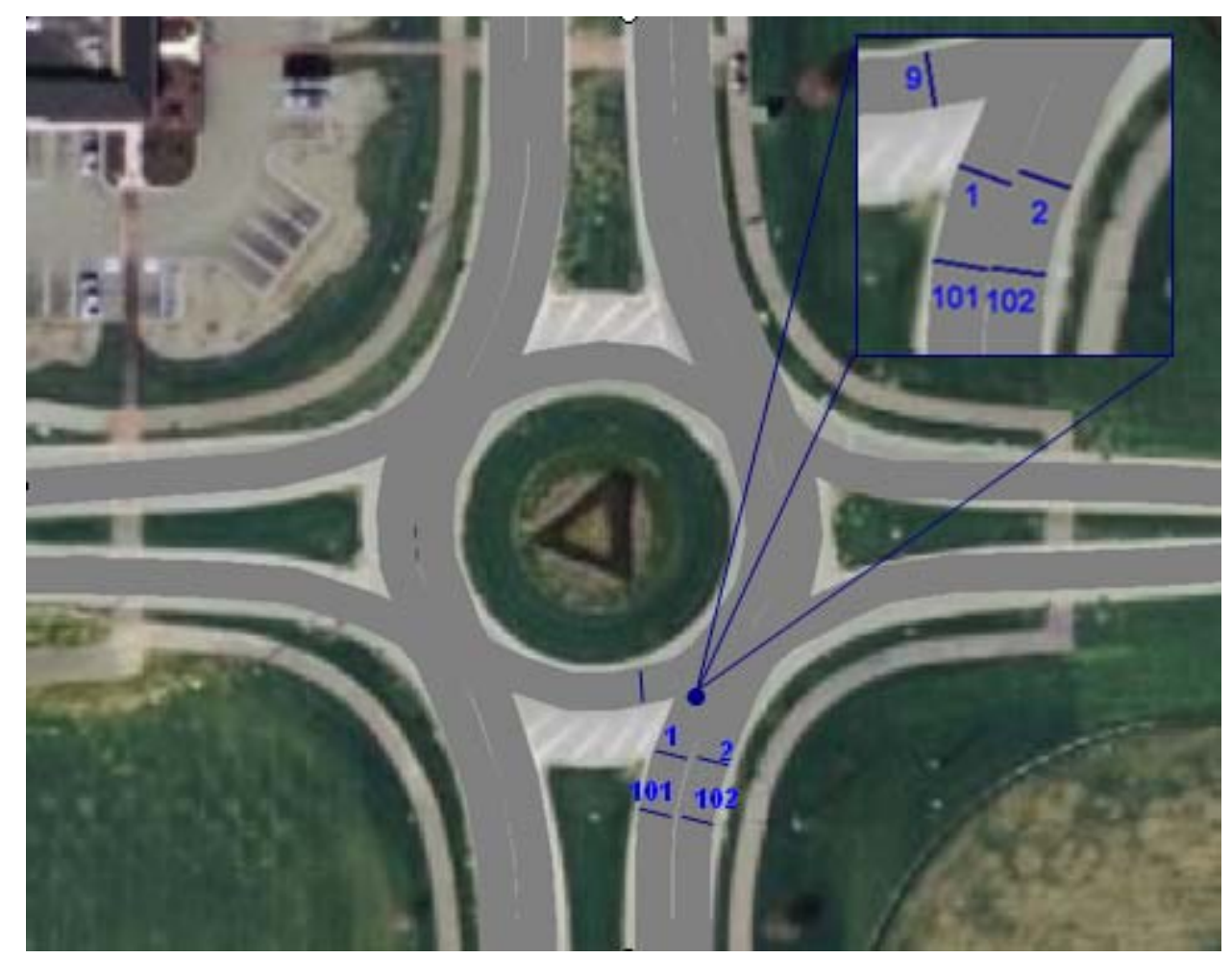

Figure 3-17 Follow-up Calibration Data Collection Setup

During the simulation, a follow-up event occurred for the Northbound Inside lane vehicle when it entered the Data Collection Point 1, with the same time in the queue as when entering Data Collection Point 101 (this implies that vehicle has not stopped in the first 
position). The time between the previous vehicle crossing Data Collection Point 1 and the considered vehicle crossing Data Collection Point 1 reflected the follow-up time of the considered vehicle.

During the simulation experiment, different values of the headway (CC1) parameter in VISSIM were investigated. For each headway parameter, one hour of simulation time was performed. The average follow-up time for each simulation hour of different headway parameter was recorded. Headway time influences how closely vehicles follow each other in simulation and the resulting follow-up time. The default VISSIM values resulted in a follow-up time equal to 2.27 seconds, which was lower than the fieldmeasured value of 2.42 seconds; thus, calibration was performed. The headway time parameter (CC1) set to 1.16 seconds yields a simulation follow-up time equal to the fieldmeasured follow-up time (Figure 3-18).

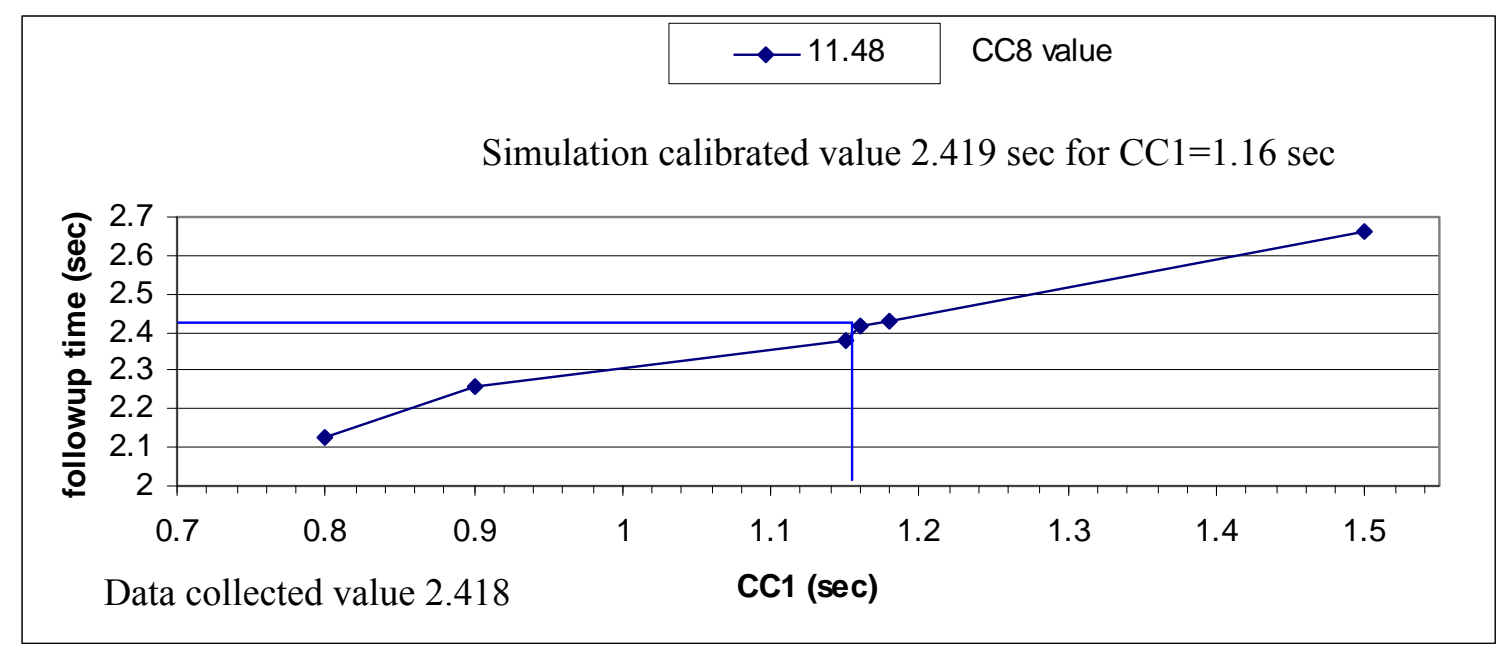

Figure 3-18 Follow-up Time Based on Headway Parameter 
In addition to the headway time (CC1) parameter, the standstill acceleration (CC8) parameter and the speed on the roundabout approach was also investigated in VISSIM to determine their effect on follow-up time in the simulation.

3.4.2.2 Effect of headway time, acceleration from stopped position, and speed on follow-up time in VISSIM simulation.

Two different headway times $(\mathrm{CC} 1=1.2 \mathrm{sec}$ and $\mathrm{CC} 1=1.5 \mathrm{sec})$ were investigated in VISSIM with different values of acceleration from the standstill acceleration parameter (CC8). It was found that lower values of the CC8 parameter have an effect on the followup time; but at higher values, this parameter is overwritten by the VISSIM base data maximum acceleration curve for a given vehicle type and has no effect. It was also found that the effect of the headway parameter $(\mathrm{CC} 1)$ is more profound than the standstill acceleration (CC8) parameter (Figure 3-19).

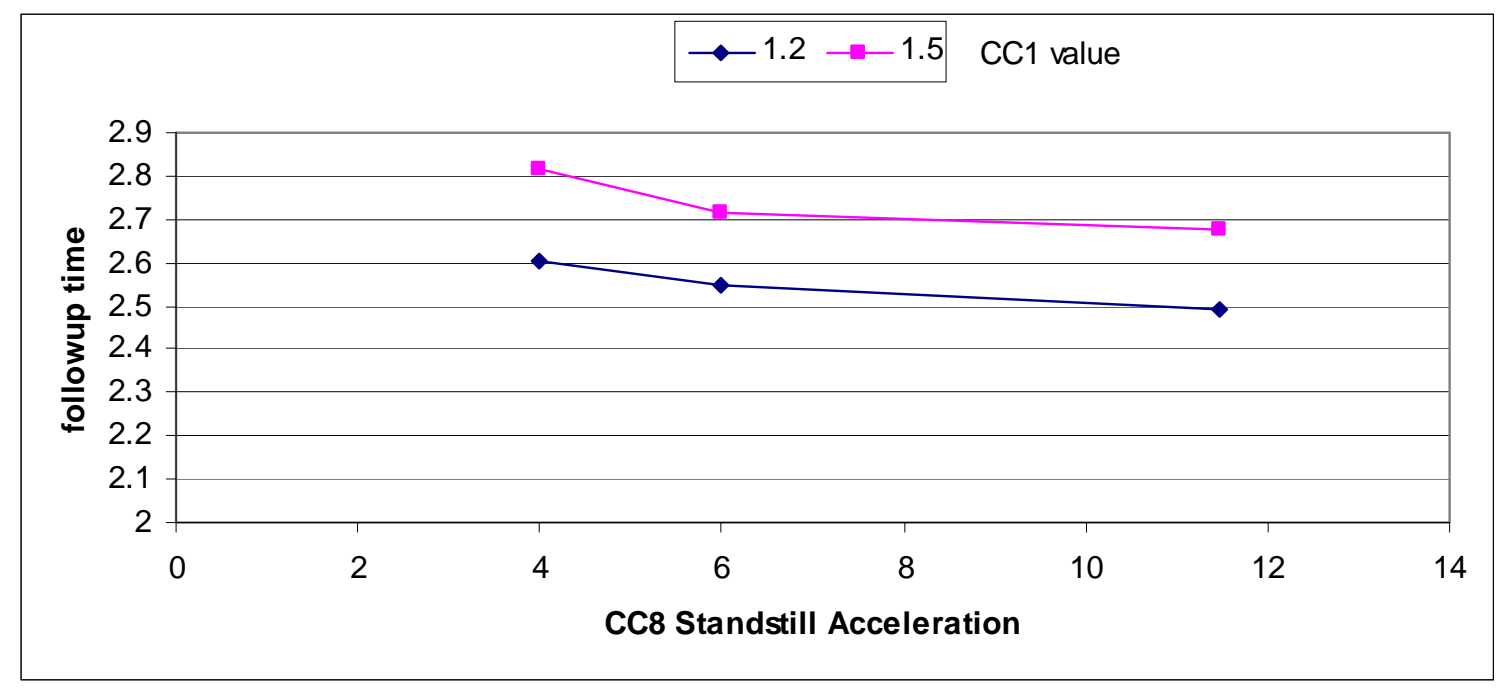

Figure 3-19 Effect of CC8 on Roundabout Follow-up Time for Different CC1 Values

The speed of the vehicle during the simulation on a roundabout approach had no effect on the follow-up time. We can see this by comparing combinations of the default parameter values for CC1 and CC8 with different speeds (Figure 3-20). 


\begin{tabular}{|c|c|c|c|c|}
\hline \multicolumn{5}{|c|}{ Simulation } \\
\hline Combination & CC1 (Headway Time) sec & CC8 (Standstill Acceleration) & Followup time (sec) & Desired Speed on roundabout (mph) \\
\hline 1 & 0.9 & 11.48 & 2.269 & $17-21$ \\
\hline 2 & 1.2 & 4 & 2.604 & $17-22$ \\
\hline 3 & 1.2 & 6 & 2.546 & $17-21$ \\
\hline 4 & 1.2 & 11.48 & 2.49 & $17-21$ \\
\hline 5 & 1.5 & 4 & 2.818 & $17-21$ \\
\hline 6 & 1.5 & 6 & 2.714 & $17-21$ \\
\hline 7 & 1.5 & 11.48 & 2.679 & $17-21$ \\
\hline 8 & 3 & 2 & 4.042 & $17-21$ \\
\hline 9 & 0.8 & 11.48 & 2.124 & $19-23$ \\
\hline 10 & 0.9 & 11.48 & 2.261 & $19-23$ \\
\hline 11 & 1.15 & 11.48 & 2.378 & $19-23$ \\
\hline 12 & 1.16 & 11.48 & 2.419 & $19-23$ \\
\hline 13 & 1.18 & 11.48 & 2.431 & $19-23$ \\
\hline 14 & 1.5 & 11.48 & 2.661 & $19-23$ \\
\hline
\end{tabular}

Figure 3-20 Summary of Tested Combination of Parameters on Follow-up Time

With the calibrated follow-up time through adjustments in the driving behavior, parameter $\mathrm{CC} 1$, and the appropriate turning volumes entered in VISSIM at the roundabout approaches, a simulation experiment comparing the service time of vehicles in the first position in the queue was performed to determine which critical gap estimates replicate most accurately the field conditions.

One hour and fifteen minutes of simulation was performed for each critical gap value tested. The critical gap tested during simulation ranged from 1.9 seconds to 3.5 seconds (Figure 3-22), which is the range for the critical gap obtained in the applied critical gap estimation methods. For each critical gap, the service times of vehicles in the first position in the queue (time at yield bar) were recorded and averaged for all approaches during the simulation run. Vehicles that did not stop at the yield bar had a service time of zero. Since the follow-up time was already calibrated, the average service time in the first position in the queue for the entire roundabout would show which critical gap estimate best replicates the field data and thus represent the critical gap of Indiana drivers in the study area. The average service time in the first position in the queue was computed as the difference between time in the queue between the data collection point at the yield bar and the data collection point located 20 feet upstream of the yield bar on the same approach. Vehicles which stopped in the first position in the queue, or severely slowed down, had different times in the queue between the two measuring data collection points 
for a given approach lane, thus, the difference between those measurements yielded the service time at the yield bar. For the Northbound Inside lane vehicle, which stopped at the first position in the queue, the service time was computed by subtracting the time in the queue of Data Collection Point 1 from the time in the queue of Data Collection Point 101 (Figure 3-21).

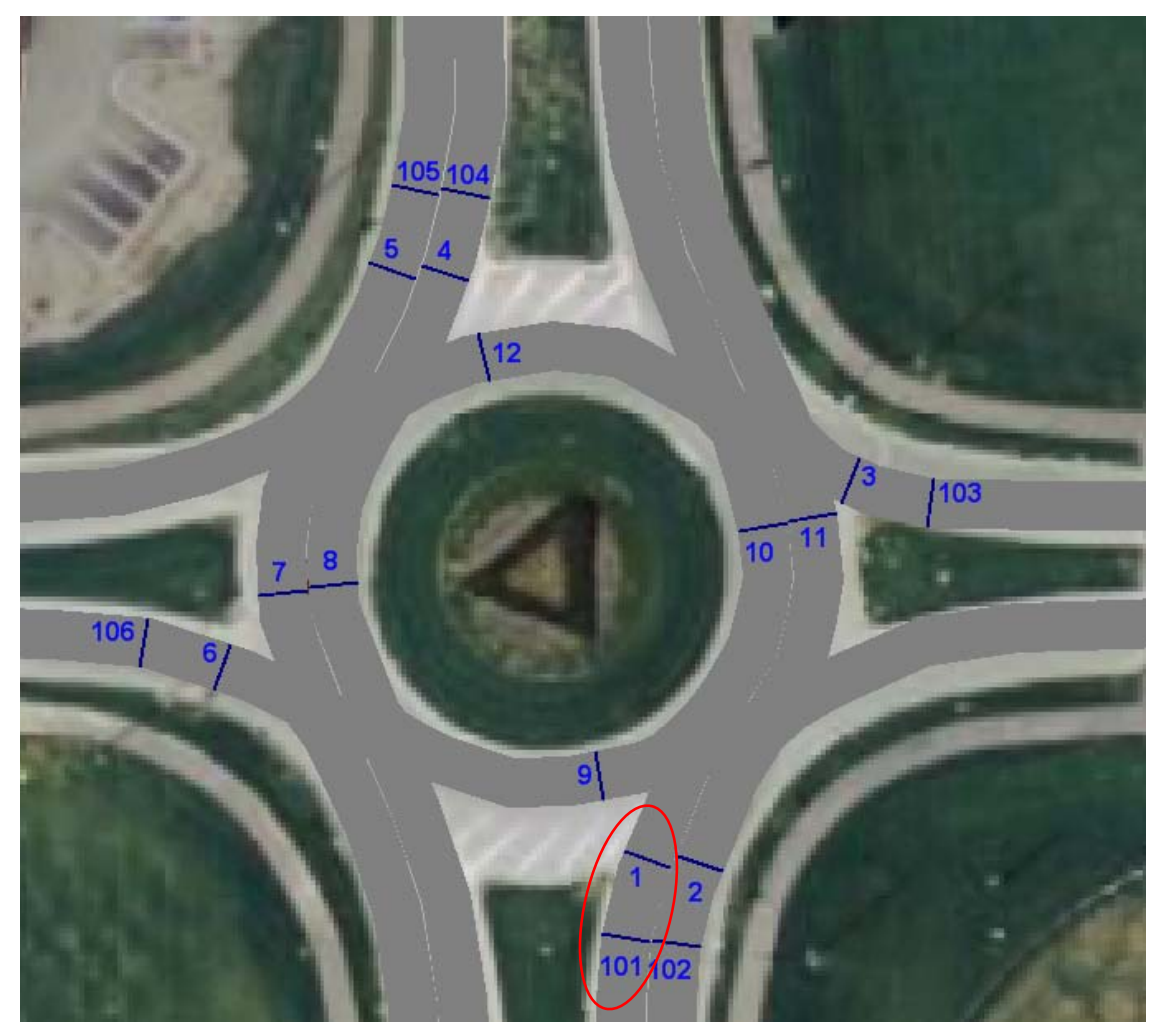

Figure 3-21 Data Collection Points in Simulation

Through a simulation experiment, it was found that the Maximum Likelihood Method using gaps only estimated the critical gap most accurately (Figure 3-22). 


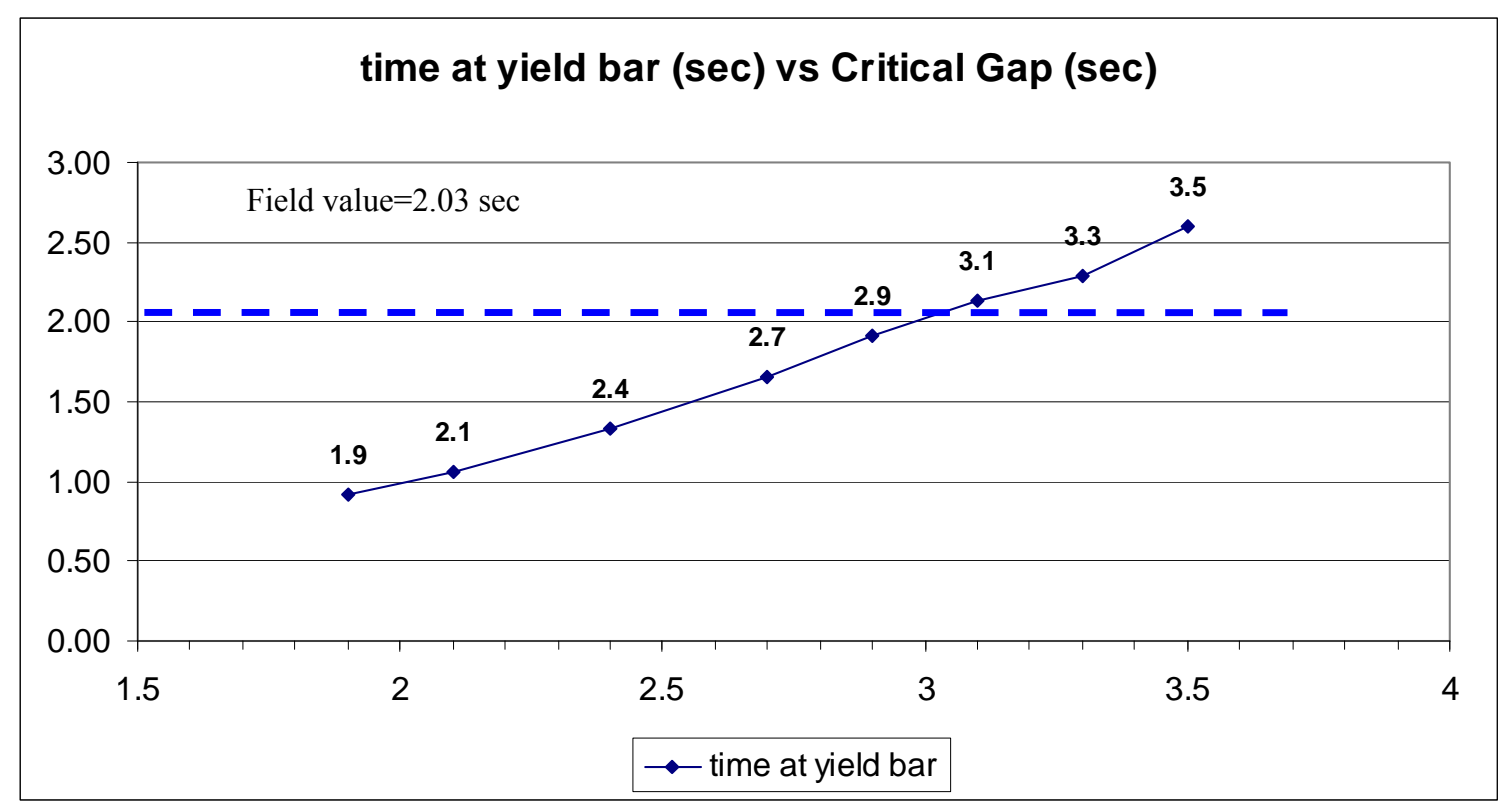

Figure 3-22 Service Time Simulation Experiment

\subsection{Conclusion}

The Tarko and Lyles Matrix Method turning movement estimation procedure works for $2 \mathrm{X} 2$ single-lane roundabouts and $4 \times 2$ roundabouts, where the number of unknowns is less than the number of equations (data collection points with known counts). This turning movement estimation process is efficient since it does not require tracking individual vehicles on the roundabout approaches.

The CC1 parameter has a greater impact on the follow-up at roundabouts than standstill acceleration. Standstill acceleration can serve as a secondary tuner to match the fieldcollected follow-up. The roundabout approach speed had no effect with small changes in speed.

By comparing both critical gap estimation methods and their extreme assumptions about consistent drivers and inconsistent drivers, it was found that the Maximum Likelihood Method using gaps only gives a more accurate critical gap estimate than the Tarko 
method for use in VISSIM simulation. This does not necessary imply that the Tarko method gives a wrong estimate of critical gap. It should be noted that VISSIM does not allow the user to enter the standard deviation for the driver's accepted gap. The variability of accepted gaps between drivers in VISSIM comes indirectly from the different speed profiles, acceleration and deceleration profiles, and safety distances maintained between vehicles. If future VISSIM versions allow for entering the distribution of minimum gap time (mean, standard deviation) for the stop bars of priority rules, even more insight could be gained from experiments about the level of a driver's consistency when accepting gaps at roundabouts. 


\section{CHAPTER 4 SIGNALIZED INTERSECTIONS CALIBRATION}

For signalized intersections, the single most important quantity to calibrate is the saturation flow rate. Expressed in units of vehphpl, the saturation flow rate represents the capacity of each approach lane at a signalized intersection, which is the maximum number of vehicle that can pass during a green signal per unit of time (assumed one hour). To replicate an Indiana driver in simulation, calibration of the saturation flow rate is necessary since it determines how many vehicles will be served during the green phase regardless of the intersection type. Calibration of signalized intersections will be performed by adjusting the VISSIM driver behavior parameters in such a way that the saturation flow rates measured during simulation are the same as the field-measured saturation flow rates for Indiana drivers. The effects of all VISSIM parameters which have an impact on the capacity of a roadway segment will be evaluated to determine their effect on the saturation flow rate. Two types of saturation flow rates were assumed for Indiana drivers, one for a rural setting and the other for an urban setting.

\subsection{Effect of VISSIM driver behavior parameters on saturation flow rate}

In VISSIM, four major driving conditions are recognized: free driving, approaching, following, and breaking. Vehicles change their driving condition when they reach a specific threshold based on the speed difference and distance. The 1999 Wiedemann car following model uses ten driver behavior parameters, which are labeled as CC0 through CC9, to model vehicle interactions. 
Out of these ten parameters, six were proven to impact the capacity of roadway segments (Lownes and Machemehl, 2006). Among these parameters are: standstill distance (CCO), headway time (CC1), following variation (CC2), following thresholds (CC4 and CC5) and stopped condition acceleration (CC8).

In addition, there is an interaction between the $\mathrm{CC} 0$ and $\mathrm{CC} 8$ parameters and the $\mathrm{CC} 1$ and CC4/CC5 parameters considering the impact on capacity (Lownes and Machemehl, 2006). With respect to $\mathrm{CC} 0$ and $\mathrm{CC} 1$, as the value of the stopped condition distance (CCO) increases, the impact on capacity due to an increase in the stopped condition acceleration (CC8) decreases (Lownes and Machemehl, 2006). With respect to CC1 and $\mathrm{CC} 4 / \mathrm{CC} 5$, as the time headway the driver wishes to maintain increases, the impact on capacity by reducing sensitivity to acceleration/deceleration CC4/CC5 decreases.

Table 4-1 below provides the parameters that have an impact on the capacity of roadway segments, along with their description, direction of impact, and units.

To determine which parameters have an impact on saturation flow rate, a series of simulation runs was performed modifying the default values for the above mentioned parameters and collecting headway times between the discharging vehicles at the stop bar. Two data collection points were used to collect the discharge rate at the Eastbound Through lanes of a $4 \mathrm{X} 2$ conventional intersection (Figure 4-1).

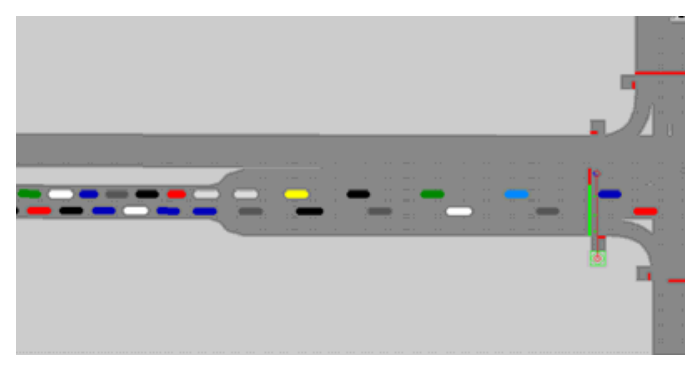

Figure 4-1 Determination of Saturation Flow Rate in Simulation Experiment 
Table 4-1 VISSIM Parameters Effecting Roadway Segment Capacity (Lownes and Machemehl., 2006)

\begin{tabular}{|c|c|c|c|c|c|}
\hline Parameter & Description & Remarks & $\begin{array}{l}\text { Impact on capacity } \\
{[\mathrm{C}]}\end{array}$ & $\begin{array}{c}\text { Default } \\
\text { value }\end{array}$ & $\begin{array}{c}\text { Unit } \\
\text { S }\end{array}$ \\
\hline $\begin{array}{l}\text { CC0 } \\
\text { (Standstill } \\
\text { distance) }\end{array}$ & $\begin{array}{l}\text { Defines the desired distance between stopped cars. } \\
\text { It has no variation. }\end{array}$ & & $\begin{array}{l}\text { As CCO } \uparrow \\
\text { capacity } \downarrow\end{array}$ & 4.92 & {$[\mathrm{ft}]$} \\
\hline $\begin{array}{l}\text { CC1 } \\
\text { (Headway } \\
\text { time) }\end{array}$ & $\begin{array}{l}\text { Time (in sec) that a driver wants to keep; the higher } \\
\text { the value, the more cautious the driver is. Thus, at a } \\
\text { given speed } \mathrm{v} \text {, the safety distance } \mathrm{dx} \text { safe is } \\
\text { computed to: dx_safe = CC } 0+\mathrm{CC} 1{ }^{*} \text { v. }\end{array}$ & $\begin{array}{l}\text { The safety distance is defined } \\
\text { in the model as the minimum } \\
\text { distance a driver will maintain } \\
\text { while following another car. } \\
\text { In the case of high volumes, } \\
\text { this distance becomes the } \\
\text { value with the strongest } \\
\text { influence on capacity. }\end{array}$ & $\begin{array}{l}\text { As CC1 } \uparrow \\
\text { capacity } \downarrow\end{array}$ & 0.9 & [sec] \\
\hline $\begin{array}{l}\mathrm{CC} 2 \\
\text { ('Following' } \\
\text { variation) }\end{array}$ & $\begin{array}{l}\text { Restricts the longitudinal oscillation or how much } \\
\text { more distance than the desired safety distance a } \\
\text { driver allows before he intentionally moves closer to } \\
\text { the car in front. }\end{array}$ & $\begin{array}{l}\text { If this value is set to } 10 \mathrm{ft} \text {, the } \\
\text { following process results in } \\
\text { distances between } \mathrm{dx} \text { _safe } \\
\text { and dx_safe }+10 \mathrm{ft} \text {. The } \\
\text { default results in a quite stable } \\
\text { following process. }\end{array}$ & $\begin{array}{l}\text { As CC2 } \uparrow \\
\text { capacity } \downarrow\end{array}$ & 13.12 & {$[\mathrm{ft}]$} \\
\hline $\begin{array}{l}\text { CC4 and } \\
\text { CC5 } \\
\text { ('Following' } \\
\text { thresholds) }\end{array}$ & $\begin{array}{l}\text { Control the speed differences during the } \\
\text { "Following" state. Smaller values result in a more } \\
\text { sensitive reaction of drivers to accelerations or } \\
\text { decelerations of the preceding car i.e., the vehicles } \\
\text { are more tightly coupled. CC4 is used for negative } \\
\text { and CC5 for positive speed differences. }\end{array}$ & $\begin{array}{l}\text { The default values result in a } \\
\text { fairly tight restriction of the } \\
\text { following process. }\end{array}$ & $\begin{array}{c}\text { As }|\mathrm{CC} 4| \& \mathrm{CC} 5 \uparrow \\
\text { capacity } \downarrow\end{array}$ & $\begin{array}{l}-0.35 \\
0.35\end{array}$ & \\
\hline $\begin{array}{l}\text { CC8 } \\
\text { (Standstill } \\
\text { acceleration) }\end{array}$ & $\begin{array}{l}\text { Desired acceleration when starting from standstill } \\
\text { (limited by maximum acceleration defined within } \\
\text { the acceleration curves). }\end{array}$ & & $\begin{array}{l}\text { As CC8 } \uparrow \\
\text { capacity } \uparrow\end{array}$ & 11.48 & $\begin{array}{l}{[\mathrm{ft} / \mathrm{se}} \\
\left.\mathrm{c}^{2}\right]\end{array}$ \\
\hline
\end{tabular}


The headway time between consecutive discharging vehicles was obtained by directly inputting into a network file a special evaluation code for the discharge rate. The Eastbound Approach has been loaded with over-capacity volumes; thus, the saturation flow rate could have been obtained for each green phase cycle for the EBT through movements. All other approaches have not been loaded with vehicles; however, their signal phases turned green, which allowed the queue to move up to the stop bar; thus, all vehicles discharging during green at the EBT movements were stopped in the queue. The cycle used for the discharge rate evaluation was 60 seconds long with 30 seconds for the EBT movements and 30 seconds for conflicting movements. Special evaluation features allowed for extraction of the headway time between the front bumpers of vehicles at the stop bar (Figure 4-2).

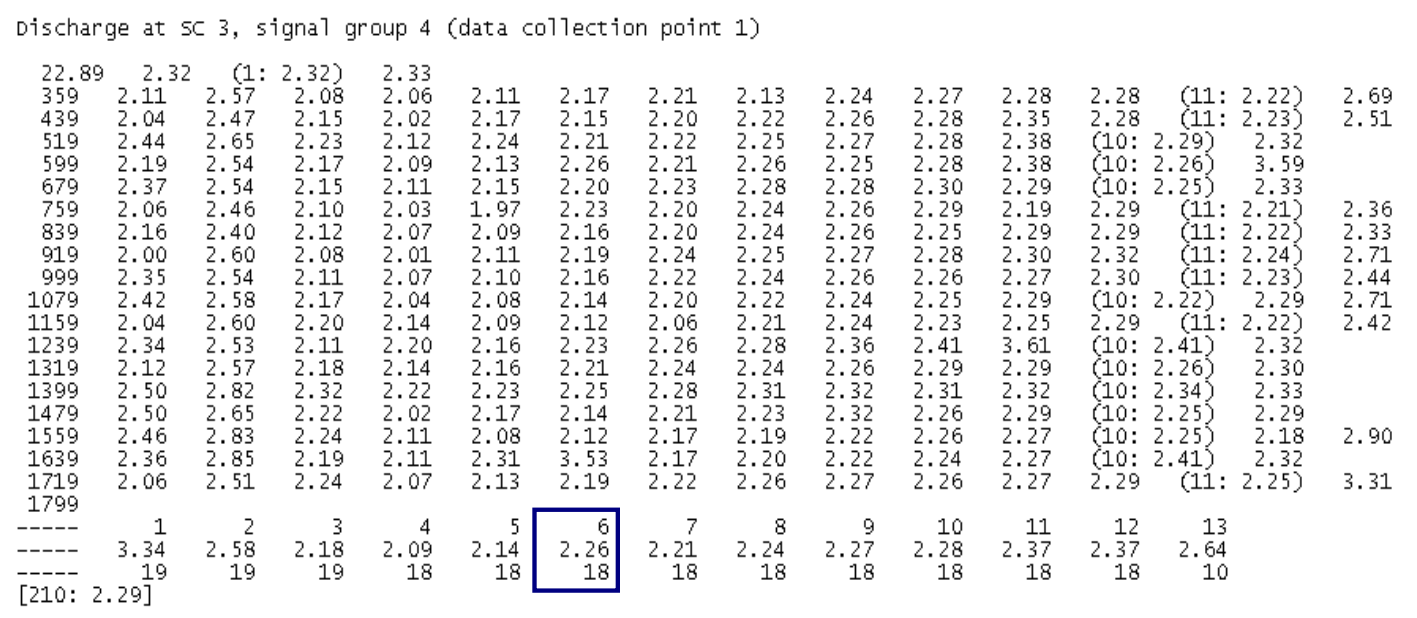

Figure 4-2 Discharge Rate Evaluation Output

Last three rows of Figure 4-2 contain, from top to bottom, the vehicle number in queue, the average discharge headway for all vehicles that were $6^{\text {th }}$ in the queue during a single simulation run, and the number of cycles during a simulation run that had a $6^{\text {th }}$ vehicles discharge during a particular green phase. The rows above represent the beginning of the EBT green phase and the discharge headway for each consecutive vehicle crossing the stop bar during a given cycle. 
For the saturation flow rate calculation, the first four vehicles discharging during the green signal were not considered. Vehicles passing on amber or red were taken into account only if their discharge headway was not smaller or larger than the considered headways collected during the green signal display. The discharge headway of vehicles passing on amber or red had to pass a check to be included in the saturation flow rate calculation because vehicles passing on amber/red will sometimes decelerate and later accelerate causing them to have discharge headway not reflecting the vehicle interaction and driver behavioral parameters entered, but rather communication between the VISSIM traffic flow model and the VISSIM controller.

Simulation runs were performed for three different speed limits of 30, 45, and $60 \mathrm{mph}$. For a $30 \mathrm{mph}$ speed, the effect of different VISSIM driver behavior parameters on the saturation flow rate was investigated. For each simulation setting, a series of three 30 minute runs was performed with a different seed number, and the collected discharge headways at the EBT stopbars were averaged to obtain the saturation flow rate (Figure 4-3). For a speed of $60 \mathrm{mph}$, the effect of heavy vehicles on the saturation flow rate was evaluated by using two different truck percentages ( 2 percent and 5 percent). In VISSIM, the default vehicle model distribution was modified to represent U.S. vehicles rather than the European fleet. The difference between the created U.S. vehicle distribution and the default European distribution is in the average length of the passenger car and heavy vehicles. 


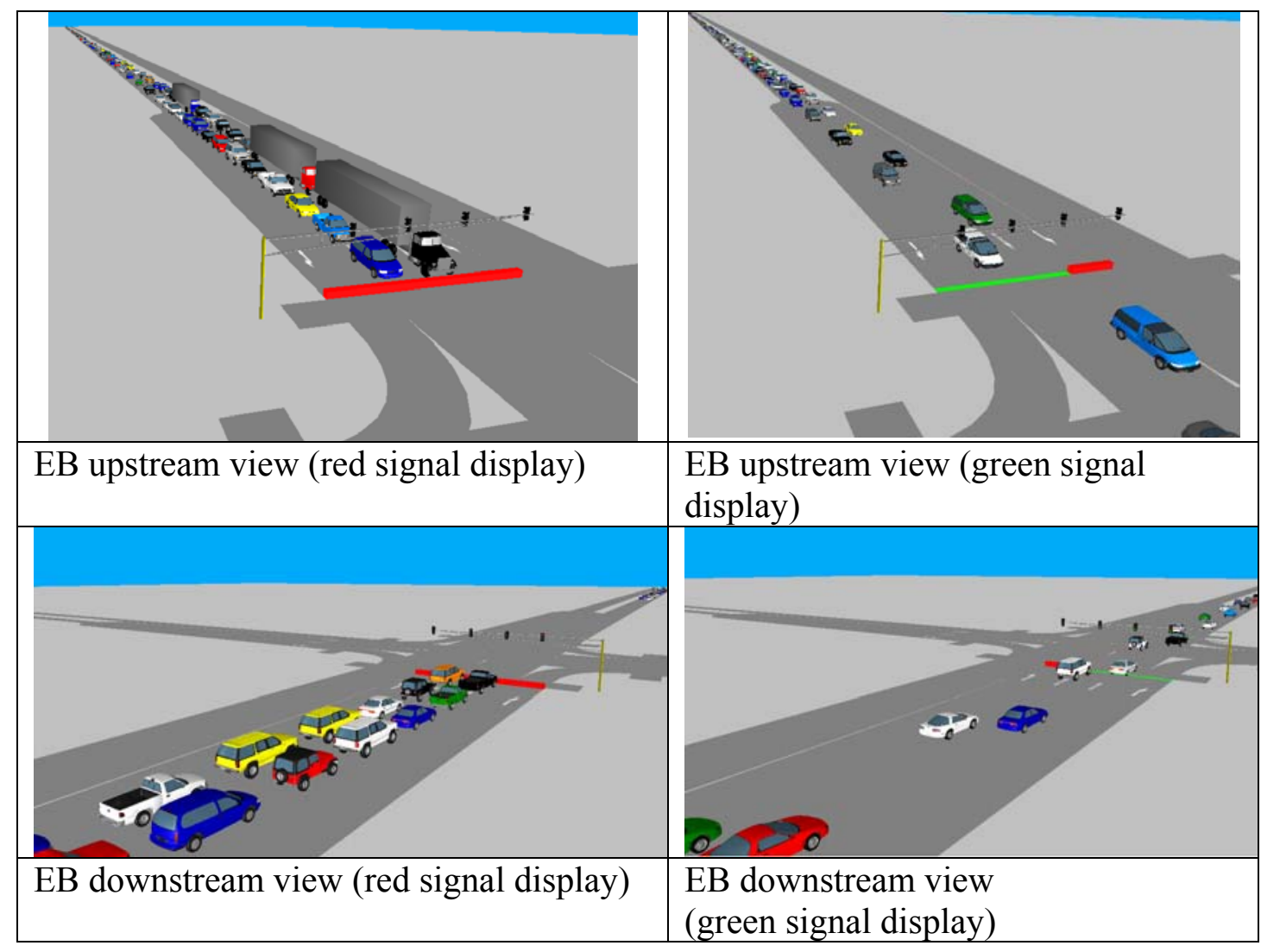

Figure 4-3 Three Dimension View of Simulation Experiment

The performed simulation experiment involved determining the effect of different driver behavior parameters on the saturation flow rate. Each parameter which proved to have an impact on the capacity of a roadway segment (Lownes and Machemehl, 2006) was modified, keeping other parameter constant to determine its effect on the saturation flow rate. The effect of the VISSIM driver behavior parameters on the saturation flow rate was performed with a speed of $30 \mathrm{mph}$.

\section{$\underline{\text { Standstill Distance (CC0) }}$}

The standstill distance parameter defines the desired distance between stopped cars in the queue. An increase in this parameter reduces the capacity while a decrease in this parameter increases the capacity (Figure 4-4). This result is as expected since the closer 
packing of vehicles, assuming all other parameters constant, will allow more vehicles to discharge during the unit time.

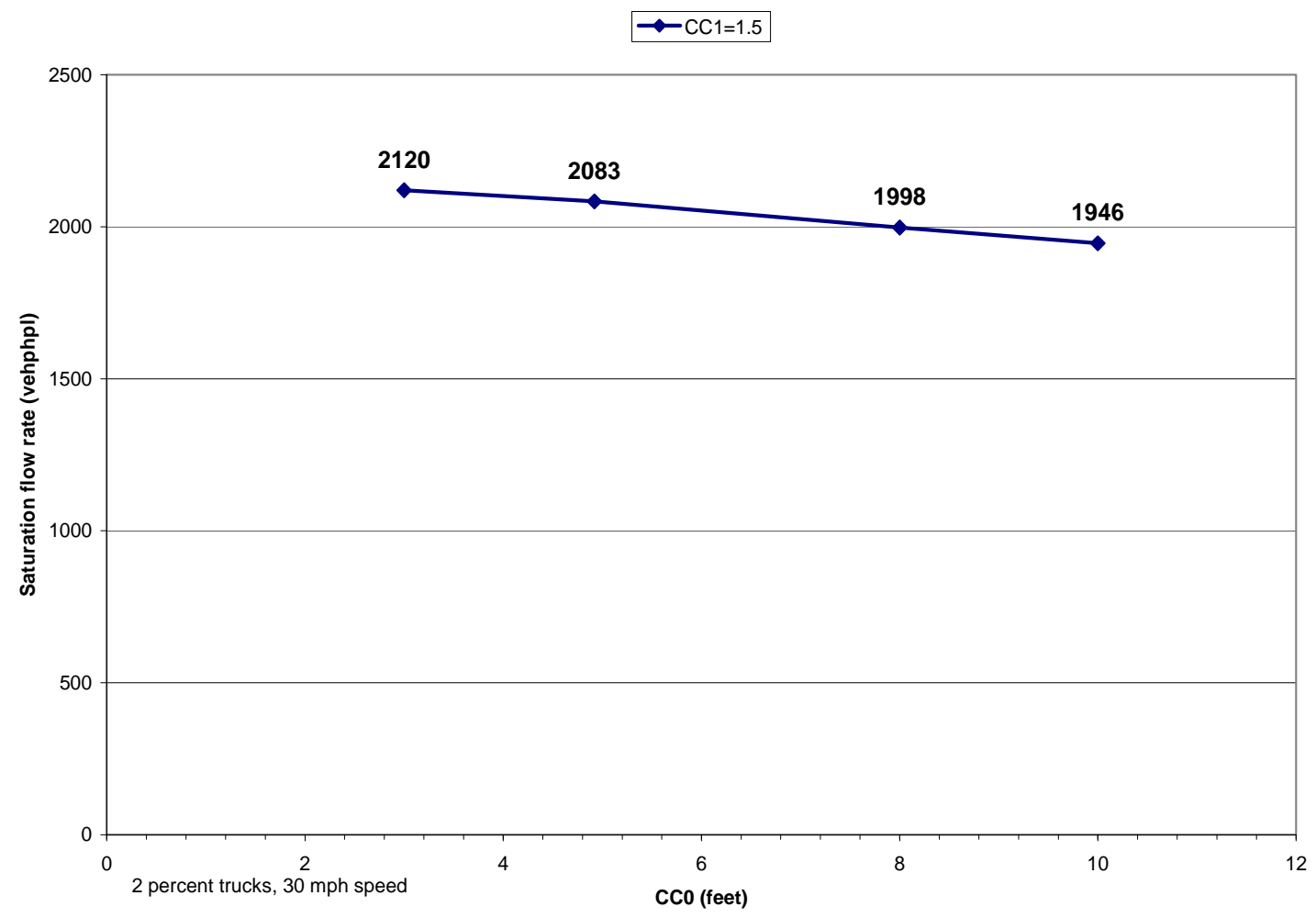

Figure 4-4 Effect of Standstill Distance (CC0) Parameter on Saturation Flow Rate

\section{$\underline{\text { Standstill Acceleration (CC8) }}$}

The standstill acceleration parameter defines the desired acceleration of a vehicle when starting from the stopped position. Two different values of headway time (CC1) of 1.5 sec and $2.0 \mathrm{sec}$ were simulated with varying standstill acceleration (CC8) parameters. At a lower $\mathrm{CC} 1$ value $(1.5 \mathrm{sec})$, the CC8 parameter had a greater effect on saturation flow rate then at higher $\mathrm{CC} 1$ value (2.0). For the same value of headway time (CC1), the standstill acceleration (CC8) parameter had a greater effect at lower values than at higher values. This is caused by the fact that in VISSIM, the CC8 parameter will be overwritten by a maximum acceleration curve in the base data functions for a given vehicle if the 
standstill acceleration exceeds the value entered in the VISSIM maximum acceleration function. It can be stated that for the same value of headway time (CC1), an increase in the standstill acceleration will increase the saturation flow rate; however, as the standstill acceleration (CC8) increases, a unit increase in this parameter will have a decreasing effect on the saturation flow rate. At high values of headway time, the standstill acceleration CC8 parameter will have a minimal effect on the saturation flow rate (Figure 4-5).

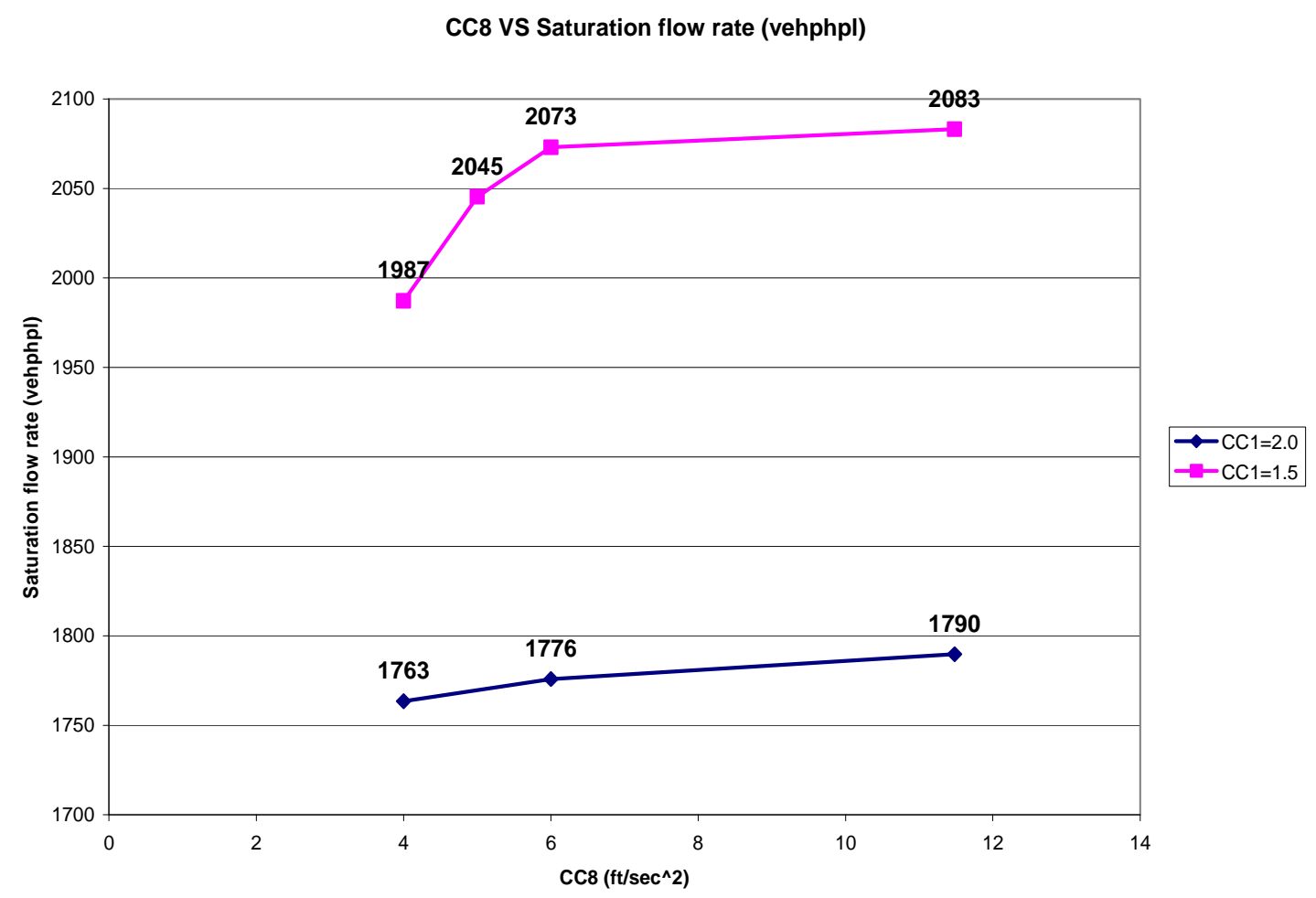

Figure 4-5 Effect of Standstill Acceleration on Saturation Flow Rate

\section{CC4 and CC5 Following threshold}

These parameters control the difference in speed during the following process. Smaller values result in a more sensitive reaction of drivers to accelerations or decelerations of the preceding car, which causes vehicles to be more tightly coupled. 
For the saturation flow rate, both parameters have no effect (Figure 4-6). During vehicle discharge at the stop bar, for low speeds, vehicles do not reach their desired speed and are not in the full following process, but rather are adjusting their position to the following process. Thus, this parameter affects segment capacity but not the saturation flow rate.

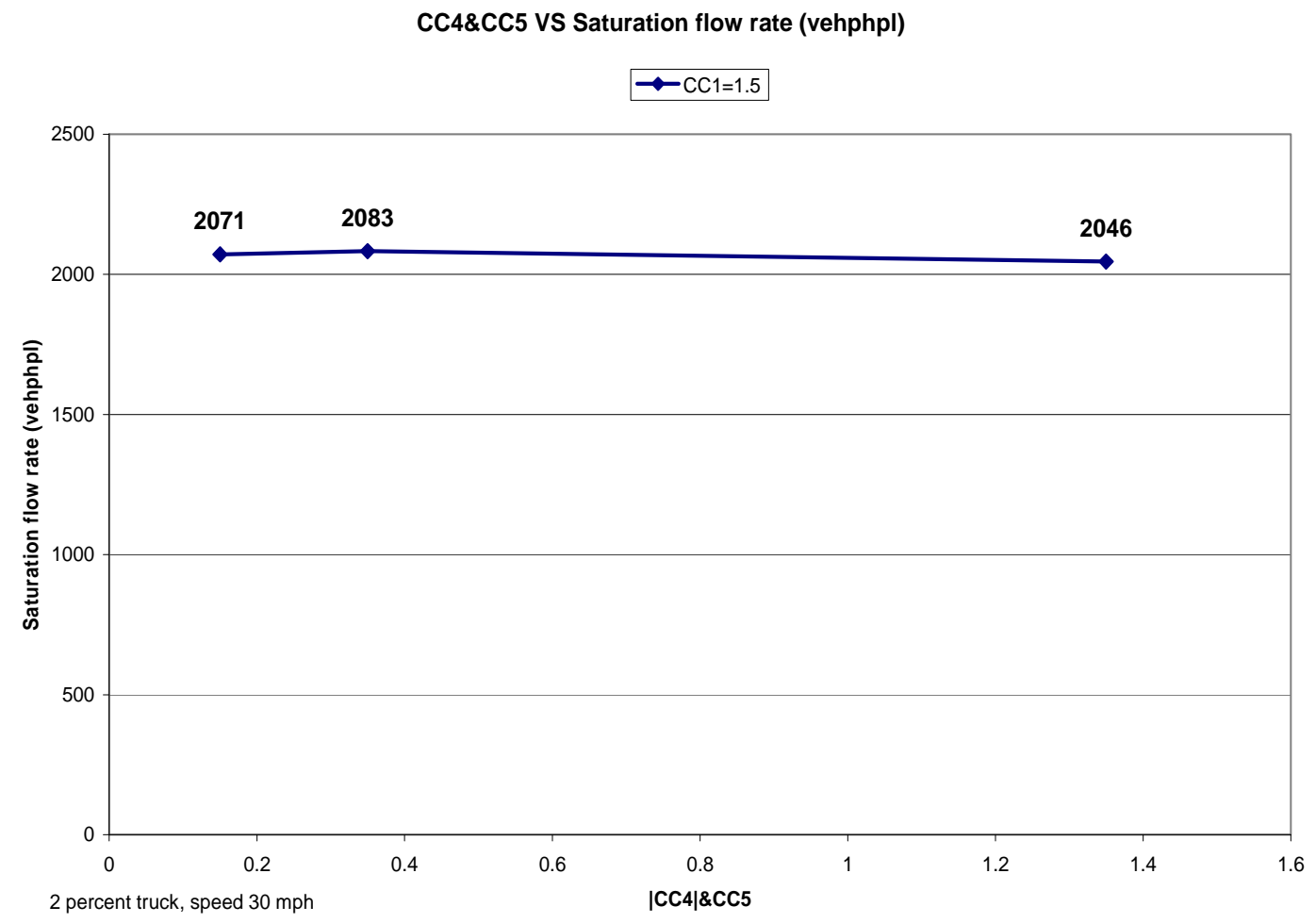

Figure 4-6 Effect of $|\mathrm{CC} 4|$ \& CC5 on Saturation Flow Rate

\section{Following variation (CC2)}

This parameter defines how much more distance then the desired safety distance a driver will allow before starting to move closer to a preceding vehicle. Safety distance is computed as dx_safe $=\mathrm{CC} 0+\mathrm{CC} 1 * \mathrm{v}$, where $\mathrm{v}$ is the speed of the vehicle. With an increase in the following variation, the saturation flow rate will decrease (Figure 4-7). This result is intuitive because the less responsive the driver, the lower the saturation flow rate. 


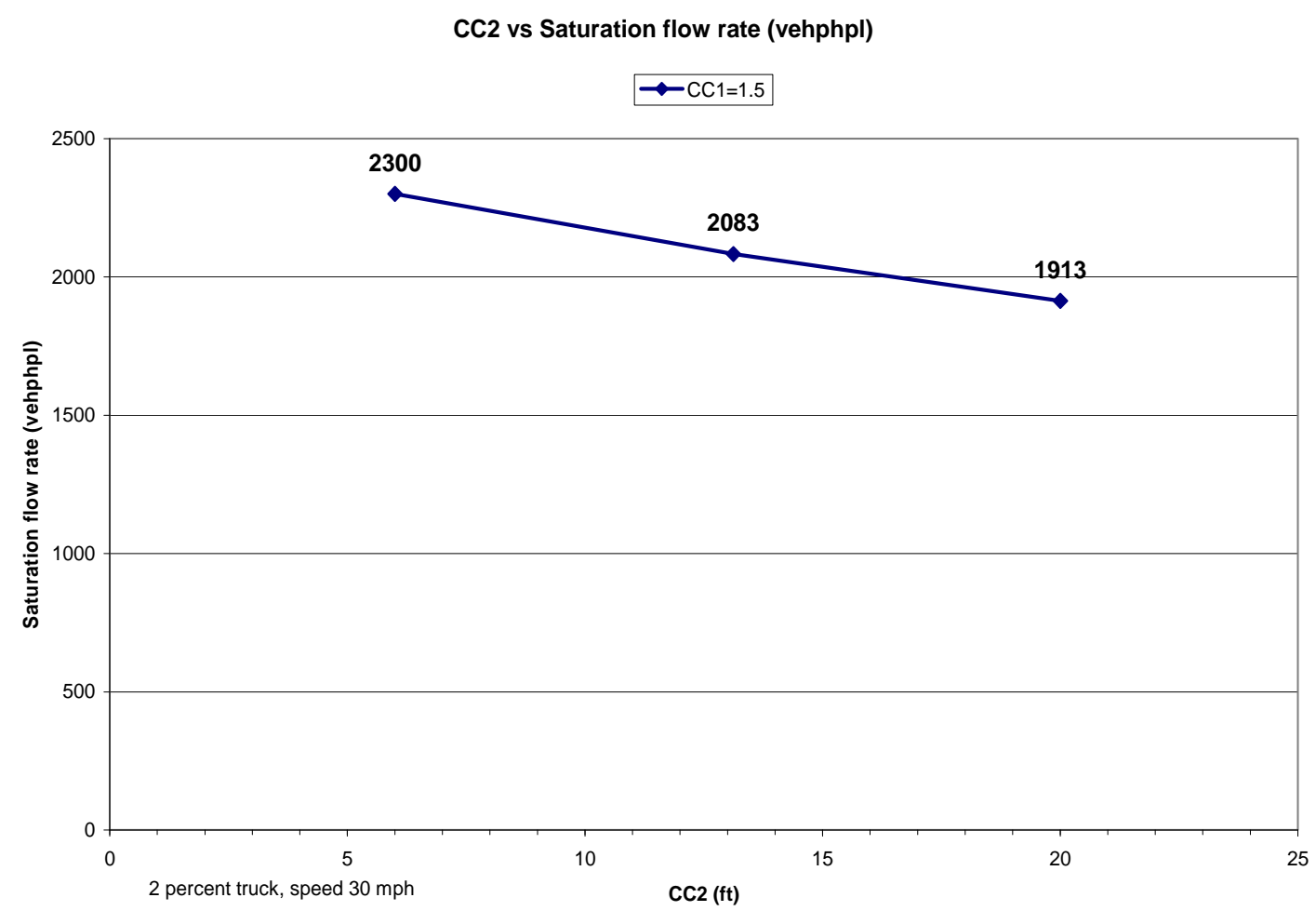

Figure 4-7 Effect of Following Variation (CC2) on the Saturation Flow Rate

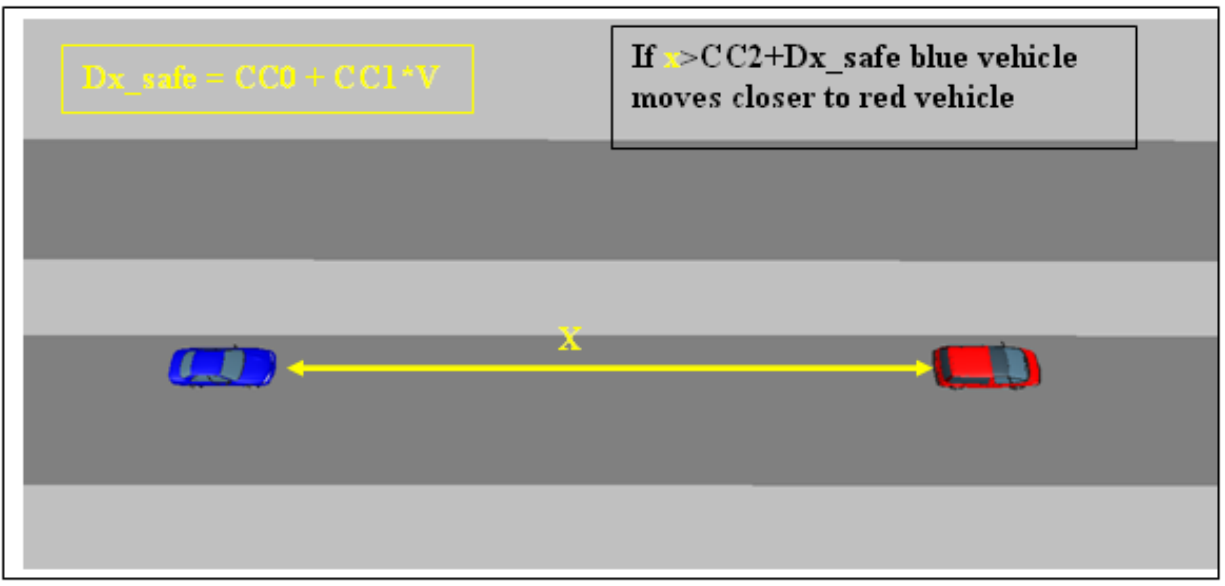

Figure 4-8 Illustration of Safety Distance in VISSIM 


\section{$\underline{\mathrm{CC} 1 \text { Headway time parameter }}$}

Headway time defines the distance a driver wants to maintain from a proceeding vehicle. While following another vehicle, a driver will maintain a minimum distance equal to headway time (CC1) converted to distance at a given speed plus standstill distance $(\mathrm{CC} 1)$. An increase in headway time $(\mathrm{CC} 1)$ reduces capacity since drivers are more cautious (Figure 4-9).

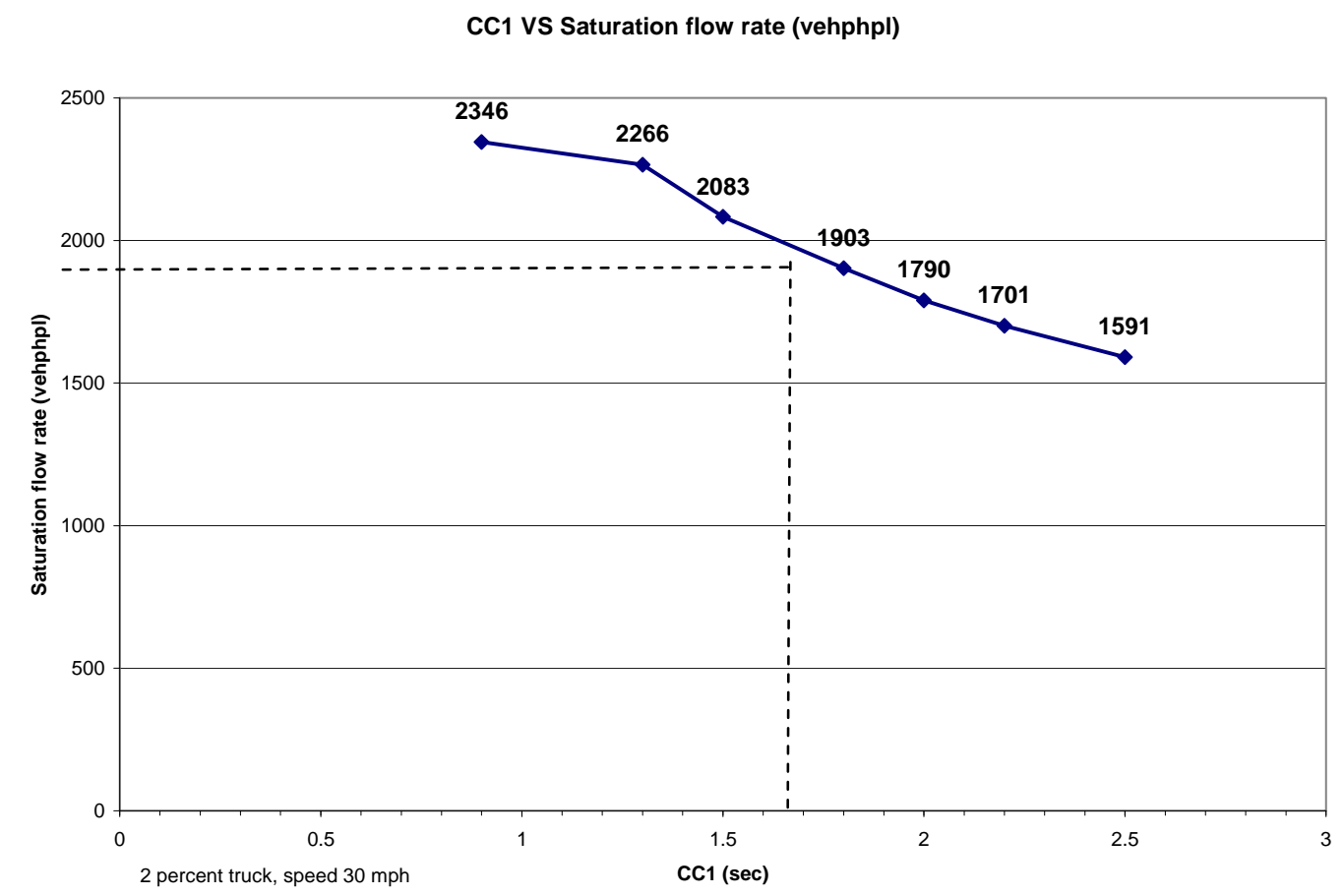

Figure 4-9 Effect of Headway Time (CC1) on Saturation Flow Rate

\section{Effect of trucks on saturation flow rate in VISSIM}

Two different truck percentages ( 2 percent and 5 percent) were investigated at a $60 \mathrm{mph}$ speed limit to determine the effect on the saturation flow rate (Figure 4-10). Two considered truck percentages were representative of urban (2\% trucks) and rural (5\% trucks) setting. It has been found that a higher truck percentage decreases the saturation flow rate. For the values investigated, the difference is not substantial; but with higher 
margins of difference between the truck percentages, there will be a greater difference in the saturation flow rate.

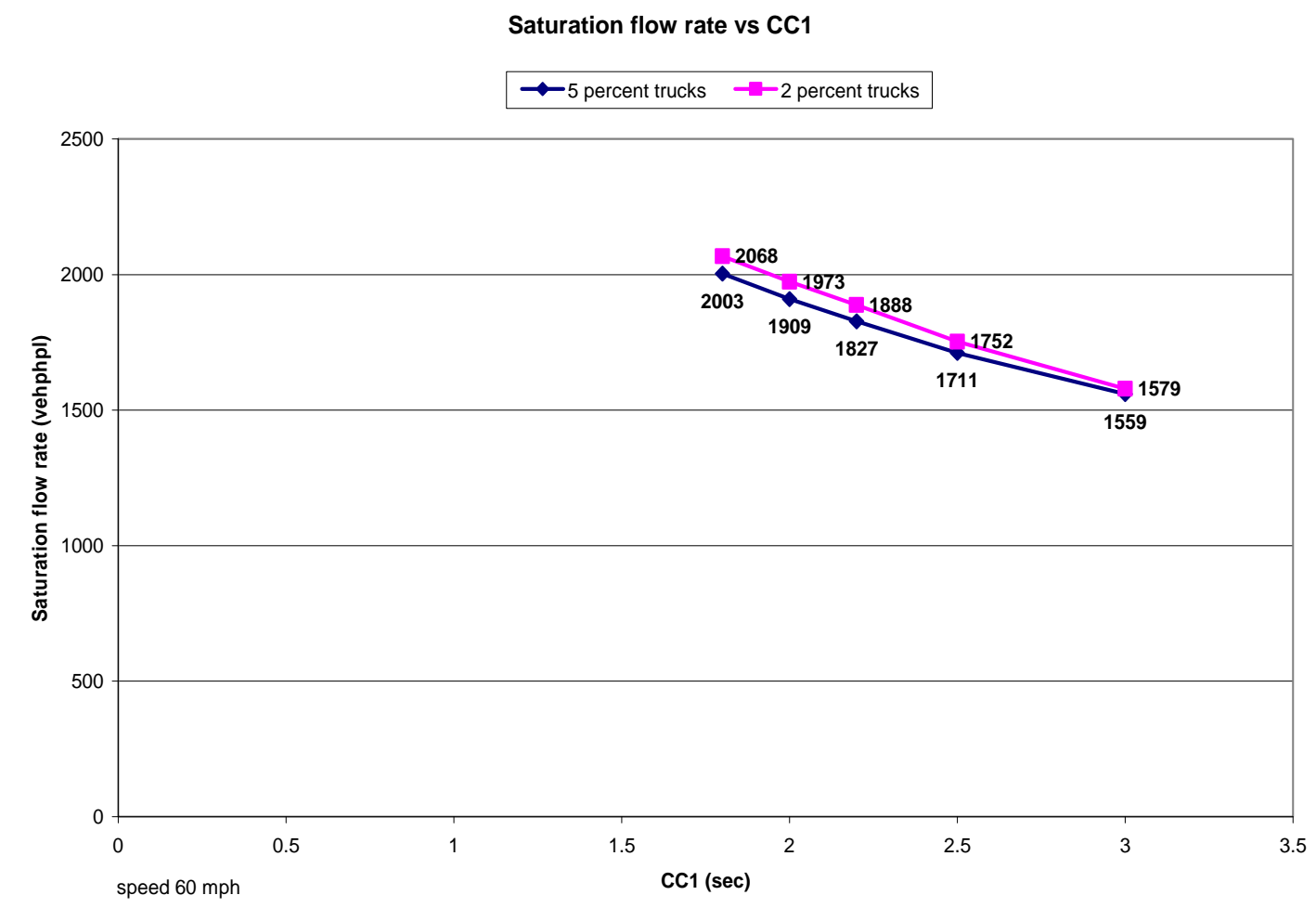

Figure 4-10 Effect of Trucks on Saturation Flow Rate

\subsection{Calibration of saturation flow rate to Indiana conditions}

This research found that the single parameter with the greatest influence on the saturation flow rate is headway time. This parameter was therefore chosen to calibrate the saturation flow rate in the simulation to Indiana conditions. For Indiana drivers, two values of saturation flow rate were assumed, 1900 vehphpl for a urban setting and 1700 vehphpl for a rural setting. These values are based on previous research which determined the saturation flow rates in Indiana towns based on the population size near the intersection (Table 4-2). 
For calibration of signalized intersections, two settings of intersections were assumed, rural and urban. In the urban setting, two speed limits were used. A speed of $30 \mathrm{mph}$ was used for two-lane roadways and $45 \mathrm{mph}$ was used for four-lane roadways. In the rural setting, a speed of $60 \mathrm{mph}$ was assumed (Table 4-3).

Table 4-2 Recommended Saturation Flow Rates for Indiana (Perez-Cartagena and Tarko, 2004)

\begin{tabular}{|c|c|c|c|}
\hline \multirow{2}{*}{$\begin{array}{c}\text { Number of Lanes in } \\
\text { lane group }\end{array}$} & \multicolumn{3}{|c|}{ Population Size Near Intersection } \\
\cline { 2 - 4 } & $<20,000$ & $20,000-100,000$ & Indianapolis \\
\hline 1 & 1540 & 1800 & 1960 \\
\hline 2 & 1580 & 1840 & 2010 \\
\hline 3 & 1600 & 1860 & 2020 \\
\hline
\end{tabular}

Table 4-3 Assumed Values for Urban and Rural Setting

\begin{tabular}{|l|l|l|}
\hline Setting & Urban & Rural \\
\hline Speed (mph) & 30,45 & 60 \\
\hline Saturation flow rate (vehphpl) & 1900 & 1700 \\
\hline Percentage of trucks (\%) & 2 & 5 \\
\hline
\end{tabular}

As can be seen from Table 4-3 the headway time parameter (CC1), which replicated in simulation a field measured saturation flow rate value of 1900 vehphpl for a speed of 30 $\mathrm{mph}$, is $\mathrm{CC}_{30 \mathrm{mph}}=1.8 \mathrm{sec}$.

A simulation experiment varying the headway time (CC1) parameter for a speed of 45 mph was repeated to determine what value of headway time gives the targeted capacity of 1900 vehphpl. It was found that a headway time (CC1) parameter of $2.1 \mathrm{sec}$ gives the targeted saturation flow rate of 1900 vehphpl (Figure 4-11). Different speed limits require different headway parameters. This is caused by the fact that at low speed ( $30 \mathrm{mph})$, 
drivers discharging almost reach their desired speed at the stop bar and are beginning the following process. For a higher speed $(45 \mathrm{mph})$, drivers are still in the accelerating stage and the following process does not occur so drivers are still adjusting themselves to the desired safety distance defined by headway time and standstill distance.

Saturation flow rate vs CC1

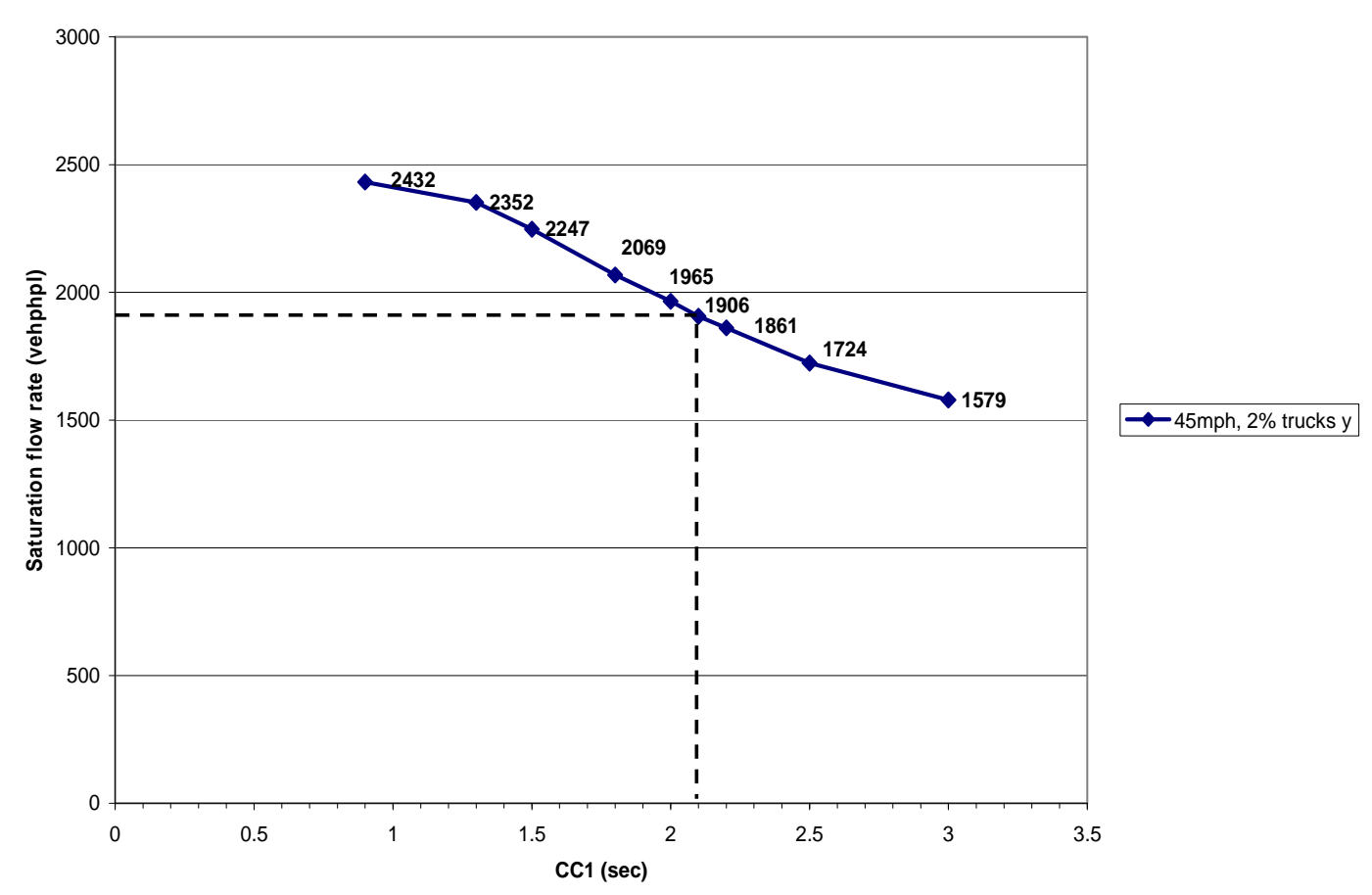

Figure 4-11 Calibration of Saturation Flow Rate for 45 mph Speed Roadway

Another simulation experiment with varying headway time for a speed of $60 \mathrm{mph}$ revealed that a headway time of $2.52 \mathrm{sec}$ gives the targeted value of saturation flow rate for a rural setting of 1700 vehphpl (Figure 4-12). 
Table 4-4 Summary of Saturation Flow Rate Calibration

\begin{tabular}{|l|c|c|c|}
\hline Speed (mph) & 30 & 45 & 60 \\
\hline $\begin{array}{l}\text { Field measured saturation flow rate } \\
\text { (vehphpl) }\end{array}$ & 1900 & 1900 & 1700 \\
\hline $\begin{array}{l}\text { Simulated saturation flow rate } \\
\text { (vehphpl) [output] }\end{array}$ & 1902 & 1906 & 1697 \\
\hline Headway time (sec) [input] & 1.8 & 2.1 & 2.52 \\
\hline $\begin{array}{l}\text { Saturation flow rate based on assumed } \\
\text { headway time neglecting CC0, CC2 } \\
\text { and vehicle length effect }\end{array}$ & 2000 & 1714 & 1428 \\
\hline
\end{tabular}

Saturation flow rate vs CC1

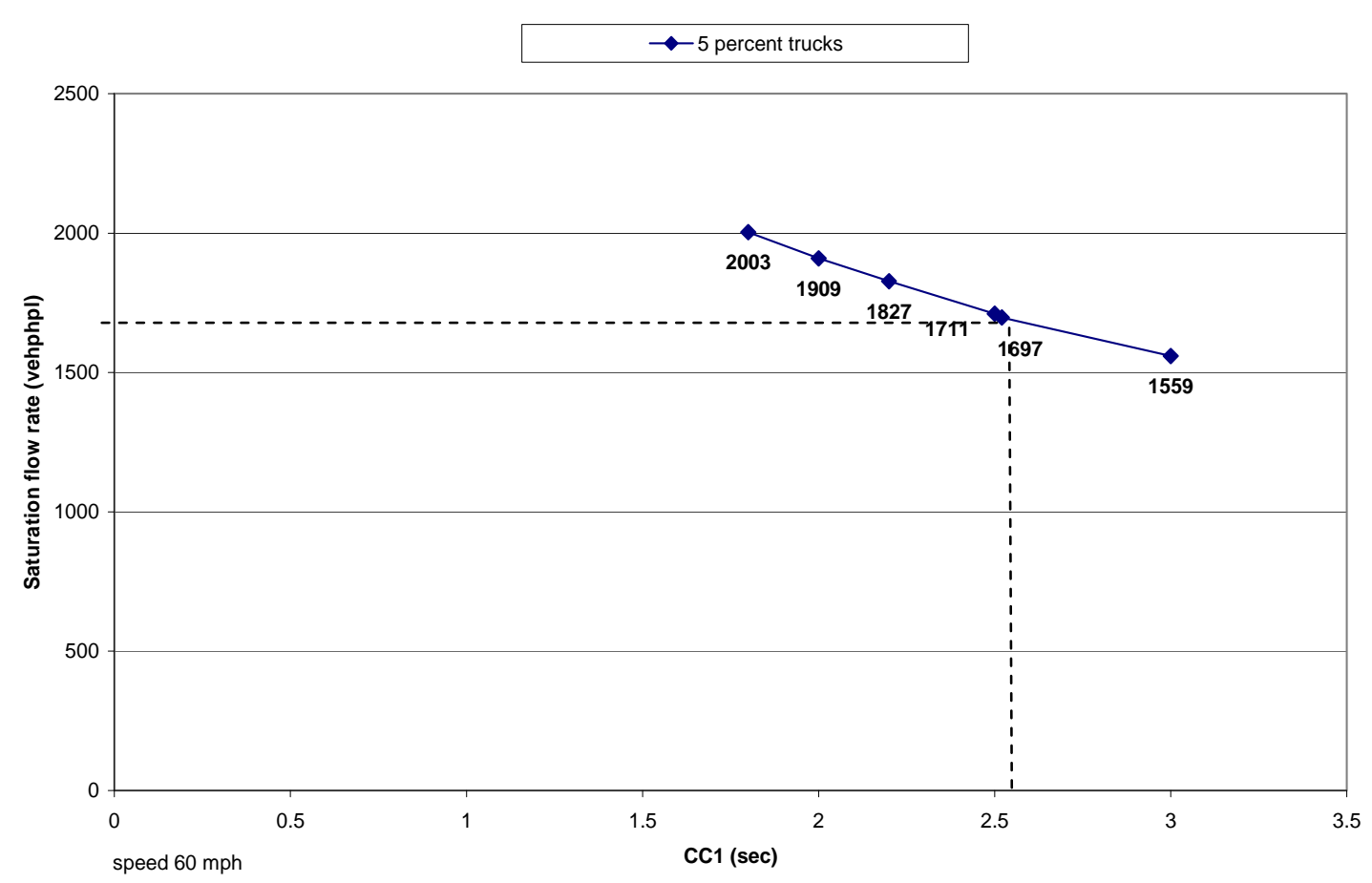

Figure 4-12 Calibration of Saturation Flow Rate for 60mph Speed

Comparing the saturation flow rate based on an assumed headway time in simulation and the actual measured saturation flow rate, we can see that these values are not the same. This is caused by the fact that, at higher speeds, vehicles discharging from the queue are adjusting themselves to the following process but are not in it so they will not comply 
with the minimum safety distance defined by $\mathrm{CC} 1$ and $\mathrm{CC} 0$. For high speeds, the saturation flow rate calculated based on an assumed headway time parameter value will underestimate the actual saturation flow rate in simulation. 


\section{CHAPTER 5 EVALUATION PROCEDURE}

To evaluate alternative intersections, three measures were used for each movement on the approaches. The measures used include stop delay, delay (different between actual travel time and ideal travel time for each movement), and average number of stops per vehicle. All measures are aggregated per 15-minute intervals during a one-hour simulation run. All measures are collected after the loading period. The extracted measures after simulation are compared for different alternatives.

The evaluation procedure was complemented with a series of VISSIM networks and SYNCHRO files for signalized intersections. The VISSIM network includes median uturn, roundabout, conventional intersection, near-sided jughandle, far-sided jughandle, quadrant roadway, and continuous flow intersection. Each intersection has been calibrated to Indiana conditions by modifying the VISSIM driver behavior parameters. For signalized intersections, different driver behavior parameters sets were created and assigned to roadway links based on speed to reach a targeted saturation flow rate for Indiana drivers.

VISSIM network files were developed for two intersection settings, urban and rural. For each setting, three geometric configurations of each intersection were built, depending on the number of crossing lanes $(4 \times 4,4 \times 2$ and $2 \times 2)$. A median $u$-turn intersection has additional network files for an urban setting with narrow and wide medians. A total of 44 VISSIM network files were constructed (Table 5-1). Examples of each intersection type are shown in Figure 5-1 through Figure 5-3. 
Table 5-1 VISSIM Network Files

\begin{tabular}{|l|l|l|}
\hline Intersection type & Urban & Rural \\
\hline Conventional & $4 \times 4,4 \times 2,2 \times 2$ & $4 \times 4,4 \times 2,2 \times 2$ \\
\hline Median u-turn & $\begin{array}{l}\text { Narrow median: } 4 \times 4,4 \times 2,2 \times 2 \\
\text { Wide median: } 4 \times 4,4 \times 2\end{array}$ & $4 \times 4,4 \times 2,2 \times 2$ \\
\hline Roundabout & $4 \times 4,4 \times 2,2 \times 2$ & $4 \times 4,4 \times 2,2 \times 2$ \\
\hline Near sided jughandle & $4 \times 4,4 \times 2,2 \times 2$ & $4 \times 4,4 \times 2,2 \times 2$ \\
\hline Far sided jughandle & $4 \times 4,4 \times 2,2 \times 2$ & $4 \times 4,4 \times 2,2 \times 2$ \\
\hline Quadrant roadway & $4 \times 4,4 \times 2,2 \times 2$ & $4 \times 4,4 \times 2,2 \times 2$ \\
\hline Continuous Flow & $4 \times 4,4 \times 2,2 \times 2$ & $4 \times 4,4 \times 2,2 \times 2$ \\
\hline
\end{tabular}

\subsection{Procedure description}

The developed VISSIM and SYNCHRO files (signalized intersections) are the starting point of the analysis. The user enters the desired volumes on the approaches with turning movement splits, and a simulation is performed using the provided files. For a signalized intersection, SYNCHRO files should be used to optimize signal timings. A conventional intersection and alternative intersections were coded as pretimed NEMA controllers so an optimization step is required for each volume scenario tested. The reason all of the signalized intersections were coded as pretimed is to use a uniform procedure for a fair comparison of all solution for specific traffic conditions. It should be noted that the signal timings obtained in SYNCHRO are not optimal. Free operations on an alternative intersection with loop detection have not been researched well, while for a conventional intersection, it has been well researched so the pretimed signals give a fairer comparison. 
Optimization of the signal timing for each traffic condition was carried out in SYNCHRO. The obtained signal settings are entered in VISSIM's interface for NEMA controllers and the simulation is run.

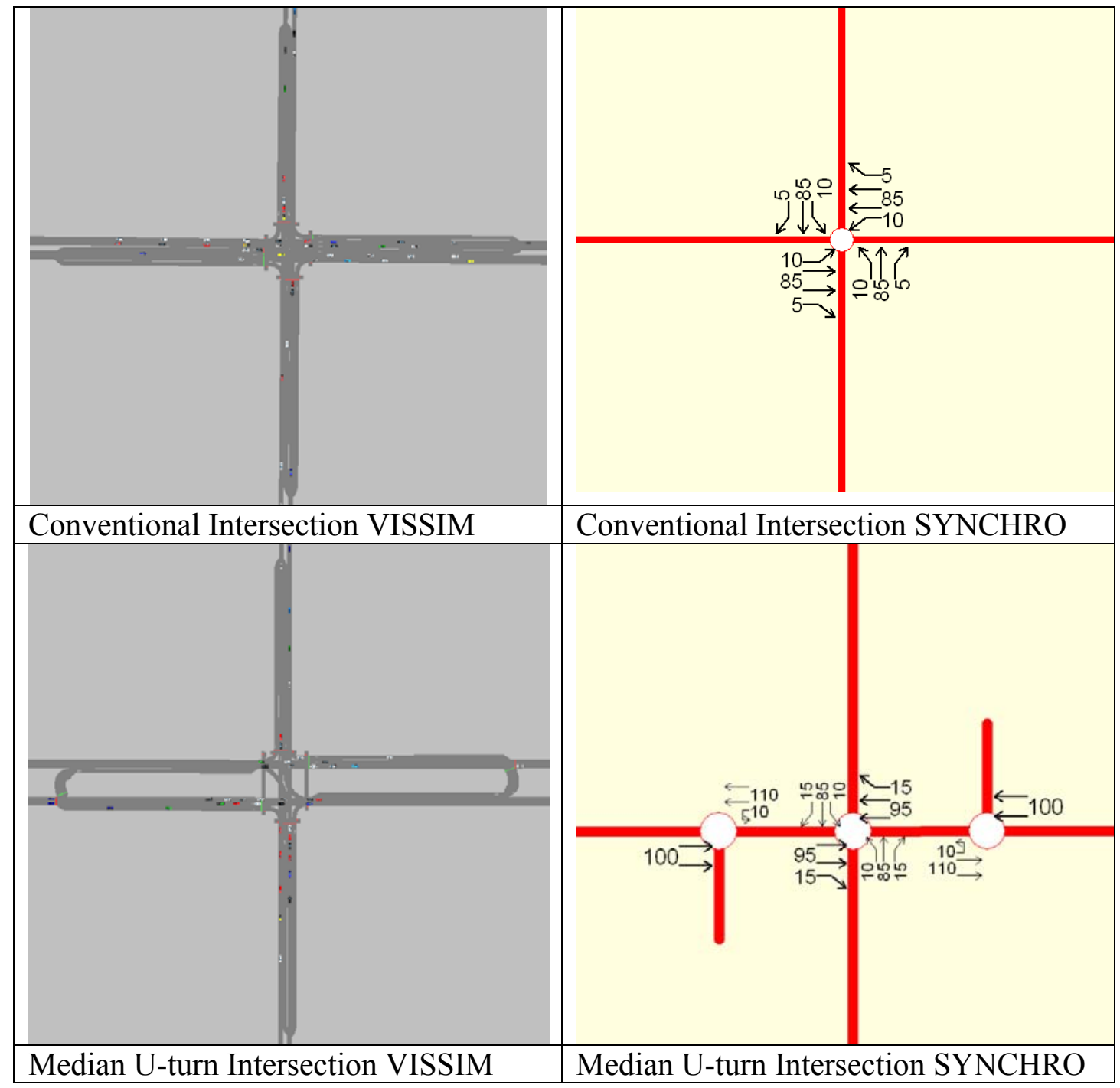

Figure 5-1 Evaluation Network Files I 


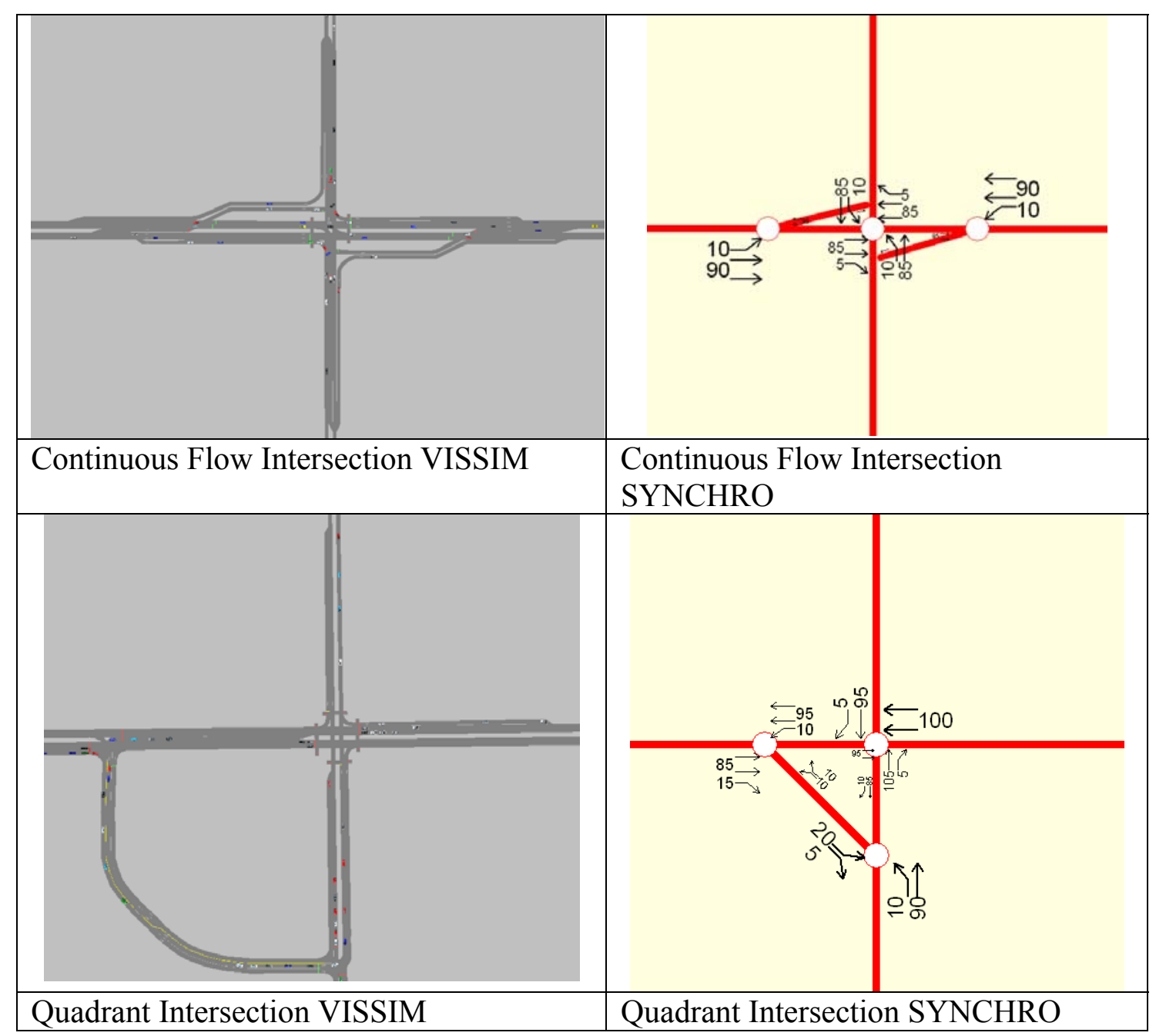

Figure 5-2 Evaluation Network Files II

For each movement, the measures are collected between data collection points located 3,000 feet upstream of the major intersection and depend on the speed downstream of the major intersection where all the movements are completed and vehicles from all upstream movements reach their desired speed. To determine the distance where vehicles reach their desired speed downstream from the stop bar, for each speed, a simple simulation 
experiment was performed, measuring the speed of vehicles at different locations downstream.

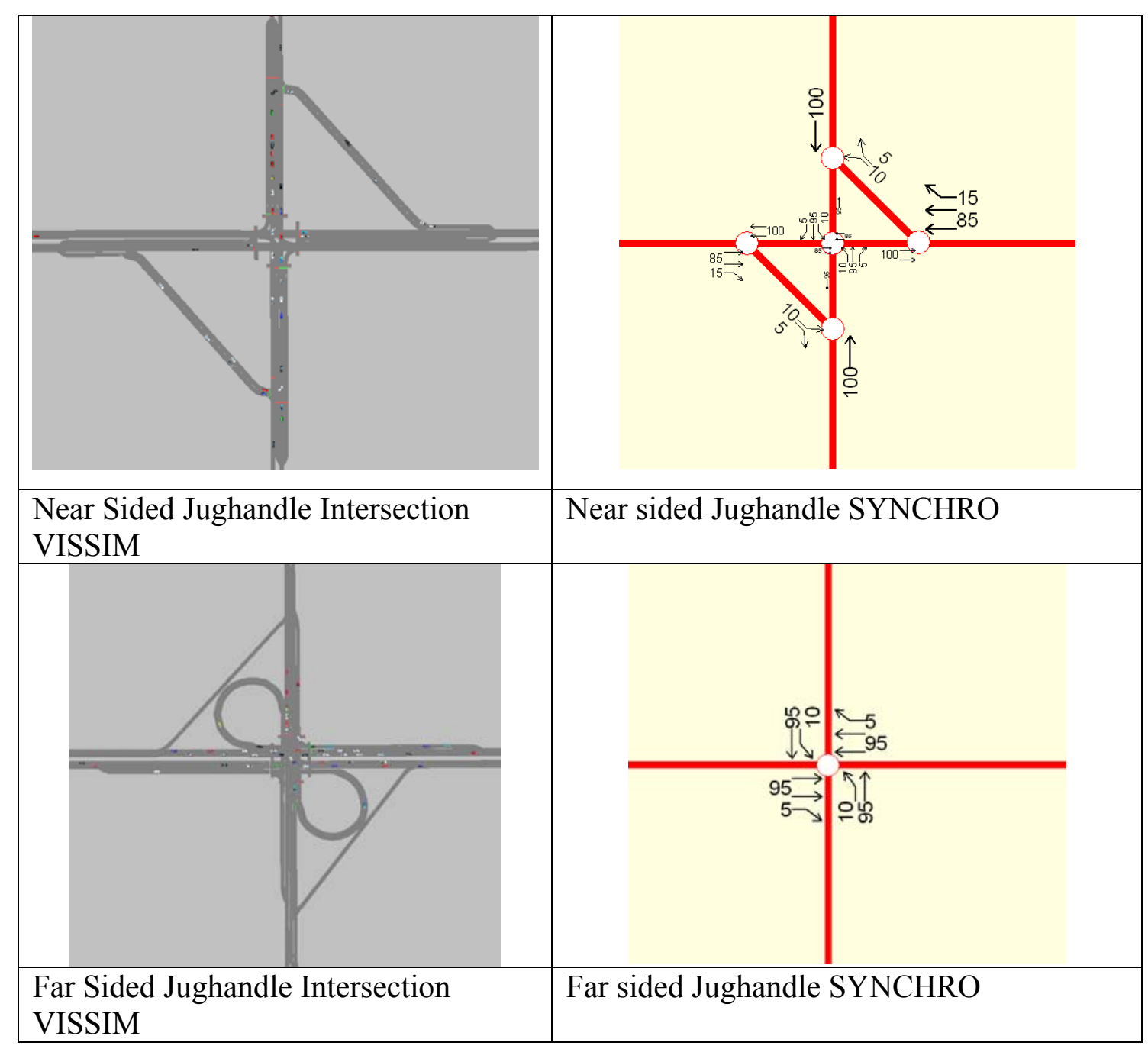




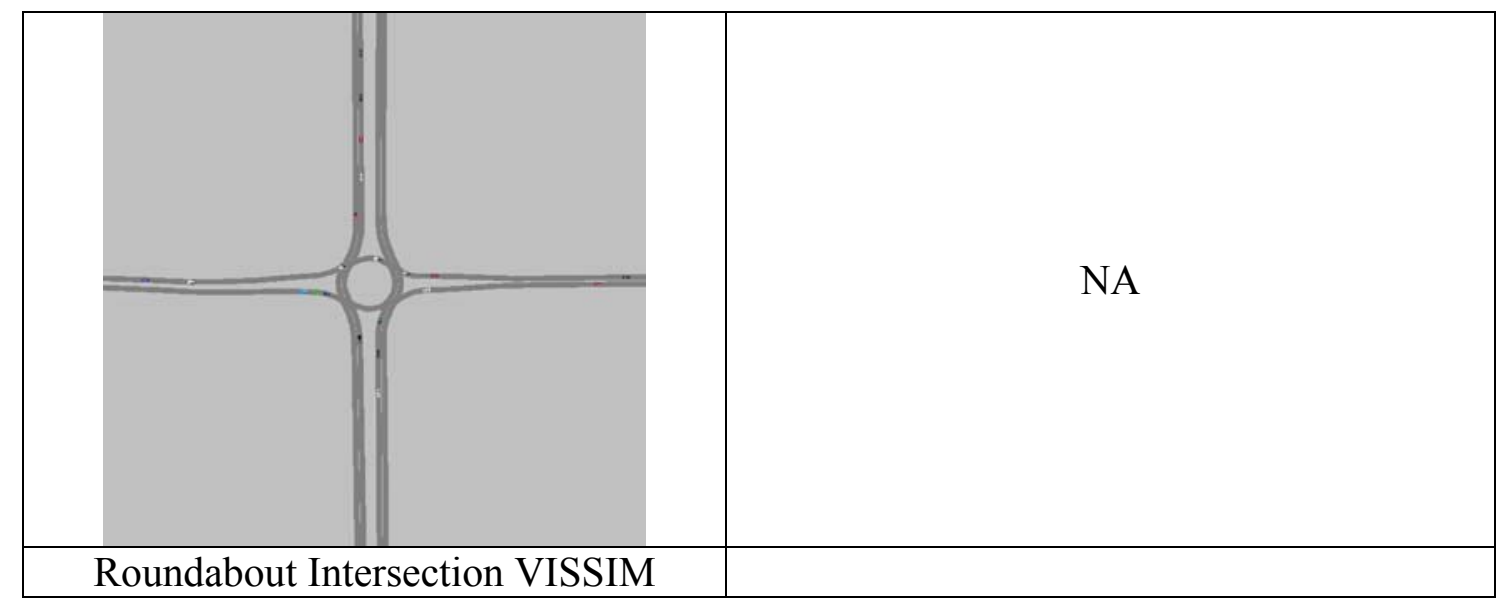

Figure 5-3 Evaluation Network Files III

Table 5-2 Distance at Which Vehicles Reach their Desired Speed

\begin{tabular}{|l|l|l|}
\hline Speed (mph) & $\begin{array}{l}\text { Distance downstream of } \\
\text { stop bar (feet) CAR }\end{array}$ & $\begin{array}{l}\text { Distance downstream of } \\
\text { stop bar(feet) HGV }\end{array}$ \\
\hline 30 & 600 & 750 \\
\hline 45 & 860 & 1300 \\
\hline 60 & 1200 & 2100 \\
\hline
\end{tabular}

\subsection{Illustrative example}

In this example, we will evaluate a $2 \times 2$ signalized intersection and a $2 \times 2$ roundabout under the same traffic conditions in an urban setting. The traffic conditions evaluated will be a 2,470 total hourly entering volume with a 55/45 roadway split, a 55/45 directional split, 10-percent left turns, and 5-percent right turns on all approaches (Figure 5-4). 


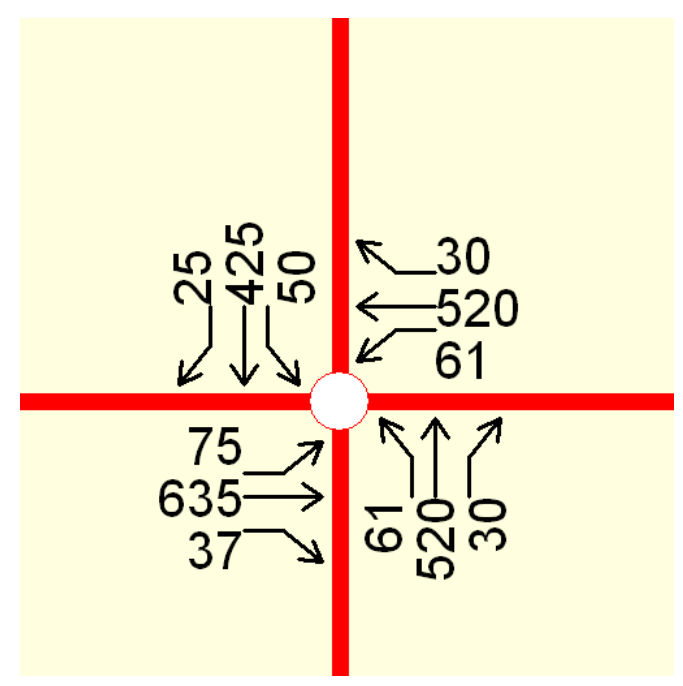

Figure 5-4 Traffic Conditions for Analyzed Case

We will start with the conventional intersection. The turning movements for a conventional intersection were entered in SYNCHRO. This is done within the volume window $\overline{\%}$

\begin{tabular}{|c|c|c|c|c|c|c|c|c|c|c|c|c|}
\hline VOLUME WINDOW & $\begin{array}{l}\Rightarrow \\
\text { EBL }\end{array}$ & $\underset{E B T}{\rightarrow}$ & $\underset{E B R}{7}$ & $\underset{W B L}{\not}$ & & $\underset{\text { WBR }}{4}$ & $\bigwedge_{\text {NBL }}^{4}$ & $\underset{\text { NBT }}{\uparrow}$ & $\underset{\text { NBR }}{F}$ & & $\underset{\text { SBT }}{\downarrow}$ & $\begin{array}{l}\downarrow \\
\text { SBR }\end{array}$ \\
\hline Traffic Volume (vph] & 75 & 635 & 37 & 61 & 520 & 30 & 61 & 520 & 30 & 50 & 425 & 25 \\
\hline
\end{tabular}

Figure 5-5 Entering Volumes in SYNCHRO

Since a conventional intersection is represented in SYNCHRO as a single node, only intersection splits and cycle lengths will be optimized (Figure 5-6). By running features the boxed in Figure 5-6 we obtained the signal timing plan shown in Figure 5-7. 


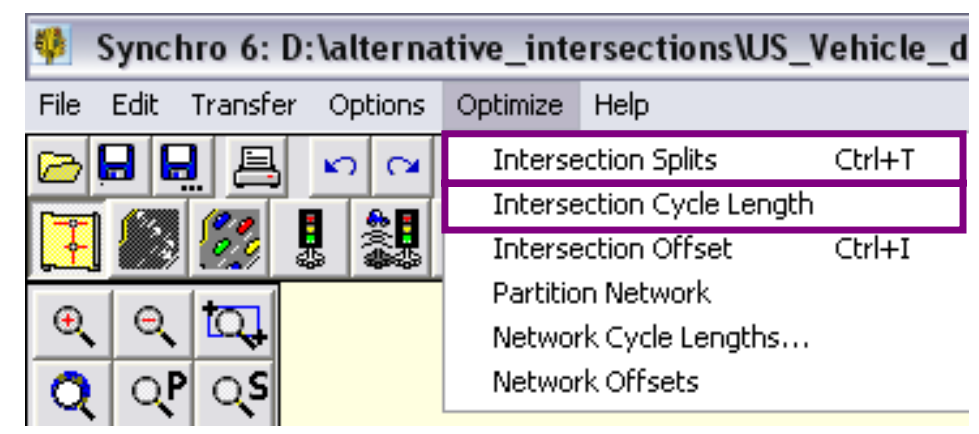

Figure 5-6 Optimizing Signal Timing in SYNCHRO

\begin{tabular}{|c|c|c|c|c|c|c|c|c|c|c|c|c|}
\hline TIMING WINDOW & EBL & EBT & EBR & WBL & WBT & WBR & NBL & NBT & NBR & SBL & SBT & SBR \\
\hline Lanes and Sharing (\#RL] & 7 & $\uparrow$ & it & 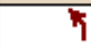 & $\uparrow$ & $\vec{i}$ & 7 & $\uparrow$ & $\vec{i}$ & 4 & $\uparrow$ & $\sqrt{t}$ \\
\hline Traffic Volume [vph] & 75 & 635 & 37 & 61 & 520 & 30 & 61 & 520 & 30 & 50 & 425 & 25 \\
\hline Turn Type & Prot & - & Perm & Prot & - & Perm & Prot & - & Perm & Prot & - & Perm \\
\hline Protected Phases & 7 & 4 & & 3 & 8 & & 5 & 2 & & 1 & 6 & \\
\hline Permitted Phases & & & 4 & & & 8 & & & 2 & & & 6 \\
\hline Detector Phases & 7 & 4 & 4 & 3 & 8 & 8 & 5 & 2 & 2 & 1 & 6 & 6 \\
\hline Minimum Initial [s] & 4.0 & 4.0 & 4.0 & 4.0 & 4.0 & 4.0 & 4.0 & 4.0 & 4.0 & 4.0 & 4.0 & 4.0 \\
\hline Minimum Split [s] & 8.0 & 20.0 & 20.0 & 8.0 & 20.0 & 20.0 & 8.0 & 20.0 & 20.0 & 8.0 & 20.0 & 20.0 \\
\hline Total Split [s] & 10.0 & 39.0 & 39.0 & 8.0 & 37.0 & 37.0 & 10.0 & 35.0 & 35.0 & 8.0 & 33.0 & 33.0 \\
\hline
\end{tabular}

Figure 5-7 Optimized signal timing plans in SYNCHRO

When recording signal timing plans from SYNCHRO, we were only concerned with the total splits because the controller we were running is pretimed. The next step was to enter the approach volumes, the turning volumes, and the optimized signal settings to the NEMA controller in VISSIM. This was done by opening the VISSIM file for a $2 \times 2$ conventional intersection.

The approach volumes were entered first, which was done by pressing the vehicle input icon $\overline{\mathrm{F}}$, and specifying the appropriate approach volumes (Figure 5-8). 


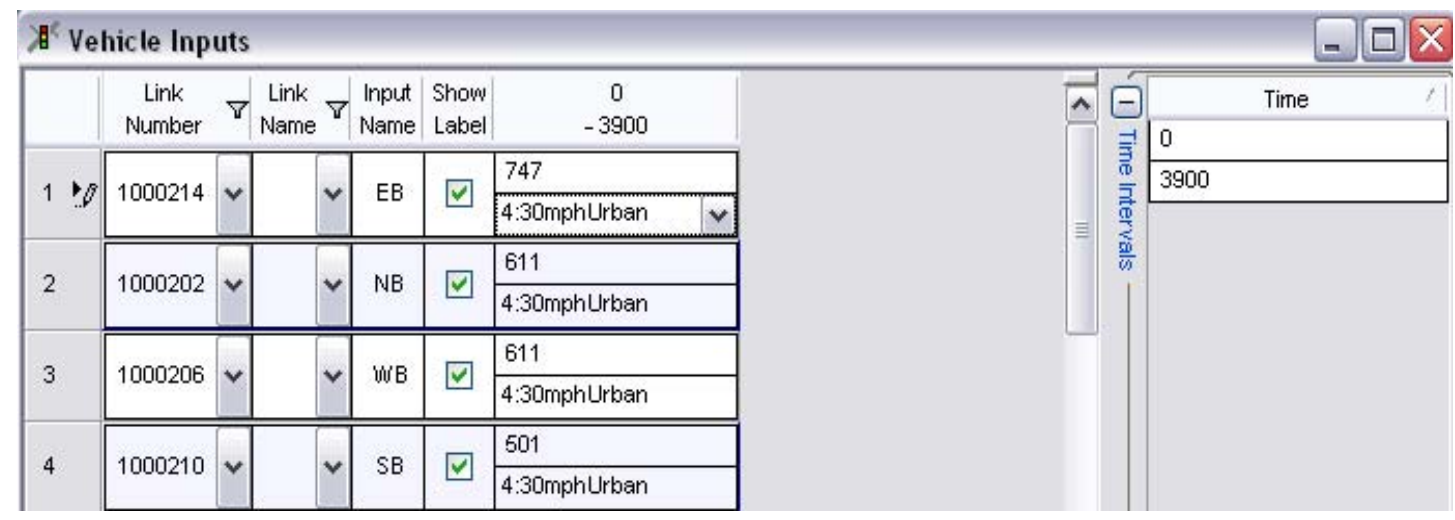

Figure 5-8 Entering Approach Volumes in VISSIM

Next, the turning movements were entered in VISSIM. Notice this additional step in VISSIM compared to SYNCHRO; you cannot simply enter turning movements, you must specify approach volumes in VISSIM also. To enter the turning movements, press the routes icon店. VISSIM can take turning movements as a percentage of the approach volume or as direct counts. If percentages are used, VISSIM will convert the approach volumes to counts using specified percentages. The percentages of approach volumes were entered (Figure 5-9). Modification should be made for all approaches.

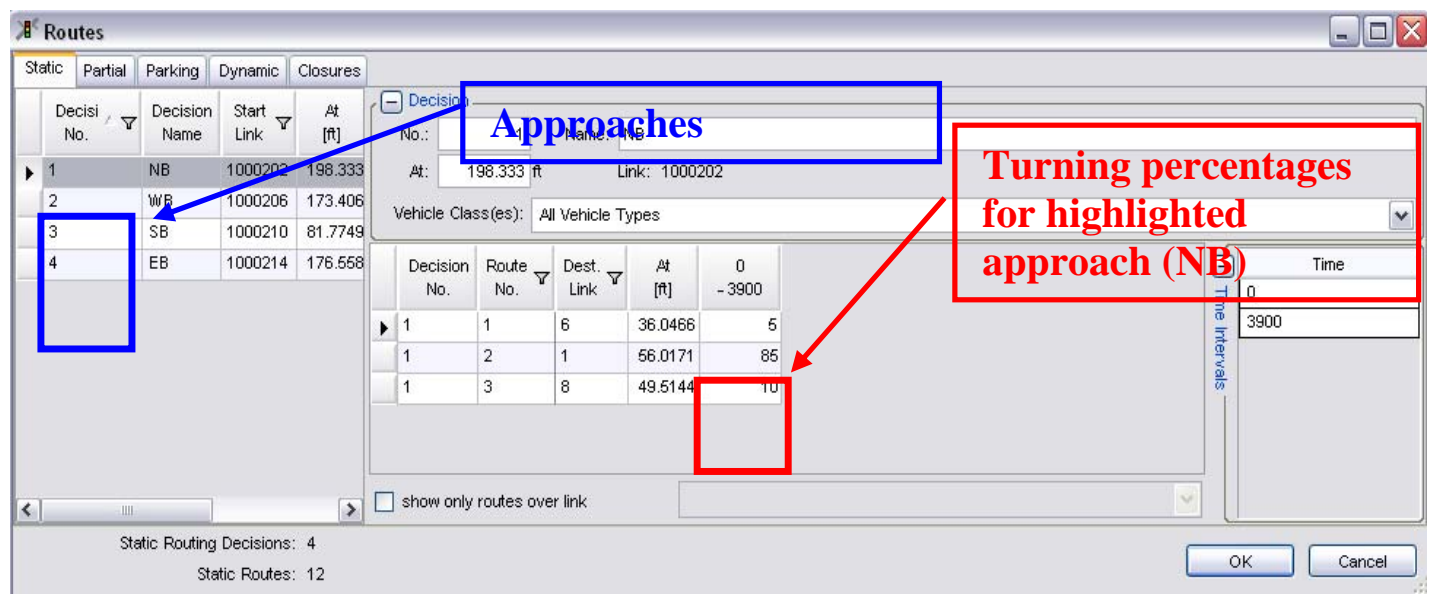

Figure 5-9 Specifying Turning Movements in VISSIM 
The optimized signal settings obtained through SYNCHRO were then entered in VISSIM. This is done by selecting in VISSIM Signal Control $\rightarrow$ Edit Controllers... and pressing the Edit Parameters button. Notice there is only one signal controller. For some alternative intersections, multiple controllers will be displayed and the signal setting should be changed for each controller by pressing the Edit Parameters button for each active signal controller and inputting the appropriate signal timings obtained through SYNCHRO.

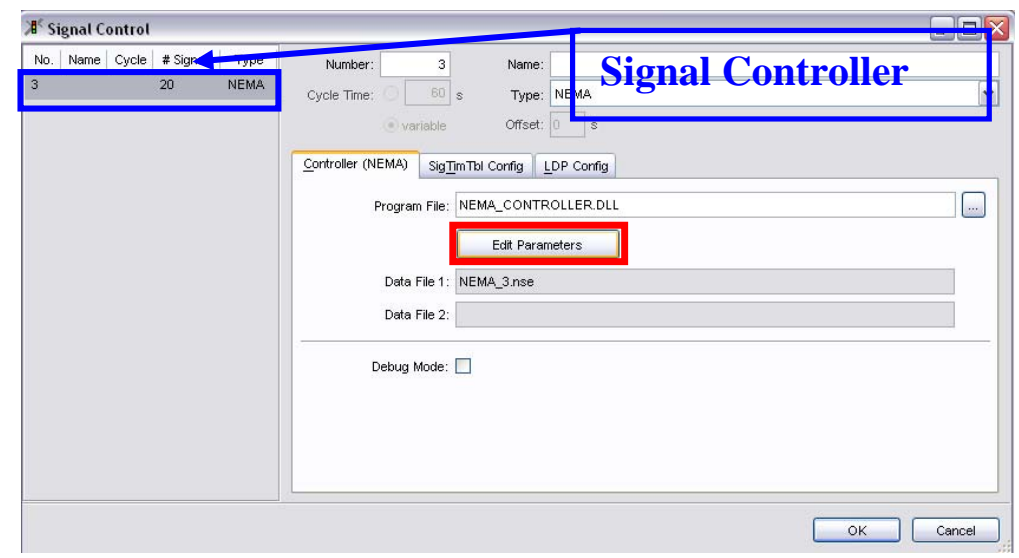

Figure 5-10 Signal Control Window

A NEMA controller signal timing window then should appear (Figure 5-11). In this window the SYNCHRO signal timings obtained earlier were entered. 


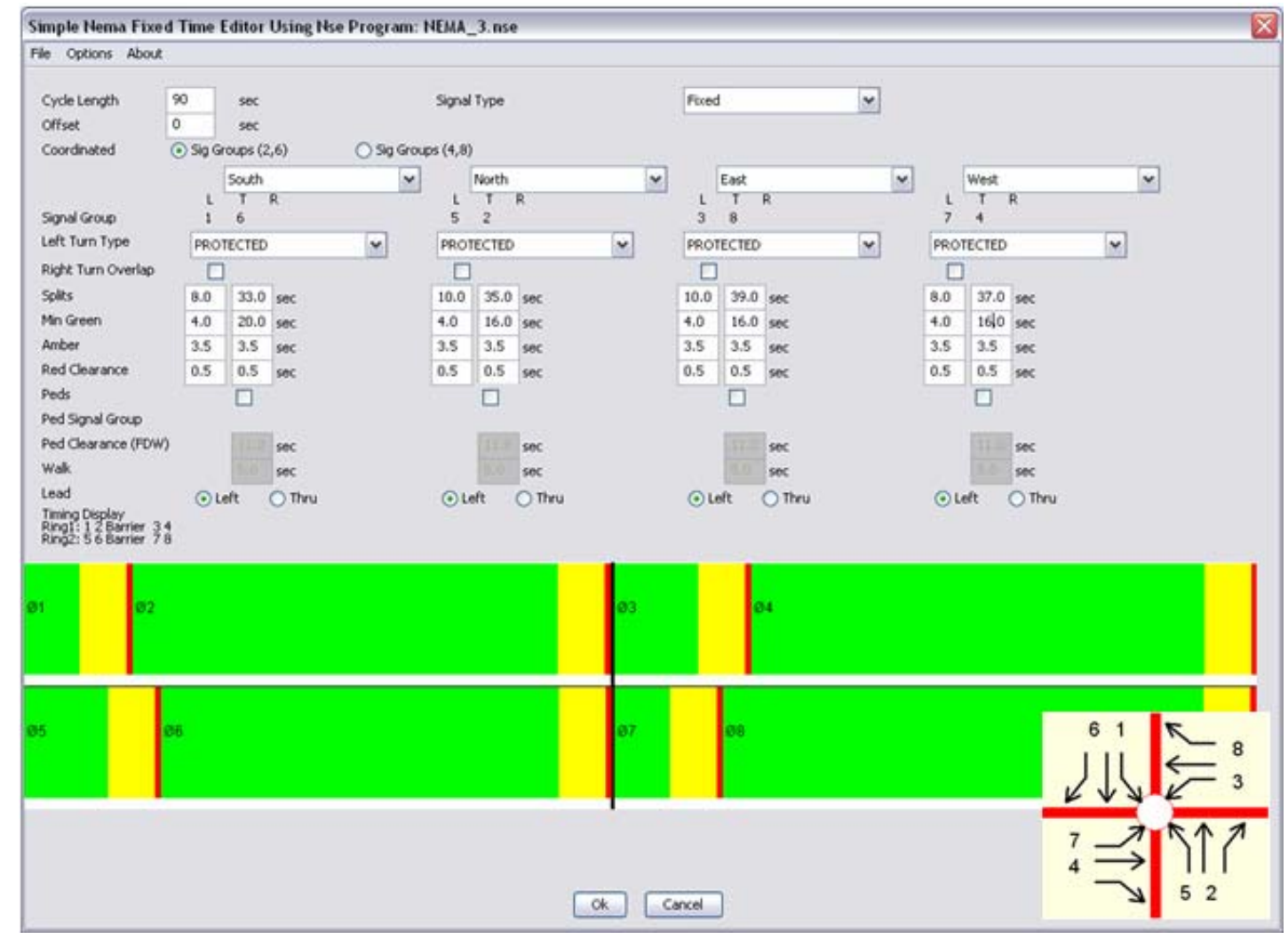

Figure 5-11Entered Signal Settings into NEMA Controller

The simulation to extract the measures of effectiveness was run. To obtain more reliable results, several simulation runs with different seed numbers should be performed for the same traffic conditions. Four simulation runs with different seed numbers were run. To run several simulation runs automatically choose in VISSIM Simulation $\rightarrow$ Multirun...

The desired number of runs was conducted and the location for the output files selected (Figure 5-12). The measures of effectiveness required for comparison were then generated. 


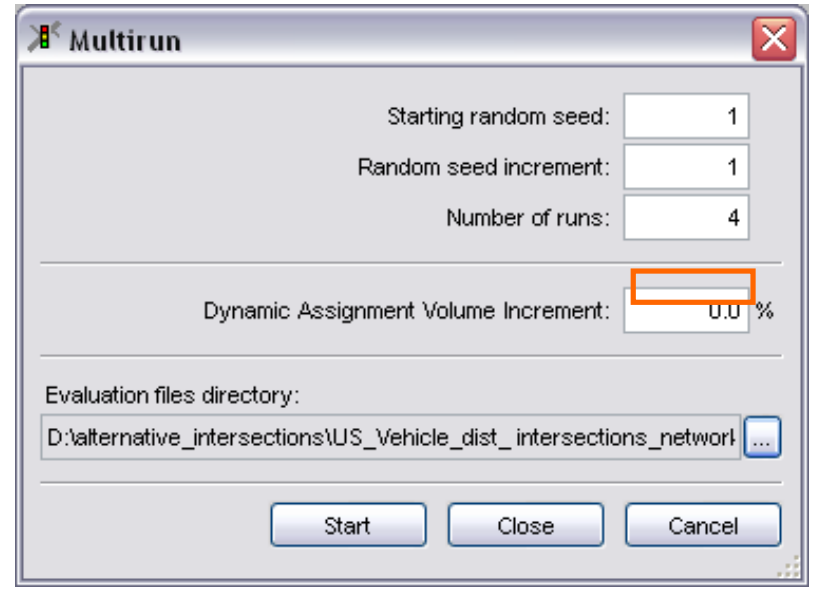

Figure 5-12 Multirun Window

To extract the measures for comparison, go to the folder specified in the Evaluation files directory (Figure 5-12). You should see for each simulation run (total of 4) two evaluation files, one containing the travel time measurements

(filename_seednumber.rsz file) and the other the delay measurements

(filename_seednumber.vlz file). All travel time measurements were imported to one sheet in Excel, and all of the delay measurements into another sheet in Excel.

The travel time measurements file contain the one-hour aggregated travel times for each movement and the number of vehicles for which the aggregation was performed (Figure 5-13, Figure 5-14). Notice our data is at the bottom of the output file, and the top of the file contains information regarding the definition of the measuring sections. All of the measuring section were predefined in the network file. 


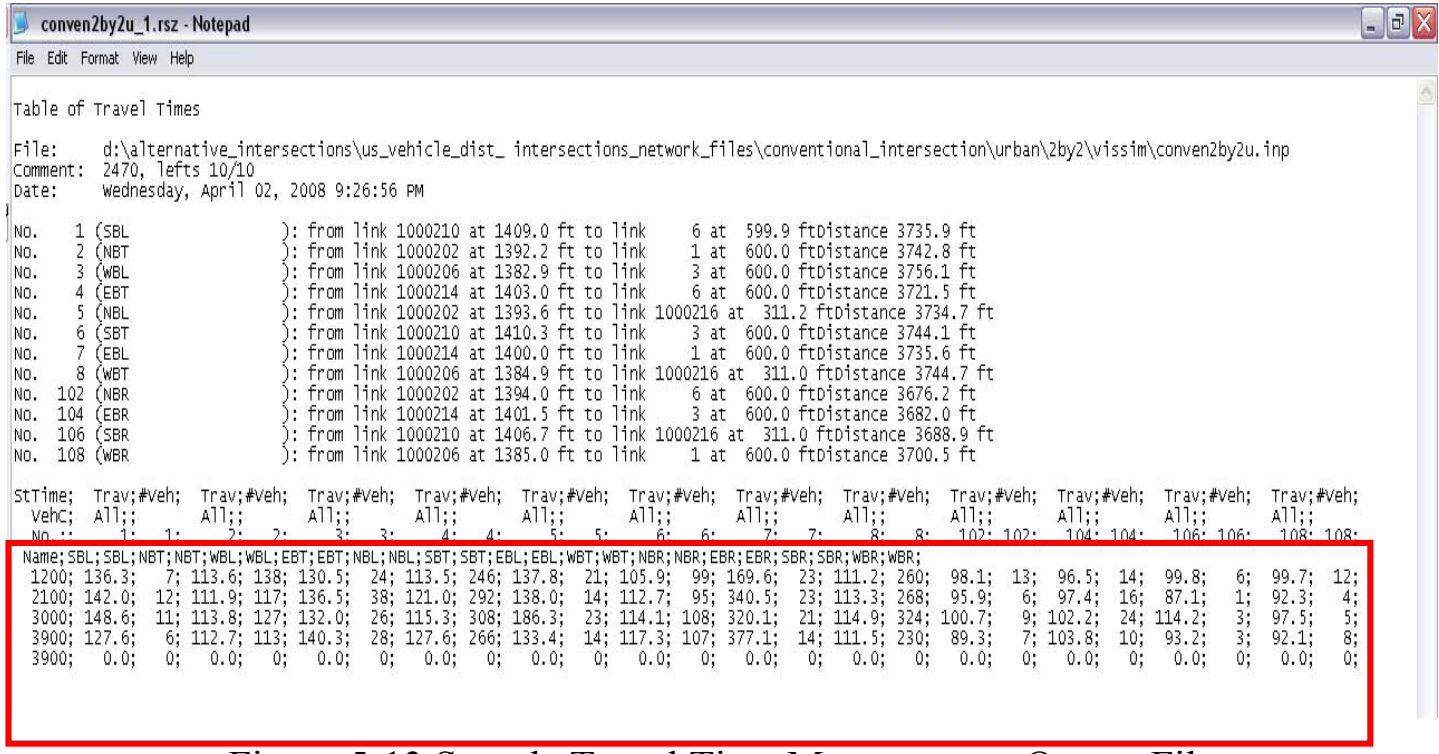

Figure 5-13 Sample Travel Time Measurement Output File

When exported to Excel, the data should resemble Figure 5-14. The data should be exported with the text import wizard as delimited with “;” The measuring sections are numbered as their respective phases at the main signal controller so the southbound left turn measuring section therefore will be numbered 1. Right turns are numbered as their respective phase plus 100, thus, the southbound right turn will be numbered 104.

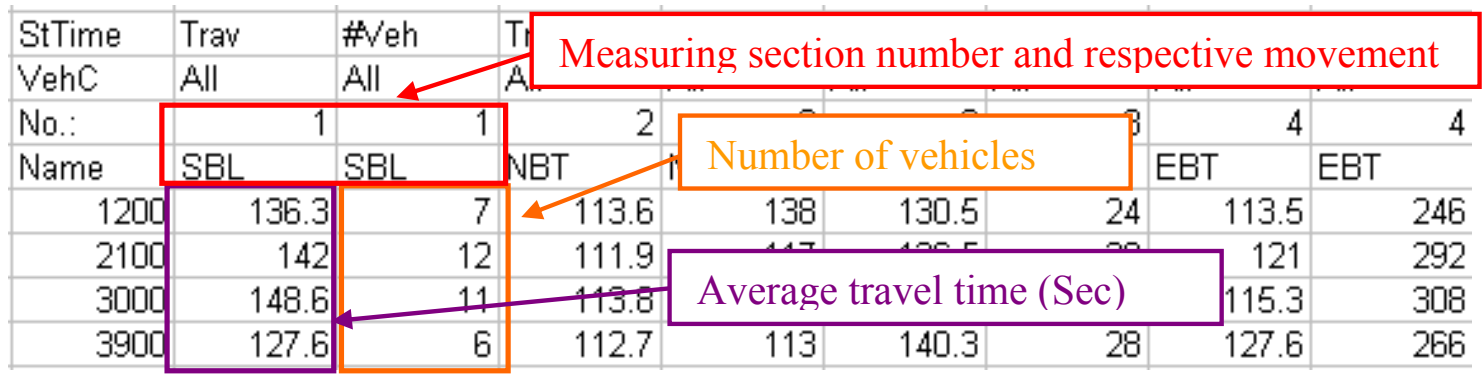

Figure 5-14 Partial View of Travel Time Data 
The travel time measurements should be converted to total delay measurements by subtracting from the actual travel time on each section the ideal travel time calculated based on the section length and the driver's speed.

The delay time measurement file contains the average total delay, the average stop delay per vehicle, the average number of stops per vehicle, the vehicle throughput, the average delay per person, and the person throughput. The measures of effectiveness used for comparison and evaluation of alternative intersections are the average stop delay and the average number of stops. The total delay computed can be used for a conventional intersection; however, for unconventional movements, it will be the delay along a specified route, rather then the delay incorporating the geometric delay due to an unusual geometry. This value then will be calculated based on the travel time measurements and the ideal travel time based on drivers' desired speed and the shortest distance, which is the direct path. To illustrate the procedure, the measures of effectiveness will also be collected on user-defined travel time sections defined at a conventional intersection.

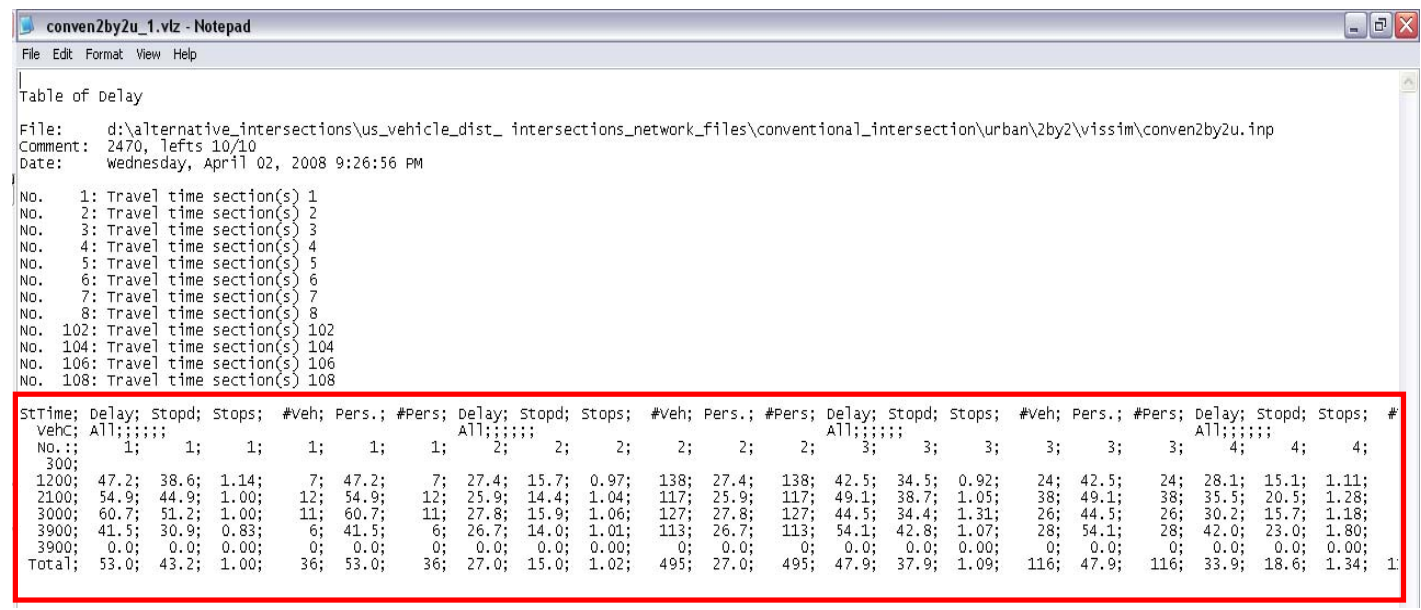

Figure 5-15 Delay Time Data 
When exported to Excel, the data should resemble Figure 5-16. The data should be exported with the text import wizard as delimited with ";". As previously noted, the measuring sections are numbered as their respective phases at the main signal controller, and the southbound left turn measuring section will be numbered 1. Right turns are numbered as their respective phase plus 100 thus the southbound right turn will be numbered 104.

\begin{tabular}{|c|c|c|c|c|c|c|}
\hline StTime; & \multirow{2}{*}{$\begin{array}{l}\text { Delay; } \\
\text { All;ii; }\end{array}$} & Stopd; & \multirow[t]{2}{*}{ Stops; } & \#veh; & \multirow[t]{2}{*}{ Pers: : } & \multirow[t]{2}{*}{ \#Pers; } \\
\hline VehC; & & & & & & \\
\hline No.:. & $1 ;$ & $1 ;$ & $1 ;$ & $1 ;$ & \multicolumn{2}{|c|}{ Average stop delay ( $\mathrm{sec}$ ) } \\
\hline 300 & & & & & & \\
\hline 1200; & 47.2 & 38.6 ; & 1.14; & $7 ;$ & \multirow{2}{*}{\multicolumn{2}{|c|}{ Average number of stops }} \\
\hline 2100; & 54.9 & 44.9 & 1.00; & 12; & & \\
\hline 3000; & 60.7 & 51.2 & 1.00; & 11; & 60.7 & $11 ;$ \\
\hline 3900; & 41.5 & 30.9 & 0.83 & 6 & 41.5; & 6 \\
\hline Total; & 53.0; & 43.2 & 1.00; & 36 ; & 53.0; & 36 \\
\hline
\end{tabular}

Figure 5-16 Partial View of Delay Data

The total delay measurements, the average number of stops measurements, and the average stop delay should be aggregated across all of the simulation runs (Table 5-3, Table 5-4).

Up to this step, a conventional signalized intersection was evaluated to determine the analyzed MOEs. For a roundabout, the same procedure should be followed as for a conventional intersection with the exception of using SYNCHRO to optimize the signal plans. Roundabouts have no signal controller so this optimization step is not required. Running a simulation for a roundabout you will obtain results shown in Table 5-5 and Table 5-6. 
Table 5-3 Conventional Intersection Total Delay

\begin{tabular}{|r|r|r|r|r|}
\hline travel time section & & \multicolumn{2}{|l|}{$\begin{array}{l}\text { ideal travel } \\
\text { time }(\mathrm{sec})\end{array}$} & \multicolumn{2}{l|}{$\begin{array}{l}\text { actual travel time } \\
(\mathrm{sec})\end{array}$} & \multicolumn{2}{l|}{$\begin{array}{l}\text { Total delay } \\
(\mathrm{sec})\end{array}$} & \multicolumn{1}{l|}{ \# veh } \\
\hline 1 & 87.0 & 158.5 & 71.5 & 191 \\
\hline 2 & 85.3 & 113.4 & 28.1 & 2035 \\
\hline 3 & 87.4 & 139.9 & 52.5 & 468 \\
\hline 4 & 85.0 & 125.2 & 40.2 & 4780 \\
\hline 5 & 85.1 & 145.8 & 60.7 & 242 \\
\hline 6 & 85.0 & 111.8 & 26.8 & 1670 \\
\hline 7 & 87.0 & 229.2 & 142.2 & 279 \\
\hline 8 & 83.3 & 113.0 & 29.7 & 4110 \\
\hline 102 & 83.3 & 97.5 & 14.2 & 135 \\
\hline 104 & 83.0 & 99.9 & 17.0 & 298 \\
\hline 106 & 80.8 & 100.4 & 19.5 & 83 \\
\hline 108 & 83.4 & 98.0 & 14.6 & 105 \\
\hline & & & 36.1 & \\
\hline & & & &
\end{tabular}

Table 5-4 Extracted Measures for a Conventional Intersection

\begin{tabular}{|r|r|r|r|}
\hline $\begin{array}{l}\text { travel time } \\
\text { section }\end{array}$ & $\begin{array}{l}\text { Stop } \\
\text { delay } \\
\text { (sec) }\end{array}$ & \# stops & \# veh \\
\hline 1.00 & 58.08 & 1.44 & 191.00 \\
\hline 2.00 & 15.35 & 1.03 & 2035.00 \\
\hline 3.00 & 41.59 & 1.28 & 468.00 \\
\hline 4.00 & 21.80 & 1.58 & 4780.00 \\
\hline 5.00 & 46.62 & 1.36 & 242.00 \\
\hline 6.00 & 15.28 & 1.03 & 1670.00 \\
\hline 7.00 & 117.93 & 3.09 & 279.00 \\
\hline 8.00 & 14.94 & 1.04 & 4110.00 \\
\hline 102.00 & 3.16 & 0.85 & 135.00 \\
\hline 104.00 & 3.53 & 1.08 & 298.00 \\
\hline 106.00 & 4.79 & 0.98 & 83.00 \\
\hline 108.00 & 2.89 & 0.82 & 105.00 \\
\hline & 20.79 & 1.27 \\
\hline \multicolumn{4}{|c}{}
\end{tabular}


Table 5-5 Roundabout Total Delay

\begin{tabular}{|c|c|c|c|c|}
\hline travel time section & $\begin{array}{l}\text { ideal travel } \\
\text { time (sec) }\end{array}$ & $\begin{array}{l}\text { actual travel time } \\
\text { (sec) }\end{array}$ & $\begin{array}{l}\text { Total delay } \\
\text { (sec) }\end{array}$ & \# veh \\
\hline 1 & 87.0 & 113.4 & 26.4 & 199 \\
\hline 2 & 85.3 & 232.4 & 147.1 & 1960 \\
\hline 3 & 87.4 & 105.1 & 17.7 & 224 \\
\hline 4 & 85.0 & 134.6 & 49.5 & 4950 \\
\hline 5 & 85.1 & 215.0 & 129.9 & 251 \\
\hline 6 & 85.0 & 110.1 & 25.2 & 1716 \\
\hline 7 & 87.0 & 136.0 & 49.0 & 264 \\
\hline 8 & 83.3 & 106.8 & 23.5 & 2121 \\
\hline 102 & 83.3 & 219.9 & 136.6 & 107 \\
\hline 104 & 83.0 & 130.3 & 47.3 & 318 \\
\hline 106 & 80.8 & 106.9 & 26.0 & 86 \\
\hline 108 & 83.4 & 95.6 & 12.1 & 126 \\
\hline & & & 58.0 & \\
\hline
\end{tabular}

Table 5-6 Extracted Measures for a Roundabout

\begin{tabular}{|r|r|r|r|}
\hline \multicolumn{1}{|l|}{$\begin{array}{l}\text { travel time } \\
\text { section }\end{array}$} & $\begin{array}{l}\text { Stop } \\
\text { delay } \\
\text { (sec) }\end{array}$ & \# stops & \# veh \\
\hline 1.00 & 4.76 & 1.43 & 199.00 \\
\hline 2.00 & 26.20 & 8.61 & 1960.00 \\
\hline 3.00 & 2.46 & 0.80 & 224.00 \\
\hline 4.00 & 4.57 & 2.06 & 4950.00 \\
\hline 5.00 & 21.87 & 7.33 & 251.00 \\
\hline 6.00 & 3.81 & 1.25 & 1716.00 \\
\hline 7.00 & 3.77 & 2.08 & 264.00 \\
\hline 8.00 & 2.48 & 0.98 & 2121.00 \\
\hline 102.00 & 23.34 & 8.21 & 107.00 \\
\hline 104.00 & 4.15 & 1.97 & 318.00 \\
\hline 106.00 & 4.05 & 1.31 & 86.00 \\
\hline 108.00 & 2.06 & 0.65 & 126.00 \\
\hline & 7.97 & 2.91 \\
\hline
\end{tabular}

Comparing both intersections, we can determine that the overall performance of a conventional intersection is better (lower total delay). It should be noted that the stop 
delay is much higher for a conventional intersection vs. a roundabout, so the perceived delay by drivers might be lower at a roundabout under the tested traffic conditions. 


\section{CHAPTER 6 SIMULATION EXPERIMENT DESIGN}

This chapter presents detail of the simulation experiments performed to generate information useful in comparing several alternative intersection designs. Six intersection types are evaluated under the same traffic conditions in 72 simulation scenarios. Each simulation scenario lasts one hour preceded with a short warm-up time. Simulation runs are repeated four times for each scenario and the results averaged to reduce the effect of the simulation pseudo randomness.

Among the evaluated intersections are (terms in parenthesis are labels used in the results presentation):

1. Conventional intersection (CONV),

2. Continuous flow intersection (CFLW),

3. Jug handle far-sided (JHFS),

4. Jug handle near-sided (JHNS),

5. Median U-turns intersection (MUT),

6. Roundabout (RNDB).

The layout of the intersections in presented in Figures: conventional intersection (Figure 6-1 ), jughandle nearsided intersection (Figure 6-2), jug handle far-sided intersection (Figure 6-3), median U-turn intersection (Figure 6-4), roundabout intersection (Figure 6-5) and continuous-flow intersection (Figure 6-6). The simulation scenarios are defined based on alternative number of lanes, urban vs. rural location, traffic load, and other major local characteristics. The following chapters provide the description of these characteristics and their combination for simulation. 


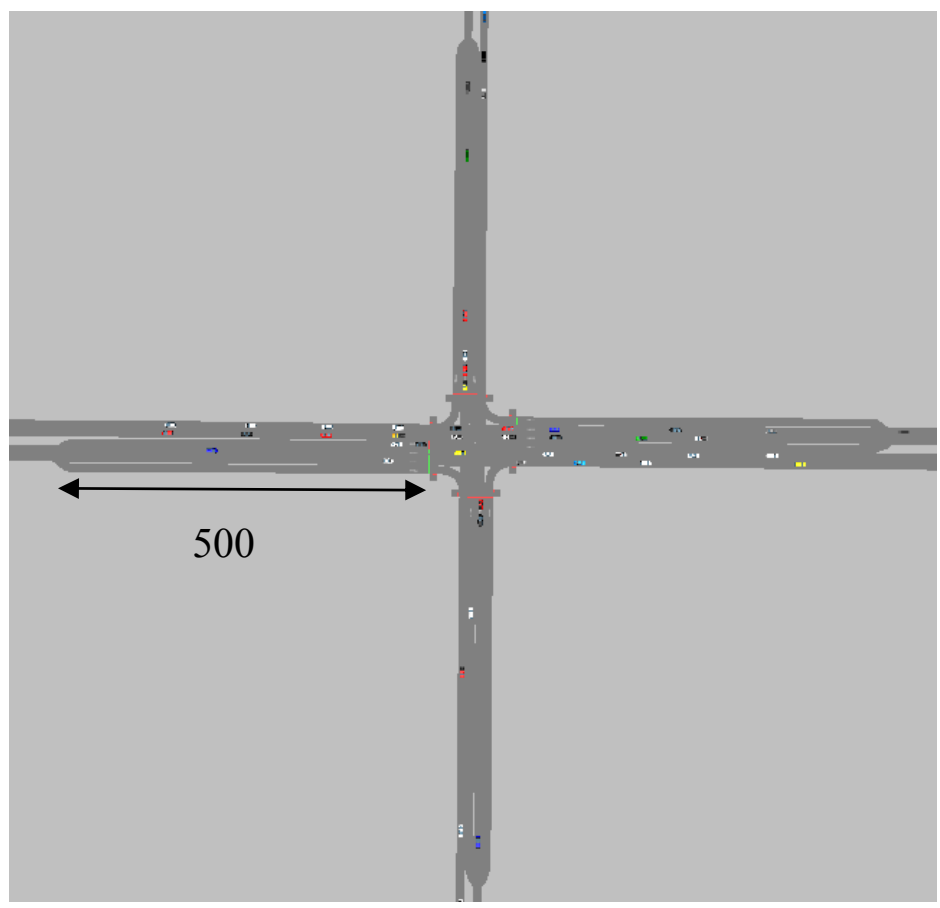

Figure 6-1 Conventional intersection $4 \mathrm{X} 2$

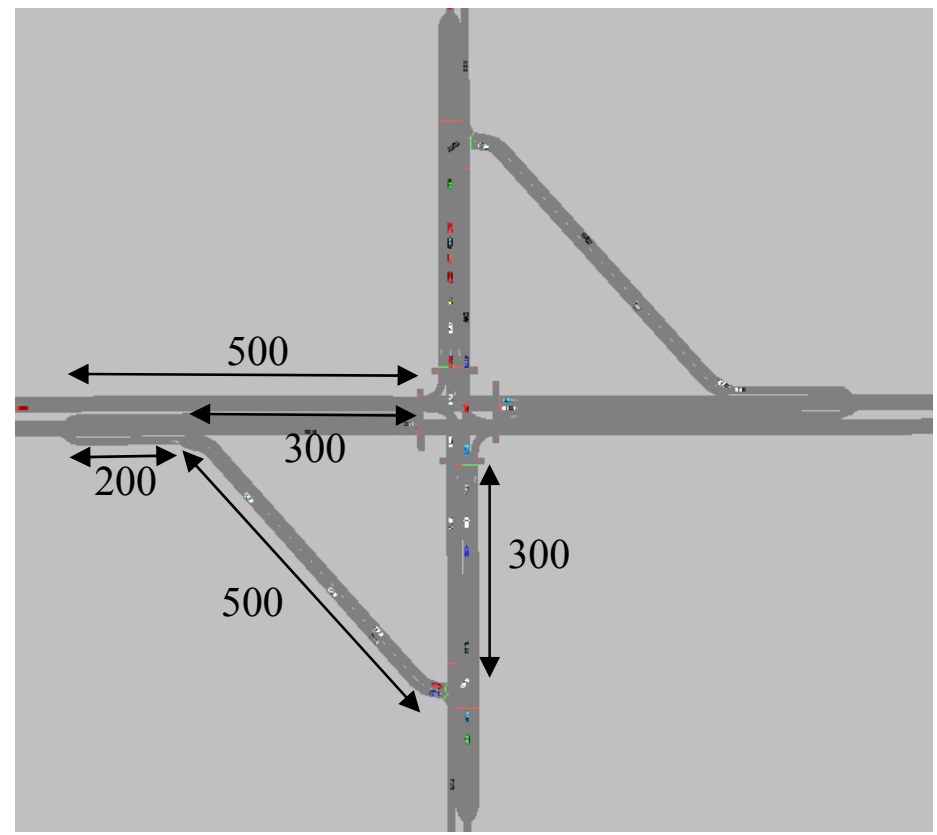

Figure 6-2 Jughandle nearsided intersection $4 \times 2$ 


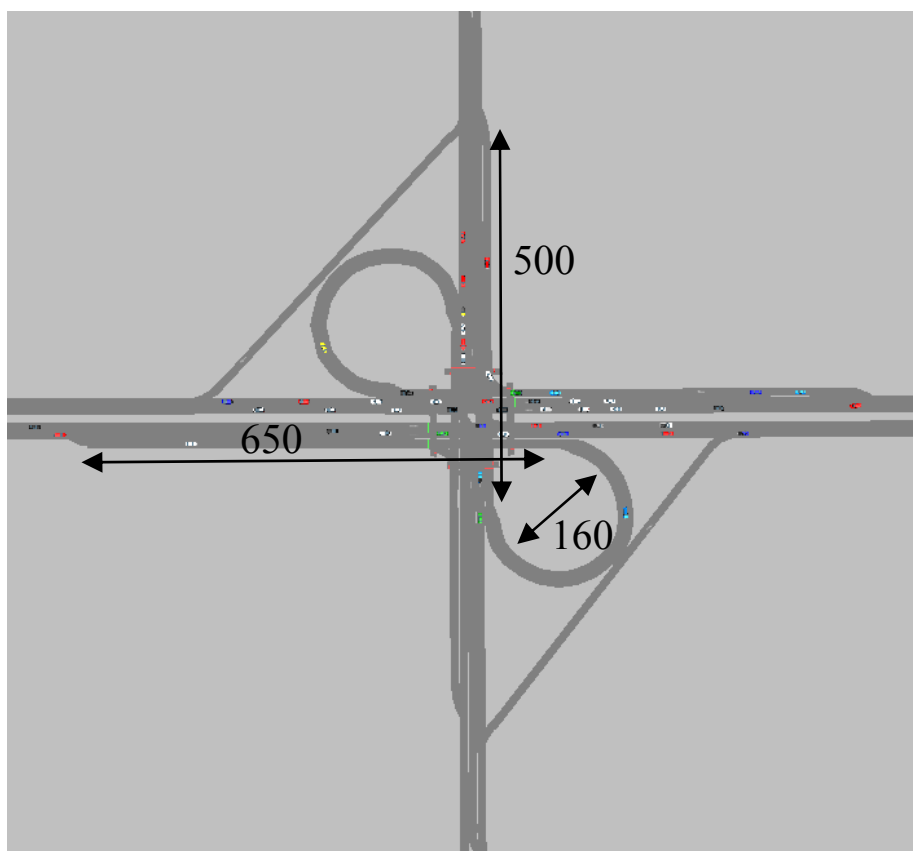

Figure 6-3 Jug handle far-sided intersection $4 \times 2$

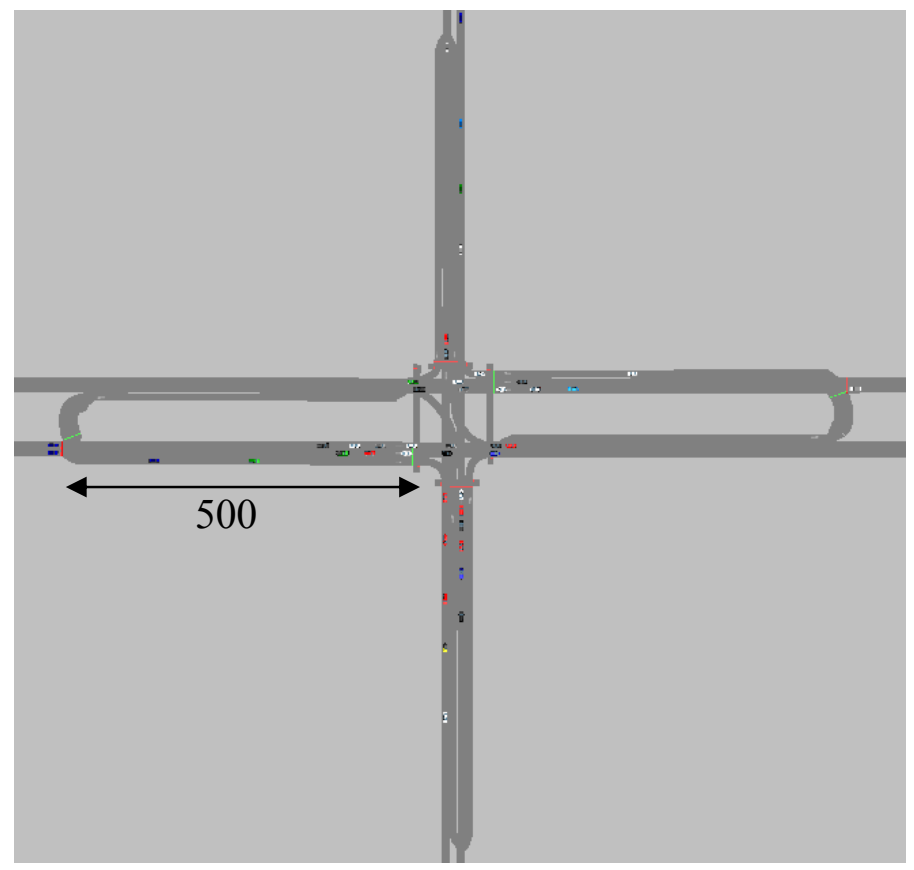

Figure 6-4 Median U-turn intersection 4x2 


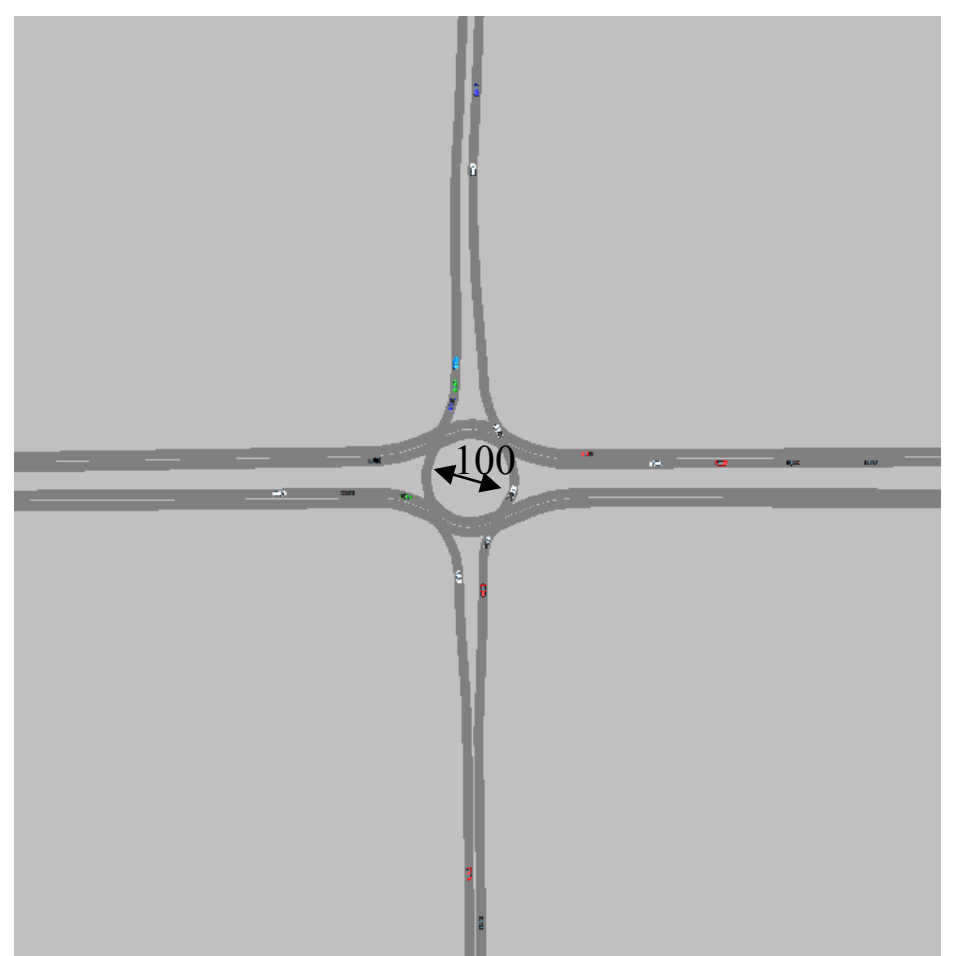

Figure 6-5 Roundabout intersection

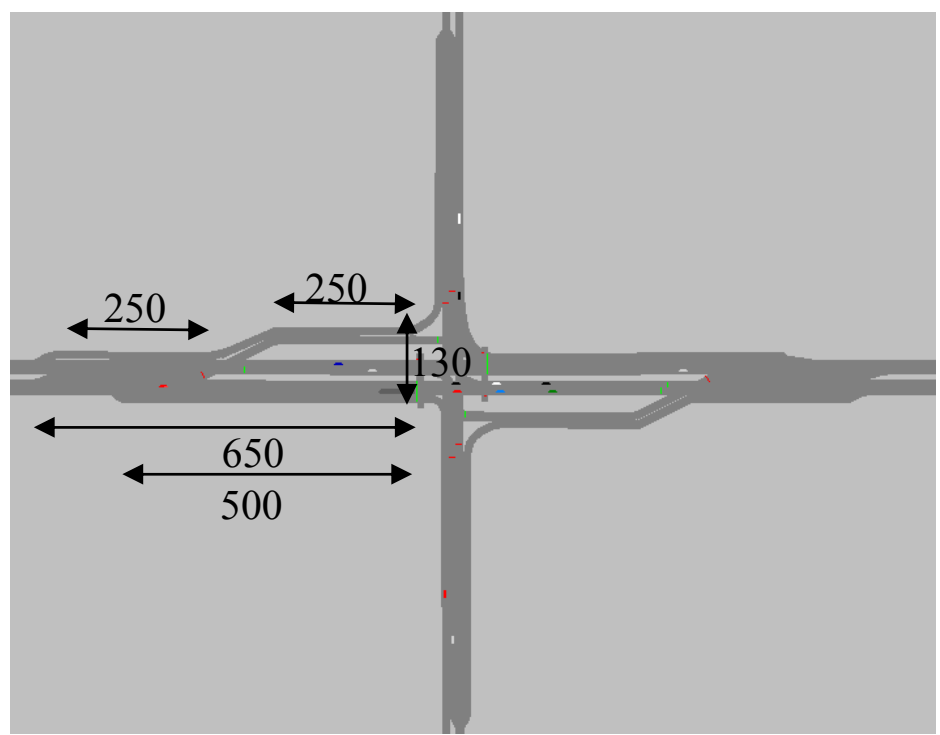

Figure 6-6 Continuous-flow intersection 


\subsection{Intersection Size and Location}

Each intersection was evaluated under two settings which represented the urban and rural conditions. For each setting three geometric configurations of each intersection where evaluated (Table 6-1):

1. four lane roadway crossing a four lane roadway $(4 \times 4)$,

2. four lane roadway crossing a two lane roadway $(4 \times 2)$, and

3. two lane roadway crossing a two lane roadway $(2 \times 2)$.

Number which describes intersection geometry indicates the total number of lanes in both directions of an approach roadway. The most important dimensions of the intersections are shown in Figure 6-1 through Figure 6-6.

Table 6-1 Intersection types, intersection geometric configuration and intersection settings evaluated

\begin{tabular}{|l|l|l|}
\hline Intersection type & Urban & Rural \\
\hline Conventional & $4 \times 4,4 \times 2,2 \times 2$ & $4 \times 4,4 \times 2,2 \times 2$ \\
\hline Near sided jughandle & $4 \times 4,4 \times 2,2 \times 2$ & $4 \times 4,4 \times 2,2 \times 2$ \\
\hline Far sided jughandle & $4 \times 4,4 \times 2,2 \times 2$ & $4 \times 4,4 \times 2,2 \times 2$ \\
\hline Median u-turn & $4 \times 4,4 \times 2,2 \times 2$ & $4 \times 4,4 \times 2,2 \times 2$ \\
\hline Roundabout & $4 \times 4,4 \times 2,2 \times 2$ & $4 \times 4,4 \times 2,2 \times 2$ \\
\hline Continuous Flow & $4 \times 4,4 \times 2,2 \times 2$ & $4 \times 4,4 \times 2,2 \times 2$ \\
\hline
\end{tabular}

Urban setting conditions were represented in the simulation with a saturation flow rate of $1900 \mathrm{vphpl}$, two percent of heavy vehicles, and a speed limit of $30 \mathrm{mph}$ for two lane approach roadways (both directions) and $45 \mathrm{mph}$ for four lane approach roadways (both directions). Rural setting conditions were represented in the simulation with a saturation flow rate of $1700 \mathrm{vphpl}$, five percent of heavy vehicles, and a speed limit of $55 \mathrm{mph}$ for two lane approach roadways (both directions) and $60 \mathrm{mph}$ for four lane approach roadways (both directions). See Table 6-2. 
Table 6-2 Characteristics of Urban and Rural settings

\begin{tabular}{|l|c|c|}
\hline Setting & Urban & Rural \\
\hline Speed (mph) & $\begin{array}{l}30 \text { for 2-lane roads } \\
45 \text { for 4-lane roads }\end{array}$ & $\begin{array}{c}55 \text { for 2-lane roads } \\
60 \text { for 4-lane roads }\end{array}$ \\
\hline Saturation flow rate (vphpl) & 1900 & 1700 \\
\hline Percentage of trucks $(\%)$ & 2 & 5 \\
\hline
\end{tabular}

For each intersection geometry three percentages of left turns were evaluated: ten percent on major and ten percent on minor (1010), ten percent on major and twenty percent on minor (2010), and twenty percent on major and twenty percent on minor (2020).

Each intersection geometry with specific left turn percentage was evaluated under twelve loading volume cases thus by combining six intersection types, each with two settings and three geometric configuration and three left turn percentages and twelve volume cases gives a total of 1296 scenarios. For each simulation scenario four simulation runs where performed giving a total of 5184 simulation runs. Output from each simulation run was stored in two text files (travel time file filename.rsv and delay file filename.vlz). For each scenario the random seed number stared at one and had a increment of one. The reason for choosing such an increment for random seed number is that VISSIM attaches the seed number next to the results text files name so it is easier to keep track of the results.

\subsection{Volume load and turning percentages}

Fore each intersection geometry three load factors, two traffic intersection splits, and two traffic directional splits where used thus giving a combination of twelve loading cases. Load factor is a number between 0 and 1 which is the ratio of the entering traffic volume per lane on the busier (critical) approach of the road and the saturation flow rate. The major road is oriented EB-WB and the EB approach carries busier traffic (critical 
approach). The minor road is oriented NB-SB and the NB approach carries busier traffic (critical approach).

A traffic intersection split tells the percent of the total intersection traffic on the busier/other intersection road. Two values are used: 55/45 intersection split (balanced) and 70/30 intersection split (imbalanced).

A traffic directional split tells the percent of the total road traffic flowing in the busier/other direction. Two values are used: 55/45 directional split (balanced) and 70/30 directional split (imbalanced). The directional splits are the same on both the intersection roads.

Knowing the load factor $(0.5,0.65,0.9,1.0)$, saturation flow rate, number of lanes, and intersection and directional splits allows calculate directional traffic volume on each of the roads. Example calculation is provide below for a $4 \times 2$ intersection in rural setting with 0.65 load factor, 55/45 roadway split and 70/30 directional split. To obtain specific loading volume case three steps are performed:

1. Determine volume in critical lanes of critical approaches. Multiply saturation flow rate of rural setting by a load factor of 0.65 , thus we have $1700 \cdot 0.65=1105$. This is the volume in critical lanes of critical approaches.

2. Determine the volume in each critical lane of critical approaches by using the roadway split and adjust for number of lanes. EB is the major critical approach thus its critical lane gets 55 percent of $1105 \mathrm{vphpl}$ while 45 percent of $1105 \mathrm{vphpl}$ goes to NB critical lane, which is the minor critical approach.

$$
\begin{aligned}
& E B_{C L}=1105 \cdot 0.55=608 \mathrm{vphpl} \\
& N B_{C L}=1105 \cdot 0.45=497 \mathrm{vphpl}
\end{aligned}
$$

Now this number is adjusted for the number of lanes in the critical approach. Since the intersection is a $4 \times 2$ thus adjustments needs only to be made to the EBWB direction which has four lanes (two in each direction). 


$$
\begin{aligned}
& E B_{\text {approach volume }}=608 \cdot 2=1216 \mathrm{veh} / \mathrm{h} \\
& N B_{\text {approach volume }}=497 \cdot 1=497 \mathrm{veh} / \mathrm{h}
\end{aligned}
$$

3. Determine the volume in non critical approaches using the directional split. Since we are using the 70/30 directional split thus critical approaches are 70 percent of volume and non critical approaches are 30 percent of given volume. Calculations are as follows:

$$
\begin{aligned}
& W B_{\text {approach volume }}=1216 \cdot \frac{30}{70}=521 \mathrm{veh} / \mathrm{h} \\
& S B_{\text {approach volume }}=497 \cdot \frac{30}{70}=213 \mathrm{veh} / \mathrm{h}
\end{aligned}
$$

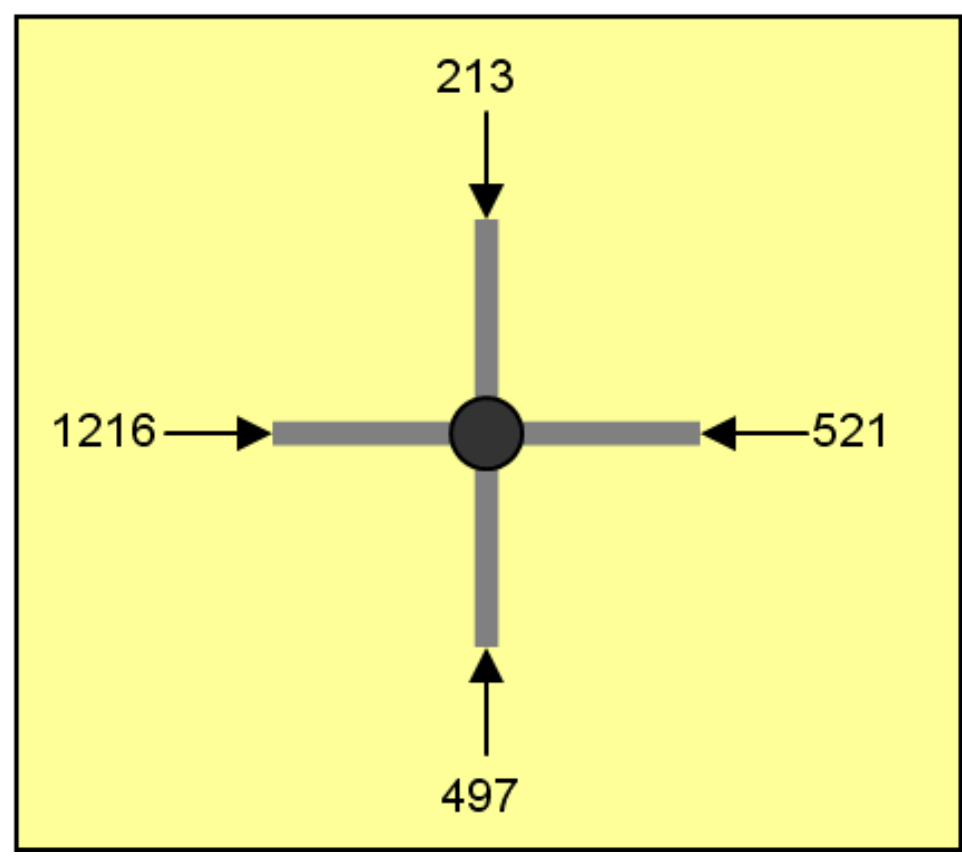

Figure 6-7 Results of the example calculations of directional traffic

The calculated directional traffic (approach traffic) is then split between turning volumes. A single value of the right turn percent was used in all simulations: $5 \%$. The left turn traffic percents has been assumed equal on the opposing approaches of the same road but may be different for different roads at the same intersection. Three left-turning scenarios has been assumed in three different turning patterns: 
1. $10 \%$ on major and minor roads,

2. $10 \%$ on major road and $20 \%$ on minor road,

3. $20 \%$ on major and minor roads.

Knowing the turning traffic percentages and the approach volumes calculated in the previous step allows calculating all 12 turning volumes at the simulated intersection.

\subsection{Signal timing}

Synchro software was used to determine signal timing setting for the assumed geometry and traffic conditions. Example turning traffic scenario displayed by Synchro is shown in Figure 6-8.

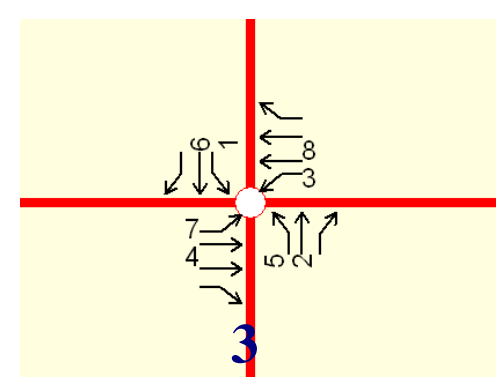

Figure 6-8 Conventional intersection $4 \times 2$ Synchro file

For all intersection SB through (SBT) and right (SBR) movements proceed on phase 6 and SB left (SBL) movement proceeds on phase 1. The traffic phases are numbered as shown in Figure 6-9.

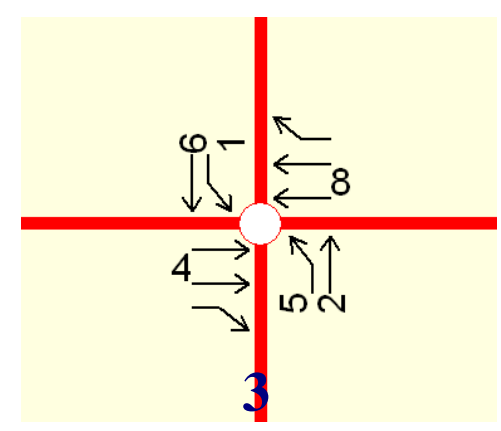

Figure 6-9 Jug handle far-sided intersection $4 \times 2$ Synchro file 
For near-sided intersection NBR and SBR movements were eliminated since they are accommodated through ramps and bypass the signals at the main intersection. There are no protected left turn movement phases for EBL and WBL since these movements are accommodated through a ramp and added to minor through movements. EBL volume was added to NBT movement volume and WBL movement volume was added to SBT movement volume (Figure 6-2 Jughandle nearsided intersection 4x2Figure 6-10).

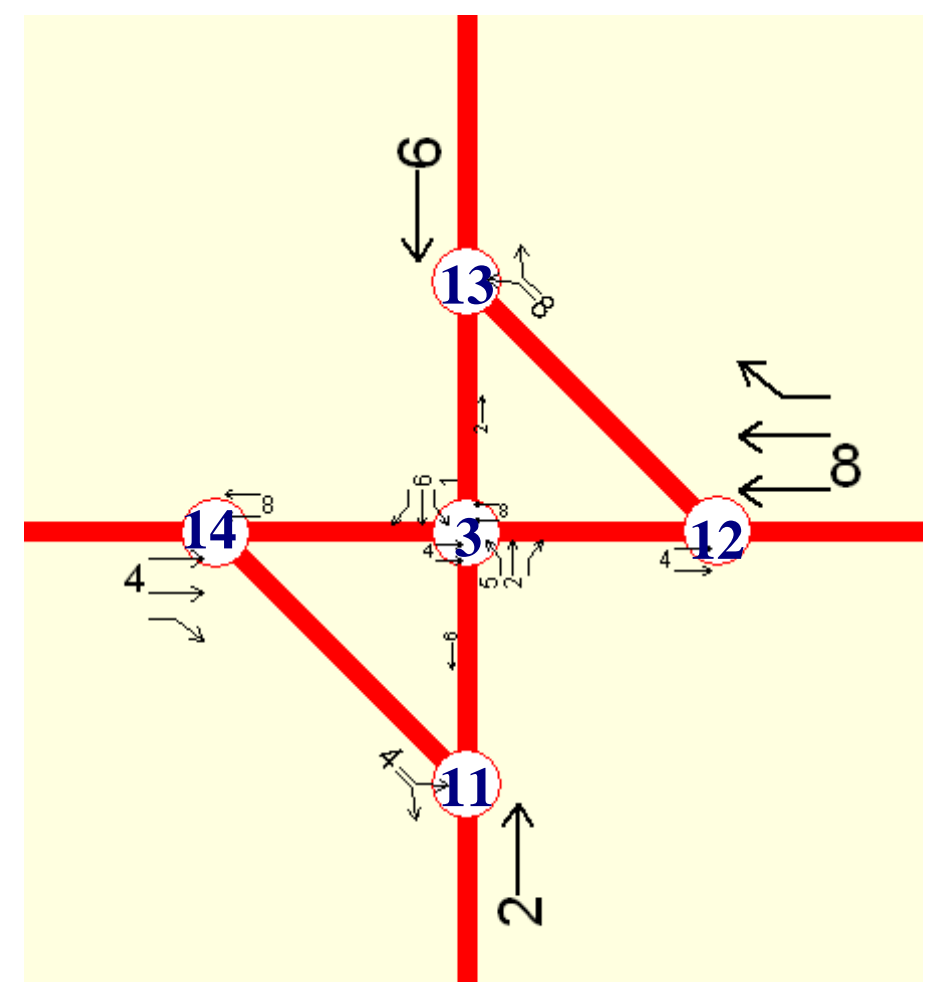

Figure 6-10 Jughandle nearsided intersection $4 \times 2$ Synchro file

For jug handle near-sided intersection five nodes where required to build this intersection in Synchro (Figure 6-10). At the main intersection (node \#3) left turn protected phases for EBL and WBL were removed and EBR and WBR turn movements have also been removed since all these movements are accommodated through the ramps. It should be noted that numbering of nodes in Figure 6-8 through Figure 6-12 is not what you would see when in Synchro when you click the node labels but is numbered according to signal controller labeling in VISSIM. EBL movement makes a right at node \#14, proceeds on phase 4 of node \#11 and phase 2 of node \#3. WBL movement makes a right at node \#12, 
proceeds on phase 8 of node \#11 and phase 6 of node \#3. Entire NB approach volume proceeds on phase 2 of node 11 and entire SB approach volume proceeds on phase \# 6 of node 13. Volume balance on the entire network is checked to make sure that entering volumes on the outside nodes $(11,12,13$, and 14) in each direction have been properly added to the respective movements on each individual node they pass through.

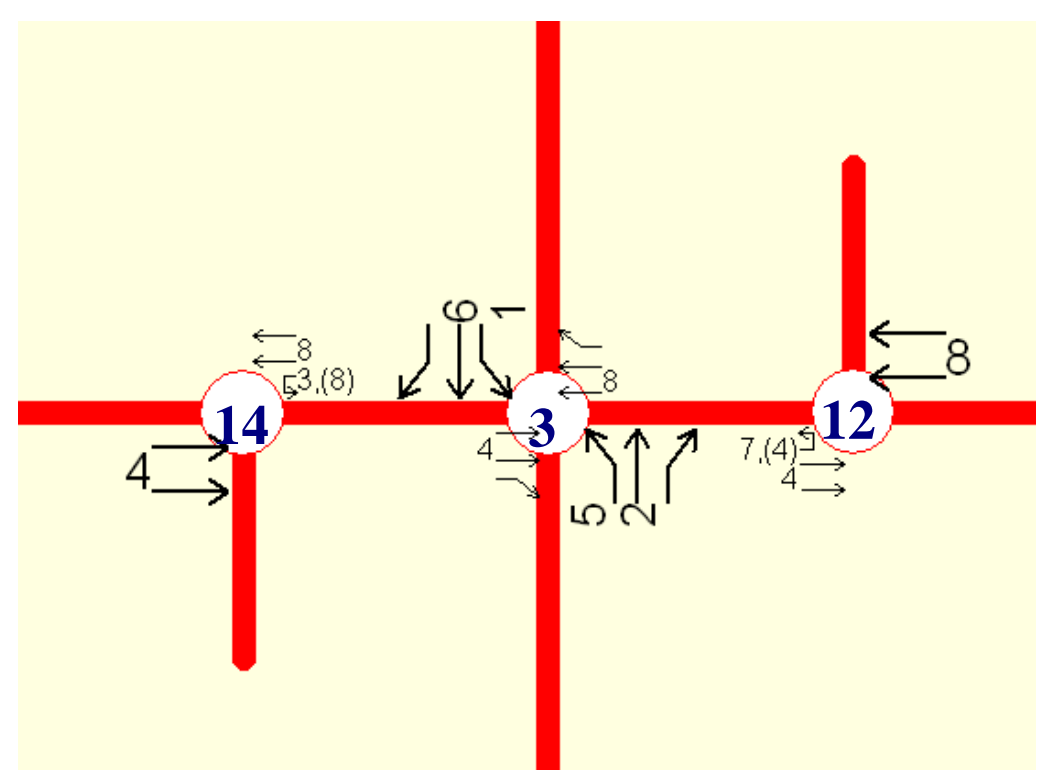

Figure 6-11 Median U-turn intersection 4x2 Synchro file

Median U-turn intersection is represented in Synchro with a three node network.

EBL and WBL protected left turn phases have been removed at the main intersection since these movements are accommodated through crossovers. EBL turn movement proceeds on phase \# 4 through node 14 and on phase \# 4 through node 3 and makes a turn on phase \# 7 of node 12 and completes its movement by making a right turn on node \# 3 . WBL turn movement proceeds on phase \# 8 through node 12 and on phase \# 8 through node 3 and makes a turn on phase \# 3 of node 14 and completes its movement by making a right turn on node \# 3. Entire EB approach volume proceeds on phase \# 4 of node 14 and entire WB approach volume proceeds on phase \# of node 12. Volume balance on the entire network is checked to make sure that entering volumes on the outside nodes (12 
and 14) in each direction have been properly added to the respective movements on each individual node they pass through.

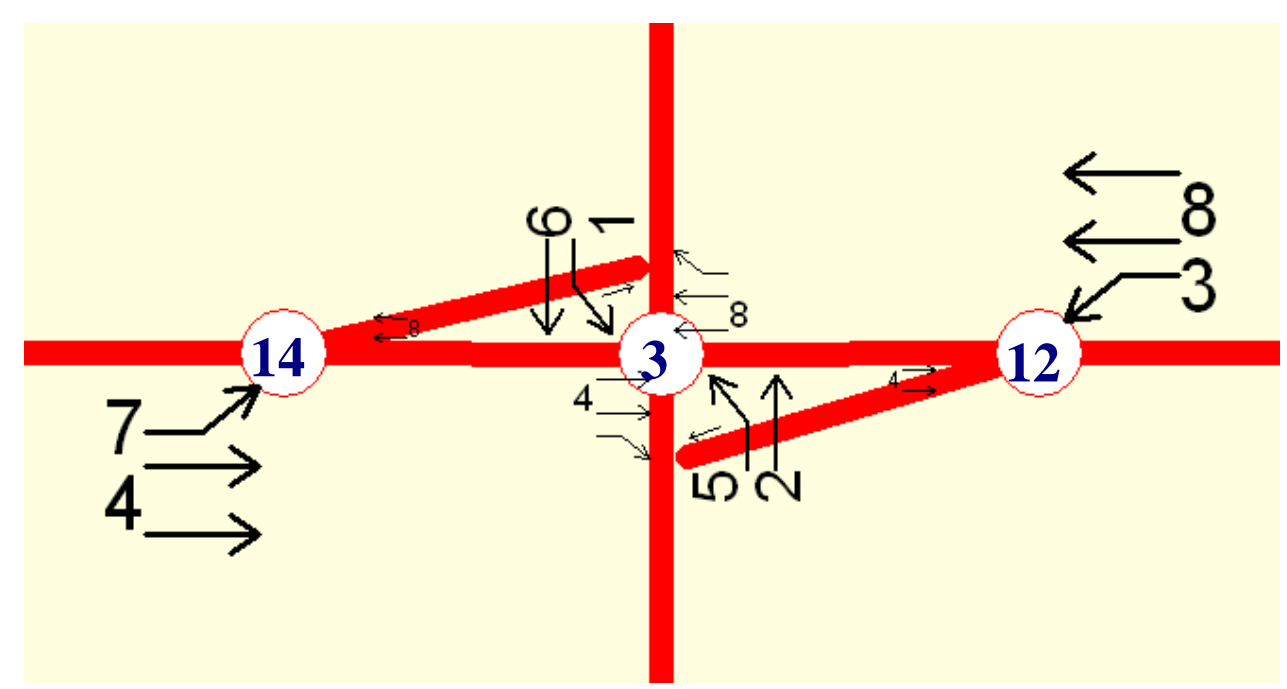

Figure 6-12 Continuous-flow intersection 4x2 Synchro file

Continuous flow intersection is represented in Synchro with a 3 node network. EBL and WBL turn movements use ramps prior to the main intersection and proceed simultaneously with EBT (phase \# 4) and WBT (phase \#8) movements at node 3. EBL movement cuts through opposing direction on phase $\# 7$ of node 14 , while WBL movement cuts through opposing direction on phase \#3 of node 12. Due to limitation in Synchro coding the left turn bays are not connected to North-South roadway but this is not required for correct signal timing setting since for percentage of left turns simulated through movements will always determine the length of phase \# 4 and phase \# 8 at node 3 where the left turns proceed simultaneously with respective through movements. EBL movement proceeds on phase $\# 8$ of node 3 while WBL proceeds on phase $\# 4$ of node 3 . NBR and SBR movements have been removed from node 3 since these movements are accommodated through ramps which bypass the signals.

All signal controllers at the nodes (intersections) in Synchro networks have been coded as fixed time NEMA controllers. Intersections which required additional node to be entered have been coded as closely spaced intersections each one operated by a fixed time 
NEMA controllers and coordinated with the main intersection (node3) through the offsets. The direction of coordination was dependent on the type of intersection. Median U-turn and continuous flow intersection was coordinated to phase \# 4 and \# 8 of node 3 . Jughandle nearsided was coordinated with reference to phase \# 2 and \# 6 of node 3.

Signal timing where obtain in Synchro by using the optimization feature. Splits and cycle lengths where optimized for each node and in case of multiple nodes representing an alternative intersection in Synchro network, each node had splits and cycle length optimized individually then network cycle lengths and network offsets where optimized. Node 3 (major intersection) has always offset equal to zero.

\subsection{Running Simulation with VISSIM}

Procedure for running a simulation run is as follows (Figure 6-13):

1. Import loading volumes to Synchro for appropriate volume case

2. Optimize signal timings for the Synchro network (one or multiple nodes)

3. Enter signal timing in VISSIM controller window (one or multiple node)

4. Enter approach loading volumes in VISSIM through vehicle input

5. Enter turning percentage in VISSIM through routes.

6. Run multiple simulations for same simulation scenario in VISSIM.

When running simulation run in VISSIM travel time and delay evaluation file option should be checked. This will record the results in two text files with the name of the VISSIM network file (.inp) random seed number and file extension (.rsz or .vlz). The detailed procedure of the entire process is explained in ChapterCHAPTER 5. 


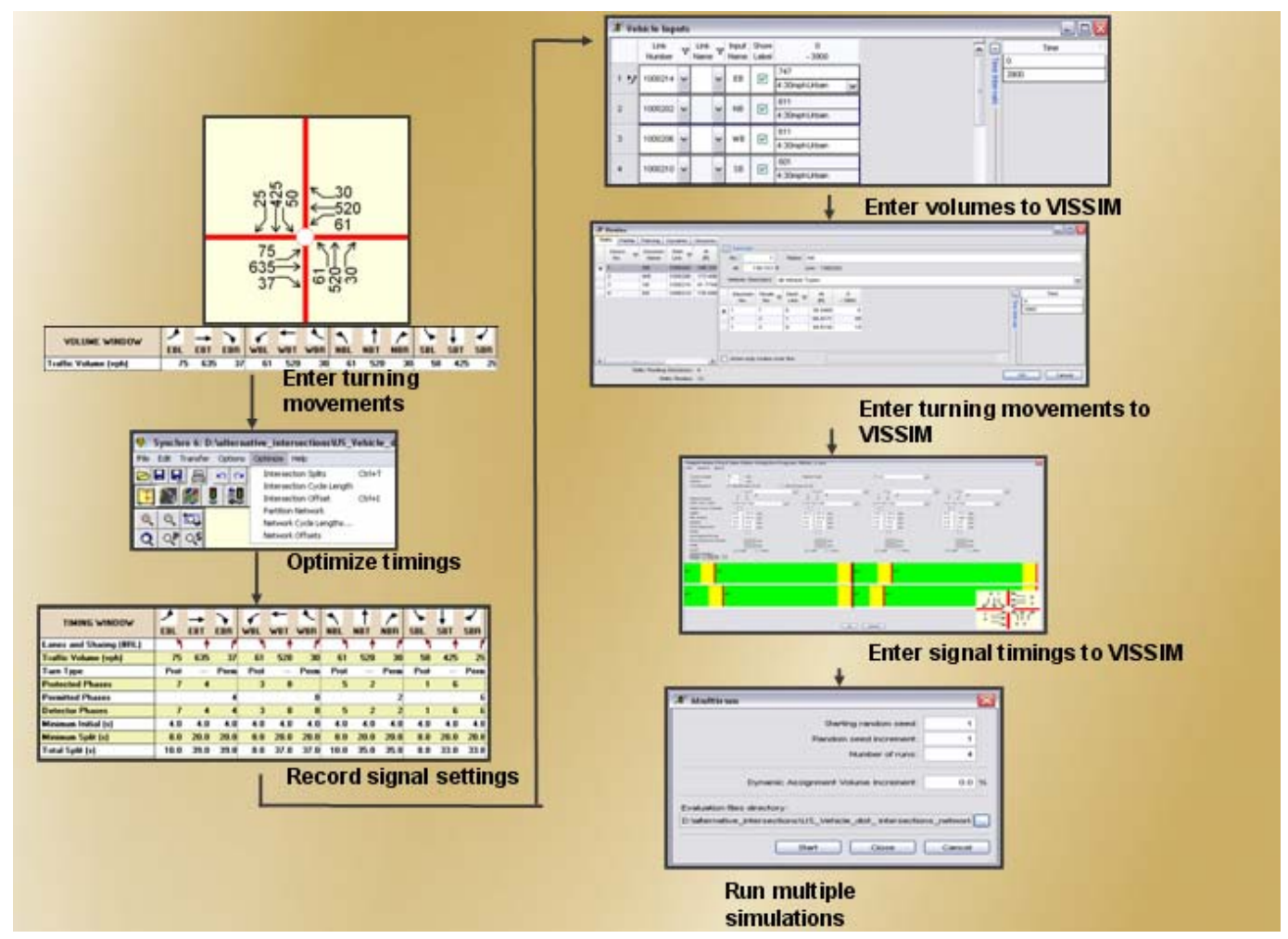

Figure 6-13 Flowchart for running a simulation scenario

The collected measures of effectiveness are total delay, stop delay and average number of stops per vehicle.

Total delay (sec): measures the delay caused by the physical presence of the intersection, other vehicles and geometric delay. Total delay is obtained by subtracting the ideal travel time from the actual travel time on specific movement paths. Ideal travel time is direct movement where vehicle does not need to slow down but proceeds from point A to point $\mathrm{B}$ with desired speed (conventional intersection with no interaction between vehicles). Low speeds caused by geometry and additional distance caused by indirect movements such surface loops or median U-turns add to this delay. The movement delays are averaged for the entire intersection. 
Stop delay (sec) measures the average time a vehicle spends in a standstill position on a specific movement path. This variable is recorded for each movement and then averaged for the entire intersection.

Average Number of Stops (stops/veh): measures number of stops made by a vehicle on specific movement path. This variable is recorded for each movement and then averaged for the entire intersection.

All performance measures are recorded along a movement path which starts 3000 feet upstream of the intersection and ends where the vehicle reaches its desired speed.

Distance downstream of intersection where travel time section end depends on the speed of the roadway on which the travel time section ends (see chapter 5). Travel time section are labeled according to phase labeling on a conventional intersection with right turn movements having a designator of a 100 (Figure 6-14), for example EBR travel time section would be 104 .

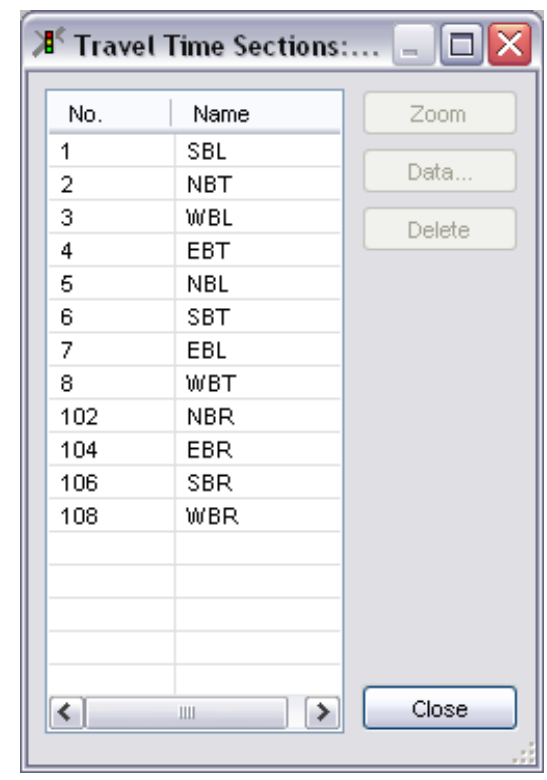

Figure 6-14 Travel time sections definition in VISSIM 
Once results are recorded they have to be extracted and averaged based on four simulation runs for each simulation scenario. Excel was used to extract the results. Since text files had predefined format they could be pasted to Excel in a predefined sheet which averaged the MOE's and weighted them for each movement with the number of vehicles. Intersection average are also computed based on movement averages and weighted with individual movement volumes.

Table 6-3 Sample results for total delay

\begin{tabular}{|c|c|c|c|c|}
\hline $\begin{array}{l}\text { travel time } \\
\text { section }\end{array}$ & $\begin{array}{l}\text { ideal } \\
\text { travel } \\
\text { time }\end{array}$ & $\begin{array}{l}\text { actual } \\
\text { travel } \\
\text { time }\end{array}$ & $\begin{array}{l}\text { Total } \\
\text { delay }\end{array}$ & \# veh \\
\hline 1 & 75.5 & 130.8 & 55.2 & 103 \\
\hline 2 & 85.1 & 103.4 & 18.3 & 1394 \\
\hline 3 & 71.1 & 86.0 & 14.9 & 364 \\
\hline 4 & 60.3 & 73.8 & 13.4 & 3391 \\
\hline 5 & 75.4 & 130.0 & 54.6 & 169 \\
\hline 6 & 85.1 & 103.8 & 18.7 & 1122 \\
\hline 7 & 70.6 & 78.9 & 8.4 & 435 \\
\hline 8 & 60.5 & 75.1 & 14.6 & 2921 \\
\hline 102 & 84.2 & 105.3 & 21.1 & 102 \\
\hline 104 & 69.6 & 72.4 & 2.7 & 202 \\
\hline 106 & 84.2 & 105.9 & 21.7 & 54 \\
\hline 108 & 70.0 & 73.4 & 3.4 & 168 \\
\hline & & Average & 15.7 & \\
\hline
\end{tabular}

Table 6-4 Sample results for stop delay and number of stops

\begin{tabular}{|c|c|c|c|}
\hline $\begin{array}{l}\text { travel time } \\
\text { section }\end{array}$ & $\begin{array}{l}\text { stop } \\
\text { delay }\end{array}$ & stops & \# veh \\
\hline 1.00 & 26.88 & 1.80 & 110.00 \\
\hline 2.00 & 8.47 & 0.64 & 1427.00 \\
\hline 3.00 & 7.53 & 0.91 & 340.00 \\
\hline 4.00 & 4.00 & 0.41 & 3445.00 \\
\hline 5.00 & 27.58 & 1.34 & 168.00 \\
\hline 6.00 & 9.22 & 0.66 & 1156.00 \\
\hline 7.00 & 7.17 & 0.55 & 413.00 \\
\hline 8.00 & 4.02 & 0.38 & 2900.00 \\
\hline 102.00 & 0.11 & 0.01 & 99.00 \\
\hline 104.00 & 1.29 & 0.78 & 207.00 \\
\hline 106.00 & 0.00 & 0.00 & 74.00 \\
\hline 108.00 & 1.58 & 0.84 & 156.00 \\
\hline Average & $\mathbf{5 . 8 9}$ & $\mathbf{0 . 5 2}$ &
\end{tabular}




\section{CHAPTER 7 PRESENTATION OF THE SIMULATION RESULTS}

The number of simulation scenarios was determined by the number of alternative designs (6), locations types (2), lane alternatives (3), intersection splits (2), directional splits (2), left-turn patterns (3), and traffic loads (3). The number of simulation was $6 \times 2 \times 3 \times 2 \times 2 \times 3 \times 3$ $=1,296$. Additional runs were needed for the continuous flow intersections with the traffic load increased to 1.0. These additional runs were performed only for urban locations which generated additional 36 simulation scenarios. Thus, the total number of scenarios was 1,332 . It is worth to note that given one-hour simulation periods repeated four times for each scenario, the total number of simulated hours is $1,332 \times 4=5,328$ hours.

It was extremely important to find a proper way of presenting the simulation results that was practical and did not lose the information obtained. The initial idea was to aggregate the results through statistical modeling to let users predict the expected delays, number of stops, and the likelihood of the capacity failure. Finally, we have decided to present the results in the least aggregated way and with a reasonable interpolation between the obtained simulated "data" points. The important details have not been lost.

The following three measures of effectiveness are presented to the user:

1. Average delay on the busiest intersection approach. This delay includes the effect of the control, traffic queues, and the additional distance covered by indirect leftturning movements. Based on the HCM recommendations, the average delay larger than 80 seconds indicates Level of Service F and the shortage of capacity.

2. Average delay at the intersection represents an overall level of service at the intersection and can be used to compare different design alternatives.

3. Average number of stops can be used as an additional measure of performance following the notion that drivers' perception of traffic quality is affected not only by the delay but also by the number of stops. 
The examples of the results presented in the Guidelines (Volume 2) are shown in Figure 7-1 through Figure 7-2.

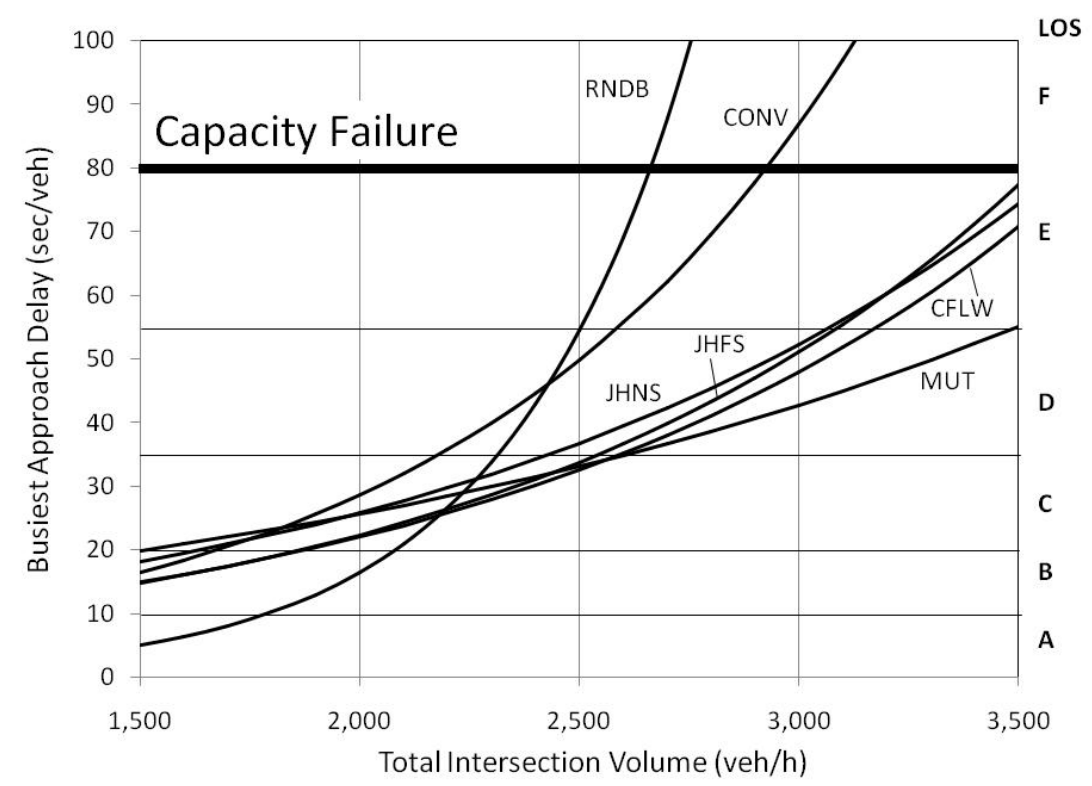

Figure 7-1 Example presentation of the delay at the busiest approach (urban intersection, lanes $2 \times 2$, intersection split 55/45, directional split 55/45, left turns on both roads $10 \%$ ) 


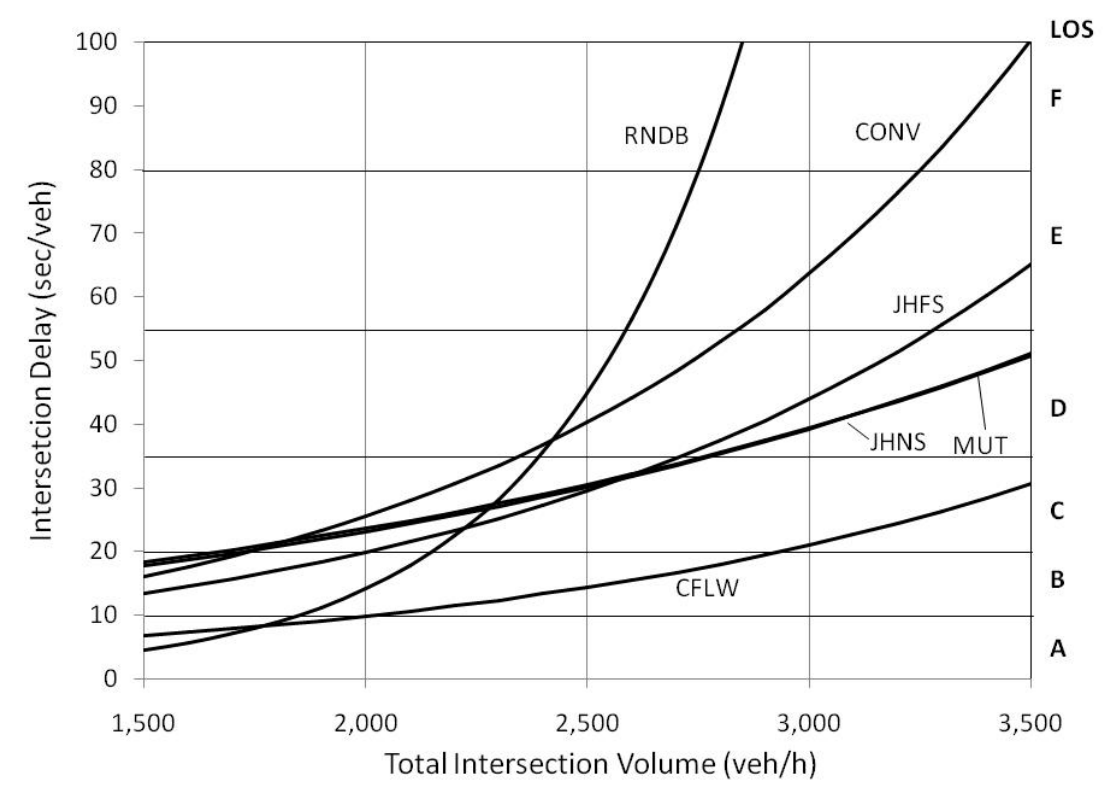

Figure 7-2 Example presentation of the intersection delay (urban intersection, lanes $2 \times 2$, intersection split $55 / 45$, directional split $55 / 45$, left turns on both roads $10 \%$ )

Table 7-1 Example presentation of the number of stops per vehicle (urban intersection, lanes $2 \times 2$, intersection split 55/45, directional split 55/45, left turns on both roads $10 \%$ )

\begin{tabular}{|c|c|c|c|}
\hline \multirow{2}{*}{ DESIGN } & \multicolumn{3}{|c|}{ Total Intersection Volume (veh/h) } \\
\cline { 2 - 4 } & 1730 & 2250 & 3110 \\
\hline CONV & 0.90 & 0.80 & 2.36 \\
\hline CFLW & 0.58 & 0.74 & 0.94 \\
\hline JHFS & 0.63 & 0.68 & 1.12 \\
\hline JHNS & 0.70 & 0.79 & 1.21 \\
\hline MUT & 0.76 & 0.81 & 1.25 \\
\hline RNDB & 0.29 & 0.73 & 11.88 \\
\hline
\end{tabular}

The volume-delay relationships shown in Figure 7-1 and Figure 7-2 are exponential interpolation between three of four point results obtained from the simulation. The curves of the form:

$$
\text { delay }=\exp (\text { par1 } \cdot \text { volume }+ \text { par2 })
$$

have been fitted by minimizing the sum of square errors. The four-hour simulation period for each point result reduces the pseudo random error and allows viewing this fitting more as interpolation then statistical modeling. Most of the times, the fitting error was 
negligible for the purpose. The conventional linear interpolation would be highly insufficient given the strongly non-linear character of the relationship and a limited number of points.

To help the users navigate through the results, each page with a set of the results has a header summarizing the simulation scenario as shown in Table 7-2.

\begin{tabular}{|c|c|c|c|c|c|}
\hline $\begin{array}{l}\text { Location } \\
\text { Through Lanes }\end{array}$ & $\begin{array}{l}\text { Urban } \\
2 \times 2\end{array}$ & $\begin{array}{l}\text { Intersection Split } \\
\text { Directional Split }\end{array}$ & $\begin{array}{l}55 / 45 \\
55 / 45\end{array}$ & $\begin{array}{l}\text { Major Road Left Turns } \\
\text { Minor Road Left Turns }\end{array}$ & $\begin{array}{l}10 \% \\
10 \%\end{array}$ \\
\hline
\end{tabular}

Table 7-2 Example simulation results header

The user is supposed to find the simulation scenario that is the closest to his/her design case. Entering the first graphs with the total volume at the design intersection allows checking which alternative intersections are likely to operate below capacity. Then, entering with the total volume the second graph allows identify the intersections with the lowest overall delay. The table with stops per vehicle gives additional guidance regarding the number of stops. 


\section{CHAPTER 8 CONCLUSIONS}

A systematic overview of the alternative intersection designs is provided in the first part of the Guidelines - a companion volume to this research report. This part presents an extensive study of the existing literature including manuals, research reports, and research publications 12 proposed new intersection designs. The Guidelines summarizes these designs' operational and safety advantages and disadvantages.

The second part of the Guidelines present six most frequently considered alternative designs in 72 local conditions, geometry, and traffic pattern scenarios. Each scenario compares side by side the six alternatives from the point of view capacity, delays, and stops.

The remainder of this chapter summarizes the most important research accomplishments and findings.

The critical gap for Indiana drivers at roundabouts was estimated at four different approaches. Two distinct assumptions were made when estimating drivers' critical gap. First, we assumed that drivers are consistent and will always accept a gap longer than their largest rejected gap. The other assumption investigated was that drivers are not always consistent and will sometimes accept gaps shorter then their largest rejected gap so all gaps rejected by drivers therefore were used to estimate critical gap.

The method for estimation of roundabout turning movements was presented based on counts at the conflict points of each approach lane.

Using field data, a simulation experiment was performed with the calibrated roundabout operational performance to determine the service time of vehicles in the first position in 
the queue. Different critical gaps were tested to determine which critical gap estimate replicates the field-measured service time in the first position.

The effect of different driver behavior parameters of the VISSIM Wiedemann 1999 model was then investigated on follow-up time at a roundabout and the saturation flow rate at signalized intersections. These findings were used to calibrate a roundabout and alternative intersections for Indiana conditions by matching the field-measured follow-up time and the saturation flow rates to the follow-up times and saturation flow rates recorded during simulation.

SYNCHRO and VISSIM network files were built for each signalized intersection and the VISSIM network file for each configuration of a roundabout. All network files were calibrated to Indiana conditions. A uniform procedure across alternatives was developed to aid in the analysis of alternative solutions under any traffic condition and the selection of prospective solutions for future consideration. Impacts other than those to operations were not evaluated, but they should be investigated prior to the implementation of a specific solution.

\subsection{Summary of Findings}

It has been found, based on the roundabout service time simulation that the critical gap estimated with the Maximum Likelihood Method using only gaps gives a reliable replication of field conditions when used in VISSIM simulation. The critical gap estimated for Indiana drivers with the Maximum Likelihood Method using only gaps yielded a critical gap of 3.1 seconds. The average follow-up time for Indiana drivers was estimated at 2.42 seconds. The critical gap and follow-up time for Indiana drivers are shorter than the national values. As drivers in the U.S. become more accustomed to roundabouts their critical gap and follow-up time will converge to the lower values of drivers in Europe, where drivers are accustomed to this intersection solution. Field data 
were collected in a location where the roundabout design has been used for many years so the drivers are familiar with it. The estimated critical gap and follow-up time values are expected to represent therefore the results when this design is implemented and drivers are accustomed to a roundabout, rather than the values right after construction of a roundabout in locations where drivers are not familiar with this design.

A simple matrix method to determine the turning movements at a $2 \times 2$ or $4 \times 2$ roundabouts, based on conflict areas vehicle counts, was presented. This method is much more efficient than determining the turning movements from tracking individual vehicles at a roundabout.

For signalized intersections, two values of the saturation flow were used to represent Indiana drivers in a rural or urban setting. For an urban setting, 1700 vehphpl were assumed and 1900 vehphpl for a rural setting. The assumed values have been taken from field data based on previous research in Indiana. Three different sets of driver behavior parameters were used in VISSIM to obtain the target saturation flow rates for each speed.

The uniform evaluation procedure for evaluating alternative intersections in Indiana was presented and complemented with an example. This procedure provides a fair comparison of all solutions across the board. For each traffic pattern, signal timing was first optimized in SYNCHRO and then entered to VISSIM for evaluation of the intersection. The total delay, the average number of stops per vehicle, and the average stop delay per vehicle serve as performance measures when evaluating different solutions under specified traffic conditions.

\subsection{Conclusions and Recommendations}

The critical gap estimated with observed gaps using the Maximum Likelihood Method yields the most reliable estimate to be used in VISSIM simulation. 
The matrix method is an efficient estimation technique for roundabout turning movements without the need for tracking individual vehicles on the roundabout entry and exit approaches.

The procedure for evaluating alternative intersections for Indiana conditions was presented and complemented with simulation networks calibrated to Indiana conditions. Calibration to Indiana conditions was performed based on the follow-up time and critical gaps for roundabouts and based on the saturation flow rate for signalized intersections. This procedure should serve as the basis for evaluating alternative intersections under any traffic conditions and for comparison across different analyzed solutions.

The measures used to determine which solution works or does not work are the average intersection delay, the average intersection stop delay, and the average number of stops per vehicle. The average intersection delay yields the overall performance of the intersection while the stop delay generally reflects the perception of drivers. The above measures were also collected for each movement to determine if any movement does not experience excessive delays. If all movements meet the desired maximum delay criteria, then the overall intersection delay determines which intersection is the preferred solution. The maximum delay criterion is based on the engineer's judgment and depends on the intersection location and a driver's maximum delay expectation at that location.

The use of VISSIM when determining MOEs for the evaluation of alternative solutions was critical since unconventional movements require custom defined paths for which measures were collected to fully and fairly compare them to a conventional solution. The measures for each provided network file were collected along each movement to a point downstream of the intersection where vehicles reach their desired speed.

Sample simulation runs of a roundabout and a conventional intersection revealed that at low entering volumes (up to $1,600 \mathrm{veh} / \mathrm{h}$ ), roundabouts will outperform conventional 
intersections in terms of all of the used MOEs. As the entering volume increases $(2,450$ $\mathrm{veh} / \mathrm{h}$ ), a conventional intersection will still serve this demand while a roundabout might fail. At high volumes $(2,450 \mathrm{veh} / \mathrm{h})$, roundabouts are sensitive to left turns while at low volumes $(1,600 \mathrm{veh} / \mathrm{h})$ left turns have no impact on roundabout performance.

\subsection{Future Research Needs}

Most of the presented alternative intersections were tested in simulation with fixed time controllers optimized for a particular traffic pattern. While a great deal of research has been conducted for conventional intersections with free operation, not much is known about the actuation of alternative intersections. Investigation of alternative intersections under actuation could result in different procedures for each intersection while still providing a fair comparison across all solutions.

The median u-turn and superstreet intersections, were simulated in an arterial corridor using field-collected data while other solutions were not. Simulation testing of alternative intersections in arterial corridors requires more investigation.

If future versions of VISSIM allow the user to enter the distribution of the minimum time headway (critical gap) at the yield bar. Additional research is needed to determine if the inconsistency would affect the results when comparing between the Maximum Likelihood Method and the Tarko Method.

All VISSIM network files developed for this research were implemented with NEMA controllers so investigation of signal actuated operation could be performed by switching the controllers from pre-timed to free operation mode. 
LIST OF REFERENCES 


\section{CHAPTER 9 LIST OF REFERENCES}

American Association of State Highway and Transportation Officials (AASHTO). (1999). Guide for the Development of Bicycle Facilities. Washington, D.C.: American Association of State Highway and Transportation Officials.

Bared, J.G. \& Edara. (2005). Simulated Capacity of Roundabouts and Impact of Roundabouts within progressed signalized road. In Transportation Research Circular EC083: National Roundabout Conference Proceedings, Vail, CO, May 22-25, 2005. Washington, DC: TRB, NRC.

Bared, J. G., \& Kaisar, E. I. (2000). Benefits of the Split Intersection. CD-ROM Compendium of Papers, $79^{\text {th }}$ Annual Meeting. Transportation Research Board (TRB), National Research Council, Washington D.C.

Bared, J. G., \& Kaisar, E. I. (2002). Median U-turn design as an alternative treatment for left turns at signalized intersection. ITE Journal, 72(2), 50-54.

Boone, J.L., \& Hummer, J.L. (1995). Calibrating and Validating Traffic Simulation Models for Unconventional Arterial Intersection Designs. In Transportation Research Record 1500. Transportation Research Board, National Research Council, Washington D.C., pp. 184-192.

Boone, J.L., \& Hummer, J.L. (1995). Unconventional Design and Operation Strategies for Over-Saturated Major Suburban Arterials. FHWA/NC/94-009, North Carolina Department of Transportation and Federal Highway Administration, Raleigh, North Carolina. 
Brilon, W., Koenig, R., Troutbeck, R. (1999). Useful estimation procedure for critical gaps. Transportation Research Part A: Policy and Practice, Volume 33, Number 3, April 1999, pp. 161-186.

Chapman, J. and Benekohal, R. (2002). Roundabouts Warrants a Proposed Framework for Future Development. In Transportation Research Record 1801. Transportation Research Board, National Research Council, Washington D.C., pp.39-45.

Eisenman, S., \& List, G. (2004). A Comparison of Operational Data and Performance Model Predictions for Several US Roundabouts. CD-ROM Compendium of Papers, 83rd Annual Meeting. Transportation Research Board (TRB), National Research Council, Washington D.C.

Flannery, A., Elefteriadou, L., Koza, P., \& McFadden, J. (1998). Safety, Delay and Capacity of Single Lane Roundabouts in the United States. In Transportation Research Record 1646. Transportation Research Board, National Research Council, Washington D.C., pp.63-70.

Goldblatt, R., Mier, F., \& Friedman, J. (1994). Continuous Flow Intersections. ITE Journal, 64, 35-42.

Hummer, J.E. (1998). Unconventional Left-Turn Alternatives for Urban and Suburban Arterials. Part One. ITE Journal, 68(9), 26-29.

Hummer, J.E. (2000). Operational Effects of New "Double Wide" Intersection Design on Suburban Arterials. CD-ROM Compendium of Papers, $79^{\text {th }}$ Annual Meeting. Transportation Research Board (TRB), National Research Council, Washington D.C.

Hummer, J.E., \& Reid, J.D. (2000). Unconventional Left-Turn Alternatives for Urban and Suburban Arterials: An Update. In Transportation Research Circular E-C019: Urban Street Symposium Conference Proceedings, Dallas, TX, June 28-30, 1999. Washington, DC: TRB, NRC. 
Jagannathan, R. (2007). Synthesis of the Median U-Turn Intersection Treatment, Safety, and Operational Benefits. McLean, VA U.S. Department of Transportation, Federal Highway Administration, TechBrief, FHWA-HR-08-033.

Jagannathan, R., \& Bared, J.G. (2004). Design and Operational Performance of the Crossover Displaced Left-Turn (XDL) Intersection (Also Called Continuous Flow Intersection (CFI)). Presented at the 2004 TRB Annual Meeting, Washington, DC.

Jagannathan, R., \& Bared, J.G. (2005). Design and Performance Analysis of Pedestrian Crossing Facilities for Continuous Flow Intersections (CFI). CD-ROM Compendium of Papers, $84^{\text {th }}$ Annual Meeting. Transportation Research Board (TRB), National Research Council, Washington D.C.

Johnson, M. \& Hange, W. (n.d). Modern Roundabouts intersections: When to use them? A comparison with signalized intersections. Retrieved December 2007 from Web Site: http://www.k-state.edu/roundabouts/news/ITEPaper.pdf

Levinson, H. S., Koepke, F. J., Geiger, D., Allyn, D., \& Palumbo, C. (2000). Indirect Left Turns-The Michigan Experience. Access Management Conference, Portland, Oregon.

Lindgren, R.V., \& Tantiyanugulchai, S. (2003). Microscopic simulation of traffic at a suburban interchange. Institute of Transportation Engineers 2003 Annual Meeting, Seattle, Washington.

Lownes, N., \& Machemehl, R. (2006). VISSIM: A multi-parameter sensitivity analysis. Winter Simulation Conference, Vol. 3, pp.1406-1413.

Mereszczak, Y., Dixon, M., Kyte, M., Rodegerdts, L., \& Blogg, M. (2006). Including Exiting Vehicles in Capacity Estimation at Single-Lane U.S. Roundabouts. In Transportation Research Record 1998, TRB, National Research Council, Washington D.C., pp.23-30. 
Michigan Department of Transportation. (n.d.). Bureau of Highways Design Guide for Crossovers. Retrieved December 2007 from Web Site:

http://www.mdot.state.mi.us/tands/plans.cfm

Nichols, A. \& Bullock, D. (2001). Design Guidelines for Deploying Closed Loop Systems. Joint Transportation Research Program (JTRP), SPR 2390.

Ourston, L., \& Hall, G. (2003). Roundabouts increase interchange capacity. In Transportation Research Record 1858, TRB, National Research Council, Washington D.C., pp.112-117.

Perez-Cartagena, R., \& Tarko, A. (2004). Predicting Traffic Conditions at Indiana Signalized Intersections, SPR-2796, Report No. FHWA/IN/JTRP-2004/29, September 2004.

Polus, A. \& Cohen, R. (1997). Operational Impact of Split Intersections. In Transportation Research Record 1579. TRB, National Research Council, Washington D.C.

Polus, J., Lazar, S., \& Livneh, M. (2003). Critical Gap as a Function of Waiting Time in Determining Roundabout Capacity. Journal of Transportation Engineering, 129, 504509.

PTV_Vision. (2007). VISSIM User's Manual, Version 4.30, 2007.

Reid, J. (2000). Using Quadrant Roadways to Improve Arterial Intersection Operations. ITE Journal, 70(6), 34-45.

Reid, J.D., \& Hummer, J.E. (2001). Travel Time Comparisons between Seven Unconventional Arterial Intersection Designs. In Transportation Research Record 1751. TRB, National Research Council, Washington D.C. 
Reid J.D., Brinckerhoff, P., \& Hummer, J.E. (1999). Analyzing System Travel Time in Arterial Corridors with Unconventional Design Using Microscopic Simulation. In Transportation Research Record 1678, TRB, National Research Council, Washington D.C., pp.208-215.

Retting, R.A., Lutterell, G., \& Russell, E.R. (2002). Public Opinion and Traffic Flow Impacts of Newly Installed Modern Roundabouts in the United States. ITE Journal 72(9).

Robinson, B.W., Rodegerdts, L., Scarbrough, W., Kittelson, W., Troutbeck, R., Brilon, W., Bondzio, L., Courage, K., Kyte, M., Mason, J., Flannery, A., Myers, E., Bunker, J., \& Jacquemart, G. (2000). Roundabouts: An Informational Guide. Report No. FHWARD-00-067. Washington, DC: United States Department of Transportation, Federal Highway Administration.

Rodegerdts, L.A., Blogg, M., Wemple, E., Myers, E., et al. (2007). Roundabouts in the United States. Washington D.C., National Cooperative Highway Research Program (NCHRP), Transportation Research Board, Report 572.

Rouphail, N., Hughes, R., \& Chae, K. (2005). Exploratory Simulation of pedestrian Crossings at Roundabouts. Journal of Transportation Engineering, 131, 211-218.

Russell, E., Retting, R.A., McCartt, A.T., \& Srinivas, M. (2006). Traffic Flow and Public Opinion: Newly Installed Roundabouts in New Hampshire, New York, and Washington. CD-ROM Compendium of Papers, $85^{\text {th }}$ Annual Meeting. Transportation Research Board (TRB), National Research Council, Washington D.C.

Russell, E., Rys, M., \& Luttrell, G. (2002). Kansas Roundabout Reluctance. Submitted to the $81^{\text {st }}$ Annual Meeting of the Transportation Research Board. Transportation Research Board, National Research Council, Washington, D.C.

Stanek, D., \& Milam, R. (2005). High-Capacity Roundabout Intersection Analysis: Going Around in Circles - Draft. National Roundabout Conference, Vail, CO. 
Tabernero, V., \& Sayed, T. (2006). Upstream Signalized Crossover Intersection: An Unconventional Intersection Scheme. Journal of Transportation Engineering. 132(11), 907-911.

Tabernero, V., Sayed, T., \& Kosicka, D. (2008). Introduction and Analysis of a New Unconventional Intersection Scheme, the Upstream Signalized Crossover (USC) Intersection. CD-ROM Compendium of Papers, $87^{\text {th }}$ Annual Meeting. Transportation Research Board (TRB), National Research Council, Washington D.C.

Tarek, S., Paul, S., \& Godwin, W. (2006). Upstream Signalized Crossover Intersection: Optimization and Performance Issues. In Transportation Research Record 1961. TRB, National Research Council, Washington D.C, pp.44-54.

U.S. Departament of Transportation. (2004). Federal Highway Administration. "Signalized Intersections: Informational Guide." Chapter 10.

\section{RELATED LITERATURE}

American Association of State Highway and Transportation Officials (AASHTO). (1999). Guide for the Development of Bicycle Facilities. Washington, D.C.: American Association of State Highway and Transportation Officials.

Dobbour, E. \& Easa, S. (2006). Proposed geometric improvements to safety of modern roundabouts. CD-ROM Compendium of Papers, $85^{\text {th }}$ Annual Meeting. Transportation Research Board (TRB), National Research Council, Washington D.C. 
Dorothy, P., Maleck, W., \& Nolf, S. (1997). Operational Aspects of Michigan design for Divided Highways. In Transportation Research Record 1579. Transportation Research Board, National Research Council, Washington, D.C., pp. 18-26.

Harkey, D.L., \& Carter, D.L. (2006). Observational analysis of bicyclist and motorist behavior at roundabouts in the United States. In Transportation Research Record 1982. Transportation Research Board, National Research Council, Washington D.C., pp.155165.

Hildebrand, T. (2007). Unconventional intersection design for improving through traffic along the arterial road. Master thesis FSU, Dec 2007.

Hummer, J.E. (1998). Unconventional Left-Turn Alternatives for Urban and Suburban Arterials. Part Two. ITE Journal, 68(11).

Hummer, J.E., \& J. Boone. (1995). Travel Efficiency of Unconventional Arterial Intersection Design. In Transportation Research Record 1500. Transportation Research Board, National Research Council, Washington D.C., pp. 153-161.

Kim, T., Edara, P., Bared, J. (2007). Operational and Safety Performance of a NonTraditional Intersection Design: The Superstreet. CD-ROM Compendium of Papers, $86^{\text {th }}$ Annual Meeting. Transportation Research Board (TRB), National Research Council, Washington D.C.

New Jersey Department of Transportation. (n.d.). Roadway Design Manual. Retrieved September 20, 2007 from Web Site:

http://www.state.nj.us/transportation/eng/documents/RDME/sect6E2001.shtm\#JUGHAN DLES

Thompson, C.D. \& Hummer, J.E. (2001). Guidance on the Safe Implementation of Unconventional Arterial Designs: Draft Final Report. North Carolina State University. 
APPENDICES 


\section{APPENDIX}

This section is a summary based on previous research tools available to analyze roundabouts.

\section{APPENDIX A:}

\section{CAPACITY}

Red Clearance $=\frac{W+L}{1.47 * V_{V}}$

$\mathrm{W}$-Width of crossing roadway (feet)

L- Length of vehicle (feet)

$\mathrm{V}_{\mathrm{V}}$-Speed of vehicle (mph)

Ped Clearance $=\frac{W}{V_{P}}$

W-Width of crossing roadway (feet)

$\mathrm{V}_{\mathrm{P}}$-Assumed speed of crossing pedestrian $(\mathrm{feet} / \mathrm{sec})$

\section{ROUNDABOUTS}

To determine roundabout capacity for single lane sites, Equation A.1 can be used [0]:

$$
\begin{aligned}
& c=1130 \cdot \exp \left(-0.0010 \cdot \mathrm{v}_{c}\right), \text { where } \\
& C=\text { entry capacity (passenger car units }[\mathrm{pcu}] / \mathrm{h}) \\
& v C=\text { conflicting flow }(\mathrm{pcu} / \mathrm{h})
\end{aligned}
$$

Knowing the local values of critical headway and follow-up headway, engineers can predict capacity more accurately by substituting these values into Equation A.2, which is exactly the same as the equation above but calibrated to local conditions (Rodegerdts et al., 2007). 
$c=\mathrm{A} \cdot \exp \left(-\mathrm{B} \cdot \mathrm{v}_{c}\right)$, where

$C=$ entry capacity $(\mathrm{pcu} / \mathrm{h})$

Equation A.2

$A=3600 / t f$

$B=\left(t_{c}-t_{f} / 2\right) / 3600$

$v_{c}=$ conflicting flow $(\mathrm{pcu} / \mathrm{h})$

$t_{f}=$ follow-up headway (s)

$t_{c}=$ critical headway $(\mathrm{s})$

To determine roundabout capacity for a critical lane of multilane roundabouts entering into two circulatory roadways can be estimated using Equation A.3 (Rodegerdts et al., 2007):

$c=1130 \cdot \exp \left(-0.007 \cdot \mathrm{v}_{c}\right)$, where

Equation A.3

$c=$ entry capacity of critical lane (passenger car units $[\mathrm{pcu}] / \mathrm{h}$ )

$v c=$ conflicting flow $(\mathrm{pcu} / \mathrm{h})$

If field data for control delay is not available, delay can be estimated.

$$
d=\frac{3600}{c}+900 \cdot T\left[\frac{v}{c}-1+\sqrt{\left(\frac{v}{c}-1\right)^{2}+\frac{\left(\frac{3600}{c}\right) \cdot \frac{v}{c}}{450 \cdot T}}\right]
$$

Equation A.4

$d=$ average control delay ( $\mathrm{s} / \mathrm{veh})$

$c=$ capacity of subject lane $(\mathrm{veh} / \mathrm{h})$

$T=$ time period (h: $T=1$ for 1 -h analysis, $T=0.25$ for 15 -min analysis)

$v=$ flow in subject lane $(\mathrm{veh} / \mathrm{h})$

The FHWA methodology and RODEL employ the U.K. empirical regression equations, rather than the gap acceptance factors or lane configuration. RODEL uses six geometric parameters: entry width, length of flare, upstream roadway width, diameter, curb return radius, and entry angle. aaSIDRA uses gap acceptance to estimate capacity. VISSIM and 
Paramics are microsimulation packages which allow the user to calibrate the results through network coding and adjustment of gap time and space headway.

The VISSIM microsimulation tool can model U.S. roundabouts more accurately then European data based on tools like RODEL an aaSIDRA for high volume conditions (Bared and Edara, 2005; Flannery et al., 1998). When comparing these tools (VISSIM, RODEL, aaSIDRA) in terms of capacity predictions, all models behave in a similar manner; and if graphed plots run parallel to each other, the only difference is that VISSIM predictions are lower than the other two models and replicate U.S. conditions better. This indicates that by reducing the predictions of RODEL and aaSIDRA by the appropriate amount, we would obtain more reasonable capacity predictions for U.S. roundabouts. For dual-lane roundabouts, this value is about 500vph (Bared and Edara, 2005). However, it should be noted that European drivers are more accustomed to roundabouts and over time drivers in the U.S. might change their gap acceptance behavior and higher capacity predictions as exist for drivers in Europe. It should also be noted that aaSIDRA predictions are close to U.S. data for low volume sites (Flannery et al., 1998). Since aaSIDRA is based on gap acceptance at low volume sites, this parameter does not have the same influence on results as for high volume locations where aaSIDRA underestimates delay.

Macroscopic methods (FHWA, RODEL and aaSIDRA) can be used to analyze highcapacity roundabouts for unsaturated conditions or isolated locations with standard geometry (Stanek and Milam, 2005). On the other hand, microsimulation provides more accurate results but requires detailed calibration to accurately analyze the system effects. Situations which warrant the use of microsimulation tools include closely spaced intersections, freeway ramps, and skewed approaches which are caused by constrained geometry. These factors would have been ignored when using FHWA methodology, RODEL or aaSIDRA (Stanek and Milam, 2005). 
VISSIM has been proven to provide accurate results when simulating roundabouts located at the off-ramps of a diamond interchange. Delay and travel time will be consistent with the HCM 2000 methodology (Lindgren and Tantiyanugulchai, 2003).

When utilizing the HCM 2000 procedure for estimating roundabout capacity, 100 percent of the exiting vehicles should be included in the conflicting flow (Mereszczak et al., 2006), unless a high proportion of exiting vehicles occur on a particular approach so that lower proportion of exiting vehicles can be included.

The procedure for estimating entry speed ( $V 1 p)$, through movement circulating speed $(V 2 p)$, through-movement exit speed (V3p), and left-turn-movement circulating speed $(V 4 p)$ on a roundabout can be found in Chapter 5 of (Rodegerdts et al., 2007). These predictions will allow designers to estimate what speeds should be expected on a roundabout and the consistency of all elements of a design. 
JOINT TRANSPORTATION RESEARCH PROGRAM

FHWA/IN/JTRP-2008/23

Final Report

SAFETY AND OPERATIONAL IMPACTS OF ALTERNATIVE INTERSECTIONS

VOLUME 2

GUIDELINES FOR USING INTERSECTION

ALTERNATIVE DESIGNS FOR INDIANA

Andrew P. Tarko

Mike Inerowicz

Natalie Villwock

December 2008 
Final Report

FHWA/IN/JTRP-2008/23

\title{
SAFETY AND OPERATIONAL IMPACTS OF ALTERNATIVE INTERSECTIONS
}

\author{
Volume 2 \\ Guidelines for Using Intersection Alternative Designs for Indiana \\ By \\ Andrew P. Tarko \\ Professor \\ Mike Inerowicz \\ Graduate Research Assistant \\ Natalie Villwock \\ Graduate Research Assistant \\ School of Civil Engineering \\ Purdue University \\ Joint Transportation Research Program \\ Project No. C-36-17ZZ \\ File No. 8-5-52 \\ SPR-3102 \\ Conducted in Cooperation with the \\ Indiana Department of Transportation and the \\ U.S. Department of Transportation \\ Federal Highway Administration
}

The contents of this report reflect the views of the authors, who are responsible for the facts and the accuracy of the data presented herein. The contents do not necessarily reflect the official views or policies of the Indiana Department of Transportation or the Federal Highway Administration at the time of publication. The report does not constitute a standard, specification, or regulation.

\author{
Purdue University \\ West Lafayette, Indiana
}

December 2008 


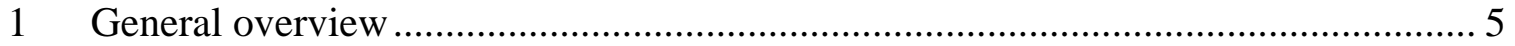

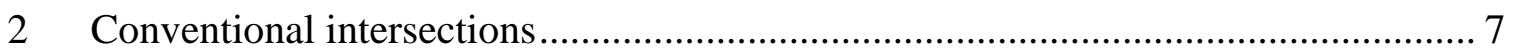

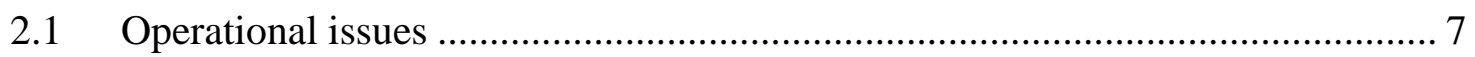

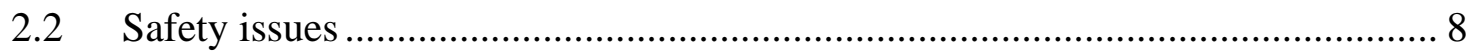

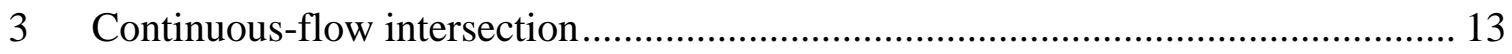

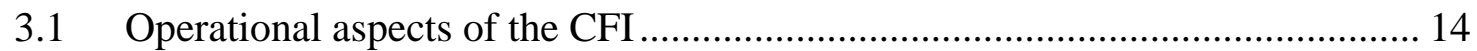

3.2 Safety Impacts of the Continuous-Flow Intersection .................................... 16

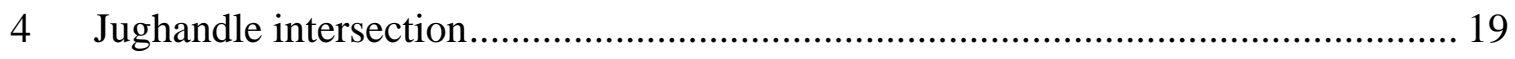

4.1 Operational aspects of a Jughandle ............................................................. 22

4.2 Safety Impacts of the Jughandle............................................................... 24

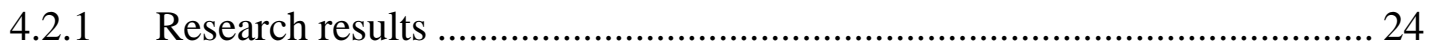

4.2.2 Potential conflict point diagrams for jughandle intersections.................... 25

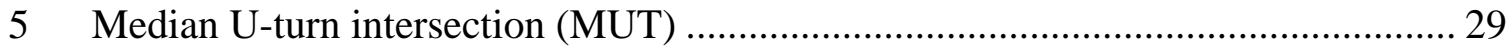

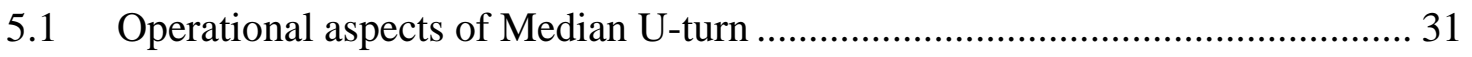

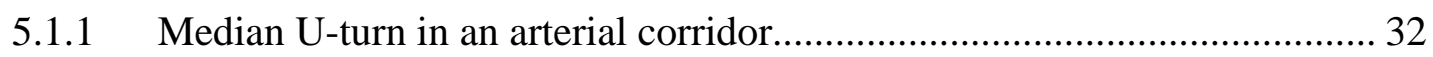

5.2 Safety Impacts of the Median U-turn ............................................................ 33

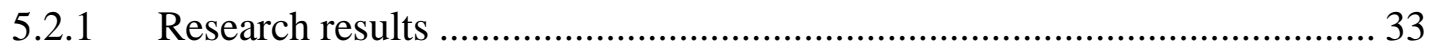

5.2.2 Conflict diagram for the median U-turn ............................................... 35

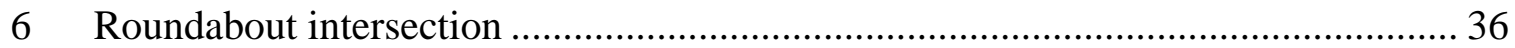

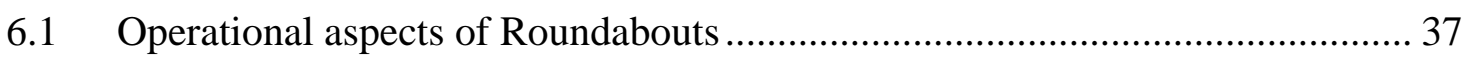

6.2 Safety Impacts of the Roundabout ............................................................ 40

7 Superstreet median (SSM) crossover intersection .............................................. 43

7.1 Operational aspects of the superstreet median .............................................. 44

7.1.1 Superstreet median in an arterial corridor.............................................. 45

7.2 Safety Impacts of the Superstreet Median................................................ 47

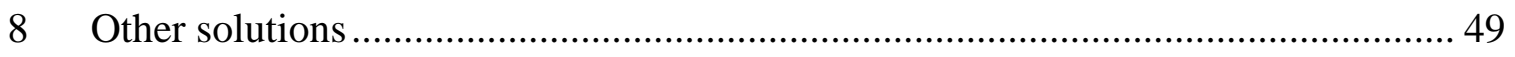

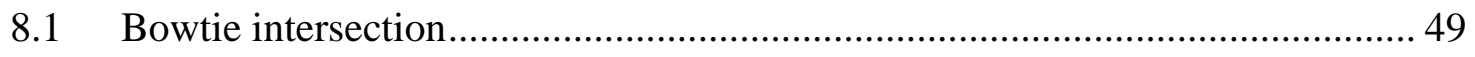

8.1.1 Safety Impacts of the Bowtie Intersection ............................................. 51

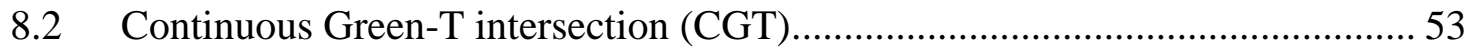

8.2.1 Operational Impacts of the Continuous Green T-Intersection .................... 53

8.2.2 Safety Impacts of the Continuous Green T-Intersection............................ 54 


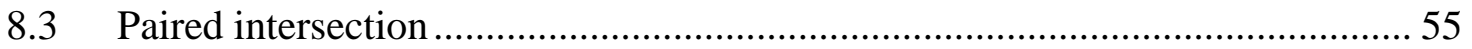

8.3.1 Safety Impacts of the Paired Intersection ……………………………….... 57

8.4 Quadrant roadway intersection (QRI) ............................................................ 59

8.4.1 Safety Impacts of the Quadrant Roadway ……………………………….... 61

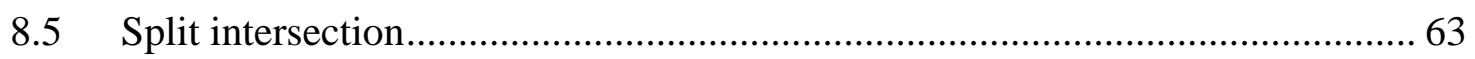

8.5.1 Operational Impacts of the Split Intersection ............................................... 63

8.5.2 Safety Impacts of the Split Intersection ......................................................... 64

8.6 Upstream Signalized Crossover ..................................................................... 66

8.6.1 Operational Impacts of the Upstream Signalized Crossover ......................... 67

8.6.2 Safety Impacts of the Upstream Signalized Crossover................................. 68

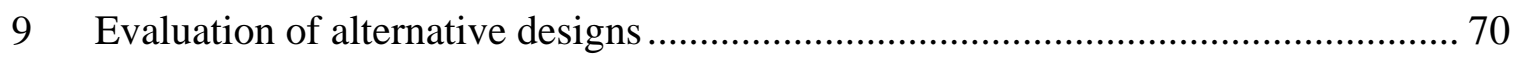

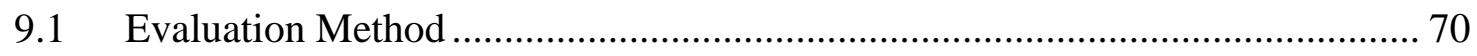

9.2 Exhibits for evaluating alternative intersection designs.................................... 75

10 References...................................................................................................... 150 


\section{Acknowledgements}

The authors would like to express their gratitute to the Study Advisory Committee

members, Rick Drumm, David Lane, Shuo Li, John Nagle, Brad Steckler, Ernie Stoops, and Jim Sturdevant for their guidance. 


\section{General overview}

The need for alternative intersections has developed as a result of a gradual degradation of service and safety at some road intersections where undesirable installation of traffic signals or costly interchanges seem to be the only modernization alternatives if a conventional engineering approach is applied. Alternative intersections, a relatively new concept, are a promising means of reaching for other solutions.

The capacity and safety improvement at alternative intersections comes from a special treatment of the left-turn movements - the frequent source of poor operational and safety conditions at conventional intersections. Signalized intersections may serve as an appealing example. Strong left-turn movements require a separate signal phase to provide sufficient capacity to these movements. This provision inherently takes away considerable capacity from the primary through movements and leads to a considerable deterioration of operations of the whole intersection with associated safety implications.

Many different alternative intersections have been proposed in the literature and some of them implemented on a limited scale. Each alternative intersection design has advantageous and disadvantages. Performance of an alternative intersection strongly depends upon the traffic pattern and other local conditions. Therefore, not a single alternative intersection is superior over all other options and in all cases. In some conditions, even a conventional intersection may be the preferred alternative.

Not all alternative intersections identified in this guideline have been implemented. Some have only been assessed on the conceptual level and their operations evaluated using microscopic simulation.

A problem with evaluating alternative intersections at present is that most of them are fairly new and have been implemented for a short period of time, if at all. Furthermore, 
some installations of the alternative intersections have been only partial implementations. From an operational standpoint, the lack of implemented alternative intersections can be overcome to a certain degree through the use of microsimulation. Safety analyses, on the other hand, are limited as a result of short and infrequent implementations. No current method exists to predict safety without using historical crash data, although there have been some recent attempts to use microsimulation to perform safety analyses. As such, safety is often analyzed using potential conflict point diagrams. Although safety analyses have been performed at some implemented alternative intersections, these analyses are few in number, small in data sets, and often limited to one region or one state.

The purpose of these guidelines is to help Indiana road designers and planners identify alternative intersections that have a potential to improve traffic operations and safety under given conditions. This document includes an overall description of alternative intersection designs along with operational and safety implications of the alternative design. Alternative intersections evaluated in this study are at-grade intersections and include: continuous flow intersections, jughandles, median u-turns, roundabouts, superstreet median crossovers, bowties, continuous green T-intersections, double wide intersections, paired intersections, quadrant roadway intersections, split intersections, and upstream signalized crossover intersections. Solutions that have not been implemented in the field (to knowledge of authors) and have been evaluated only at the conceptual level are placed in the chapter titled "Other solutions."

In this guideline you will find specific conditions which might favor some alternative intersections over other. This document also contains a comparison of alternative intersections with a conventional intersection from the operational and safety perspectives. The user should not treat any solution(s) identified with the guidelines as final. Detail analysis of implications of local conditions supported with micro-simulation and supplemented with good engineering judgment is advised. 


\section{Conventional intersections}

A conventional at-grade intersection can be defined as an intersection where all movements are allowed and direct. The conventional intersection can be a two or fourway stop controlled intersection, or it may be signalized. It may have three or four legs with as few as one traffic lane on each leg or may have many more lanes. Finally, the intersection may be in a rural, suburban, or urban setting.

\subsection{Operational issues}

Conventional unsignalized intersections with strong through movements can serve only a limited number of left turning vehicles as these vehicles have to cross in front of through vehicles coming from the opposite direction. Increasing the number of traffic lanes is typically not an option due to the limited capacity benefit and the adverse effect on safety. Signalized intersections, on the other hand, may require protection of left-turn movements via exclusive left turn phases, thus reducing capacity and increasing delays of primary through movements. Increasing the number of turning lanes at signalized intersections is possible but it is limited to the number of lanes available on the intersection leg which the vehicles desire to enter. Increasing the number of through lanes in the intersection vicinity is possible but not recommended.

In terms of arterial progression, good coordination for conventional intersections with protected turn bays can only be achieved in both directions for even intersection spacing. With uneven intersection spacing, progression can usually be accommodated only in one direction (Figure 2-1). Furthermore, capacity shortage at intersections with coordinated signals dramatically reduces the effectiveness of coordination due to additional stops caused by long vehicle queues. 


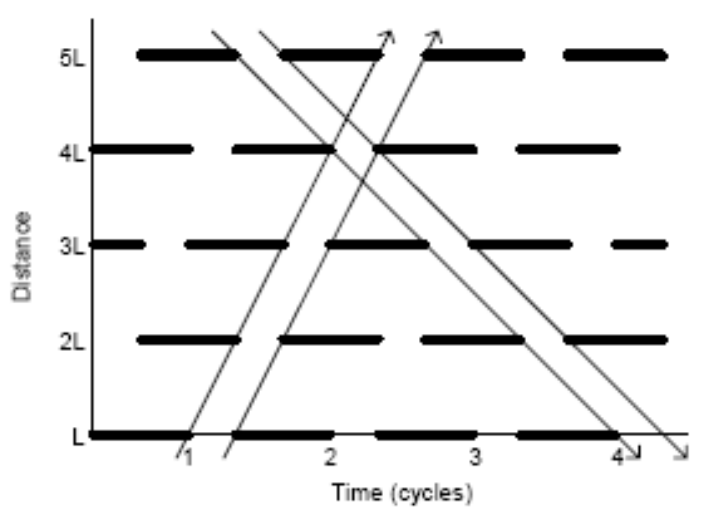

(a) Evenly Spaced Intersections

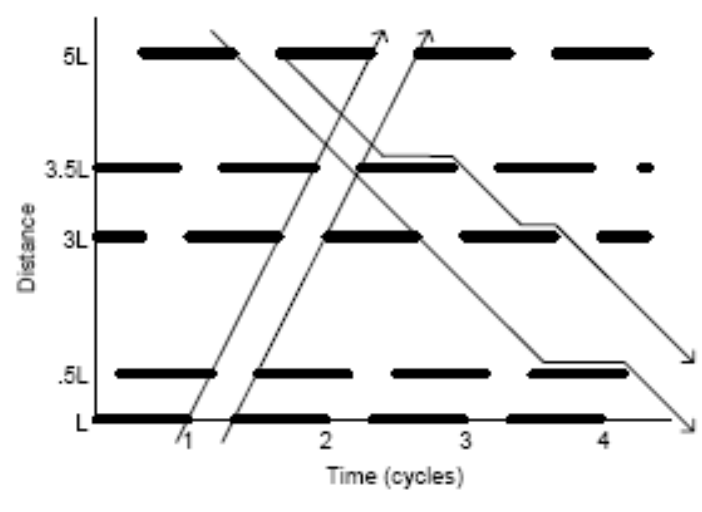

(b) Randomly Spaced Intersections

Figure 2-1 Effect of intersection spacing on progression (Nichols and Bullock, 2001)

\subsection{Safety issues}

Knowledge of safety at alternative intersections is limited due to a short, if any, implementation period of the alternative solutions. Safety at most alternative intersections can be evaluated only qualitatively by comparing potential conflict point diagrams (PCPD) of alternative and conventional intersections. Figure 2-2 shows the potential vehicle-to-vehicle conflict points for a four-legged signalized intersection with one traffic lane approaching from every direction. Figure 2-3 shows the potential vehicle-to-vehicle conflict points for a three-legged signalized intersection with one traffic lane approaching from each direction. To simplify these and other PCPDs, each traffic movement is represented with a single line regardless of the number of traffic lanes used by the movements. Therefore, as lanes are added, the number of potential conflict points will also increase.

Conflict point diagrams provided previously typically separated the conflict points into three categories: crossing, diverging, and merging. The PCPDs that follow further subdivide these categories into whether or not the potential conflict point is expected to lead to a more or less severe collision. In general, diverging and merging conflict points 
tend to be more severe if the merge or diverge occurred between two streams that were close to originating from perpendicular streams. Similarly, crossing conflict points are considered to be more severe when one of the streams of traffic crossed was a through stream. Therefore, when two turning movements cross each other, the crossing potential conflict point is categorized as possibly leading to more severe crashes.

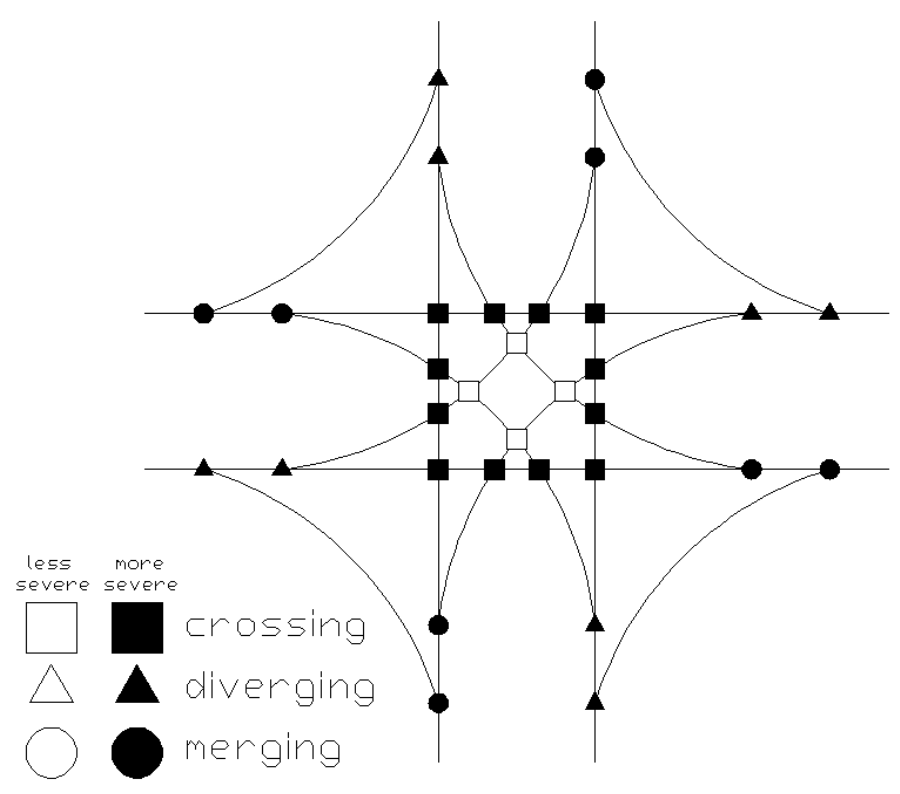

Figure 2-2 A four-legged intersection PCPD, assuming signalization

Figure 2-2 identifies 16 crossing conflict points, 12 of which may lead to more severe collisions. Notice, that as described previously, when two turning movements cross, the potential conflict point is categorized as less severe. There are 8 diverging and merging conflict points, respectively, all which may lead to severe collisions. Again, as described previously, since the merges and diverges are between traffic streams that are perpendicular with each other, the conflict points are expected to cause potentially more severe collisions. Of the three types of potential conflict points, the crossing conflict points may lead to the most severe collisions; therefore, eliminating these types of conflict points or reducing the expected severity is desirable. 


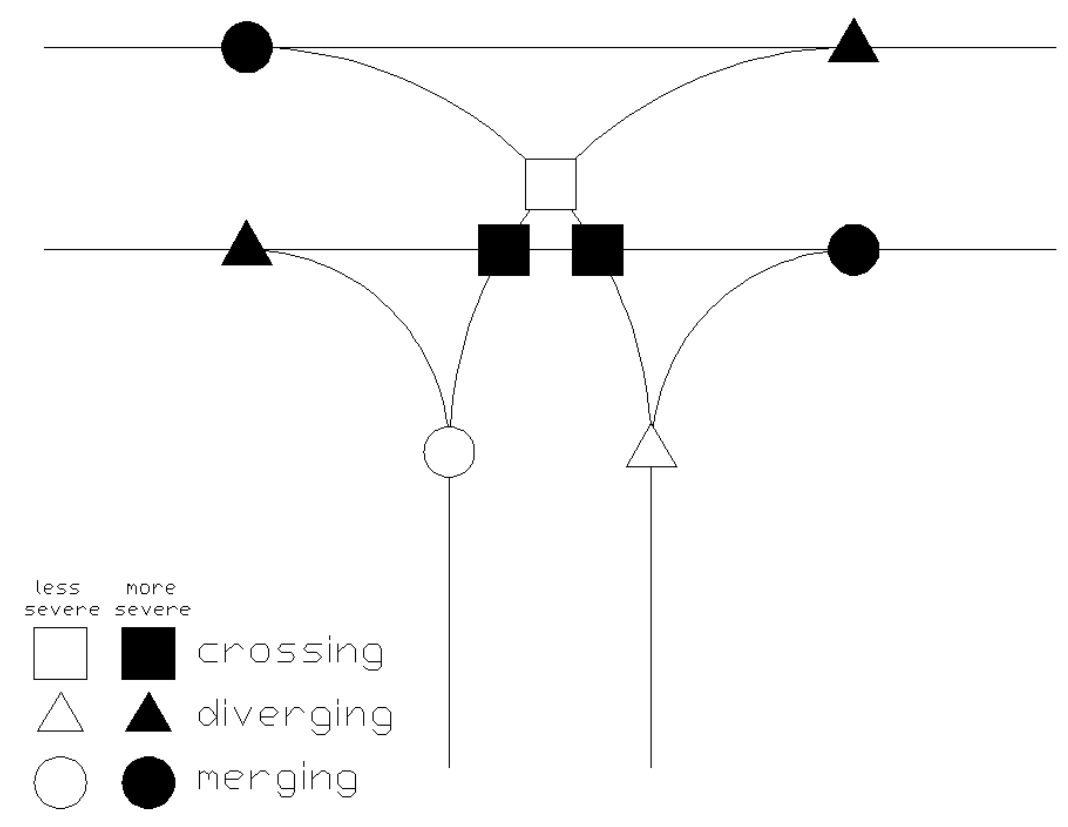

Figure 2-3 A T-intersection PCPD, assuming signalization or stop control on the discontinuous leg

Figure 2-3 identifies 3 crossing potential conflict points, 2 of which may lead to more severe collisions. There are 3 diverging potential conflict points, 2 of which may lead to severe collisions. There are 3 merging potential conflict points, again 2 of which may lead to severe collisions.

\section{PEDESTRIANS}

Another aspect that must also be considered when comparing conventional solutions to alternative intersections on the basis of safety is vehicle to pedestrian conflicts. Figure 2-4 below shows the pedestrian/vehicle conflict points for a four-legged, signalized intersection with one approach lane from each direction. As can be seen from the figure, there are 4 potential conflict points for each leg of the intersection, for a total of 16 pedestrian/vehicle potential conflict points. 


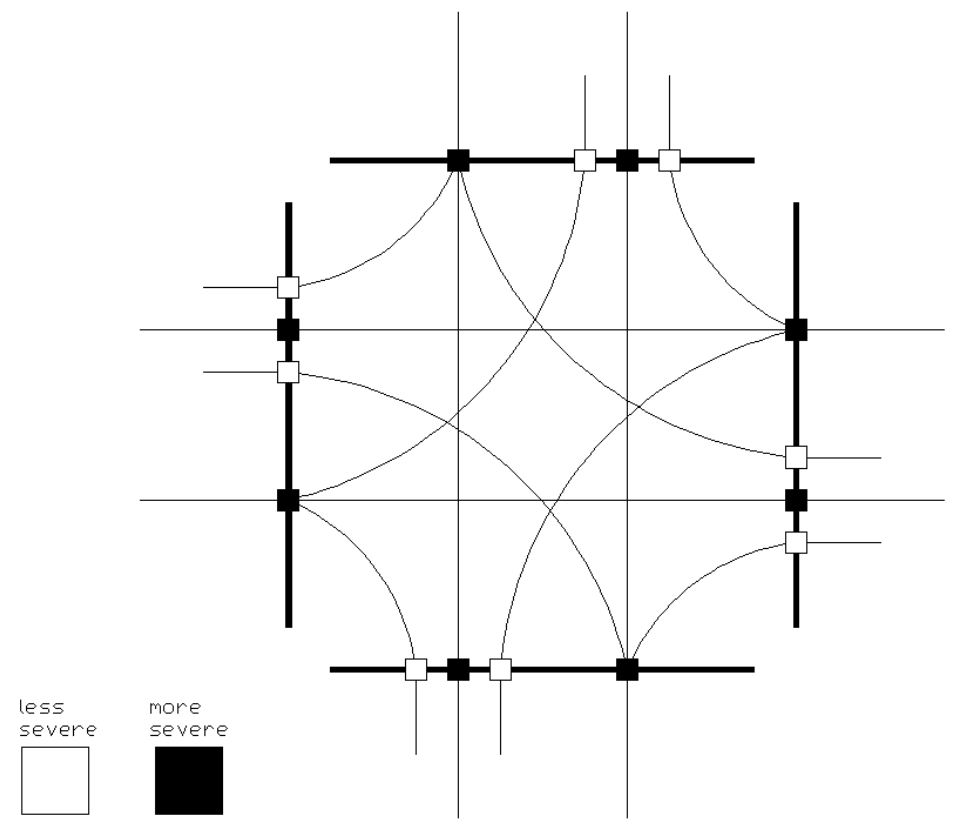

Figure 2-4 Pedestrian/vehicle conflict points for a four-legged intersection

\section{BICYCLES}

Bicycle traffic is another important consideration at intersections. If a bicyclist travels to the right of the through travel lane, rather than as a vehicle, they pass more potential crossing conflict points than a through vehicle does. For example, Figure 2-5 shows the crossing conflict points that a bicycle encounters when completing a left-turn and through movement. The bicycle movements are identified by the thicker lines. As shown in the figure, some of the additional crossing conflict points are the result of crossings between the bicycle and turning vehicle paths. Furthermore, when a bicyclist turns left, a bicyclist typically crosses the through traffic to remain to the outside of the traveled way. Therefore, the bicyclist is exposed to additional crossing conflicts. 


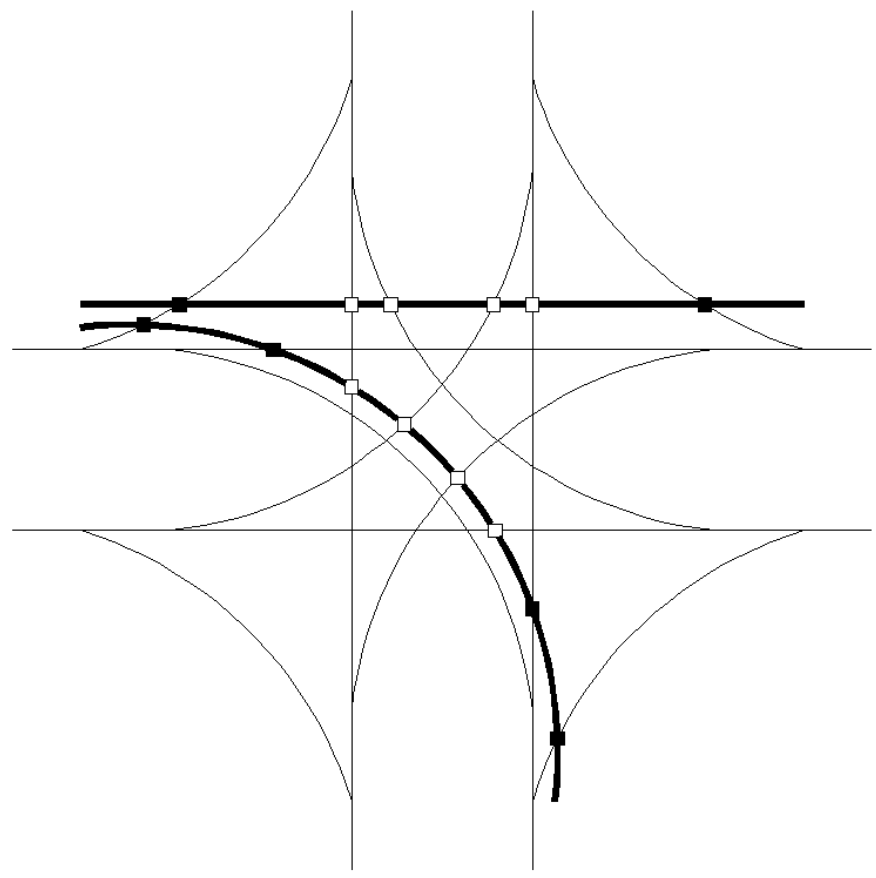

Figure 2-5 Bicycle/vehicle potential conflict points for a four-legged intersection 


\section{Continuous-flow intersection}

A continuous-flow intersection (CFI), sometimes called the crossover-displaced leftturn (XDL) intersection, provides left-turn connectors between the arterial and cross streets placed upstream of the intersection and to the left of the street. Figure 3-1 demonstrates how left and right-turning vehicles from Major Street (a) and Minor Street (b) would traverse the intersection.

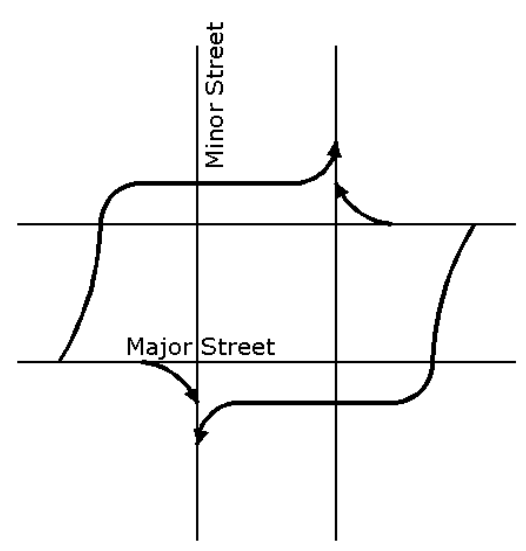

(a) Major Street Turning Movements

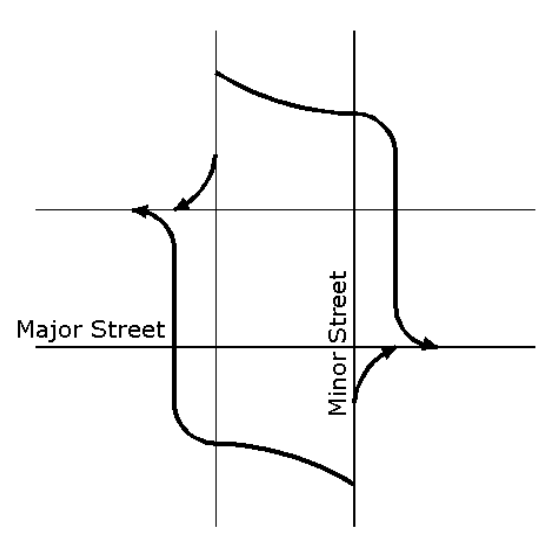

(b) Minor Street Turning Movements

Figure 3-1 Vehicle movement at a full continuous-flow intersection

Partial continuous-flow intersections have been implemented. A partial CFI has left-turn connectors on the major roadway and no connectors on the minor roadway.

The major advantage with this design is that through traffic and traffic using the left-turn connector can move during the same signal phase without conflict. The signals at the connectors should be coordinated with the primary intersection signal so through arterial traffic does not stop more than once. A single signal controller which operates the primary intersection and left-turn connector/minor street intersection (Figure 3-2) helps to achieve this coordination. The left-turn connector should cross the opposing traffic at a point which prevents spill back from the primary intersection which would result in blockage of the crossover signal. 


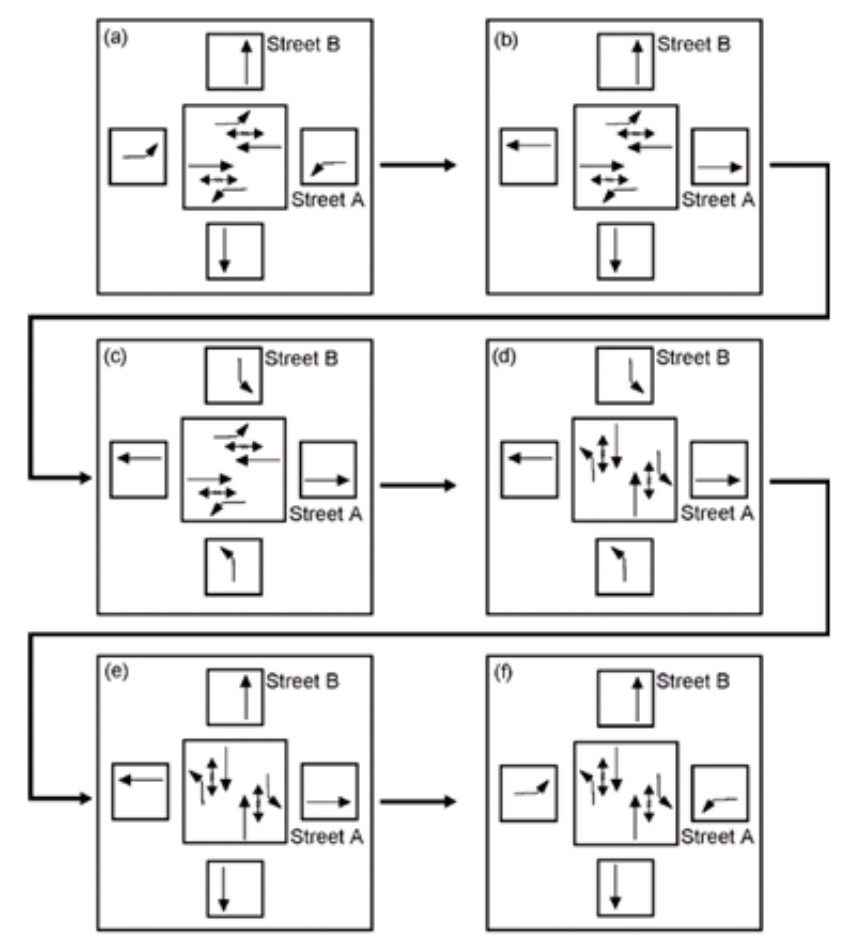

Figure 3-2 Signal phasing of continuous flow intersection (USDOT, 2004)

\subsection{Operational aspects of the CFI}

Full or partial implementations of a continuous-flow intersection can provide significant savings in delay, queue length and the average number of stops and may add additional capacity when compared with a conventional intersection design with left-turn pockets (Hummer and Reid, 2000). The benefits of a CFI grow as traffic volumes increase. Thus, locations with high demand throughout the day experience greater benefits than locations with high demand for short peak periods.

Advantages of a continuous-flow intersection over conventional intersections are greatest where left turn volumes are high and intersection capacity is exceeded (Goldblatt et al., 1994). As left turn volumes increase, protected left turn phases at a conventional intersection increase, extending the cycle length and increasing delays for all traffic movements. The CFI design, on the other hand, allows left turn movements to proceed 
simultaneously with the through movements. Hence, delays at continuous-flow intersections with heavy left-turn and through movements are considerably reduced.

Pedestrian travel through a continuous-flow intersection is accommodated within two cycle lengths (Jagannathan and Bared, 2005), which may be considered disadvantageous. Pedestrians crossing a continuous-flow intersection may experience additional delay when compared to a conventional intersection. The larger delay that a continuous-flow intersection creates for a pedestrian should be considered where heavy pedestrian volumes are present.

A continuous-flow intersection has characteristics summarized in Table 3-1.

Table 3-1 Characteristics of a continuous-flow intersection (Hummer, 1998; Hummer and Reid, 2000)

\begin{tabular}{|c|c|c|c|}
\hline Advantages & Disadvantages & $\begin{array}{l}\text { When to } \\
\text { consider }\end{array}$ & $\begin{array}{l}\text { When not to } \\
\text { consider }\end{array}$ \\
\hline $\begin{array}{l}\bullet \text { Reduced delay } \\
\text { for through arterial } \\
\text { traffic } \\
\text { - Reduced stops } \\
\text { for through traffic } \\
\text { - Easier } \\
\text { progression for } \\
\text { through arterial } \\
\text { traffic } \\
\text { - Applicable to all } \\
\text { median widths } \\
\text { including roads } \\
\text { with no median or } \\
\text { with a narrow } \\
\text { median } \\
\text { - Reduced and } \\
\text { more separated } \\
\text { conflict points }\end{array}$ & $\begin{array}{l}\text { - Driver and pedestrian confusion } \\
\text { - Increased stops for left-turns } \\
\text { from the arterial } \\
\text { - Restricted U-turn possibilities } \\
\text { - Pedestrians must cross } \\
\text { connectors and the main } \\
\text { intersection (and pedestrians must } \\
\text { cross the four-quadrant design in } \\
\text { a slow two-stage process) } \\
\text { - Additional right-of-way for } \\
\text { connectors } \\
\text { - Additional construction and } \\
\text { maintenance costs for connectors } \\
\text { - Lack of access to arterial for } \\
\text { parcels next to connectors } \\
\text { - There may be costs associated } \\
\text { with obtaining the rights to use } \\
\text { the design }\end{array}$ & $\begin{array}{l}\text { • High through } \\
\text { volumes with } \\
\text { little demand } \\
\text { for U-turns } \\
\text { - Sufficient } \\
\text { intersection } \\
\text { spacing to } \\
\text { outweigh the } \\
\text { savings } \\
\text { elsewhere } \\
\text { - Restricted } \\
\text { access to the } \\
\text { arterial for } \\
\text { parcels near } \\
\text { intersection }\end{array}$ & $\begin{array}{l}\bullet \text { Narrow } \\
\text { right of way } \\
\text { at the } \\
\text { intersection } \\
\text { and no } \\
\text { possibility } \\
\text { for } \\
\text { obtaining } \\
\text { extra right- } \\
\text { of-way at } \\
\text { the } \\
\text { intersection }\end{array}$ \\
\hline
\end{tabular}


Table 3-2 Summary of continuous-flow intersection (USDOT, 2004)

\begin{tabular}{|c|c|c|}
\hline Characteristics & Potential Benefits & Potential Liabilities \\
\hline Safety & $\begin{array}{l}\text { Left turns removed from } \\
\text { main intersection. }\end{array}$ & None identified. \\
\hline Operations & More green for through. & $\begin{array}{l}\text { More stops and delay for } \\
\text { left turns. }\end{array}$ \\
\hline \multirow[t]{2}{*}{ Multimodal } & \multirow[t]{2}{*}{$\begin{array}{l}\text { No conflicts during } \\
\text { pedestrian crossing. }\end{array}$} & $\begin{array}{l}\text { Two-stage pedestrian } \\
\text { crossing. }\end{array}$ \\
\hline & & $\begin{array}{l}\text { Layout may not be } \\
\text { immediately apparent, } \\
\text { especially for visually } \\
\text { impaired persons. }\end{array}$ \\
\hline \multirow[t]{3}{*}{ Physical } & \multirow{3}{*}{$\begin{array}{l}\text { Similar footprint than } \\
\text { interchange alternative. }\end{array}$} & Right-of-way needed. \\
\hline & & $\begin{array}{l}\text { Larger footprint than } \\
\text { conventional intersection. }\end{array}$ \\
\hline & & Access management. \\
\hline \multirow[t]{2}{*}{ Socioeconomic } & \multirow[t]{2}{*}{ Air quality. } & Construction cost. \\
\hline & & Access management. \\
\hline $\begin{array}{l}\text { Enforcement, Education, } \\
\text { and Maintenance }\end{array}$ & None identified. & $\begin{array}{l}\text { Public information } \\
\text { campaign may be needed. }\end{array}$ \\
\hline
\end{tabular}

\subsection{Safety Impacts of the Continuous-Flow Intersection}

The safety impacts of a continuous-flow intersection are assessed on the basis of potential conflict points. Figure 3-3 and Figure 3-4 show the potential conflict points for a half and full continuous-flow intersection, respectively. When either the half or full CFI are compared with the conventional intersection found in Figure 2-2, one possible benefit that a continuous-flow intersection provides is further separation of potential conflict points. 


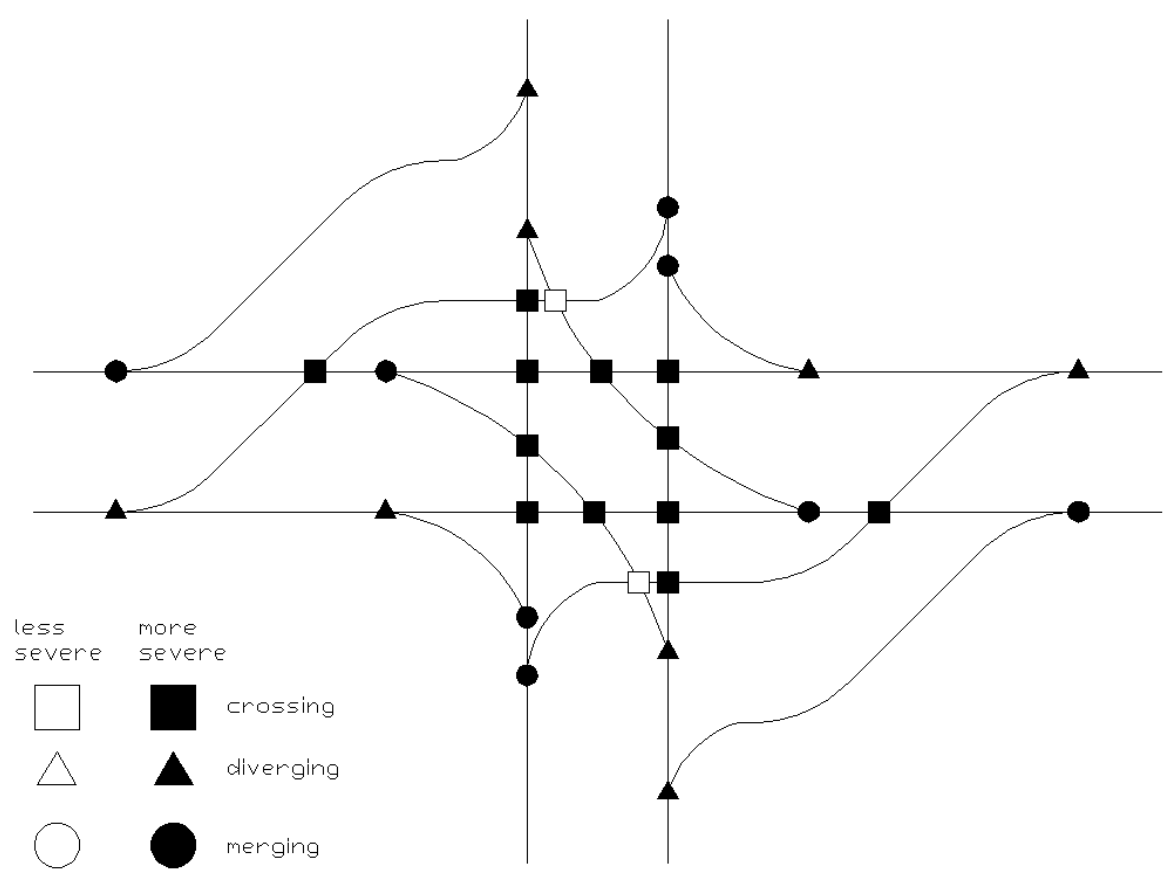

Figure 3-3: A half continuous-flow intersection potential conflict point diagram

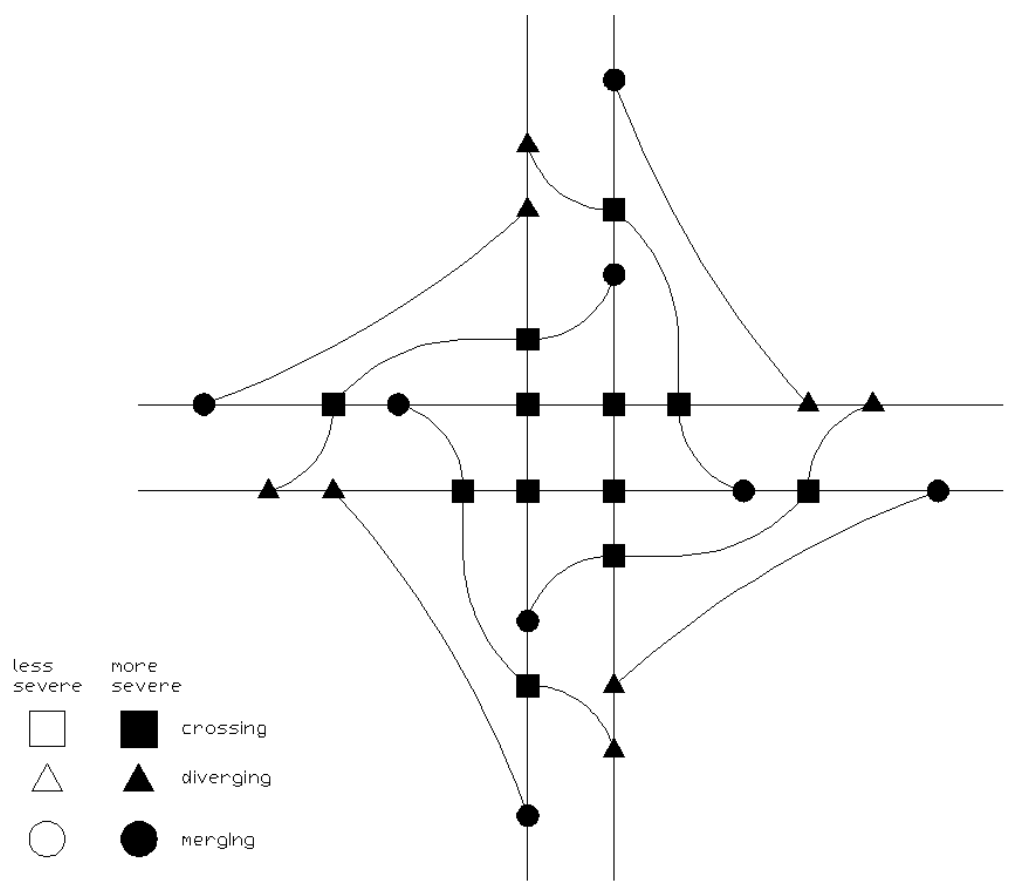

Figure 3-4: A full continuous-flow intersection potential conflict point diagram

Table 3-3 presents the number of potential conflict points for a half and full continuousflow intersection contrasted with a comparable conventional intersection. 
Table 3-3 Potential conflict points for a conventional intersection, half continuous-flow intersection and full continuous-flow intersection

\begin{tabular}{|l|c|c|c|c|c|c|c|c|c|}
\hline & \multicolumn{2}{|c|}{ Crossing } & \multicolumn{2}{c|}{ Diverging } & \multicolumn{2}{c|}{ Merging } & \multicolumn{2}{|c|}{ Total } & \multirow{2}{*}{ Overall } \\
\cline { 2 - 9 } & $\begin{array}{c}\text { Less } \\
\text { Severe }\end{array}$ & $\begin{array}{c}\text { More } \\
\text { Severe }\end{array}$ & $\begin{array}{c}\text { Less } \\
\text { Severe }\end{array}$ & $\begin{array}{c}\text { More } \\
\text { Severe }\end{array}$ & $\begin{array}{c}\text { Less } \\
\text { Severe }\end{array}$ & $\begin{array}{c}\text { More } \\
\text { Severe }\end{array}$ & $\begin{array}{c}\text { Less } \\
\text { Severe }\end{array}$ & $\begin{array}{c}\text { More } \\
\text { Severe }\end{array}$ & \begin{tabular}{c} 
Total \\
\hline $\begin{array}{l}\text { Conventional, } \\
\text { signalized } \\
\text { 4-legged }\end{array}$
\end{tabular} \\
\hline Half-CFI & 2 & 12 & 0 & 8 & 0 & 8 & 4 & 28 & 32 \\
\hline Full CFI & 0 & 12 & 0 & 8 & 0 & 8 & 0 & 28 & 28 \\
\hline
\end{tabular}

As exemplified in the table, the half-CFI may bring some safety benefits, as there is a reduction in the total number of potential conflict points. The reduction of potential conflict points occurs in the less severe category for the crossing conflict type. A full CFI further reduces the number of potential conflict points when compared with a half CFI. Again, the reduction is in the number of less severe crossing potential conflict points. The implications of a reduction in potential conflict points should be carefully considered, as a link between the number of potential conflict points and frequency or severity of crashes has not yet been established.

When considering pedestrian/vehicle interactions, the continuous-flow intersection might be confusing to pedestrians as a result of the more complex geometry. As compared with other alternatives, the total number of roadways and the number of free-flowing roadways that need to be crossed by a pedestrian is relatively high (Thompson and Hummer, 2001). Furthermore, the more complex intersection geometry might cause driver confusion, thus compromising pedestrian and vehicle safety. 


\section{Jughandle intersection}

The jughandle intersection uses connectors diverging to the right side of the arterial to accommodate the left and right turns from the arterial. For example, in Figure 4-1, the upper forward jughandle removes left and right turns from traffic traveling to the left. Therefore, the left and right turning movements exit onto the jughandle connector, to the right of the arterial, and then make either a left or right turn onto the minor street, as shown in Figure 4-1a. The minor street turning movements proceed as normal, as is shown in Figure 4-1b, as the minor street does not have a connector.

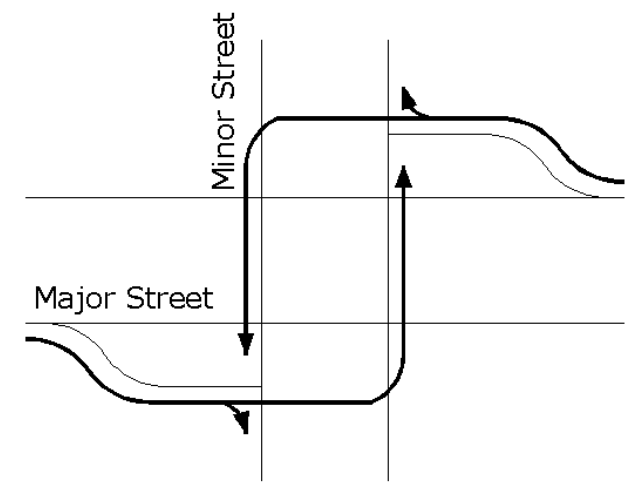

(a) Major Street Turning Movements

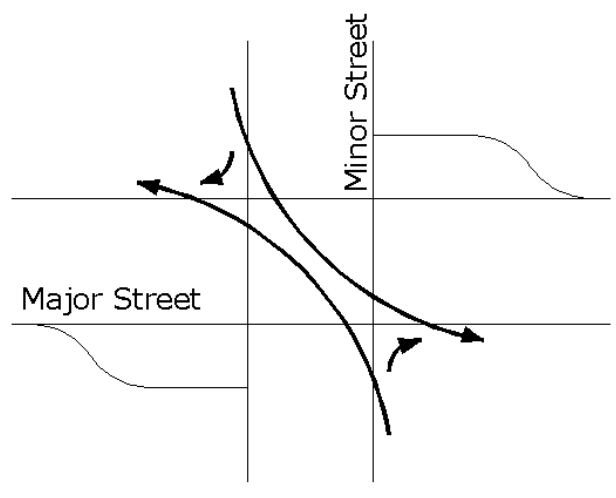

(b) Minor Street Turning Movements

Figure 4-1 Turning movements for a forward-forward jughandle

There are two types of jughandle connectors, combinations of which can form three distinct intersection configurations shown in Figure 4-1, Figure 4-2 and Figure 4-3. Left and right turn movements at a forward-forward jughandle intersection are shown in Figure 4-1. A reverse-reverse junghandle intersection is presented in Figure 4-2. Figure 4-3 shows how turning vehicles proceed at a forward-reverse jughandle intersection. A forward jughandle connector is also called a near-sided connector while a reverse jughandle connector is also called a far-sided connector. 


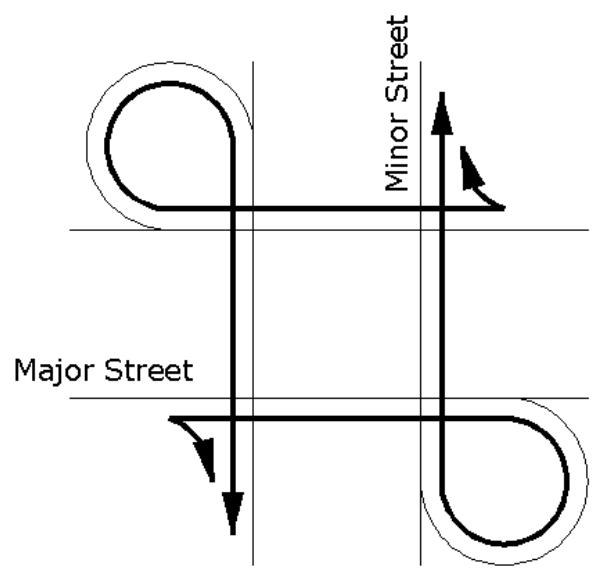

(a) Major Street Turning Movements

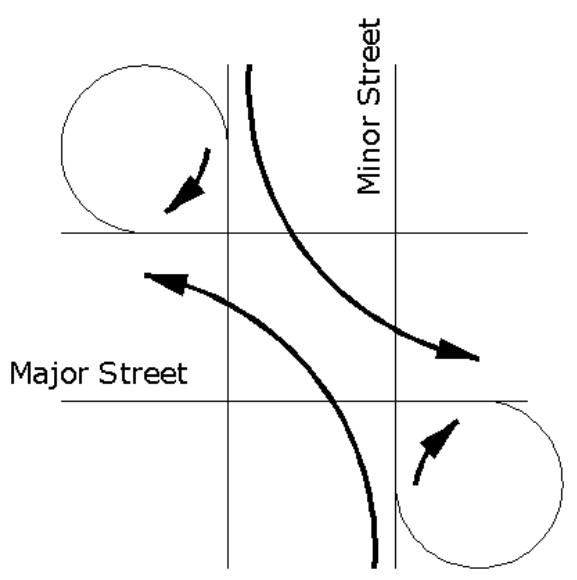

(b) Minor Street Turning Movements

Figure 4-2 Turning movements for a reverse-reverse jughandle

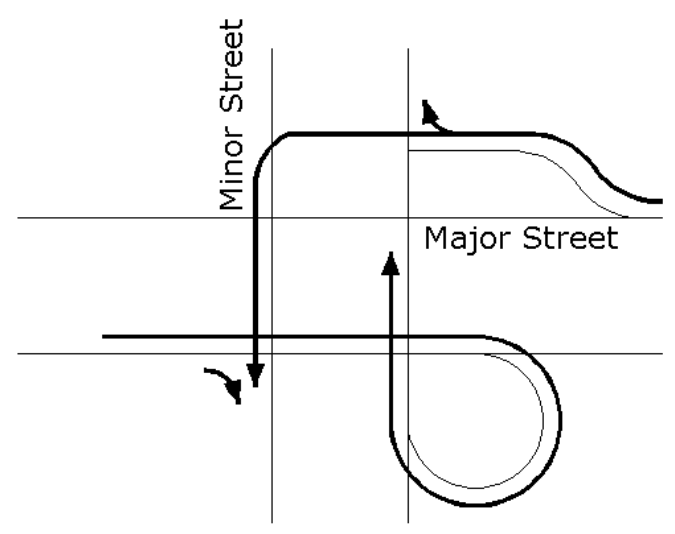

(a) Major Street Turning Movements

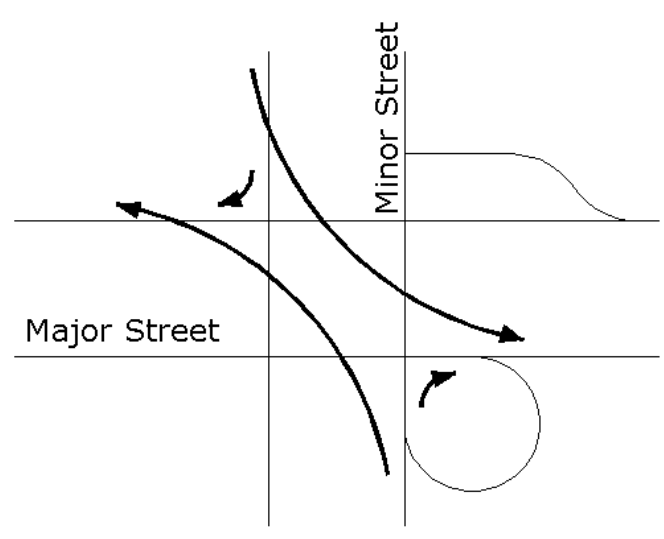

(b) Minor Street Turning Movements

Figure 4-3 Turning movements for a forward-reverse jughandle

A reverse connector requires the user to first proceed through the intersection then exit on the reverse connector. The user is redirected back onto the minor roadway via the reverse connector. The user then proceeds through the primary intersection for a second time (i.e. backtracking) to complete a left-hand turn. There is no back-tracking in a forward 
connector. The implementation of a combination of forward and reverse jughandle connectors can be used to accommodate right-of-way restrictions.

Design guidelines for jughandle intersections can be found in (New Jersey DOT, n.d.). They include design recommendations regarding connector speeds, exit curves, connector right turn radius at a cross-street, connector length and placement, length of a deceleration lane and signage. The guidelines identify three types of jughandles: Type A, Type B, Type C. Type A resembles the previously described forward-forward jughandle intersection. Type B resembles the median U-turn alternative intersection discussed in Section 5, although there are some differences. Type $\mathrm{C}$ resembles the previously described forward-reverse jughandle intersection.

The primary road crossing at a jughandle intersection is signalized. The signals at the primary crossing area should be set so that vehicle queues on the minor street do not block the termini of the jughandle connectors. The signals may have two or three phases. A three-phase signal setting is applied if the left-turning movements from the minor street need to be protected. The two-phase and three-phase alternatives are shown in Figure 4-4.

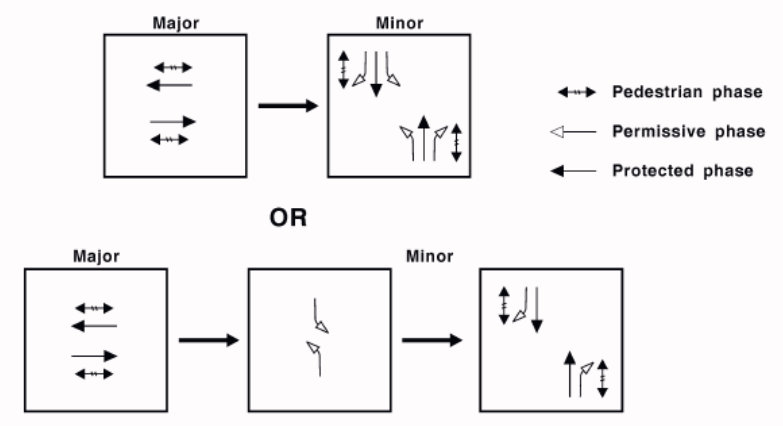

Figure 4-4 Signal phasing for a jughandle (USDOT, 2004)

The traffic control at the secondary crossing areas formed by the jughandle connectors and the minor street depends on the volume of traffic using the jughandle connectors. The 
traffic control at the secondary crossing areas may be a combination of stop signs, yield signs, and traffic signals. If the secondary crossing area is not signalized then the leftturn movements at the secondary crossing area are typically stop-controlled while the right-turn movements are yield-controlled.

\subsection{Operational aspects of a Jughandle}

The forward jughandle intersections can accommodate light to moderate left turn movements on the major road. This configuration may experience operational problems if vehicle queues on the minor road extend back from the primary crossing and block the jughandle termini.

The Type B jughandle is used to provide a U-turn possibility for heavy vehicles on roadway sections with a narrow median. It can also be used as a directional crossover for left turns.

The reverse jughandle design can be used to accommodate left turns heavier than allowed at the forward jughandle design. The reverse connector should be sufficiently long to accommodate the queue that can build up during one signal cycle. An important consideration associated with the reverse jughandle is the provision of an additional lane for motorists exiting the reverse jughandle onto the minor street. The reverse jungle connector requires greater right of way than the forward jughandle connector.

Jughandle connectors require left-turning vehicles to drive a longer distance through the intersection, which leads to longer travel times. Under heavy traffic at a forward jughandle intersection, the queue spillback from the primary crossing area may block the termini of the jughandle connectors, which would result in an additional delay for left turning movements. Additionally, if traffic on a forward jughandle connector is 
controlled with a stop sign, the number of stops experienced by that traffic increases.

Even so, the intersection may operate at a lower average delay than experienced at a conventional solution (USDOT, 2004). It is recommended that the tradeoff between the advantages to through movements and the disadvantages to left-turn movements is evaluated for this design. Table 4-1 shows characteristics of a forward jughandle intersection.

Table 4-1 Characteristics of a forward jughandle (Hummer, 1998; Hummer and Reid, 2000)

\begin{tabular}{|c|c|c|c|}
\hline Advantages & Disadvantages & When to Consider & $\begin{array}{l}\text { When not to } \\
\text { Consider }\end{array}$ \\
\hline $\begin{array}{l}\text { - Reduced delay } \\
\text { for through arterial } \\
\text { traffic } \\
\text { • Reduced stops } \\
\text { for through traffic } \\
\text { • Easier } \\
\text { progression for } \\
\text { through arterial } \\
\text { traffic } \\
\text { - Fewer and more } \\
\text { separated conflict } \\
\text { points }\end{array}$ & $\begin{array}{l}\text { - Driver confusion } \\
\text { - Driver disregard for } \\
\text { left-turn prohibitions at } \\
\text { the main intersection } \\
\text { • Increased travel } \\
\text { distances for left turns } \\
\text { from the arterial } \\
\text { • Increased delay for left } \\
\text { turns from the arterial, } \\
\text { especially if queues of } \\
\text { cross-street vehicles } \\
\text { block the connector } \\
\text { terminal } \\
\text { • Increased stops for left } \\
\text { turns from the arterial } \\
\text { • Additional costs for } \\
\text { construction and } \\
\text { maintenance of } \\
\text { connectors } \\
\text { • Lack of access to } \\
\text { arterial for parcels next to } \\
\text { connectors } \\
\text { • Pedestrians must cross } \\
\text { connectors and the main } \\
\text { intersection }\end{array}$ & $\begin{array}{l}\text { • High arterial } \\
\text { through volumes } \\
\text { with low or } \\
\text { moderate cross } \\
\text { street left-turn } \\
\text { volumes }\end{array}$ & $\begin{array}{l}\bullet \text { Limited } \\
\text { right-of-way at } \\
\text { the intersection }\end{array}$ \\
\hline
\end{tabular}


Table 4-2 Summary of the jughandle (USDOT, 2004)

Characteristics

\begin{tabular}{lll}
\hline \multicolumn{1}{c}{ Characteristics } & \multicolumn{1}{c}{ Potential Benefits } & \multicolumn{1}{c}{ Potential Liabilities } \\
\hline Safety & $\begin{array}{l}\text { Potential reduction in left- } \\
\text { turn collisions. }\end{array}$ & None identified. \\
Operations & $\begin{array}{l}\text { Potential reduction in } \\
\text { overall travel time and } \\
\text { stops. }\end{array}$ & $\begin{array}{l}\text { Longer travel time and } \\
\text { more stops for left-turning } \\
\text { vehicles using the } \\
\text { jughandle. }\end{array}$ \\
& & $\begin{array}{l}\text { Potential for high-speed } \\
\text { conflicts near connector } \\
\text { diverges }\end{array}$ \\
Multimodal & $\begin{array}{l}\text { Pedestrian crossing distance } \\
\text { may be shorter due to lack } \\
\text { of left-turn lanes on the }\end{array}$ & $\begin{array}{l}\text { Increased exposure for } \\
\text { pedestrians crossing the } \\
\text { connector terminal. }\end{array}$ \\
major street. & $\begin{array}{l}\text { Transit stops may need to } \\
\text { be relocated outside the }\end{array}$ \\
& $\begin{array}{l}\text { Pedestrian delay may be } \\
\text { reduced due to potentially } \\
\text { shorter cycle lengths. }\end{array}$ & $\begin{array}{l}\text { influence area of the } \\
\text { intersection. }\end{array}$ \\
None identified. & $\begin{array}{l}\text { Additional right-of-way } \\
\text { may be required. }\end{array}$ \\
& & Access management. \\
Physical & None identified. & None identified. \\
& &
\end{tabular}

\section{Potential Benefits}

Potential Liabilities

\subsection{Safety Impacts of the Jughandle}

\subsubsection{Research results}

Jughandle intersections may substantially reduce the frequency of head-on and left-turn collisions as compared to conventional intersections with the same traffic volume (Jagannathan et al., 2006). The drawback of a jughandle design, from the safety perspective, is that jughandles are associated with a slight increase in the annual frequency of rear-end collisions as compared to a conventional intersection (Jagannathan et al., 2006). Even so, rear-end collisions tend to be much less severe than head-on and 
left-turn collisions. Therefore, the reduction in head-on and left-turn collisions has the possibility of outweighing the costs associated with a slight increase in rear-end collisions.

With respect to pedestrian safety, jughandles have the possibility of halving the frequency of pedestrian-vehicle crashes (Jagannathan et al., 2006). This result should be carefully considered because exposure was not incorporated into the analysis as a result of unavailable data.

Special considerations should be taken when considering pedestrian presence at a jughandle intersection on cross-streets near the connector terminal (Rodegerdts et al., 2007). Adequate design will improve not only pedestrian safety, but vehicle safety and operations as well.

Comparing the total crash rate (per million vehicle miles) between the three jughandle intersection designs, the forward-forward jughandle design was found to have the highest total crash rate (Jagannathan et al., 2006). The total crash rate for the other two jughandle designs, the forward-reverse and reverse-reverse jughandle, were comparable, although there were some indications that the reverse-reverse jughandle is associated with a slightly lower total crash rate.

\subsubsection{Potential conflict point diagrams for jughandle intersections}

The safety of jughandle intersections can also be evaluated on the basis of potential conflict points. Figure 4-5, Figure 4-6, Figure 4-7 show the conflict points for the forward-forward, reverse-reverse, and forward-reverse jughandle intersections. 


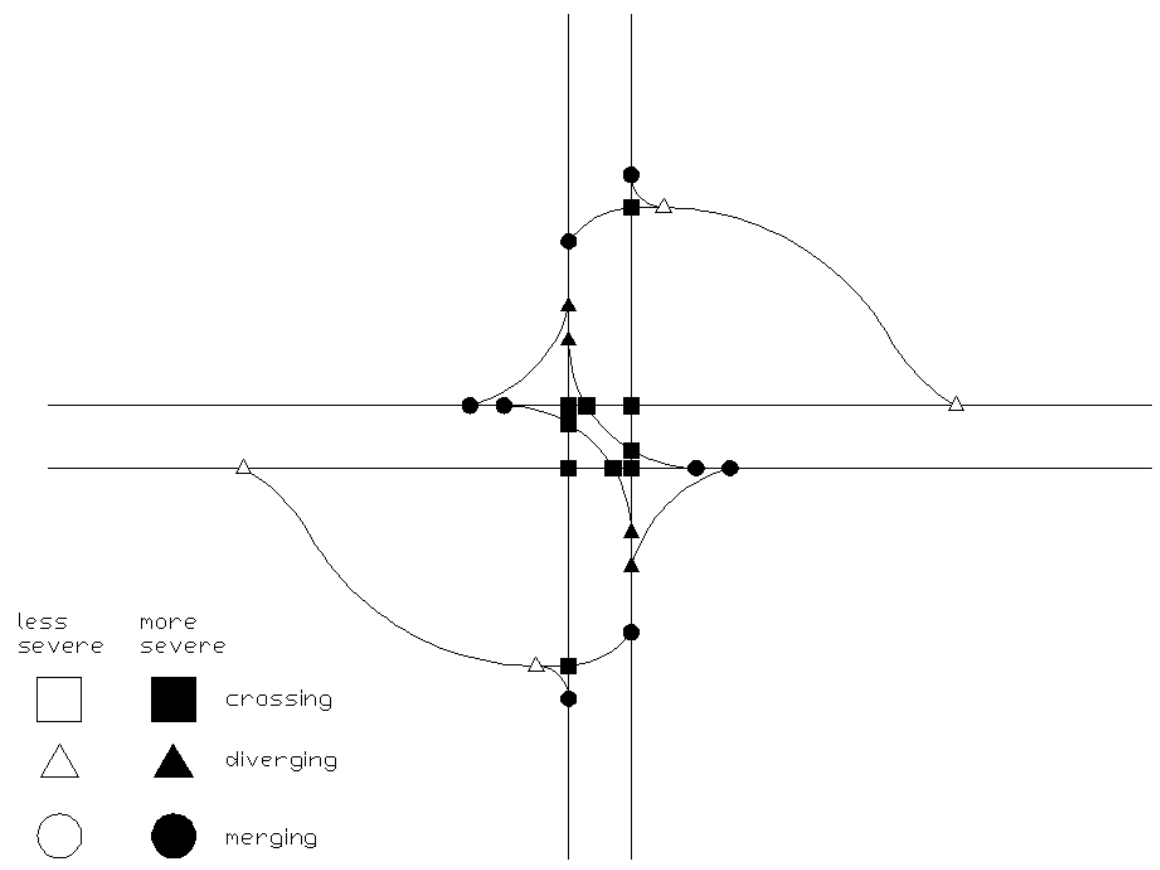

Figure 4-5 Forward-forward jughandle potential conflict point diagram

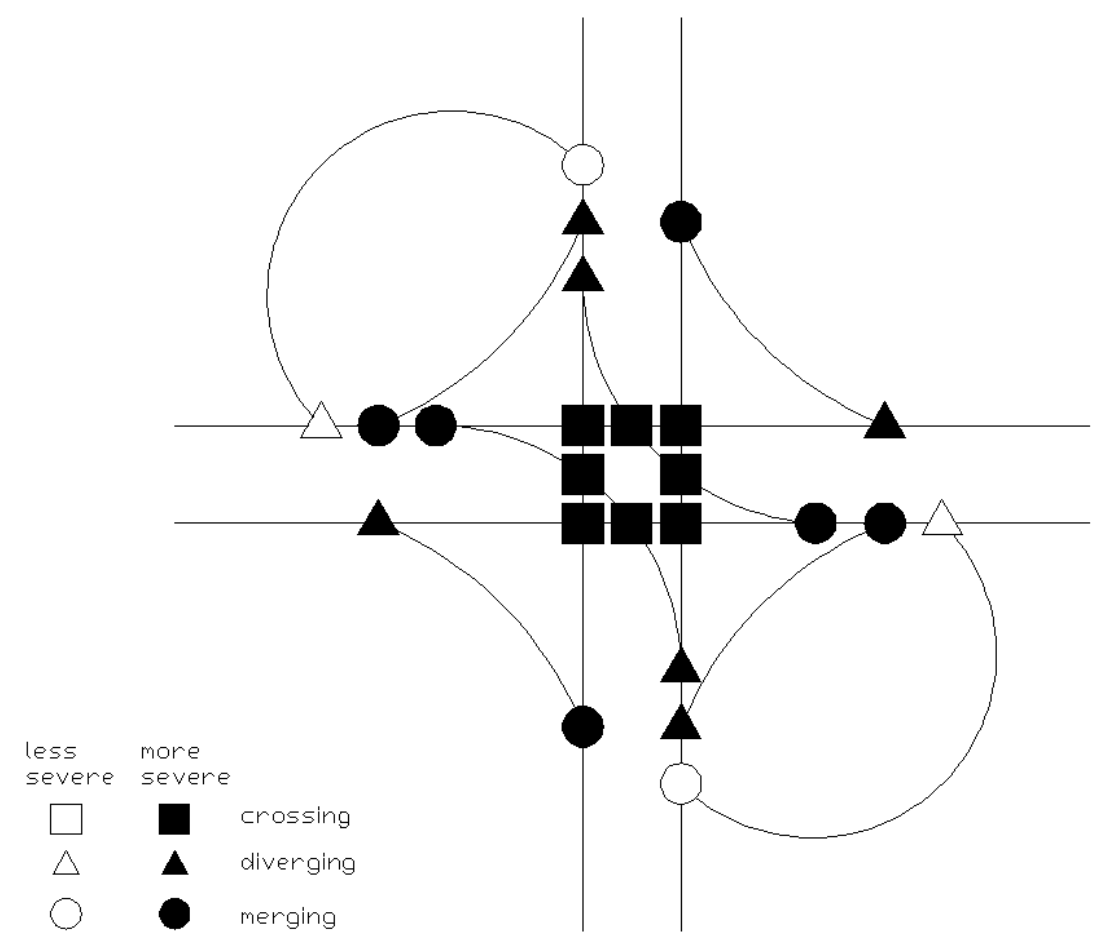

Figure 4-6 Reverse-reverse juhandle potential conflict point diagram 


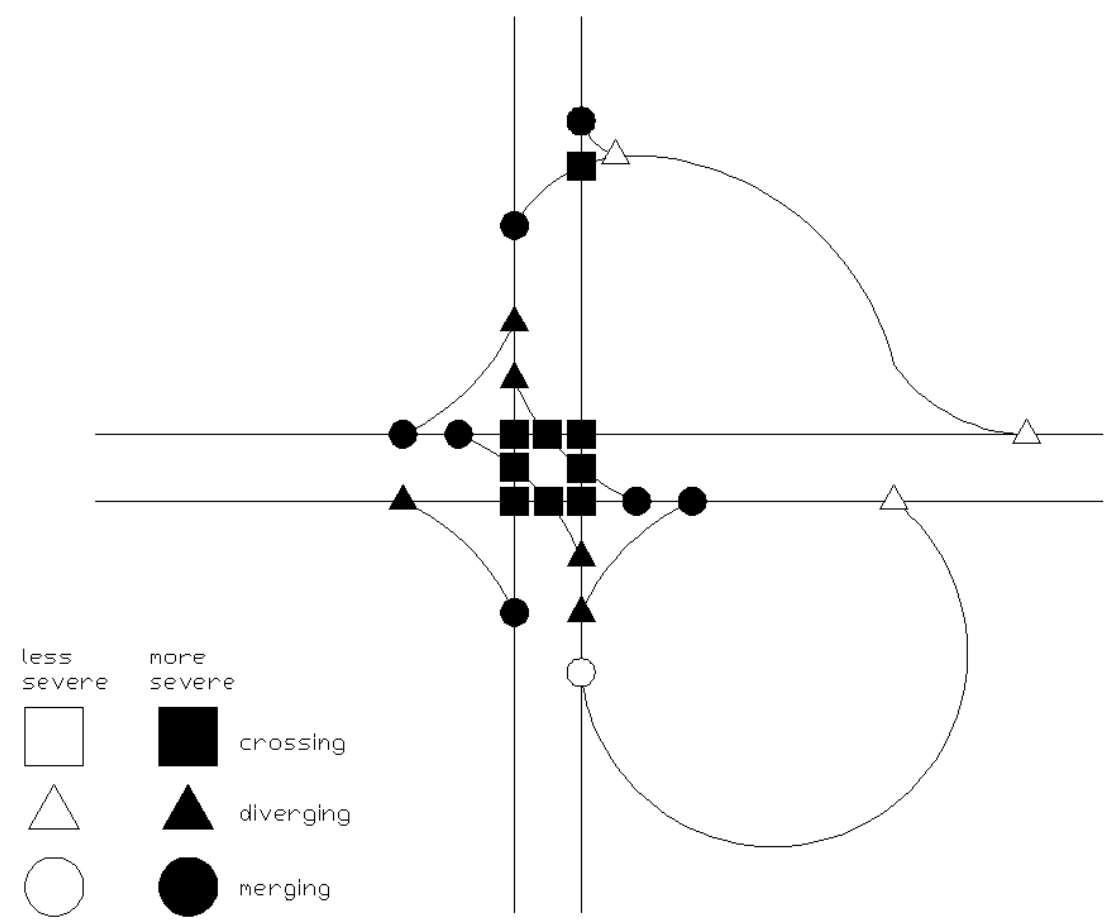

Figure 4-7 Forward-reverse jughandle potential conflict point diagram

Table 4-3 provides a summary of the number of diverging, merging, and crossing potential conflict points that can be expected with each jughandle intersection design. Information about a conventional intersection design is also provided for comparison.

Table 4-3 Potential conflict points for jughandle alternatives compared to a conventional intersection

\begin{tabular}{|l|c|c|c|c|c|c|c|c|c|}
\hline \multirow{2}{*}{\multicolumn{1}{c|}{ Intersection Type }} & \multicolumn{2}{c|}{ Crossing } & \multicolumn{2}{c|}{ Diverging } & \multicolumn{2}{c|}{ Merging } & \multicolumn{2}{c|}{ Total } & Overall \\
\cline { 2 - 11 } & $\begin{array}{c}\text { Less } \\
\text { Severe }\end{array}$ & $\begin{array}{c}\text { More } \\
\text { Severe }\end{array}$ & $\begin{array}{c}\text { Less } \\
\text { Severe }\end{array}$ & $\begin{array}{c}\text { More } \\
\text { Severe }\end{array}$ & $\begin{array}{c}\text { Less } \\
\text { Severe }\end{array}$ & $\begin{array}{c}\text { More } \\
\text { Severe }\end{array}$ & $\begin{array}{c}\text { Less } \\
\text { Severe }\end{array}$ & $\begin{array}{c}\text { More } \\
\text { Severe }\end{array}$ & $\begin{array}{c}\text { Total } \\
\text { Conventional, signalized, 4-legs }\end{array}$ \\
\hline Forward-Forward Jughandle & 0 & 12 & 0 & 8 & 0 & 8 & 4 & 28 & 32 \\
\hline Reverse-Reverse Jughandle & 0 & 8 & 2 & 6 & 2 & 6 & 4 & 20 & 24 \\
\hline Forward-Reverse Jughandle & 0 & 9 & 3 & 5 & 1 & 7 & 4 & 21 & 25 \\
\hline
\end{tabular}

Table 4-3 shows that when comparing any jughandle alternative to a conventional intersection, the total number of potential conflict points is reduced. The reduction in potential conflict points could mean an increase in safety. Additionally, the jughandle 
designs also provide further separation of the potential conflict points, which may provide some safety benefit.

The forward-forward design has the highest number of potential conflict points among the three jughandle intersections; therefore, the safety benefits of the forward-forward design is expected to be less than the other jughandle alternatives. A research study of the three types of jughandle intersections found results consistent with the above observations (Jagannathan et al., 2007). The reverse-reverse design provides the highest level of safety, followed by the forward-reverse design and then the forward-forward design. 


\section{Median U-turn intersection (MUT)}

Motorists who want to turn left at the median U-turn intersection must use a directional crossover in the median, the median U-turn, which is located downstream of the primary intersection. Direct left turns are prohibited at the intersection while right turns proceed as usual. To make a left-turn, motorists on the road with the U-turn proceed through the intersection, make a U-turn at the directional median crossover, and then turn right at the intersection (Figure 5-1) (Jagannathan, 2007).

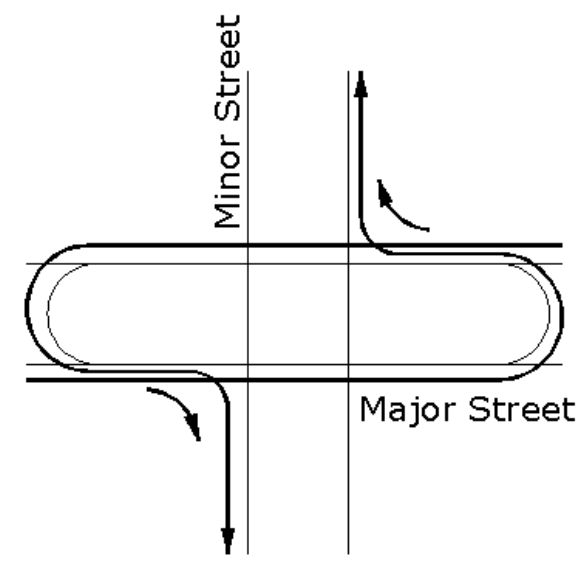

(a) Major Street Turning Movements

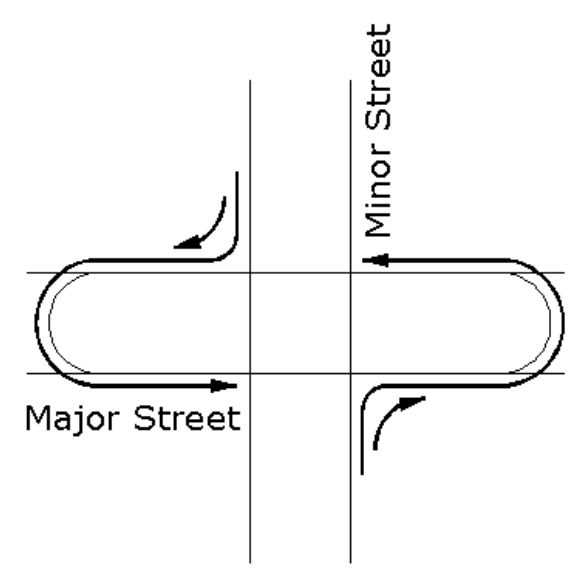

(b) Minor Street Turning Movements

Figure 5-1 Median U-turn turning movements

Median U-turns can be implemented on the major road, the secondary road, or both. Implementation of a median U-turn is restricted to roads with sufficiently wide medians. The minimum median width that allows a median U-turn depends on the design vehicle's turning radius and the number of opposing lanes (Jagannathan, 2007). Implementing loons in the median U-turn design can help reduce the required median width.

The median U-turns create two secondary intersections. There are several ways that these two intersections can be controlled. First, vehicles approaching the major intersection on the minor road and those making U-turns may be controlled by stop signs. Second, traffic 
signals can be implemented at both the primary and secondary intersections. If both the primary and secondary intersections are signalized, they should be coordinated. Proper coordination of signals reduces the number of stops of through vehicles considerably. This solution performs well if a left turn maneuver is allowed on a red signal on one-way facilities. Third, only the primary intersection is signalized while the median U-turn movements are controlled by stop signs at the secondary intersections. Traffic signals at the primary intersection will have two phases.

The location of the median U-turn downstream of the primary intersection should be carefully considered. Agencies provide varying recommendations for the location, which range from 400 to 760 feet beyond the primary intersection (Hummer, 1998; AASHTO, 2004; Jagannathan, 2007). The location of the median U-turn is a tradeoff between travel time for left turns and storage capacity for left turning vehicles. As the distance between the median U-turn and the primary intersection increases, the travel time for left turns will increase; however, with heavy left turns, increasing the distance between the median U-turn and the primary intersection will prevent spillback and blockage of through movements.

Tapering the median width when approaching the primary intersection can reduce the minimum green time for the cross street (Jagannathan, 2007). From a safety standpoint, this would result in a reduction in the time during which the pedestrian is exposed to vehicular traffic because their path is shorter. From an operational standpoint, this would result in a reduced cycle length, which results in a reduction in delay. No indication was given that this concept was implemented, or if so, the effects quantified.

Special attention should also be considered to address key design elements including deceleration length, storage, location and spacing of the crossovers on the arterial. The Michigan Department of Transportation successfully operates over a large number of intersections with median U-turns. The design guide developed by the Michigan 
Department of Transportation can assist in addressing the design issues (Michigan DOT, n.d.).

\subsection{Operational aspects of Median U-turn}

The removal of the left-turning movements from the major intersection has allowed elimination of the left-turn phases thus reducing the cycle length and delay for through movements and at the same time providing better conditions for coordination of the street with the median U-turns.

Proper signage is important for efficient operation of a median U-turns facility. The Michigan Department of Transportation has developed signage plans based on past experience (Thompson and Hummer, 2001; Michigan DOT, n.d.). Operations at the existing median U-turns in Michigan have shown that understandable traffic control devices and signing can mitigate confusion among drivers of rerouted movements (Hummer and Reid, 2000). Table 5-1 shows general characteristics of the MUT design and can be used for initial screening.

When compared to the conventional intersection, the median U-turn design brings considerable savings for though movements while increasing delays of the left-turning movements. The benefits exceed the costs if left-turn volumes are small (Bared and Kaisar, 2002), particularly, if the through volumes are large. With the increase in the volume of left turns, the net benefit decreases. At low to medium through volumes, the median U-turn will perform similarly to a comparable conventional intersection (Bared and Kaisar, 2002; Dorothy). Urban arterials with median U-turns have reduced travel times during peak periods (Hummer and Ried, 2000).

A considerable gain in capacity can be achieved for the median U-turn design as compared to a conventional design with dual left turns (Levinson et al., 2000). 
Table 5-1 Characteristics of a median U-turn intersection (Jagannathan, 2007; Hummer, 1998; Hummer and Ried, 2000)

\begin{tabular}{|c|c|c|c|}
\hline Advantages & Disadvantages & $\begin{array}{l}\text { When to } \\
\text { Consider }\end{array}$ & $\begin{array}{l}\text { When not to } \\
\text { Consider }\end{array}$ \\
\hline $\begin{array}{l}\text { • Reduced delay of } \\
\text { through arterial traffic } \\
\text { • Improved } \\
\text { progression along } \\
\text { through arterial. } \\
\text { • Fewer stops for } \\
\text { through traffic, } \\
\text { particularly at } \\
\text { intersections with } \\
\text { stop-controlled U- } \\
\text { turns } \\
\text { • Fewer threats to } \\
\text { crossing pedestrians } \\
\text { • Fewer and better } \\
\text { separated conflict } \\
\text { points } \\
\text { - Increased capacity at } \\
\text { primary intersection } \\
\text { - Allows to operate } \\
\text { signal at shorter cycle } \\
\text { lengths }\end{array}$ & $\begin{array}{l}\text { - Potential of driver } \\
\text { confusion } \\
\text { - Some drivers } \\
\text { disregard of the left- } \\
\text { turn prohibition at } \\
\text { primary intersection } \\
\text { - Reduced } \\
\text { performance of left- } \\
\text { turning traffic } \\
\text { (increased delays, } \\
\text { travelled distance, } \\
\text { and stops) } \\
\text { - Additional cost of } \\
\text { extra signals } \\
\text { - Longer cross street } \\
\text { minimum green times } \\
\text { or two cycle } \\
\text { pedestrian crossing } \\
\text { - Larger right of way } \\
\text { to accommodate } \\
\text { required median } \\
\text { width }\end{array}$ & $\begin{array}{l}\text { • High arterial } \\
\text { through } \\
\text { volumes with } \\
\text { low or moderate } \\
\text { arterial left turn } \\
\text { volumes }\end{array}$ & $\begin{array}{l}\text { - Arterials with } \\
\text { narrow median } \\
\text { and no prospect } \\
\text { for obtaining extra } \\
\text { right of way, } \\
\text { except where wide } \\
\text { median and } \\
\text { crossovers can be } \\
\text { built on the cross } \\
\text { street } \\
\text { - High left turn } \\
\text { volumes on } \\
\text { arterial; extra } \\
\text { delays with } \\
\text { spillback may } \\
\text { outweigh the } \\
\text { savings for } \\
\text { through traffic }\end{array}$ \\
\hline
\end{tabular}

\subsubsection{Median U-turn in an arterial corridor}

During peak periods, a median U-turn corridor can improve system travel time by twenty percent and average speed by twenty five percent as compared to a conventional design. During off-peak periods, a median U-turn corridor will operate as efficient as a corridor with conventional intersections (Reid et al., 1999).

The benefit of converting conventional intersections to the median U-turn design on arterial streets grows with the growing ratio of arterial left-turn volumes to arterial through volumes (Reid et al., 1999). In the majority of cases tested in (Reid et al., 1999), 
the arterial street with median U-turns experienced a higher number of stops than the arterial with conventional intersections. Table 5-2 summarizes advantages and disadvantages of a MUT corridor as compared to a conventional two-way left-turn lane (TWLTL) corridor.

The median U-turn may be applied as a corridor treatment or at isolated intersections (Jagannathan, 2007). Insertion of a isolated median U-turn into a coordinated arterial composed of conventional intersections is not recommended.

\subsection{Safety Impacts of the Median U-turn}

\subsubsection{Research results}

Median U-turn designs may reduce the total number of crashes and injury crashes by more than half when compared to a conventional design (Jagannathan, 2007). A reduction in the number of rear-end, angle, and sideswipe crashes can be expected (Jagannathan, 2007). This safety benefit is probably produced by the decreased number and increased separation in conflict points and the elimination of left turns from the primary intersection.

Table 5-2 A median U-turn corridor relative to a TWLTL corridor. (Based on findings in Reid et al., 1999)

\begin{tabular}{|l|l|}
\hline Advantages & Disadvantages \\
\hline $\begin{array}{l}\text { - Two phase signal operation justified by } \\
\text { removal of left turns from main } \\
\text { intersection }\end{array}$ & $\begin{array}{l}\bullet \quad \text { Increase in left turns VMT due to } \\
\text { increased travel distance }\end{array}$ \\
- Improved progression & $\begin{array}{l}\text { Higher delay than at conventional } \\
\text { intersections if volumes are low }\end{array}$ \\
- Potential delay reduction for through & $\bullet \quad$ Increased potential of driver confusion \\
movements & $\bullet \quad$ Greater right of way requirements \\
- Reduced number of conflict points & \\
- Better visual aesthetics & \\
\hline
\end{tabular}


Table 5-3 Summary of the median U-turn intersection (USDOT, 2004)

\begin{tabular}{|c|c|c|}
\hline Characteristics & Potential Benefits & Potential Liabilities \\
\hline \multirow[t]{2}{*}{ Safety } & $\begin{array}{l}\text { Potential reduction in left- } \\
\text { turn collisions. }\end{array}$ & None identified. \\
\hline & $\begin{array}{l}\text { Potential minor reduction in } \\
\text { merging/diverging collisions. }\end{array}$ & \\
\hline \multirow[t]{3}{*}{ Operations } & $\begin{array}{l}\text { Potential reduction in overall } \\
\text { travel time. }\end{array}$ & $\begin{array}{l}\text { Mixed findings with respect to } \\
\text { overall stops. }\end{array}$ \\
\hline & $\begin{array}{l}\text { Reduction in number of stops } \\
\text { for arterial through } \\
\text { movements. }\end{array}$ & \\
\hline & $\begin{array}{l}\text { Mixed findings with respect } \\
\text { to overall stops. }\end{array}$ & \\
\hline \multirow[t]{2}{*}{ Multimodal } & \multirow{2}{*}{$\begin{array}{l}\text { Number of conflicting } \\
\text { movements at intersections is } \\
\text { reduced. }\end{array}$} & $\begin{array}{l}\text { Increased crossing distance for } \\
\text { pedestrians. }\end{array}$ \\
\hline & & $\begin{array}{l}\text { Turning paths of the median U-turn } \\
\text { may encroach in bike lanes. }\end{array}$ \\
\hline Physical & None identified. & $\begin{array}{l}\text { May be additional right-of-way } \\
\text { needs depending on width of } \\
\text { existing median. }\end{array}$ \\
\hline Socioeconomic & None identified. & $\begin{array}{l}\text { Access may need to be restricted } \\
\text { within the influence of the median } \\
\text { U-turn locations. }\end{array}$ \\
\hline $\begin{array}{l}\text { Enforcement, } \\
\text { Education, and } \\
\text { Maintenance }\end{array}$ & None identified. & $\begin{array}{l}\text { Enforcement and education may be } \\
\text { necessary to prevent illegal left turns } \\
\text { at the main intersection. }\end{array}$ \\
\hline
\end{tabular}




\subsubsection{Conflict diagram for the median U-turn}

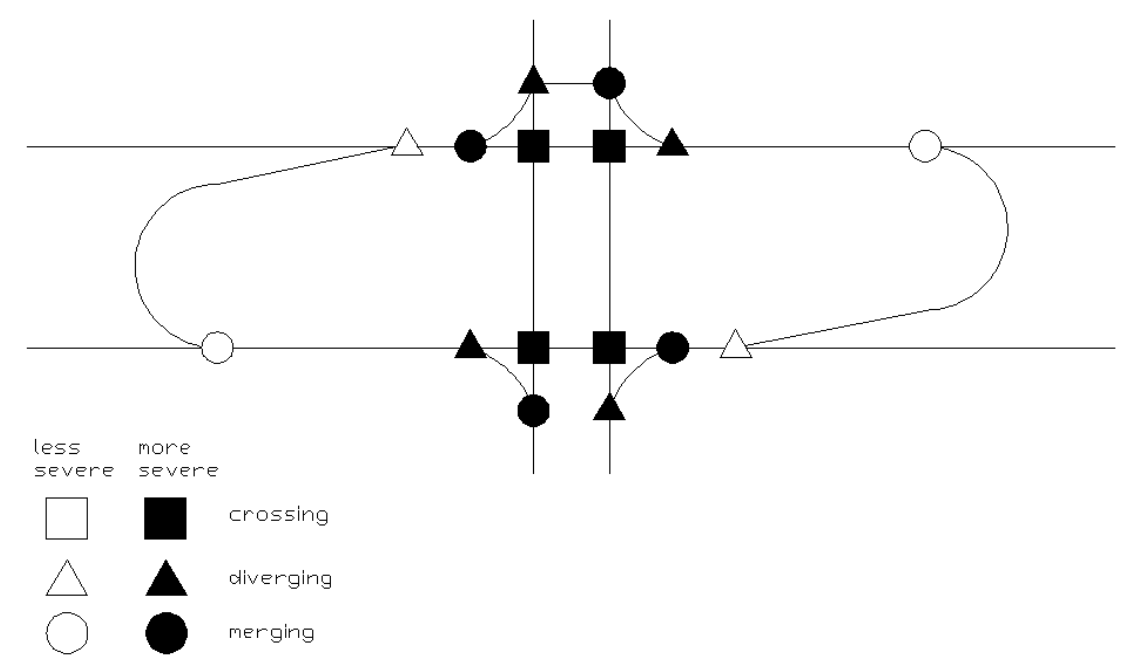

Figure 5-2 Median U-turn intersection potential conflict point diagram

Table 5-4 Potential conflict points for a median U-turn and a conventional intersection

\begin{tabular}{|c|c|c|c|c|c|c|c|c|c|}
\hline & \multicolumn{2}{|c|}{ Crossing } & \multicolumn{2}{|c|}{ Diverging } & \multicolumn{2}{|c|}{ Merging } & \multicolumn{2}{|c|}{ Total } & \multirow{2}{*}{$\begin{array}{c}\text { Overall } \\
\text { Total }\end{array}$} \\
\hline & $\begin{array}{l}\text { Less } \\
\text { Severe }\end{array}$ & $\begin{array}{l}\text { More } \\
\text { Severe }\end{array}$ & $\begin{array}{c}\text { Less } \\
\text { Severe }\end{array}$ & $\begin{array}{c}\text { More } \\
\text { Severe }\end{array}$ & $\begin{array}{l}\text { Less } \\
\text { Severe }\end{array}$ & $\begin{array}{l}\text { More } \\
\text { Severe }\end{array}$ & $\begin{array}{l}\text { Less } \\
\text { Severe }\end{array}$ & $\begin{array}{c}\text { More } \\
\text { Severe }\end{array}$ & \\
\hline $\begin{array}{l}\text { Conventional, } \\
\text { signalized } \\
\text { 4-legged }\end{array}$ & 4 & 12 & 0 & 8 & 0 & 8 & 4 & 28 & 32 \\
\hline Median U-turn & 0 & 4 & 2 & 4 & 2 & 4 & 4 & 12 & 16 \\
\hline
\end{tabular}

Comparing Figure 5-2 with Figure 2-2 and analyzing Table 5-4 reveal a reduction in the number and severity of potential conflict points at median U-turns. One of the most significant reductions is in the number of crossing potential conflict points. The total number of crossing potential conflict points is reduced from 16 to 4 . Additionally, the median U-turn intersection brings two benefits when considering diverging and merging potential conflict points: the total number is reduced, and the severity of two of the remaining six, respectively, is expected to be less severe. The positive safety impact of the median U-turn design has been confirmed with research (Jagannathan, 2007). 


\section{Roundabout intersection}

Roundabout intersections allow multiple vehicles to enter the intersection simultaneously from any approach when no conflicting vehicle is present in the circulatory roadway. The entry onto a roundabout is controlled by a yield sign. Roundabouts are characterized by the number of circulatory lanes, the number of entry lanes, the central island diameter, the approach deflection, the entry flare, and the splitter islands. The Federal Highway Administration (FHWA) Roundabout Guide (Robinson et al., 2000) can be helpful to classify and determine roundabout geometrical dimensions based on desired operational characteristics. The reader, however, should be cognizant of the fact that the mentioned FHWA Roundabout Guide was developed based on research from Europe and Australia and that a version updated with US roundabout data may be available at the time of reading these guidelines. Figure 6-1, below, provides an example of how a vehicle approaching from the major (a) and minor (b) streets would traverse a roundabout. Note that the figure demonstrates the movement from one approach at a time, while simultaneous entries from all approaches are permitted.

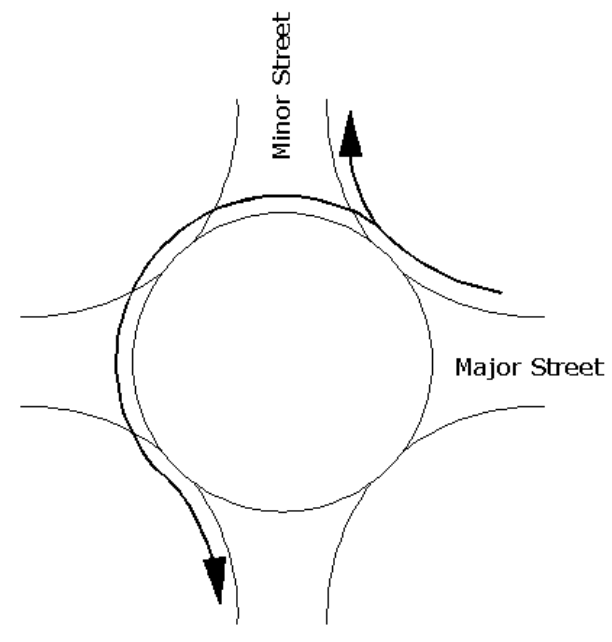

(a) Major Street Turning Movements

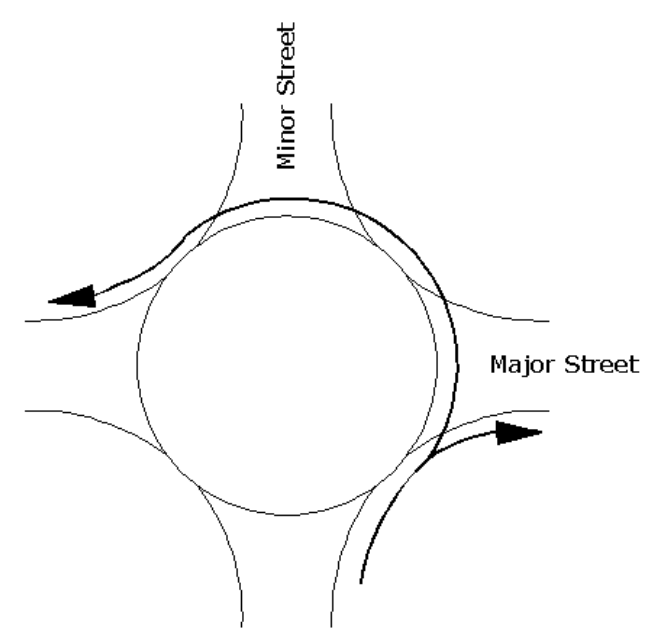

(b) Minor Street Turning Moyements

Figure 6-1 Example turning movements for major and minor street approaches 
It is important to distinguish between modern roundabouts - a subject of these guidelines - and conventional traffic circles or rotaries. Roundabouts are different from the latter two because entering traffic must yield to circulating traffic. In a rotary, circulating traffic must yield to entering traffic. Furthermore, roundabouts have deflection on the approach legs so that the speed of vehicle entering the roundabout is sufficiently reduced to minimize the speed differential between the vehicle in the circulatory roadway and the vehicle on the approach.

Prior to construction of roundabouts in communities not accustomed to them, designers and planners might experience opposition mainly due to unfamiliarity with the design (Retting et al., 2002). Opposition to roundabout intersections can also be attributed to confusing roundabouts with traffic circles, rotaries, or traffic calming islands (Russell et al., 2002). Agencies should consider providing educational classes and informational sessions regarding roundabouts when implementing them within communities unfamiliar with this design. After implementation of well designed roundabouts, a considerable improvement in public perception of roundabouts is expected (Retting et al., 2002; Traffic Flow and Public Opinion).

\subsection{Operational aspects of Roundabouts}

Roundabouts have the potential to provide improved operations at locations with high left turn volumes, skewed approaches, more than four legs, or limited queue storage. In general, roundabouts require shorter sight distance than conventional intersections due to lower speeds on approaches as compared to conventional intersections and right turn merge on entry. Traffic leaving roundabouts tends to be more random than at intersections with other types of control. Furthermore, gaps downstream tend to be shorter but more frequent as compared to signals. Thus, roundabouts have the potential to provide more opportunities for side street traffic downstream of the roundabout to enter the major street. When designing a roundabout, designers should consider factors 
such as overall size, entry angles, entry widths, flare length, speed, trucks, pedestrians and bikes, proper signing and markings (Johnson and Hange, n.d.). For multilane roundabouts, special attention to design details like vehicle path alignment, especially the shortest path; lane widths; and positive guidance to drivers through the use of lane markings should be carefully considered to achieve a successful roundabout design (Rodegerdts, 2007).

From an operational perspective, the two most important driver behavior parameters considered during roundabout capacity analysis are critical gap and follow up time. For cities with no prior roundabout experience these parameters can be assumed to be more conservative than for cities with prior installations of roundabouts (Rodegerdts et al., 2007; Eisenman and List, 2004).

To determine roundabout feasibility for a given site, data on vehicle and pedestrian volumes, and horizontal and vertical alignment should be considered (Chapman and Benekohal, 2002). Factors that favor roundabout construction include (Chapman and Benekohal, 2002):

$>$ Geometric realignment of the approaches is cost prohibitive

$>$ Current alignment is not conducive to the installation of a traffic signal system without geometric improvements

$>$ There are more than four approaches to an intersection at a single unsignalized location.

Factors that discourage roundabout consideration include (Chapman and Benekohal, 2002; Retting et al., 2002):

$>$ Grades through the intersection are greater than four percent

$>$ Crest vertical curves with steep approaches are present

> Vertical profile cannot be adjusted without a significant expense

$>$ Intersection cannot be relocated

$>$ Highly unbalanced volumes 
Locations where terrain or right-of-way limit appropriate geometry

$>$ Close proximity to persistent bottlenecks

Also, there are cases where certain geometric and site characteristics may favor roundabout construction over signals. Specific case studies where roundabouts proved to be more efficient than signals can be found in (Johnson and Hange, n.d.). Placing roundabouts on a signalized arterial requires careful analysis including the possibility of a queue spillback from signalized intersections to the roundabout and generally is discouraged for medium and heavy arterial traffic (Chapman and Benekohal, 2002). Planning roundabouts on arterials with light traffic are easier to justify.

Converting a stop-controlled intersection with low or moderate traffic (up to 20,000 veh/day) to a roundabout reduces the intersection control delay and distributes it more evenly across approaches (Flannery et al., 1998). Fair distribution of delay becomes a factor on two-way stop controlled intersections where the stop controlled legs may experience excessive delays even when the average delay for the intersection does not indicate any problems.

Construction of roundabouts at signalized interchanges with high left turns can in some cases reduce construction costs and increase capacity (Robinson et al., 2000; Johnson and Hange, n.d.). Roundabouts have been found to be the most cost-effective solution at the end of tunnels and bridges where adding additional storage and turning lanes required at traffic signals are expensive (Robinson et al., 2000).

Converting stop controlled intersections to roundabouts reduces delay and vehicle stops. Reduction of average intersection delay can range from relatively low to significant (Retting et al., 2002; Russell et al., 2006). 
Pedestrian crossings placed at splitter islands close to the roundabout reduce pedestrian walking distance. When pedestrian-actuated signals are considered for these crossings, from an operational standpoint, it is preferred if the crosswalk is further offset from the circulatory roadway. Placing the signalized crosswalks at a distance from the roundabout reduces the risk of a queue of exiting vehicles spilling back towards the roundabout and blocking the circulatory roadway. The crosswalk only affects the exiting vehicles on the leg on which it is installed (Rouphail et al., 2005). The above consideration applies to signalized pedestrian crossings and should not be applied to unsignalized crossings.

\subsection{Safety Impacts of the Roundabout}

The past safety research of signalized and two-way stop controlled intersections converted to roundabouts indicates substantial and statistically significant reduction in the number of crashes and particularly injury crashes (Rodegerdts et al., 2007). All-waystop-controlled intersections converted to roundabouts, on the other hand, seem to have no safety effect (Rodegerdts et al., 2007; Tyra et al., 2007). The latter results can be explained with already good safety records of all-way-stop-controlled intersections. Furthermore, the safety benefits at rural locations are greater than in urban and suburban settings (Rodegerdts et al., 2007). This difference can be explained by the difference in operating speeds in rural versus urban and suburban areas. Rural areas tend to have higher operating speeds. Thus the speed reduction caused by the roundabout is more significant in rural than in urban or suburban conditions. Due to the lower volumes, roundabouts in rural locations are single-lane installations.

To ensure safe bicycle operations at roundabouts, emphasis should be placed on the junction of exit lanes to the circulatory roadway (Harkey and Carter, 2006). For low traffic volume sites, bicycles may share the circulatory roadway with vehicles. When designing a roundabout for low traffic volumes, the designer should assume that bicycles fully utilize the circulatory lanes. For heavier volume conditions, separate cycle paths or other solutions may be more suitable (Harkey and Carter, 2006). Special design 
provisions for bicycles can be found in the FHWA Roundabout Guide (Robinson et al., 2000) and in the ASSHTO Development of Bicycle Facilities (AASHTO, 1999).

Implementing a bicycle bypass at roundabouts can enhance bicycle safety and reduce the total delay and travel time (Dobbour and Easa).

Figure 6-2 and Figure 6-3 exemplify the safety benefit of a roundabout - elimination of potential crossing conflict points. No other alternative intersection eliminates crossing potential conflict points completely. Because crossing potential conflicts are generally associated with the highest level of severity, eliminating crossing potential conflict points reduces the severity of crashes. As a matter of fact, none of the conflict points at roundabouts are severe (see Table 6-1 and Table 6-2), which makes this solution superior to a four-legged conventional intersection. The total number of potential conflict points at four-legged roundabouts are one-fourth that of a comparable signalized conventional intersection (Table 6-1). There is a two-third reduction in the number of conflict points for a three-legged roundabout compared to a T-intersection.

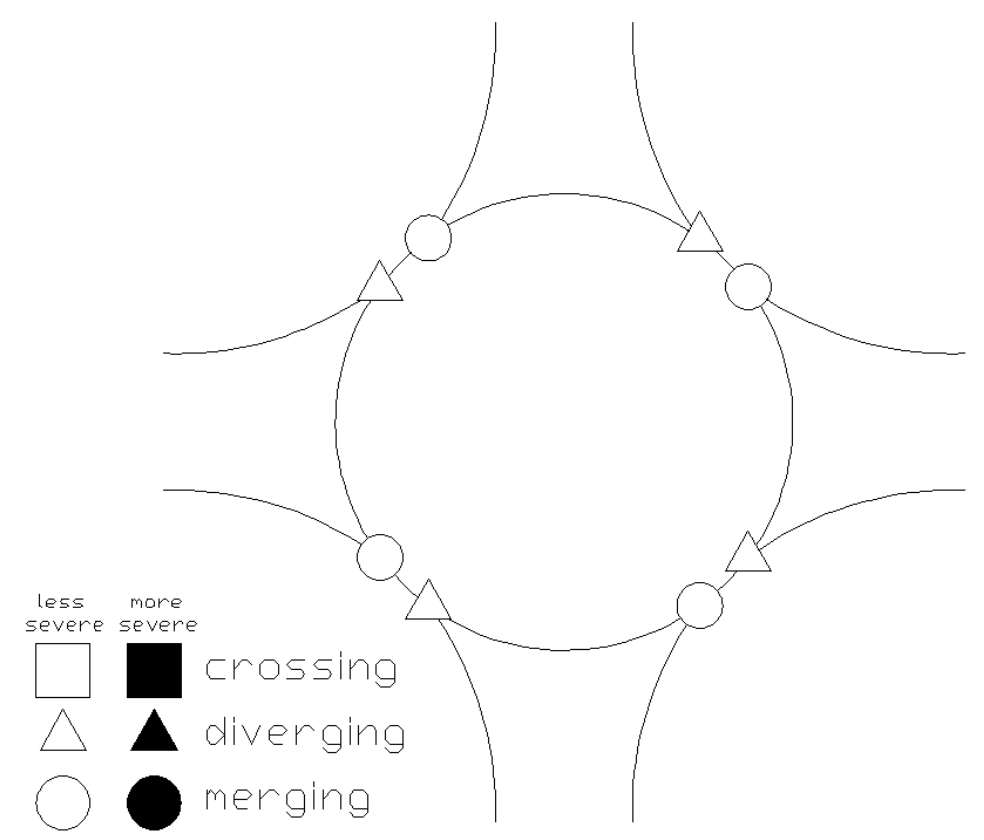

Figure 6-2 Four-legged roundabout potential conflict point diagram 
Table 6-1 Frequency of total crashes for a roundabout intersection

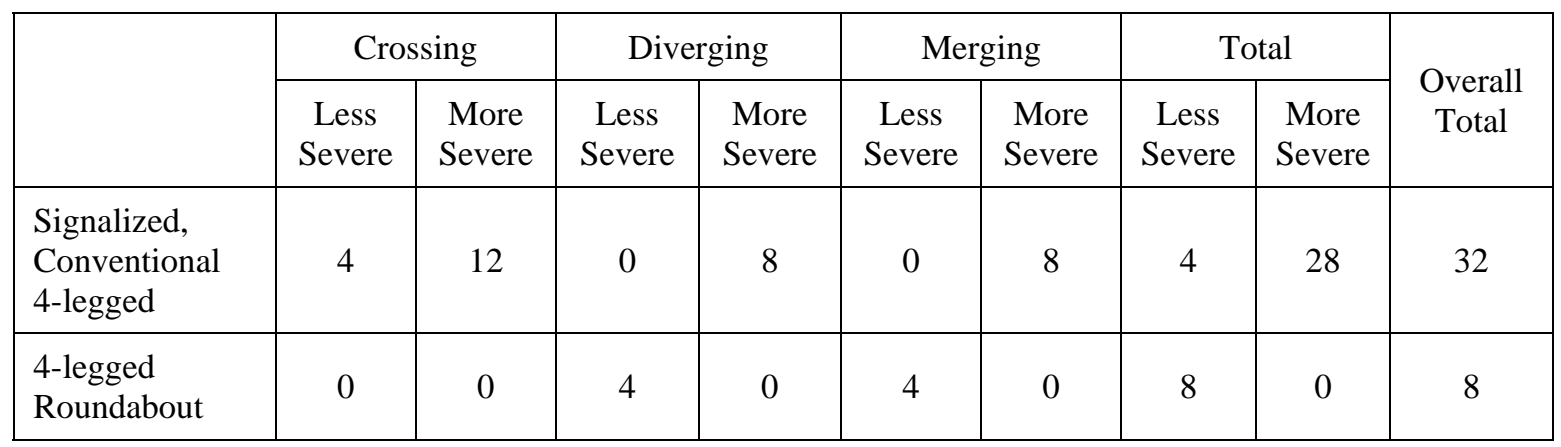

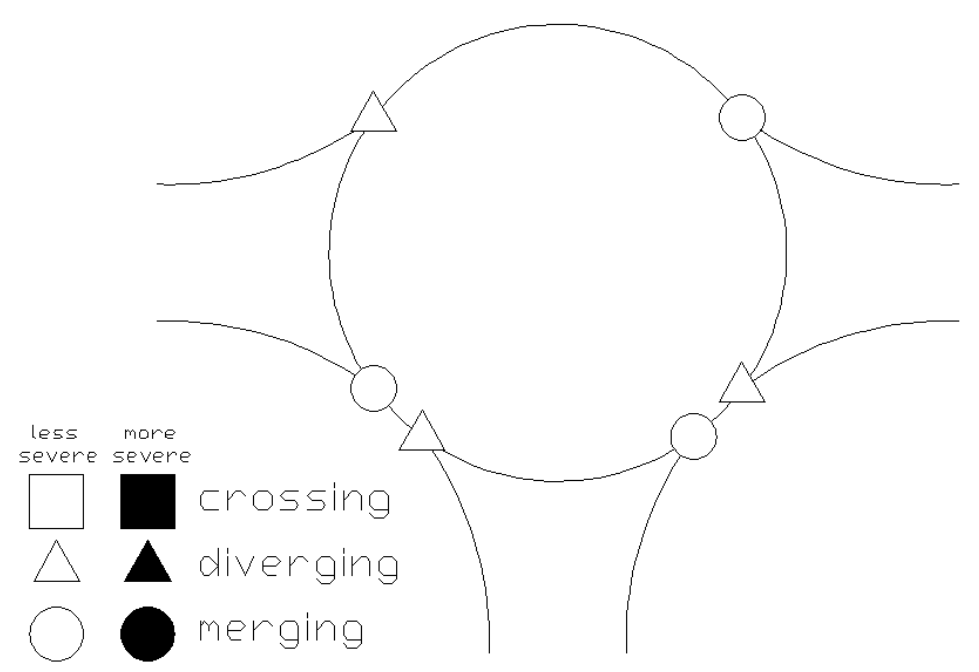

Figure 6-3 Three-legged roundabout potential conflict point diagram

Table 6-2 Frequency of Total Crashes for a Roundabout Intersection

\begin{tabular}{|c|c|c|c|c|c|c|c|c|c|}
\hline & \multicolumn{2}{|c|}{ Crossing } & \multicolumn{2}{|c|}{ Diverging } & \multicolumn{2}{|c|}{ Merging } & \multicolumn{2}{|c|}{ Total } & \multirow{2}{*}{$\begin{array}{c}\text { Overall } \\
\text { Total }\end{array}$} \\
\hline & $\begin{array}{l}\text { Less } \\
\text { Severe }\end{array}$ & $\begin{array}{l}\text { More } \\
\text { Severe }\end{array}$ & $\begin{array}{l}\text { Less } \\
\text { Severe }\end{array}$ & $\begin{array}{l}\text { More } \\
\text { Severe }\end{array}$ & $\begin{array}{l}\text { Less } \\
\text { Severe }\end{array}$ & $\begin{array}{l}\text { More } \\
\text { Severe }\end{array}$ & $\begin{array}{l}\text { Less } \\
\text { Severe }\end{array}$ & $\begin{array}{l}\text { More } \\
\text { Severe }\end{array}$ & \\
\hline $\begin{array}{l}\text { Conventional, } \\
\text { signalized } \\
\text { 3-legged }\end{array}$ & 1 & 2 & 1 & 2 & 1 & 2 & 3 & 6 & 9 \\
\hline $\begin{array}{l}\text { 3-legged } \\
\text { Roundabout }\end{array}$ & 0 & 0 & 3 & 0 & 3 & 0 & 6 & 0 & 6 \\
\hline
\end{tabular}




\section{Superstreet median (SSM) crossover intersection}

The superstreet median (SSM) crossover intersection requires cross-street through movements and left turns to and from the arterial to use the directional crossover (Figure 7-1). This geometric layout allows each direction of the arterial to have its own independent signal timing including different cycle lengths. The lack of interaction between the two arterial directions converts a two-way arterial into two one-way arterials allowing good signal progression in each direction. The cross street through movement is required to make a right turn at the main intersection, then make use of the median U-turn located in the median downstream of the primary signal, and turn right when coming back to the primary intersection (Figure 7-1). Left turns at the main intersection are direct and protected. There is an alternative superstreet median design which removes the direct left turns from the major roadway and allows this movement through a median as found at median u-turn intersections.

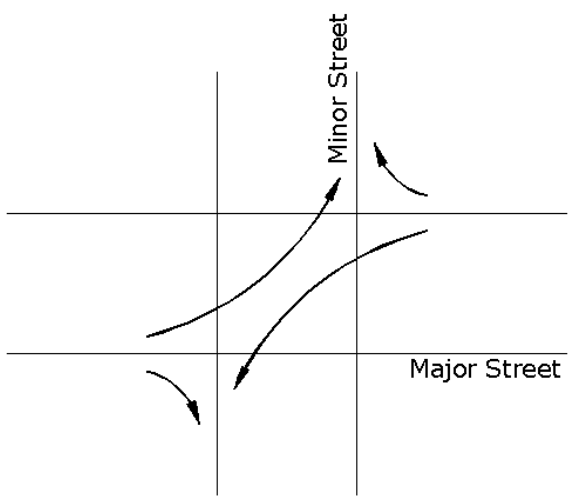

(a) Major Street Turning Movements

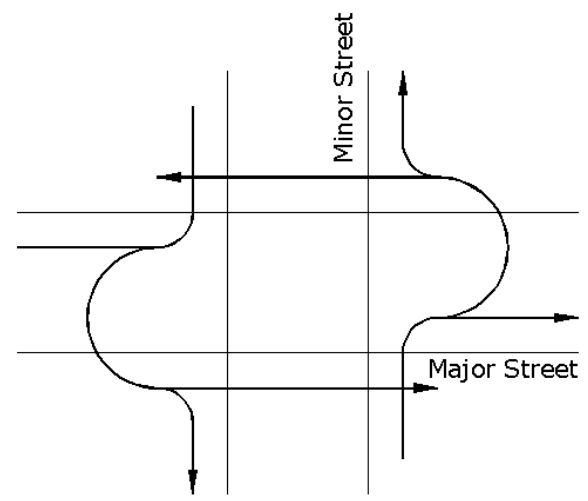

(b) Minor Street Turning Movements

Figure 7-1 Super-street traffic movement 
The superstreet median u-turns shown in Figure 7-1 utilize a two-phase signal.

Prohibition of direct through and left turning movements for the cross street allows the two phase signals to function independently. Thus, different cycle lengths can be used for each direction (Figure 7-2). This characteristic can be used to achieve good coordination with uneven intersection spacing. An arterial street with unevenly spaced conventional intersections can be efficiently coordinated only in one direction while the other direction is typically compromised.

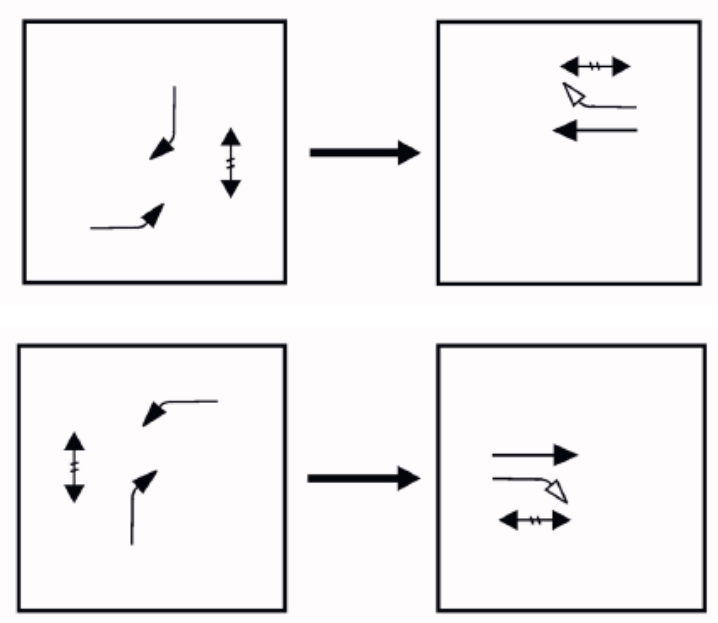

Figure 7-2 Typical phasing for the superstreet median primary intersection (USDOT, 2004)

\subsection{Operational aspects of the superstreet median}

The superstreet median improves performance of the arterial through and left turn movements at the expense of the minor street through and left turn movements that become indirect with longer distances to travel. Therefore, this solution is not desirable for intersections where the cross street carries considerable traffic.

Table 7-1 shows general characteristics of the SSM design and can be used for initial screening for applicable designs. 
Table 7-1 Characteristics of the superstreet median design (Hummer, 1998; Hummer and Reid, 2000)

\begin{tabular}{|c|c|c|c|}
\hline Advantages & Disadvantages & When to Consider & $\begin{array}{l}\text { When not to } \\
\text { Consider }\end{array}$ \\
\hline $\begin{array}{l}\text { - Reduced delay for } \\
\text { through arterial } \\
\text { traffic and for } \\
\text { arterial left turns } \\
\text { - Efficient } \\
\text { progression in both } \\
\text { directions regardless } \\
\text { of signal spacing } \\
\text { - Fewer stops for } \\
\text { arterial through } \\
\text { traffic } \\
\text { - Fewer threats to } \\
\text { crossing pedestrians } \\
\text { - Fewer and more } \\
\text { separated conflict } \\
\text { points }\end{array}$ & $\begin{array}{l}\text { - Driver confusion } \\
\text { - Increased stops, } \\
\text { delay, and travel } \\
\text { distance for cross } \\
\text { street both left turns } \\
\text { and through traffic } \\
\text { - Longer two-stage } \\
\text { crossing for } \\
\text { pedestrians across } \\
\text { the arterial street }\end{array}$ & $\begin{array}{l}\text { • High arterial } \\
\text { through volumes } \\
\text { with low and } \\
\text { moderate cross } \\
\text { street through } \\
\text { volumes. Usually in } \\
\text { suburban arterials } \\
\text { where roadside } \\
\text { development } \\
\text { generates most of } \\
\text { the traffic } \\
\text { • } 50 / 50 \text { arterial } \\
\text { through traffic split } \\
\text { exists for most of } \\
\text { the day with uneven } \\
\text { street spacing }\end{array}$ & $\begin{array}{l}\text { - Arterials with } \\
\text { narrow medians } \\
\text { and no prospect } \\
\text { for obtaining extra } \\
\text { right of way for } \\
\text { widening }\end{array}$ \\
\hline
\end{tabular}

\subsubsection{Superstreet median in an arterial corridor}

With uneven intersection spacing and during peak periods, a superstreet median corridor may provide improvements in overall travel time and average speed as compared to a conventional design (Reid et al., 1999). It should be noted that this benefit may be less significant than the benefit of median u-turn intersections. During off-peak periods, a superstreet median road will operate with similar efficiency as a conventional road (Reid et al., 1999). On the other hand, the superstreet median design becomes more beneficial with the growing ratio of left-turn and through traffic volumes on the major street. 
Table 7-2 summarizes the advantages and disadvantages of a superstreet median as compared to a conventional street with two-way left-turn lanes (TWLTL) at signalized intersections (Reid et al., 1999).

Table 7-2 Superstreet median road compared to a two-way left-turn lane road (based on Reid et al., 1999)

\begin{tabular}{|c|c|}
\hline Advantage & Disadvantage \\
\hline $\begin{array}{l}\text { Two-phase signal operation by removal } \\
\text { of direct left and through from the cross } \\
\text { street } \\
\text { - Perfect progression in both directions } \\
\text { of arterial }\end{array}$ & $\begin{array}{l}\text { - Increased VMT for cross street } \\
\text { movements } \\
\text { - Driver confusion due to discontinued } \\
\text { cross street } \\
\text { - Not beneficial if the cross street } \\
\text { through volumes is considerable } \\
\text { - Greater right of way requirements (25- } \\
50 \text { feet) }\end{array}$ \\
\hline
\end{tabular}

Table 7-3 Summary of the superstreet median intersection (adapted from USDOT, 2004)

\begin{tabular}{|c|c|c|}
\hline Characteristics & Potential Benefits & Potential Liabilities \\
\hline Safety & Fewer conflict points. & None identified. \\
\hline Operations & $\begin{array}{l}\text { Reduced delay for major } \\
\text { street movements. }\end{array}$ & $\begin{array}{l}\text { Longer travel distance and } \\
\text { time for minor street } \\
\text { movements. }\end{array}$ \\
\hline Multimodal & None identified. & $\begin{array}{l}\text { Two-stage pedestrian } \\
\text { crossing. }\end{array}$ \\
\hline Physical & None identified. & Wide median needed. \\
\hline Socioeconomic & None identified. & $\begin{array}{l}\text { Restricted access from the } \\
\text { cross street. }\end{array}$ \\
\hline $\begin{array}{l}\text { Enforcement, Education, } \\
\text { and Maintenance }\end{array}$ & None identified. & $\begin{array}{l}\text { Potential for driver and } \\
\text { pedestrian confusion. }\end{array}$ \\
\hline
\end{tabular}




\subsection{Safety Impacts of the Superstreet Median}

No crash-based studies of the safety impact of a superstreet median were available at the time of writing these guidelines. A simulation-based safety evaluation has yielded mixed results (Kim et al., 2007). The analysis was performed for two cases: a superstreet design with one and two median u-turn lanes. The findings indicated that when compared with a similar conventional intersection, the superstreet with one median u-turn lane is safer (Kim et al., 2007). A superstreet with two median u-turn lanes, on the other hand, was found to be less safe than a comparable conventional intersection (Kim et al., 2007). These results have to be considered with caution because this method of analysis has not been validated.

The potential safety impacts of the superstreet median can also be evaluated through a potential conflict point diagram. Figure 7-3 is a potential conflict point diagram for a superstreet.

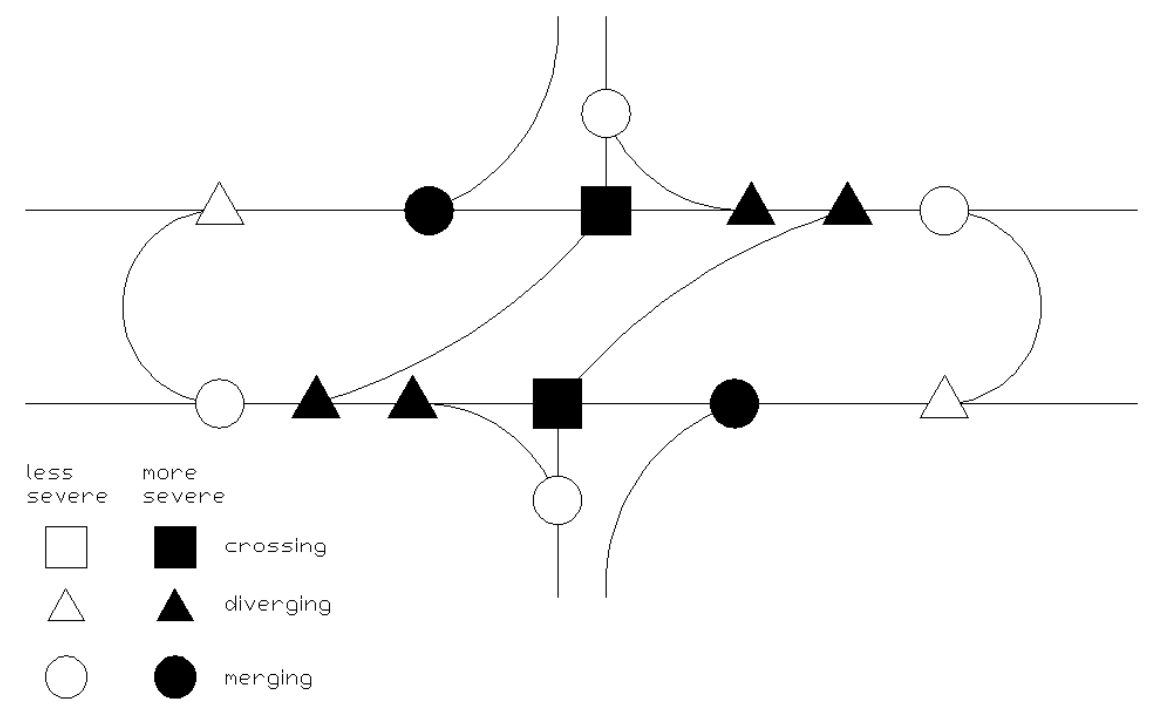

Figure 7-3 Superstreet potential conflict point diagram 
Table 7-4 Comparison of potential conflict points for a superstreet median and a conventional intersection

\begin{tabular}{|c|c|c|c|c|c|c|c|c|c|}
\hline & \multicolumn{2}{|c|}{ Crossing } & \multicolumn{2}{|c|}{ Diverging } & \multicolumn{2}{|c|}{ Merging } & \multicolumn{2}{|c|}{ Total } & \multirow{2}{*}{$\begin{array}{c}\text { Overal } \\
\text { Total }\end{array}$} \\
\hline & $\begin{array}{l}\text { Less } \\
\text { Severe }\end{array}$ & $\begin{array}{l}\text { More } \\
\text { Severe }\end{array}$ & $\begin{array}{l}\text { Less } \\
\text { Severe }\end{array}$ & $\begin{array}{l}\text { More } \\
\text { Severe }\end{array}$ & $\begin{array}{l}\text { Less } \\
\text { Severe }\end{array}$ & $\begin{array}{l}\text { More } \\
\text { Severe }\end{array}$ & $\begin{array}{l}\text { Less } \\
\text { Severe }\end{array}$ & $\begin{array}{c}\text { More } \\
\text { Severe }\end{array}$ & \\
\hline $\begin{array}{l}\text { Conventional, } \\
\text { signalized } \\
\text { 4-legged }\end{array}$ & 4 & 12 & 0 & 8 & 0 & 8 & 4 & 28 & 32 \\
\hline Superstreet & 0 & 2 & 2 & 4 & 4 & 2 & 6 & 8 & 14 \\
\hline
\end{tabular}

As is shown in Figure 7-3, the superstreet median crossover may bring potential safety benefits through the reduction and separation of potential conflict points.

One of the most significant reductions is in the number of crossing potential conflict points from 16, for a conventional intersection, to 2 for the superstreet median crossover. Additionally, the number of diverging potential conflict points is reduced and some of the remaining diverging potential conflict points are possibly converted to less severe potential conflict points. A similar reduction in the number of merge potential conflict points is evident, with an additional benefit of more merge potential conflict points considered to be less severe. Table 7-4 shows that the reduction in the number of potential conflict points for a superstreet median compared to a conventional intersection is more than half. 


\section{Other solutions}

This chapter includes solutions that have only been evaluated on the conceptual level or are suitable only under specific roadway geometric conditions. Alternative intersections discussed in this chapter are the bowtie, continuous green T-intersection (CGT), quadrant roadway intersection (QRI), and upstream signalized crossover (USC).

\subsection{Bowtie intersection}

The bowtie intersection accommodates indirect left turns by the use of roundabouts on the cross street (Figure 8-1). All left turns are prohibited at the primary intersection. The left turning vehicles on the main road turn right at the primary intersection and proceed to make a u-turn at the roundabout. The left turning vehicles on the cross street pass the primary intersection, then make a u-turn and finally turn right at the primary intersection. The concept of the bowtie is similar to an interchange with roundabouts without grade separation. The distance from the primary intersection to each roundabout varies from 200 to 600 feet which is a tradeoff between limiting the extra distance traveled by left turning vehicles and required storage for vehicle queues. 


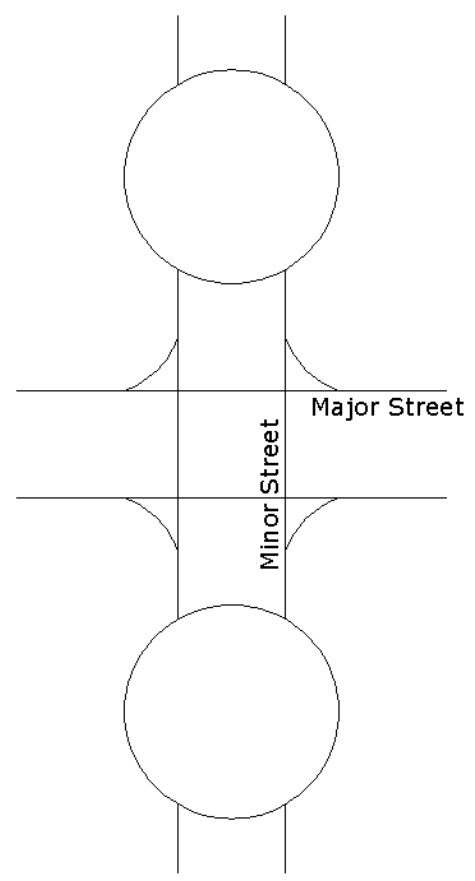

Figure 8-1 Bowtie intersection diagram

Table 8-1 shows general characteristics of bowtie design and can be used for initial screening for applicable designs.

Table 8-1 Characteristics of a bowtie intersection (Hummer, 1998; Hummer and Reid, 2000)

\begin{tabular}{|c|c|c|c|}
\hline Advantages & Disadvantages & $\begin{array}{l}\text { When to } \\
\text { Consider }\end{array}$ & $\begin{array}{l}\text { When not to } \\
\text { Consider }\end{array}$ \\
\hline $\begin{array}{l}\text { - Reduced delay for } \\
\text { through arterial traffic. } \\
\text { - Easier progression for } \\
\text { through arterial. } \\
\text { - Fewer stops for } \\
\text { through traffic } \\
\text { - Fewer threats to } \\
\text { crossing pedestrians } \\
\text { - Fewer and better }\end{array}$ & $\begin{array}{l}\text { - Driver confusion } \\
\text { - Driver disregard of } \\
\text { the left-turn } \\
\text { prohibition at main } \\
\text { intersection } \\
\text { - Increased stops for } \\
\text { left turning traffic } \\
\text { and cross street } \\
\text { through traffic } \\
\text { - Increased travel }\end{array}$ & $\begin{array}{l}\text { • High arterial } \\
\text { through volumes } \\
\text { with low and } \\
\text { moderate left } \\
\text { turn volumes and } \\
\text { low and } \\
\text { moderate cross } \\
\text { street volumes } \\
\text { - Arterials with } \\
\text { narrow or } \\
\text { nonexistent }\end{array}$ & $\begin{array}{l}\text { - High left turn } \\
\text { volumes with } \\
\text { spillback } \\
\text { potential } \\
\text { - Close spacing } \\
\text { between } \\
\text { adjacent } \\
\text { intersections on } \\
\text { the cross road }\end{array}$ \\
\hline
\end{tabular}




\begin{tabular}{|c|c|c|}
\hline $\begin{array}{l}\text { separated conflict } \\
\text { points }\end{array}$ & $\begin{array}{l}\text { distance for left } \\
\text { turning traffic }\end{array}$ & medians \\
\hline $\begin{array}{l}\text { - Increased capacity at } \\
\text { the main intersection }\end{array}$ & • Difficult U-turns & \\
\hline
\end{tabular}

For more information regarding simulation results of bowtie intersections see Boone and Hummer, 1995; Boone and Hummer, 1995; and Hummer and Boone, 1995.

\subsubsection{Safety Impacts of the Bowtie Intersection}

Figure 8-2 shows the potential conflict points at a bowtie intersection. When compared with Figure 2-2, a potential safety benefit that the bowtie intersection may provide is separation of the conflict points.

Table 8-2 shows that a primary benefit that the bowtie intersection provides is a reduction in the total number of conflict points. This reduction is entirely in the crossing potential conflict point category. Additionally, although the bowtie and conventional intersection have the same number of diverging and merging potential conflict points, half of the respective potential conflict points are expected to be less severe for the bowtie intersection. 


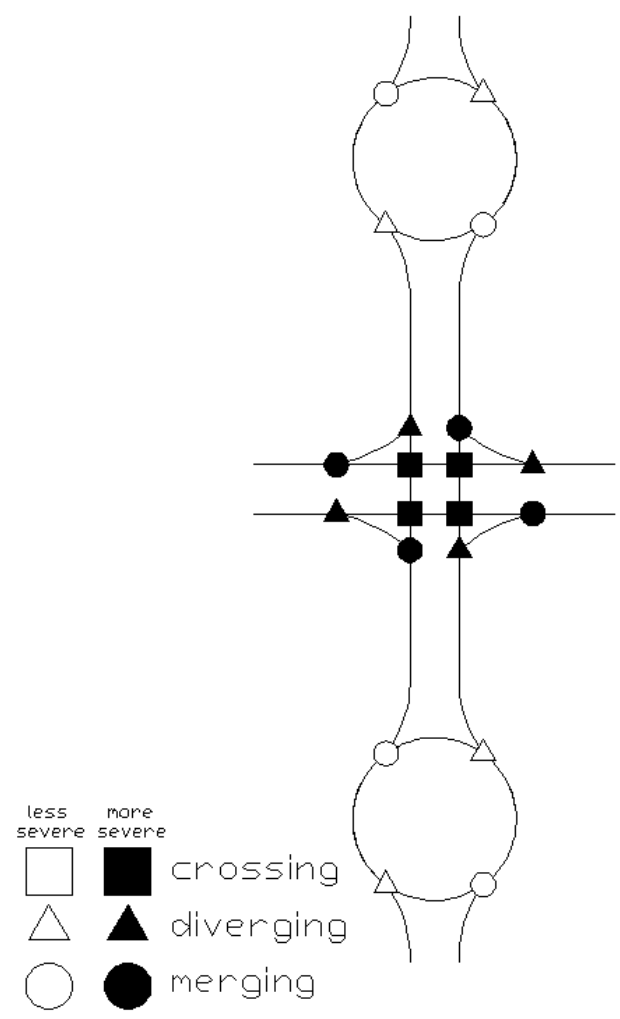

Figure 8-2 Potential conflict diagram for a bowtie Intersection

Table 8-2 Comparison of potential conflict points for a bowtie and a conventional intersection

\begin{tabular}{|c|c|c|c|c|c|c|c|c|c|}
\hline & \multicolumn{2}{|c|}{ Crossing } & \multicolumn{2}{|c|}{ Diverging } & \multicolumn{2}{|c|}{ Merging } & \multicolumn{2}{|c|}{ Total } & \multirow{2}{*}{$\begin{array}{c}\text { Overall } \\
\text { Total }\end{array}$} \\
\hline & $\begin{array}{l}\text { Less } \\
\text { Severe }\end{array}$ & $\begin{array}{l}\text { More } \\
\text { Severe }\end{array}$ & $\begin{array}{l}\text { Less } \\
\text { Severe }\end{array}$ & $\begin{array}{l}\text { More } \\
\text { Severe }\end{array}$ & $\begin{array}{c}\text { Less } \\
\text { Severe }\end{array}$ & $\begin{array}{l}\text { More } \\
\text { Severe }\end{array}$ & $\begin{array}{l}\text { Less } \\
\text { Severe }\end{array}$ & $\begin{array}{l}\text { More } \\
\text { Severe }\end{array}$ & \\
\hline $\begin{array}{l}\text { Conventional, } \\
\text { Signalized } \\
\text { 4-legged }\end{array}$ & 4 & 12 & 0 & 8 & 0 & 8 & 4 & 28 & 32 \\
\hline Bowtie & 0 & 4 & 4 & 4 & 4 & 4 & 8 & 12 & 20 \\
\hline
\end{tabular}




\subsection{Continuous Green-T intersection (CGT)}

The continuous green T-intersection is applicable only to T-intersections (3-legged intersections). Three-phase traffic signals control left turns to and from the major road. The outside lane receives a green signal display during all phases (Figure 8-3). The separation between the inside lane from the lane with the continuous green signal is an important aspect of this design. The separation should extend several hundred feet upstream and downstream from the intersection to minimize weaving. This separation can be achieved by using raised reflectors or rumble strips (Hummer, 1998). A raised median prevents vehicles from crossing the separation. A limitation of the continuous green T-intersection is that it does not provide a phase for pedestrian crossing (Hummer, 1998). This aspect of the design limits its use with heavy pedestrian volumes unless a pedestrian overpass or underpass can be justified.

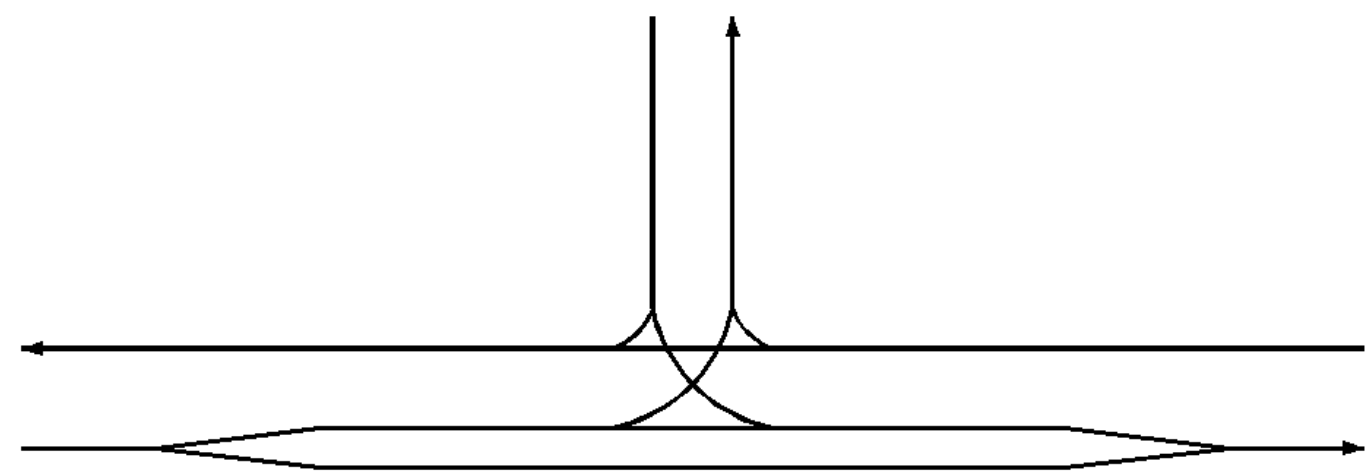

Figure 8-3 Diagram of a continuous green T-intersection

\subsubsection{Operational Impacts of the Continuous Green T-Intersection}

Benefits achieved with the continuous green T-intersection (CGT) design are highly dependent on the percent of drivers choosing the continuous green movement. For a four 
lane arterial, you might expect approximately three-fourths of drivers to choose the continuous green lane. Only a slight increase may be observed on a six lane arterial (Boone and Hummer, 1995).

Table 8-3 shows general characteristics of a continuous green T-intersection design and it can be used for initial screening for applicable designs.

Table 8-3 Characteristics of a continuous green T-intersection (Hummer, 1998)

\begin{tabular}{|c|c|c|}
\hline Advantages & Disadvantages & When to Consider \\
\hline $\begin{array}{l}\text { - Reduced delay for } \\
\text { through arterial traffic in } \\
\text { one direction } \\
\text { - Reduced stops for } \\
\text { through arterial traffic in } \\
\text { one direction }\end{array}$ & $\begin{array}{l}\text { - Driver and pedestrian } \\
\text { confusion } \\
\text { - Driver disregard of the } \\
\text { separation between the through } \\
\text { lanes } \\
\text { - No signal protection for } \\
\text { pedestrians to cross the arterial } \\
\text { - Increased lane changing } \\
\text { conflicts before and after the } \\
\text { separation of through lanes } \\
\text { - Restricted access to parcels } \\
\text { adjacent to the continuous green } \\
\text { through lanes }\end{array}$ & $\begin{array}{l}\text { - At signalized three } \\
\text { approach intersections } \\
\text { with moderate to low } \\
\text { left-turn volumes from } \\
\text { the minor-street and high } \\
\text { arterial through volumes, } \\
\text { where there are no } \\
\text { crossing pedestrians and } \\
\text { few driveways along the } \\
\text { top of } T\end{array}$ \\
\hline
\end{tabular}

\subsubsection{Safety Impacts of the Continuous Green T-Intersection}

No research on the safety impacts of the continuous green T-intersection is available.

Figure 8-4 below shows the potential conflict point diagram for the continuous green Tintersection. 


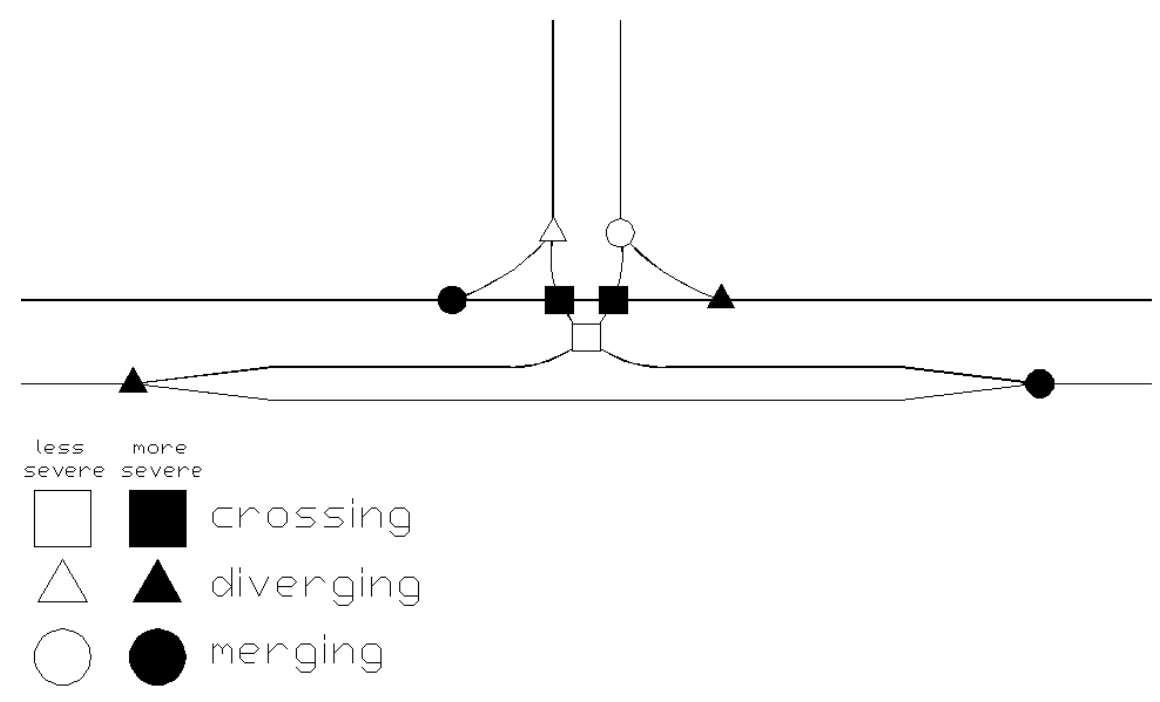

Figure 8-4 Potential conflict point diagram for a continuous green T-intersection

A continuous green T-intersection provides no reduction in the number of conflict points. Therefore, this design appears to only provide capacity benefits.

Table 8-4 Comparison of potential conflict points for a continuous green $T$-intersection and a conventional intersection

\begin{tabular}{|c|c|c|c|c|c|c|c|c|c|}
\hline & \multicolumn{2}{|c|}{ Crossing } & \multicolumn{2}{|c|}{ Diverging } & \multicolumn{2}{|c|}{ Merging } & \multicolumn{2}{|c|}{ Total } & \multirow{2}{*}{$\begin{array}{c}\text { Overall } \\
\text { Total }\end{array}$} \\
\hline & $\begin{array}{c}\text { Less } \\
\text { Severe }\end{array}$ & $\begin{array}{l}\text { More } \\
\text { Severe }\end{array}$ & $\begin{array}{c}\text { Less } \\
\text { Severe }\end{array}$ & $\begin{array}{c}\text { More } \\
\text { Severe }\end{array}$ & $\begin{array}{c}\text { Less } \\
\text { Severe }\end{array}$ & $\begin{array}{l}\text { More } \\
\text { Severe }\end{array}$ & $\begin{array}{c}\text { Less } \\
\text { Severe }\end{array}$ & $\begin{array}{c}\text { More } \\
\text { Severe }\end{array}$ & \\
\hline $\begin{array}{l}\text { Conventional } \\
\text { 3-legged }\end{array}$ & 1 & 2 & 1 & 2 & 1 & 2 & 3 & 6 & 9 \\
\hline $\begin{array}{l}\text { Continuous } \\
\text { Green-T }\end{array}$ & 1 & 2 & 1 & 2 & 1 & 2 & 3 & 6 & 9 \\
\hline
\end{tabular}

\subsection{Paired intersection}

Paired Intersections are formed by two consecutive intersections where direct left turns from the major road is allowed at one intersection and a pair of direct left turns to the major road is allowed at the second intersection. Other left turns at these two intersections are forbidden and they are replaced by indirect left turns performed on an adjacent network of streets. Convenient traffic circulation throughout the corridor can be 
provided through continuous two-way collector roads parallel to the arterial. The collector roads must be set back at least several hundred feet from the arterial to avoid queue spillback (Hummer, 1998). The intersections between the cross streets and the parallel collector roads may be stop controlled or signalized depending on the traffic volumes and other factors (Hummer, 1998). Figure 8-5 provides a schematic of the split intersection.

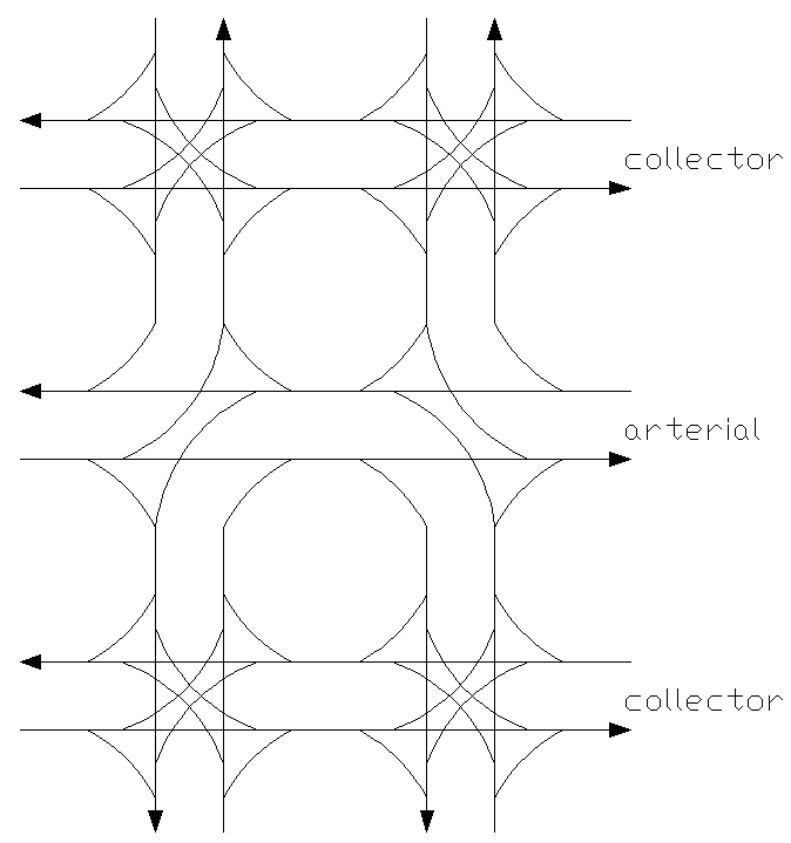

Figure 8-5 Traffic flows for a paired intersection

Table 8-7 shows general characteristics of a paired intersection design and can be used for initial screening for applicable designs. 
Table 8-5 Characteristics of a paired intersection (Hummer, 1998)

\begin{tabular}{|c|c|c|c|}
\hline Advantages & Disadvantages & $\begin{array}{l}\text { When to } \\
\text { Consider }\end{array}$ & $\begin{array}{l}\text { When not to } \\
\text { Consider }\end{array}$ \\
\hline $\begin{array}{l}\text { - Reduced delay for } \\
\text { through arterial } \\
\text { traffic. } \\
\text { - Fewer stops for } \\
\text { through traffic } \\
\text { - Easier progression } \\
\text { for through arterial } \\
\text { traffic, and with the } \\
\text { left merge variation } \\
\text { “perfect” two-way } \\
\text { progression } \\
\text { - Fewer threats to } \\
\text { crossing pedestrians } \\
\text { - Fewer and more } \\
\text { separated conflict } \\
\text { points }\end{array}$ & $\begin{array}{l}\text { - Driver and pedestrian } \\
\text { confusion } \\
\text { - Increased travel } \\
\text { distances for cross-street } \\
\text { through traffic and for } \\
\text { some left-turning traffic } \\
\text { - Increased delay for cross } \\
\text { street through traffic and } \\
\text { for some left turn traffic } \\
\text { - Increased stops for cross } \\
\text { street through traffic and } \\
\text { for some left turning } \\
\text { traffic } \\
\text { - Slow two-stage crossing } \\
\text { for pedestrians on the } \\
\text { arterial }\end{array}$ & $\begin{array}{l}\text { - High arterial } \\
\text { through } \\
\text { volumes with } \\
\text { low cross street } \\
\text { through } \\
\text { volumes } \\
\text { - Means to build } \\
\text { and operate the } \\
\text { parallel } \\
\text { collector road } \\
\text { are available }\end{array}$ & $\begin{array}{l}\text { - Existing } \\
\text { parallel streets } \\
\text { are not capable } \\
\text { of carrying } \\
\text { additional } \\
\text { traffic } \\
\text { - There is no } \\
\text { means to build } \\
\text { and operate } \\
\text { parallel } \\
\text { collector roads }\end{array}$ \\
\hline
\end{tabular}

\subsubsection{Safety Impacts of the Paired Intersection}

Research on the safety benefits of paired intersections had not been conducted by the time of writing these guidelines. Qualitative analysis of the safety benefits indicates a reduction in the number of potential conflict points and increased separation between these points. Figure 8-6 illustrates these findings. 


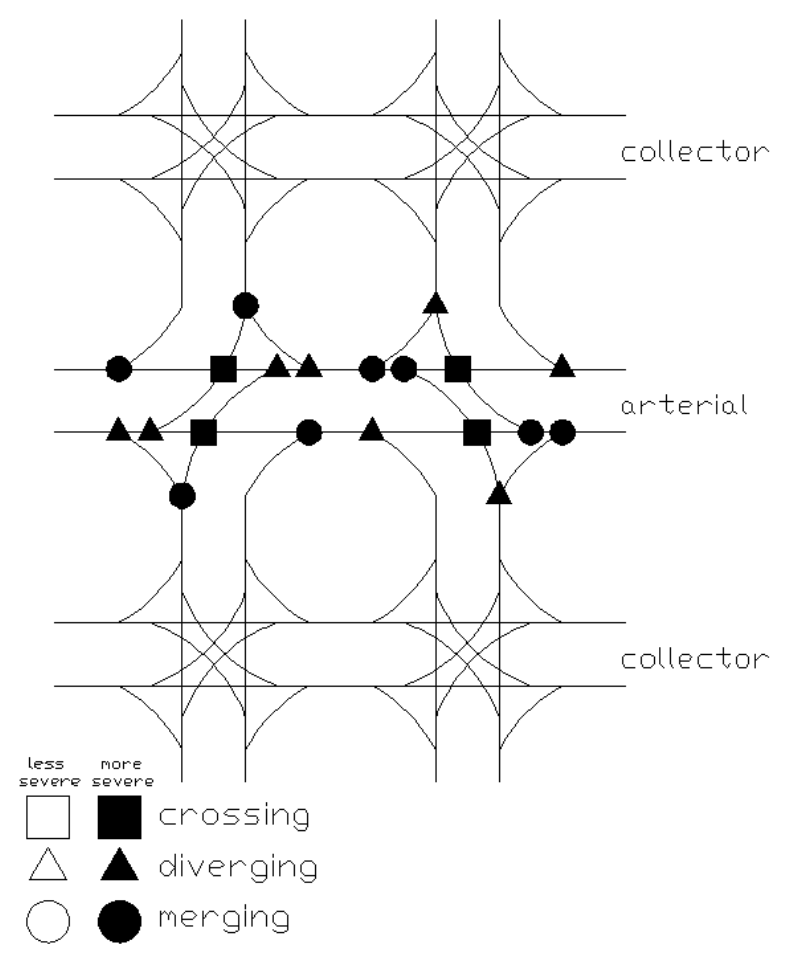

Figure 8-6 Potential conflict points for a paired intersection

Table 8-6 Comparison of potential conflict points for a paired intersection and a conventional intersection

\begin{tabular}{|c|c|c|c|c|c|c|c|c|c|}
\hline & \multicolumn{2}{|c|}{ Crossing } & \multicolumn{2}{|c|}{ Diverging } & \multicolumn{2}{|c|}{ Merging } & \multicolumn{2}{|c|}{ Total } & \multirow{2}{*}{$\begin{array}{c}\text { Overall } \\
\text { Total }\end{array}$} \\
\hline & $\begin{array}{l}\text { Less } \\
\text { Severe }\end{array}$ & $\begin{array}{l}\text { More } \\
\text { Severe }\end{array}$ & $\begin{array}{l}\text { Less } \\
\text { Severe }\end{array}$ & $\begin{array}{l}\text { More } \\
\text { Severe }\end{array}$ & $\begin{array}{l}\text { Less } \\
\text { Severe }\end{array}$ & $\begin{array}{l}\text { More } \\
\text { Severe }\end{array}$ & $\begin{array}{l}\text { Less } \\
\text { Severe }\end{array}$ & $\begin{array}{l}\text { More } \\
\text { Severe }\end{array}$ & \\
\hline $\begin{array}{l}\text { Conventional, } \\
\text { Signalized, } \\
\text { 4-legged }\end{array}$ & 4 & 12 & 0 & 8 & 0 & 8 & 4 & 28 & 32 \\
\hline $\begin{array}{l}\text { Paired } \\
\text { Intersection }\end{array}$ & 0 & 4 & 0 & 8 & 0 & 8 & 0 & 20 & 20 \\
\hline
\end{tabular}

Table 8-6 provides a comparison between the potential conflict points for a paired intersection with that of a comparable conventional intersection. Table 8-6 shows that the paired intersection brings some potential safety benefits because of a reduction in the total number of potential conflict points. The reduction in potential conflict points is only in the crossing category. As aforementioned, reducing the number of crossing potential conflict points is particularly beneficial because crossing conflicts tend to be the most severe conflict type at an intersection. 


\subsection{Quadrant roadway intersection (QRI)}

The quadrant roadway intersection eliminates left turns at the main intersection with a two-way connector which can be located in any of the four quadrants. In Figure 8-7 the connector roadway is located in the bottom left quadrant. The minor two T-intersections allow for direct left turns and may be stop controlled or signalized. Instead of making left turns at the primary intersection, drivers will have to make appropriate turning maneuvers on the minor T-intersections to direct them on the desired route (Figure 8-8). Turning maneuvers carried out by drivers on the minor T-intersections will be dependent upon which quadrant the connector roadway is located. Like the jughandle alternatives, the flexibility associated with the location of the connector roadway makes this alternative appealing when the existing land development eliminates the possibility of applying other alternative intersections.

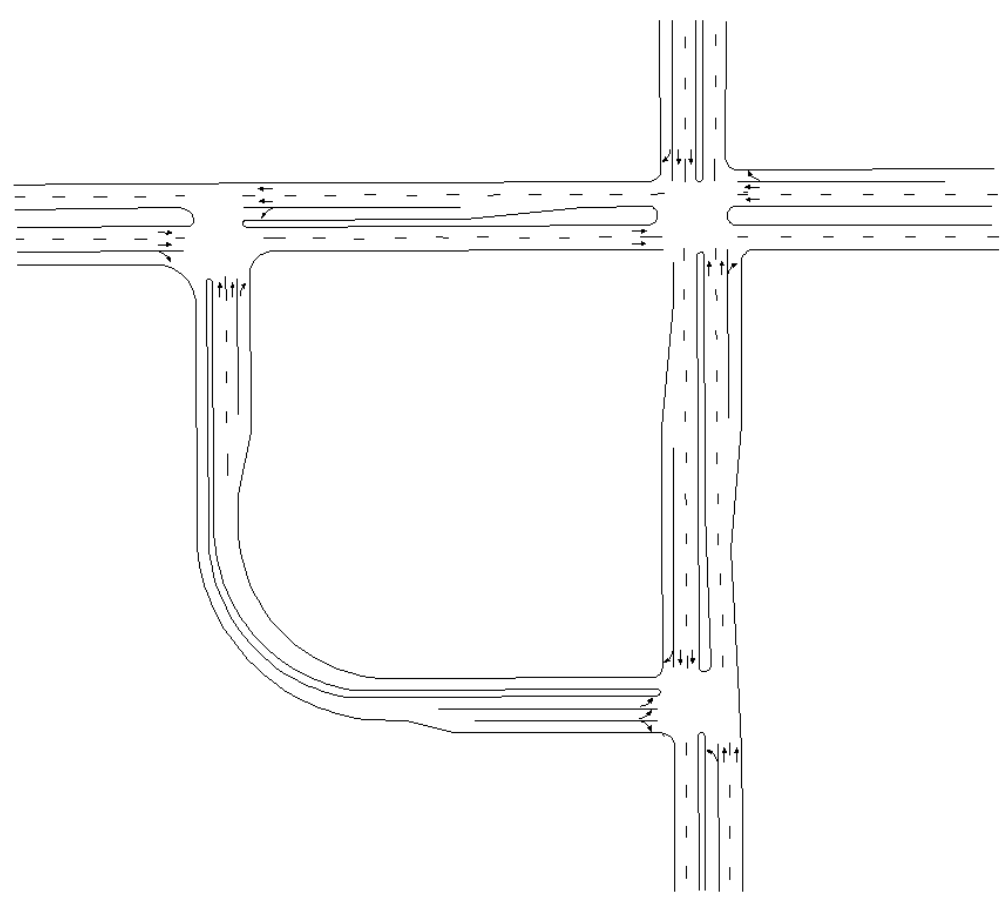

Figure 8-7 Diagram of a quadrant roadway intersection [adapted from Reid and Hummer, 2001] 


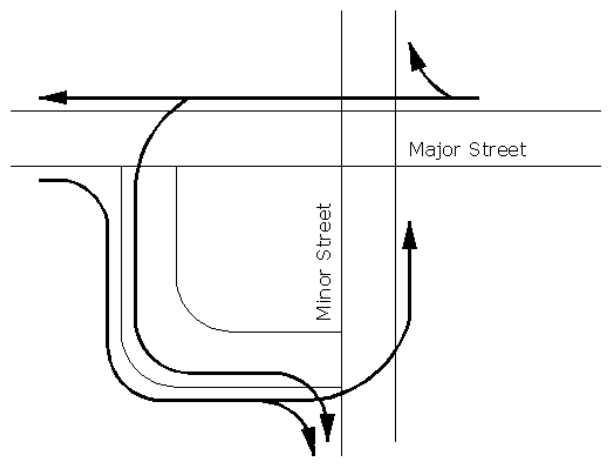

(a) Major Street Turning Movements

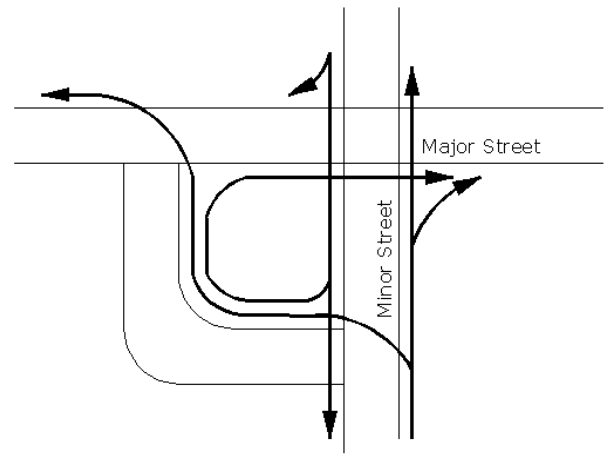

(b) Minor Street Turning Movements

Figure 8-8 Quadrant roadway intersection traffic patterns with the quadrant located in the bottom left corner

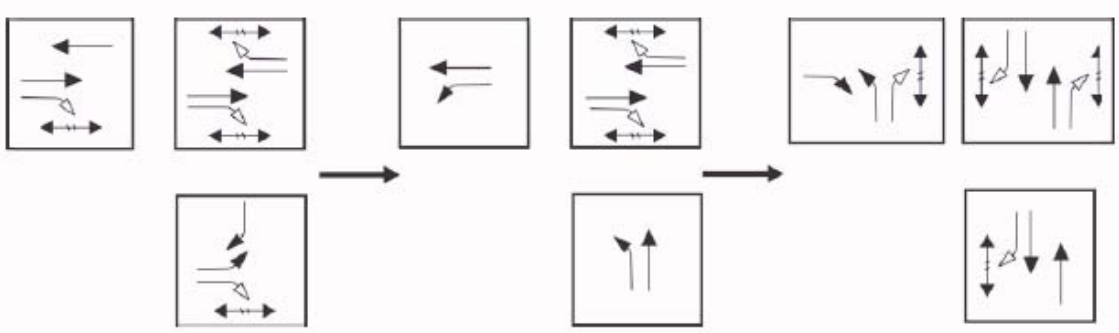

Figure 8-9 Phasing plan for the quadrant roadway intersection (Hummer and Reid, 2000)

A quadrant roadway intersection operated by a single controller can bring slight reductions in travel time and more significant reductions in queuing when compared with a conventional intersection (Reid, 2000). The reduction in travel time for the through movement will be slight, while the delay at the primary intersection and maximum queue length will be substantially reduced (Reid, 2000). Such a large reduction of delay and maximum queue length at the primary intersection is due to the fact that the delay for the quadrant roadway intersection is distributed between the primary intersection and the two secondary T-intersections. As the through and left-turn volumes increase, the quadrant roadway intersection design outperforms the conventional design by a higher margin (Reid, 2000). The secondary intersection on the major road should be coordinated with 
the primary intersection so that the through movement does not have to stop more than once.

The quadrant roadway intersection reduces stopped delay and system travel time without adding lanes on the major road.

Table 8-7 Characteristics of the quadrant roadway intersection based on (Reid, 2000)

\begin{tabular}{|l|l|}
\hline Advantages & Disadvantages \\
\hline$\bullet$ Reduced total intersection delay & $\bullet$ Increased travel distance for left turns \\
$\bullet$ Reduced queuing under heavy volumes & $\bullet$ Increased stops per vehicle for left turns \\
$\bullet$ Fewer vehicular conflict points & $\bullet$ Driver confusion \\
$\bullet$ Narrower intersection width & $\bullet$ Additional right-of-way for the quadrant \\
& roadway \\
& $\bullet$ Additional signing \\
\hline
\end{tabular}

\subsubsection{Safety Impacts of the Quadrant Roadway}

Research on the safety benefits of the quadrant roadway intersection had not been conducted by the time of writing these guidelines.

Figure 8-10 provides a visual of the potential conflict points for a quadrant roadway intersection. As can be seen when comparing Figure 8-10 with Figure 2-2, the quadrant roadway intersection separates the conflict points to a greater degree than a comparable conventional intersection, which could produce some safety benefits. 


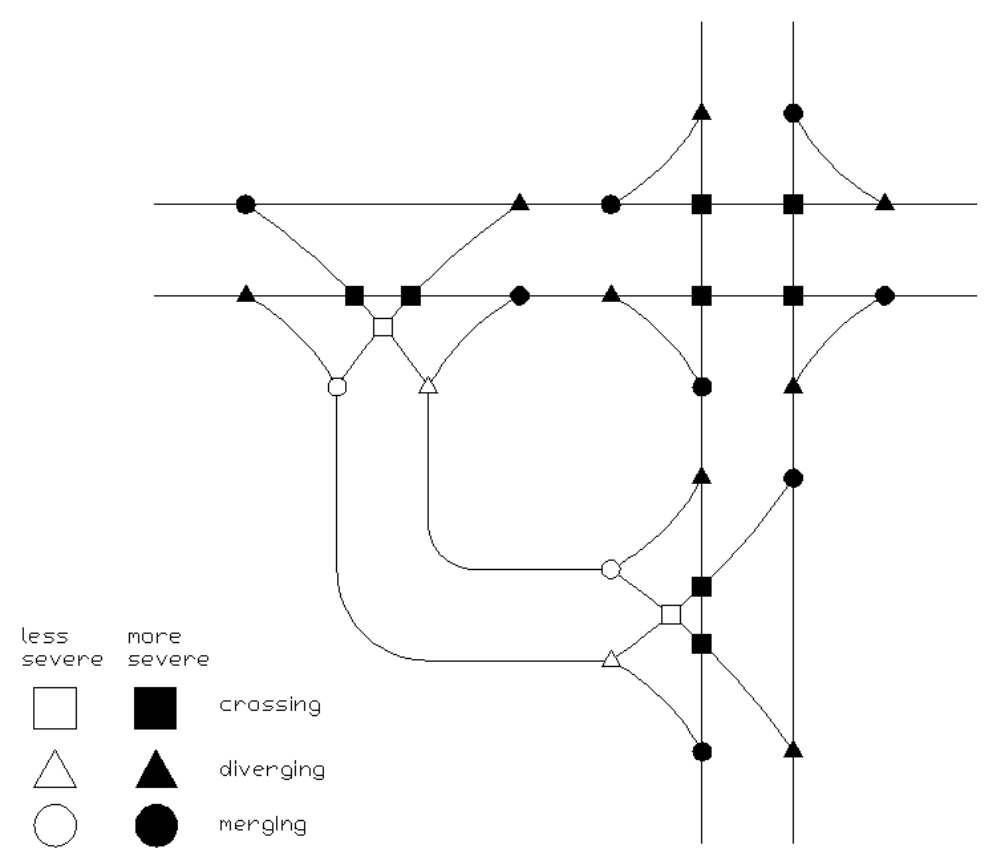

Figure 8-10 Quadrant roadway intersection potential conflict point diagram

Table 8-8 Comparison of potential conflict points for a quadrant roadway intersection and a conventional intersection

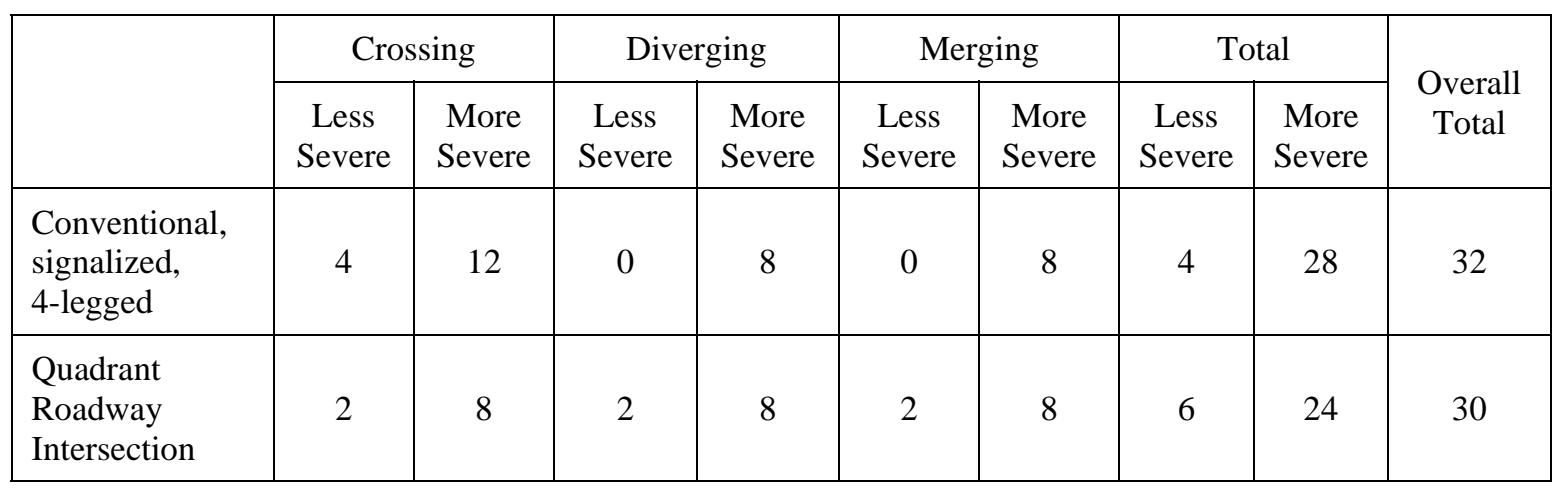

Table 8-8 summarizes the potential conflict points of a quadrant roadway intersection in comparison to potential conflict points for a conventional, signalized, four-legged intersection. The quadrant roadway intersection provides little reduction in the total number of potential conflict points. It does, however, sufficiently reduce the number of crossing potential conflict points, particularly those considered to be more severe in nature. In general, the quadrant roadway intersection seems to transfer some of the 
crossing potential conflict points found in a conventional intersection to diverging and merging conflict types. The number of diverging and merging potential conflict points both increase by two, respectively, in the less severe category. Therefore, the overall potential safety benefits brought by the quadrant roadway intersection are a reduction in the number of crossing potential conflict points and further separation of potential conflict points.

\subsection{Split intersection}

The split intersection separates the primary two-way street segment in the vicinity of the intersection into two one-way streets resembling an at-grade diamond (Figure 8-11). As such, the split intersection can be used as an intermediate phase to the creation of an interchange (Bared and Kaisar, 2000; Polus and Cohen, 1997). Traffic signals at the two separated intersections run a three phase cycle operation. It is recommended that a single controller operates both intersections. Using a single controller eliminates the risk of poor offset, which can occur when two separate controllers loose coordination. A potential consequence of poor offsets is an operational failure of the intersection under heavy volumes.

\subsubsection{Operational Impacts of the Split Intersection}

A split intersection has the potential to carry higher traffic volumes and reduce the delay for each vehicle with appropriate signal timing. With an increase in approach volumes and proportion of left turns, benefits in reducing delay at a split intersection, as compared to a conventional intersection, increase (Bared and Kaisar, 2000). 


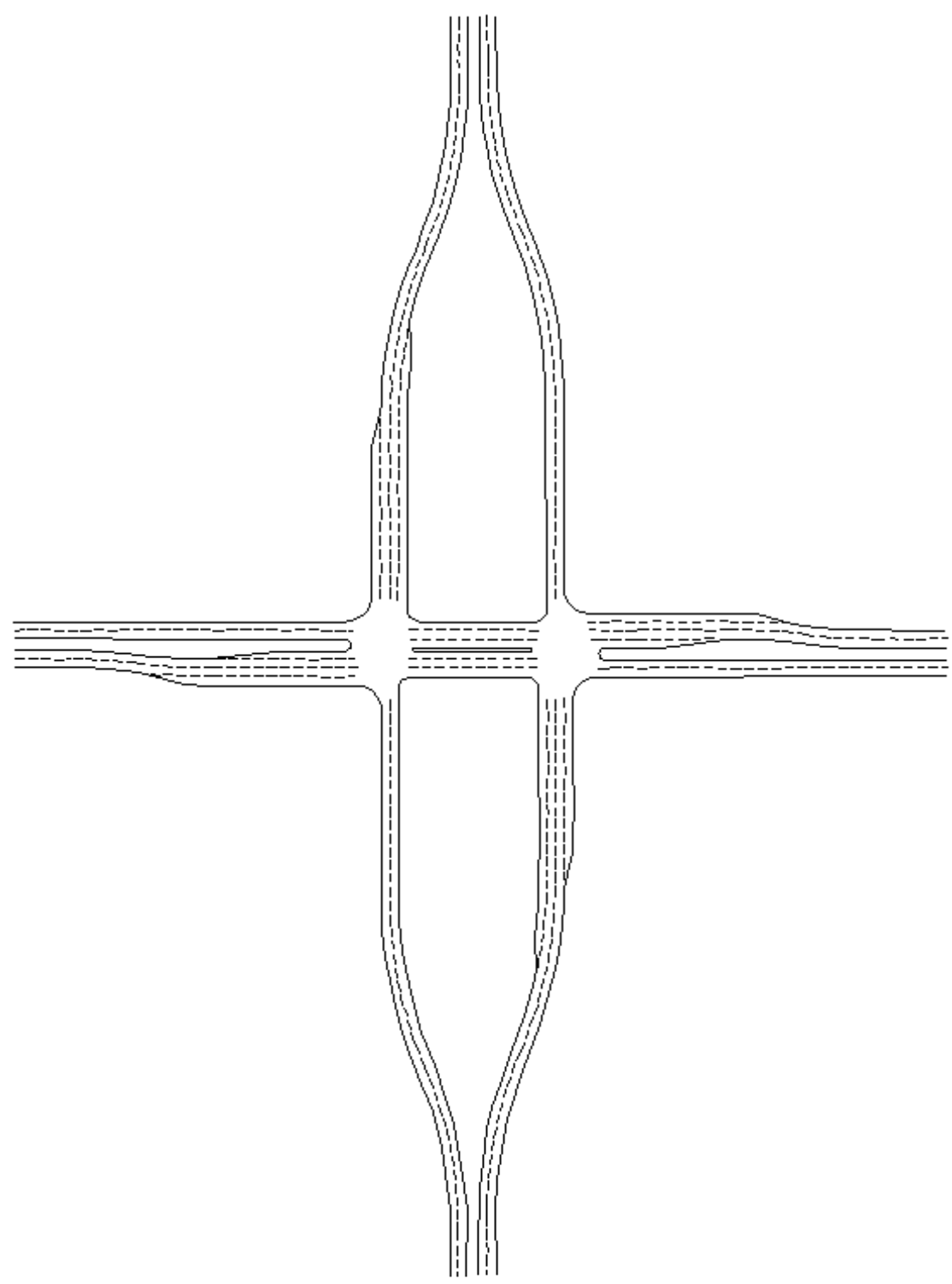

Figure 8-11 Diagram of a split intersection (adapted from Bared and Kaisar, 2000)

\subsubsection{Safety Impacts of the Split Intersection}

Research on the safety benefits of the split intersection had not been conducted by the time of writing these guidelines. As shown in Figure 8-12, a potential safety benefit of a split intersection as compared to a conventional intersection is further separation in potential conflict points. 


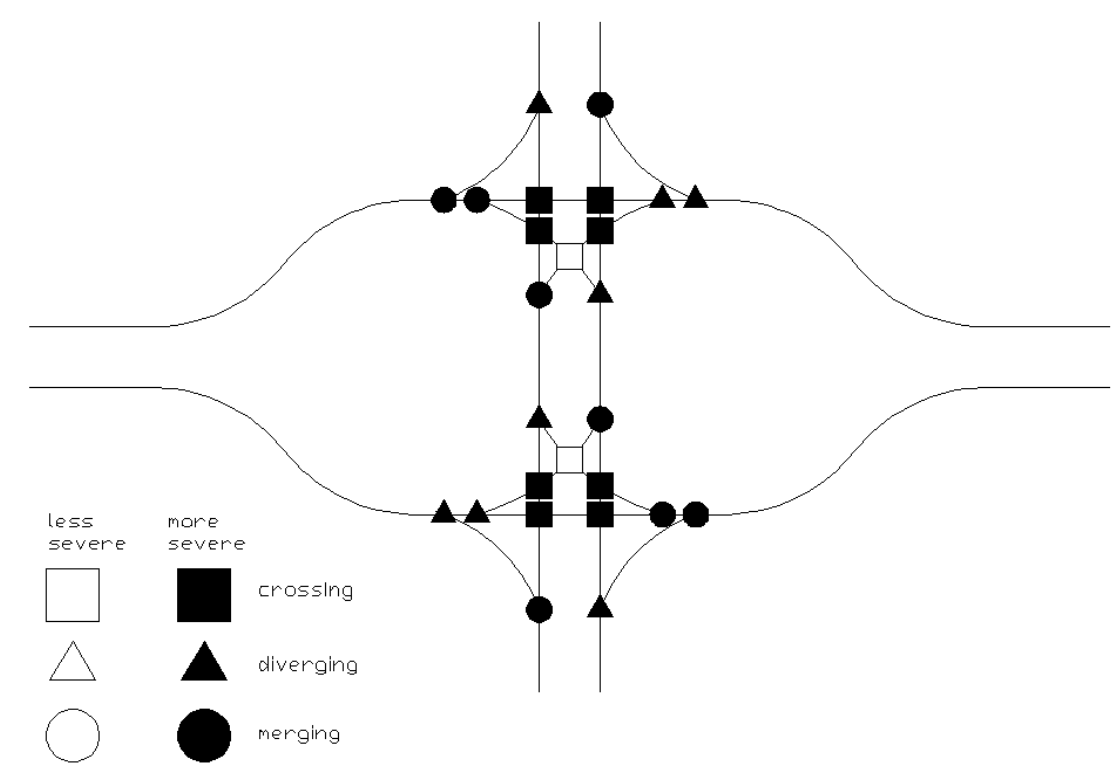

Figure 8-12 Split intersection potential conflict points

Table 8-9 provides a comparison of the number of potential conflict points for a split intersection with a comparable conventional intersection. Overall, the split intersection provides a reduction in the total number of potential conflict points. The reduction in the number of potential conflict points is only in the crossing conflict point category. The split intersection reduces the number of crossing conflict points in both the less and more severe categories. There is a greater reduction in the more severe category which is especially desirable.

Table 8-9 Comparison of potential conflict points for a split intersection and a conventional intersection

\begin{tabular}{|l|c|c|c|c|c|c|c|c|c|}
\hline & \multicolumn{2}{|c|}{ Crossing } & \multicolumn{2}{c|}{ Diverging } & \multicolumn{2}{c|}{ Merging } & \multicolumn{2}{|c|}{ Total } & Overall \\
\cline { 2 - 9 } & $\begin{array}{c}\text { Less } \\
\text { Severe }\end{array}$ & $\begin{array}{c}\text { More } \\
\text { Severe }\end{array}$ & $\begin{array}{c}\text { Less } \\
\text { Severe }\end{array}$ & $\begin{array}{c}\text { More } \\
\text { Severe }\end{array}$ & $\begin{array}{c}\text { Less } \\
\text { Severe }\end{array}$ & $\begin{array}{c}\text { More } \\
\text { Severe }\end{array}$ & $\begin{array}{c}\text { Less } \\
\text { Severe }\end{array}$ & $\begin{array}{c}\text { More } \\
\text { Severe }\end{array}$ & \\
\hline $\begin{array}{l}\text { Conventional, } \\
\text { signalized, } \\
\text { 4-legged }\end{array}$ & 4 & 12 & 0 & 8 & 0 & 8 & 4 & 28 & 32 \\
\hline $\begin{array}{l}\text { Split } \\
\text { Intersection }\end{array}$ & 2 & 8 & 0 & 8 & 0 & 8 & 2 & 24 & 26 \\
\hline
\end{tabular}




\subsection{Upstream Signalized Crossover}

The upstream signalized crossover (USC) intersection is an alternative intersection which eliminates left turn opposing conflicts by crossing left turns with the through traffic to the left side of the roadway prior to the primary intersection on all four approaches (Figure 8-13). Crossing of the through movements and left turns prior to the primary intersection is accomplished through secondary signals coordinated with the primary signal. Traffic is allowed to cross back to the right side of the road after the primary intersection at a second, secondary signal. The optimum location of the secondary intersection is a function of the operating speed and the desired green-band widths (Tabernero et al., 2008).

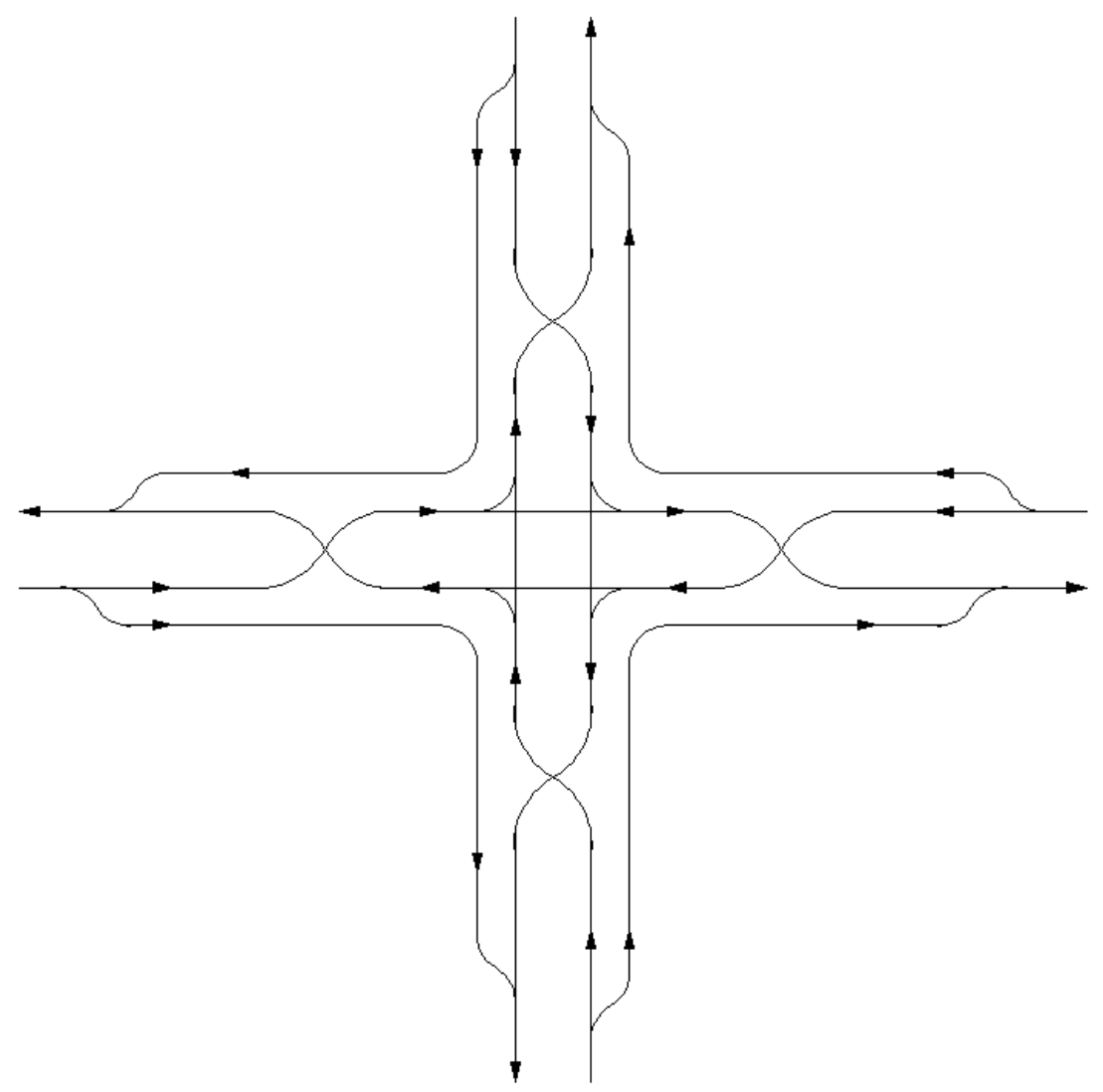

Figure 8-13 Diagram of an upstream signalized crossover intersection [adapted from Tabernero et al., 2008] 
To prevent drivers from entering the wrong side of the road, a central median should be extended towards the intersection to properly channel traffic at the secondary intersection where the approaches meet (Tarek et al., 2006).

\subsubsection{Operational Impacts of the Upstream Signalized Crossover}

The upstream signalized crossover intersection has a higher capacity for left turns and can serve greater volumes before reaching saturation when compared with a conventional intersection, assuming balanced approach volumes (Tabernero et al., 2008). The operational performance of through vehicles is not compromised in this design. The upstream signalized crossover performs with at least the same efficiency as a conventional intersection, again assuming balanced volume conditions. It should be noted that the delay for left turns does not decrease; however, split intersection operations are less affected by an increase in left turn volumes than at conventional intersections (Tabernero et al., 2008).

A shorter distance between the primary and secondary intersections for an upstream signalized crossover will perform better for lower traffic volumes and reduce average delay as compared to longer spacing between the primary and secondary intersections (Tarek et al., 2006). However, shorter spacing between primary and secondary intersections reduces capacity (Tarek et al., 2006).

For unbalanced volumes, the upstream signalized crossover intersection will perform worse than conventional intersections unless the conventional intersection is near its capacity. For mildly unbalanced volumes, the impact will not be as severe, and the upstream signalized crossover intersection will perform similar to a conventional solution, even for volumes below the capacity of the conventional intersection (Tarek et al., 2006). An optimized signal timing of an upstream signalized crossover intersection based on 
design volumes will perform better than setting signal timings based on simple progression between primary and secondary intersections which are separated by a specific distance (Tarek et al., 2006).

Table 8-10 An upstream signalized crossover intersection based on (Tabernero et al., 2008; Tarek et al., 2006)

\begin{tabular}{|l|l|}
\hline \multicolumn{1}{|c|}{ When to consider } & \multicolumn{1}{c|}{ Disadvantages } \\
\hline $\begin{array}{l}\text { • Balanced high volumes near capacity of } \\
\text { conventional intersection design }\end{array}$ & $\bullet$ Driver confusion \\
• Somewhat unbalanced volumes which are & $\bullet$ Additional right of way needed \\
over capacity of conventional design & $\begin{array}{l}\bullet \text { Limited access to/from adjacent corner } \\
\text { properties to right-in/right-out and } \\
\text { • Heavy left turn volumes with excessive } \\
\text { restricted exiting vehicles to a right turn } \\
\text { only }\end{array}$ \\
\hline
\end{tabular}

\subsubsection{Safety Impacts of the Upstream Signalized Crossover}

Research on the safety benefits of the upstream signalized crossover intersection had not been conducted by the time of writing these guidelines. It may be anticipated that the upstream signalized crossover design may cause pedestrian confusion because the direction from which traffic approaches may be unexpected.

Figure 8-14 presents the potential conflict diagram for an upstream signalized crossover intersection. As is shown in the figure, the potential conflict points are further separated when compared with a conventional intersection (Figure 2-2). Table 8-11 provides a comparison of the number of potential conflict points for an upstream signalized crossover intersection compared to a conventional intersection. As the table shows, there is a reduction in the total number of potential conflict points. The reduction occurs in the more severe crossing category. This is particularly beneficial because the crossing conflict is typically the most severe. Additionally, the upstream signalized crossover 
intersection also converts half of the merging and diverging conflict points from more severe to less severe conflict types, respectively.

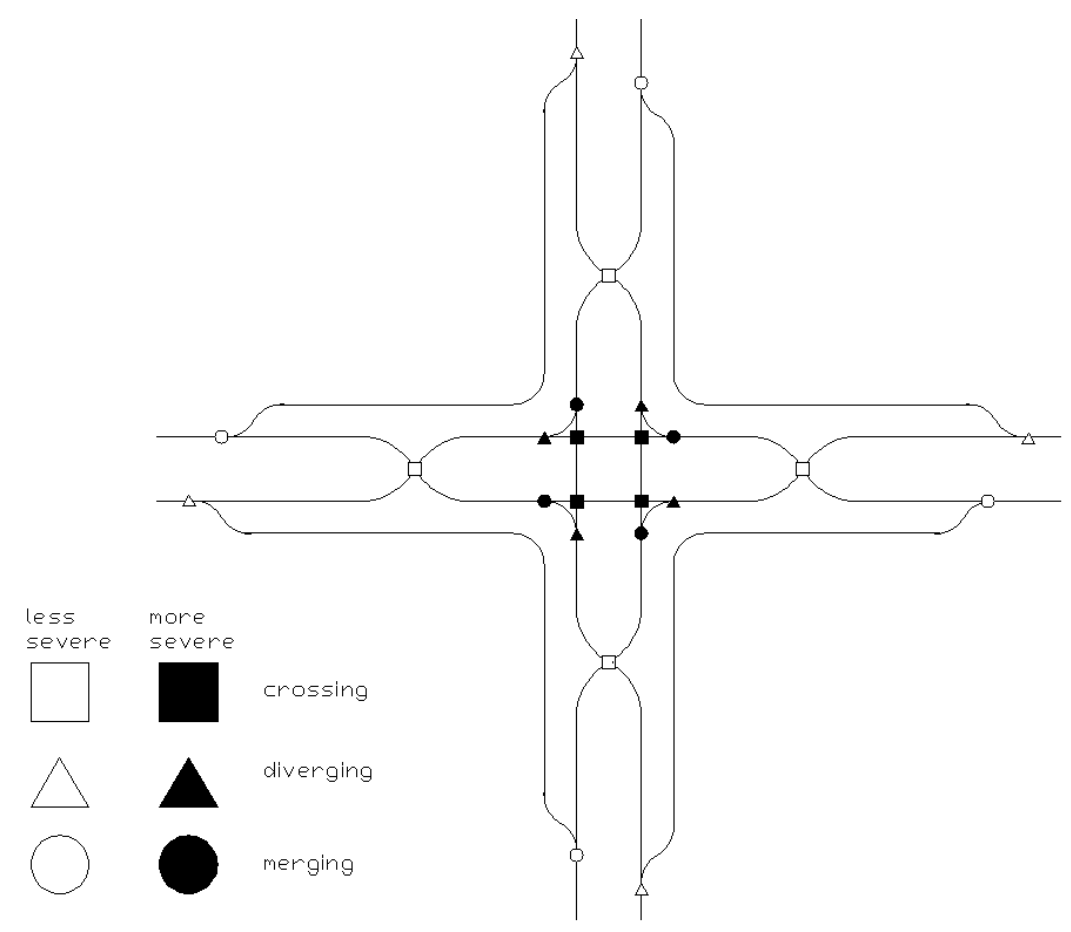

Figure 8-14 Upstream signalized crossover intersection potential conflict point diagram

Table 8-11 Comparison of potential conflict points for an upstream signalized crossover intersection and a conventional intersection

\begin{tabular}{|c|c|c|c|c|c|c|c|c|c|}
\hline & \multicolumn{2}{|c|}{ Crossing } & \multicolumn{2}{|c|}{ Diverging } & \multicolumn{2}{|c|}{ Merging } & \multicolumn{2}{|c|}{ Total } & \multirow{2}{*}{$\begin{array}{c}\text { Overall } \\
\text { Total }\end{array}$} \\
\hline & $\begin{array}{l}\text { Less } \\
\text { Severe }\end{array}$ & $\begin{array}{l}\text { More } \\
\text { Severe }\end{array}$ & $\begin{array}{l}\text { Less } \\
\text { Severe }\end{array}$ & $\begin{array}{l}\text { More } \\
\text { Severe }\end{array}$ & $\begin{array}{l}\text { Less } \\
\text { Severe }\end{array}$ & $\begin{array}{l}\text { More } \\
\text { Severe }\end{array}$ & $\begin{array}{l}\text { Less } \\
\text { Severe }\end{array}$ & $\begin{array}{l}\text { More } \\
\text { Severe }\end{array}$ & \\
\hline $\begin{array}{l}\text { Conventional, } \\
\text { signalized 4-legged }\end{array}$ & 4 & 12 & 0 & 8 & 0 & 8 & 4 & 28 & 32 \\
\hline $\begin{array}{l}\text { Upstream Signalized } \\
\text { Crossover }\end{array}$ & 4 & 4 & 4 & 4 & 4 & 4 & 12 & 12 & 24 \\
\hline
\end{tabular}




\section{Evaluation of alternative designs}

This chapter provides guidance for evaluating six types of intersections to help select the most promising ones for given local geometry and traffic conditions.

1. Conventional intersection (CONV),

2. Continuous flow intersection (CFLW),

3. Jug handle far-sided (JHFS),

4. Jug handle near-sided (JHNS),

5. Median U-turns intersection (MUT),

6. Roundabout (RNDB).

The method has been developed based on extensive simulation experiments with VISSIM calibrated to Indiana conditions. Details of the method development can be found in Volume I of this report. The following section explains the method and details needed to properly use the tool.

\subsection{Evaluation Method}

Seventy two various scenarios are identified based on the following criteria:

1. Intersection location: rural or urban,

2. Number of through lanes or the major and minor roads: $2 \times 2,4 \times 2,4 \times 4$,

3. Traffic intersection split 55/45 and 70/30,

4. Traffic directional split (same on both the roads): 55/45 and 70/30,

5. Percent of left-turn movements on the major and minor roads (same on opposing approaches): 10/10, 10/20, 20/20.

Each scenario is described by a table (example shown in Table 9-1) placed on the top of a page with exhibits for the scenario: 
Table 9-1 Example description of a scenario

\begin{tabular}{|llllll|}
\hline Location & Urban & Intersection Split & $\mathbf{5 5 / 4 5}$ & Major Road Left Turns & $\mathbf{1 0} \%$ \\
Through Lanes & $\mathbf{2 \times 2}$ & Directional Split & $\mathbf{5 5 / 4 5}$ & Minor Road Left Turns & $\mathbf{1 0} \%$ \\
\hline
\end{tabular}

The rural conditions are characterized with the following traffic characteristics:

1. Saturation flow rate $=1,700 \mathrm{veh} / \mathrm{h} / \mathrm{lane}$,

2. Speed on two-lane roads $=55 \mathrm{mi} / \mathrm{h}$,

3. Speed on four-lane roads $=60 \mathrm{mi} / \mathrm{h}$,

4. Percent of trucks $=5 \%$,

5. Percent of right-turning vehicles $=5 \%$.

The urban conditions are characterized with the following traffic characteristics:

1. Saturation flow rate $=1,900 \mathrm{veh} / \mathrm{h} / \mathrm{lane}$,

2. Speed on two-lane roads $=30 \mathrm{mi} / \mathrm{h}$,

3. Speed on four-lane roads $=45 \mathrm{mi} / \mathrm{h}$,

4. Percent of trucks $=2 \%$,

5. Percent of right-turning vehicles $=5 \%$.

The major geometry dimensions are presented for the six design alternatives in Figure 9-1 through Figure 9-6. All the primary and secondary intersection areas are controlled by pre-timed traffic signals optimized with SYNCHRO each time to traffic and speed conditions. The yellow and all-red periods are SYNCHRO defaults. 


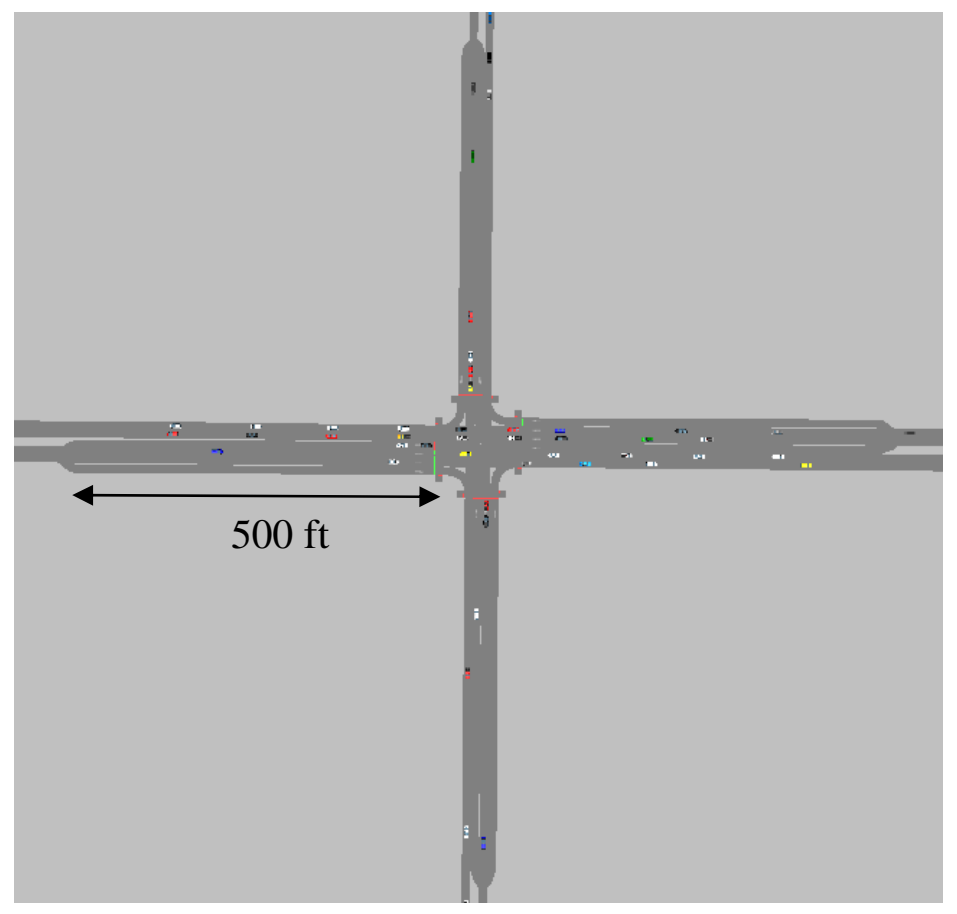

Figure 9-1 Conventional intersection 4x2 (dimensions in feet)

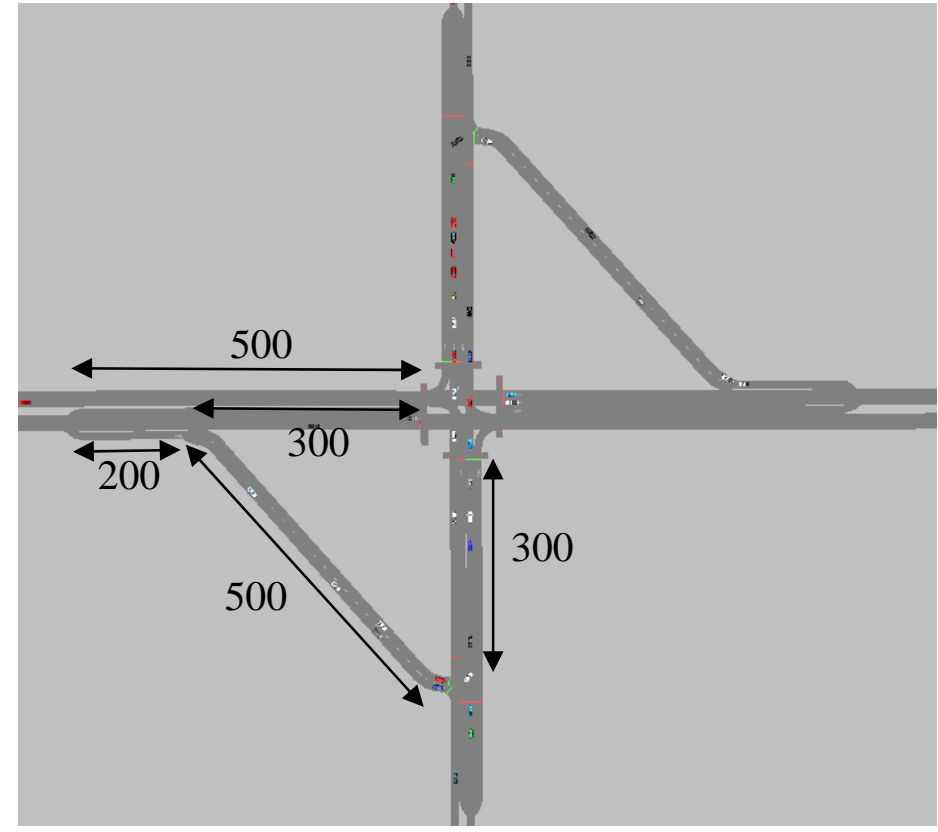

Figure 9-2 Jughandle nearsided intersection 4x2 (dimensions in feet) 


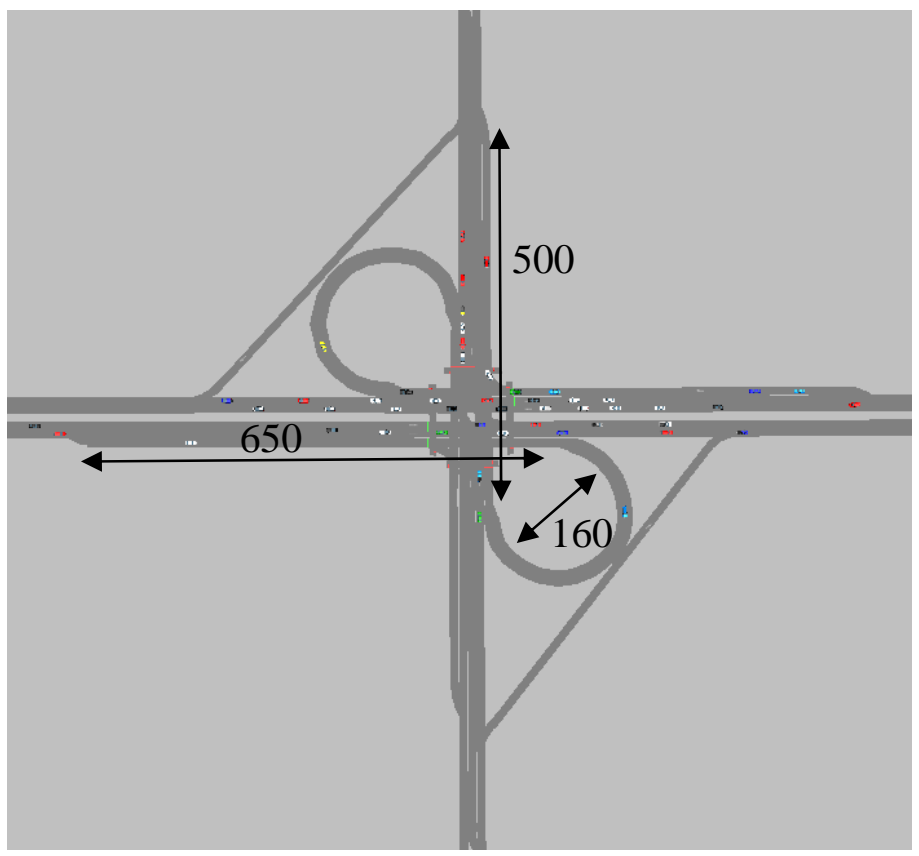

Figure 9-3 Jug handle far-sided intersection 4x2 (dimensions in feet)

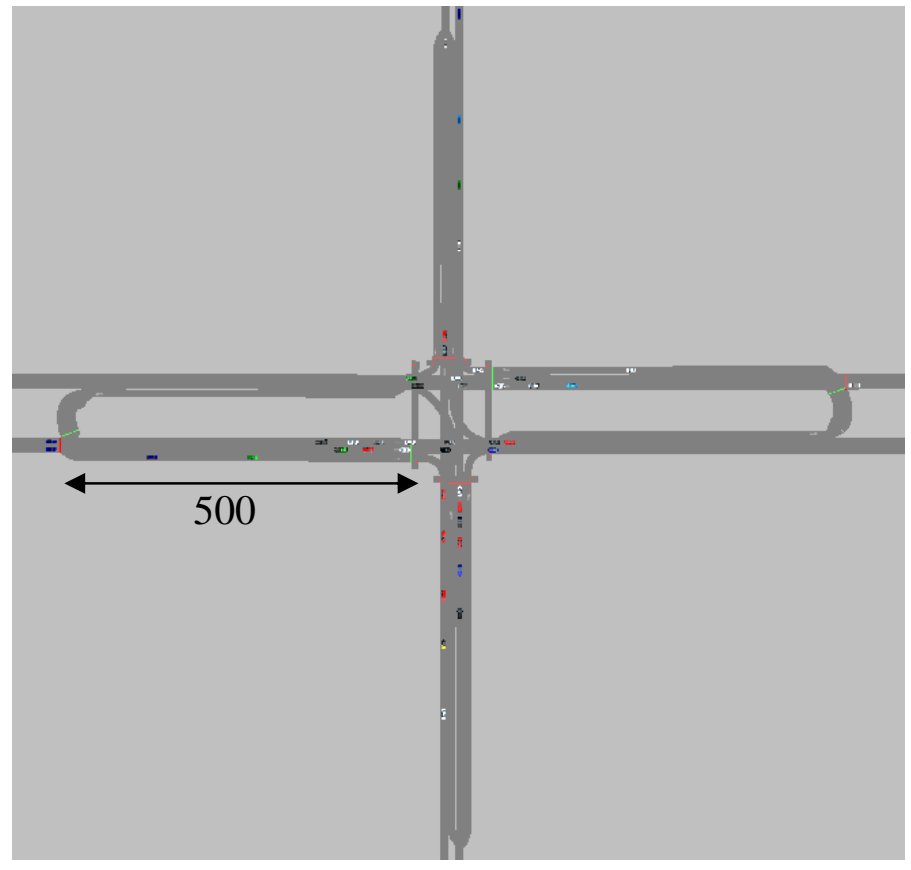

Figure 9-4 Median U-turn intersection 4x2 (dimensions in feet) 


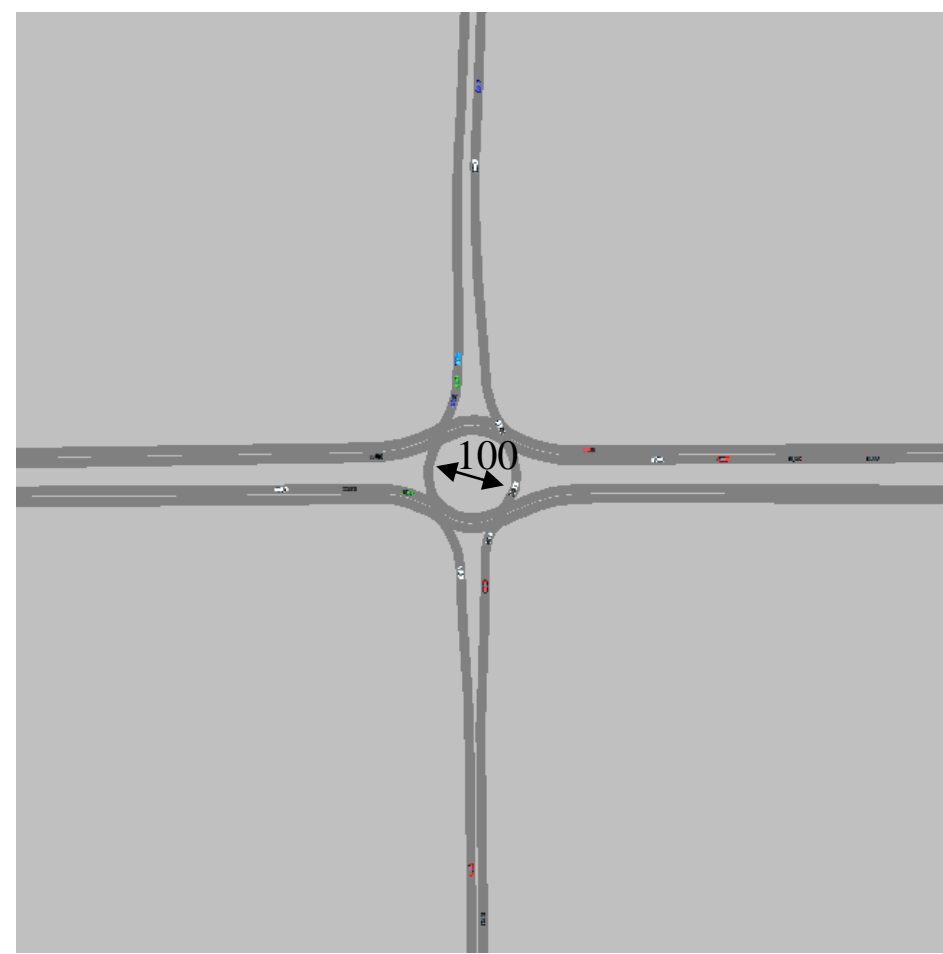

Figure 9-5 Roundabout intersection (dimensions in feet)

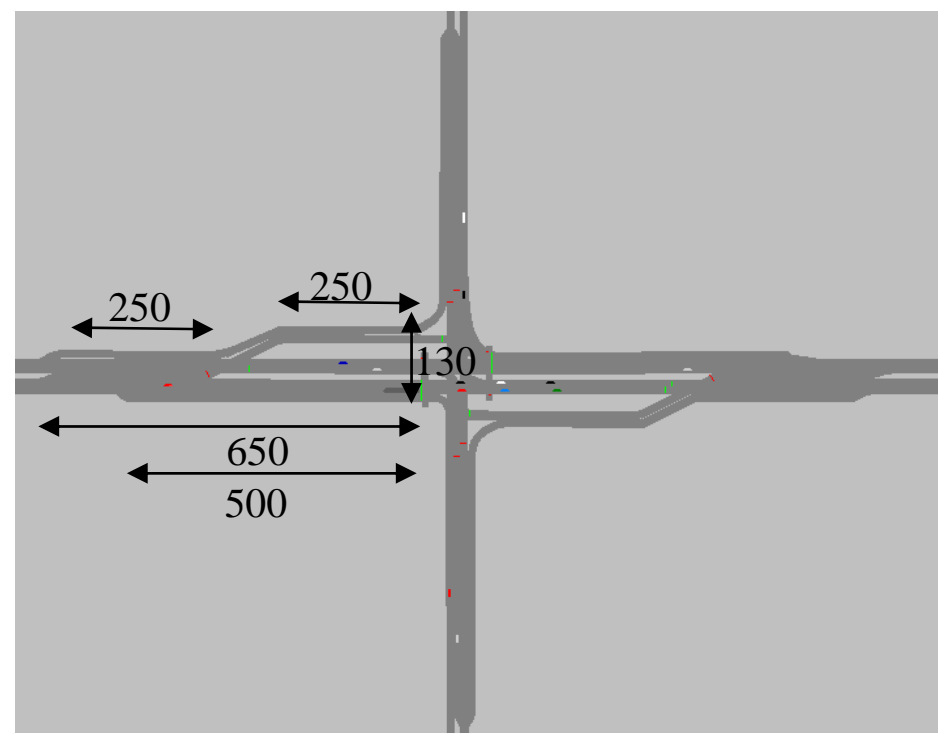

Figure 9-6 Continuous-flow intersection (dimensions in feet) 
The following three measures of effectiveness are presented for each scenario:

1. Average delay on the busiest intersection approach. This delay includes the effect of the control, traffic queues, and the additional distance covered by indirect leftturning movements. Based on the HCM recommendations, the average delay larger than 80 seconds indicates Level of Service F and the shortage of capacity.

2. Average delay at the intersection represents an overall level of service at the intersection and can be used to compare different design alternatives.

3. Average number of stops can be used as an additional measure of performance following the notion that drivers' perception of traffic quality is affected not only by the delay but also by the number of stops.

The user is supposed to find the simulation scenario that is the closest to his/her design case. Entering the first graphs with the total volume at the design intersection allows checking which alternative intersections are likely to operate below capacity. Then, entering with the total volume the second graph allows identify the intersections with the lowest overall delay. The table with stops per vehicle gives additional guidance regarding the number of stops.

\subsection{Exhibits for evaluating alternative intersection designs}

Seventy two following pages include graphs and tables - one page per scenario. To help identify the needed scenario, the following table includes all the scenarios and the corresponding page numbers. 


\section{Urban Scenarios \\ Saturation flow rate $=1,900 \mathrm{veh} / \mathrm{h} / \mathrm{lane}$ \\ Percent of trucks $=2 \%$ \\ Percent of right turns $=5 \%$}

\begin{tabular}{|c|c|c|c|c|c|c|c|c|c|}
\hline 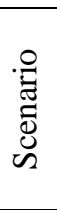 & $\begin{array}{l}\text { Lanes } \\
\text { on } \\
\text { major } \\
\text { road }\end{array}$ & $\begin{array}{l}\text { Lanes } \\
\text { on } \\
\text { minor } \\
\text { road }\end{array}$ & $\begin{array}{l}\text { Speed } \\
\text { on } \\
\text { major } \\
\text { road }\end{array}$ & $\begin{array}{l}\text { Speed } \\
\text { on } \\
\text { minor } \\
\text { road }\end{array}$ & $\begin{array}{l}\text { Percent of } \\
\text { traffic on } \\
\text { major road }\end{array}$ & $\begin{array}{l}\text { Percent of } \\
\text { traffic in } \\
\text { busier } \\
\text { direction }\end{array}$ & $\begin{array}{c}\text { Percent } \\
\text { of left } \\
\text { turns on } \\
\text { major } \\
\text { road }\end{array}$ & $\begin{array}{c}\text { Percent } \\
\text { of left } \\
\text { turns on } \\
\text { minor } \\
\text { road }\end{array}$ & Page \\
\hline 1 & 2 & 2 & 30 & 30 & 55 & 55 & 10 & 10 & 78 \\
\hline 2 & 2 & 2 & 30 & 30 & 55 & 55 & 10 & 20 & 79 \\
\hline 3 & 2 & 2 & 30 & 30 & 55 & 55 & 20 & 20 & 80 \\
\hline 4 & 2 & 2 & 30 & 30 & 55 & 70 & 10 & 10 & 81 \\
\hline 5 & 2 & 2 & 30 & 30 & 55 & 70 & 10 & 20 & 82 \\
\hline 6 & 2 & 2 & 30 & 30 & 55 & 70 & 20 & 20 & 83 \\
\hline 7 & 2 & 2 & 30 & 30 & 70 & 55 & 10 & 10 & 84 \\
\hline 8 & 2 & 2 & 30 & 30 & 70 & 55 & 10 & 20 & 85 \\
\hline 9 & 2 & 2 & 30 & 30 & 70 & 55 & 20 & 20 & 86 \\
\hline 10 & 2 & 2 & 30 & 30 & 70 & 70 & 10 & 10 & 87 \\
\hline 11 & 2 & 2 & 30 & 30 & 70 & 70 & 10 & 20 & 88 \\
\hline 12 & 2 & 2 & 30 & 30 & 70 & 70 & 20 & 20 & 89 \\
\hline 13 & 4 & 2 & 45 & 30 & 55 & 55 & 10 & 10 & 90 \\
\hline 14 & 4 & 2 & 45 & 30 & 55 & 55 & 10 & 20 & 91 \\
\hline 15 & 4 & 2 & 45 & 30 & 55 & 55 & 20 & 20 & 92 \\
\hline 16 & 4 & 2 & 45 & 30 & 55 & 70 & 10 & 10 & 93 \\
\hline 17 & 4 & 2 & 45 & 30 & 55 & 70 & 10 & 20 & 94 \\
\hline 18 & 4 & 2 & 45 & 30 & 55 & 70 & 20 & 20 & 95 \\
\hline 19 & 4 & 2 & 45 & 30 & 70 & 55 & 10 & 10 & 96 \\
\hline 20 & 4 & 2 & 45 & 30 & 70 & 55 & 10 & 20 & 97 \\
\hline 21 & 4 & 2 & 45 & 30 & 70 & 55 & 20 & 20 & 98 \\
\hline 22 & 4 & 2 & 45 & 30 & 70 & 70 & 10 & 10 & 99 \\
\hline 23 & 4 & 2 & 45 & 30 & 70 & 70 & 10 & 20 & 100 \\
\hline 24 & 4 & 2 & 45 & 30 & 70 & 70 & 20 & 20 & 101 \\
\hline 25 & 4 & 4 & 45 & 45 & 55 & 55 & 10 & 10 & 102 \\
\hline 26 & 4 & 4 & 45 & 45 & 55 & 55 & 10 & 20 & 103 \\
\hline 27 & 4 & 4 & 45 & 45 & 55 & 55 & 20 & 20 & 104 \\
\hline 28 & 4 & 4 & 45 & 45 & 55 & 70 & 10 & 10 & 105 \\
\hline 29 & 4 & 4 & 45 & 45 & 55 & 70 & 10 & 20 & 106 \\
\hline 30 & 4 & 4 & 45 & 45 & 55 & 70 & 20 & 20 & 107 \\
\hline 31 & 4 & 4 & 45 & 45 & 70 & 55 & 10 & 10 & 108 \\
\hline 32 & 4 & 4 & 45 & 45 & 70 & 55 & 10 & 20 & 109 \\
\hline 33 & 4 & 4 & 45 & 45 & 70 & 55 & 20 & 20 & 110 \\
\hline 34 & 4 & 4 & 45 & 45 & 70 & 70 & 10 & 10 & 111 \\
\hline 35 & 4 & 4 & 45 & 45 & 70 & 70 & 10 & 20 & 112 \\
\hline 36 & 4 & 4 & 45 & 45 & 70 & 70 & 20 & 20 & 113 \\
\hline
\end{tabular}




\section{Rural Scenarios \\ Saturation flow rate $=1,700 \mathrm{veh} / \mathrm{h} / \mathrm{lane}$ \\ Percent of trucks $=5 \%$ \\ Percent of right turns $=5 \%$}

\begin{tabular}{|c|c|c|c|c|c|c|c|c|c|}
\hline 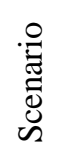 & $\begin{array}{l}\text { Lanes } \\
\text { on } \\
\text { major } \\
\text { road }\end{array}$ & $\begin{array}{l}\text { Lanes } \\
\text { on } \\
\text { minor } \\
\text { road }\end{array}$ & $\begin{array}{l}\text { Speed } \\
\text { on } \\
\text { major } \\
\text { road }\end{array}$ & $\begin{array}{l}\text { Speed } \\
\text { on } \\
\text { minor } \\
\text { road }\end{array}$ & $\begin{array}{c}\text { Percent } \\
\text { of traffic } \\
\text { on major } \\
\text { road }\end{array}$ & $\begin{array}{l}\text { Percent of } \\
\text { traffic in } \\
\text { busier } \\
\text { direction }\end{array}$ & $\begin{array}{l}\text { Percent of } \\
\text { left turns } \\
\text { on major } \\
\text { road }\end{array}$ & $\begin{array}{l}\text { Percent of } \\
\text { left turns } \\
\text { on minor } \\
\text { road }\end{array}$ & Page \\
\hline 37 & 2 & 2 & 55 & 55 & 55 & 55 & 10 & 10 & 114 \\
\hline 38 & 2 & 2 & 55 & 55 & 55 & 55 & 10 & 20 & 115 \\
\hline 39 & 2 & 2 & 55 & 55 & 55 & 55 & 20 & 20 & 116 \\
\hline 40 & 2 & 2 & 55 & 55 & 55 & 70 & 10 & 10 & 117 \\
\hline 41 & 2 & 2 & 55 & 55 & 55 & 70 & 10 & 20 & 118 \\
\hline 42 & 2 & 2 & 55 & 55 & 55 & 70 & 20 & 20 & 119 \\
\hline 43 & 2 & 2 & 55 & 55 & 70 & 55 & 10 & 10 & 120 \\
\hline 44 & 2 & 2 & 55 & 55 & 70 & 55 & 10 & 20 & 121 \\
\hline 45 & 2 & 2 & 55 & 55 & 70 & 55 & 20 & 20 & 122 \\
\hline 46 & 2 & 2 & 55 & 55 & 70 & 70 & 10 & 10 & 123 \\
\hline 47 & 2 & 2 & 55 & 55 & 70 & 70 & 10 & 20 & 124 \\
\hline 48 & 2 & 2 & 55 & 55 & 70 & 70 & 20 & 20 & 125 \\
\hline 49 & 4 & 2 & 60 & 55 & 55 & 55 & 10 & 10 & 126 \\
\hline 50 & 4 & 2 & 60 & 55 & 55 & 55 & 10 & 20 & 127 \\
\hline 51 & 4 & 2 & 60 & 55 & 55 & 55 & 20 & 20 & 128 \\
\hline 52 & 4 & 2 & 60 & 55 & 55 & 70 & 10 & 10 & 129 \\
\hline 53 & 4 & 2 & 60 & 55 & 55 & 70 & 10 & 20 & 130 \\
\hline 54 & 4 & 2 & 60 & 55 & 55 & 70 & 20 & 20 & 131 \\
\hline 55 & 4 & 2 & 60 & 55 & 70 & 55 & 10 & 10 & 132 \\
\hline 56 & 4 & 2 & 60 & 55 & 70 & 55 & 10 & 20 & 133 \\
\hline 57 & 4 & 2 & 60 & 55 & 70 & 55 & 20 & 20 & 134 \\
\hline 58 & 4 & 2 & 60 & 55 & 70 & 70 & 10 & 10 & 135 \\
\hline 59 & 4 & 2 & 60 & 55 & 70 & 70 & 10 & 20 & 136 \\
\hline 60 & 4 & 2 & 60 & 55 & 70 & 70 & 20 & 20 & 137 \\
\hline 61 & 4 & 4 & 60 & 60 & 55 & 55 & 10 & 10 & 138 \\
\hline 62 & 4 & 4 & 60 & 60 & 55 & 55 & 10 & 20 & 139 \\
\hline 63 & 4 & 4 & 60 & 60 & 55 & 55 & 20 & 20 & 140 \\
\hline 64 & 4 & 4 & 60 & 60 & 55 & 70 & 10 & 10 & 141 \\
\hline 65 & 4 & 4 & 60 & 60 & 55 & 70 & 10 & 20 & 142 \\
\hline 66 & 4 & 4 & 60 & 60 & 55 & 70 & 20 & 20 & 143 \\
\hline 67 & 4 & 4 & 60 & 60 & 70 & 55 & 10 & 10 & 144 \\
\hline 68 & 4 & 4 & 60 & 60 & 70 & 55 & 10 & 20 & 145 \\
\hline 69 & 4 & 4 & 60 & 60 & 70 & 55 & 20 & 20 & 146 \\
\hline 70 & 4 & 4 & 60 & 60 & 70 & 70 & 10 & 10 & 147 \\
\hline 71 & 4 & 4 & 60 & 60 & 70 & 70 & 10 & 20 & 148 \\
\hline 72 & 4 & 4 & 60 & 60 & 70 & 70 & 20 & 20 & 149 \\
\hline
\end{tabular}




\begin{tabular}{|c|c|c|c|}
\hline $\begin{array}{l}\text { ocation } \\
\text { hrough Lanes }\end{array}$ & $\begin{array}{l}\text { Urban } \\
2 \times 2\end{array}$ & $\begin{array}{l}\text { Intersection Split } \\
\text { Directional Split }\end{array}$ & $\begin{array}{l}55 / 45 \\
55 / 45\end{array}$ \\
\hline
\end{tabular}

Busiest Approach Delay

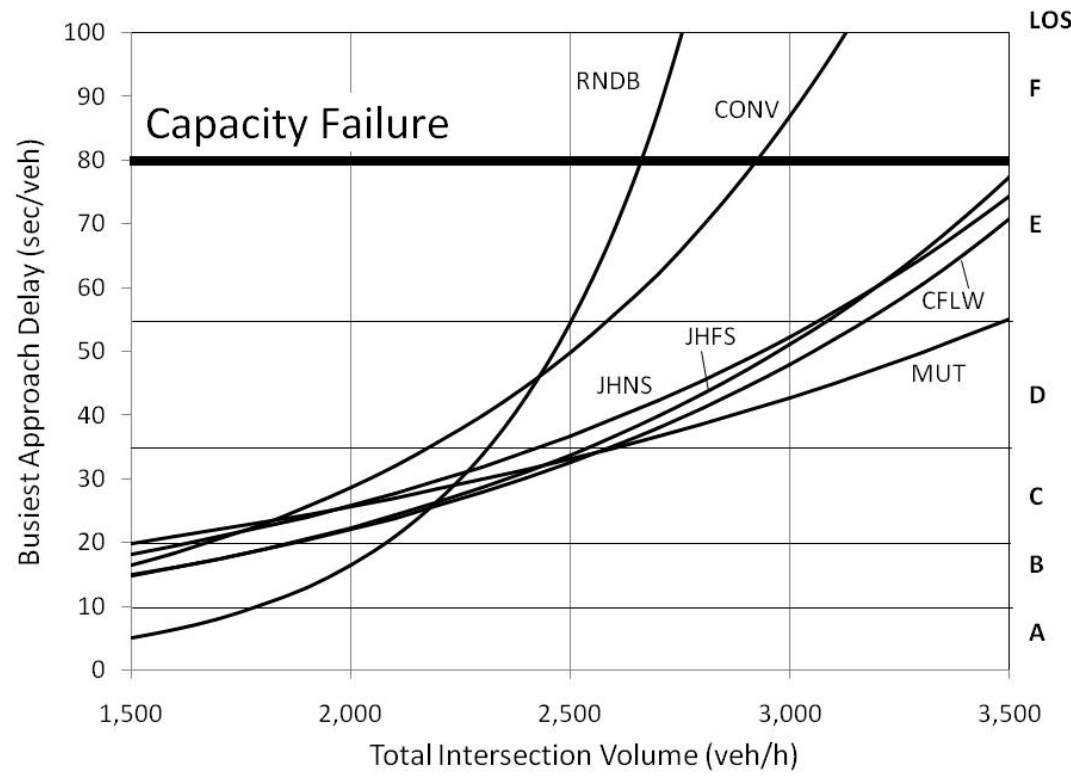

Intersection Delay

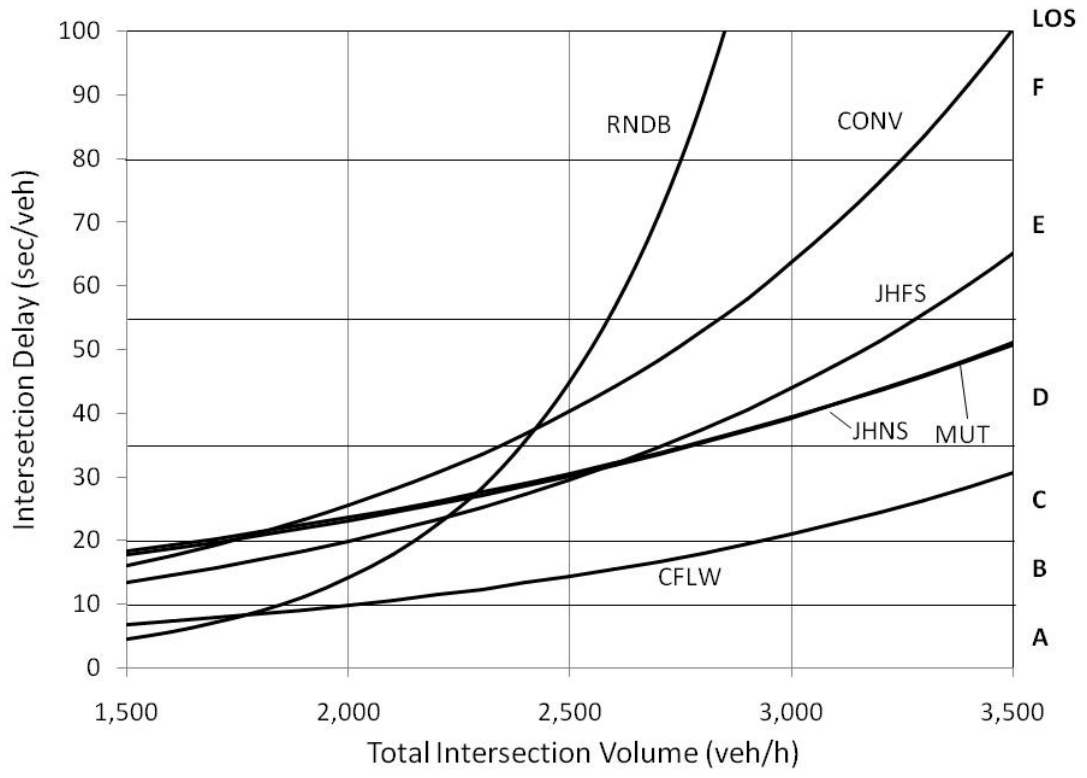

Stops Per Vehicle

\begin{tabular}{|c|c|c|c|}
\hline \multirow{2}{*}{ DESIGN } & \multicolumn{3}{|c|}{ Total Intersection Volume $($ veh/h) } \\
\cline { 2 - 4 } & 1730 & 2250 & 3110 \\
\hline CONV & 0.90 & 0.80 & 2.36 \\
\hline CFLW & 0.58 & 0.74 & 0.94 \\
\hline JHFS & 0.63 & 0.68 & 1.12 \\
\hline JHNS & 0.70 & 0.79 & 1.21 \\
\hline MUT & 0.76 & 0.81 & 1.25 \\
\hline RNDB & 0.29 & 0.73 & 11.88 \\
\hline
\end{tabular}



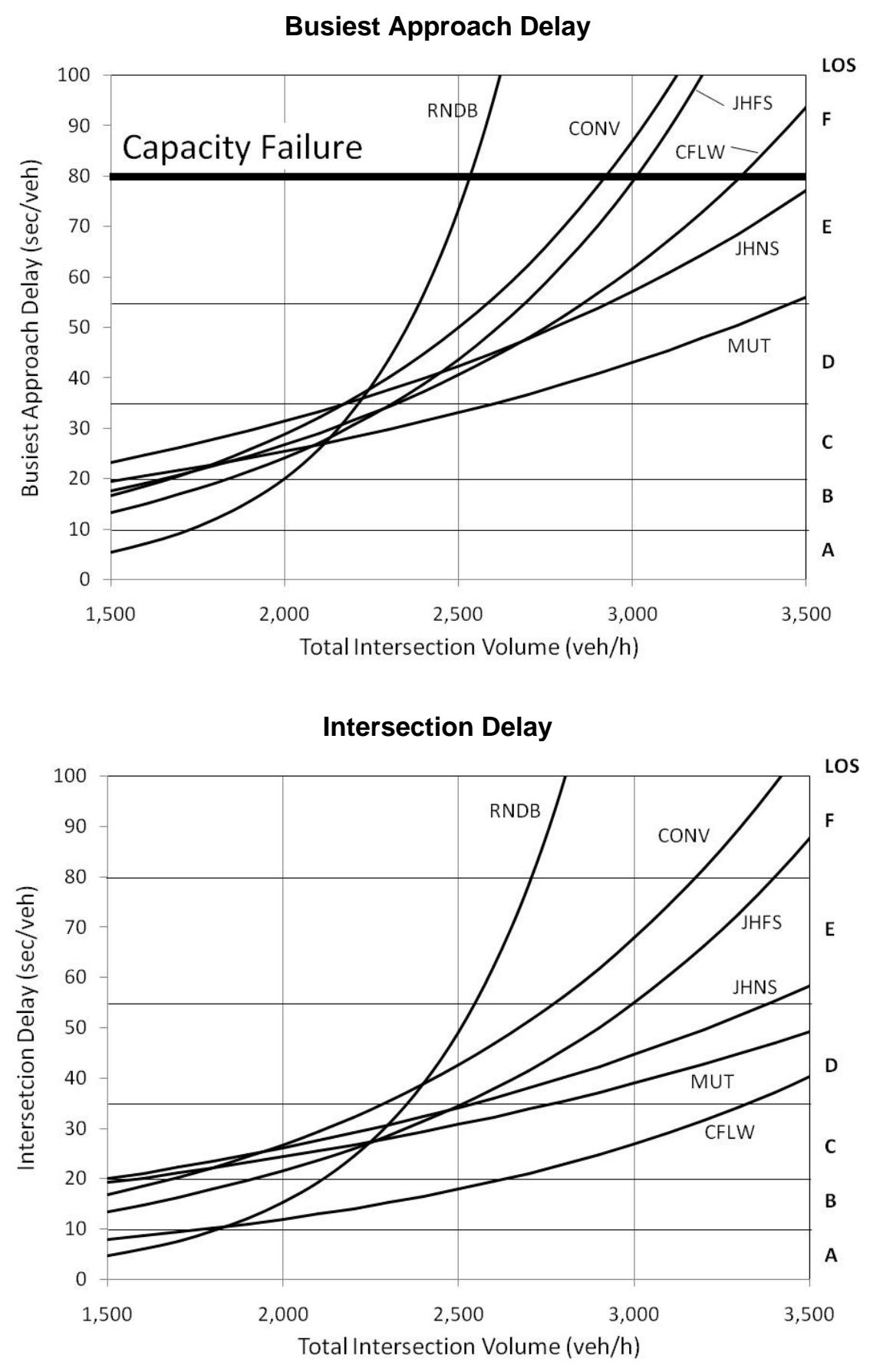

Stops Per Vehicle

\begin{tabular}{|c|c|c|c|}
\hline \multirow{2}{*}{ DESIGN } & \multicolumn{3}{|c|}{ Total Intersection Volume (veh/h) } \\
\cline { 2 - 4 } & 1730 & 2250 & 3110 \\
\hline CONV & 0.73 & 0.82 & 1.81 \\
\hline CFLW & 0.69 & 0.74 & 1.02 \\
\hline JHFS & 0.64 & 0.73 & 1.35 \\
\hline JHNS & 0.76 & 0.84 & 1.25 \\
\hline MUT & 0.77 & 0.82 & 1.20 \\
\hline RNDB & 0.33 & 0.86 & 13.07 \\
\hline
\end{tabular}




\section{Busiest Approach Delay}

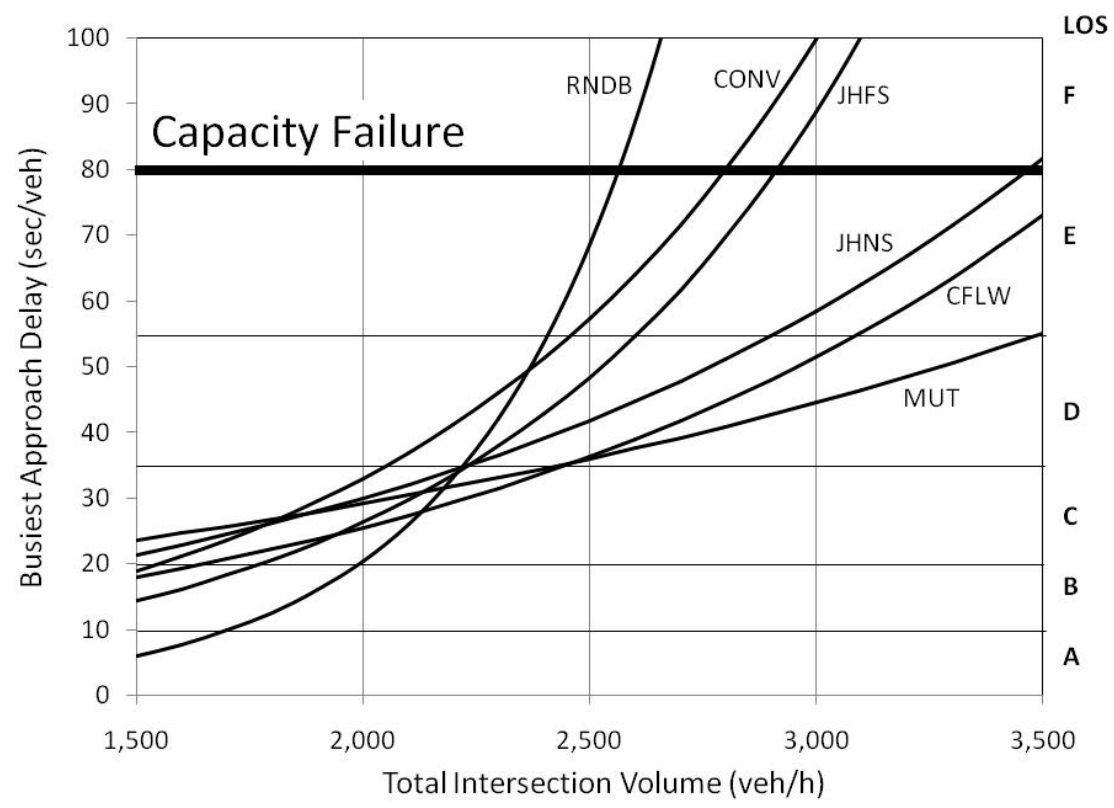

Intersection Delay

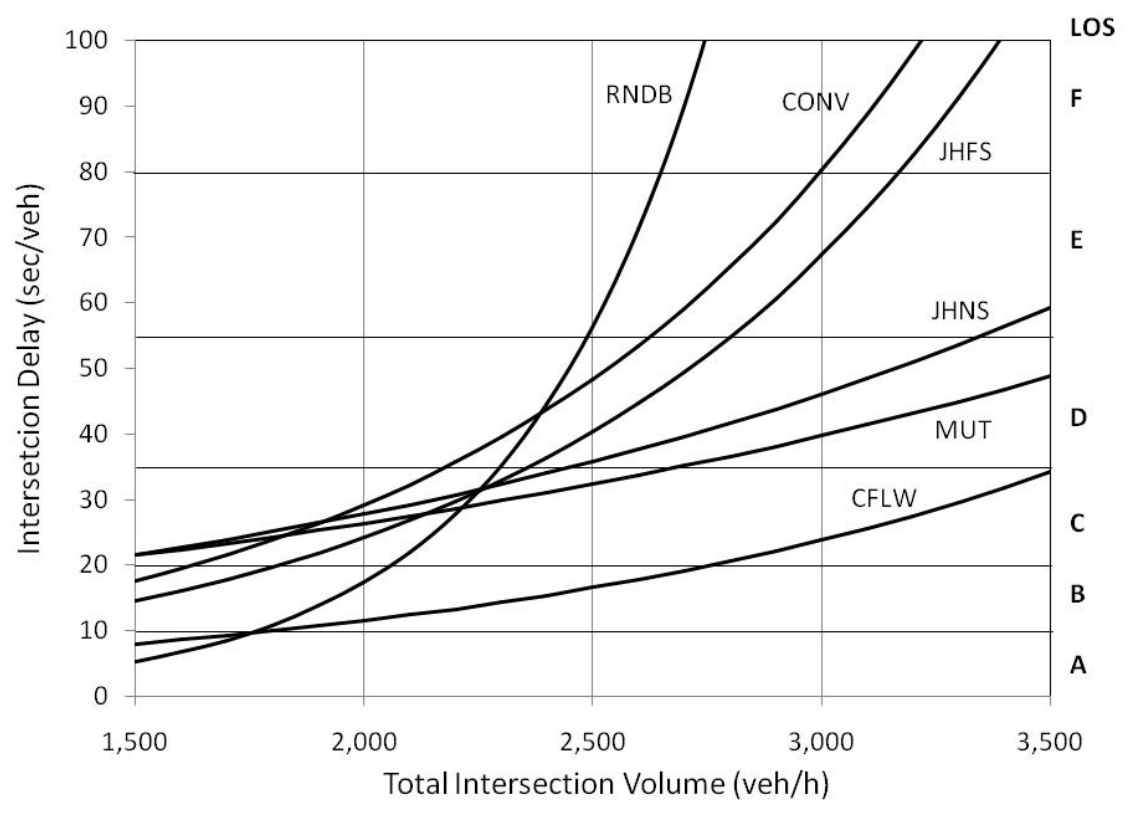

Stops Per Vehicle

\begin{tabular}{|c|c|c|c|}
\hline \multirow{2}{*}{ DESIGN } & \multicolumn{3}{|c|}{ Total Intersection Volume $(\mathrm{veh} / \mathrm{h})$} \\
\cline { 2 - 4 } & 1730 & 2250 & 3110 \\
\hline CONV & 0.76 & 0.86 & 2.10 \\
\hline CFLW & 0.71 & 0.74 & 0.99 \\
\hline JHFS & 0.68 & 0.78 & 1.50 \\
\hline JHNS & 0.80 & 0.88 & 1.39 \\
\hline MUT & 0.85 & 0.92 & 1.32 \\
\hline RNDB & 0.37 & 1.17 & 14.87 \\
\hline
\end{tabular}




\section{Busiest Approach Delay}
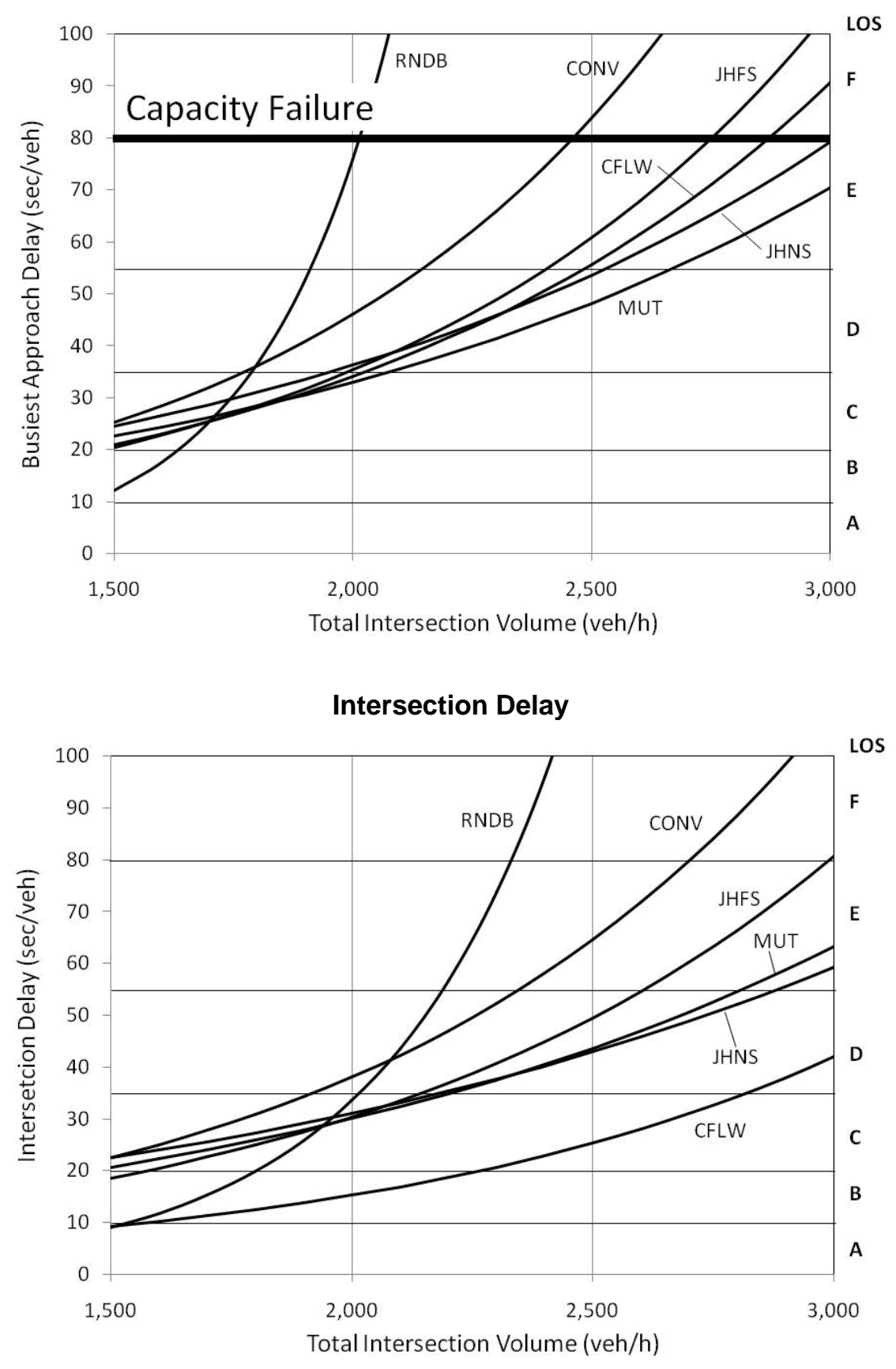

Stops Per Vehicle

\begin{tabular}{|c|c|c|c|}
\hline \multirow{2}{*}{ DESIGN } & \multicolumn{3}{|c|}{ Total Intersection Volume (veh/h) } \\
\cline { 2 - 4 } & 1360 & 1760 & 2450 \\
\hline CONV & 0.86 & 1.02 & 2.05 \\
\hline CFLW & 0.57 & 0.61 & 0.90 \\
\hline JHFS & 0.60 & 0.67 & 1.09 \\
\hline JHNS & 0.70 & 0.76 & 1.11 \\
\hline MUT & 0.67 & 0.78 & 1.23 \\
\hline RNDB & 0.20 & 0.43 & 7.32 \\
\hline
\end{tabular}




\section{Busiest Approach Delay}
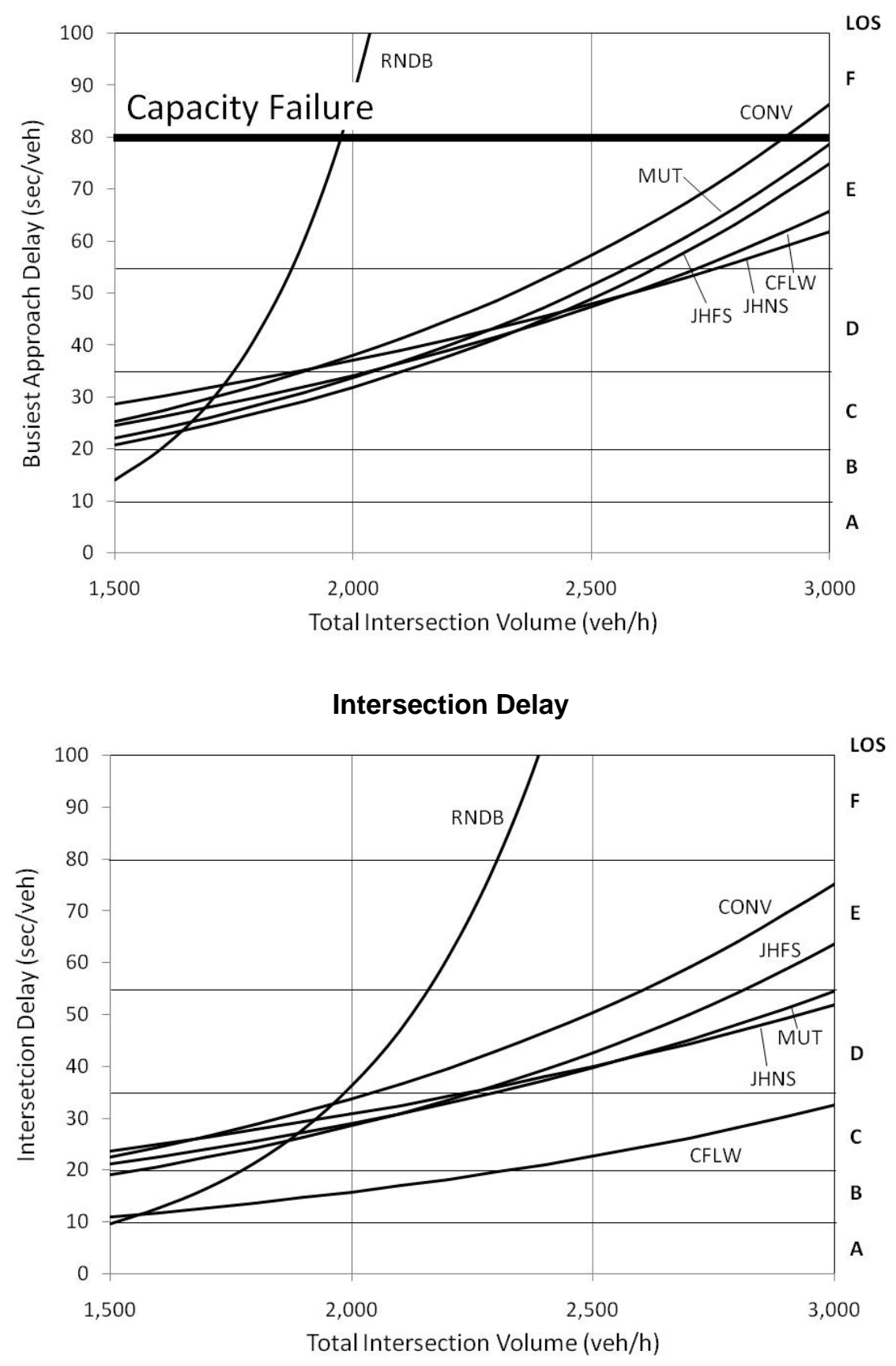

Stops Per Vehicle

\begin{tabular}{|c|c|c|c|}
\hline \multirow{2}{*}{ DESIGN } & \multicolumn{3}{|c|}{ Total Intersection Volume $($ veh/h) } \\
\cline { 2 - 4 } & 1360 & 1760 & 2450 \\
\hline CONV & 0.71 & 0.77 & 1.17 \\
\hline CFLW & 0.66 & 0.72 & 0.88 \\
\hline JHFS & 0.62 & 0.68 & 0.94 \\
\hline JHNS & 0.73 & 0.79 & 1.07 \\
\hline MUT & 0.71 & 0.76 & 1.10 \\
\hline RNDB & 0.22 & 0.51 & 7.90 \\
\hline
\end{tabular}



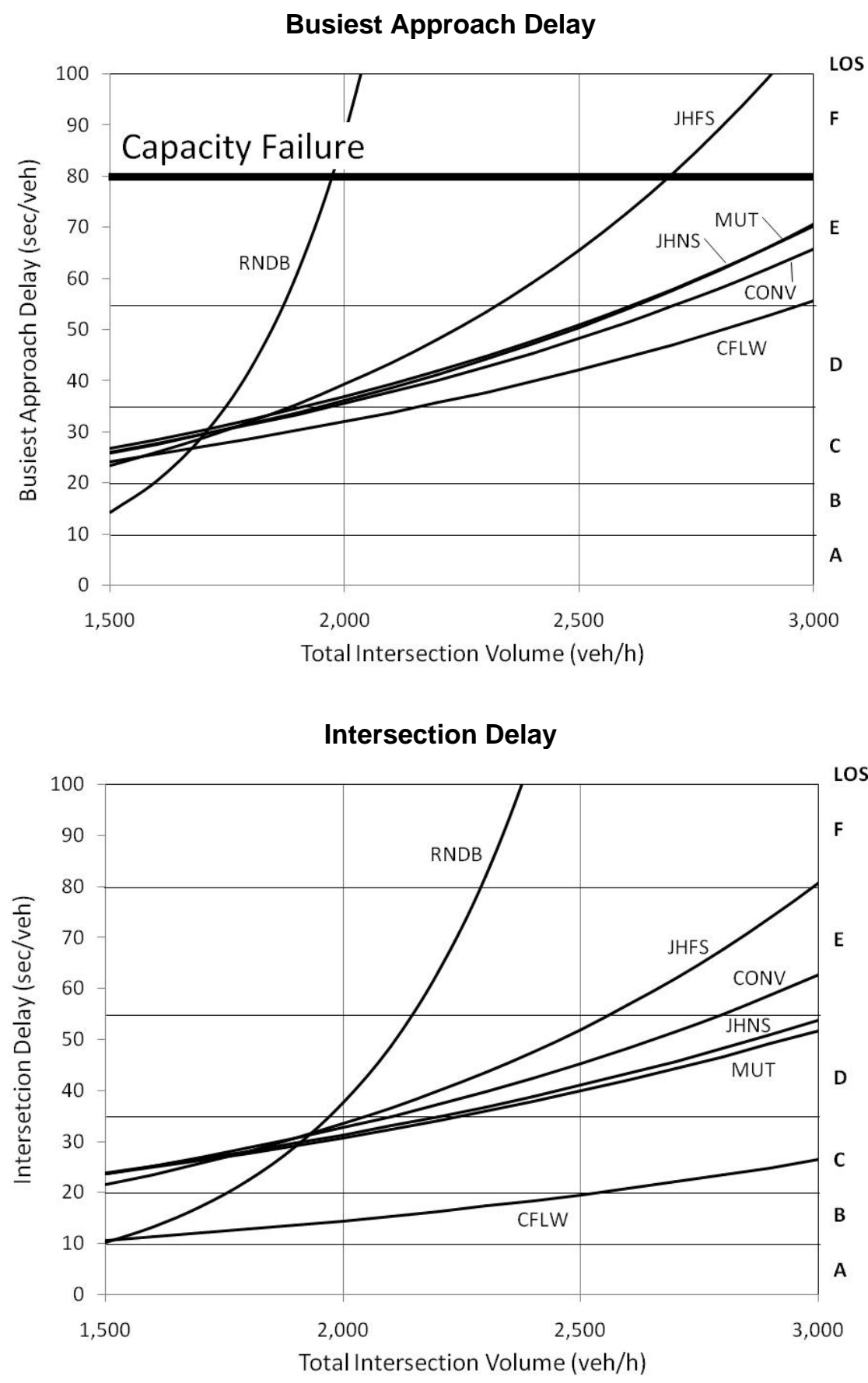

Stops Per Vehicle

\begin{tabular}{|c|c|c|c|}
\hline \multirow{2}{*}{ DESIGN } & \multicolumn{3}{|c|}{ Total Intersection Volume (veh/h) } \\
\cline { 2 - 4 } & 1360 & 1760 & 2450 \\
\hline CONV & 0.72 & 0.79 & 1.01 \\
\hline CFLW & 0.68 & 0.74 & 0.79 \\
\hline JHFS & 0.66 & 0.74 & 1.01 \\
\hline JHNS & 0.79 & 0.84 & 1.18 \\
\hline MUT & 0.77 & 0.85 & 1.22 \\
\hline RNDB & 0.24 & 0.55 & 7.92 \\
\hline
\end{tabular}



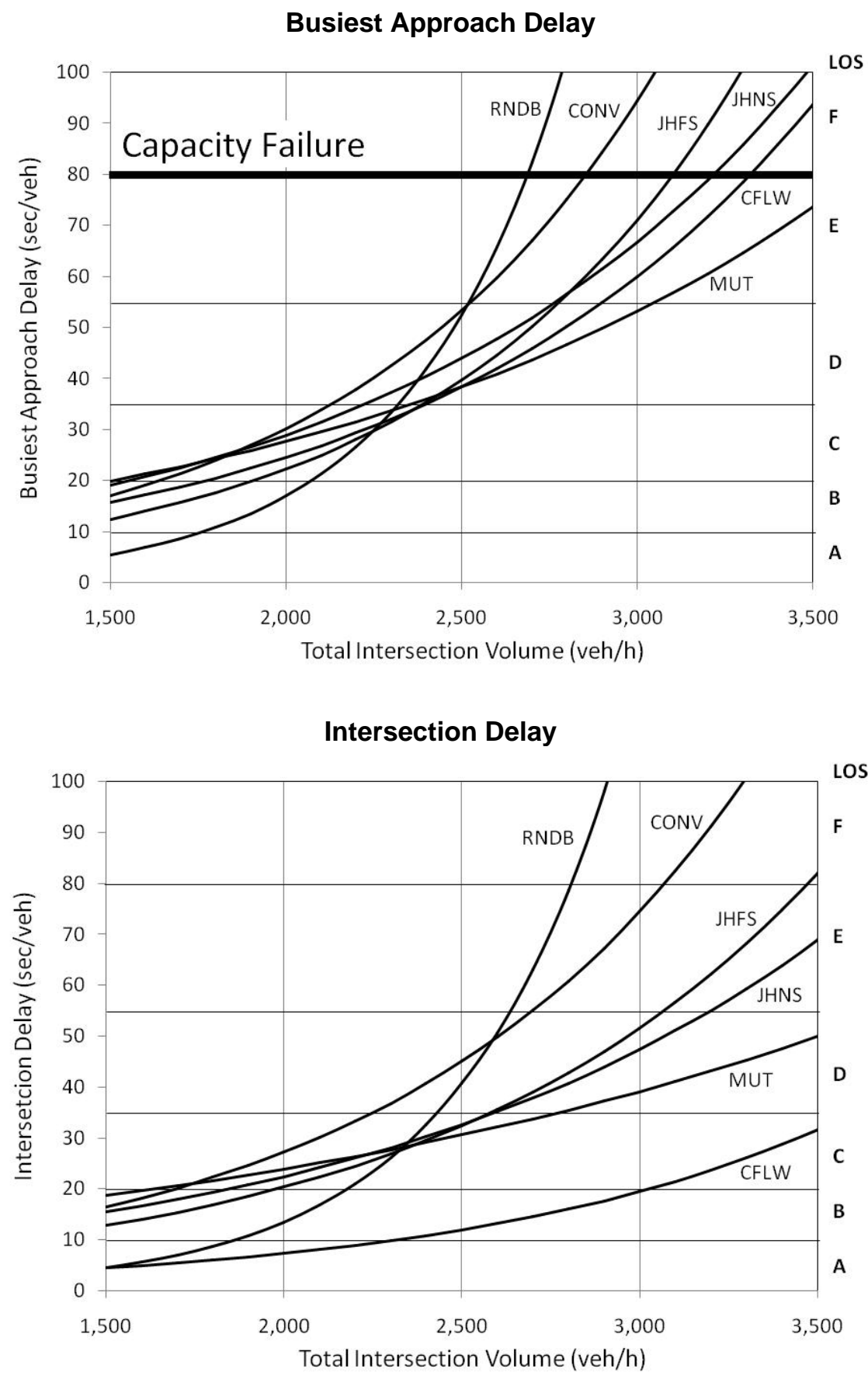

Stops Per Vehicle

\begin{tabular}{|c|c|c|c|}
\hline \multirow{2}{*}{ DESIGN } & \multicolumn{3}{|c|}{ Total Intersection Volume $($ veh/h) } \\
\cline { 2 - 4 } & 1730 & 2250 & 3110 \\
\hline CONV & 0.93 & 0.77 & 2.14 \\
\hline CFLW & 0.52 & 0.54 & 0.84 \\
\hline JHFS & 0.62 & 0.66 & 1.29 \\
\hline JHNS & 0.68 & 0.73 & 1.14 \\
\hline MUT & 0.74 & 0.81 & 1.00 \\
\hline RNDB & 0.24 & 0.59 & 9.58 \\
\hline
\end{tabular}



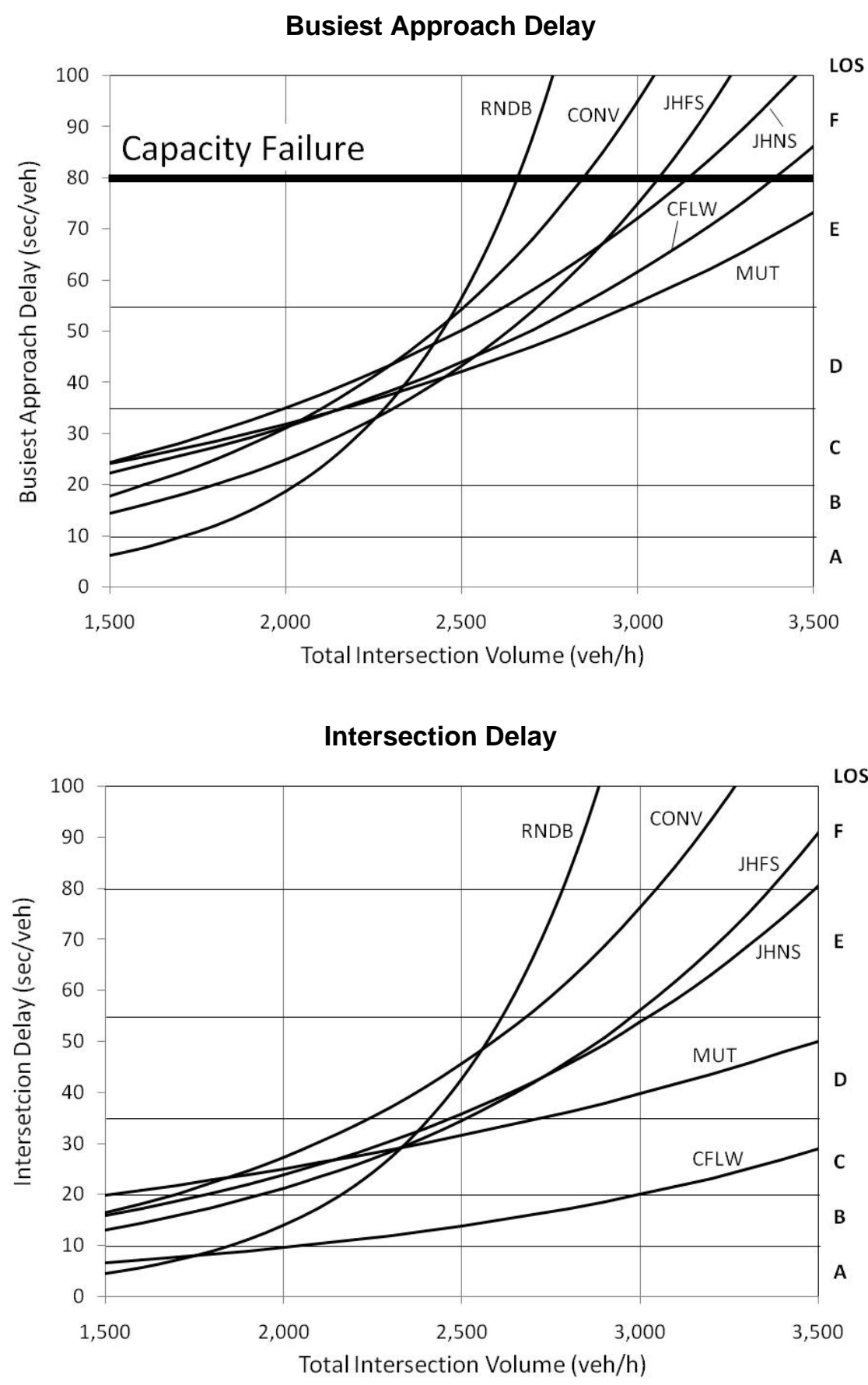

Stops Per Vehicle

\begin{tabular}{|c|c|c|c|}
\hline \multirow{2}{*}{ DESIGN } & \multicolumn{3}{|c|}{ Total Intersection Volume $(\mathrm{veh} / \mathrm{h})$} \\
\cline { 2 - 4 } & 1730 & 2250 & 3110 \\
\hline CONV & 0.73 & 0.80 & 1.97 \\
\hline CFLW & 0.61 & 0.62 & 0.85 \\
\hline JHFS & 0.63 & 0.68 & 1.36 \\
\hline JHNS & 0.69 & 0.76 & 1.25 \\
\hline MUT & 0.76 & 0.85 & 0.92 \\
\hline RNDB & 0.26 & 0.63 & 10.19 \\
\hline
\end{tabular}



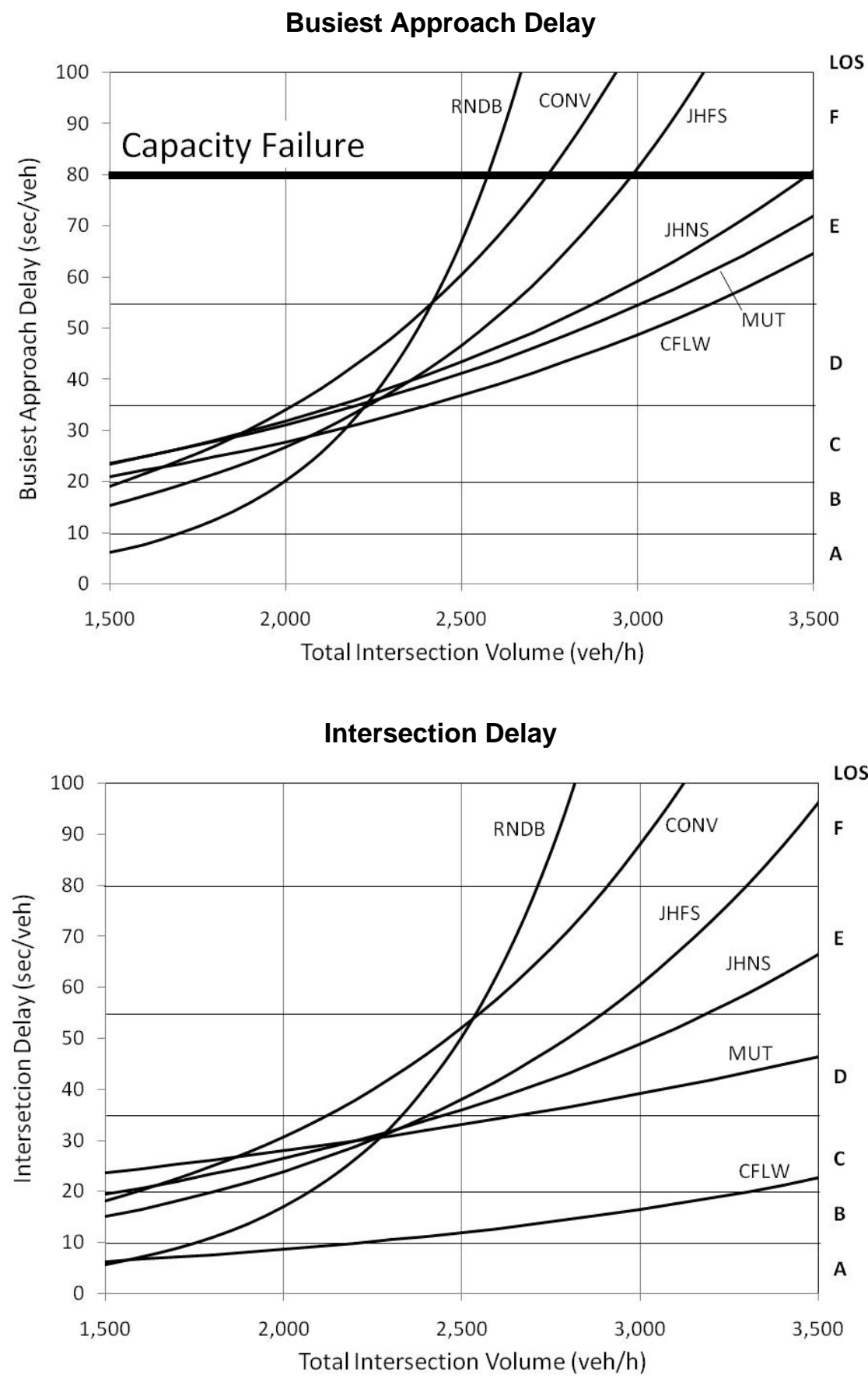

Stops Per Vehicle

\begin{tabular}{|c|c|c|c|}
\hline \multirow{2}{*}{ DESIGN } & \multicolumn{3}{|c|}{ Total Intersection Volume (veh/h) } \\
\cline { 2 - 4 } & 1730 & 2250 & 3110 \\
\hline CONV & 0.80 & 0.85 & 2.36 \\
\hline CFLW & 0.63 & 0.65 & 0.86 \\
\hline JHFS & 0.67 & 0.74 & 1.30 \\
\hline JHNS & 0.77 & 0.85 & 1.25 \\
\hline MUT & 0.87 & 0.93 & 1.09 \\
\hline RNDB & 0.32 & 1.00 & 11.23 \\
\hline
\end{tabular}



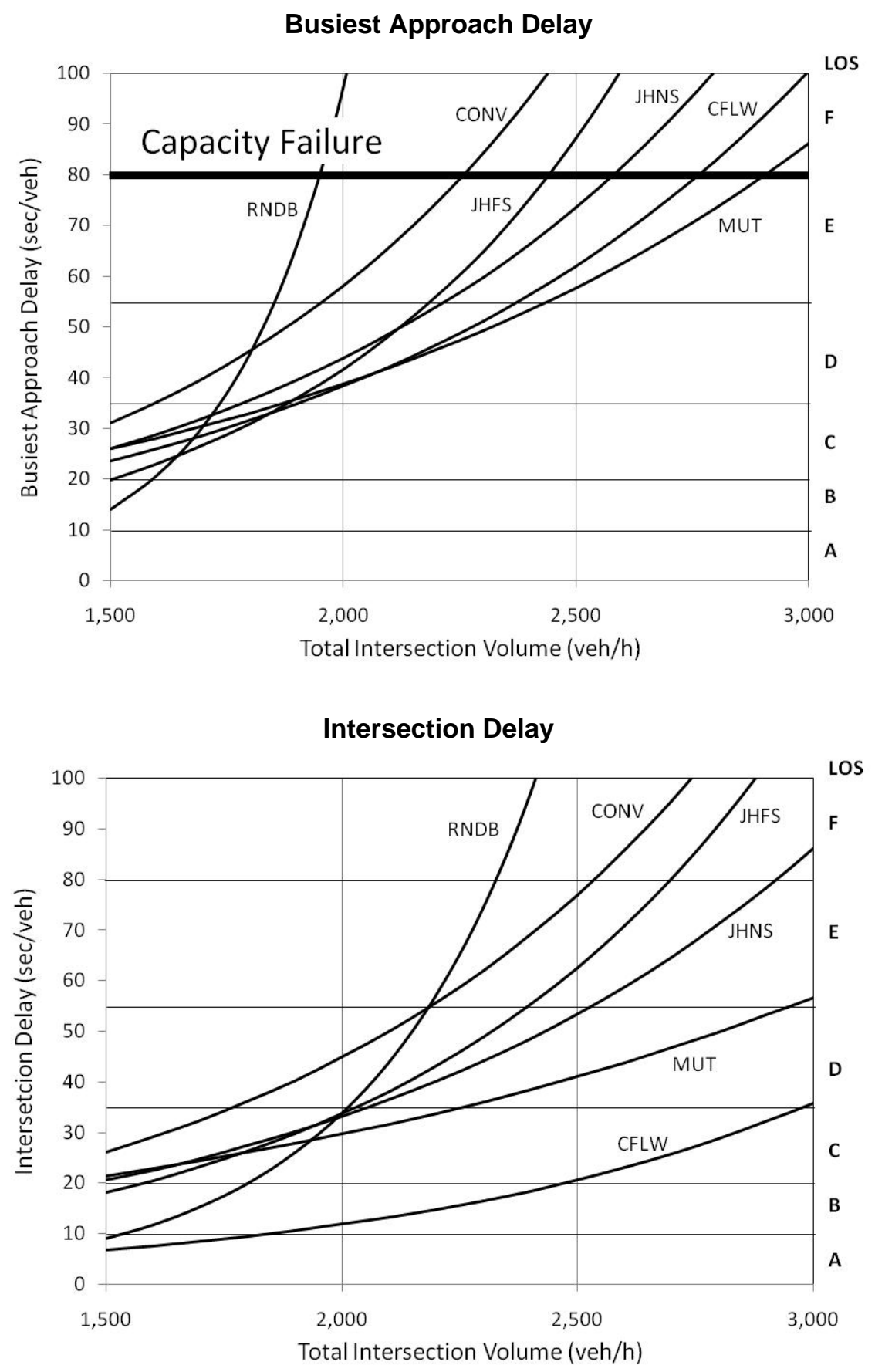

Stops Per Vehicle

\begin{tabular}{|c|c|c|c|}
\hline \multirow{2}{*}{ DESIGN } & \multicolumn{3}{|c|}{ Total Intersection Volume $(\mathrm{veh} / \mathrm{h})$} \\
\cline { 2 - 4 } & 1360 & 1760 & 2450 \\
\hline CONV & 0.87 & 1.36 & 1.68 \\
\hline CFLW & 0.52 & 0.56 & 0.79 \\
\hline JHFS & 0.60 & 0.64 & 1.36 \\
\hline JHNS & 0.67 & 0.72 & 1.14 \\
\hline MUT & 0.70 & 0.70 & 0.96 \\
\hline RNDB & 0.18 & 0.41 & 6.51 \\
\hline
\end{tabular}



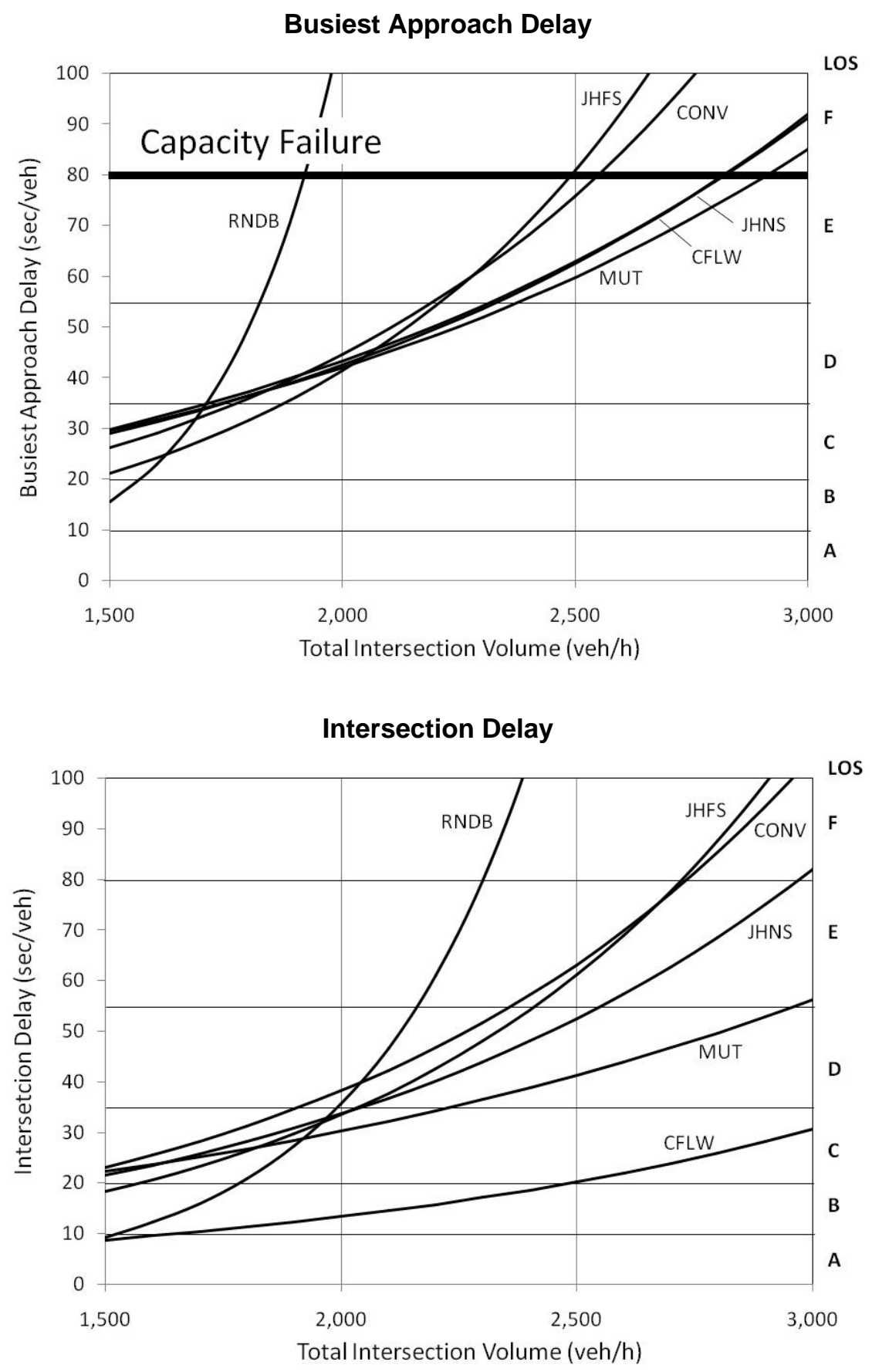

Stops Per Vehicle

\begin{tabular}{|c|c|c|c|}
\hline \multirow{2}{*}{ DESIGN } & \multicolumn{3}{|c|}{ Total Intersection Volume (veh/h) } \\
\cline { 2 - 4 } & 1360 & 1760 & 2450 \\
\hline CONV & 0.70 & 0.72 & 1.23 \\
\hline CFLW & 0.59 & 0.64 & 0.80 \\
\hline JHFS & 0.61 & 0.62 & 1.23 \\
\hline JHNS & 0.69 & 0.73 & 1.07 \\
\hline MUT & 0.72 & 0.65 & 0.86 \\
\hline RNDB & 0.19 & 0.45 & 6.85 \\
\hline
\end{tabular}



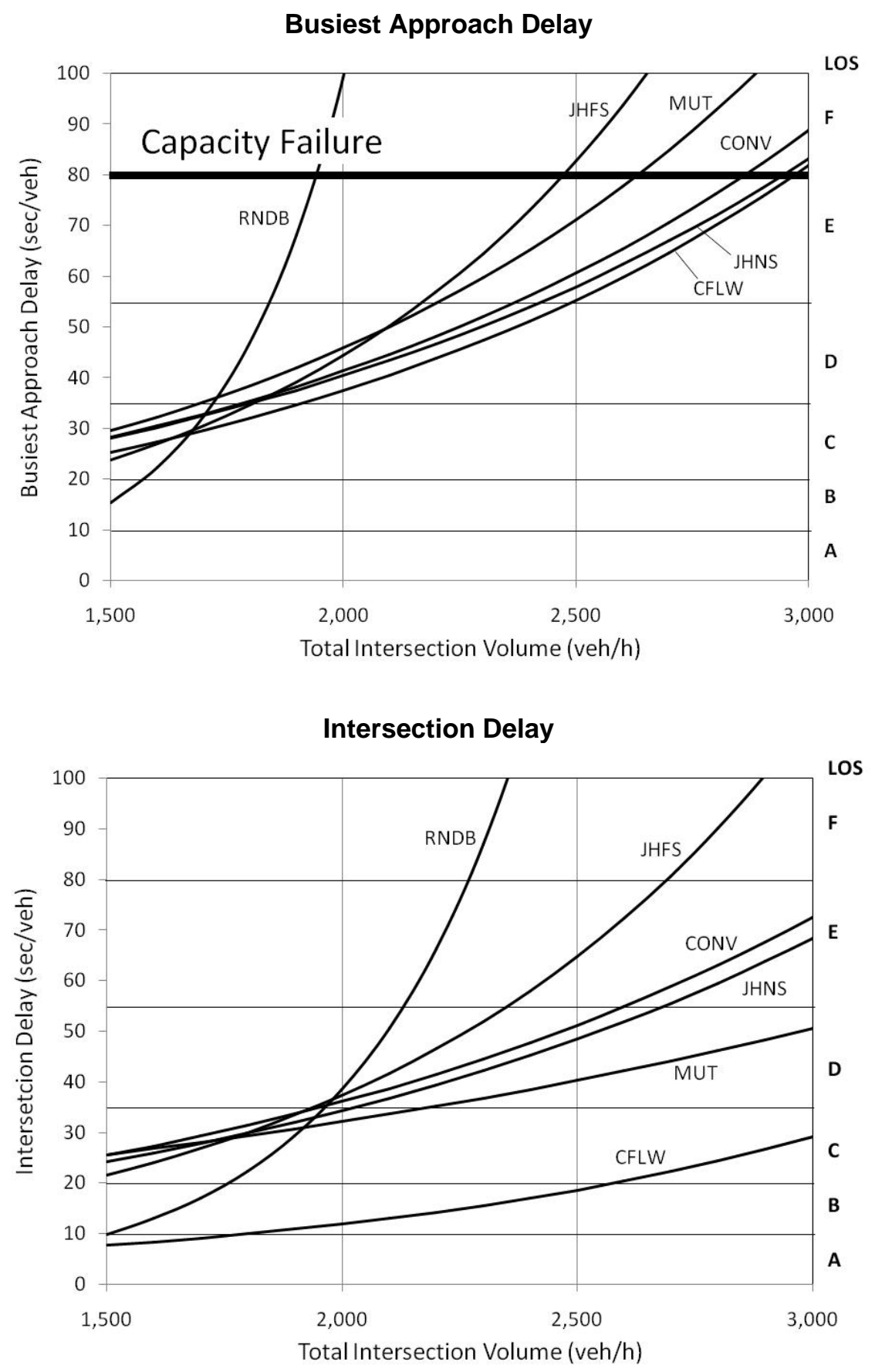

Stops Per Vehicle

\begin{tabular}{|c|c|c|c|}
\hline \multirow{2}{*}{ DESIGN } & \multicolumn{3}{|c|}{ Total Intersection Volume (veh/h) } \\
\cline { 2 - 4 } & 1360 & 1765 & 2445 \\
\hline CONV & 0.79 & 0.79 & 1.04 \\
\hline CFLW & 0.61 & 0.66 & 0.83 \\
\hline JHFS & 0.66 & 0.71 & 1.20 \\
\hline JHNS & 0.76 & 0.82 & 1.12 \\
\hline MUT & 0.82 & 0.76 & 0.91 \\
\hline RNDB & 0.21 & 0.51 & 7.69 \\
\hline
\end{tabular}




\section{Busiest Approach Delay}

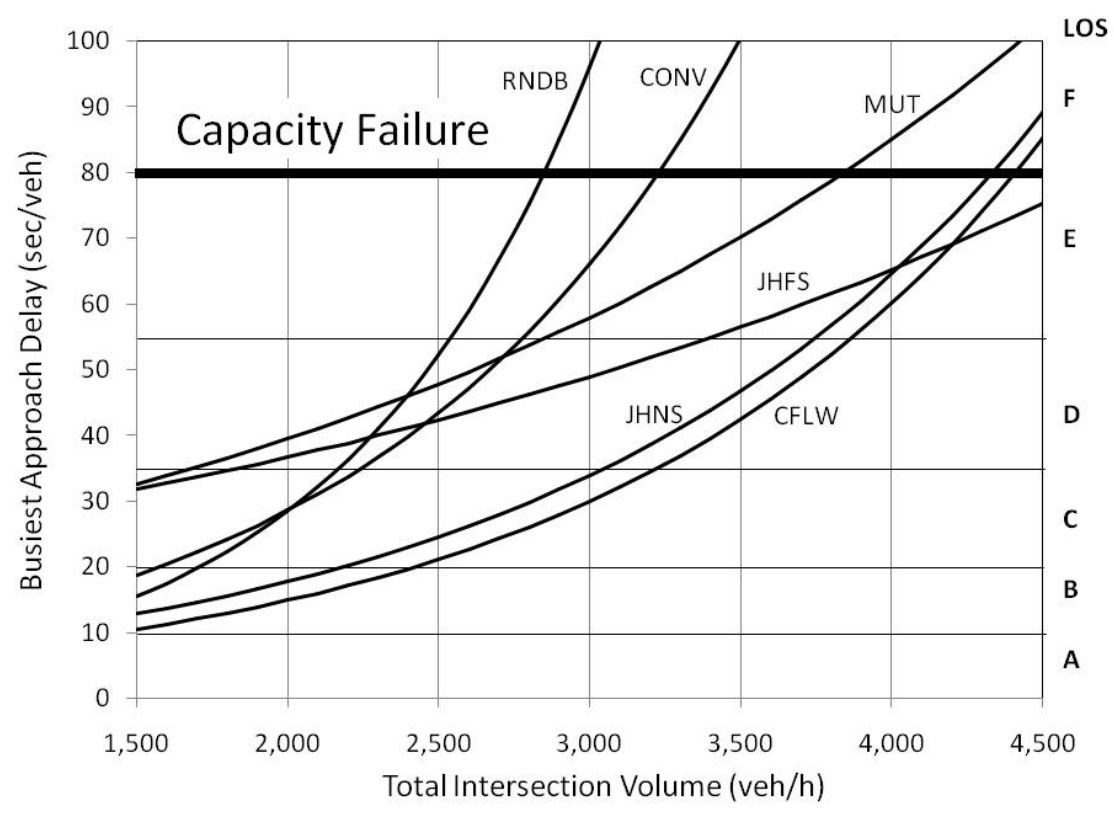

Intersection Delay

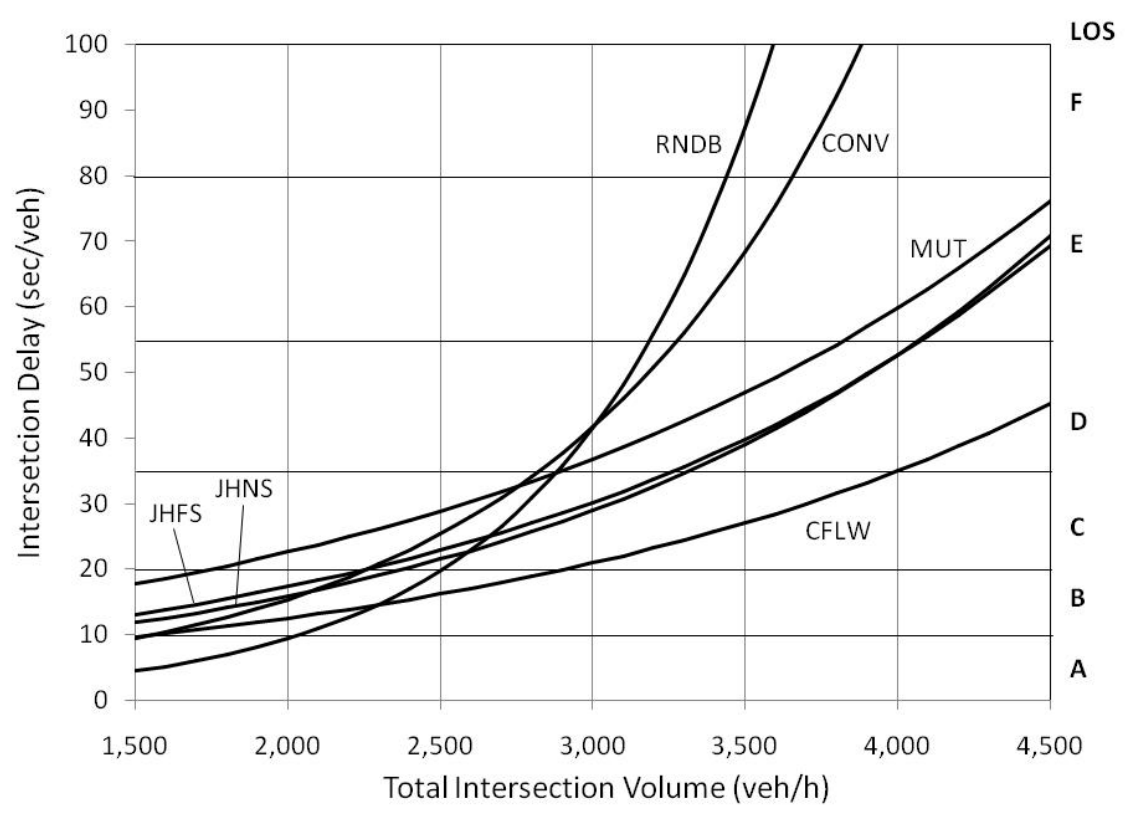

Stops Per Vehicle

\begin{tabular}{|c|c|c|c|}
\hline \multirow{2}{*}{ DESIGN } & \multicolumn{3}{|c|}{ Total Intersection Volume (veh/h) } \\
\cline { 2 - 4 } & 2385 & 3100 & 4290 \\
\hline CONV & 0.69 & 1.05 & 3.85 \\
\hline CFLW & 0.52 & 0.68 & 0.91 \\
\hline JHFS & 0.60 & 0.74 & 1.19 \\
\hline JHNS & 0.68 & 0.75 & 1.47 \\
\hline MUT & 0.93 & 1.23 & 1.74 \\
\hline RNDB & 0.54 & 2.69 & 14.17 \\
\hline
\end{tabular}




\section{Busiest Approach Delay}

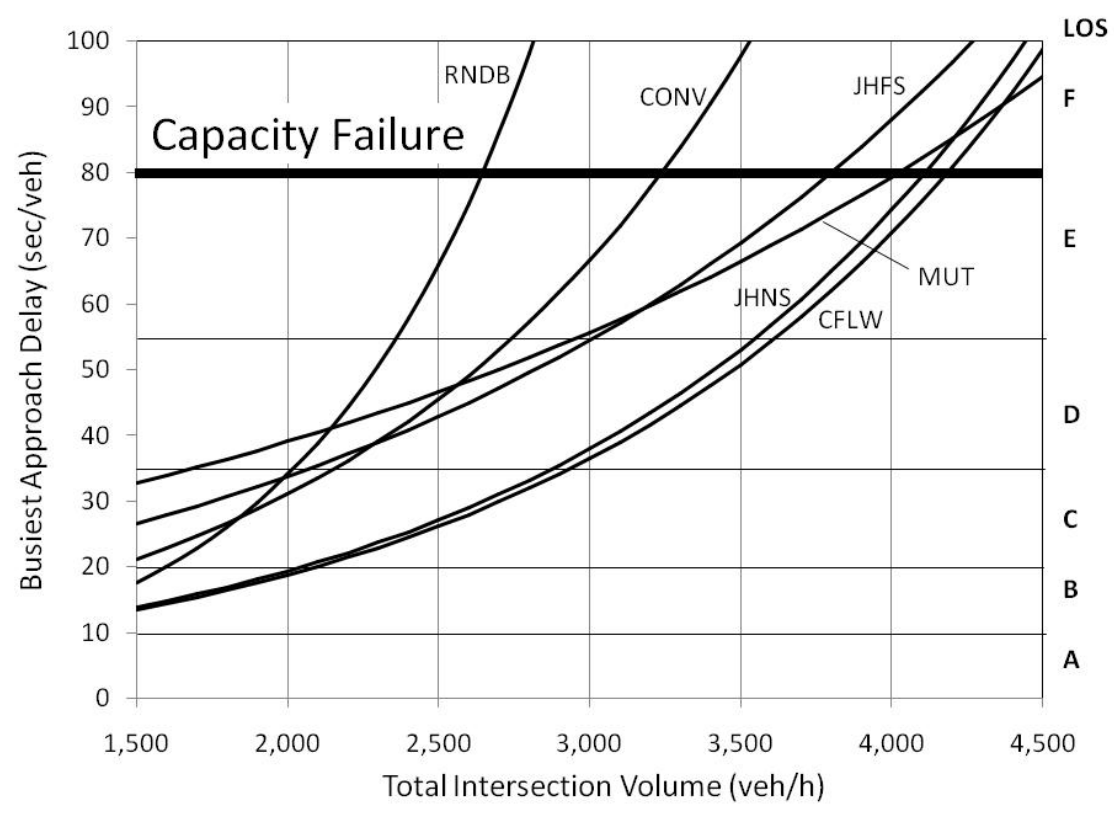

Intersection Delay

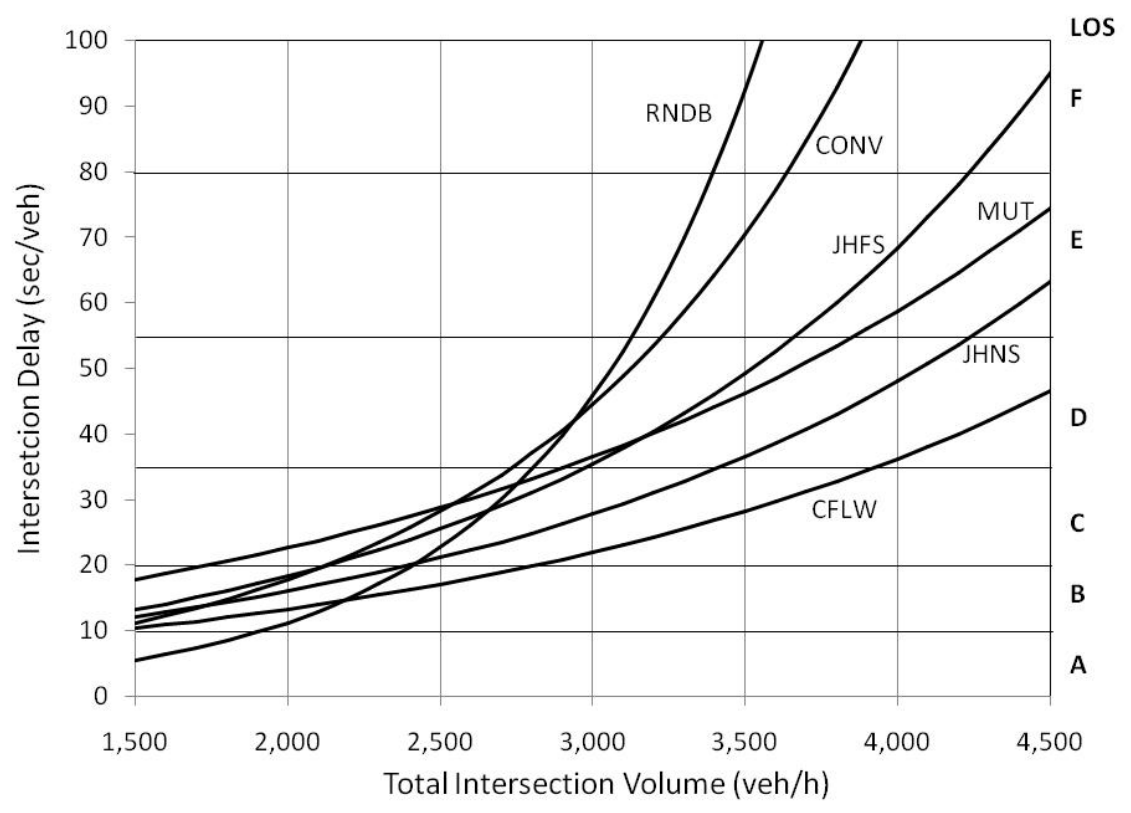

Stops Per Vehicle

\begin{tabular}{|c|c|c|c|}
\hline \multirow{2}{*}{ DESIGN } & \multicolumn{3}{|c|}{ Total Intersection Volume (veh/h) } \\
\cline { 2 - 4 } & 2385 & 3100 & 4290 \\
\hline CONV & 0.76 & 0.82 & 3.19 \\
\hline CFLW & 0.60 & 0.65 & 0.97 \\
\hline JHFS & 0.64 & 0.76 & 1.61 \\
\hline JHNS & 0.69 & 0.77 & 1.41 \\
\hline MUT & 0.88 & 1.18 & 1.80 \\
\hline RNDB & 0.61 & 3.38 & 13.52 \\
\hline
\end{tabular}




\section{Busiest Approach Delay}

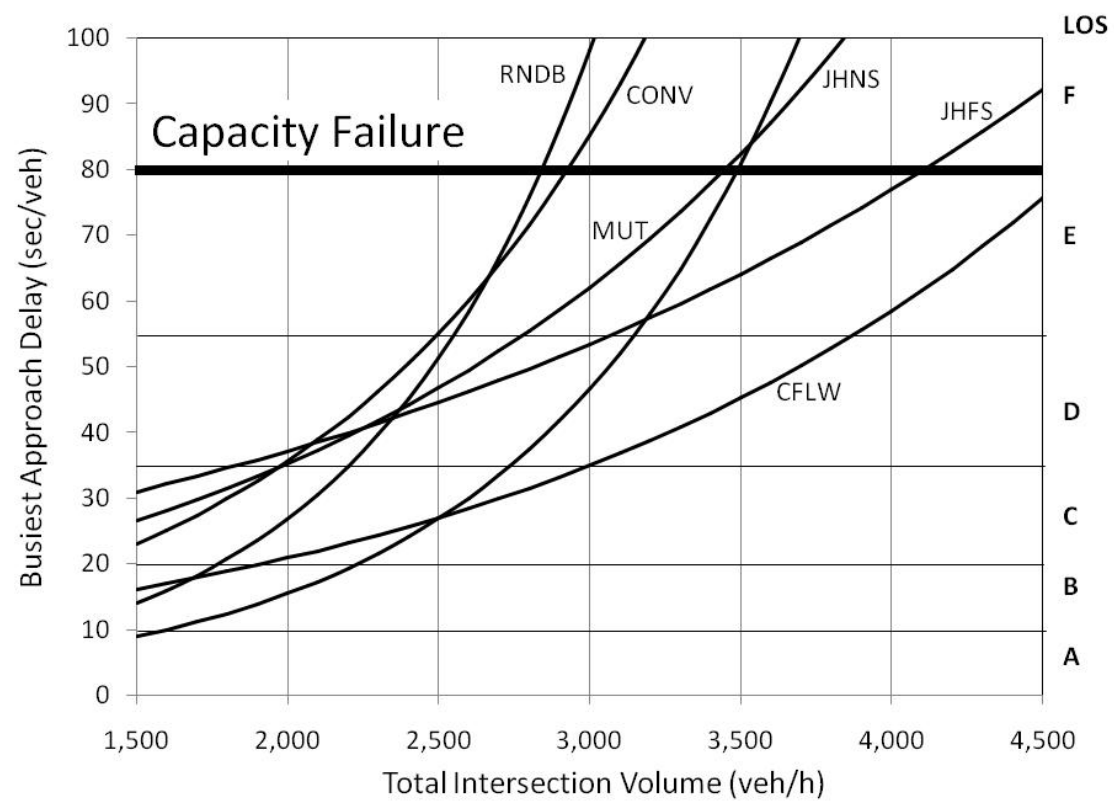

Intersection Delay

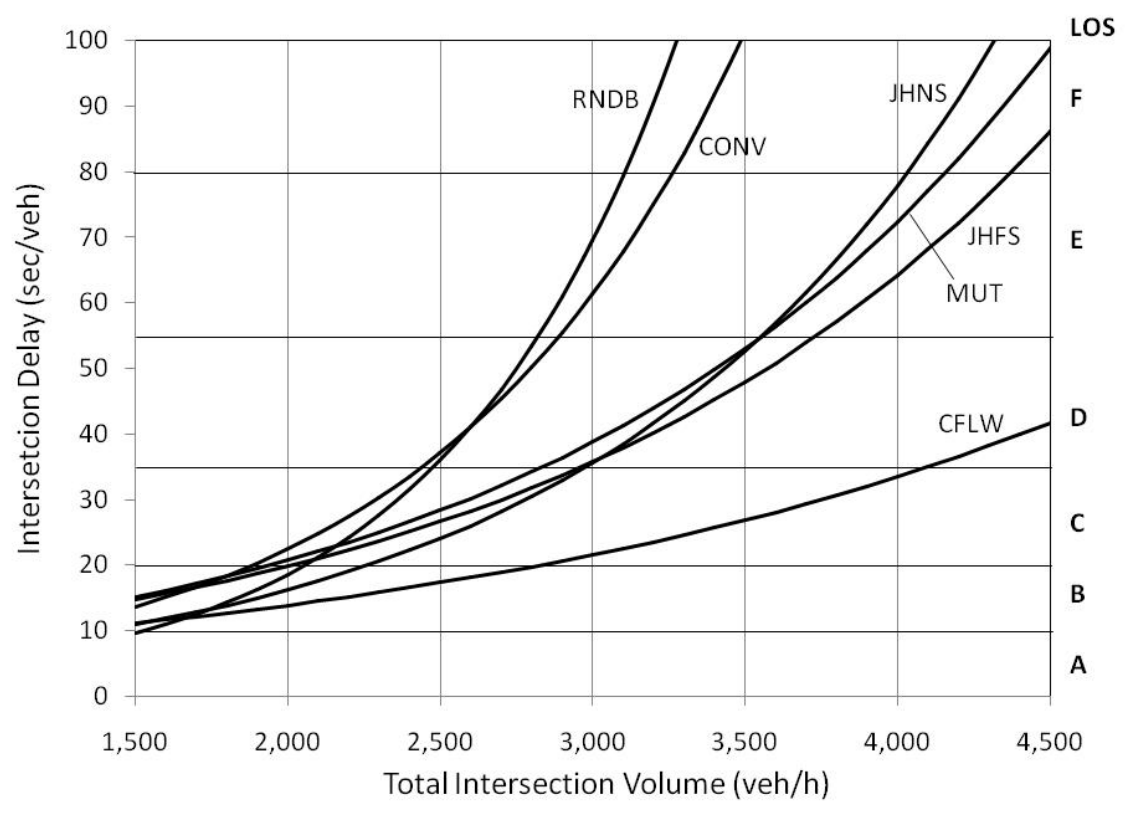

Stops Per Vehicle

\begin{tabular}{|c|c|c|c|}
\hline \multirow{2}{*}{ DESIGN } & \multicolumn{3}{|c|}{ Total Intersection Volume $(\mathrm{veh} / \mathrm{h})$} \\
\cline { 2 - 4 } & 2385 & 3100 & 4290 \\
\hline CONV & 0.88 & 1.36 & 4.60 \\
\hline CFLW & 0.62 & 0.66 & 1.03 \\
\hline JHFS & 0.67 & 0.88 & 1.42 \\
\hline JHNS & 0.78 & 0.92 & 2.73 \\
\hline MUT & 0.82 & 1.07 & 2.65 \\
\hline RNDB & 0.68 & 5.53 & 18.21 \\
\hline
\end{tabular}




\section{Busiest Approach Delay}

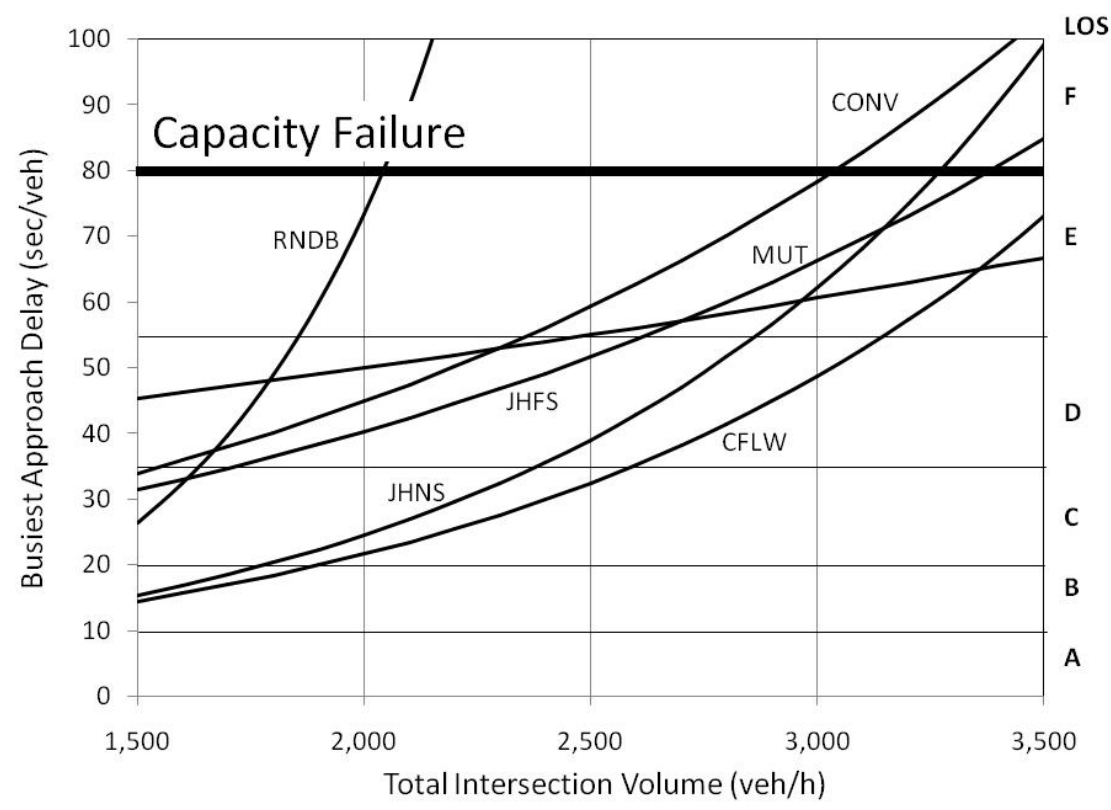

Intersection Delay

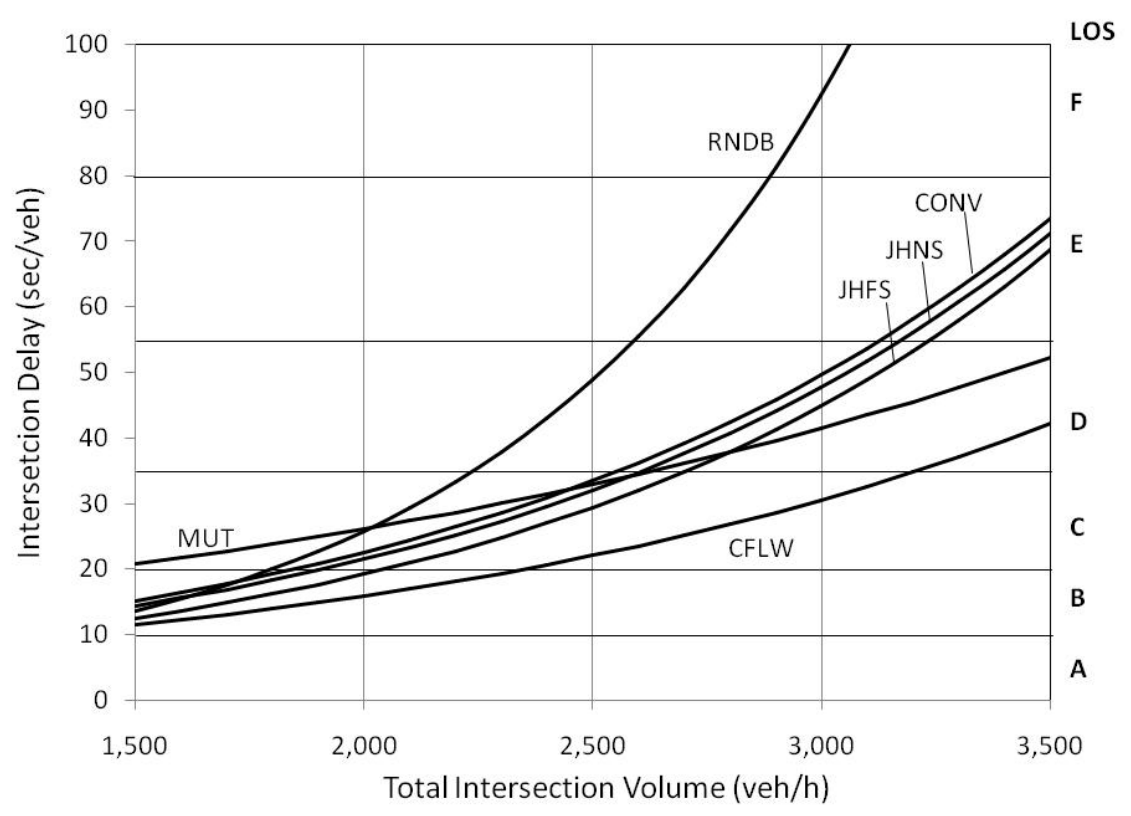

Stops Per Vehicle

\begin{tabular}{|c|c|c|c|}
\hline \multirow{2}{*}{ DESIGN } & \multicolumn{3}{|c|}{ Total Intersection Volume (veh/h) } \\
\cline { 2 - 4 } & 1880 & 2440 & 3370 \\
\hline CONV & 0.65 & 0.73 & 1.45 \\
\hline CFLW & 0.54 & 0.62 & 0.90 \\
\hline JHFS & 0.59 & 0.71 & 1.23 \\
\hline JHNS & 0.68 & 0.73 & 1.51 \\
\hline MUT & 0.93 & 1.16 & 1.20 \\
\hline RNDB & 0.46 & 4.90 & 6.02 \\
\hline
\end{tabular}



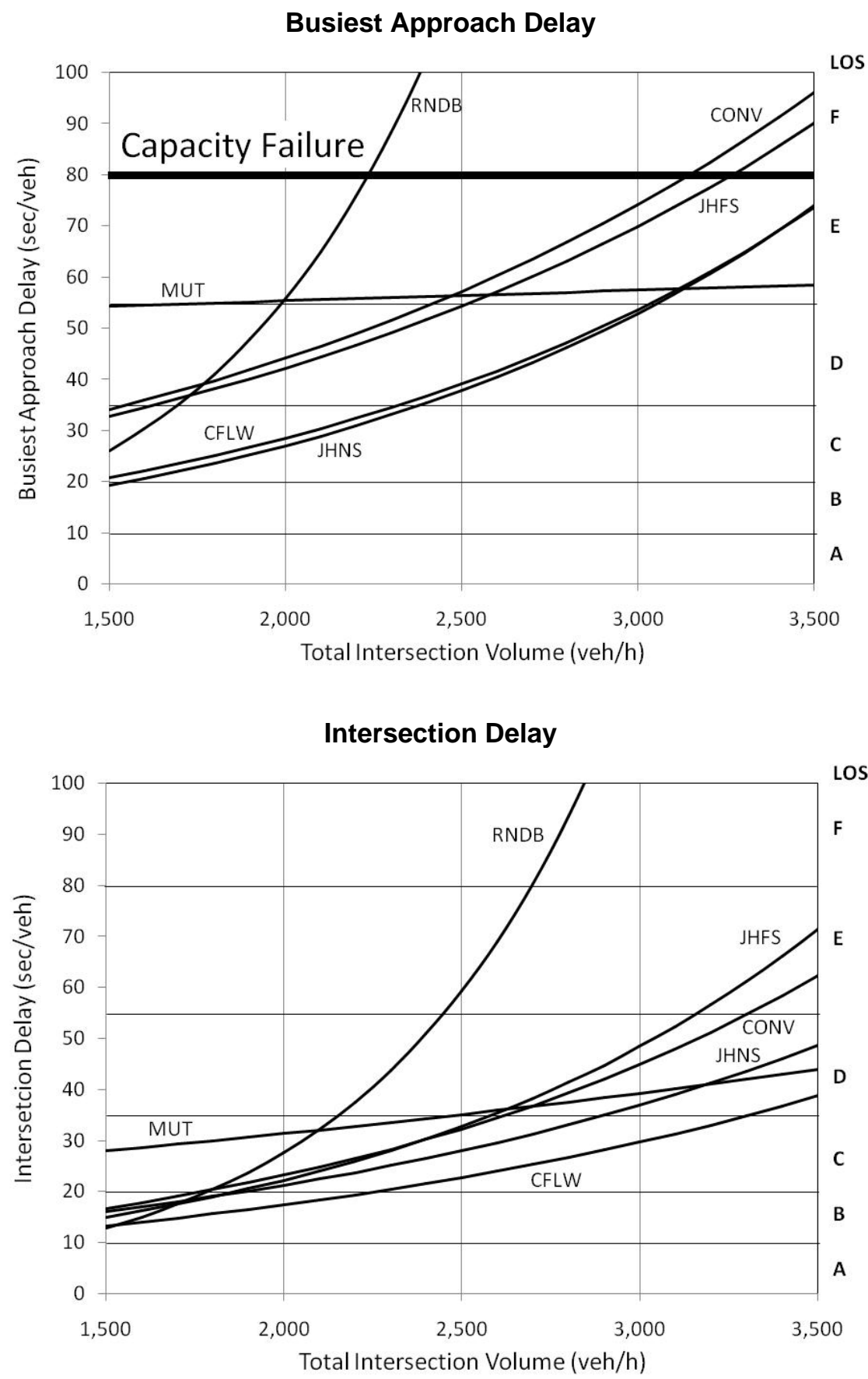

Stops Per Vehicle

\begin{tabular}{|c|c|c|c|}
\hline \multirow{2}{*}{ DESIGN } & \multicolumn{3}{|c|}{ Total Intersection Volume $(\mathrm{veh} / \mathrm{h})$} \\
\cline { 2 - 4 } & 1880 & 2440 & 3370 \\
\hline CONV & 0.67 & 0.72 & 1.11 \\
\hline CFLW & 0.60 & 0.64 & 0.86 \\
\hline JHFS & 0.61 & 0.71 & 1.32 \\
\hline JHNS & 0.68 & 0.74 & 1.09 \\
\hline MUT & 1.11 & 1.16 & 1.12 \\
\hline RNDB & 0.53 & 5.29 & 5.29 \\
\hline
\end{tabular}




\section{Busiest Approach Delay}

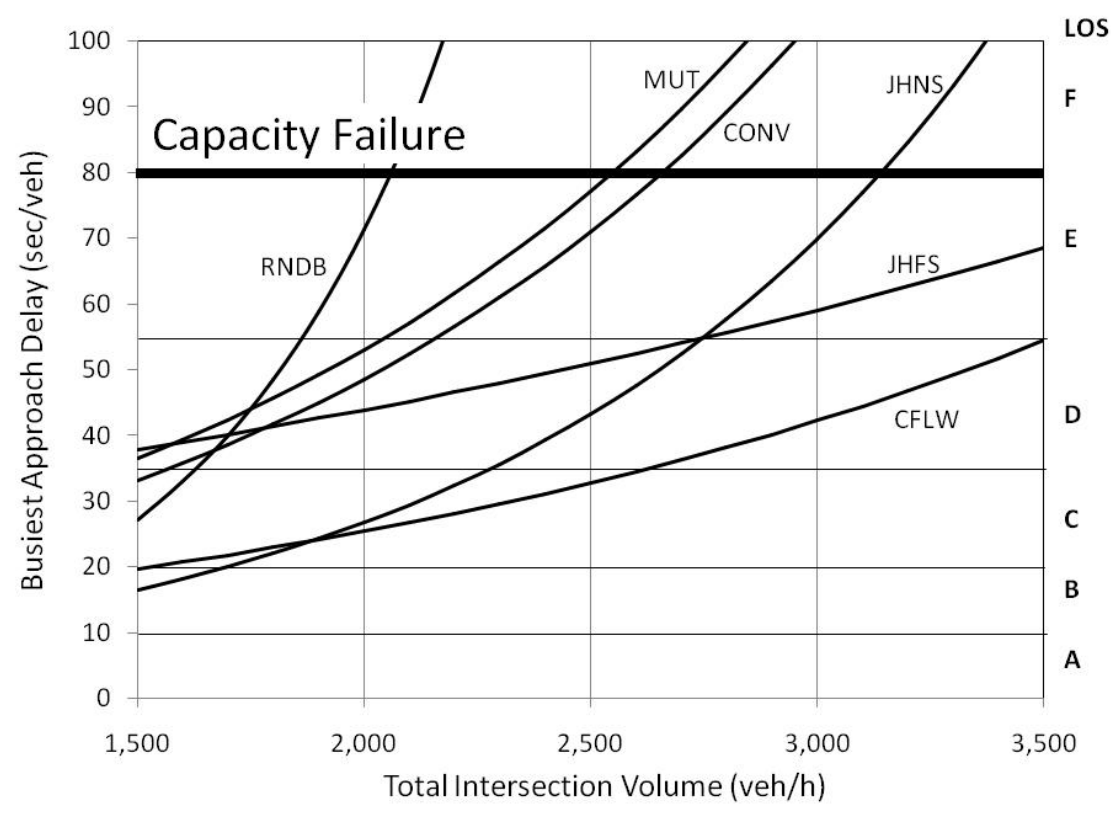

Intersection Delay

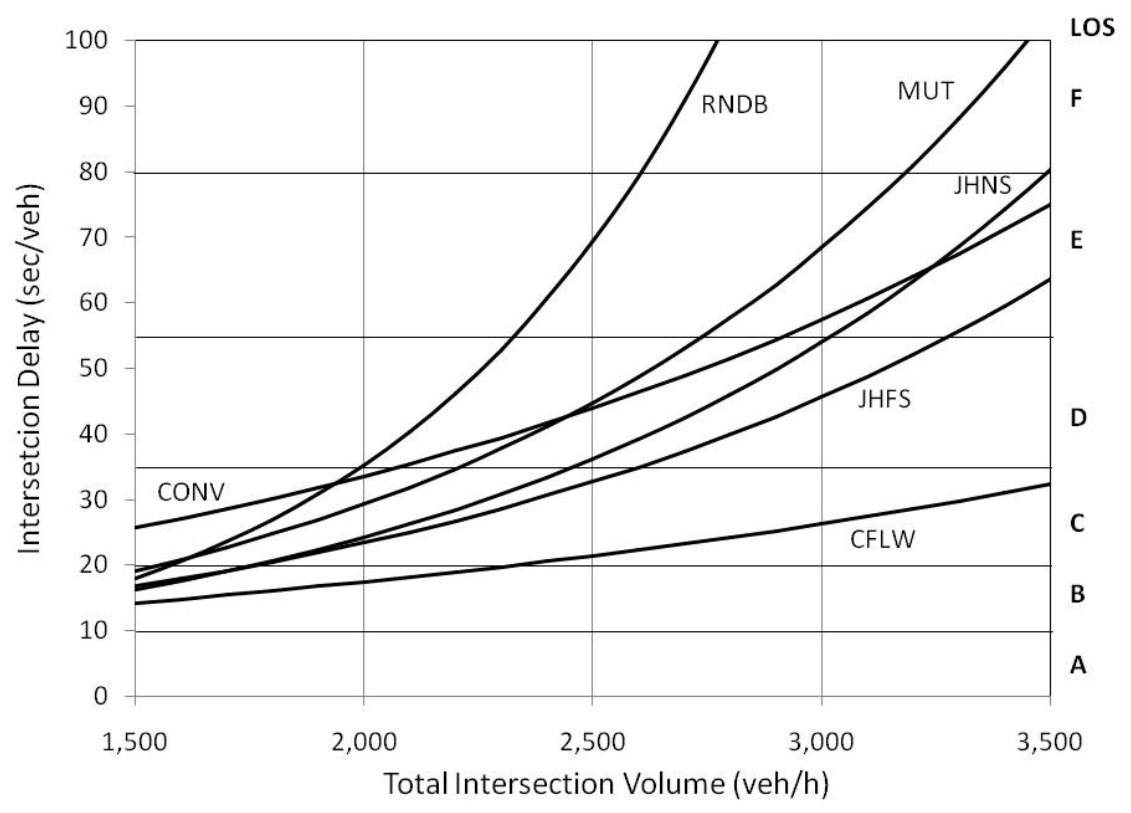

Stops Per Vehicle

\begin{tabular}{|c|c|c|c|}
\hline \multirow{2}{*}{ DESIGN } & \multicolumn{3}{|c|}{ Total Intersection Volume $($ veh/h) } \\
\cline { 2 - 4 } & 1880 & 2440 & 3370 \\
\hline CONV & 1.06 & 0.85 & 1.47 \\
\hline CFLW & 0.61 & 0.70 & 0.81 \\
\hline JHFS & 0.65 & 0.83 & 1.19 \\
\hline JHNS & 0.76 & 0.88 & 1.88 \\
\hline MUT & 1.05 & 1.36 & 2.58 \\
\hline RNDB & 0.51 & 4.71 & 9.78 \\
\hline
\end{tabular}




\section{Busiest Approach Delay}

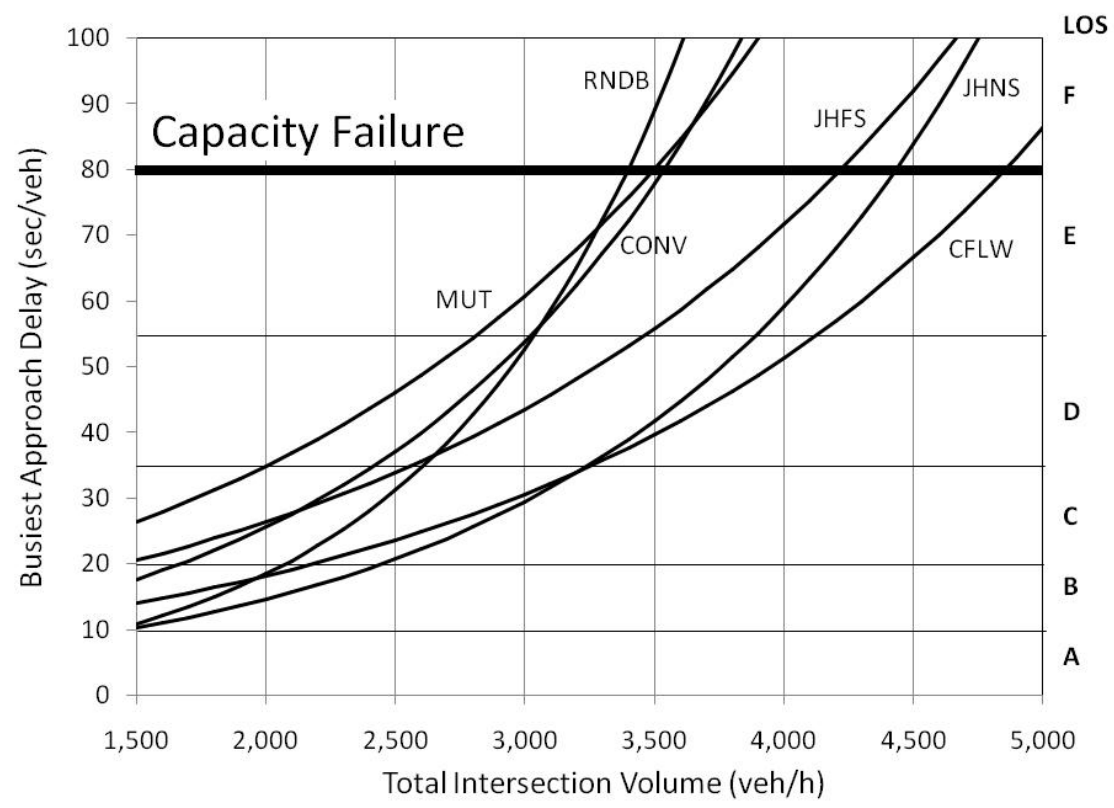

Intersection Delay

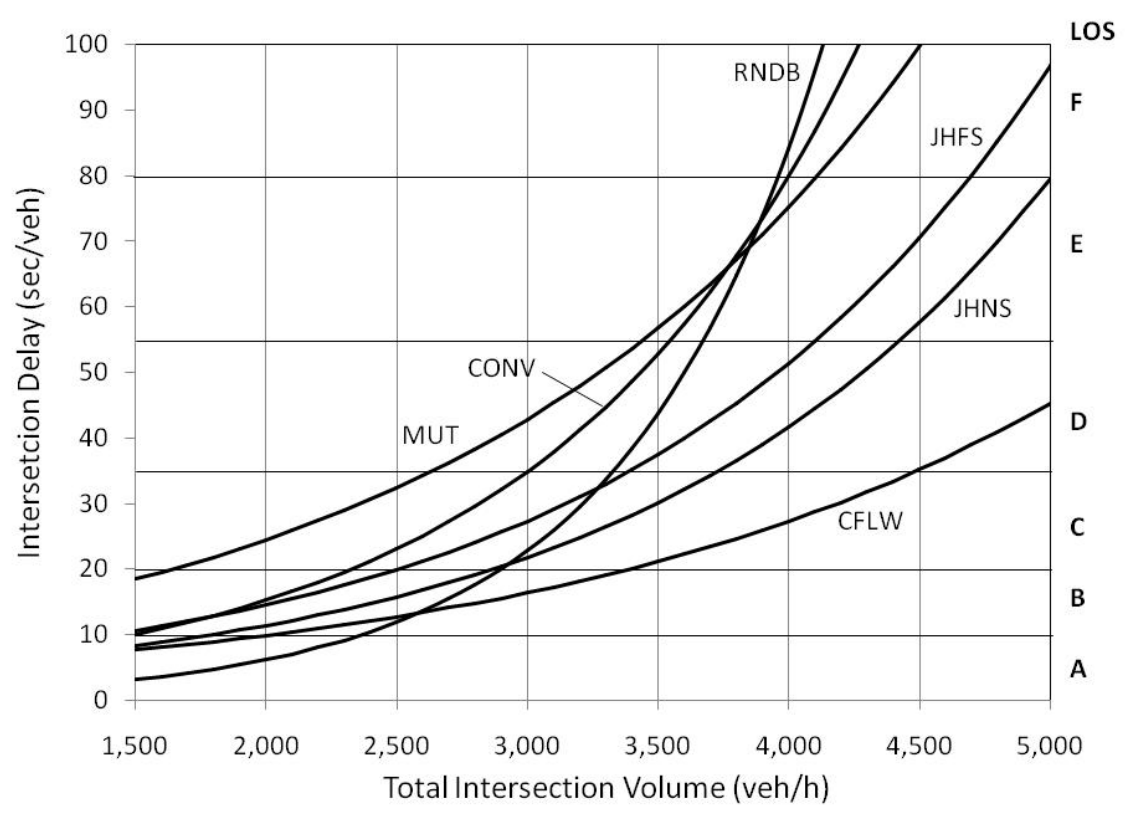

Stops Per Vehicle

\begin{tabular}{|c|c|c|c|}
\hline \multirow{2}{*}{ DESIGN } & \multicolumn{3}{|c|}{ Total Intersection Volume $($ veh/h) } \\
\cline { 2 - 4 } & 2660 & 3455 & 4785 \\
\hline CONV & 0.72 & 0.84 & 3.97 \\
\hline CFLW & 0.49 & 0.50 & 0.83 \\
\hline JHFS & 0.57 & 0.66 & 1.39 \\
\hline JHNS & 0.63 & 0.70 & 1.30 \\
\hline MUT & 1.26 & 1.32 & 2.18 \\
\hline RNDB & 0.39 & 1.59 & 11.22 \\
\hline
\end{tabular}




\section{Busiest Approach Delay}

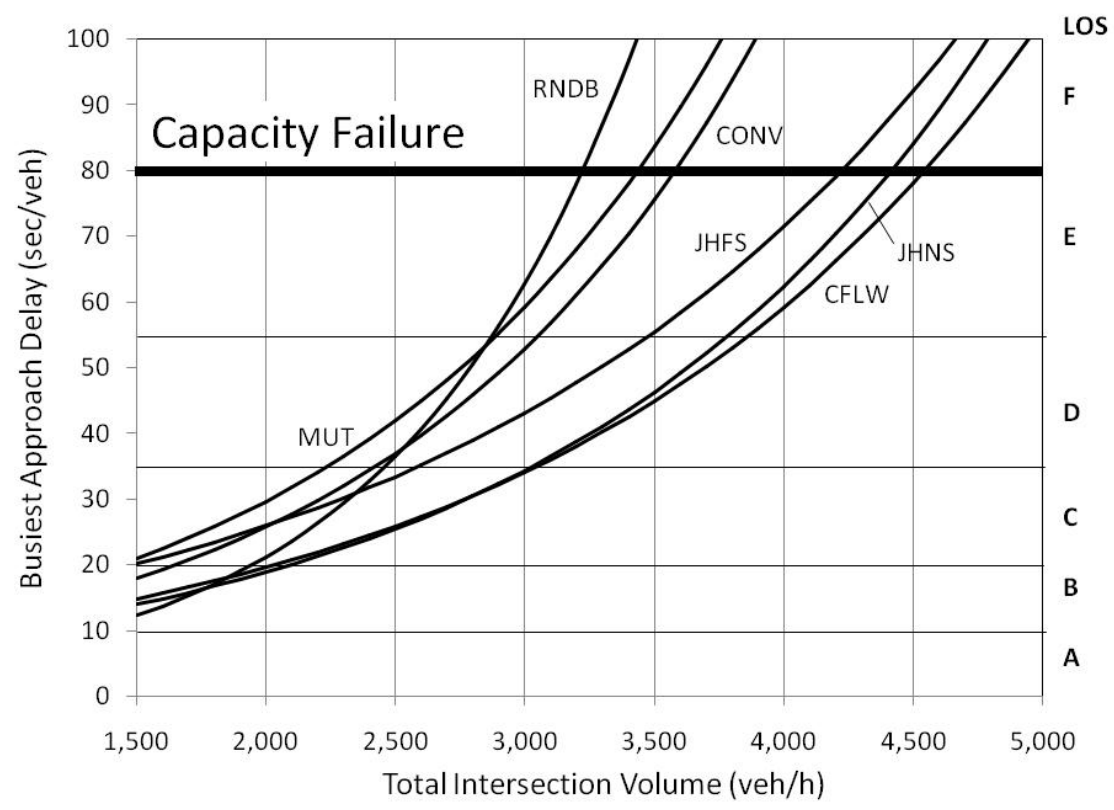

Intersection Delay

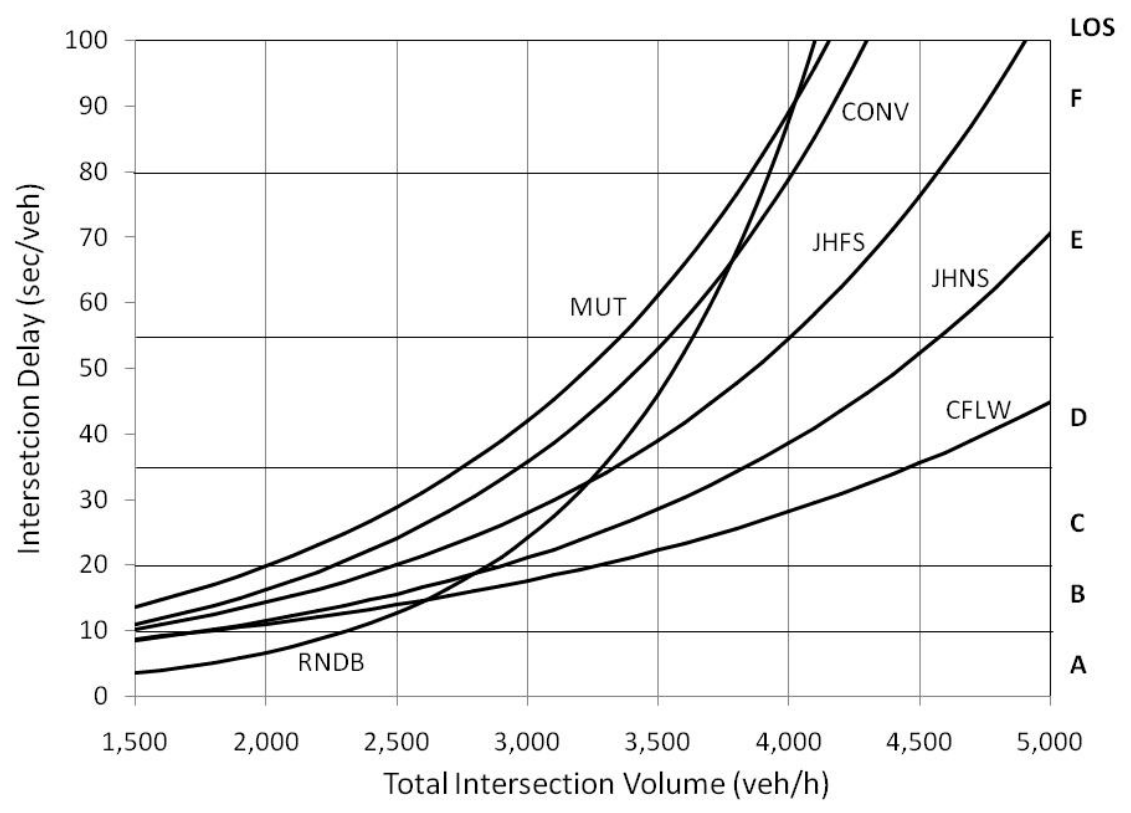

Stops Per Vehicle

\begin{tabular}{|c|c|c|c|}
\hline \multirow{2}{*}{ DESIGN } & \multicolumn{3}{|c|}{ Total Intersection Volume (veh/h) } \\
\cline { 2 - 4 } & 2660 & 3455 & 4785 \\
\hline CONV & 0.72 & 0.82 & 2.97 \\
\hline CFLW & 0.55 & 0.55 & 0.82 \\
\hline JHFS & 0.58 & 0.66 & 1.48 \\
\hline JHNS & 0.61 & 0.70 & 1.19 \\
\hline MUT & 1.19 & 1.32 & 3.81 \\
\hline RNDB & 0.40 & 1.84 & 11.30 \\
\hline
\end{tabular}




\section{Busiest Approach Delay}

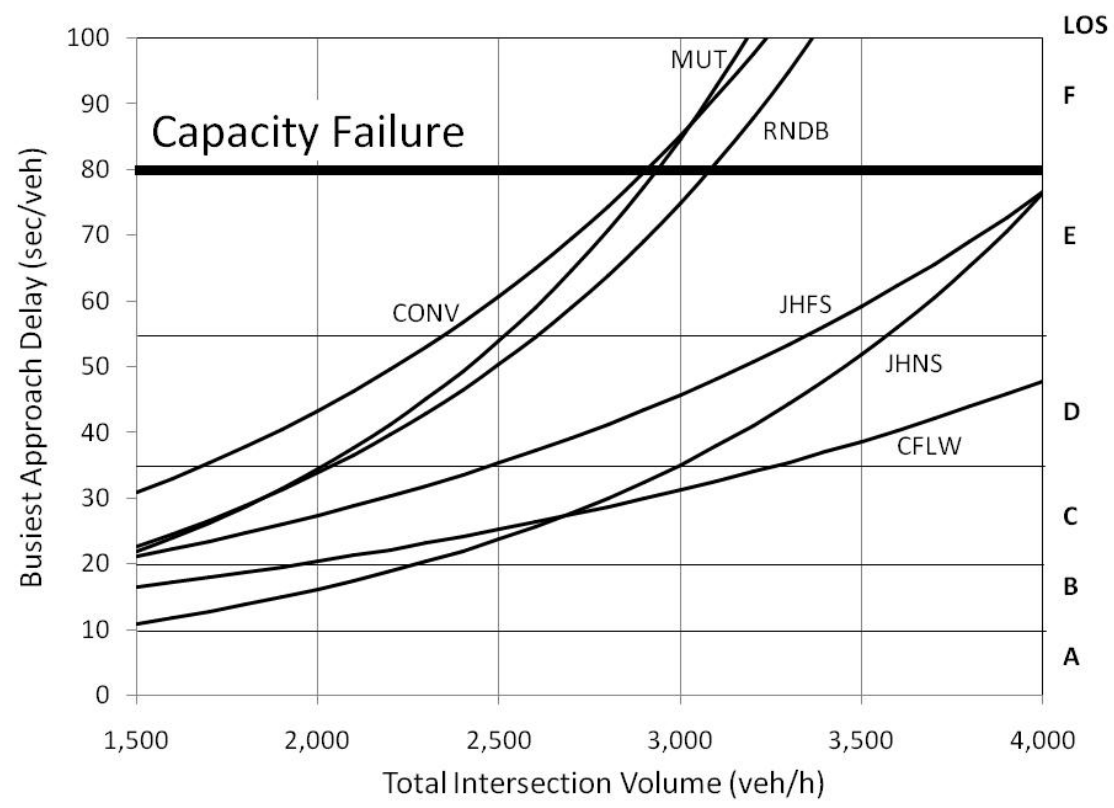

\section{Intersection Delay}

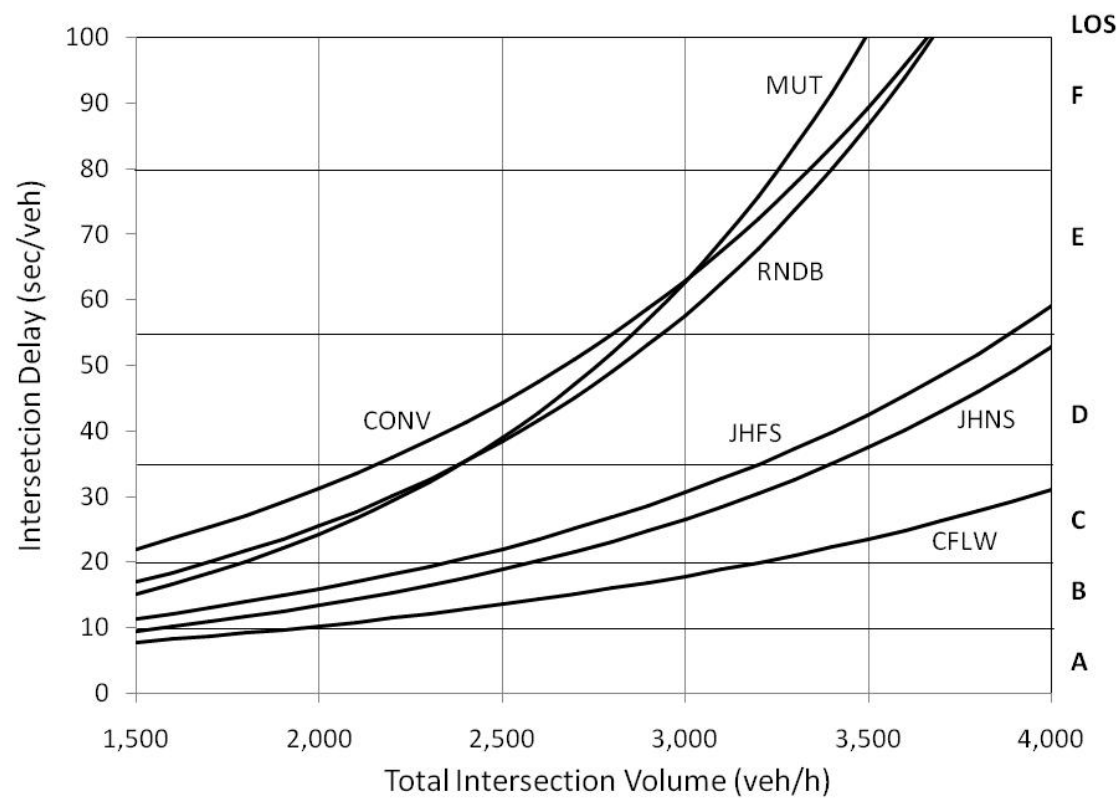

Stops Per Vehicle

\begin{tabular}{|c|c|c|c|}
\hline \multirow{2}{*}{ DESIGN } & \multicolumn{3}{|c|}{ Total Intersection Volume $(\mathrm{veh} / \mathrm{h})$} \\
\cline { 2 - 4 } & 2660 & 3455 & 4785 \\
\hline CONV & 1.06 & 2.25 & 4.15 \\
\hline CFLW & 0.55 & 0.61 & 0.93 \\
\hline JHFS & 0.65 & 0.77 & 1.95 \\
\hline JHNS & 0.75 & 0.92 & 2.05 \\
\hline MUT & 1.41 & 2.38 & 7.18 \\
\hline RNDB & 0.63 & 8.67 & 8.67 \\
\hline
\end{tabular}




\section{Busiest Approach Delay}

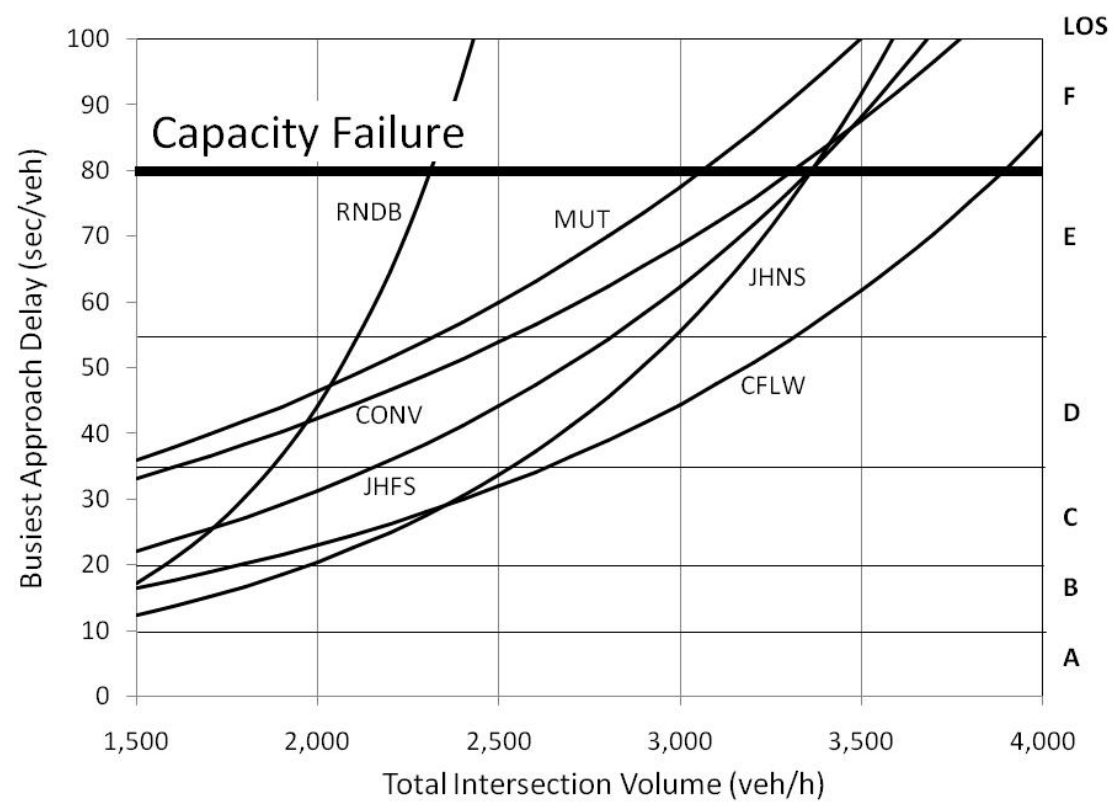

\section{Intersection Delay}

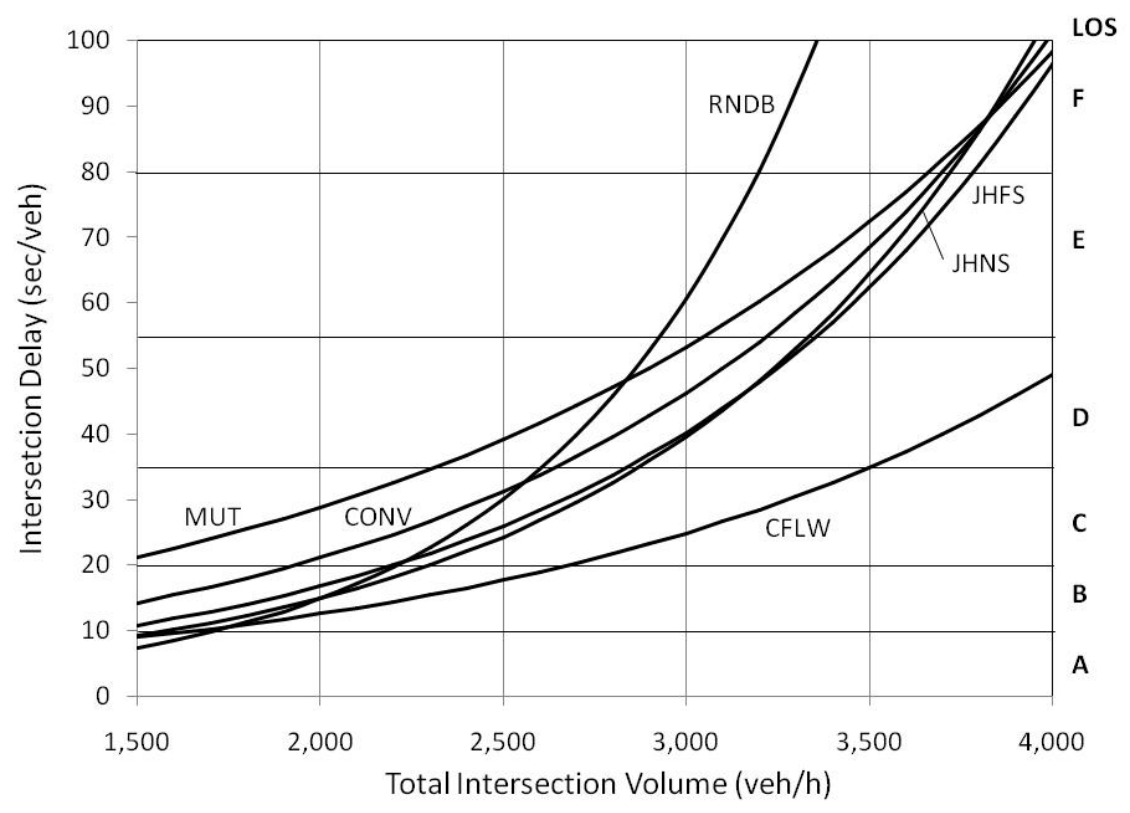

Stops Per Vehicle

\begin{tabular}{|c|c|c|c|}
\hline \multirow{2}{*}{ DESIGN } & \multicolumn{3}{|c|}{ Total Intersection Volume $(\mathrm{veh} / \mathrm{h})$} \\
\cline { 2 - 4 } & 2090 & 2715 & 3760 \\
\hline CONV & 0.66 & 0.72 & 1.34 \\
\hline CFLW & 0.49 & 0.54 & 0.79 \\
\hline JHFS & 0.55 & 0.63 & 1.20 \\
\hline JHNS & 0.62 & 0.69 & 1.62 \\
\hline MUT & 1.17 & 1.04 & 1.88 \\
\hline RNDB & 0.32 & 2.93 & 6.41 \\
\hline
\end{tabular}




\section{Busiest Approach Delay}

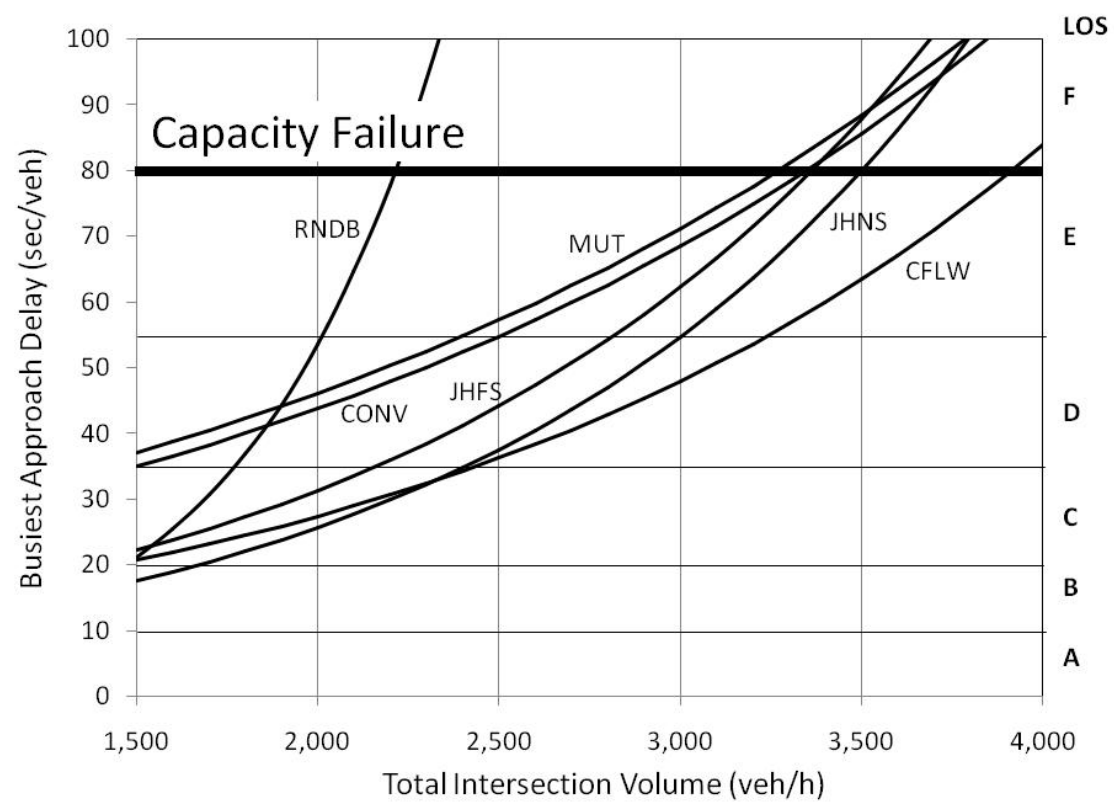

Intersection Delay

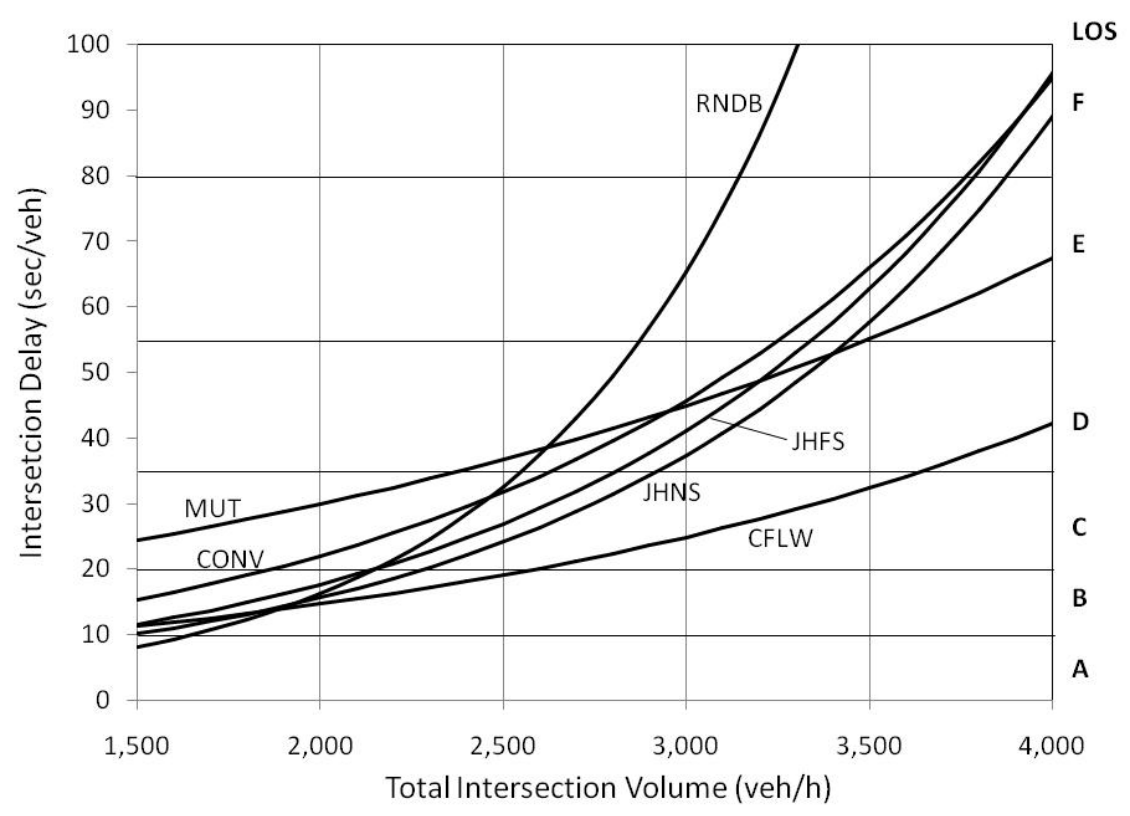

Stops Per Vehicle

\begin{tabular}{|c|c|c|c|}
\hline \multirow{2}{*}{ DESIGN } & \multicolumn{3}{|c|}{ Total Intersection Volume (veh/h) } \\
\cline { 2 - 4 } & 2090 & 2715 & 3760 \\
\hline CONV & 0.66 & 0.74 & 1.12 \\
\hline CFLW & 0.54 & 0.59 & 0.77 \\
\hline JHFS & 0.55 & 0.63 & 1.18 \\
\hline JHNS & 0.61 & 0.68 & 1.23 \\
\hline MUT & 1.15 & 0.94 & 1.39 \\
\hline RNDB & 0.35 & 3.46 & 6.64 \\
\hline
\end{tabular}




\section{Busiest Approach Delay}
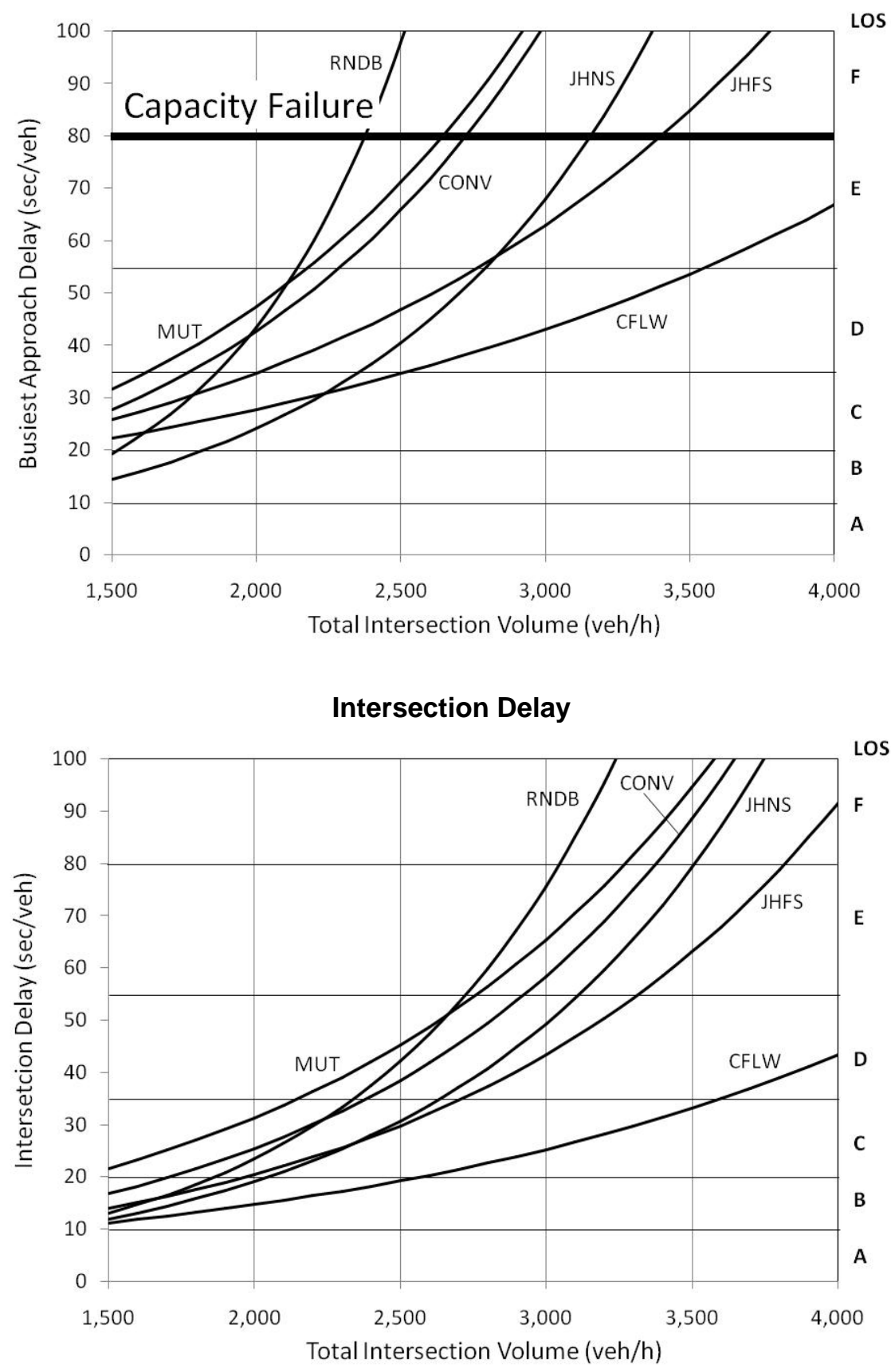

Stops Per Vehicle

\begin{tabular}{|c|c|c|c|}
\hline \multirow{2}{*}{ DESIGN } & \multicolumn{3}{|c|}{ Total Intersection Volume (veh/h) } \\
\cline { 2 - 4 } & 2090 & 2715 & 3760 \\
\hline CONV & 0.81 & 0.89 & 1.88 \\
\hline CFLW & 0.57 & 0.66 & 0.84 \\
\hline JHFS & 0.63 & 0.75 & 1.30 \\
\hline JHNS & 0.74 & 0.90 & 2.17 \\
\hline MUT & 1.34 & 1.17 & 2.49 \\
\hline RNDB & 0.39 & 2.52 & 7.98 \\
\hline
\end{tabular}




\section{Busiest Approach Delay}

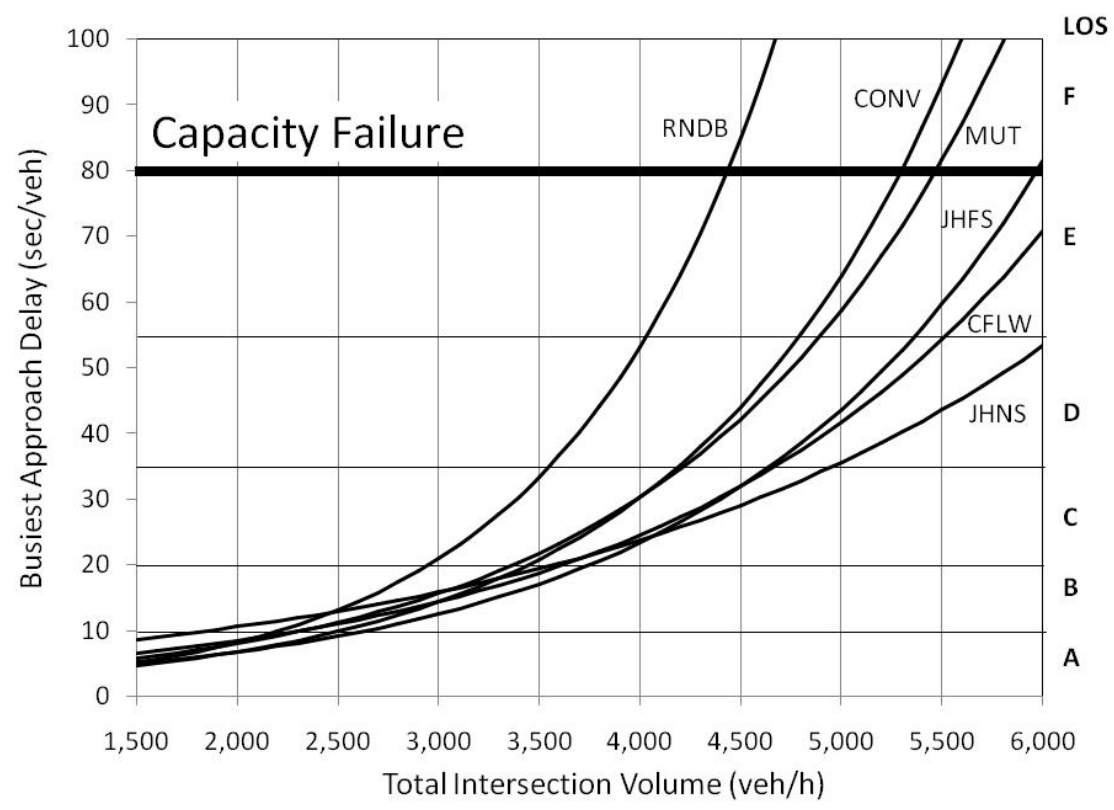

Intersection Delay

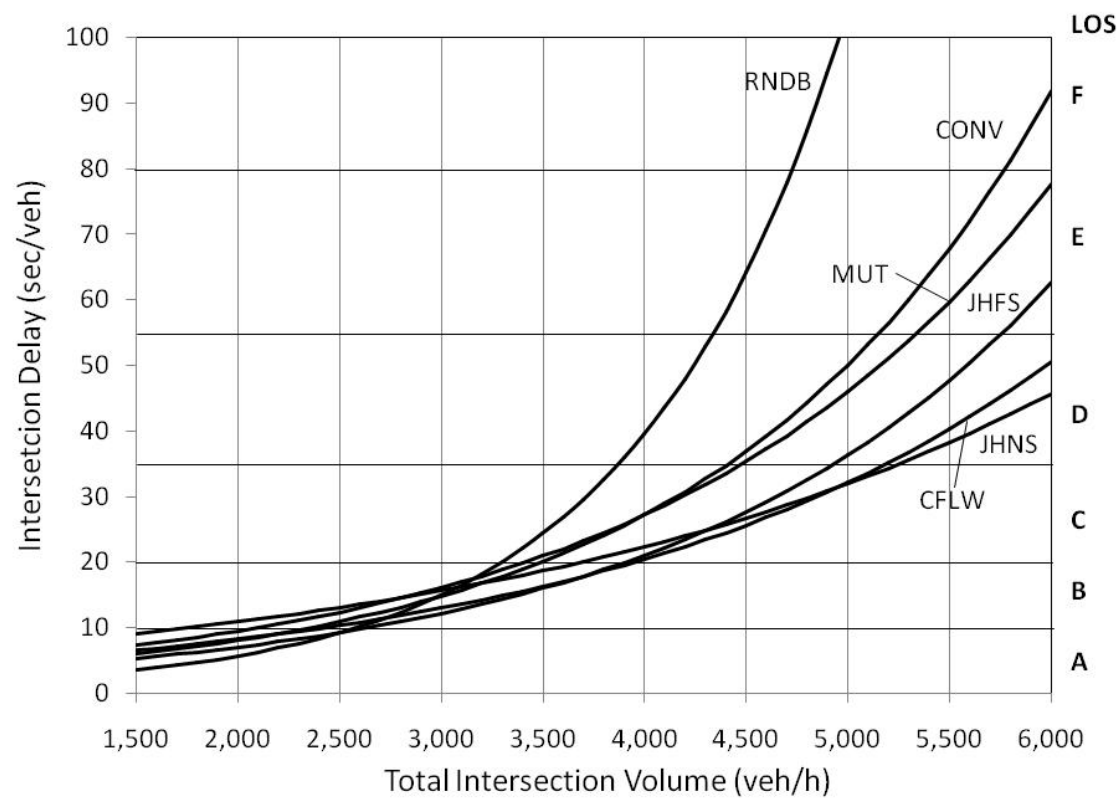

Stops Per Vehicle

\begin{tabular}{|c|c|c|c|}
\hline \multirow{2}{*}{ DESIGN } & \multicolumn{3}{|c|}{ Total Intersection Volume $(\mathrm{veh} / \mathrm{h})$} \\
\cline { 2 - 4 } & 3455 & 4495 & 6220 \\
\hline CONV & 0.63 & 0.75 & 2.11 \\
\hline CFLW & 0.55 & 0.67 & 1.10 \\
\hline JHFS & 0.52 & 0.67 & 1.40 \\
\hline JHNS & 0.62 & 0.70 & 1.14 \\
\hline MUT & 0.62 & 0.96 & 2.06 \\
\hline RNDB & 0.69 & 3.31 & 16.74 \\
\hline
\end{tabular}




\section{Busiest Approach Delay}

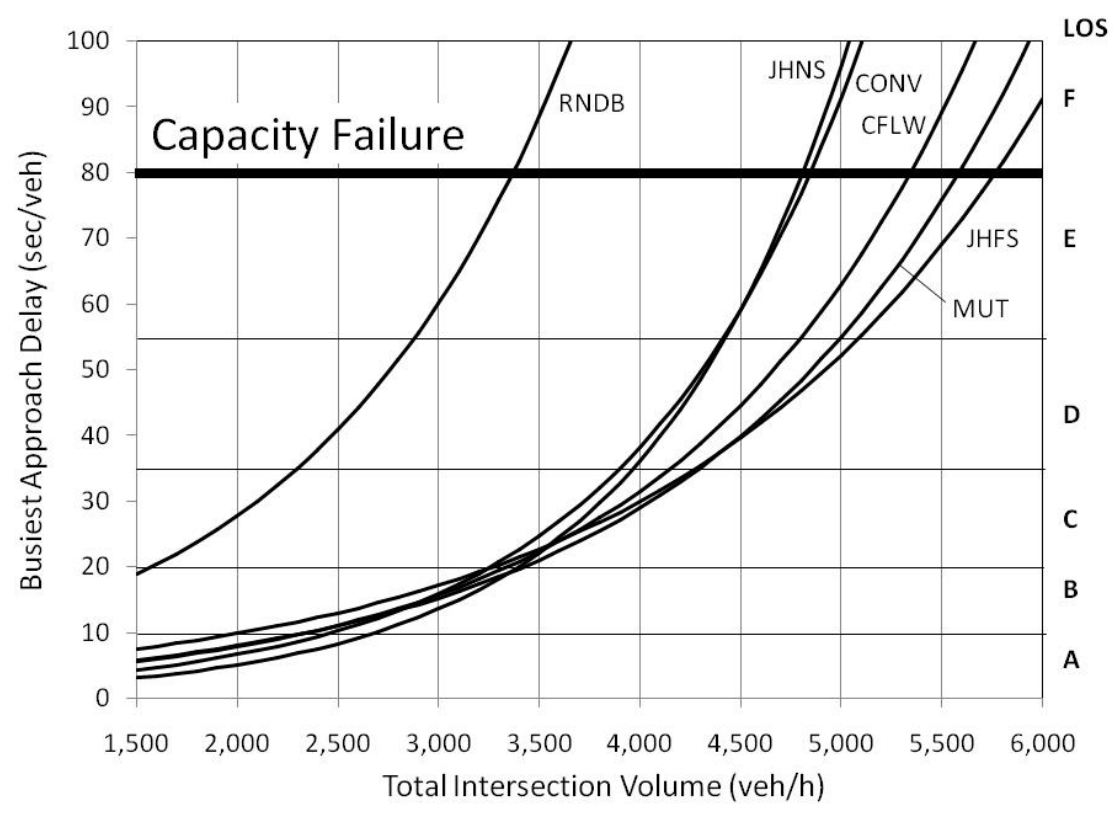

Intersection Delay

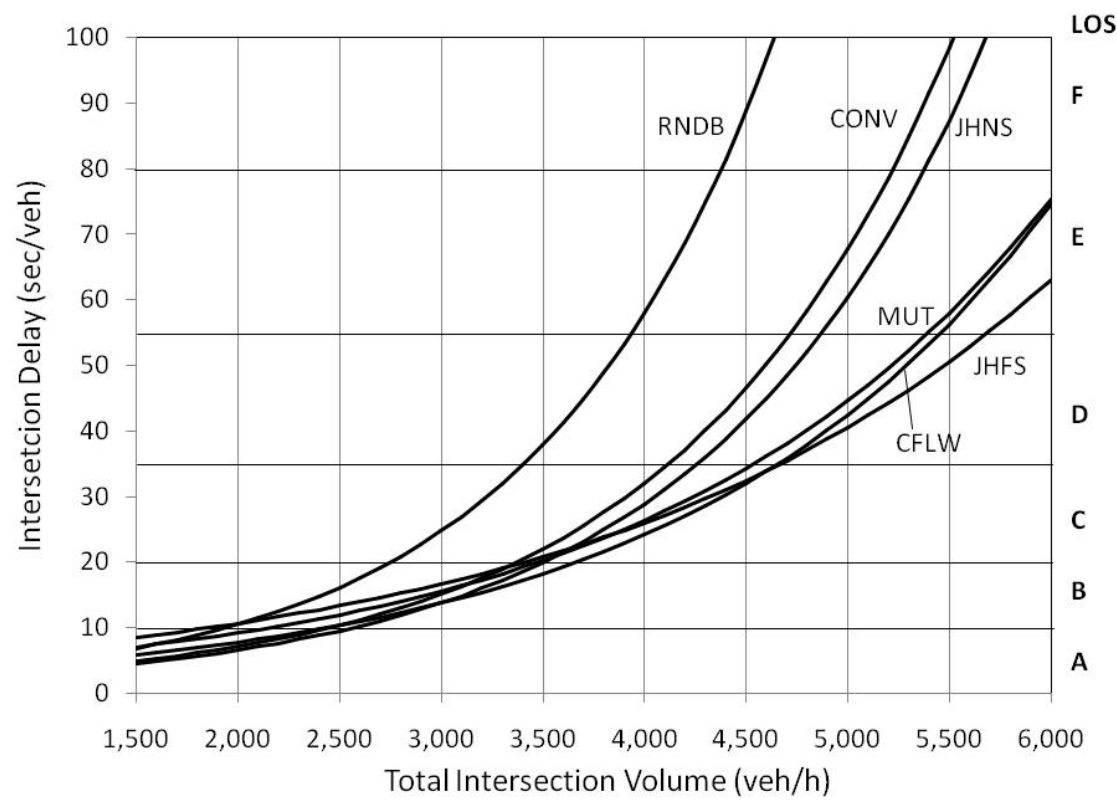

Stops Per Vehicle

\begin{tabular}{|c|c|c|c|}
\hline \multirow{2}{*}{ DESIGN } & \multicolumn{3}{|c|}{ Total Intersection Volume $(\mathrm{veh} / \mathrm{h})$} \\
\cline { 2 - 4 } & 3455 & 4495 & 6220 \\
\hline CONV & 0.68 & 0.84 & 3.83 \\
\hline CFLW & 0.68 & 0.77 & 1.49 \\
\hline JHFS & 0.61 & 0.79 & 1.27 \\
\hline JHNS & 0.71 & 0.85 & 3.90 \\
\hline MUT & 0.63 & 0.72 & 1.97 \\
\hline RNDB & 1.10 & 6.79 & 17.14 \\
\hline
\end{tabular}




\section{Busiest Approach Delay}

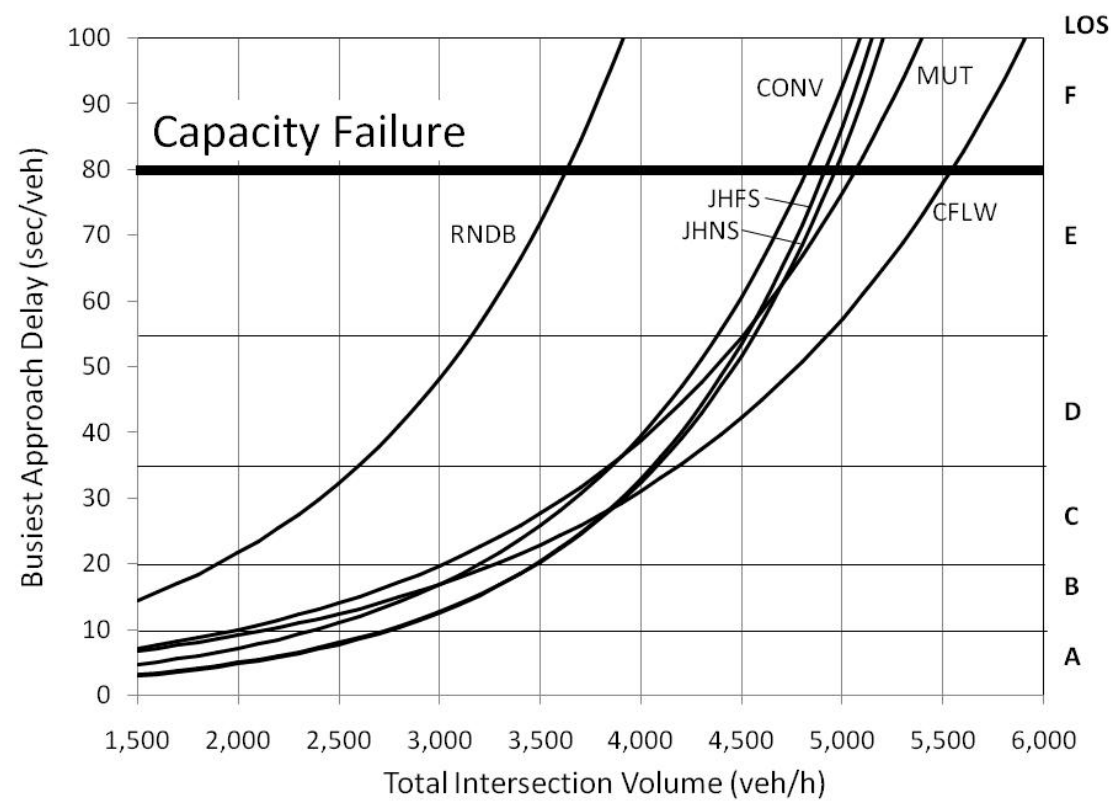

Intersection Delay

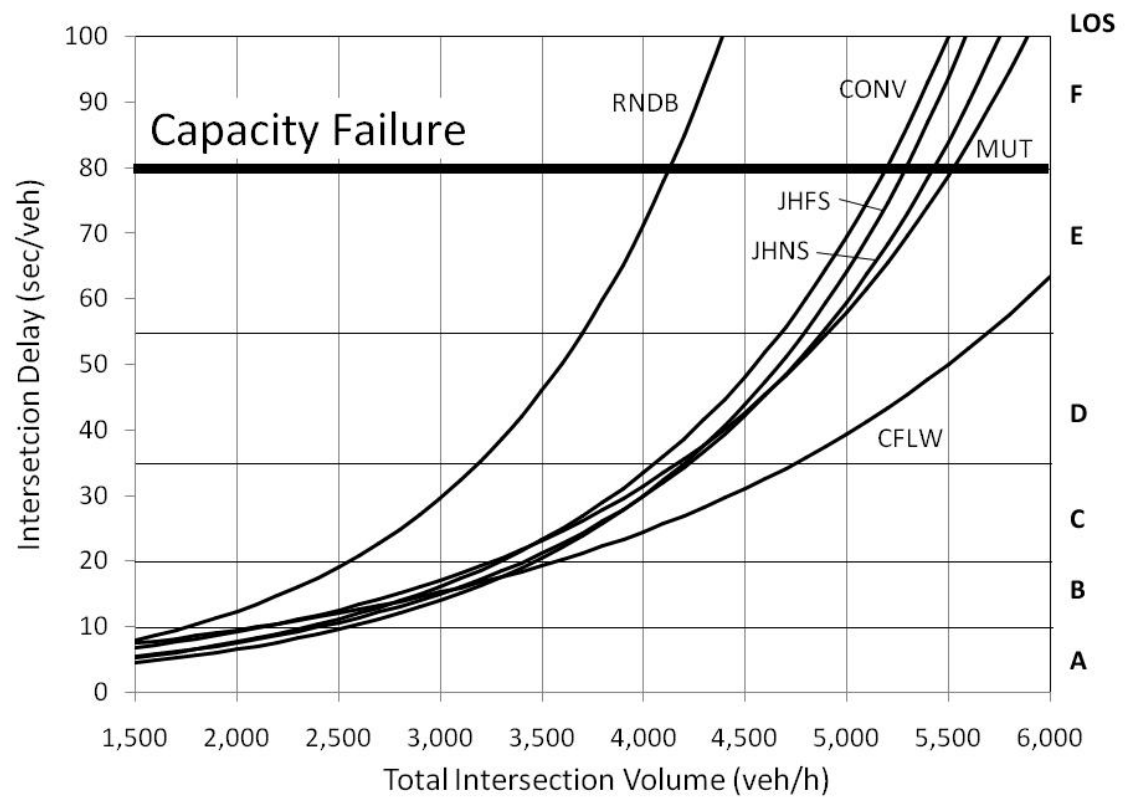

Stops Per Vehicle

\begin{tabular}{|c|c|c|c|}
\hline \multirow{2}{*}{ DESIGN } & \multicolumn{3}{|c|}{ Total Intersection Volume $(\mathrm{veh} / \mathrm{h})$} \\
\cline { 2 - 4 } & 3455 & 4495 & 6220 \\
\hline CONV & 0.73 & 0.86 & 3.71 \\
\hline CFLW & 0.72 & 0.82 & 1.42 \\
\hline JHFS & 0.65 & 0.88 & 3.55 \\
\hline JHNS & 0.75 & 0.85 & 3.63 \\
\hline MUT & 0.69 & 0.91 & 2.97 \\
\hline RNDB & 1.18 & 10.78 & 21.48 \\
\hline
\end{tabular}




\section{Busiest Approach Delay}

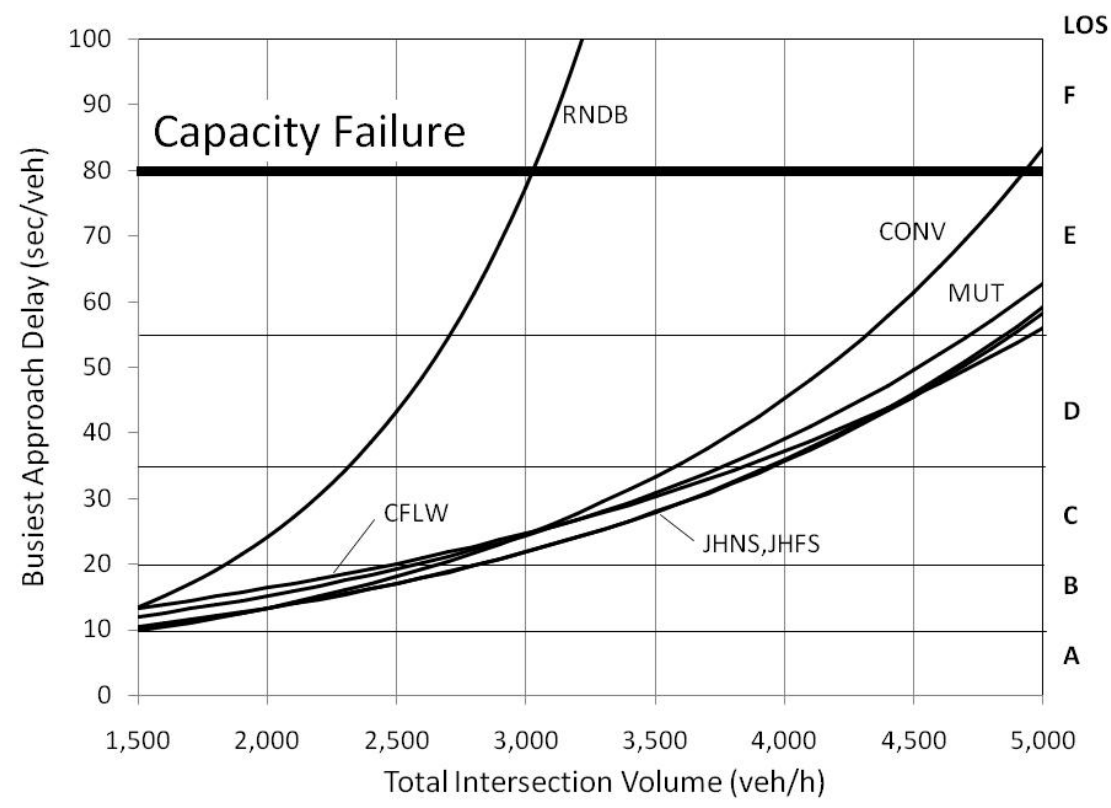

Intersection Delay

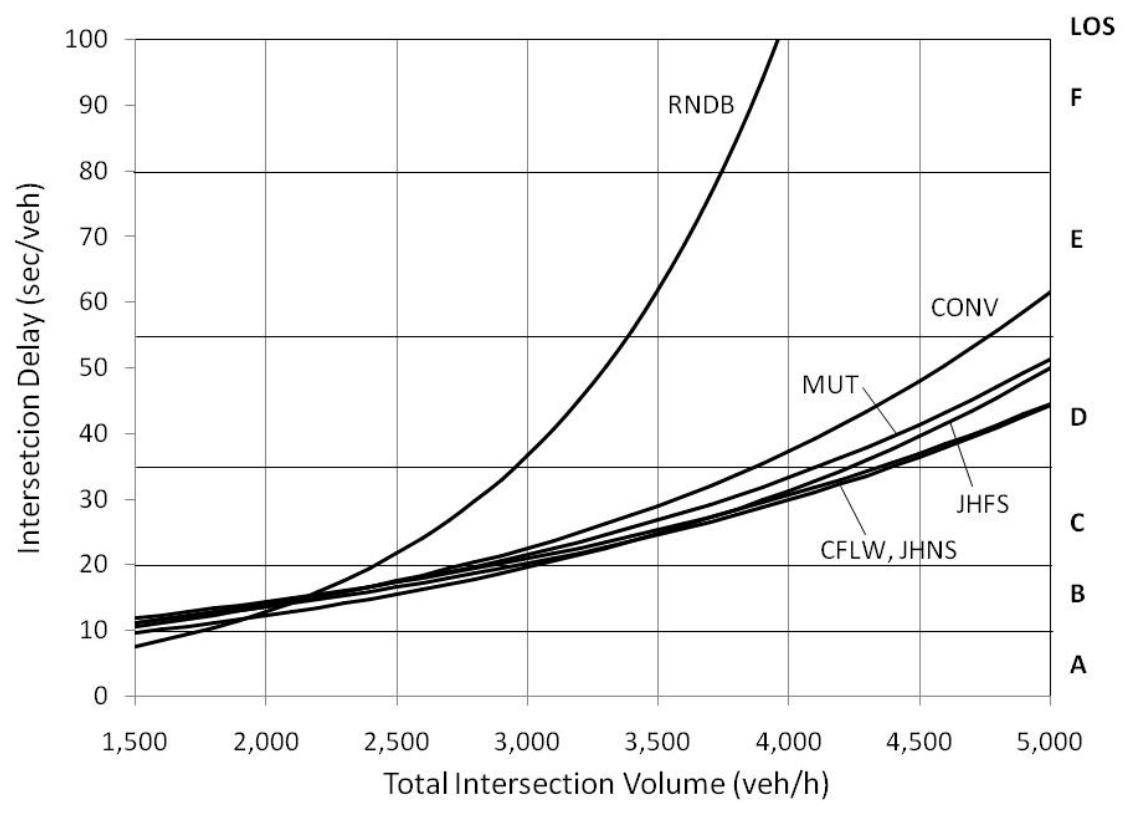

Stops Per Vehicle

\begin{tabular}{|c|c|c|c|}
\hline \multirow{2}{*}{ DESIGN } & \multicolumn{3}{|c|}{ Total Intersection Volume $(\mathrm{veh} / \mathrm{h})$} \\
\cline { 2 - 4 } & 2715 & 3530 & 4890 \\
\hline CONV & 0.61 & 0.67 & 1.20 \\
\hline CFLW & 0.60 & 0.67 & 0.95 \\
\hline JHFS & 0.55 & 0.64 & 0.96 \\
\hline JHNS & 0.61 & 0.67 & 0.96 \\
\hline MUT & 0.58 & 0.63 & 1.29 \\
\hline RNDB & 0.60 & 5.19 & 11.01 \\
\hline
\end{tabular}




\section{Busiest Approach Delay}

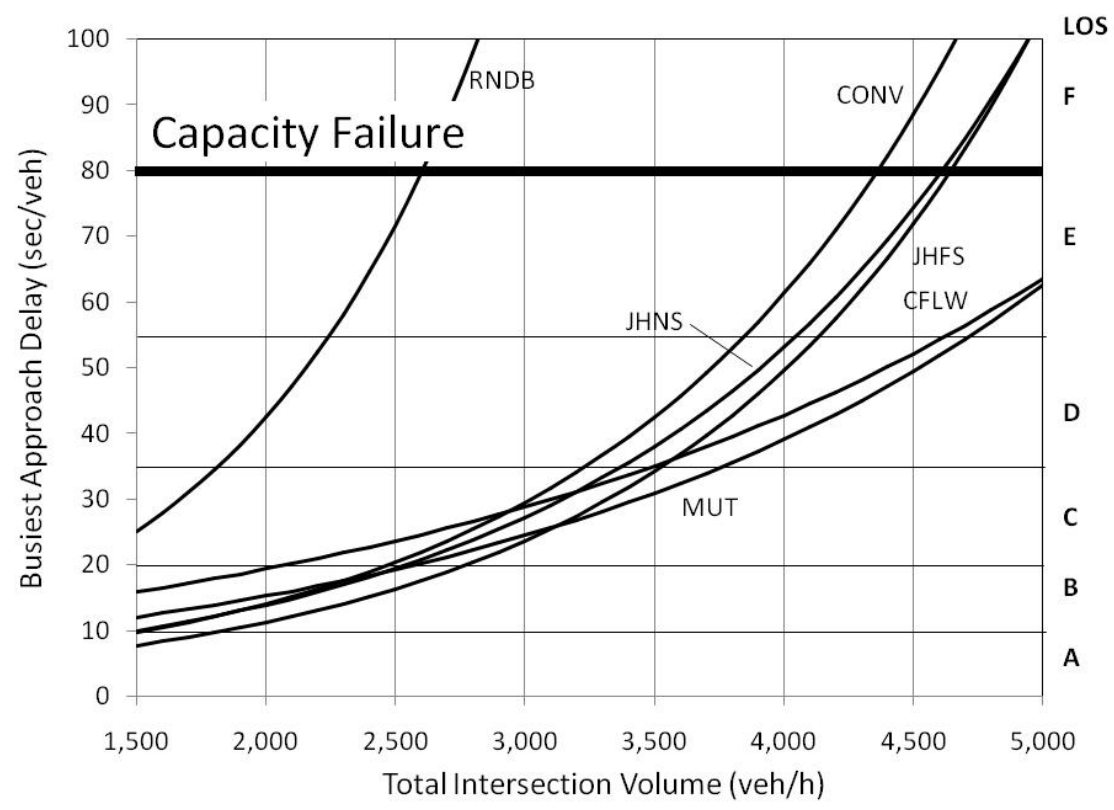

Intersection Delay

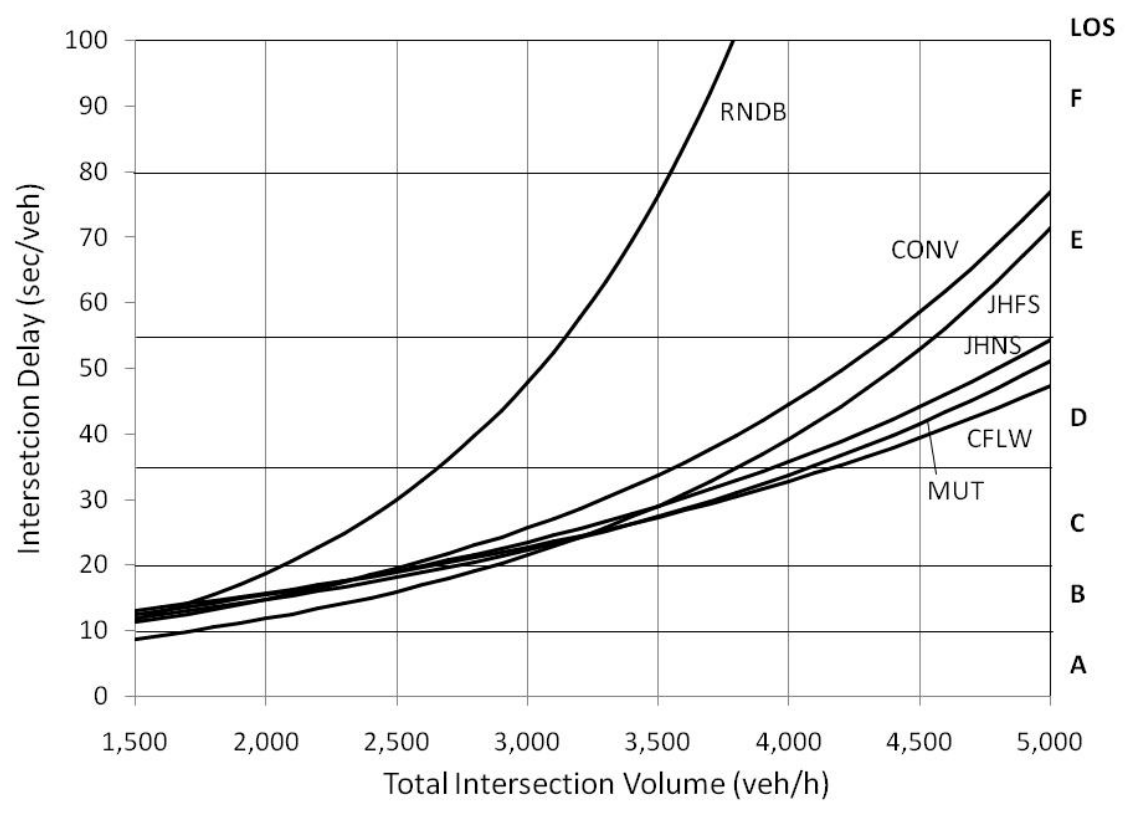

Stops Per Vehicle

\begin{tabular}{|c|c|c|c|}
\hline \multirow{2}{*}{ DESIGN } & \multicolumn{3}{|c|}{ Total Intersection Volume $(\mathrm{veh} / \mathrm{h})$} \\
\cline { 2 - 4 } & 2715 & 3530 & 4890 \\
\hline CONV & 0.67 & 0.71 & 1.35 \\
\hline CFLW & 0.68 & 0.76 & 1.02 \\
\hline JHFS & 0.58 & 0.66 & 1.27 \\
\hline JHNS & 0.68 & 0.74 & 1.21 \\
\hline MUT & 0.60 & 0.65 & 1.24 \\
\hline RNDB & 0.96 & 6.99 & 11.45 \\
\hline
\end{tabular}




\section{Busiest Approach Delay}

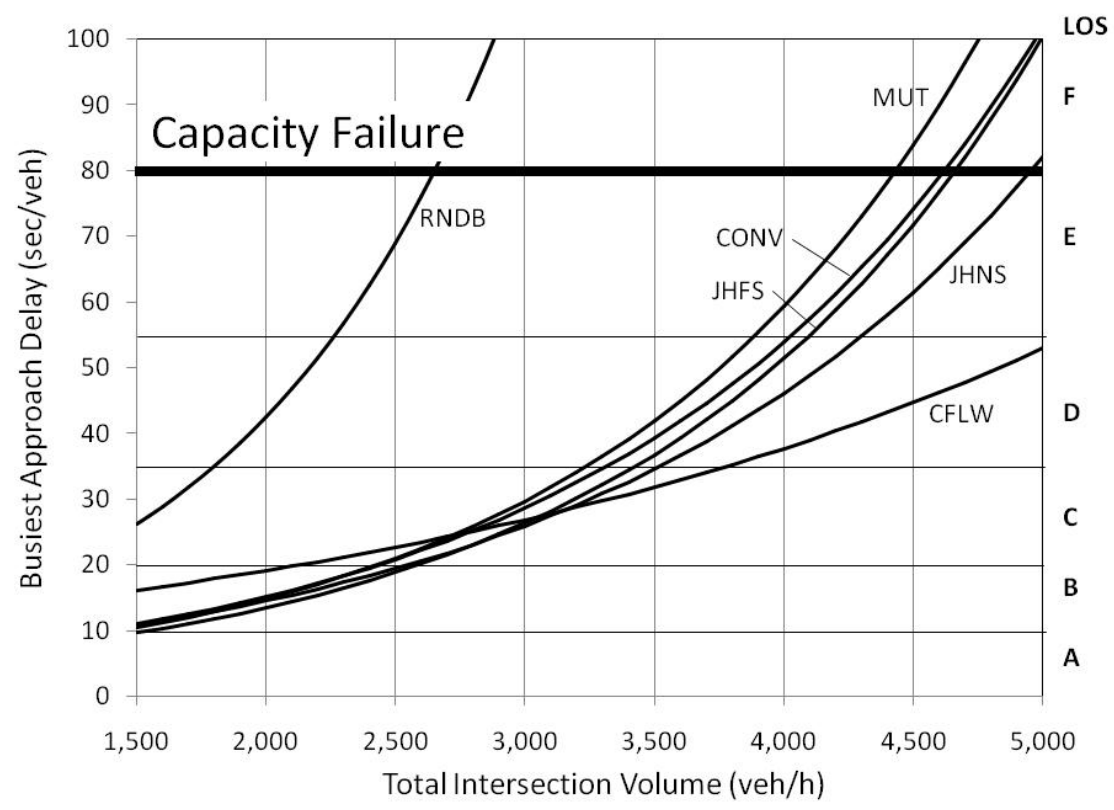

Intersection Delay

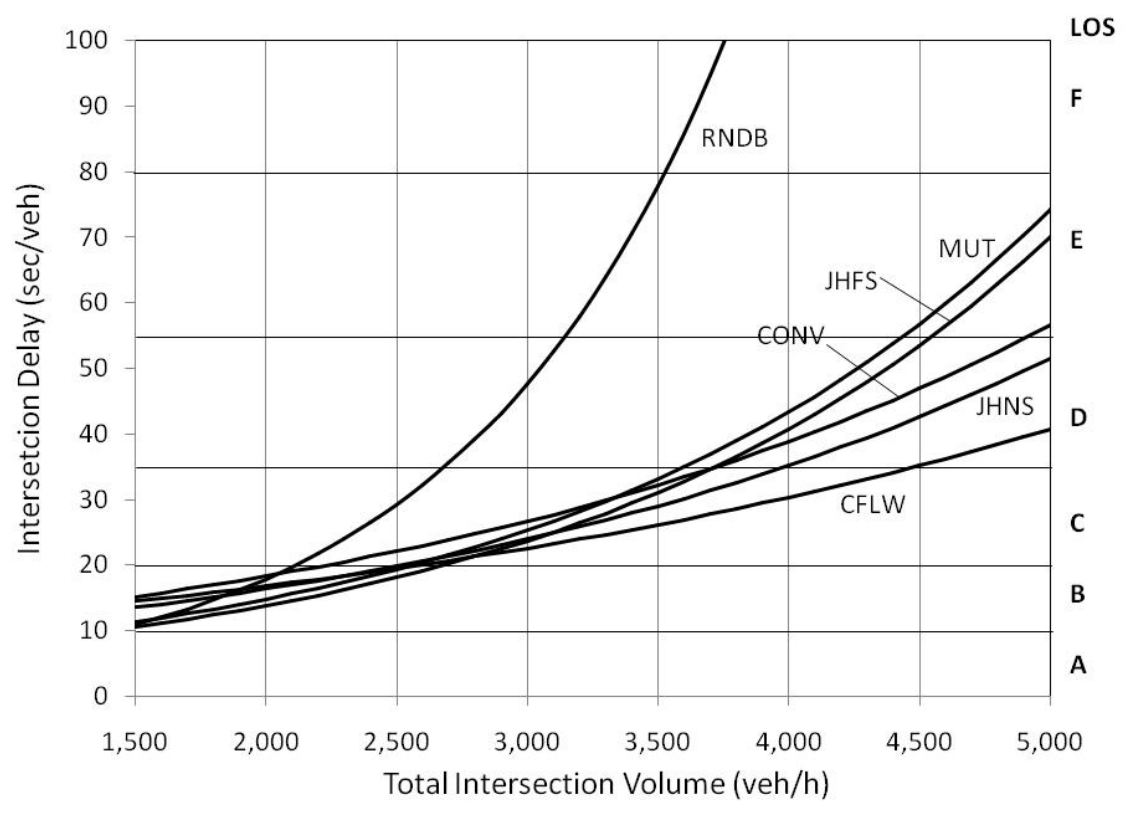

Stops Per Vehicle

\begin{tabular}{|c|c|c|c|}
\hline \multirow{2}{*}{ DESIGN } & \multicolumn{3}{|c|}{ Total Intersection Volume $(\mathrm{veh} / \mathrm{h})$} \\
\cline { 2 - 4 } & 2715 & 3530 & 4890 \\
\hline CONV & 0.71 & 0.75 & 1.06 \\
\hline CFLW & 0.70 & 0.81 & 0.83 \\
\hline JHFS & 0.62 & 0.75 & 1.26 \\
\hline JHNS & 0.71 & 0.77 & 1.24 \\
\hline MUT & 0.66 & 0.75 & 1.67 \\
\hline RNDB & 0.90 & 7.11 & 13.29 \\
\hline
\end{tabular}




\section{Busiest Approach Delay}

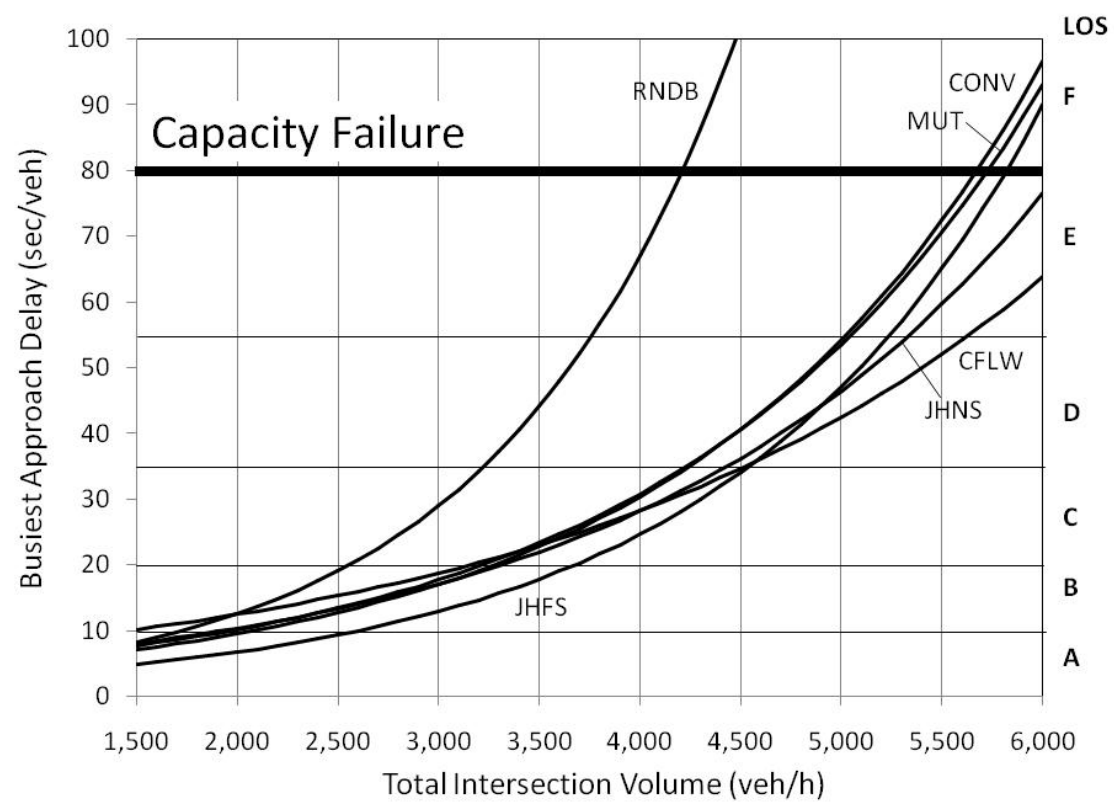

Intersection Delay

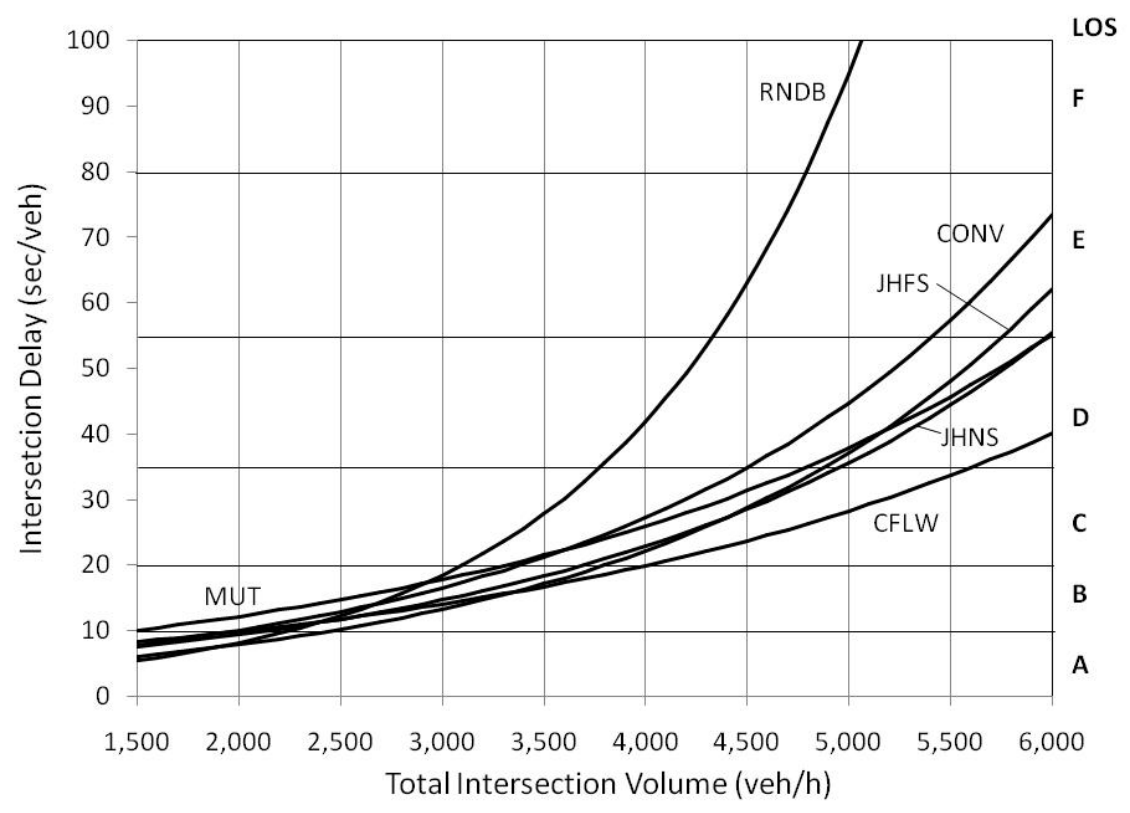

Stops Per Vehicle

\begin{tabular}{|c|c|c|c|}
\hline \multirow{2}{*}{ DESIGN } & \multicolumn{3}{|c|}{ Total Intersection Volume $(\mathrm{veh} / \mathrm{h})$} \\
\cline { 2 - 4 } & 3455 & 4495 & 6220 \\
\hline CONV & 0.64 & 0.72 & 1.28 \\
\hline CFLW & 0.54 & 0.58 & 0.87 \\
\hline JHFS & 0.55 & 0.62 & 1.11 \\
\hline JHNS & 0.61 & 0.65 & 1.00 \\
\hline MUT & 0.62 & 0.71 & 1.13 \\
\hline RNDB & 0.61 & 3.93 & 11.35 \\
\hline
\end{tabular}




\section{Busiest Approach Delay}

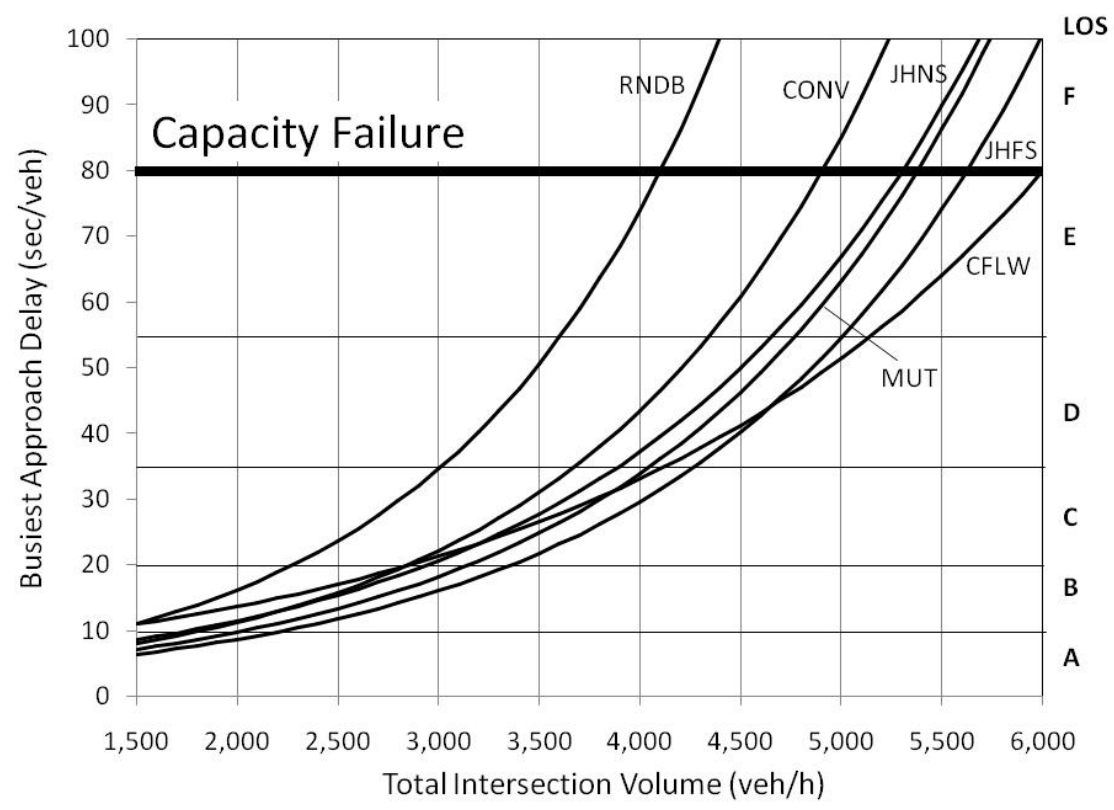

Intersection Delay

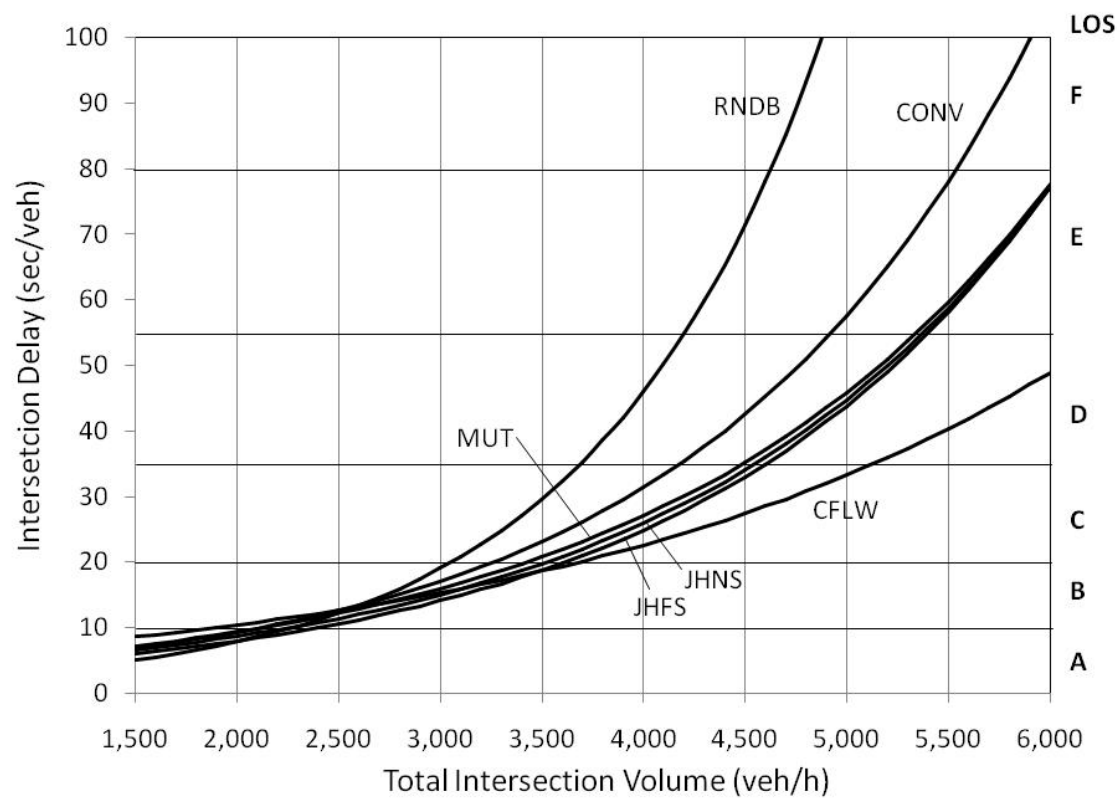

Stops Per Vehicle

\begin{tabular}{|c|c|c|c|}
\hline \multirow{2}{*}{ DESIGN } & \multicolumn{3}{|c|}{ Total Intersection Volume $(\mathrm{veh} / \mathrm{h})$} \\
\cline { 2 - 4 } & 3455 & 4495 & 6220 \\
\hline CONV & 0.67 & 0.80 & 2.18 \\
\hline CFLW & 0.61 & 0.71 & 1.02 \\
\hline JHFS & 0.60 & 0.66 & 1.39 \\
\hline JHNS & 0.66 & 0.73 & 1.55 \\
\hline MUT & 0.63 & 0.69 & 1.65 \\
\hline RNDB & 0.74 & 4.46 & 14.34 \\
\hline
\end{tabular}




\section{Busiest Approach Delay}

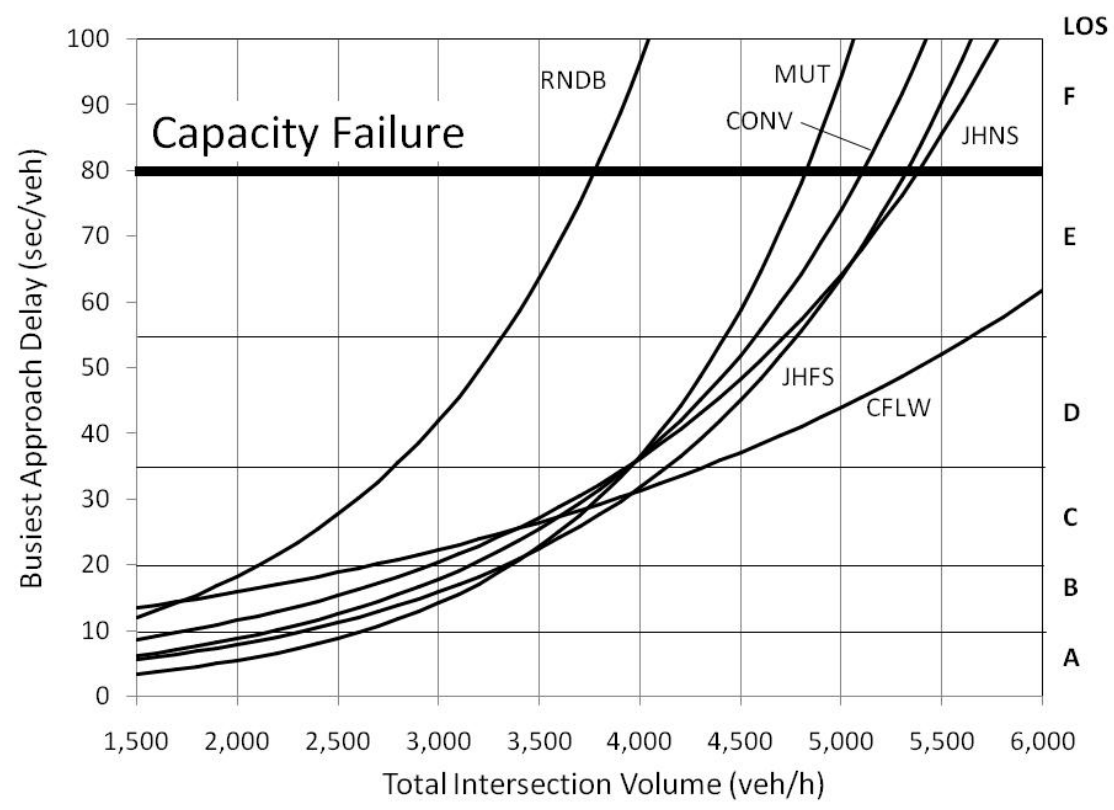

Intersection Delay

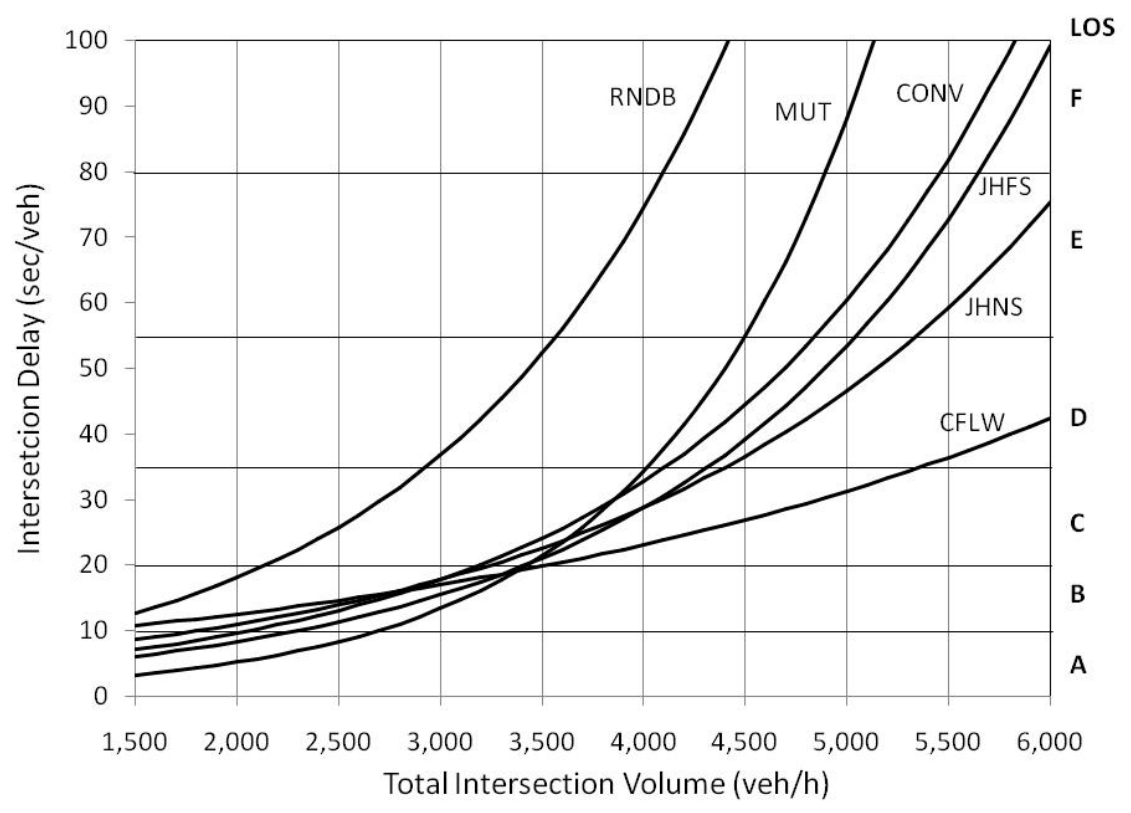

Stops Per Vehicle

\begin{tabular}{|c|c|c|c|}
\hline \multirow{2}{*}{ DESIGN } & \multicolumn{3}{|c|}{ Total Intersection Volume $(\mathrm{veh} / \mathrm{h})$} \\
\cline { 2 - 4 } & 3455 & 4495 & 6220 \\
\hline CONV & 0.71 & 0.79 & 2.32 \\
\hline CFLW & 0.63 & 0.70 & 0.98 \\
\hline JHFS & 0.66 & 0.78 & 2.08 \\
\hline JHNS & 0.73 & 0.82 & 1.53 \\
\hline MUT & 0.72 & 0.85 & 7.57 \\
\hline RNDB & 1.15 & 11.07 & 14.74 \\
\hline
\end{tabular}




\section{Busiest Approach Delay}

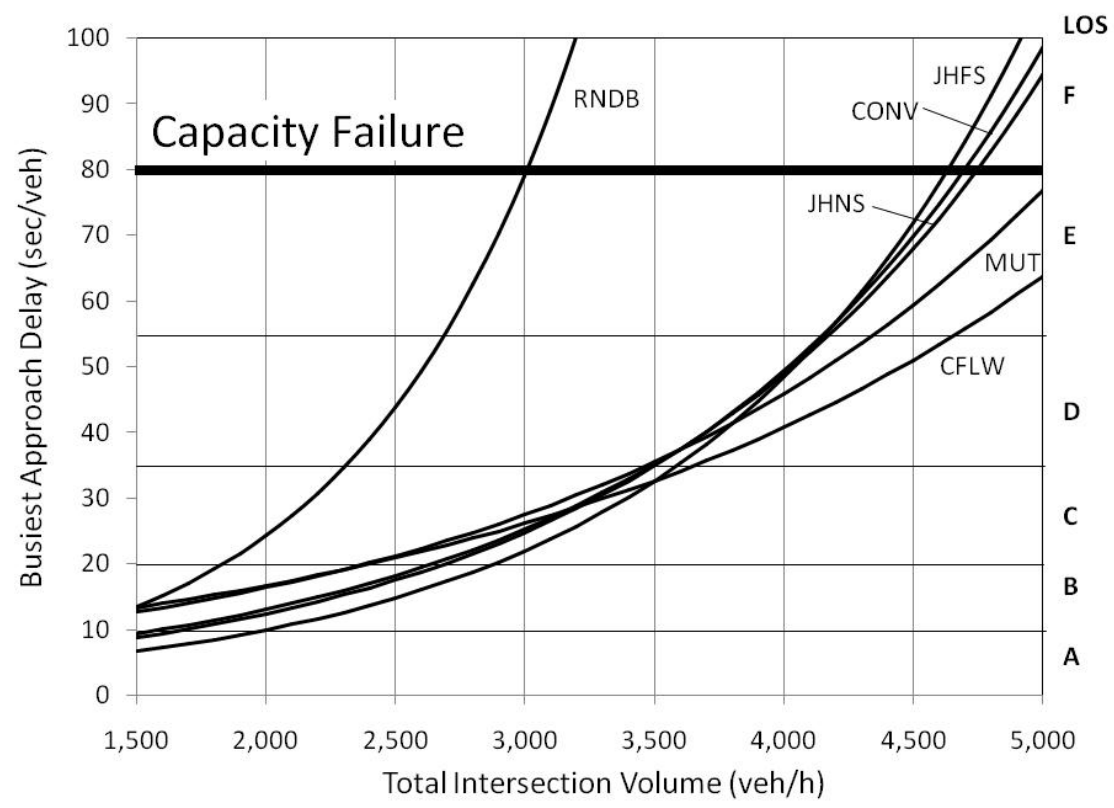

Intersection Delay

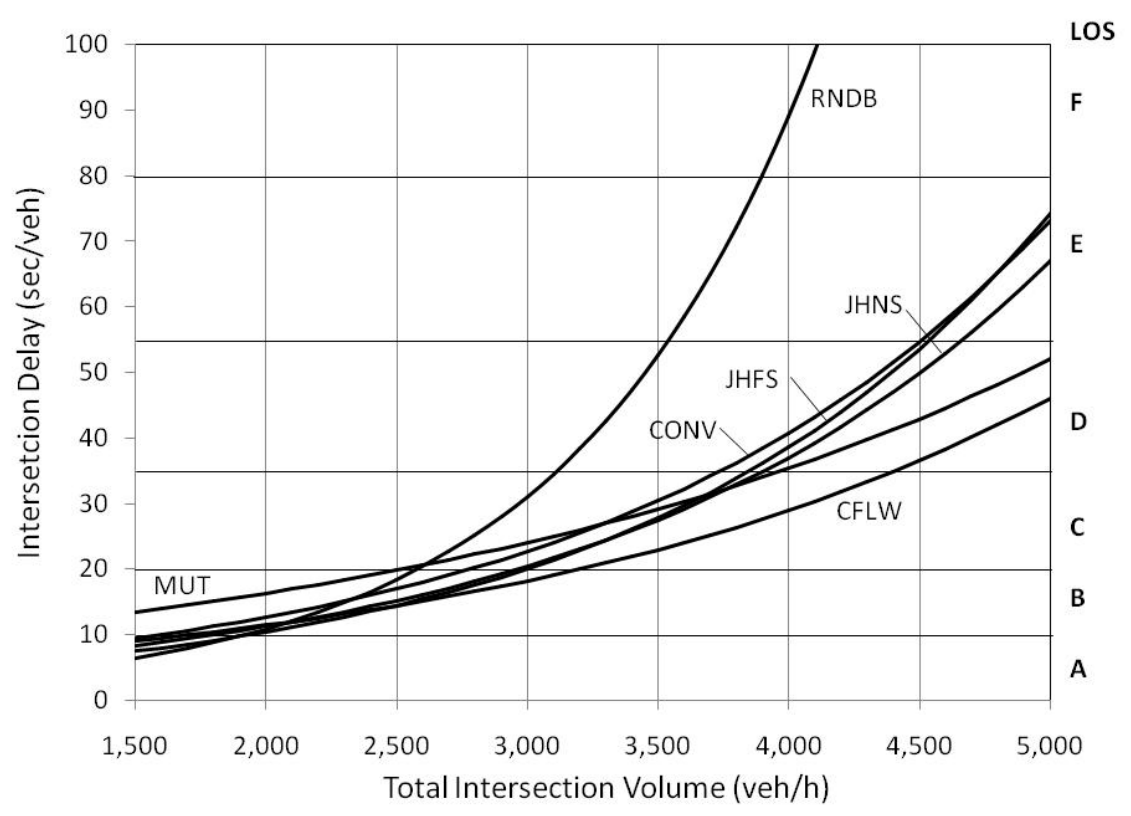

Stops Per Vehicle

\begin{tabular}{|c|c|c|c|}
\hline \multirow{2}{*}{ DESIGN } & \multicolumn{3}{|c|}{ Total Intersection Volume $($ veh/h) } \\
\cline { 2 - 4 } & 2715 & 3530 & 4890 \\
\hline CONV & 0.61 & 0.65 & 1.03 \\
\hline CFLW & 0.53 & 0.60 & 0.88 \\
\hline JHFS & 0.53 & 0.62 & 1.02 \\
\hline JHNS & 0.59 & 0.64 & 0.95 \\
\hline MUT & 0.60 & 0.63 & 0.90 \\
\hline RNDB & 0.52 & 3.62 & 9.32 \\
\hline
\end{tabular}




\section{Busiest Approach Delay}

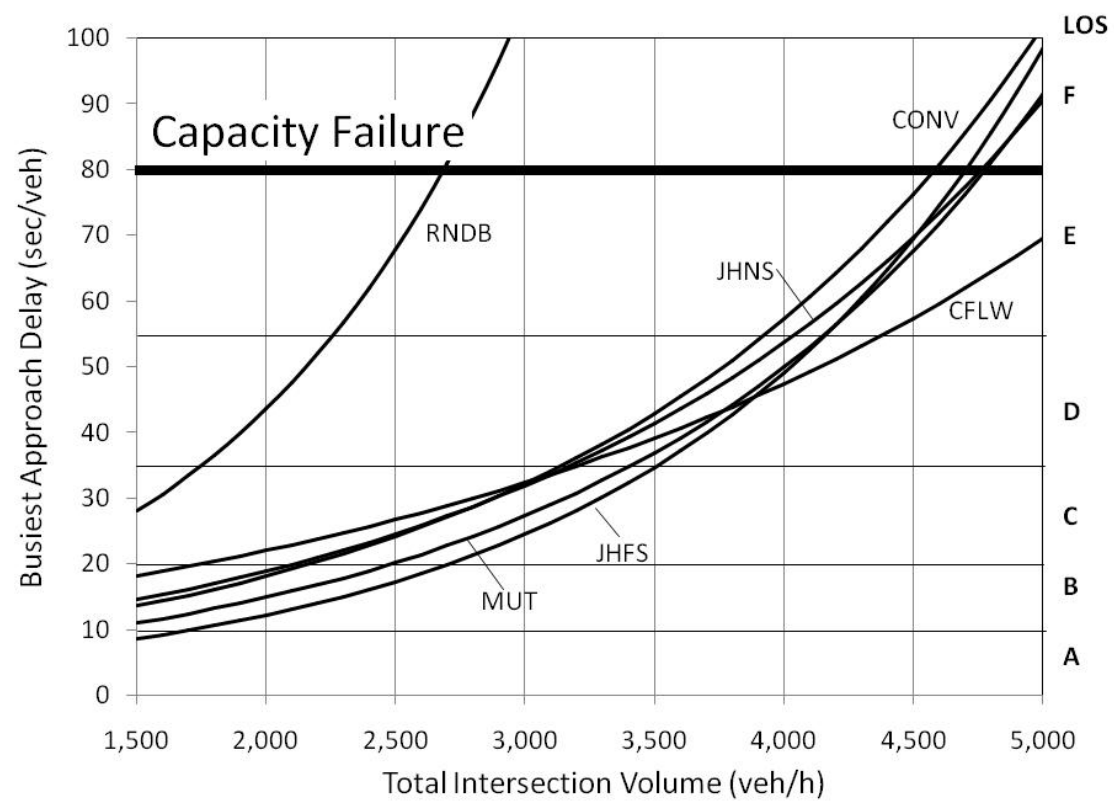

Intersection Delay

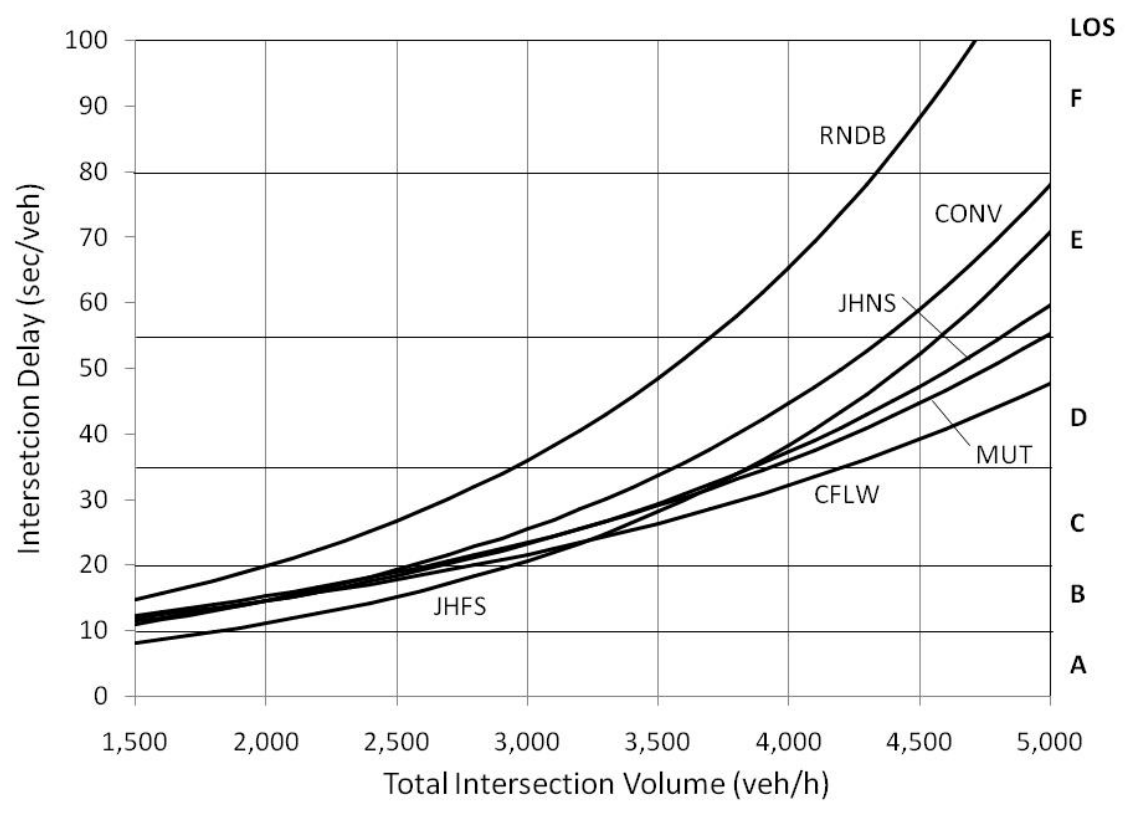

Stops Per Vehicle

\begin{tabular}{|c|c|c|c|}
\hline \multirow{2}{*}{ DESIGN } & \multicolumn{3}{|c|}{ Total Intersection Volume (veh/h) } \\
\cline { 2 - 4 } & 2715 & 3530 & 4890 \\
\hline CONV & 0.65 & 0.69 & 1.07 \\
\hline CFLW & 0.63 & 0.71 & 0.83 \\
\hline JHFS & 0.57 & 0.60 & 0.98 \\
\hline JHNS & 0.63 & 0.69 & 0.92 \\
\hline MUT & 0.61 & 0.62 & 0.93 \\
\hline RNDB & 0.66 & 4.24 & 4.24 \\
\hline
\end{tabular}




\section{Busiest Approach Delay}

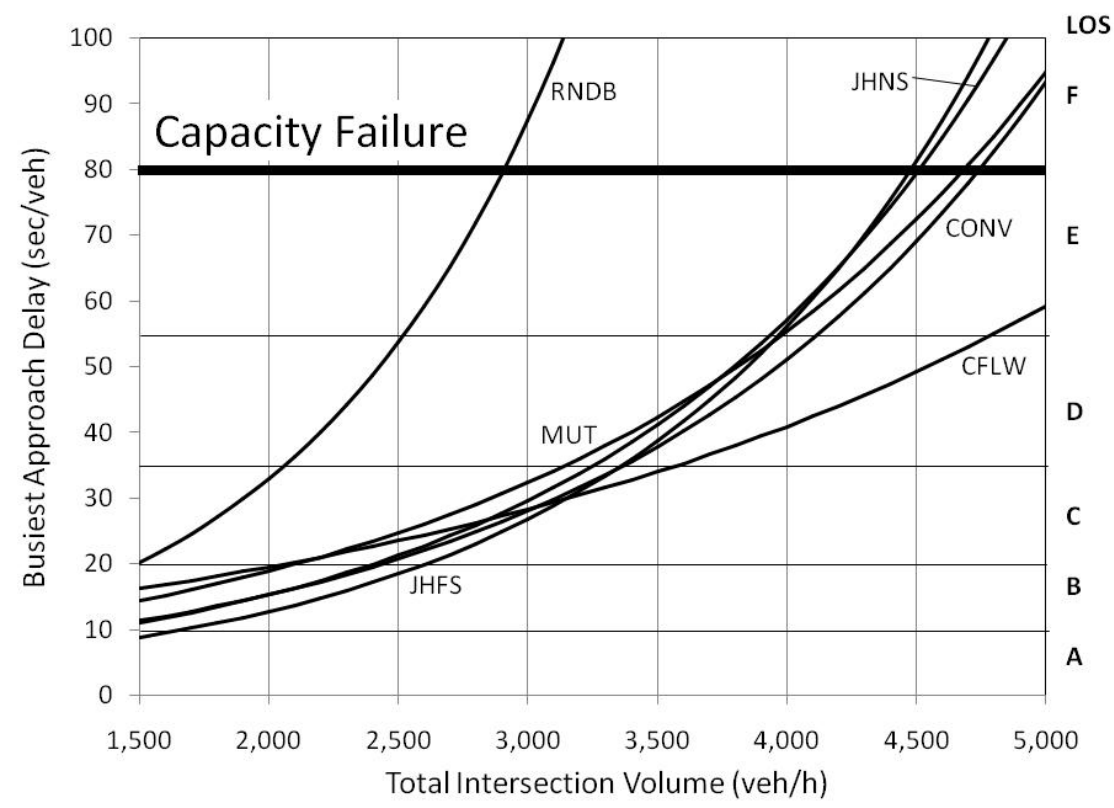

Intersection Delay

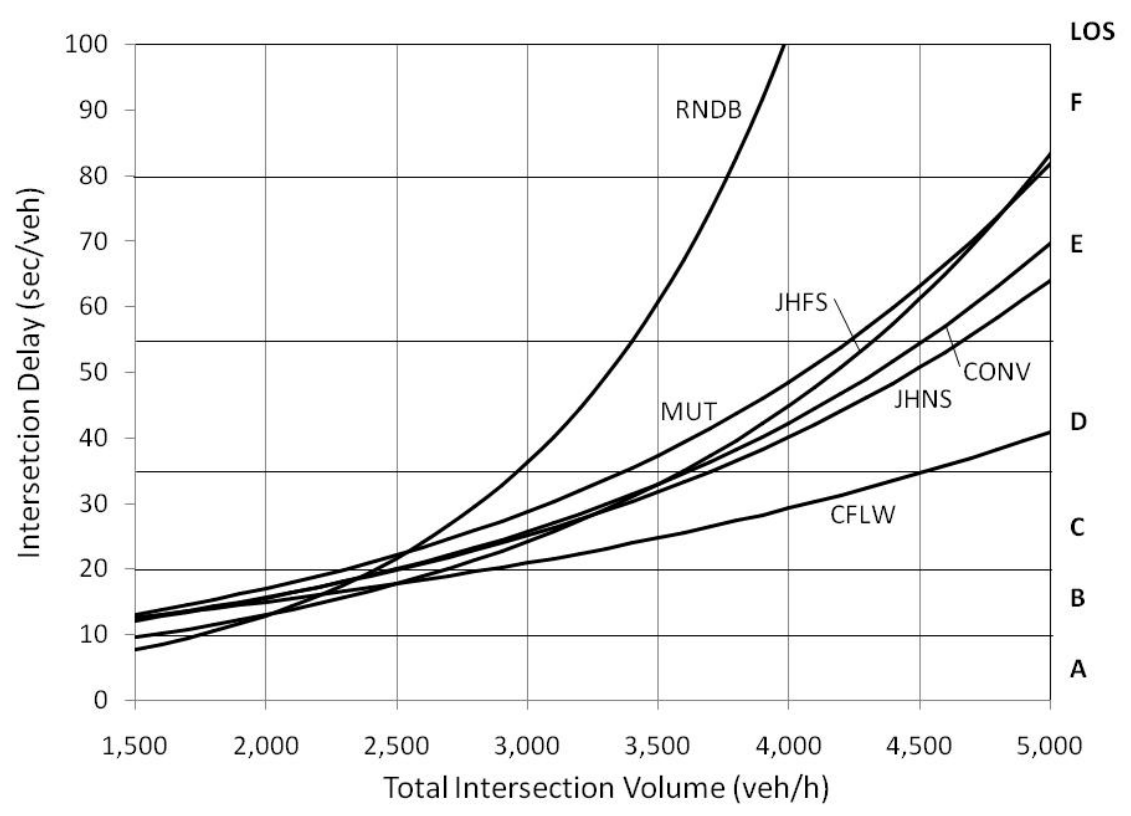

Stops Per Vehicle

\begin{tabular}{|c|c|c|c|}
\hline \multirow{2}{*}{ DESIGN } & \multicolumn{3}{|c|}{ Total Intersection Volume $(\mathrm{veh} / \mathrm{h})$} \\
\cline { 2 - 4 } & 2715 & 3530 & 4890 \\
\hline CONV & 0.67 & 0.71 & 1.01 \\
\hline CFLW & 0.65 & 0.72 & 0.82 \\
\hline JHFS & 0.63 & 0.72 & 1.22 \\
\hline JHNS & 0.70 & 0.76 & 1.06 \\
\hline MUT & 0.70 & 0.78 & 1.41 \\
\hline RNDB & 0.68 & 3.93 & 10.91 \\
\hline
\end{tabular}



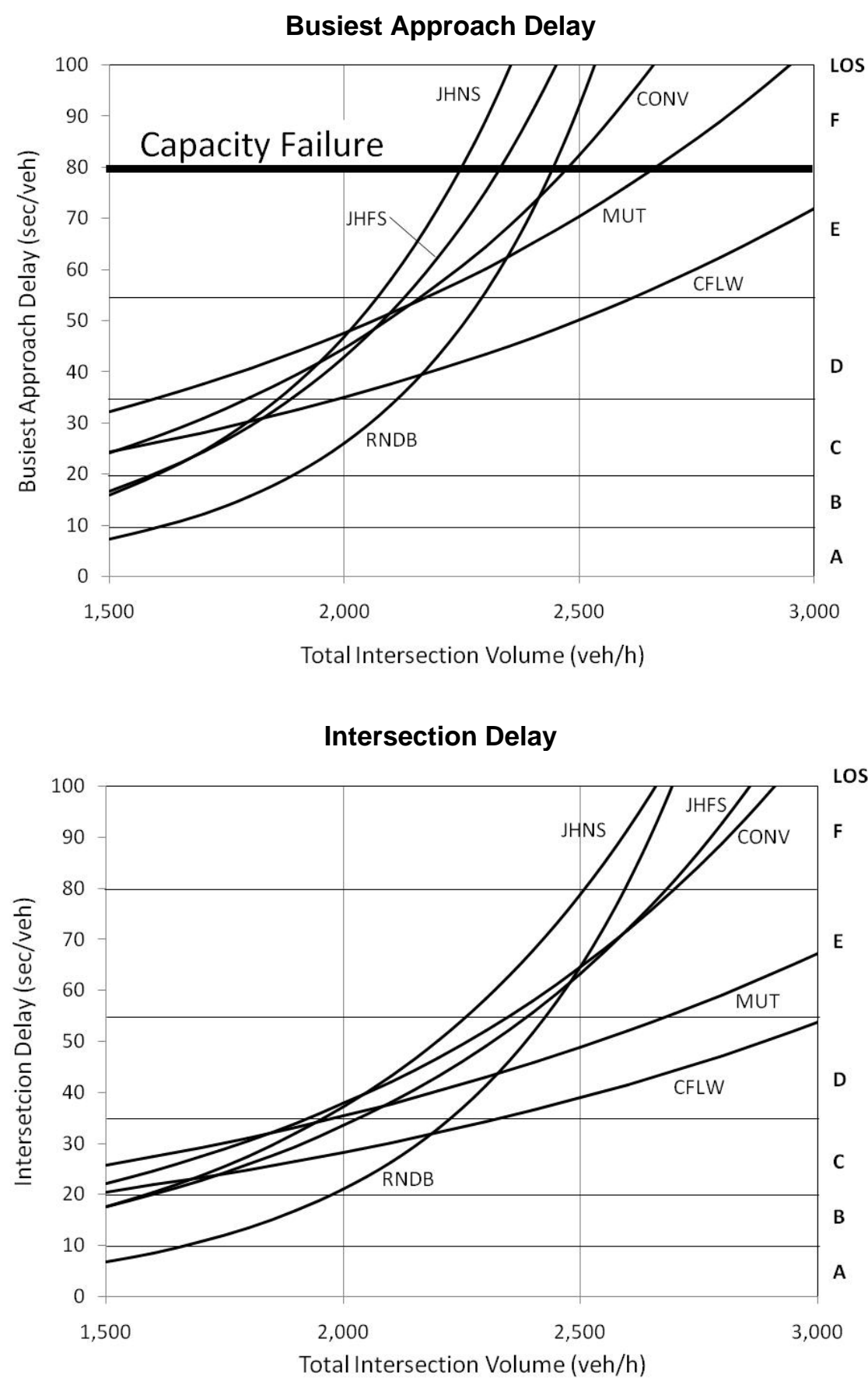

Stops Per Vehicle

\begin{tabular}{|c|c|c|c|}
\hline \multirow{2}{*}{ DESIGN } & \multicolumn{3}{|c|}{ Total Intersection Volume (veh/h) } \\
\cline { 2 - 4 } & 1550 & 2010 & 2785 \\
\hline CONV & 0.81 & 1.04 & 1.43 \\
\hline CFLW & 0.58 & 0.68 & 1.03 \\
\hline JHFS & 0.55 & 0.66 & 1.64 \\
\hline JHNS & 0.62 & 0.74 & 2.98 \\
\hline MUT & 0.63 & 0.70 & 1.17 \\
\hline RNDB & 0.20 & 0.45 & 6.72 \\
\hline
\end{tabular}



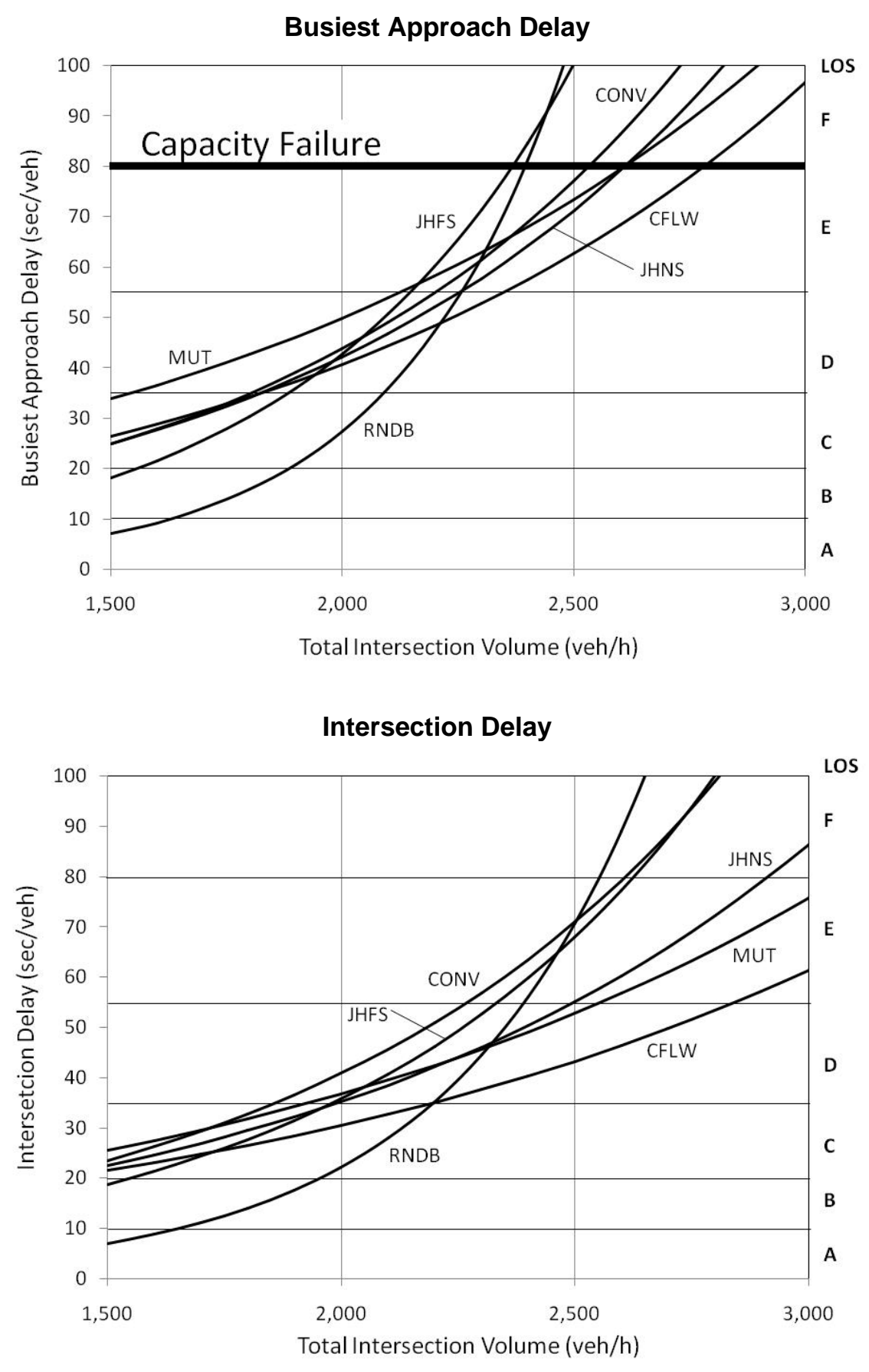

Stops Per Vehicle

\begin{tabular}{|c|c|c|c|}
\hline \multirow{2}{*}{ DESIGN } & \multicolumn{3}{|c|}{ Total Intersection Volume (veh/h) } \\
\cline { 2 - 4 } & 1550 & 2010 & 2785 \\
\hline CONV & 0.71 & 0.82 & 1.67 \\
\hline CFLW & 0.66 & 0.72 & 1.13 \\
\hline JHFS & 0.60 & 0.69 & 1.67 \\
\hline JHNS & 0.67 & 0.81 & 1.55 \\
\hline MUT & 0.65 & 0.73 & 1.26 \\
\hline RNDB & 0.23 & 0.46 & 7.72 \\
\hline
\end{tabular}



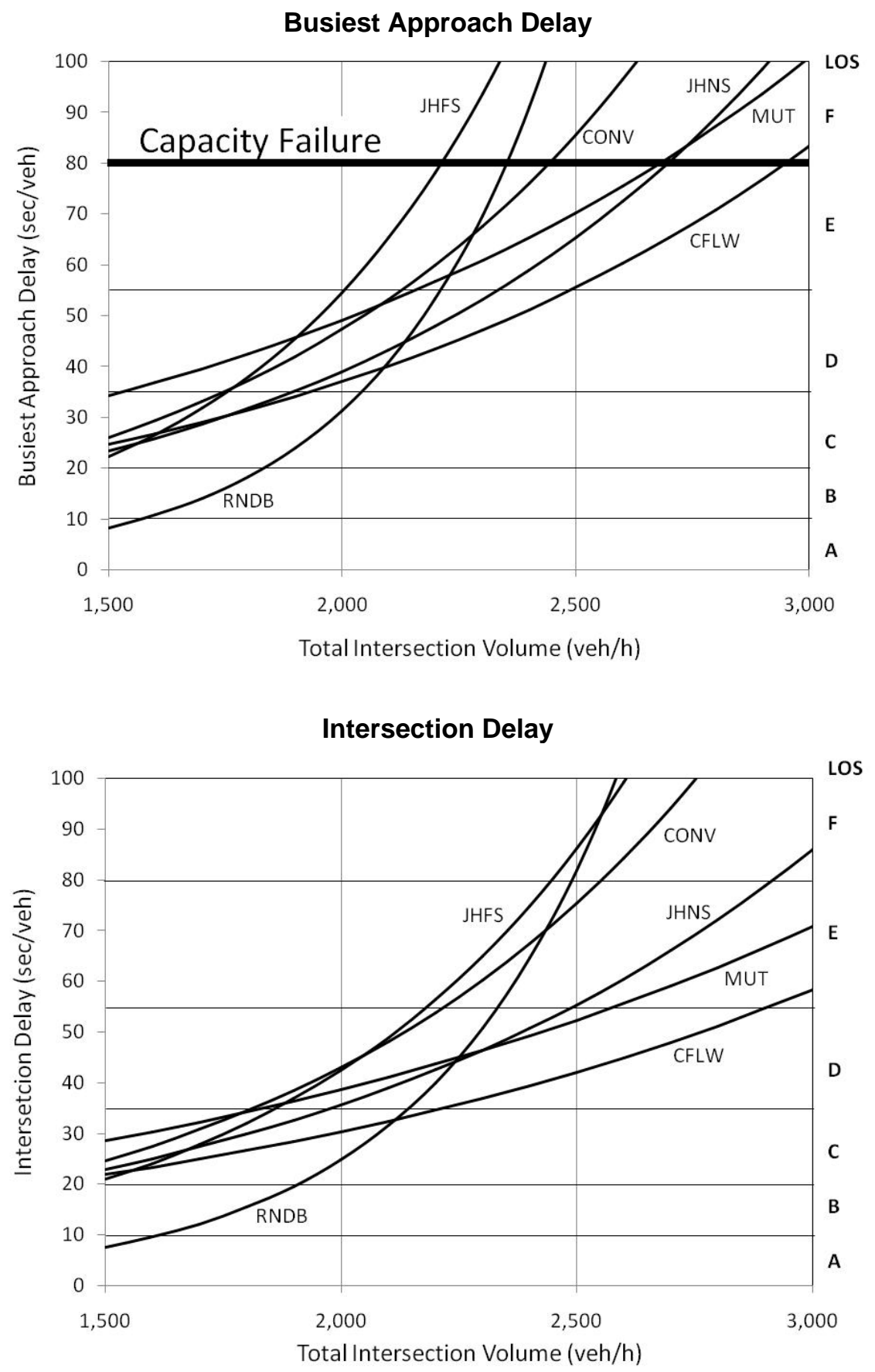

Stops Per Vehicle

\begin{tabular}{|c|c|c|c|}
\hline \multirow{2}{*}{ DESIGN } & \multicolumn{3}{|c|}{ Total Intersection Volume $(\mathrm{veh} / \mathrm{h})$} \\
\cline { 2 - 4 } & 1550 & 2010 & 2785 \\
\hline CONV & 0.71 & 0.87 & 1.84 \\
\hline CFLW & 0.69 & 0.76 & 1.16 \\
\hline JHFS & 0.64 & 0.87 & 2.34 \\
\hline JHNS & 0.71 & 0.82 & 1.55 \\
\hline MUT & 0.74 & 0.83 & 1.30 \\
\hline RNDB & 0.26 & 0.60 & 9.21 \\
\hline
\end{tabular}



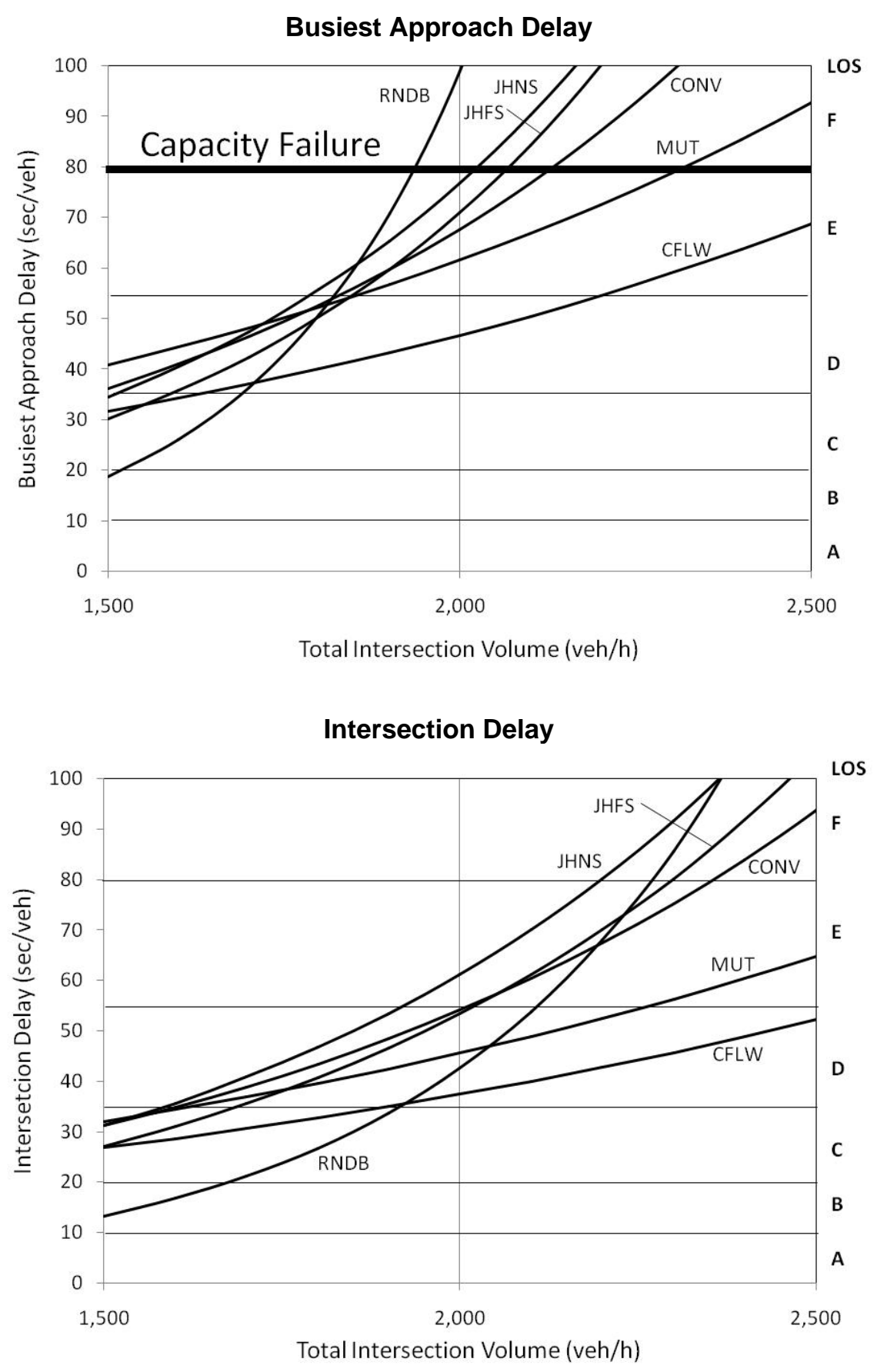

Stops Per Vehicle

\begin{tabular}{|c|c|c|c|}
\hline \multirow{2}{*}{ DESIGN } & \multicolumn{3}{|c|}{ Total Intersection Volume (veh/h) } \\
\cline { 2 - 4 } & 1215 & 1580 & 2190 \\
\hline CONV & 0.78 & 0.95 & 1.17 \\
\hline CFLW & 0.63 & 0.71 & 0.92 \\
\hline JHFS & 0.54 & 0.63 & 1.11 \\
\hline JHNS & 0.64 & 0.73 & 1.72 \\
\hline MUT & 0.67 & 0.67 & 1.06 \\
\hline RNDB & 0.12 & 0.24 & 3.76 \\
\hline
\end{tabular}



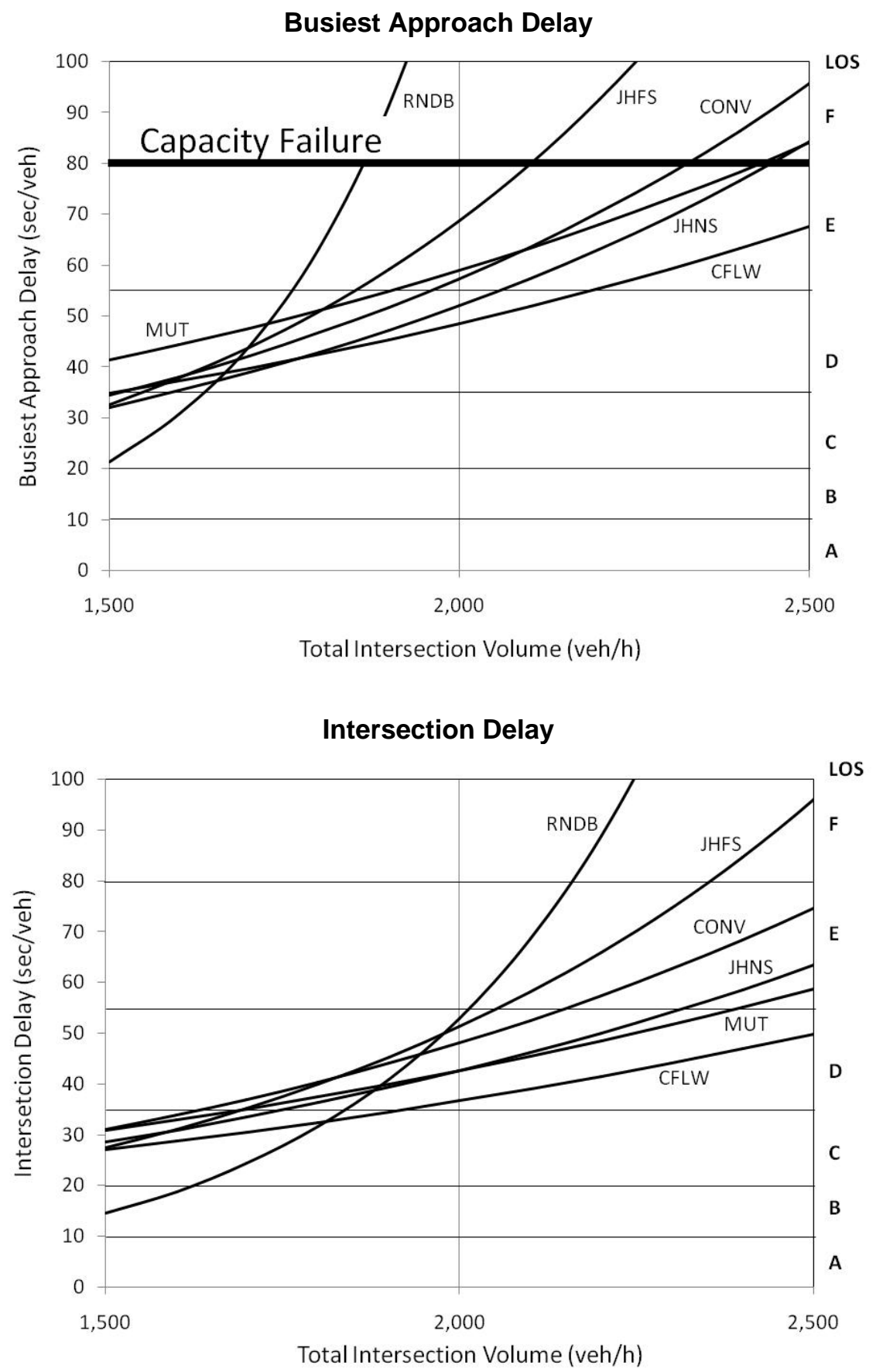

Stops Per Vehicle

\begin{tabular}{|c|c|c|c|}
\hline \multirow{2}{*}{ DESIGN } & \multicolumn{3}{|c|}{ Total Intersection Volume $(\mathrm{veh} / \mathrm{h})$} \\
\cline { 2 - 4 } & 1215 & 1580 & 2190 \\
\hline CONV & 0.69 & 0.73 & 1.06 \\
\hline CFLW & 0.65 & 0.72 & 0.94 \\
\hline JHFS & 0.57 & 0.62 & 1.10 \\
\hline JHNS & 0.65 & 0.74 & 1.03 \\
\hline MUT & 0.61 & 0.67 & 0.99 \\
\hline RNDB & 0.13 & 0.27 & 5.18 \\
\hline
\end{tabular}



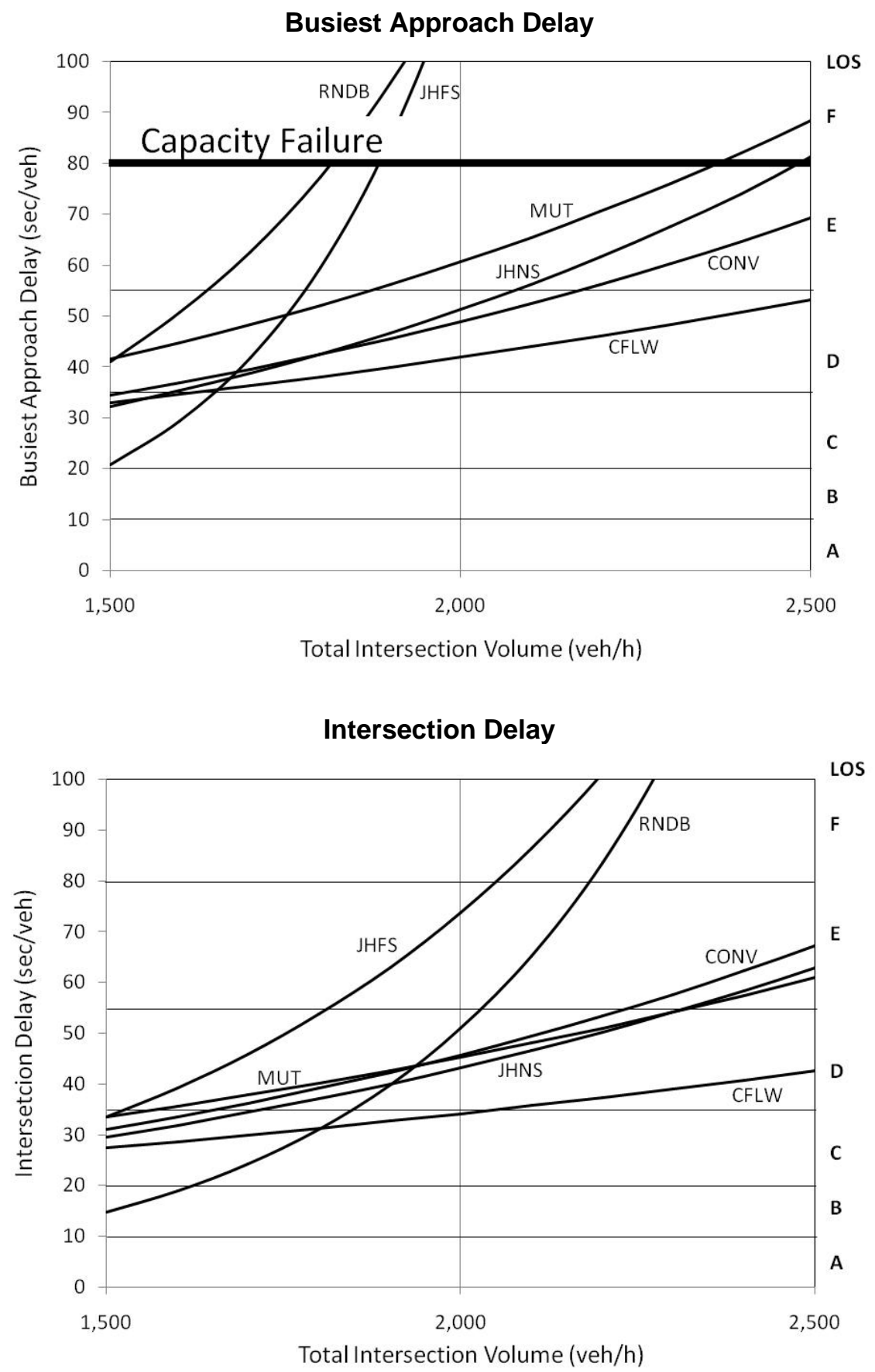

Stops Per Vehicle

\begin{tabular}{|c|c|c|c|}
\hline \multirow{2}{*}{ DESIGN } & \multicolumn{3}{|c|}{ Total Intersection Volume $($ veh/h) } \\
\cline { 2 - 4 } & 1215 & 1580 & 2190 \\
\hline CONV & 0.69 & 0.74 & 1.03 \\
\hline CFLW & 0.71 & 0.79 & 0.82 \\
\hline JHFS & 0.62 & 0.76 & 1.81 \\
\hline JHNS & 0.69 & 0.78 & 1.10 \\
\hline MUT & 0.73 & 0.78 & 1.09 \\
\hline RNDB & 0.15 & 0.29 & 4.78 \\
\hline
\end{tabular}



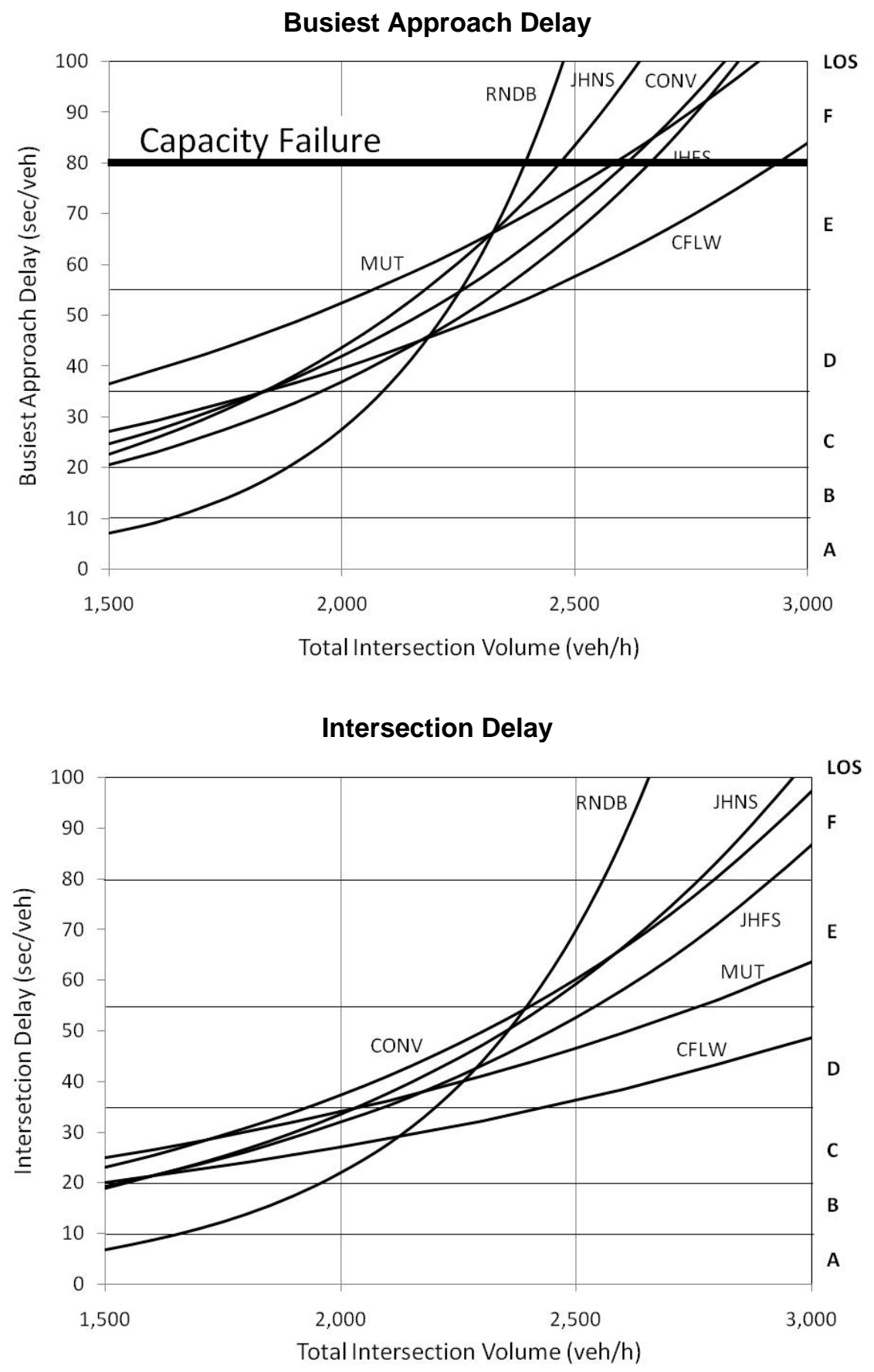

Stops Per Vehicle

\begin{tabular}{|c|c|c|c|}
\hline \multirow{2}{*}{ DESIGN } & \multicolumn{3}{|c|}{ Total Intersection Volume $(\mathrm{veh} / \mathrm{h})$} \\
\cline { 2 - 4 } & 1550 & 2010 & 2785 \\
\hline CONV & 0.84 & 0.93 & 1.12 \\
\hline CFLW & 0.55 & 0.63 & 0.87 \\
\hline JHFS & 0.51 & 0.62 & 0.91 \\
\hline JHNS & 0.58 & 0.70 & 1.37 \\
\hline MUT & 0.60 & 0.72 & 1.01 \\
\hline RNDB & 0.17 & 0.41 & 7.03 \\
\hline
\end{tabular}



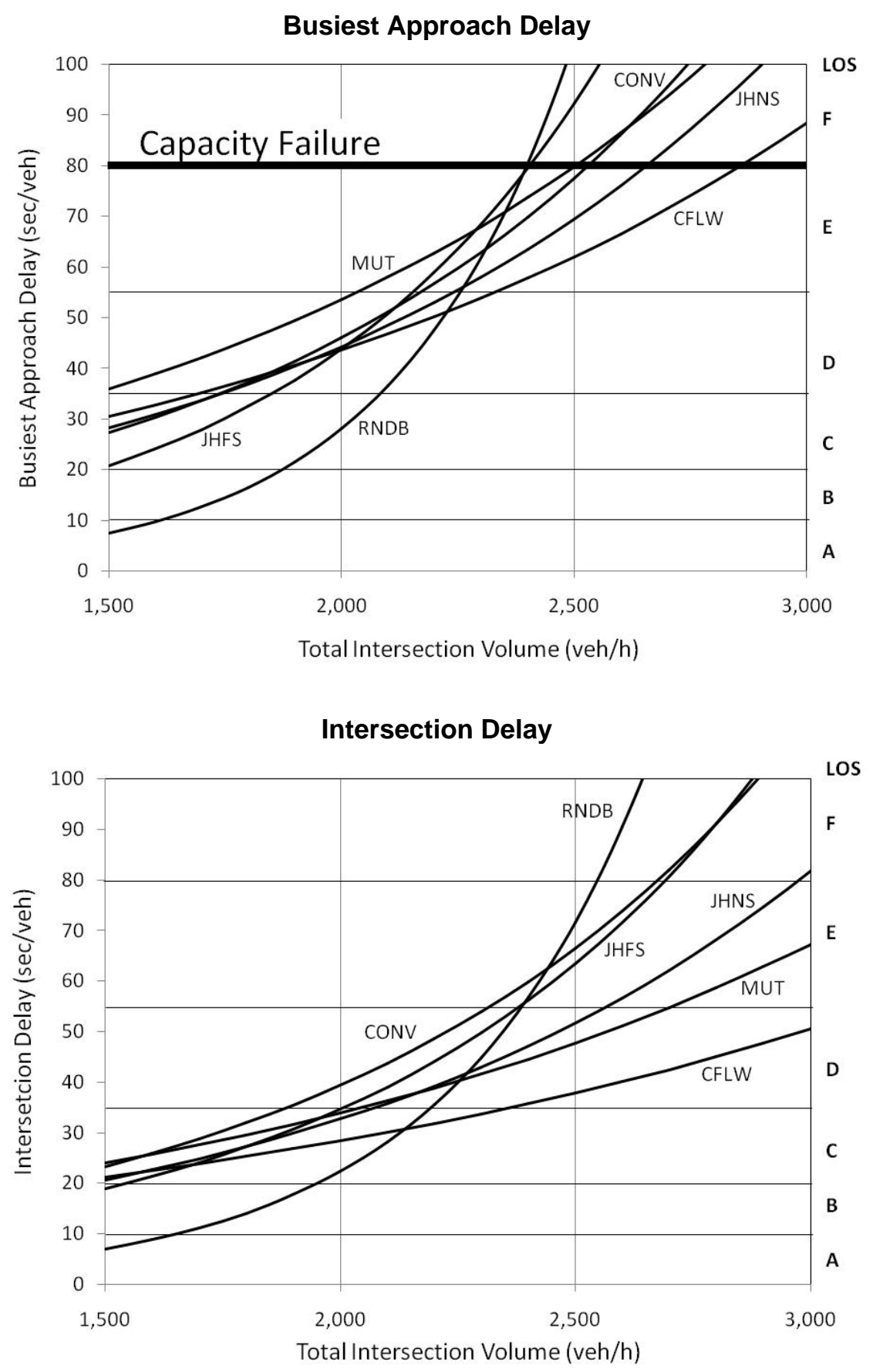

Stops Per Vehicle

\begin{tabular}{|c|c|c|c|}
\hline \multirow{2}{*}{ DESIGN } & \multicolumn{3}{|c|}{ Total Intersection Volume (veh/h) } \\
\cline { 2 - 4 } & 1550 & 2010 & 2785 \\
\hline CONV & 0.68 & 0.74 & 1.27 \\
\hline CFLW & 0.61 & 0.62 & 0.87 \\
\hline JHFS & 0.53 & 0.61 & 1.17 \\
\hline JHNS & 0.61 & 0.70 & 1.16 \\
\hline MUT & 0.59 & 0.68 & 1.03 \\
\hline RNDB & 0.19 & 0.42 & 7.31 \\
\hline
\end{tabular}



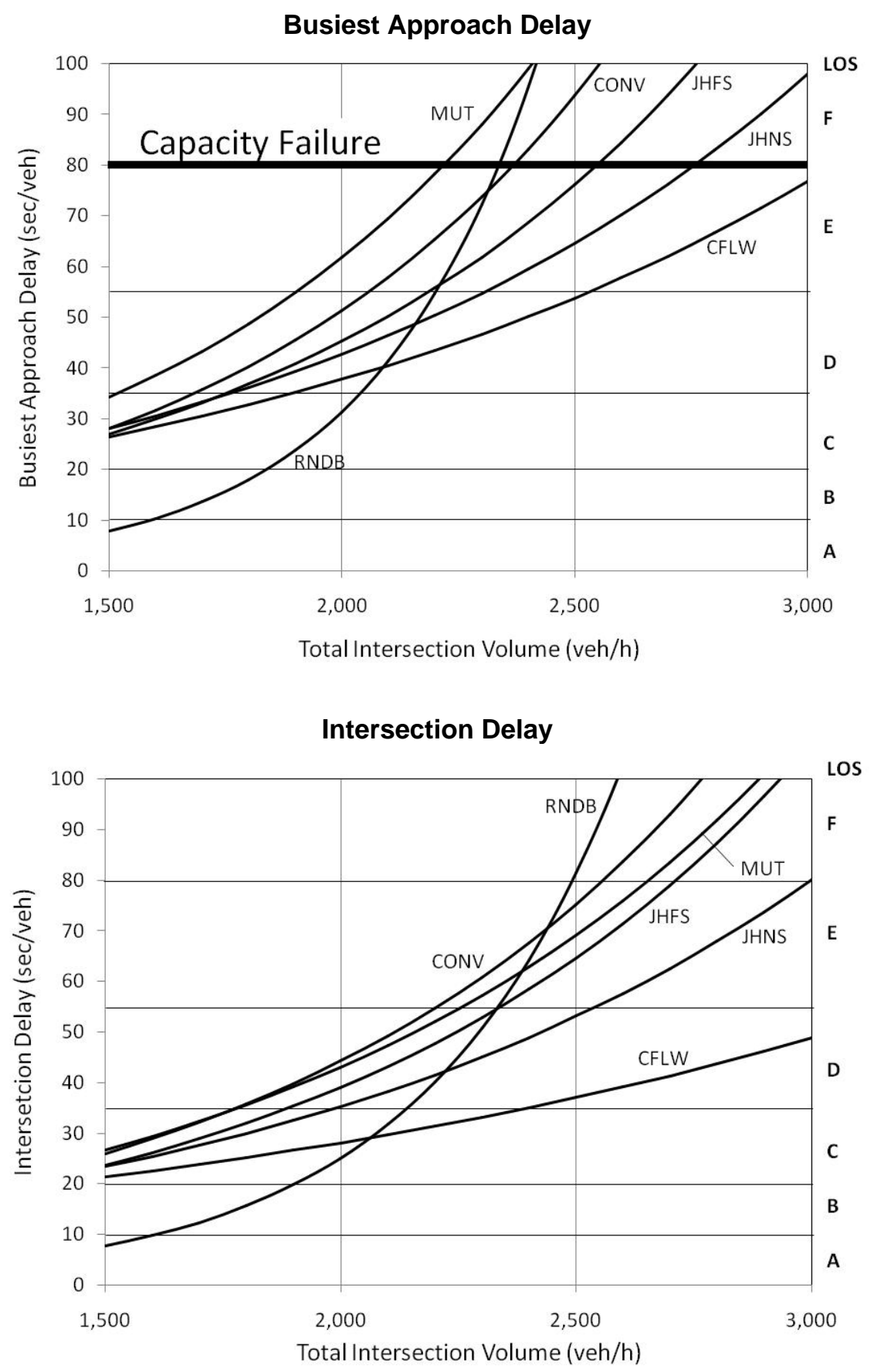

Stops Per Vehicle

\begin{tabular}{|c|c|c|c|}
\hline \multirow{2}{*}{ DESIGN } & \multicolumn{3}{|c|}{ Total Intersection Volume $(\mathrm{veh} / \mathrm{h})$} \\
\cline { 2 - 4 } & 1550 & 2010 & 2785 \\
\hline CONV & 0.75 & 0.81 & 1.57 \\
\hline CFLW & 0.64 & 0.66 & 0.93 \\
\hline JHFS & 0.62 & 0.80 & 1.18 \\
\hline JHNS & 0.67 & 0.76 & 1.22 \\
\hline MUT & 0.67 & 0.80 & 1.64 \\
\hline RNDB & 0.23 & 0.55 & 8.83 \\
\hline
\end{tabular}



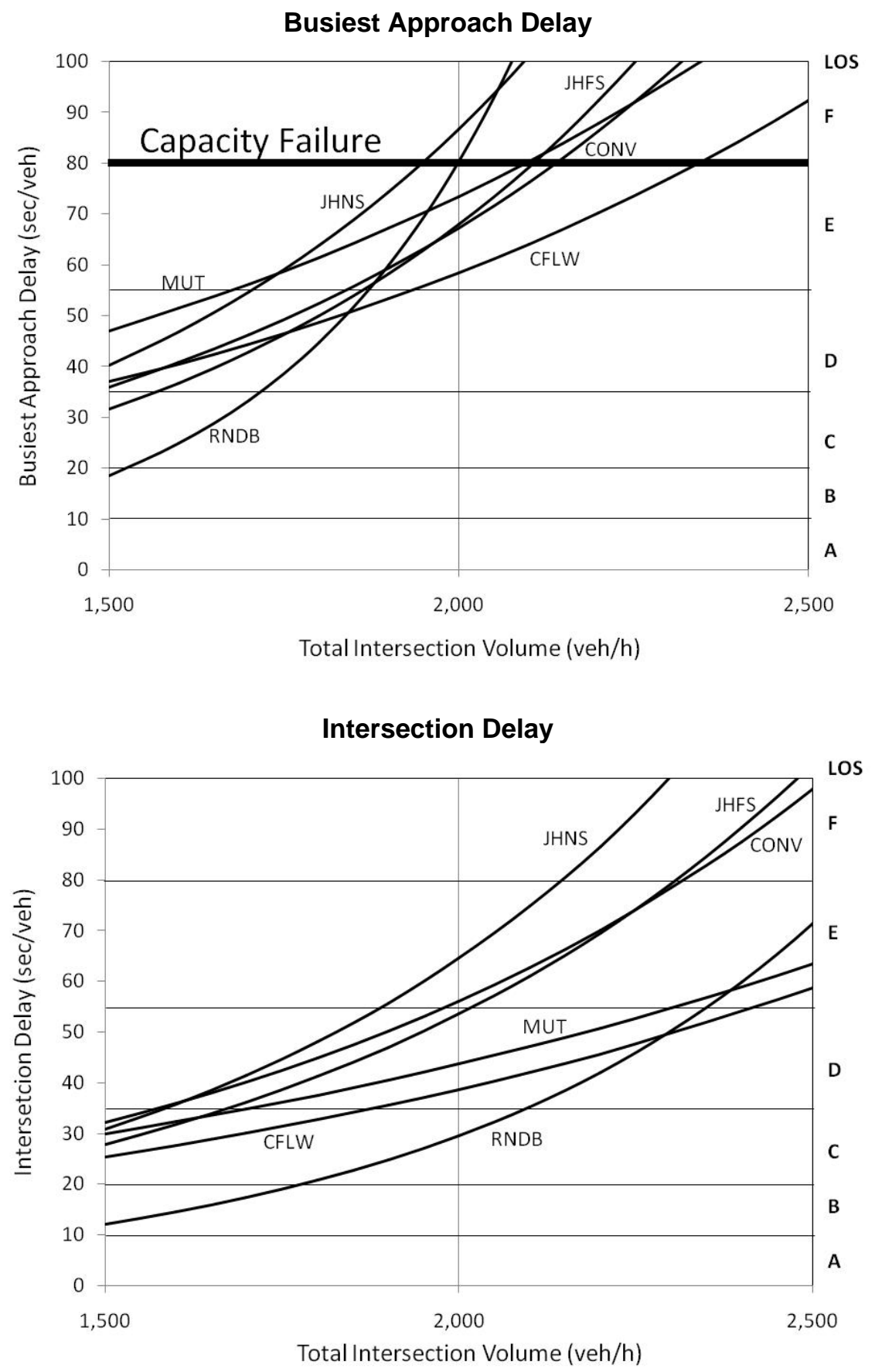

Stops Per Vehicle

\begin{tabular}{|c|c|c|c|}
\hline \multirow{2}{*}{ DESIGN } & \multicolumn{3}{|c|}{ Total Intersection Volume $(\mathrm{veh} / \mathrm{h})$} \\
\cline { 2 - 4 } & 1215 & 1580 & 2190 \\
\hline CONV & 0.81 & 0.86 & 0.95 \\
\hline CFLW & 0.55 & 0.62 & 0.85 \\
\hline JHFS & 0.51 & 0.46 & 0.87 \\
\hline JHNS & 0.62 & 0.67 & 1.44 \\
\hline MUT & 0.57 & 0.59 & 0.87 \\
\hline RNDB & 0.11 & 0.24 & 1.95 \\
\hline
\end{tabular}



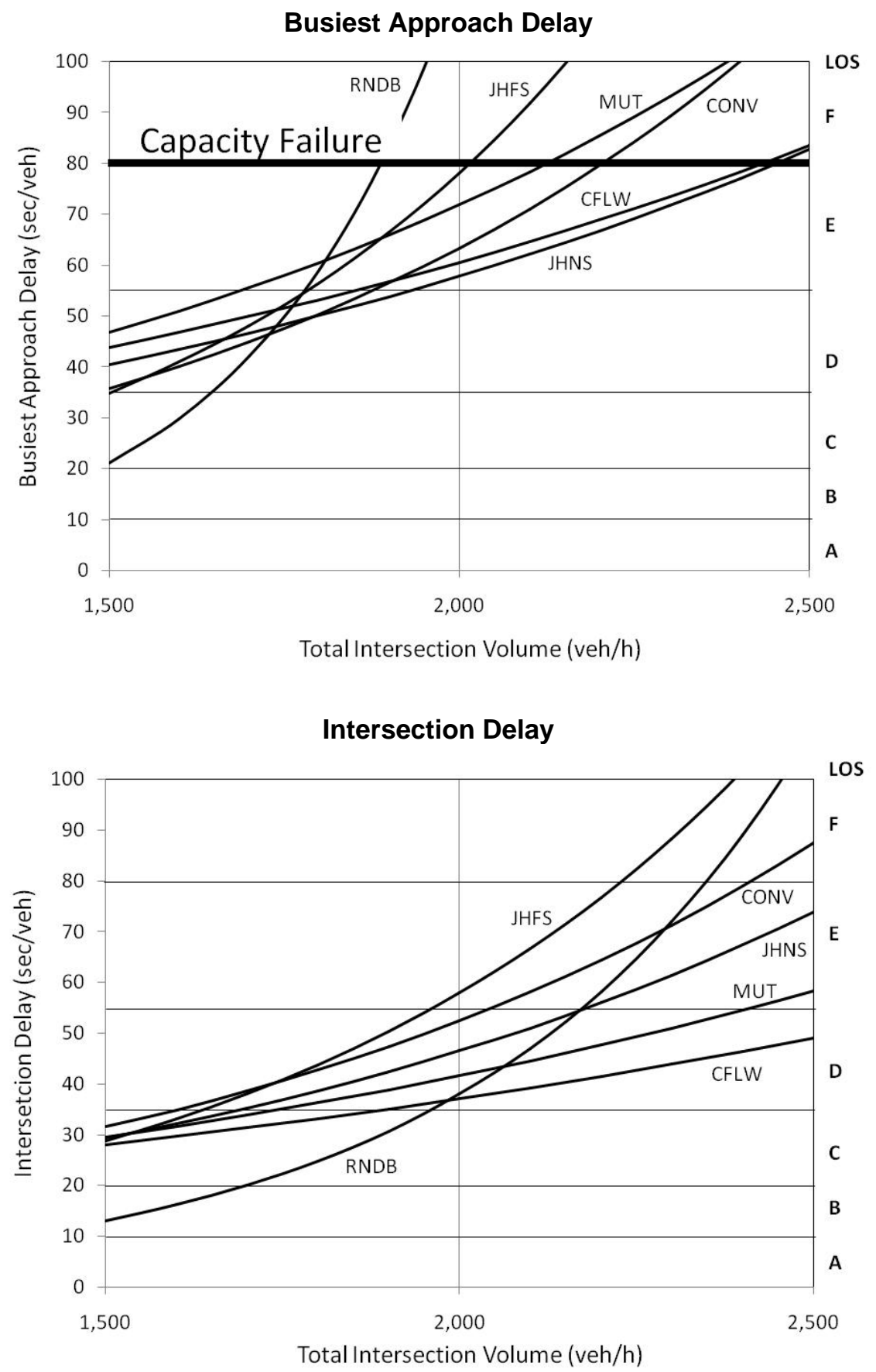

Stops Per Vehicle

\begin{tabular}{|c|c|c|c|}
\hline \multirow{2}{*}{ DESIGN } & \multicolumn{3}{|c|}{ Total Intersection Volume $(\mathrm{veh} / \mathrm{h})$} \\
\cline { 2 - 4 } & 1215 & 1580 & 2190 \\
\hline CONV & 0.66 & 0.69 & 0.90 \\
\hline CFLW & 0.64 & 0.64 & 0.84 \\
\hline JHFS & 0.52 & 0.44 & 0.88 \\
\hline JHNS & 0.64 & 0.67 & 0.96 \\
\hline MUT & 0.56 & 0.59 & 0.79 \\
\hline RNDB & 0.12 & 0.24 & 3.10 \\
\hline
\end{tabular}



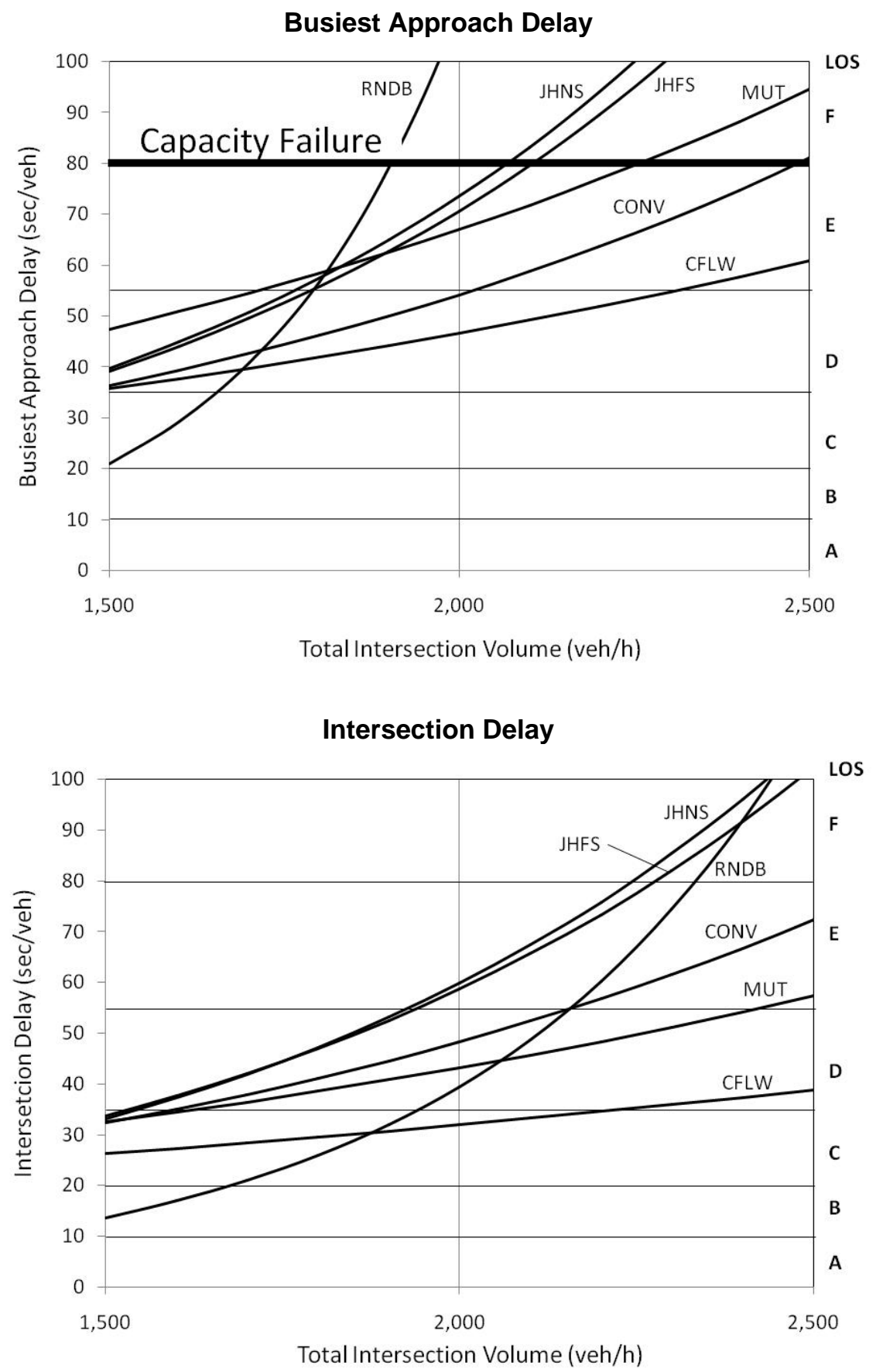

Stops Per Vehicle

\begin{tabular}{|c|c|c|c|}
\hline \multirow{2}{*}{ DESIGN } & \multicolumn{3}{|c|}{ Total Intersection Volume $($ veh/h) } \\
\cline { 2 - 4 } & 1215 & 1580 & 2190 \\
\hline CONV & 0.71 & 0.72 & 0.91 \\
\hline CFLW & 0.64 & 0.69 & 0.74 \\
\hline JHFS & 0.62 & 0.47 & 1.01 \\
\hline JHNS & 0.69 & 0.75 & 1.37 \\
\hline MUT & 0.67 & 0.67 & 0.89 \\
\hline RNDB & 0.13 & 0.27 & 3.09 \\
\hline
\end{tabular}



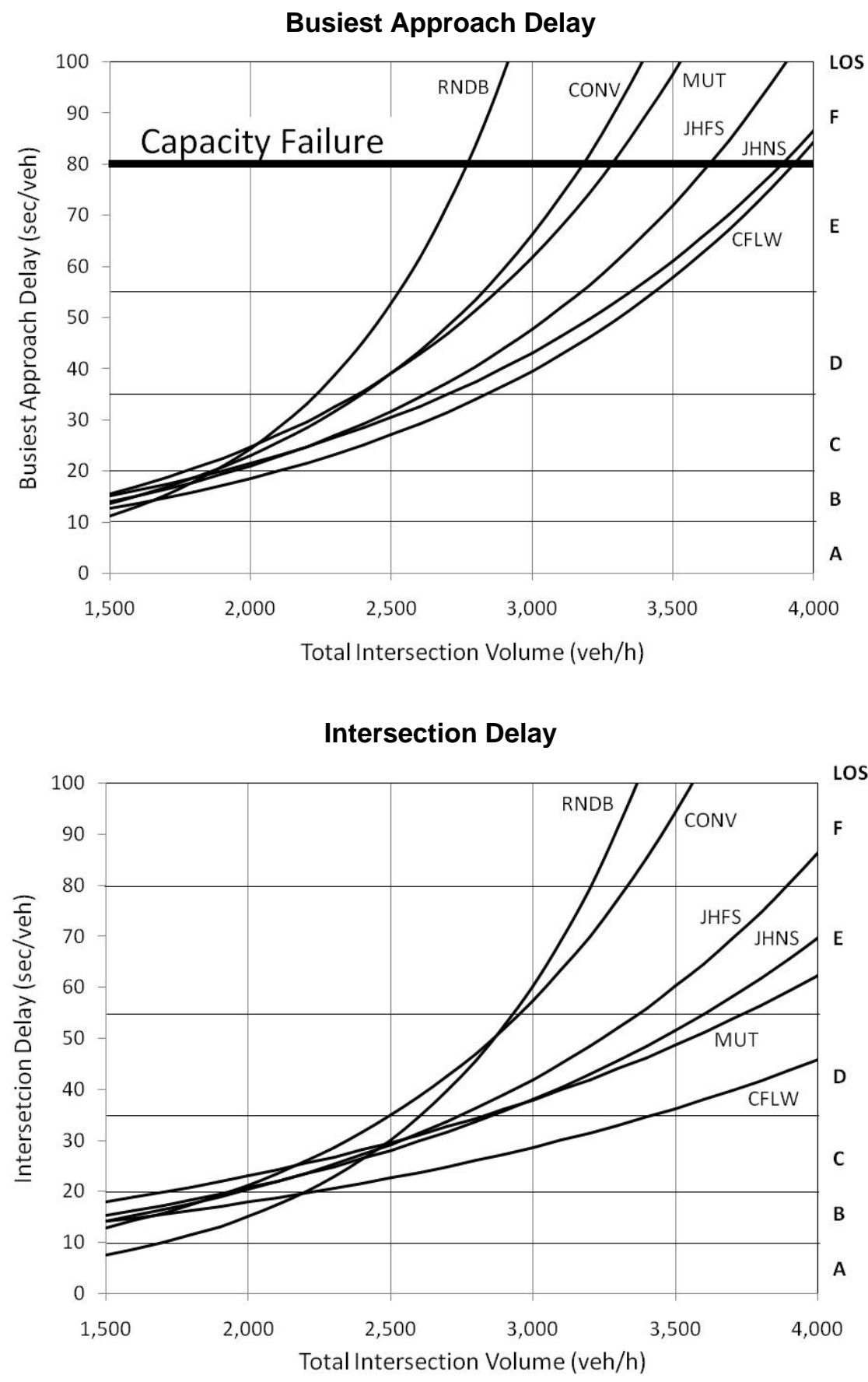

Stops Per Vehicle

\begin{tabular}{|c|c|c|c|}
\hline \multirow{2}{*}{ DESIGN } & \multicolumn{3}{|c|}{ Total Intersection Volume (veh/h) } \\
\cline { 2 - 4 } & 2135 & 2275 & 3840 \\
\hline CONV & 0.69 & 0.88 & 3.03 \\
\hline CFLW & 0.52 & 0.63 & 1.00 \\
\hline JHFS & 0.57 & 0.70 & 1.27 \\
\hline JHNS & 0.63 & 0.73 & 1.28 \\
\hline MUT & 0.52 & 0.58 & 1.03 \\
\hline RNDB & 0.33 & 1.11 & 9.40 \\
\hline
\end{tabular}



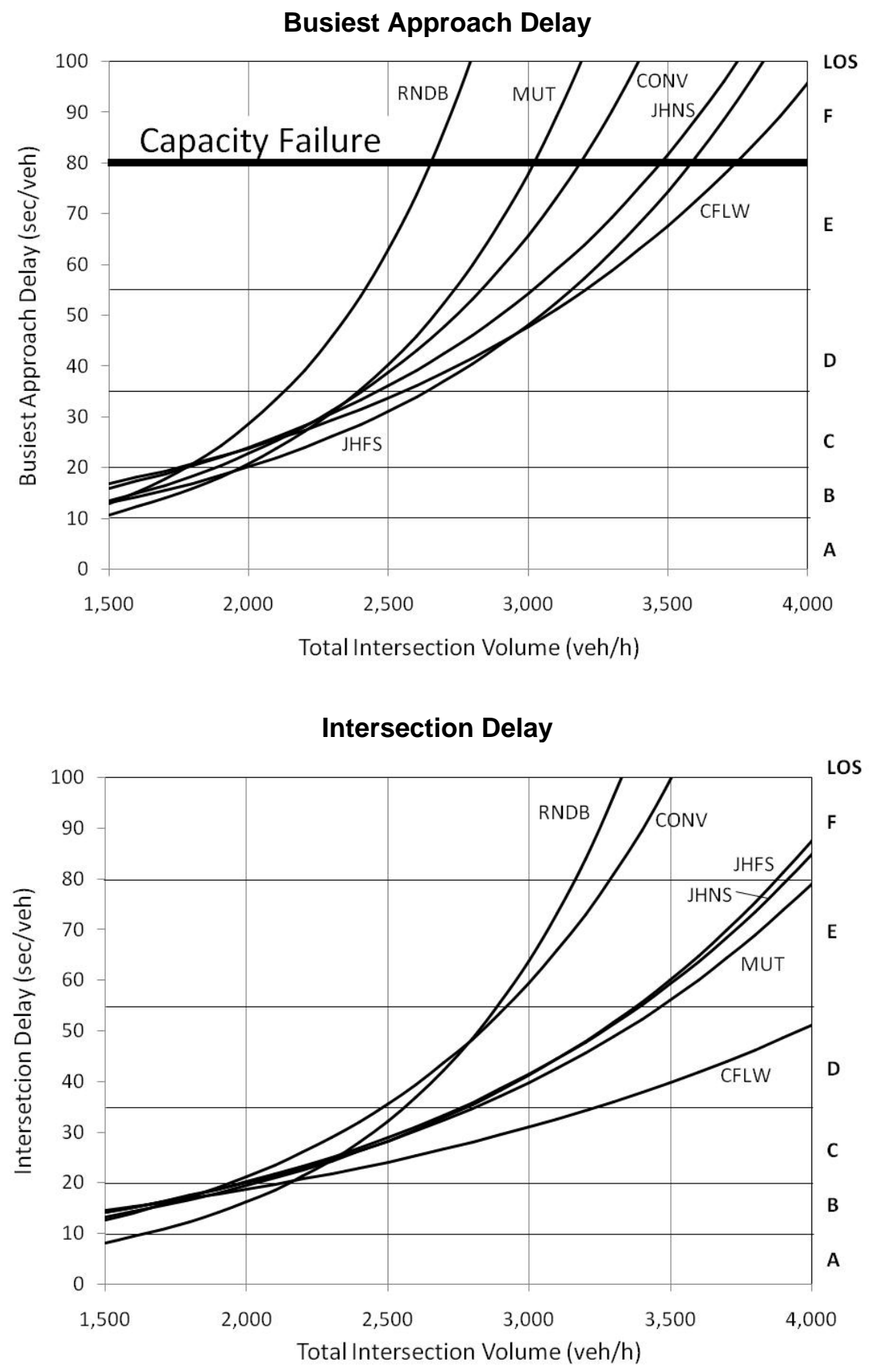

Stops Per Vehicle

\begin{tabular}{|c|c|c|c|}
\hline \multirow{2}{*}{ DESIGN } & \multicolumn{3}{|c|}{ Total Intersection Volume $(\mathrm{veh} / \mathrm{h})$} \\
\cline { 2 - 4 } & 2135 & 2275 & 3840 \\
\hline CONV & 0.70 & 0.84 & 2.51 \\
\hline CFLW & 0.58 & 0.66 & 1.01 \\
\hline JHFS & 0.55 & 0.70 & 1.27 \\
\hline JHNS & 0.62 & 0.76 & 1.50 \\
\hline MUT & 0.54 & 0.58 & 1.07 \\
\hline RNDB & 0.37 & 1.43 & 9.71 \\
\hline
\end{tabular}



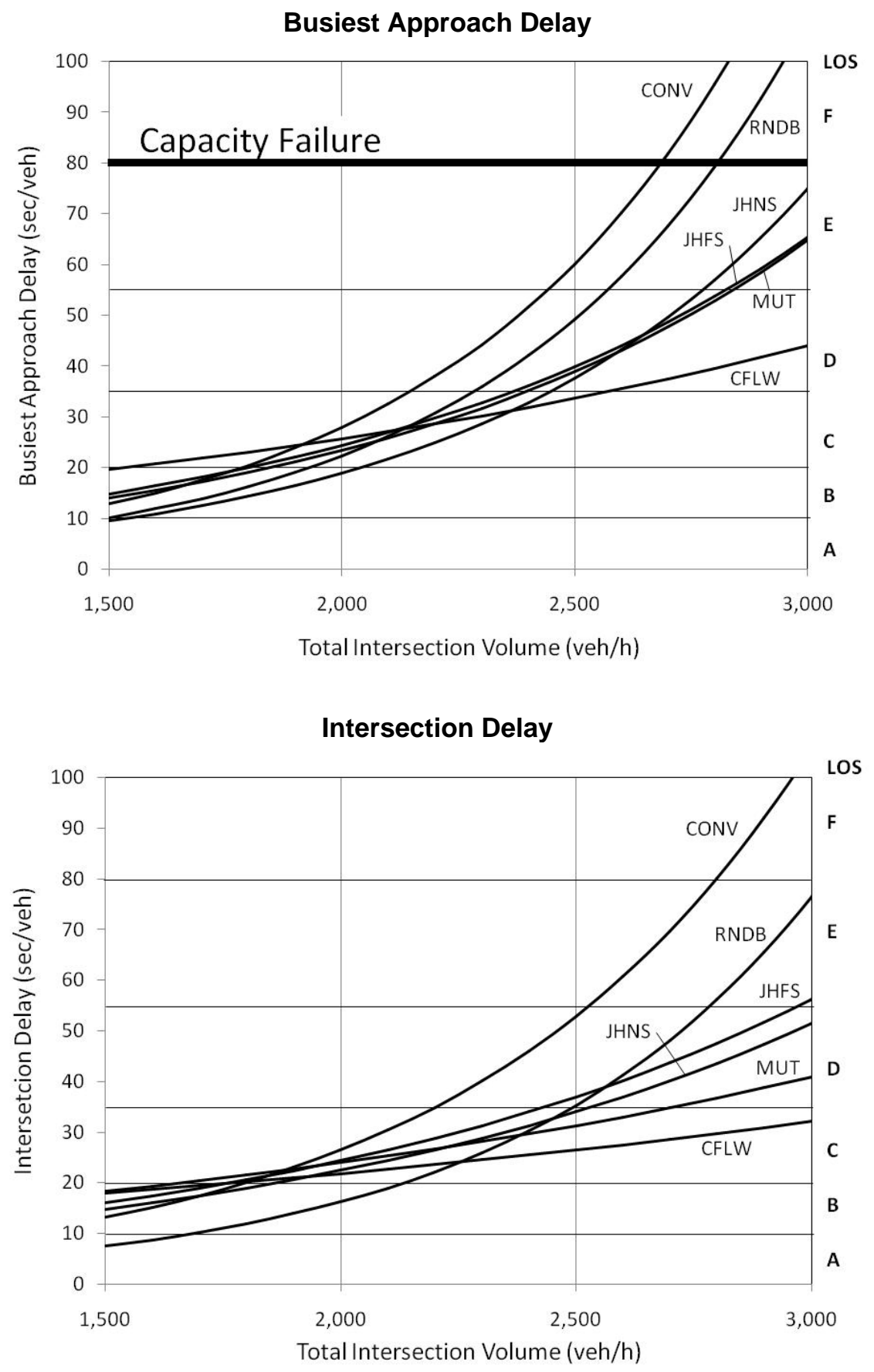

Stops Per Vehicle

\begin{tabular}{|c|c|c|c|}
\hline \multirow{2}{*}{ DESIGN } & \multicolumn{3}{|c|}{ Total Intersection Volume (veh/h) } \\
\cline { 2 - 4 } & 2135 & 2275 & 3840 \\
\hline CONV & 0.79 & 1.60 & 2.51 \\
\hline CFLW & 0.64 & 0.73 & 1.00 \\
\hline JHFS & 0.68 & 0.93 & 1.95 \\
\hline JHNS & 0.70 & 0.88 & 2.26 \\
\hline MUT & 0.58 & 0.66 & 1.06 \\
\hline RNDB & 0.44 & 1.55 & 15.13 \\
\hline
\end{tabular}



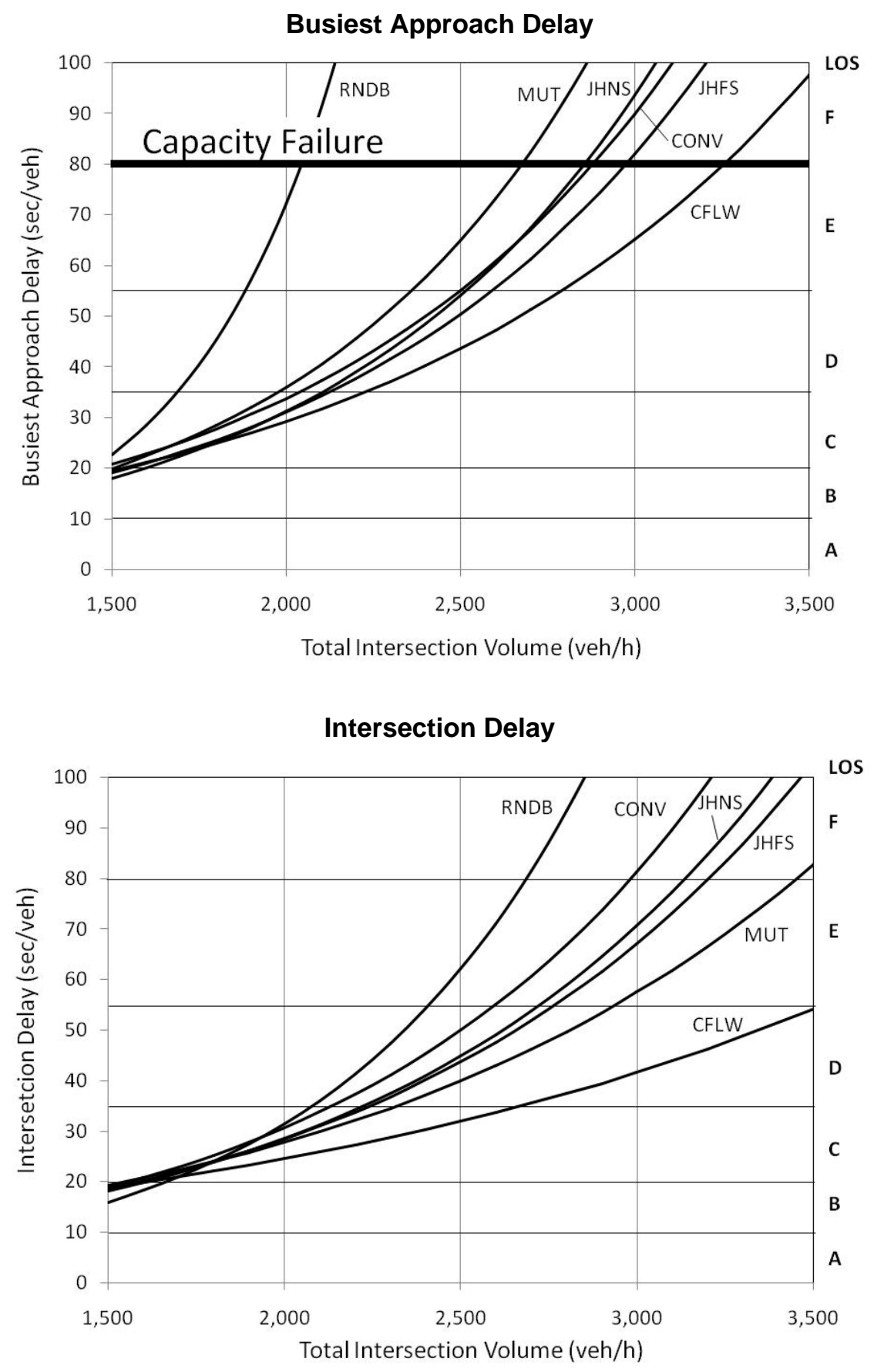

Stops Per Vehicle

\begin{tabular}{|c|c|c|c|}
\hline \multirow{2}{*}{ DESIGN } & \multicolumn{3}{|c|}{ Total Intersection Volume (veh/h) } \\
\cline { 2 - 4 } & 1675 & 2180 & 3015 \\
\hline CONV & 0.65 & 0.74 & 1.75 \\
\hline CFLW & 0.64 & 0.59 & 0.95 \\
\hline JHFS & 0.56 & 0.68 & 1.14 \\
\hline JHNS & 0.62 & 0.72 & 1.40 \\
\hline MUT & 0.56 & 0.58 & 1.02 \\
\hline RNDB & 0.28 & 1.50 & 5.71 \\
\hline
\end{tabular}



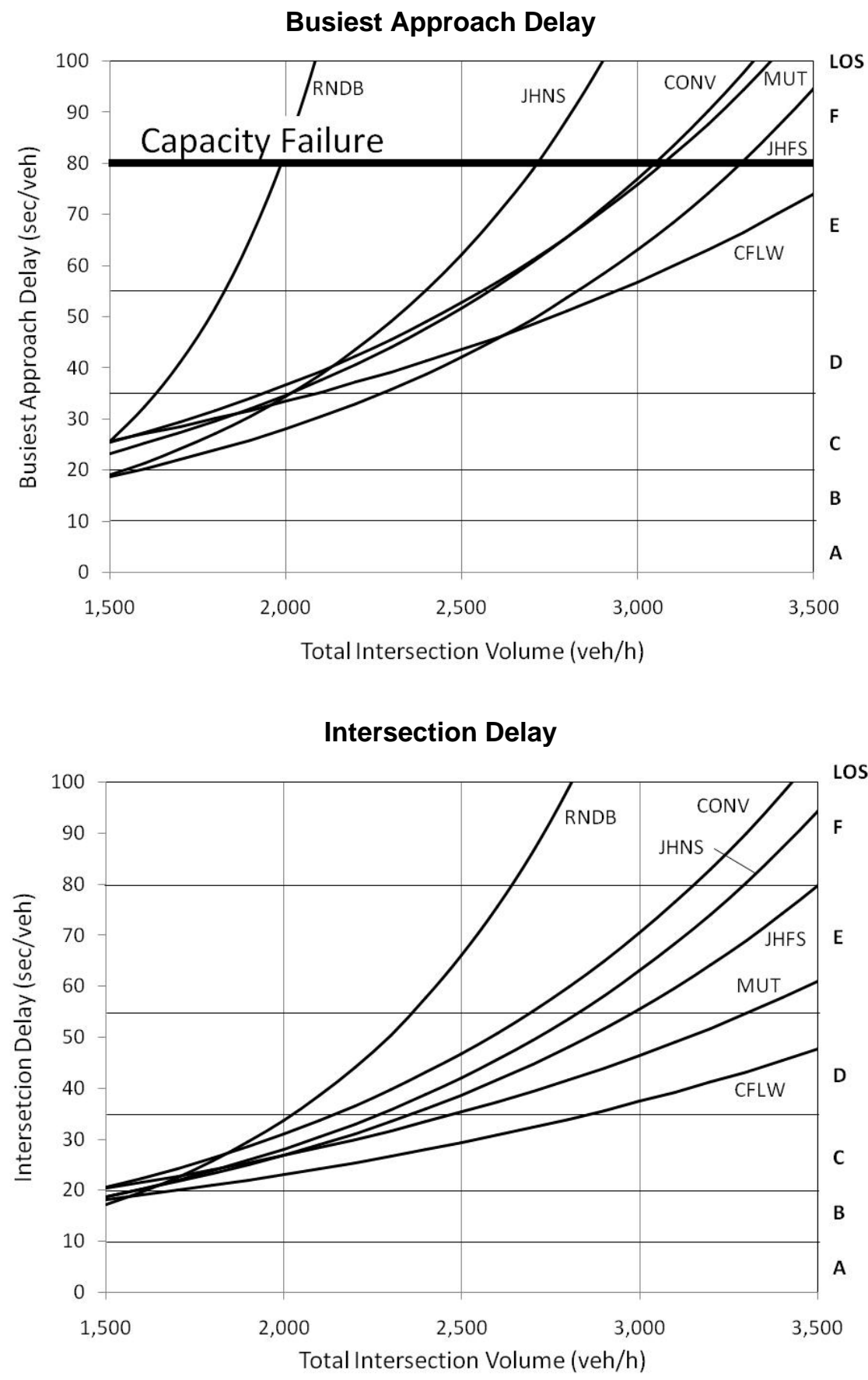

Stops Per Vehicle

\begin{tabular}{|c|c|c|c|}
\hline \multirow{2}{*}{ DESIGN } & \multicolumn{3}{|c|}{ Total Intersection Volume (veh/h) } \\
\cline { 2 - 4 } & 1675 & 2180 & 3015 \\
\hline CONV & 0.68 & 0.72 & 1.18 \\
\hline CFLW & 0.55 & 0.63 & 0.82 \\
\hline JHFS & 0.56 & 0.64 & 0.97 \\
\hline JHNS & 0.64 & 0.71 & 1.22 \\
\hline MUT & 0.50 & 0.56 & 0.84 \\
\hline RNDB & 0.29 & 1.94 & 5.86 \\
\hline
\end{tabular}



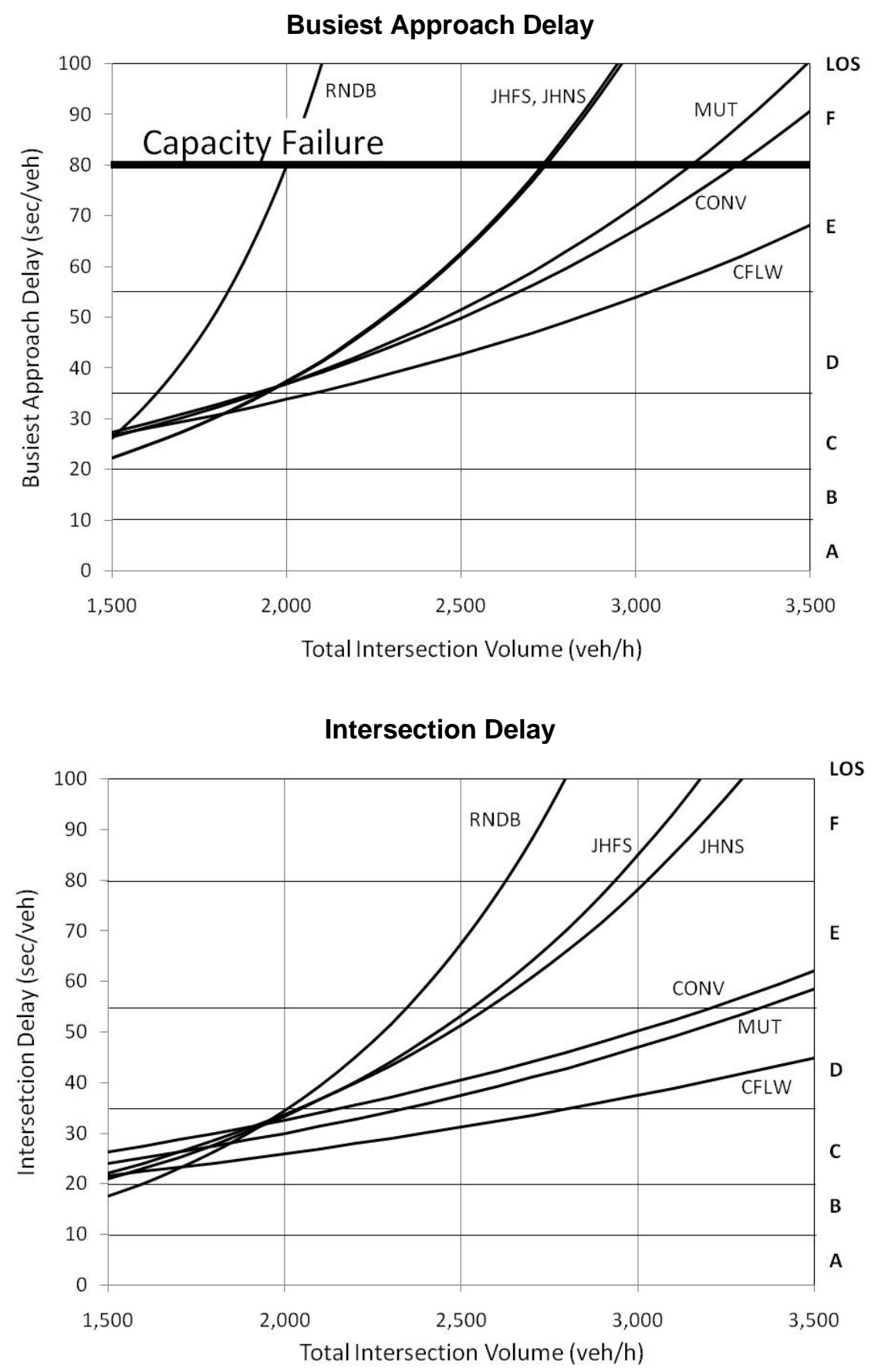

Stops Per Vehicle

\begin{tabular}{|c|c|c|c|}
\hline \multirow{2}{*}{ DESIGN } & \multicolumn{3}{|c|}{ Total Intersection Volume (veh/h) } \\
\cline { 2 - 4 } & 1675 & 2180 & 3015 \\
\hline CONV & 0.72 & 0.81 & 0.81 \\
\hline CFLW & 0.64 & 0.69 & 0.84 \\
\hline JHFS & 0.63 & 0.83 & 1.52 \\
\hline JHNS & 0.72 & 0.86 & 1.69 \\
\hline MUT & 0.58 & 0.60 & 0.85 \\
\hline RNDB & 0.34 & 1.89 & 5.99 \\
\hline
\end{tabular}



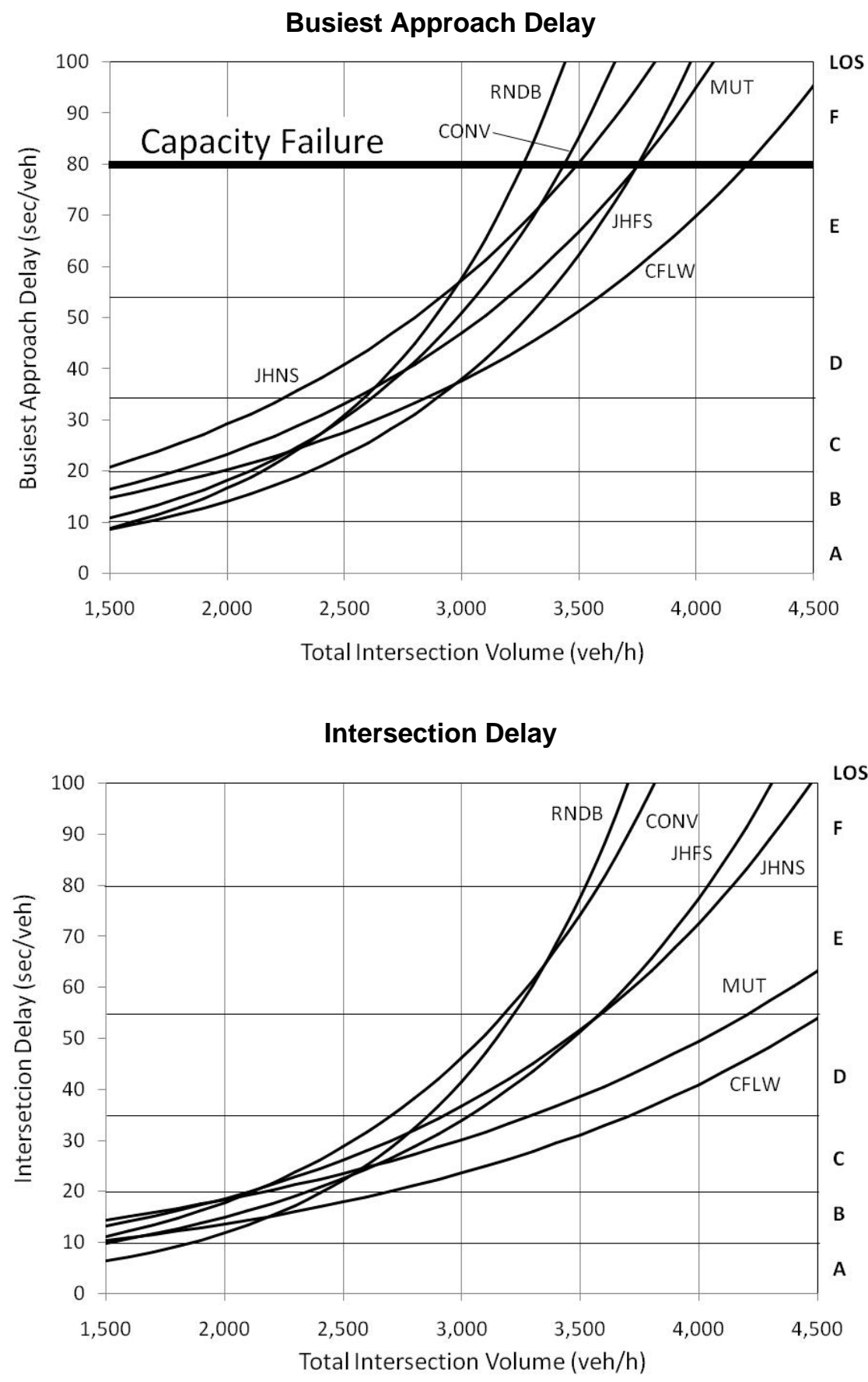

Stops Per Vehicle

\begin{tabular}{|c|c|c|c|}
\hline \multirow{2}{*}{ DESIGN } & \multicolumn{3}{|c|}{ Total Intersection Volume (veh/h) } \\
\cline { 2 - 4 } & 2380 & 3095 & 4280 \\
\hline CONV & 0.72 & 0.98 & 3.18 \\
\hline CFLW & 0.45 & 0.50 & 0.85 \\
\hline JHFS & 0.52 & 0.64 & 1.39 \\
\hline JHNS & 0.61 & 0.90 & 1.21 \\
\hline MUT & 0.49 & 0.52 & 0.85 \\
\hline RNDB & 0.32 & 0.93 & 9.46 \\
\hline
\end{tabular}



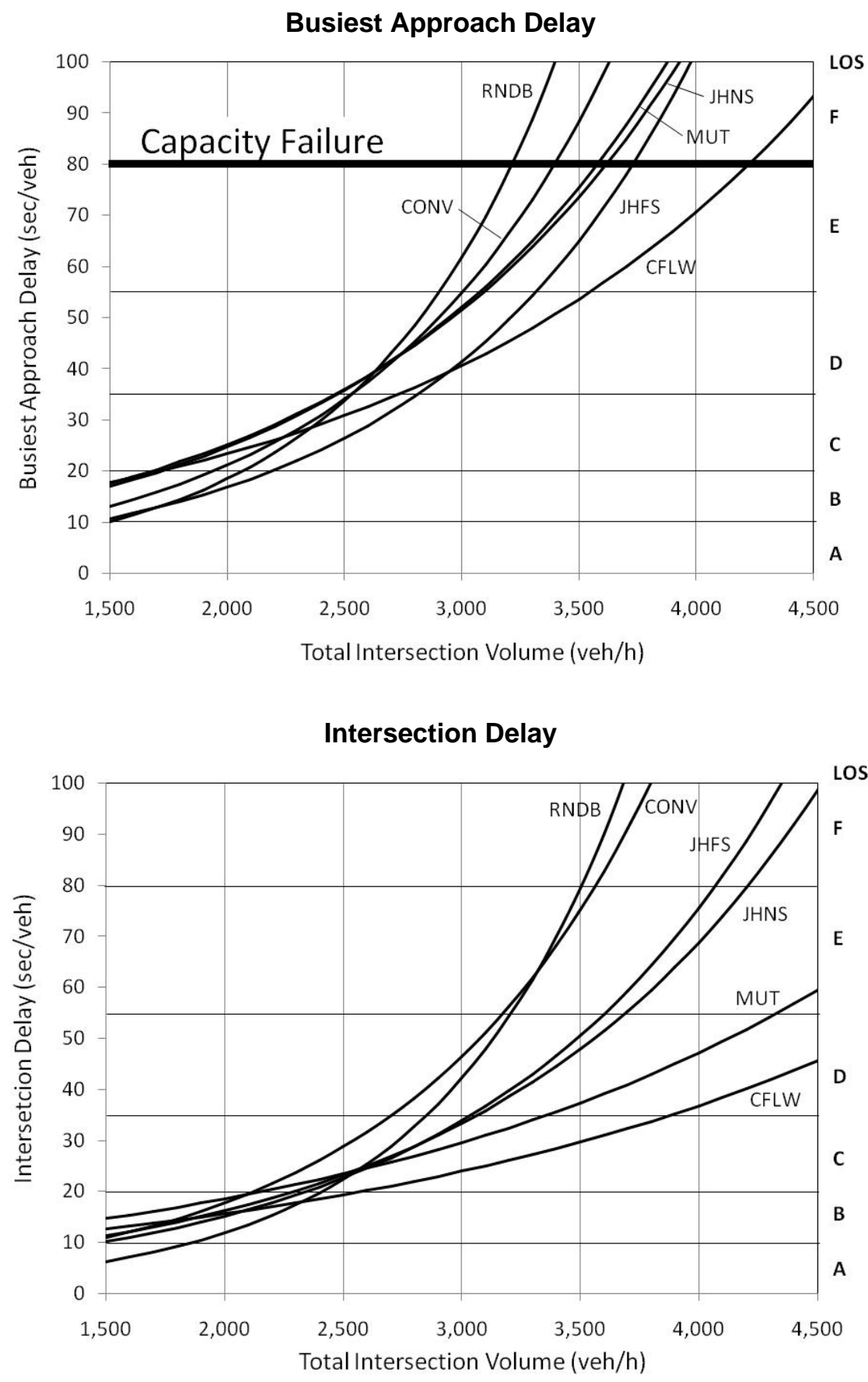

Stops Per Vehicle

\begin{tabular}{|c|c|c|c|}
\hline \multirow{2}{*}{ DESIGN } & \multicolumn{3}{|c|}{ Total Intersection Volume $($ veh/h) } \\
\cline { 2 - 4 } & 2380 & 3095 & 4280 \\
\hline CONV & 0.69 & 0.79 & 2.51 \\
\hline CFLW & 0.49 & 0.53 & 0.77 \\
\hline JHFS & 0.51 & 0.63 & 1.22 \\
\hline JHNS & 0.58 & 0.69 & 1.21 \\
\hline MUT & 0.48 & 0.51 & 0.82 \\
\hline RNDB & 0.33 & 0.98 & 9.93 \\
\hline
\end{tabular}



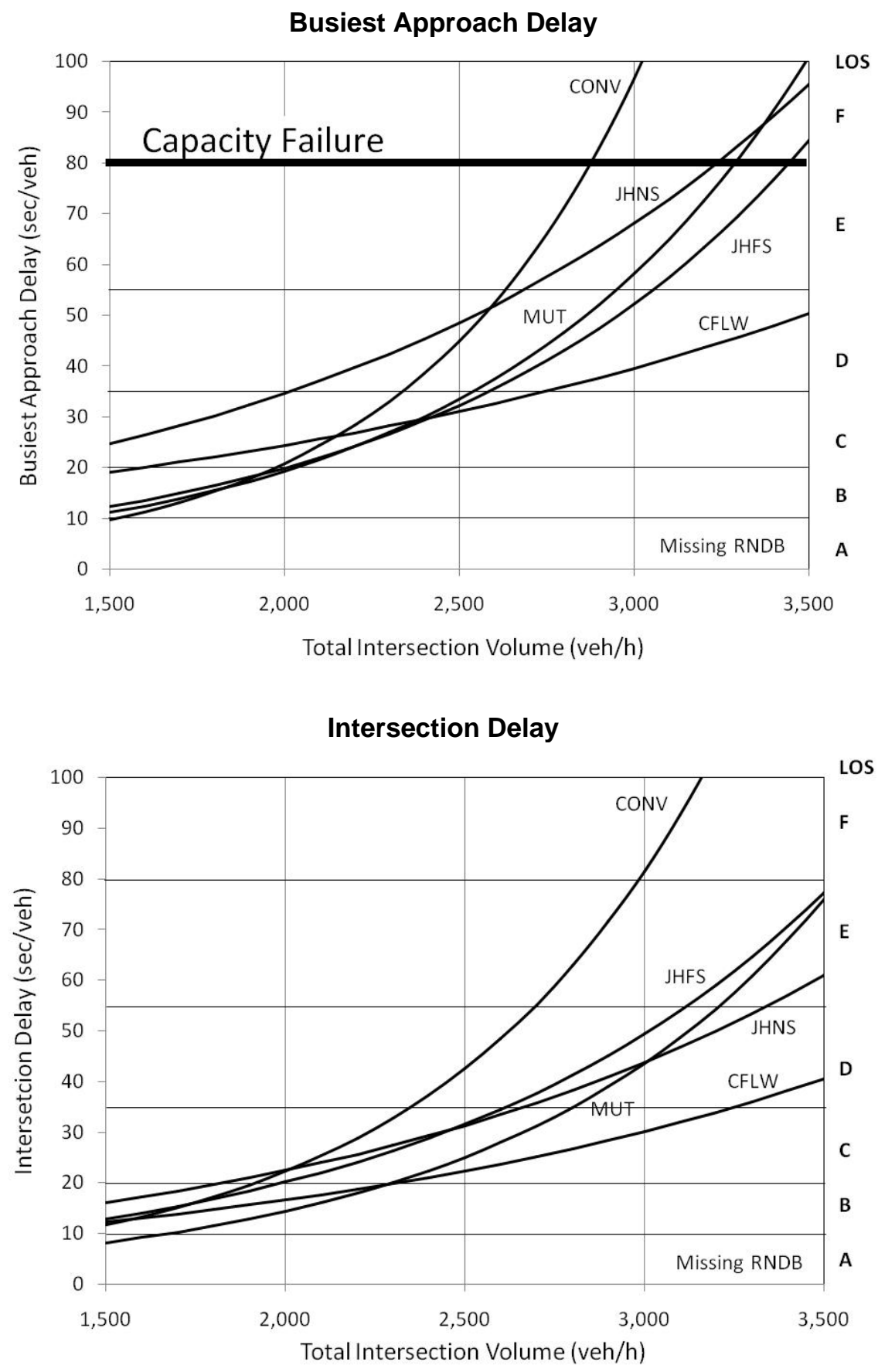

Stops Per Vehicle

\begin{tabular}{|c|c|c|c|}
\hline \multirow{2}{*}{ DESIGN } & \multicolumn{3}{|c|}{ Total Intersection Volume $(\mathrm{veh} / \mathrm{h})$} \\
\cline { 2 - 4 } & 2380 & 3095 & 4280 \\
\hline CONV & 0.83 & 1.77 & 2.51 \\
\hline CFLW & 0.57 & 0.60 & 1.10 \\
\hline JHFS & 0.74 & 0.93 & 2.55 \\
\hline JHNS & 0.68 & 1.01 & 1.94 \\
\hline MUT & 0.53 & 0.59 & 3.36 \\
\hline RNDB & & & \\
\hline
\end{tabular}



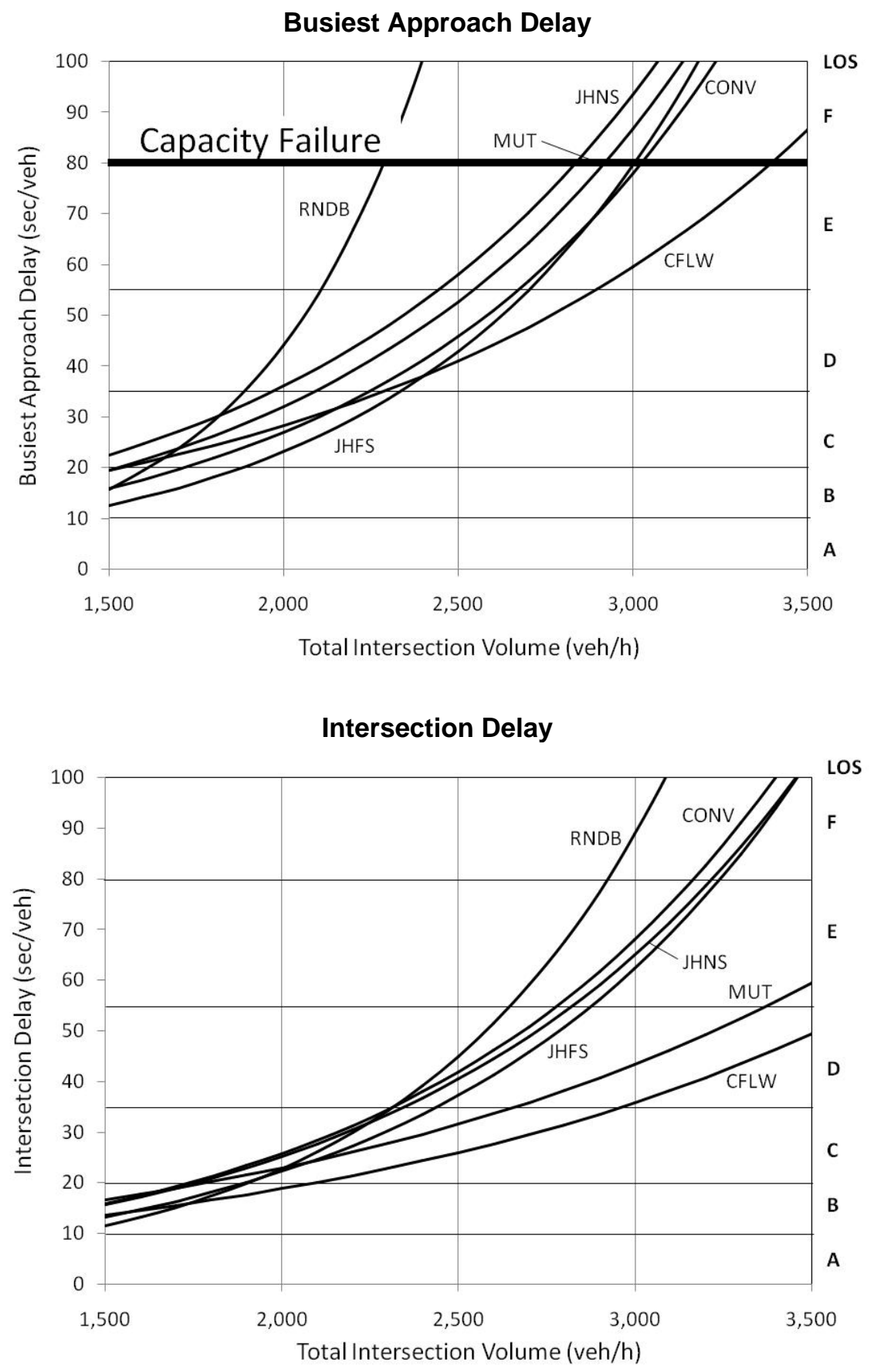

Stops Per Vehicle

\begin{tabular}{|c|c|c|c|}
\hline \multirow{2}{*}{ DESIGN } & \multicolumn{3}{|c|}{ Total Intersection Volume $(\mathrm{veh} / \mathrm{h})$} \\
\cline { 2 - 4 } & 1870 & 2430 & 3365 \\
\hline CONV & 0.62 & 0.78 & 1.43 \\
\hline CFLW & 0.45 & 0.52 & 0.82 \\
\hline JHFS & 0.51 & 0.61 & 1.13 \\
\hline JHNS & 0.61 & 0.78 & 1.21 \\
\hline MUT & 0.48 & 0.63 & 0.77 \\
\hline RNDB & 0.25 & 1.11 & 5.75 \\
\hline
\end{tabular}



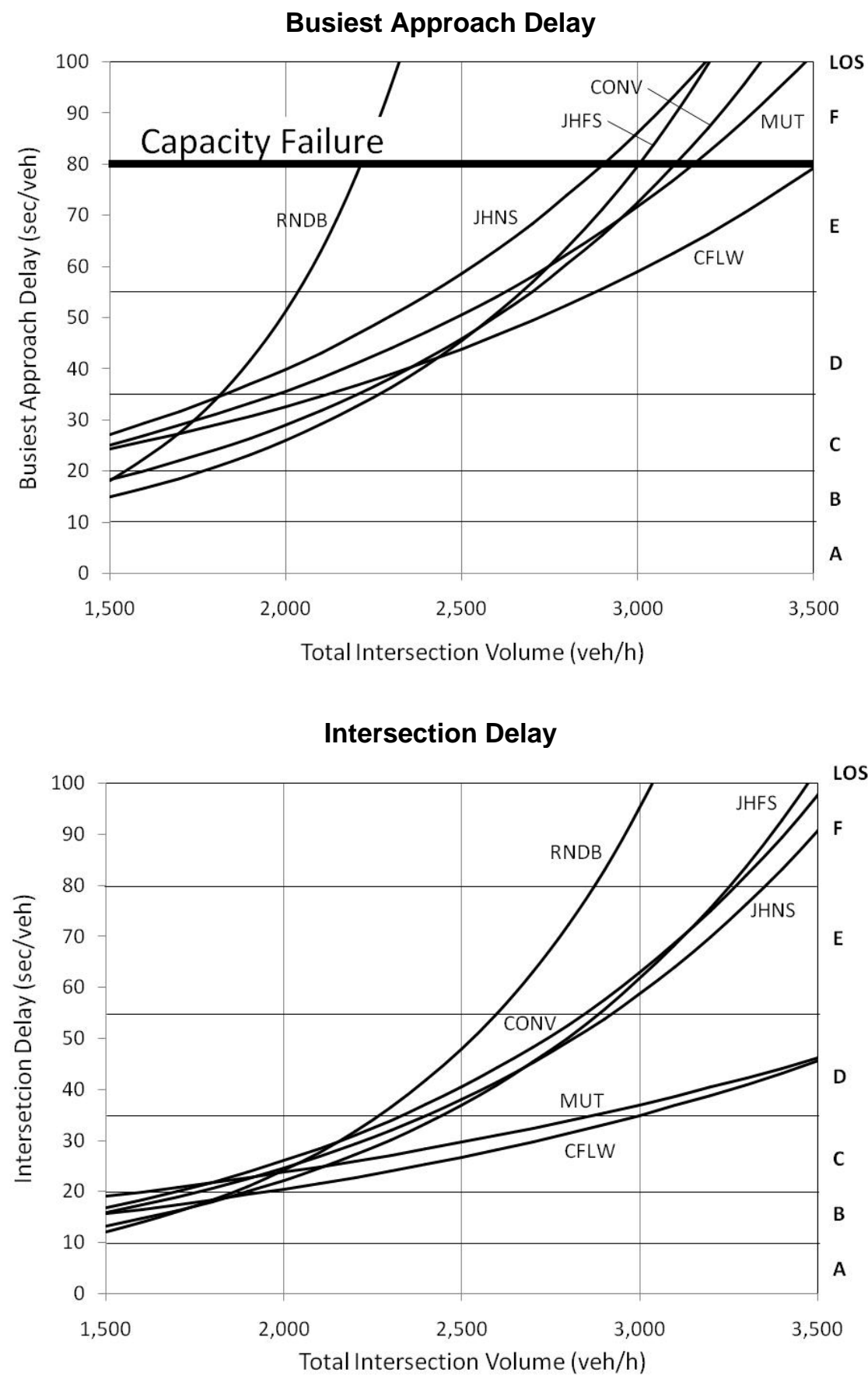

Stops Per Vehicle

\begin{tabular}{|c|c|c|c|}
\hline \multirow{2}{*}{ DESIGN } & \multicolumn{3}{|c|}{ Total Intersection Volume (veh/h) } \\
\cline { 2 - 4 } & 1870 & 2430 & 3365 \\
\hline CONV & 0.62 & 0.68 & 1.05 \\
\hline CFLW & 0.53 & 0.54 & 0.77 \\
\hline JHFS & 0.50 & 0.60 & 1.10 \\
\hline JHNS & 0.59 & 0.81 & 1.04 \\
\hline MUT & 0.50 & 0.60 & 0.60 \\
\hline RNDB & 0.25 & 1.49 & 6.12 \\
\hline
\end{tabular}



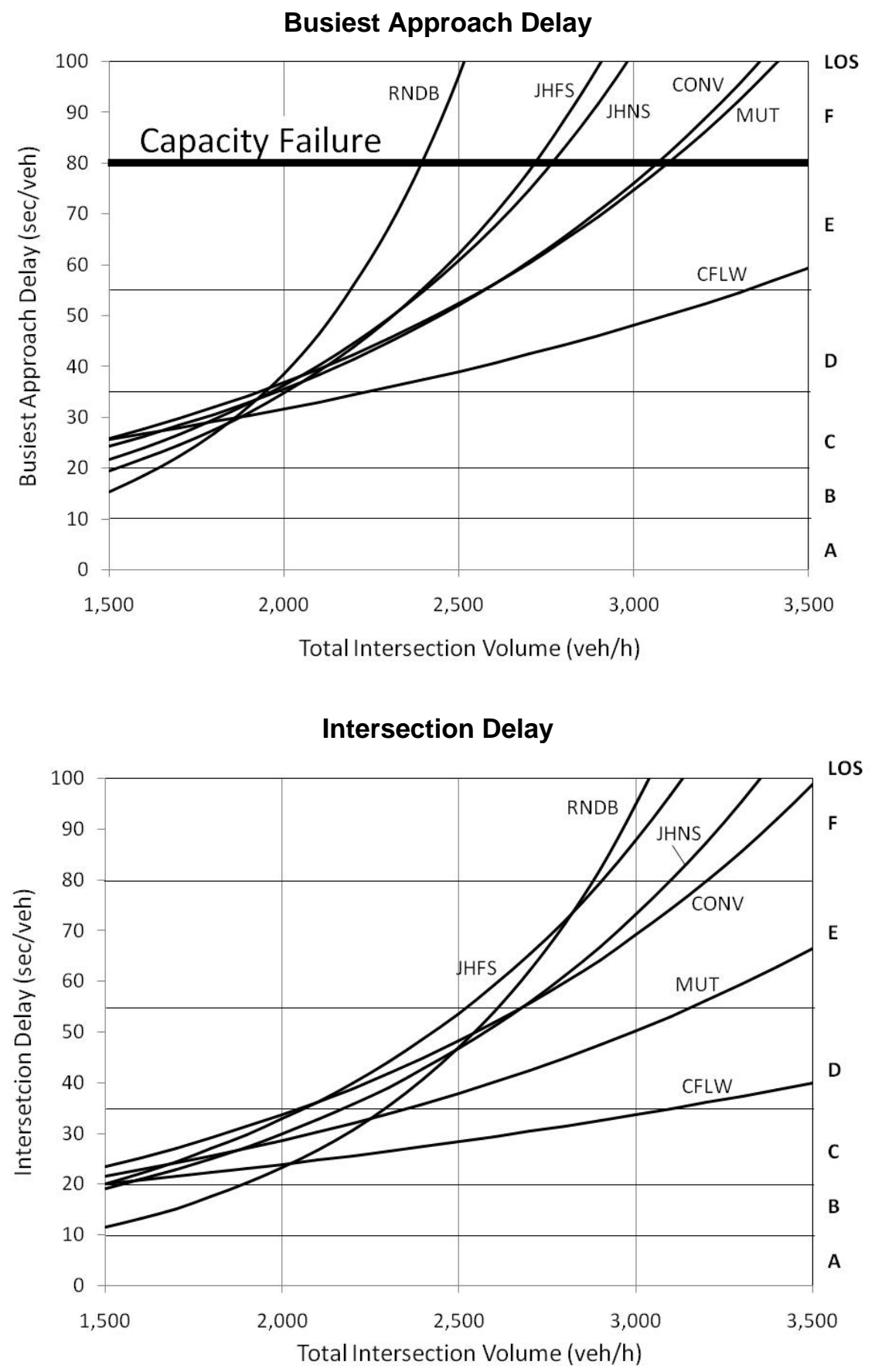

Stops Per Vehicle

\begin{tabular}{|c|c|c|c|}
\hline \multirow{2}{*}{ DESIGN } & \multicolumn{3}{|c|}{ Total Intersection Volume $(\mathrm{veh} / \mathrm{h})$} \\
\cline { 2 - 4 } & 1870 & 2430 & 3365 \\
\hline CONV & 0.78 & 0.88 & 1.05 \\
\hline CFLW & 0.60 & 0.68 & 0.70 \\
\hline JHFS & 0.72 & 0.92 & 1.89 \\
\hline JHNS & 0.73 & 0.89 & 1.64 \\
\hline MUT & 0.57 & 0.71 & 0.84 \\
\hline RNDB & 0.30 & 0.97 & 6.77 \\
\hline
\end{tabular}



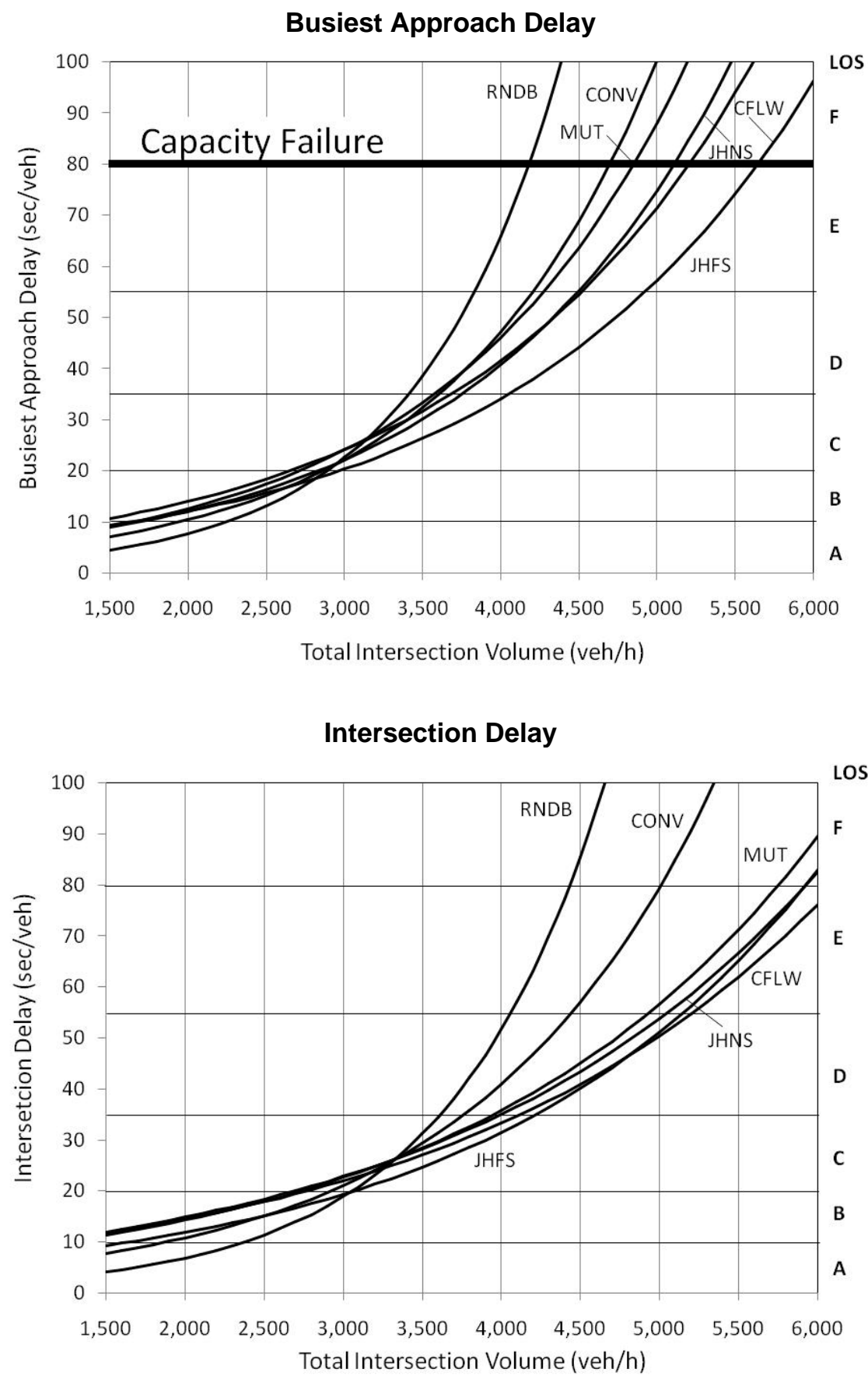

Stops Per Vehicle

\begin{tabular}{|c|c|c|c|}
\hline \multirow{2}{*}{ DESIGN } & \multicolumn{3}{|c|}{ Total Intersection Volume $(\mathrm{veh} / \mathrm{h})$} \\
\cline { 2 - 4 } & 3095 & 4020 & 5565 \\
\hline CONV & 0.64 & 0.75 & 2.00 \\
\hline CFLW & 0.63 & 0.77 & 1.36 \\
\hline JHFS & 0.51 & 0.71 & 1.11 \\
\hline JHNS & 0.66 & 0.73 & 1.27 \\
\hline MUT & 0.65 & 0.88 & 1.48 \\
\hline RNDB & 0.55 & 1.53 & 13.06 \\
\hline
\end{tabular}



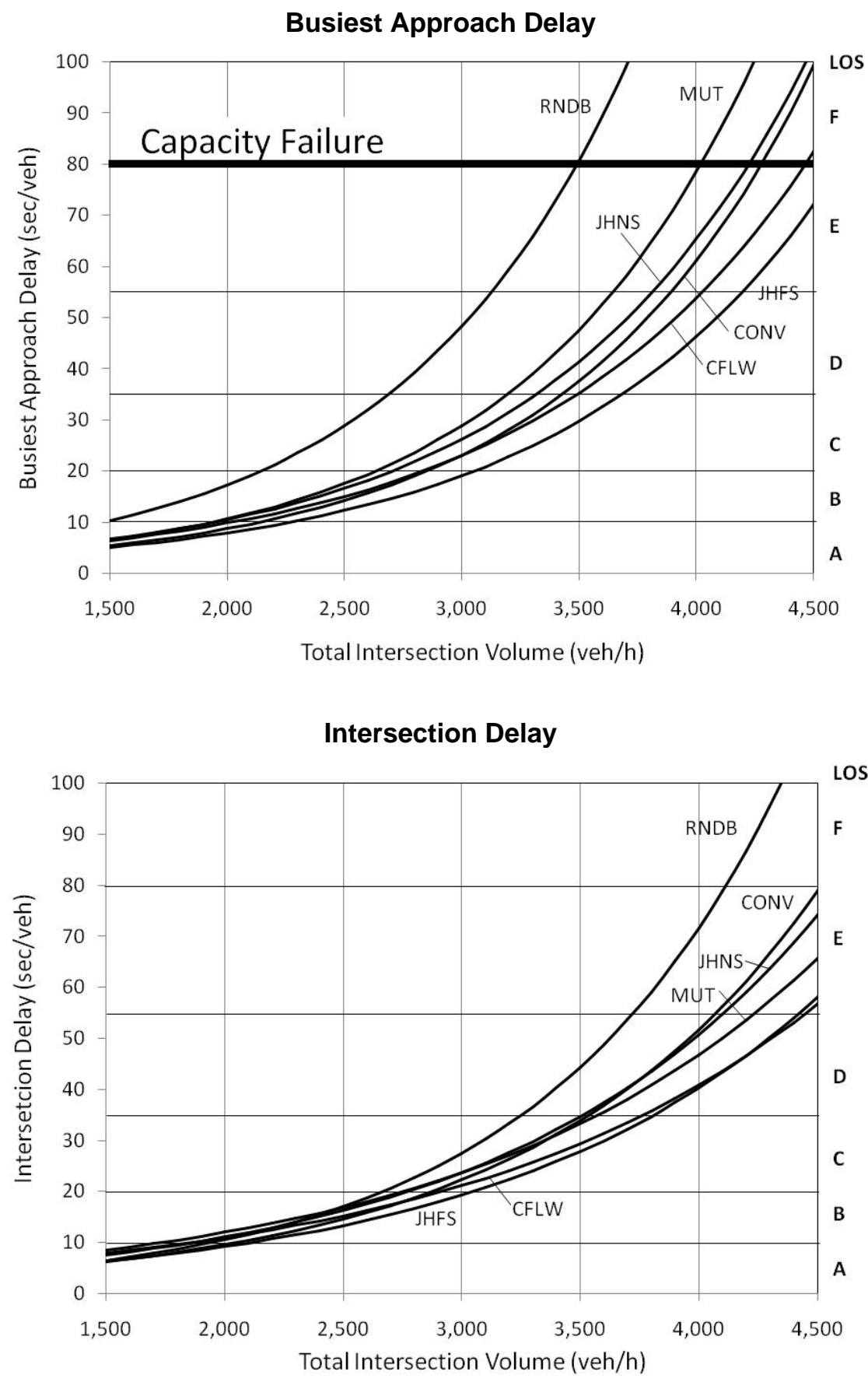

Stops Per Vehicle

\begin{tabular}{|c|c|c|c|}
\hline \multirow{2}{*}{ DESIGN } & \multicolumn{3}{|c|}{ Total Intersection Volume (veh/h) } \\
\cline { 2 - 4 } & 3095 & 4020 & 5565 \\
\hline CONV & 0.70 & 0.87 & 3.64 \\
\hline CFLW & 0.70 & 0.80 & 2.36 \\
\hline JHFS & 0.60 & 0.74 & 2.29 \\
\hline JHNS & 0.77 & 0.87 & 3.50 \\
\hline MUT & 0.68 & 1.04 & 2.71 \\
\hline RNDB & 0.67 & 4.43 & 14.17 \\
\hline
\end{tabular}



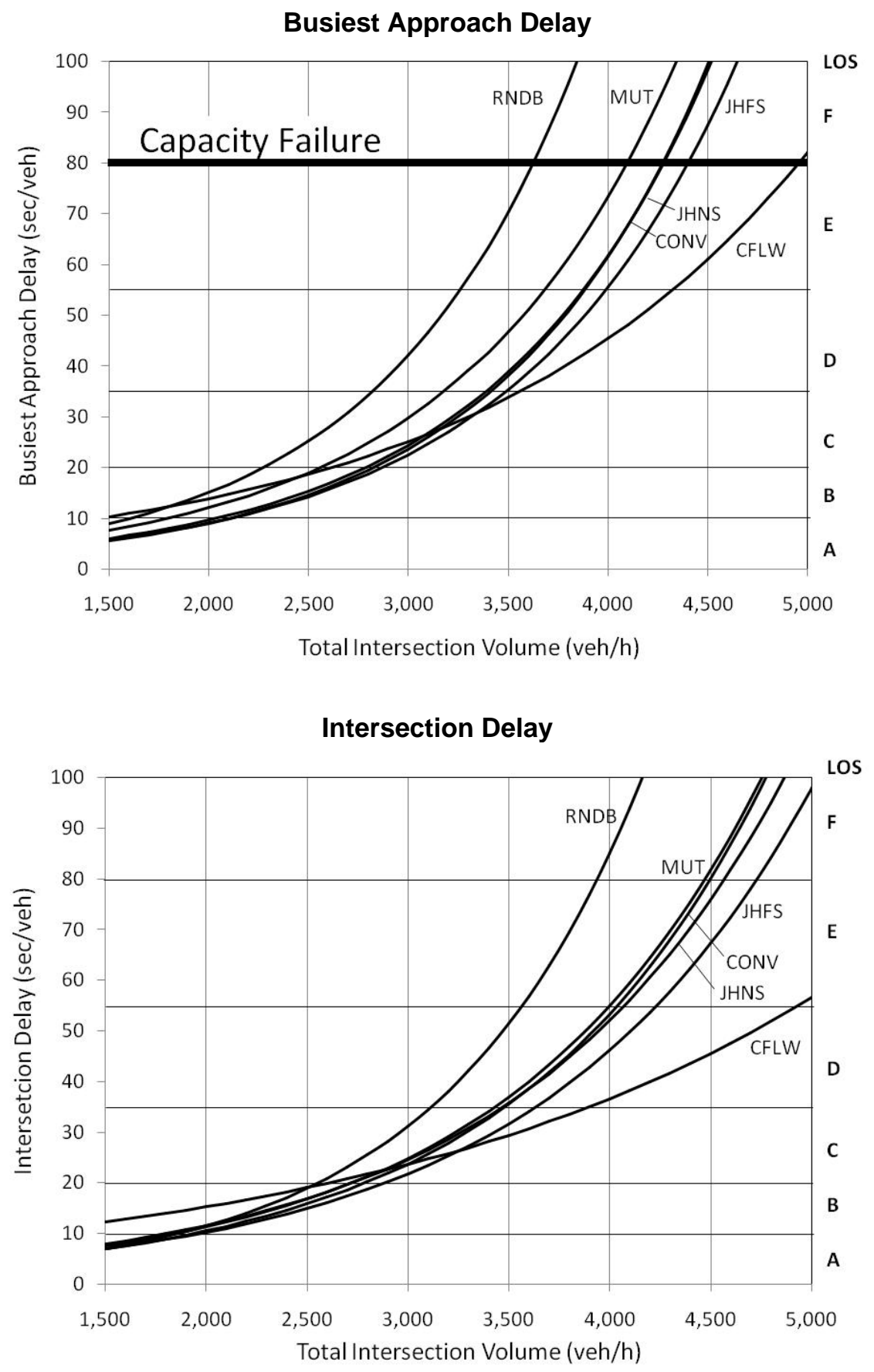

Stops Per Vehicle

\begin{tabular}{|c|c|c|c|}
\hline \multirow{2}{*}{ DESIGN } & \multicolumn{3}{|c|}{ Total Intersection Volume $($ veh/h) } \\
\cline { 2 - 4 } & 3095 & 4020 & 5565 \\
\hline CONV & 0.73 & 0.91 & 3.48 \\
\hline CFLW & 0.75 & 0.85 & 1.53 \\
\hline JHFS & 0.66 & 0.89 & 2.80 \\
\hline JHNS & 0.78 & 0.97 & 3.59 \\
\hline MUT & 0.75 & 1.24 & 4.38 \\
\hline RNDB & 0.78 & 5.91 & 18.30 \\
\hline
\end{tabular}



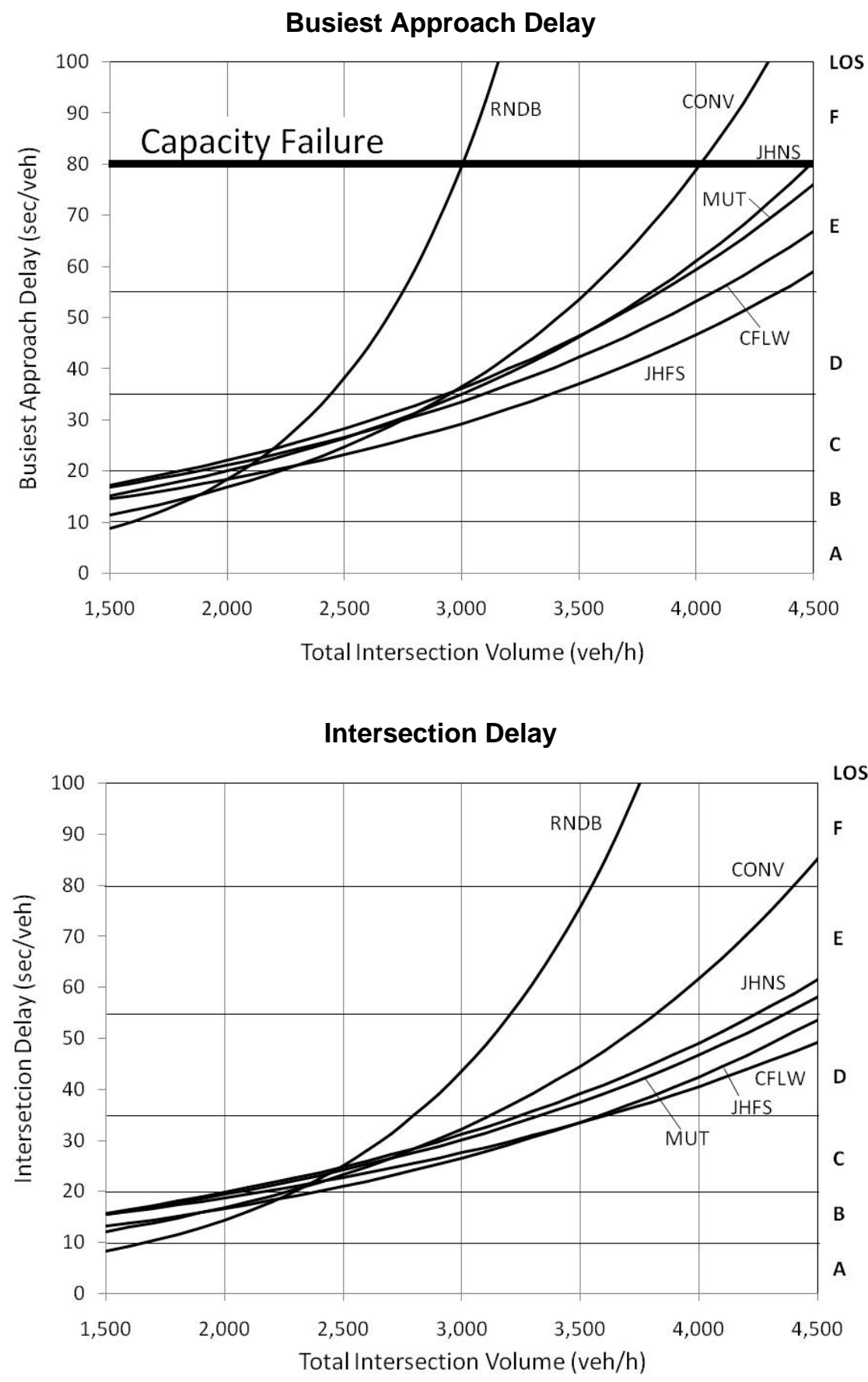

Stops Per Vehicle

\begin{tabular}{|c|c|c|c|}
\hline \multirow{2}{*}{ DESIGN } & \multicolumn{3}{|c|}{ Total Intersection Volume (veh/h) } \\
\cline { 2 - 4 } & 2430 & 3160 & 4375 \\
\hline CONV & 0.61 & 0.71 & 1.27 \\
\hline CFLW & 0.61 & 0.70 & 1.07 \\
\hline JHFS & 0.53 & 0.63 & 0.91 \\
\hline JHNS & 0.63 & 0.73 & 1.08 \\
\hline MUT & 0.64 & 0.70 & 1.08 \\
\hline RNDB & 0.44 & 2.46 & 8.88 \\
\hline
\end{tabular}



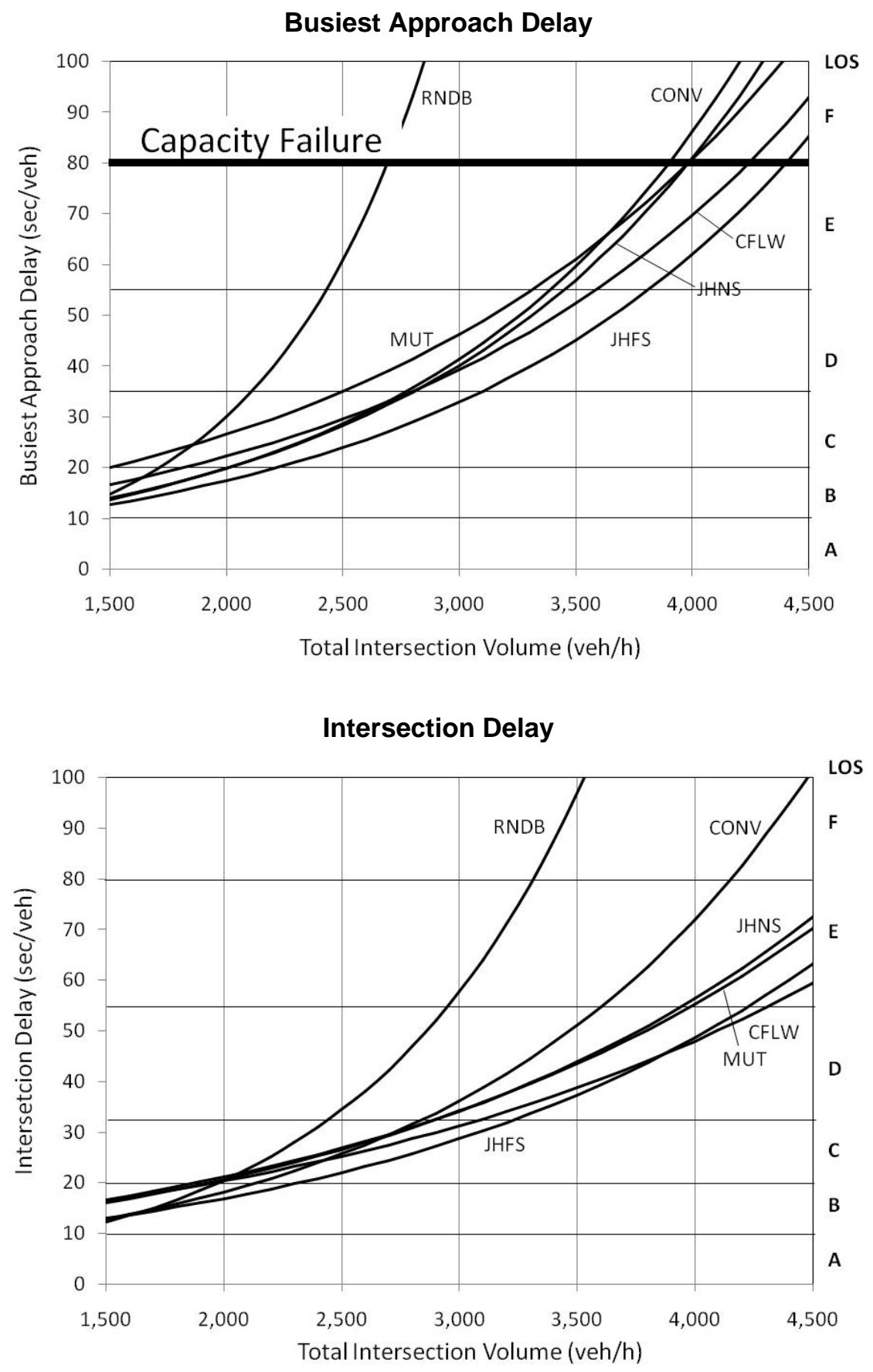

Stops Per Vehicle

\begin{tabular}{|c|c|c|c|}
\hline \multirow{2}{*}{ DESIGN } & \multicolumn{3}{|c|}{ Total Intersection Volume (veh/h) } \\
\cline { 2 - 4 } & 2430 & 3160 & 4375 \\
\hline CONV & 0.67 & 0.75 & 1.56 \\
\hline CFLW & 0.71 & 0.75 & 1.22 \\
\hline JHFS & 0.56 & 0.66 & 1.00 \\
\hline JHNS & 0.70 & 0.76 & 1.35 \\
\hline MUT & 0.74 & 0.75 & 1.29 \\
\hline RNDB & 0.54 & 5.33 & 9.04 \\
\hline
\end{tabular}



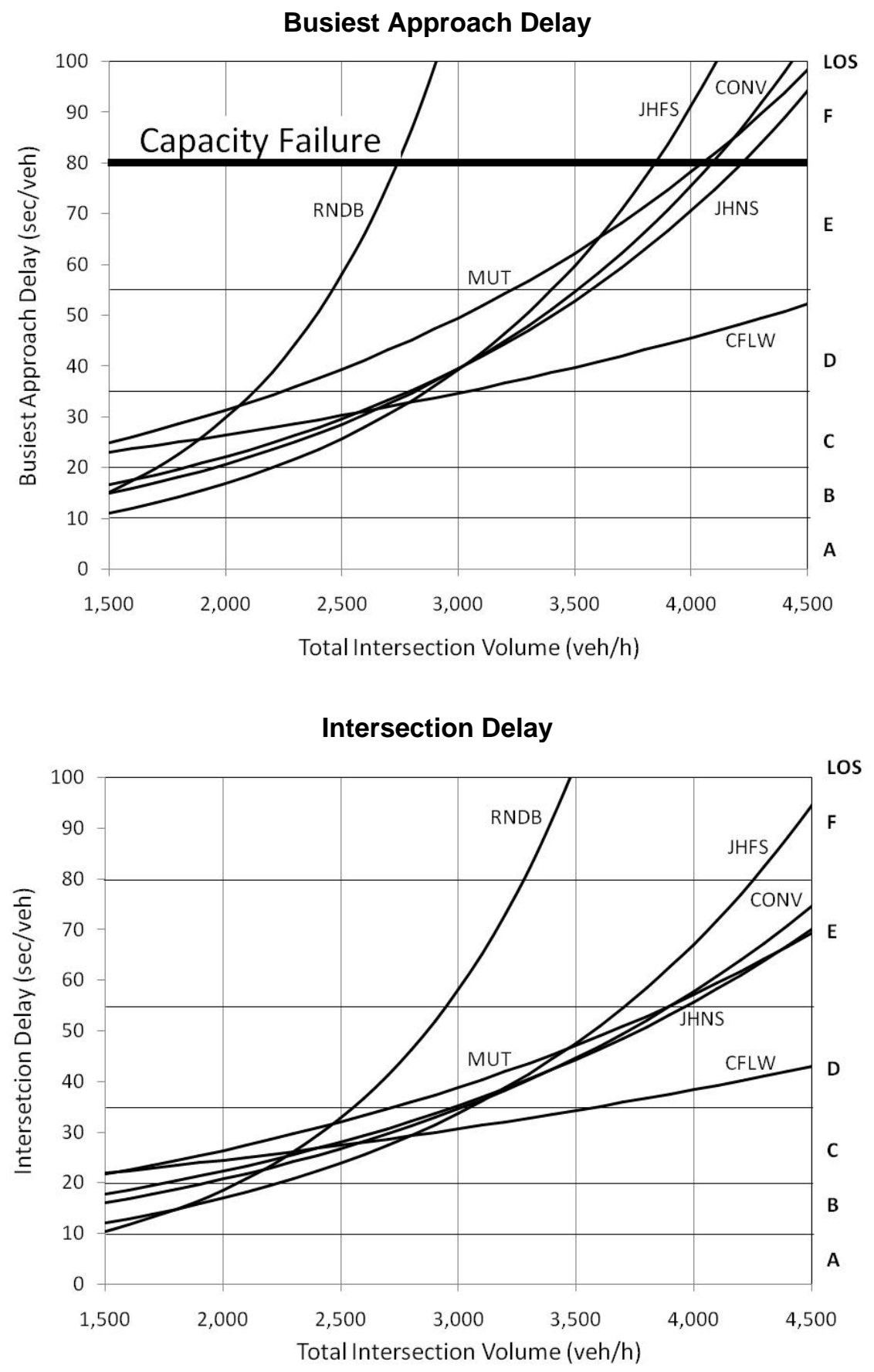

Stops Per Vehicle

\begin{tabular}{|c|c|c|c|}
\hline \multirow{2}{*}{ DESIGN } & \multicolumn{3}{|c|}{ Total Intersection Volume (veh/h) } \\
\cline { 2 - 4 } & 2430 & 3160 & 4375 \\
\hline CONV & 0.69 & 0.76 & 1.20 \\
\hline CFLW & 0.76 & 0.81 & 0.93 \\
\hline JHFS & 0.61 & 0.78 & 1.15 \\
\hline JHNS & 0.74 & 0.84 & 1.39 \\
\hline MUT & 0.88 & 0.83 & 1.44 \\
\hline RNDB & 0.55 & 4.88 & 11.78 \\
\hline
\end{tabular}



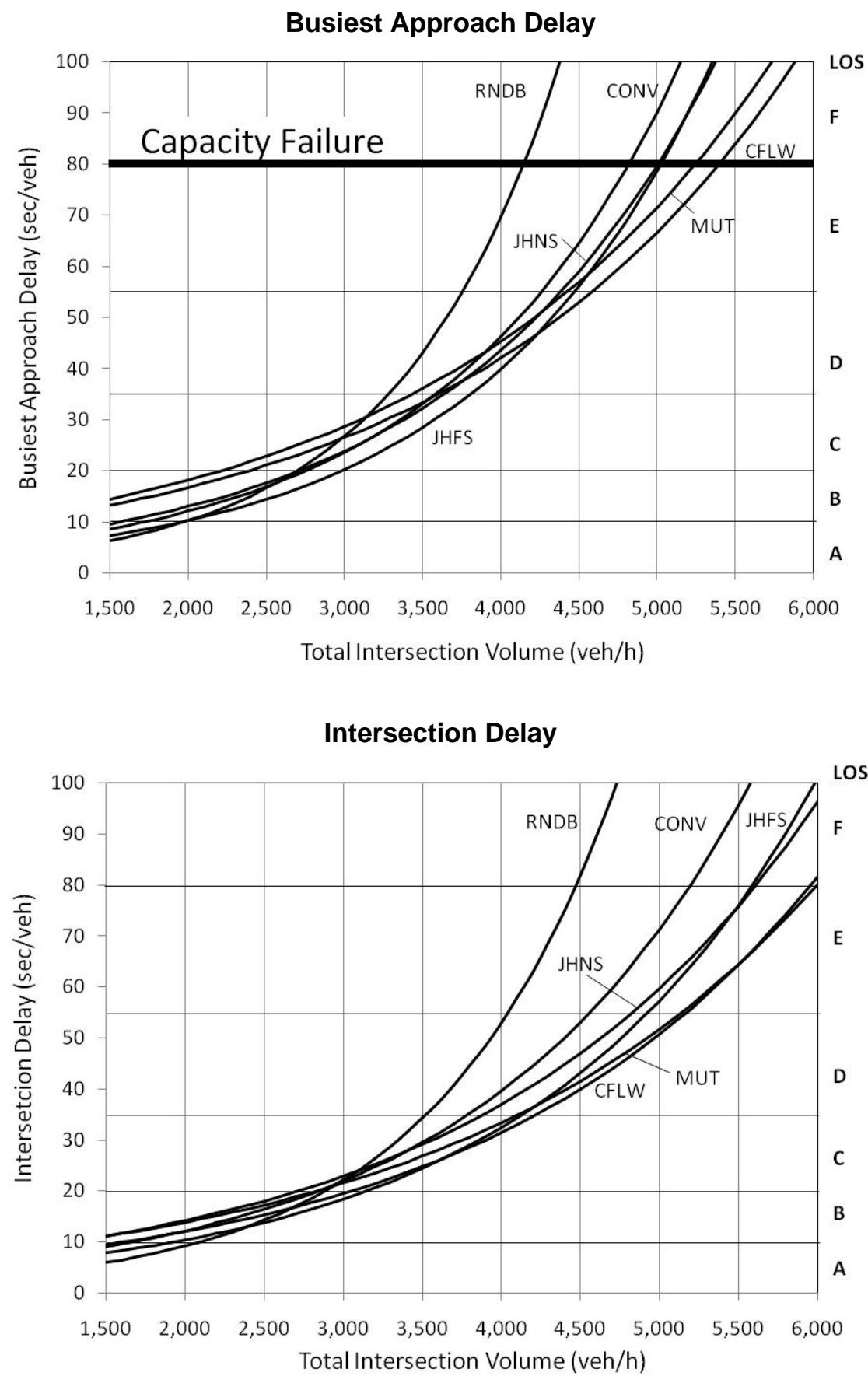

Stops Per Vehicle

\begin{tabular}{|c|c|c|c|}
\hline \multirow{2}{*}{ DESIGN } & \multicolumn{3}{|c|}{ Total Intersection Volume (veh/h) } \\
\cline { 2 - 4 } & 3095 & 4020 & 5565 \\
\hline CONV & 0.62 & 0.69 & 1.27 \\
\hline CFLW & 0.56 & 0.62 & 1.31 \\
\hline JHFS & 0.51 & 0.62 & 0.99 \\
\hline JHNS & 0.65 & 0.70 & 1.06 \\
\hline MUT & 0.60 & 0.63 & 1.16 \\
\hline RNDB & 0.50 & 1.59 & 9.51 \\
\hline
\end{tabular}




\section{Busiest Approach Delay}

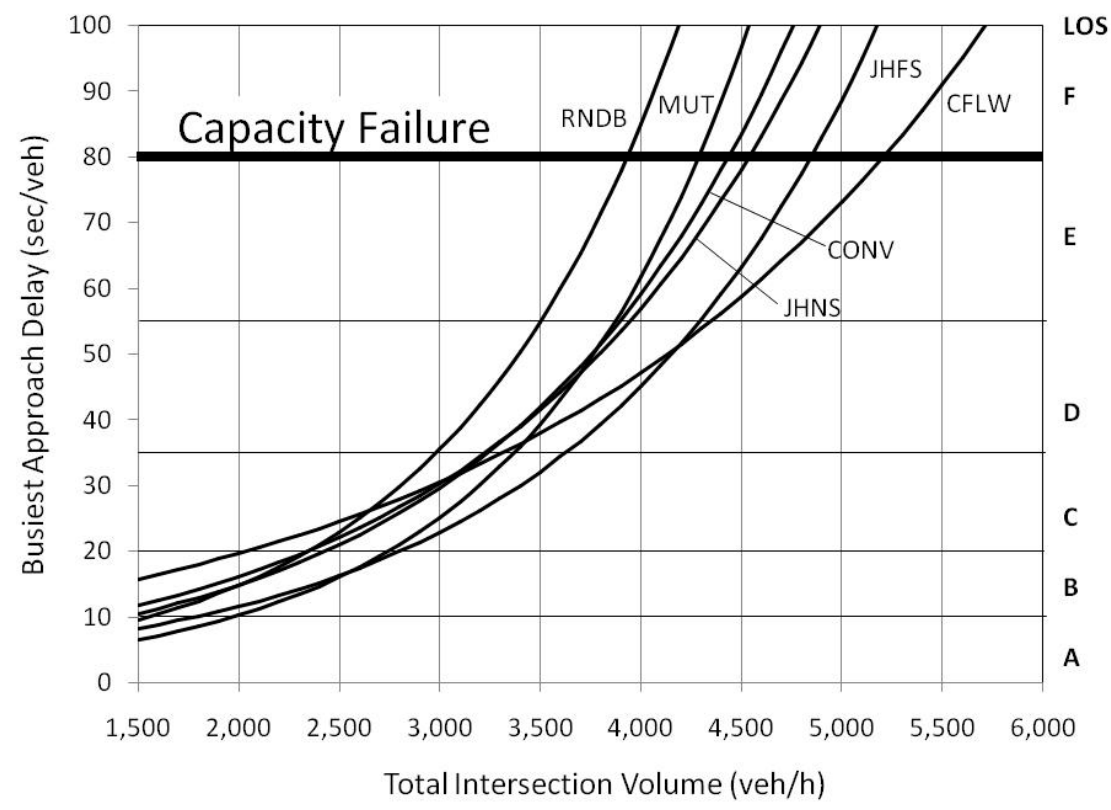

Intersection Delay

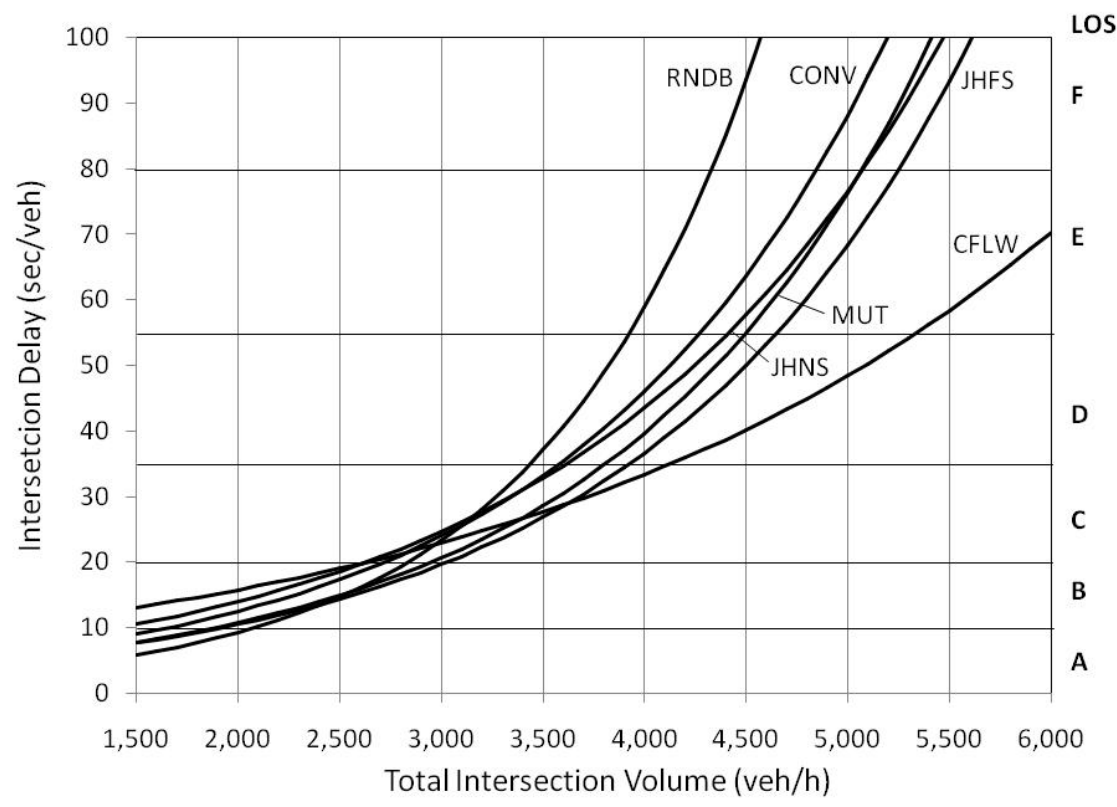

Stops Per Vehicle

\begin{tabular}{|c|c|c|c|}
\hline \multirow{2}{*}{ DESIGN } & \multicolumn{3}{|c|}{ Total Intersection Volume $(\mathrm{veh} / \mathrm{h})$} \\
\cline { 2 - 4 } & 3095 & 4020 & 5565 \\
\hline CONV & 0.69 & 0.77 & 1.76 \\
\hline CFLW & 0.65 & 0.71 & 1.11 \\
\hline JHFS & 0.56 & 0.67 & 1.24 \\
\hline JHNS & 0.71 & 0.78 & 1.62 \\
\hline MUT & 0.61 & 0.68 & 1.79 \\
\hline RNDB & 0.59 & 2.00 & 11.68 \\
\hline
\end{tabular}




\section{Busiest Approach Delay}

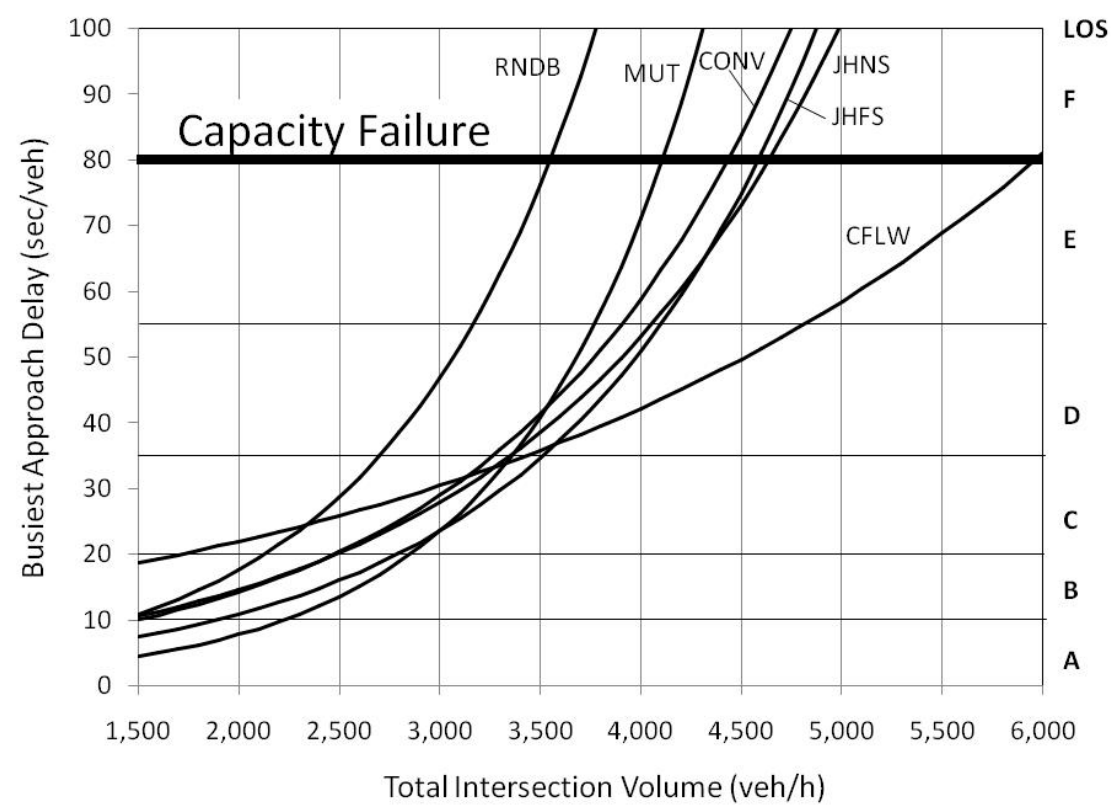

Intersection Delay

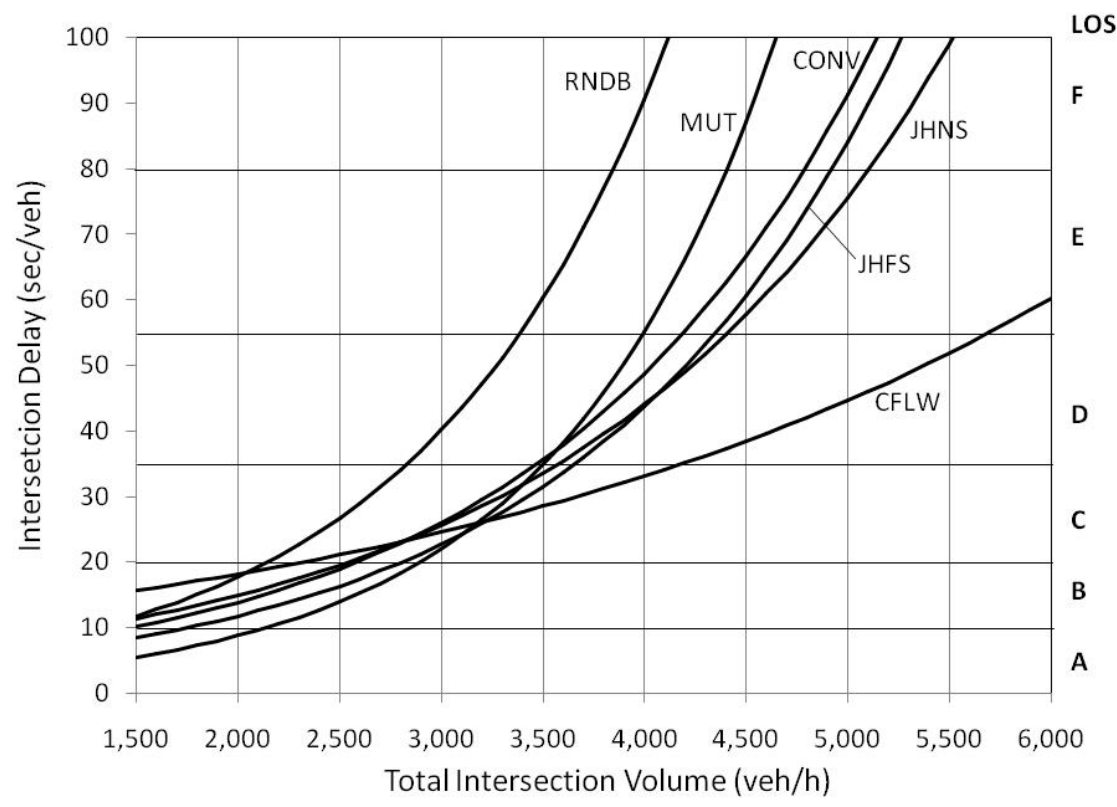

Stops Per Vehicle

\begin{tabular}{|c|c|c|c|}
\hline \multirow{2}{*}{ DESIGN } & \multicolumn{3}{|c|}{ Total Intersection Volume $(\mathrm{veh} / \mathrm{h})$} \\
\cline { 2 - 4 } & 3095 & 4020 & 5565 \\
\hline CONV & 0.73 & 0.84 & 1.89 \\
\hline CFLW & 0.71 & 0.75 & 1.04 \\
\hline JHFS & 0.63 & 0.87 & 1.76 \\
\hline JHNS & 0.75 & 0.89 & 1.66 \\
\hline MUT & 0.69 & 0.93 & 4.66 \\
\hline RNDB & 0.78 & 7.87 & 13.15 \\
\hline
\end{tabular}



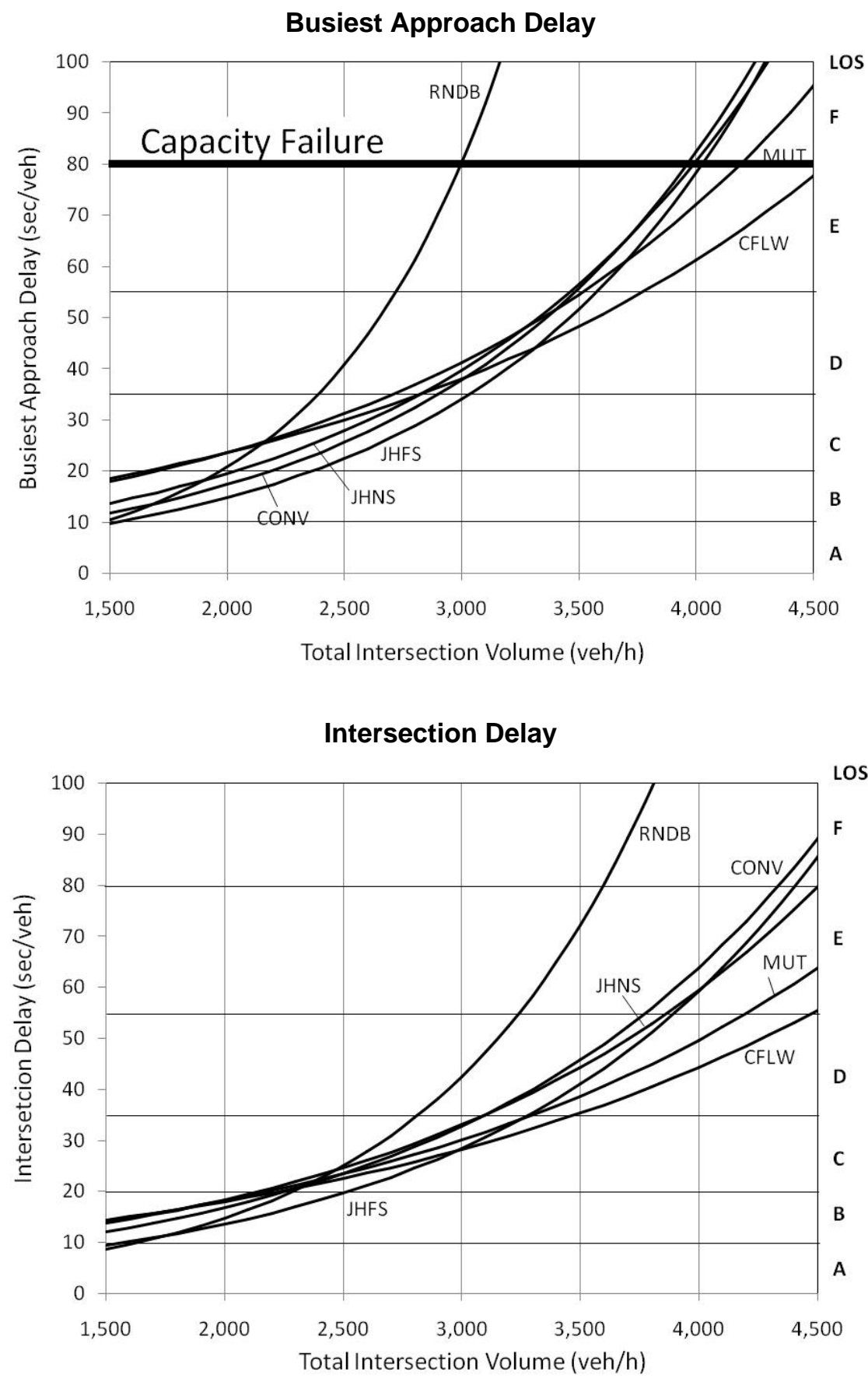

Stops Per Vehicle

\begin{tabular}{|c|c|c|c|}
\hline \multirow{2}{*}{ DESIGN } & \multicolumn{3}{|c|}{ Total Intersection Volume (veh/h) } \\
\cline { 2 - 4 } & 2430 & 3160 & 4375 \\
\hline CONV & 0.61 & 0.65 & 0.95 \\
\hline CFLW & 0.60 & 0.63 & 0.91 \\
\hline JHFS & 0.50 & 0.60 & 0.93 \\
\hline JHNS & 0.63 & 0.68 & 0.95 \\
\hline MUT & 0.59 & 0.72 & 0.94 \\
\hline RNDB & 0.44 & 1.81 & 7.48 \\
\hline
\end{tabular}



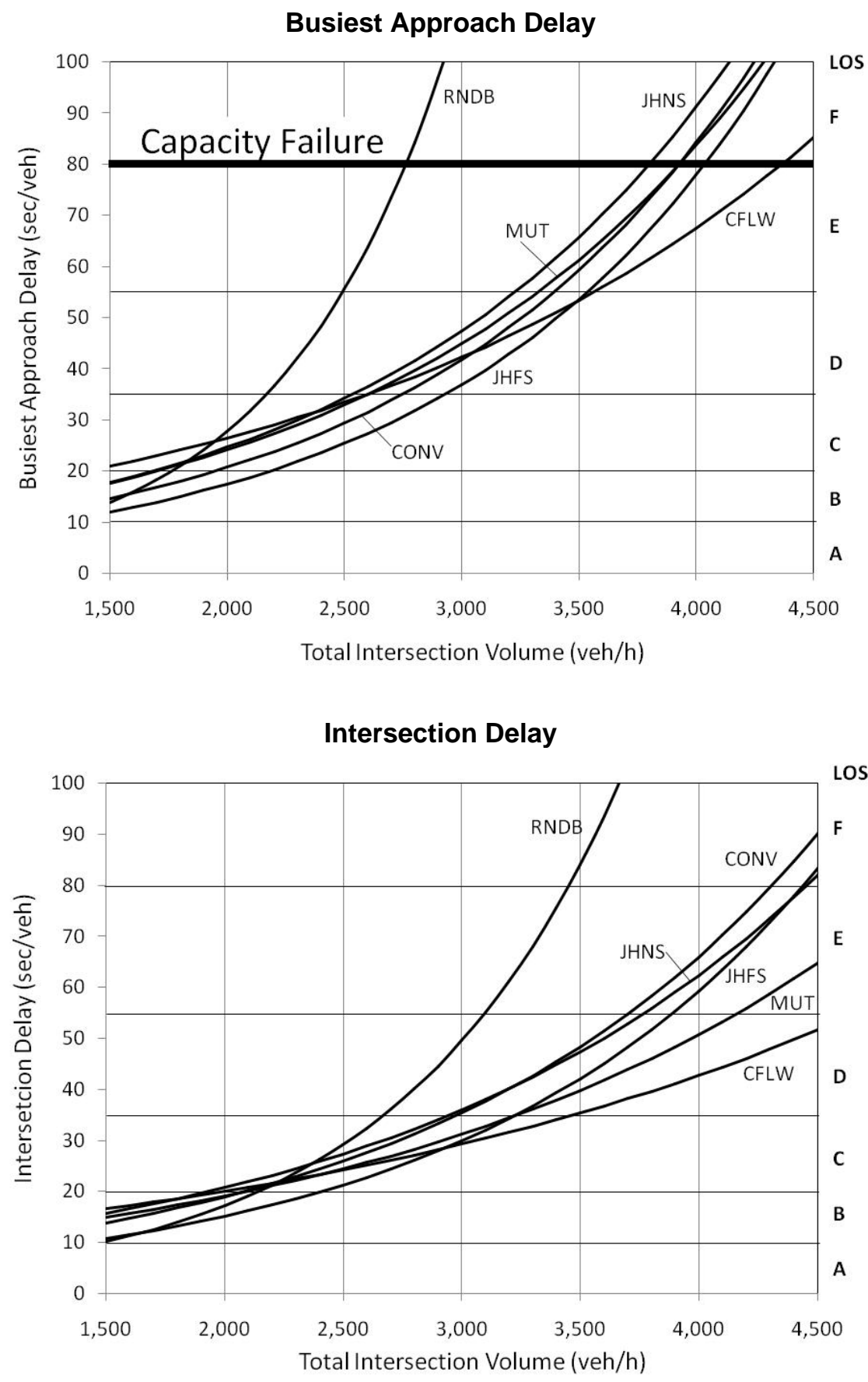

Stops Per Vehicle

\begin{tabular}{|c|c|c|c|}
\hline \multirow{2}{*}{ DESIGN } & \multicolumn{3}{|c|}{ Total Intersection Volume (veh/h) } \\
\cline { 2 - 4 } & 2430 & 3160 & 4375 \\
\hline CONV & 0.67 & 0.69 & 0.98 \\
\hline CFLW & 0.62 & 0.67 & 0.91 \\
\hline JHFS & 0.54 & 0.61 & 0.92 \\
\hline JHNS & 0.69 & 0.73 & 1.11 \\
\hline MUT & 0.61 & 0.74 & 0.98 \\
\hline RNDB & 0.47 & 3.03 & 8.29 \\
\hline
\end{tabular}



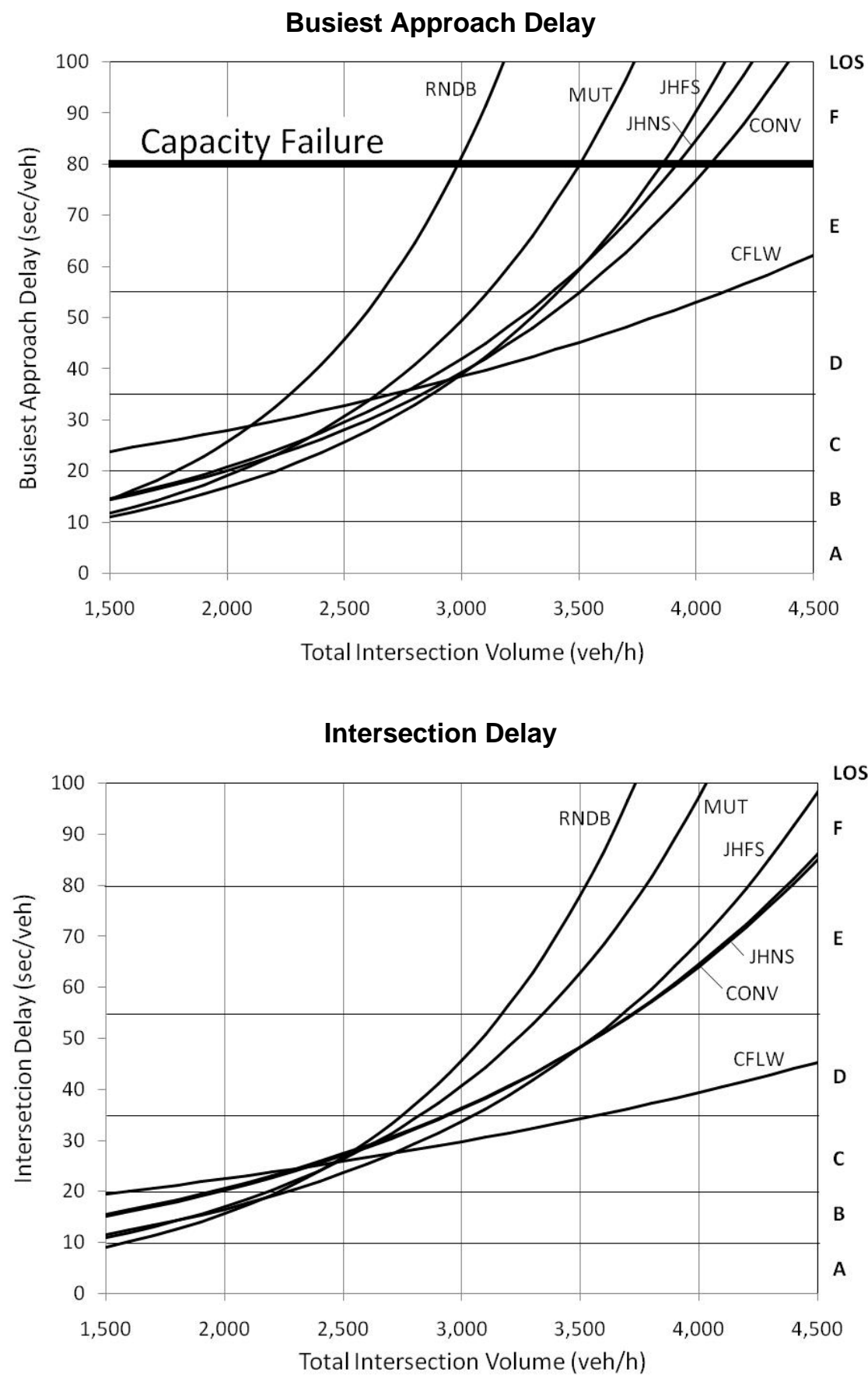

Stops Per Vehicle

\begin{tabular}{|c|c|c|c|}
\hline \multirow{2}{*}{ DESIGN } & \multicolumn{3}{|c|}{ Total Intersection Volume $(\mathrm{veh} / \mathrm{h})$} \\
\cline { 2 - 4 } & 2430 & 3160 & 4375 \\
\hline CONV & 0.68 & 0.73 & 1.02 \\
\hline CFLW & 0.71 & 0.63 & 0.88 \\
\hline JHFS & 0.62 & 0.74 & 1.22 \\
\hline JHNS & 0.73 & 0.82 & 1.34 \\
\hline MUT & 0.72 & 0.82 & 2.60 \\
\hline RNDB & 0.51 & 2.09 & 8.86 \\
\hline
\end{tabular}




\section{References}

American Association of State Highway and Transportation Officials (AASHTO). (1999). Guide for the Development of Bicycle Facilities. Washington, D.C.: American Association of State Highway and Transportation Officials.

American Association of State and Highway Transportation Officials (AASHTO). (2004). A Policy on Geometric Design of Highways and Streets. Washington, D.C.: American Association of State and Highway Transportation Officials.

Bared, J. G., \& Kaisar, E. I. (2000). Benefits of the Split Intersection. CD-ROM Compendium of Papers, $79^{\text {th }}$ Annual Meeting. Transportation Research Board (TRB), National Research Council, Washington D.C.

Bared, J. G., \& Kaisar, E. I. (2002). Median U-turn design as an alternative treatment for left turns at signalized intersection. ITE Journal, 72(2), 50-54.

Boone, J.L., \& Hummer, J.L. (1995). Calibrating and Validating Traffic Simulation Models for Unconventional Arterial Intersection Designs. In Transportation Research Record 1500.

Transportation Research Board, National Research Council, Washington D.C., pp. 184-192.

Boone, J.L., \& Hummer, J.L. (1995). Unconventional Design and Operation Strategies for OverSaturated Major Suburban Arterials. FHWA/NC/94-009, North Carolina Department of Transportation and Federal Highway Administration, Raleigh, North Carolina.

Chapman, J. and Benekohal, R. (2002). Roundabouts Warrants a Proposed Framework for Future Development. In Transportation Research Record 1801. Transportation Research Board, National Research Council, Washington D.C., pp.39-45.

Dobbour, E. \& Easa, S. (2006). Proposed geometric improvements to safety of modern roundabouts. CD-ROM Compendium of Papers, $85^{\text {th }}$ Annual Meeting. Transportation Research Board (TRB), National Research Council, Washington D.C.

Eisenman, S., \& List, G. (2004). A Comparison of Operational Data and Performance Model Predictions for Several US Roundabouts. CD-ROM Compendium of Papers, 83rd Annual Meeting. Transportation Research Board (TRB), National Research Council, Washington D.C.

Flannery, A., Elefteriadou, L., Koza, P., \& McFadden, J. (1998). Safety, Delay and Capacity of Single Lane Roundabouts in the United States. In Transportation Research Record 1646. Transportation Research Board, National Research Council, Washington D.C., pp.63-70.

Goldblatt, R., Mier, F., \& Friedman, J. (1994). Continuous Flow Intersections. ITE Journal, 64, 35-42.

Harkey, D.L., \& Carter, D.L. (2006). Observational analysis of bicyclist and motorist behavior at roundabouts in the United States. In Transportation Research Record 1982. Transportation Research Board, National Research Council, Washington D.C., pp.155-165. 
Hummer, J.E. (1998). Unconventional Left-Turn Alternatives for Urban and Suburban Arterials. Part One. ITE Journal, 68(9), 26-29.

Hummer, J.E. (1998). Unconventional Left-Turn Alternatives for Urban and Suburban Arterials. Part Two. ITE Journal, 68(11).

Hummer, J.E., \& J. Boone. (1995). Travel Efficiency of Unconventional Arterial Intersection Design. In Transportation Research Record 1500. Transportation Research Board, National Research Council, Washington D.C., pp. 153-161.

Hummer, J.E., \& Reid, J.D. (2000). Unconventional Left-Turn Alternatives for Urban and Suburban Arterials: An Update. In Transportation Research Circular E-C019: Urban Street Symposium Conference Proceedings, Dallas, TX, June 28-30, 1999. Washington, DC: TRB, NRC.

Jagannathan, R. (2007). Synthesis of the Median U-Turn Intersection Treatment, Safety, and Operational Benefits. McLean, VA U.S. Department of Transportation, Federal Highway Administration, TechBrief, FHWA-HR-08-033.

Jagannathan, R., Gimbel, J., Bared, J., Hughes, W. E., Persaud, B., \& Lyon, C. (2006). Safety Comparison of New Jersey Jug Handle Intersections and Conventional Intersections. In Transportation Research Record 1953, Transportation Research Board, National Research Council, Washington D.C., pp. 187-200.

Johnson, M. \& Hange, W. (n.d). Modern Roundabouts intersections: When to use them? A comparison with signalized intersections. Retrieved December 2007 from Web Site: http://www.k-state.edu/roundabouts/news/ITEPaper.pdf

Kim, T., Edara, P., Bared, J. (2007). Operational and Safety Performance of a Non-Traditional Intersection Design: The Superstreet. CD-ROM Compendium of Papers, $86^{\text {th }}$ Annual Meeting. Transportation Research Board (TRB), National Research Council, Washington D.C.

Levinson, H. S., Koepke, F. J., Geiger, D., Allyn, D., \& Palumbo, C. (2000). Indirect Left Turns-The Michigan Experience. Access Management Conference, Portland, Oregon.

Michigan Department of Transportation. (n.d.). Bureau of Highways Design Guide for Crossovers. Retrieved December 2007 from Web Site:

http://www.mdot.state.mi.us/tands/plans.cfm

New Jersey Department of Transportation. (n.d.). Roadway Design Manual. Retrieved September 20, 2007 from Web Site:

http://www.state.nj.us/transportation/eng/documents/RDME/sect6E2001.shtm\#JUGHANDLES

New Jersey Department of Transportation. (n.d.). Highway Design Manual. Retrieved December 2007 from Web Site: http://www.state.nj.us/transportation/cpm/RDMEnglish/. 
Nichols, A. \& Bullock, D. (2001). Design Guidelines for Deploying Closed Loop Systems. Joint Transportation Research Program (JTRP), SPR 2390.

Polus, A. \& Cohen, R. (1997). Operational Impact of Split Intersections. In Transportation Research Record 1579. TRB, National Research Council, Washington D.C.

Reid, J. (2000). Using Quadrant Roadways to Improve Arterial Intersection Operations. ITE Journal, 70(6), 34-45.

Reid J.D., Brinckerhoff, P., \& Hummer, J.E. (1999). Analyzing System Travel Time in Arterial Corridors with Unconventional Design Using Microscopic Simulation. In Transportation Research Record 1678, TRB, National Research Council, Washington D.C., pp.208-215.

Reid, J.D., \& Hummer, J.E. (2001). Travel Time Comparisons between Seven Unconventional Arterial Intersection Designs. In Transportation Research Record 1751. TRB, National Research Council, Washington D.C.

Retting, R.A., Lutterell, G., \& Russell, E.R. (2002). Public Opinion and Traffic Flow Impacts of Newly Installed Modern Roundabouts in the United States. ITE Journal 72(9).

Robinson, B.W., Rodegerdts, L., Scarbrough, W., Kittelson, W., Troutbeck, R., Brilon, W., Bondzio, L., Courage, K., Kyte, M., Mason, J., Flannery, A., Myers, E., Bunker, J., \& Jacquemart, G. (2000). Roundabouts: An Informational Guide. Report No. FHWA-RD-00-067. Washington, DC: United States Department of Transportation, Federal Highway Administration.

Rodegerdts, L.A., Blogg, M., Wemple, E., Myers, E., et al. (2007). Roundabouts in the United States. Washington D.C., National Cooperative Highway Research Program (NCHRP), Transportation Research Board, Report 572.

Rouphail, N., Hughes, R., \& Chae, K. (2005). Exploratory Simulation of pedestrian Crossings at Roundabouts. Journal of Transportation Engineering, 131, 211-218.

Russell, E., Retting, R.A., McCartt, A.T., \& Srinivas, M. (2006). Traffic Flow and Public Opinion: Newly Installed Roundabouts in New Hampshire, New York, and Washington. CDROM Compendium of Papers, $85^{\text {th }}$ Annual Meeting. Transportation Research Board (TRB), National Research Council, Washington D.C.

Russell, E., Rys, M., \& Luttrell, G. (2002). Kansas Roundabout Reluctance. Submitted to the $81^{\text {st }}$ Annual Meeting of the Transportation Research Board. Transportation Research Board, National Research Council, Washington, D.C.

Tabernero, V., Sayed, T., \& Kosicka, D. (2008). Introduction and Analysis of a New Unconventional Intersection Scheme, the Upstream Signalized Crossover (USC) Intersection. CD-ROM Compendium of Papers, $87^{\text {th }}$ Annual Meeting. Transportation Research Board (TRB), National Research Council, Washington D.C. 
Tarek, S., Paul, S., \& Godwin, W. (2006). Upstream Signalized Crossover Intersection: Optimization and Performance Issues. In Transportation Research Record 1961. TRB, National Research Council, Washington D.C, pp.44-54.

Thompson, C.D. \& Hummer, J.E. (2001). Guidance on the Safe Implementation of Unconventional Arterial Designs: Draft Final Report. North Carolina State University.

Tyra, A., Villwock, N.M., Tarko, A.P. (2007). Safety Impacts of Roundabouts in Indiana. Unpublished manuscript.

U.S. Departament of Transportation. (2004). Federal Highway Administration. "Signalized Intersections: Informational Guide.” Chapter 10.

\section{RELATED LITERATURE}

Bared, J.G. \& Edara. (2005). Simulated Capacity of Roundabouts and Impact of Roundabouts within progressed signalized road. In Transportation Research Circular E-C083: National Roundabout Conference Proceedings, Vail, CO, May 22-25, 2005. Washington, DC: TRB, NRC.

Dorothy, P., Maleck, W., \& Nolf, S. (1997). Operational Aspects of Michigan design for Divided Highways. In Transportation Research Record 1579. Transportation Research Board, National Research Council, Washington, D.C., pp. 18-26.

Hummer, J.E. (2000). Operational Effects of New “Double Wide” Intersection Design on Suburban Arterials. CD-ROM Compendium of Papers, $79^{\text {th }}$ Annual Meeting. Transportation Research Board (TRB), National Research Council, Washington D.C.

Jagannathan, R., \& Bared, J.G. (2004). Design and Operational Performance of the Crossover Displaced Left-Turn (XDL) Intersection (Also Called Continuous Flow Intersection (CFI)). Presented at the 2004 TRB Annual Meeting, Washington, DC.

Jagannathan, R., \& Bared, J.G. (2005). Design and Performance Analysis of Pedestrian Crossing Facilities for Continuous Flow Intersections (CFI). CD-ROM Compendium of Papers, $84^{\text {th }}$ Annual Meeting. Transportation Research Board (TRB), National Research Council, Washington D.C.

Lindgren, R.V., \& Tantiyanugulchai, S. (2003). Microscopic simulation of traffic at a suburban interchange. Institute of Transportation Engineers 2003 Annual Meeting, Seattle, Washington.

Mereszczak, Y., Dixon, M., Kyte, M., Rodegerdts, L., \& Blogg, M. (2006). Including Exiting Vehicles in Capacity Estimation at Single-Lane U.S. Roundabouts. In Transportation Research Record 1998, TRB, National Research Council, Washington D.C., pp.23-30.

Ourston, L., \& Hall, G. (2003). Roundabouts increase interchange capacity. In Transportation Research Record 1858, TRB, National Research Council, Washington D.C., pp.112-117. 
Potts, I. B., Harwood, D.W., Torbic, D.J., Richard, K.R., et al. (2004). Safety of U-Turns at Unsignalized Median Openings. Washington D.C., National Cooperative Highway Research Program (NCHRP), Transportation Research Board, Report 524.

Rodegerdts, L. A., Nevers, B., Robinson, B., et al. (2004). Signalized Intersections:

Informational Guide. Publication FHWA-HRT-04-091. Federal Highway Administration, U.S. Department of Transportation.

Stanek, D., \& Milam, R. (2005). High-Capacity Roundabout Intersection Analysis: Going Around in Circles - Draft. National Roundabout Conference, Vail, CO.

Tabernero, V., \& Sayed, T. (2006). Upstream Signalized Crossover Intersection: An Unconventional Intersection Scheme. Journal of Transportation Engineering. 132(11), 907-911. 